

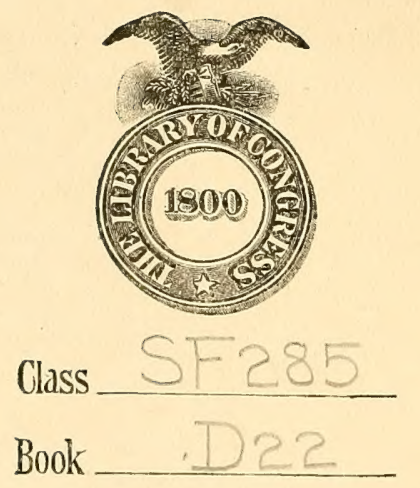

Copyright No.

COFYRIGHT DEPOST. 





\section{THE AMERICAN FARMER'S}

\section{$\mathrm{H}$
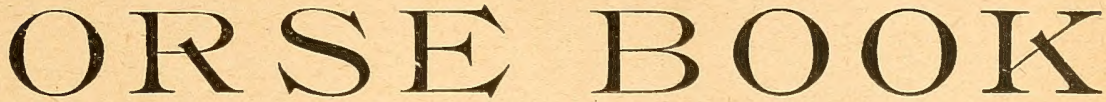

A PICTORIAL CYCLOPEDIA

- OF-

FACTS CONCERNING THE PROMINENT BREEDS, PRINCIPLES OF BREEDING, BEST METHODS of training, STABLE MaNagement, GeNeral Care, ETC.,

WITH SPECIFIC DIRECTIONS

\section{HOW TO BUY AND HOW TO SELL,}

INCLUDING A SERIES OF

INVALUABLE OBJECT-LESSONS ON CONFORMATIONS, POINTS OF THE HORSE, AND HOW TO DETECT UNSOUNDNESS OR VICE,

AND ESPECIALLY

\section{DESCRIBING ALL KNOWN DISEASES TO WHICH THE HORSE IS SUBJECT:}

THEIR CAUSES, SYMPTOMS, PREVENTION AND CURE, HOW TO BE DISCRIMINATED, THE SURGICAL OPERATIONS REQUIRED, HYGIENIC CARE, ETC.

THE WHOLE VERY FULLY ILLUSTRATED AND GIVEN IN

PLAIN, SIMPLE LANGUAGE, FREE FROM TECHNICALITIES, BUT SCIENTIFICALLY CORRECT, AND PRESCRIBING

REMEDIES READILY OBTAINED AND EASILY APPLIED

Expressly Prepared for the Successful and Profitable Use -OF THE-

AMERICAN FARMER AND HORSE OWNER

BY

ANDREW DARIING, D. V.S. st. LOUIS, MO.,

Graduate of the Veterinary Department of McGill University, Montreal; Honorary Fellow of the Montreal Veterinary Medical Association, and of the Society for the Study of Comparative Psychology; Member

of the U. S. Veterinary Medical Association; Author of "Vices and Unsoundnesses of the

Horse;" Veterinary Editor of the "Journal of Agriculture," etc.

WITH OVER 300 HIGHLY INSTRUCTIVE ENGRAVINGS, Many of them Executed for this Work from Actual Photographs.

ST. LOUIS, MO. :

JOURnal OF AGRiCulture CO., Publishers, 1120 Pine Street. 
[Copyright, 1s66, by C. F. Vent \& Ca.]

Entered, according to Act of Congress in the year 1892, by JOURNAL OF AGRICULTURE CO.,

In the Offlce of the Librarian of Congress, at Washington, D. C. 


\section{THE FARMERS OF AMERICA}

TO WHOSE NOBLEST AND MOST USEFUL SERVITOR ITS PAGES ARE DEVOTED, AND IN WHOSE ESPECIAL INTEREST IT HAS BEEN WRITTEN, THIS VOLUME IS CORDIALLY DEDICATED BY THE PUBLISHERS. 



\section{PUBLISHERS’ PREFACE.}

The aim of this book is defined by its title. That it is comprehensive in detail, the Table of Contents will show. That the subjects treated are intimately and vitally associated with the best interest and success of every horse owner will likewise appear. That these sub- jects are practically treated, so as to contribute to this end, it is confidently believed their study and application will demonstrate. If any further guarantee on these points is necessary, it is furnished in the professional training, character and wide experience of the distinguished author. A life devoted to the study of the horse-to veterinary practice, and to editorial work in that interest-has given him rare qualifications for so important a task. He here opens a bountiful storehouse of knowledge for the horse owner, and negligence alone is barred from its use. To lessen popular ignorance; to bring the best knowledge of that noble animal, the horse, within the reach of all; to make every farmer acquainted with such facts as can be profitably used,-this has been his high aim. In brief, yet simple and comprehensive language, he has condensed in one book what all should be familiar with regarding the horse. It is accomplished in one volume of such size that all can use it.

Dr. Darling's strength, and his great popularity as a veterinary writer, are mainly due to his being a thorough student from a practical standpoint. It is confidently believed that in no other work ever prepared for the great mass of readers can there be found equally clear and lucid descriptions of the diseases, etc., to which the horse is subject, and the means of making a correct diagnosis of each ; and, especially, how to discriminate accurately between different diseases which in their symptoms are perplexingly similar. The importance 
of such discrimination is often equaled only by its difficulty. By the use of this volume the difficulty will, in large measure, be removed.

A like pre-eminence belongs to this the author's latest work, as regards the insight which it gives the ordinary reader into what might be termed the philosophy of disease and cure-the origin, process and results of unhealthy conditions, and in what way certain remedies may be relied on to work beneficially. The advantages accruing from this practical knowledge cannot be understood fully, short of an actual and extended use of this work in the care and treatment of stock; yet the reader will be struck with them on even a casual reading. Chapters XIV and XXIII, for instance, well illustrate and enforce these facts.

The tried and approved method of Object-Teaching-of instructing through the eye, as well as by printed word-has been utilized throughout. The value of correct Object-Lessons in elucidating written or spoken words is now so well established that the system has been generally adopted, not only in the better examples of successful books and journals, but also in our common schools, academies and colleges. Hence, no apology is offered for introducing here what the most successful instructors have advocated and practiced. While adding immensely to the expense of producing a book (single illustrations often costing hundreds of dollars), by this method the reader can see at a glance what would take pages of written matter to explain; and, besides, what might otherwise be dull reading becomes a pleasure, and the mind more permanently retains what has been impressed upon the eye.

In preparing this work, the effort throughout has been to present information not generally attainable, except through the study of many books-to give the thoughts and experience of the best minds, whon they conform to modern practice-and this with the least verbiage possible.

A study of these pages will enable any one to ascertain the age of a horse, and aceurately judge his characteristies and adaptability to pecifie or needed purposes, and to determine his value. The subject 
of training, as here elucidated by a master of the subject, will be found practical and especially valuable. Kind and gentle methods have been advocated in every department, as being the most profitable, as well as most humane.

Special painstaking has been devoted to giving the causes producing disease, so that knowing the cause the disease may be obviated. Prevention is better than cure, and this fact is duly emphasized. When the services of a skilled veterinary surgeon are required, it has been candidly advised, and care has been taken to distinguish between popular treatment and that requiring scientific and skillful management.

In prescribing remedies, the preference has invariably been given to those within reach of the ordinary farmer-remedies such as any one can procure, prepare and easily administer. In like manner, unfamiliar words and technical phrases have been avoided, as far as was possible, consistent with scientific accuracy of statement. Clearness and conciseness of expression have been carefully consulted, and, to further conduce to a correct understanding, an elaborate glossary has been appended, thoroughly explanatory of the meaning of every word in the book not familiar to every-day life.

To the Hon. Jonathan Periam the credit is wholly due for the first eleven chapters. This veteran writer needs no introduction to an American public. In the capacity of author and journalist his constituency has, for more than a quarter of a century, been the whole American people-his name everywhere a household word. Nor is it confined to the limits of our own country; former books, the product of his pen, have reached the phenomenal sale of 100,000 copies beyond the confines of the American continent. His practical work has thus won its way to every English-speaking people, and his reputation, as an authority on the horse, is the very highest.

In like manner, to Major E. B. Abercrombie is due the credit for the final portion on trotting and racing horses, and their development. As an authority on this branch of the subject, his facile pen 
has long been employed in the editorial columns of those well-known periodicals, "The Horseman" and "The Spirit of the Times."

Believing that it has unusual claims to popular favor, and that it will conduce to the knowledge, success and pleasure of all who may consult its pages and will be governed by its teachings, this volume is submitted, with pride as well as confidence, to the consideration of the public.

THE PUBLISHERS.

[NотE.-The copyright and plates of "The American Farmer's Horse Book," by Robert Stewart, M. D., V. S., which was published in 1866, are owned by the publishers of the present work. It must be understood that Dr. Darling's is an entirely new work, much more thorough, and embodying all that is useful in the very latest researches in veterinary science.] 


\section{TABLE OF CONTENTS.}

\section{CHAPTER I.}

HORSES FOR LABOR.

I. Whence Our Horses Came.-II. The Hunting Horse.-III. The Hackney.-IV. Carriage Horses.-V. English Draft Horses.-VI. 'The Suffolk Punch. - VII. The Clydesdale Horse.-VIII. The English Carthorse--IX. The Flemish Horse.-X. French Draft Horses.-XI. The Percheron Horse.-XII. The French Coach Horse.-XIII. Hanoverian and German Coach Horses......................................

\section{CHAPTER II.}

THOROUGHBREDS AND TROTTING HORSES.

I. The Thoroughbred a Composite Horse.-II. External Points.-III. Varying Standard for Different Breeds.-IV. The Head and Neck.-V. The Fore Quarters.-VI. The Trotting Horse the Only Breed Distinctively American.-VII. Wide Diffusion of His Blood.-VIII. History Outlined. -IX. Trotting Events in the Period of Development.-X. Breeding and

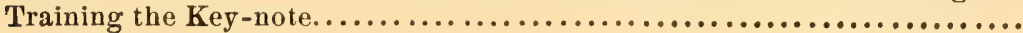

\section{CHAPTER III.}

THE BREEDING OF HORSES.

I. How Excellence is Attained.-II. Importance of Exercise to Breeding Animals.-III. The Law of Similarity.-IV. Careful Study the Key to Success.-V. Breed to the End sought.-VI. About Form and Proportion. -VII. I'he Points to be Studied are Many.-VIII. Importance of Accurate Knowledge.-IX. Stonehenge's Laws of Generation.................

\section{CHAPTER IV.}

THE HORSE AT REST AND IN MOTION.

I. The Horse's Attitude in Standing.-II. Mode of Progression.-III. The Walk.-IV. Good and Bad Walkers.-V. The Trot.-VI. The Canter.-VII. The Hand Gallop.-VIII. 'The Extended or True Gallop.-IX. How to Judge a Horse........................................ 


\section{CHAPTER V. \\ HYGIENE, FOODS AND EXERCISE.}

I. Practical Value of Hygienic Knowledge.-II. About Perfect Foods and Shelter.-III. 'The Horse's Stomach and Digestion.-IV. Oats.-V. Hay.-VI. Straw.-VII. Green Forage.-VIII. Corn.-IX. Artificial and Condimental Foods.-X. What Constitutes Good Care.-XI. Good Shelter is True Economy.-XII. Exercise is Indispensable.-XIII. Comfortable Bedding.-XIV. Cleaning the Horse-XV. Keep the Stabie

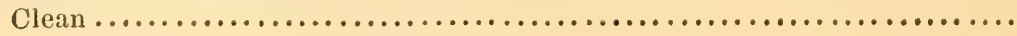

\section{CHAPTER VI.}

STABLE: CARE, WATER AND MANAGEMENT.

I. The Use and Abuse of Water.-II. Horses Like Clean Water.-III. Use Common Sense.-IV. Cleaning the Limbs.-V. Curry Comb and Brush.VI. Cleanliness of the Skin.-VII. Look Well to the Exhausted Horse. -VIII. Temperature of the Stable.-IX. Saddle Horses.-X. Pacers...

\section{CHAPTER VII.}

TRAINING AND RESTRICTIVE MEASURES.

I. Concerning the Employment of Force.-II. 'The Lesson of Subserviency. -III. Docility 'Through Training.-IV. Use the Whip with Discretion. -V. Intelligent Restraint.-VI. Animal Language:-VII. Gentling and Training the Colt.-VIII. Use of the Voice and of Signals.-IX. Special Modes of Horse 'Taming.-X. Rarey's Three Fundamental Principles.XI. Rarey's Apparatus.-XII. The Struggle Deseribed.-XII. 'The 'Tamer's Victory.-XIV. Dr. Walsh's Summing Up.-XV. Rarey's Favorite Halter. -XVI. A Bit of History .........................

\section{CHAPTER VIII.}

\section{HOW TO BUY A HOLSE, AND HOW TO SELL.}

I. The Warrantee.-II. An Unqualified Warrantee.-III. The Condition of Unsoundness.-IV. Vice.-V. Blemishes.-VI. Directions for Buying. -VII. Look Out for Disabilities and 'Tricks.-VIII. Directions for

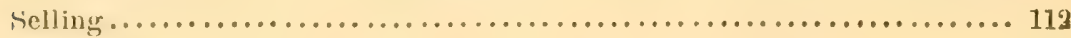

\section{CHAPTER IX.}

OBJECT LESSONS IN CONHORMATION.

I. 'I'he Ifead and Neck.-II. 'The Back-III. The Shoulders.-IV. 'The Hind Quarters.-V. Lines of Divergence.-VI. 'The Hind Limbs.-VII. The Fore Limbs.-VIII. Do Not Invest in Faulty Limbs............... 119 


\section{CHAPTER X. \\ THE CONSTRUCTION OF STABLES.}

I. A Simple and Excellent Horse Stable.-II. True Principles of Construction.-III. Louvre Boards for Ventilation.-IV. Paving for Stables.-V. Stable Floor Higher than the Ground Outside.-VI. Slope of Stalls.-VII. Site of Stables.-VIII. Light.-IX. Modifying a Farm Barn.-X. A Model Barn.-XI. The Horse Stables.-XII. The Cattle Stalls, etc.......

\section{CHAPTER XI.}

\section{ASSES AND MULES.}

I. The Wild Ass.-II. General Washington's Jacks.-III. The South is the Jack's Congenial Home.-IV. Uses of the Jennet, and What is a Mule?V. Longevity of the Mule.-VI. Value of Mules for Labor.-VII. A Healthier Animal than the Horse.-VIII. Dr. Stewart's Testimony.-IX. The Breeding of Mules....................................

\section{CHAPTER XII.}

OUTLINE OF THE HORSE'S STRUCTURE.

I. True Method of Treating this Subject.-II. The Horse's Frame-work.-III. Structure and Classification of the Bones.-IV. The Muscles.-V. Muscle Versus Fat.-VI. The Tendons.-VII. The Membranes.-VIII. The Skin and its Three Layers.-IX. Appendages and Functions of the Skin.-X. The Pores and Perspiration.-XI. The Hair.-XII. The Blood.-XIII. Plan of the Circulation.-XIV. The Circulatory System.-XV. The Circulatory Process Described.-XVI. The Heart.-XVII. The Feet....... 144

\section{CHAPTER XIII.}

\section{OUTLINE OF THE HORSE'S STRUCTURE (Continued).}

I. The Brain and Adjoining Parts.-II. Anatomy of the Brain.-III. The Nervous System.-IV. Anatomy of the Eye.-V. The Eye's Principal Parts and Their Functions.-VI. Physiology of Respiration.-VII. The Lungs.-VIII. Other Respiratory Organs.-LX. Gland, Secretion and Excretion Defined.-X. Glands of the Mouth and Throat.-XI. The Gullet and Digestive Apparatus.-XII. The Stomach.-XIII. 'The Intestines.-XIV. The Liver.-XV. The Pancreas, or Sweet-bread.-XVI. The Spleen, or Milt.-XVII. The Urinary Organs.-XVIII. Male Generative Organs.-XIX. Generative Organs of the Mare............... 168

\section{CHAP'TER XIV.}

THE PROCESS AND EFFECTS OF INFLAMMATION.

I. Concerning Inflammation in General.-II. Causes of Inflammation.-III. The Symptoms of Inflammation.-IV. Termination by Resolution.-V. Effusion and Suppuration.-VI. Abscesses.-VII. Uleeration.-VIII. Interstitial Deposits.-IX. Mortification, or Gangrene.-X. Treatment of Local Inflammation.-XI. Blisters.-XII. 'Treatment of General Inflam-

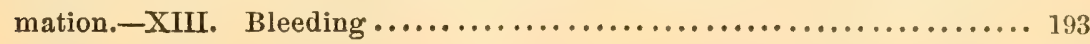




\section{CHAPTER XV. \\ DISEASES OF THE BONES.}

I. Inflammation of the Bone and Its Covering.-II. Sore Shins.-III. Caries, or Ulceration of a Bone.-IV. Necrosis, or Mortification of a Bone.-V. Nasal Gleet.-VI. Lumpy Jaw.-VII. Bone Cancer.-VIII. Bone and Cartilage Tumors.-IX. Big Head.-X. Dr. Stewart's Remarkable Account of Big Head.-XI. Former Inhuman Modes of Treatment.-XII. What Brings On Big Head?-XIII. Symptoms, as Described by Stewart. -XIV. Dr. Stewart's Method of Treatment.......................

\section{CHAP'TER XVI.}

INJURIES AND RESULTANT DISEASES OF THE BONES.

I. Poll Evil.-II. Fistula of the Withers.-III. Bone Spavin.-IV. Splints.

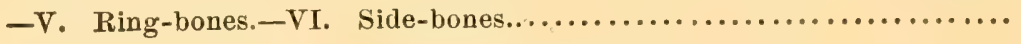

\section{CHAPTER XVII.}

\section{FRACTURES.}

I. Concerning Fractures in General.-II. How a Broken Bone Unites or "Knits."-III. Broken Limbs.-IV. Construction and Use of Slings, etc. -V. Fracture of the Skull.-VI. Fracture of the Upper Jaw.-VII. Fracture of the Lower Jaw.-VIII. Fracture of the Spine.-IX. Broken Ribs. -X. Fractures of the Pelvis.-XI. Fractures of the Fare Legs.-XII.

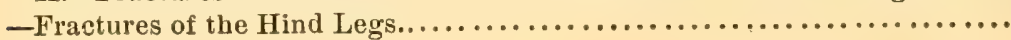

\section{CHAPTER XVIII.}

DISEASES AND INJURIES OF TIE FEET.

I. Nail Wounds.-II. Corns.-III. Bruises of the Sole.-IV. Treads.-V. Over-reaching, or Grabbing.-VI. Forging, or Clicking.-VII. Quittor, or Fistula of the Foot.-VIII. Contracted Heels or Hoof.-IX. Sandcrack, or Cracked Hoof.-X. False Quarter.-XI. 'Thrush.-XII. Canker. -XIII. Founder.-XIV. Horny Tumor of the Wall, or Keratoma.-XV.

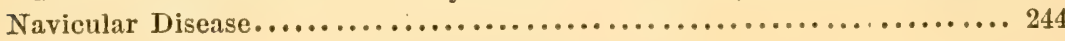

\section{CHAPTER XIX.}

TIE FOUNDATION PRINCIPLES OF SHOEING.

I. Shoeing a Great but Necessary Evil.-II. Importance of Accurate Knowledge in Shoeing.-III. 'The 'Two-fold Object of Shoeing.-IV. Appearance Versus Uility.-V. General Plan of the Foot's Structure.-VI. -Bon's of the Shank and Fetlock.-VII. Bones of the Foot.-VIII. Ligaments and Tendons of the Foot.-IX. 'The Cartilages and Cusbions of the Horse's Foot.-X. The Sensitive Foot, or "Quick."-XI. The Wall, or Crust, of the Hoof.-XII. The Sole.-XIII. 'Ihe Frog-XIV. As to Mutual Dependence of the Parts, and Symmetry.-XV. Structure of the IIoof.-XVI. 'The Production, Growth and Decay of Iloof.-XVI. 'I'wo Pertinent Questions.-XVIII. Proper Relative Position of Foot. and Leg.

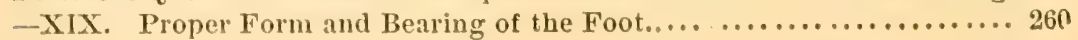




\section{CHAPTER XX.}

THE ART OF SHOEING.

I. Preparing the Foot for Shoeing.-II. The Three Requirements of a Prepared Foot.-III. The Bearing Surface--IV. The Surface in Special Cases.-V. The Proper Medium as to the Horny Covering.-VI. Lowering the Heels.-VII. Don't Pare the Sole.-VIII. As to the Frog and Over-reduced Feet.-IX. Correct Relationship of Foot and Limb.-X. To Secure a Proportionate Foot.-XI. Treatment of Over-grown Feet.-XII. Have the Sides of the Foot Left Even.-XIJI. Characteristies of the Shoe.-XIV. Foot and Ground Surfaces of the Sole.-XV. Calkins and Claws.-XVI. The Shoes for Carriage Horses, Hacks, etc.-XVII. The Nails and Nailing On.-XVIII. Clips and Other Preliminaries to Fitting. -XIX. Comparative Unimportance of Outline Fitting.-XX. Avoid Wrong Shoeing in Anticipation of Evil.-XXI. Good Surface-fitting Most of All Essential.-XXII. The Final Putting On.-XXII. The Charlier System of Shoeing.-XXIV. Discard Leather Soles, Pads, etc.-XXV. What is the Proper Interval Between Shoeings?-XXVI. How to Care for the Stabled Horse's Feet,-XXVII. Care of the Horse's Feet When at

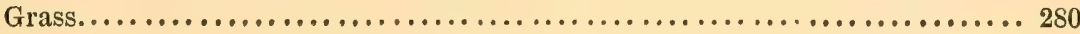

\section{CHAPTER XXI.}

\section{DISEASES AND INJURIES OF THE JOINTS.}

I. Inflammation of the Joints.-II. Open Joints.-III. Rheumatic Joints.IV. Dislocations in General.-V. Dislocation of the Patella, or Stiflejoint.-VI. Bog Spavin.-VII. Thorough-pin.-VIII. Blood Spavin.IX. Wind-galls, or Wind-puffs.-X. Kuuckling, or Standing Over....... 300

\section{CHAPTER XXII.}

Diseases AND iNJURIES OF THE MUSCles, TENDONS AND CELlulaR Tissues.

I. Atrophy, or Wasting Away, of a Muscle.-II. Broken or Cut Muscles.-III. Cramp of the Muscles.-IV. Sprained Shoulder.-V. Setons, and How to Insert Them.-VI. Sprained Elbow.-VII. Sprained Tendons.-VIII. Sprained Fetlock.-IX. Sprains of the Hind Leg.-X. Shoulder Slip, or Sweeny.-XI. Capped Elbow, or Shoe-boil.-XII. Capped Hock.-XIII. Curb.-XIV. Contracted Tendons.-XV. Swelled Legs.-XVI. Swelled Ankles.......................................................

\section{CHAPTER XXIII.}

WOUNDS, BURNS, ETC.

I. Classes or Kinds of Wounds.-II. Causes of Wounds.-III. Cleansing a Wound.-IV. Sewing a Wound.-V. Sutures.-VI. Bandages.-VII. 'The Threads and Needles to Use.-VIII. Nature's Different Modes of Healing.-IX. Dressing Wounds.-X. Burns and Scalds.............. 322 


\section{CHAP'THR XXIV.}

IUSEASES OF THE TEETH, AND THE MARKS OH AGE.

1. The 'Teeth a Frequent Source of Suffering.-II. The Horse's 'Teeth.-III. 'Iecthing, or Dentition.-IV. Shedding the Teeth.-V. Decay of the 'I'ecth, and 'Toothache.-VI. Extracting the Teeth.-VII. The Marks of Age-VIII. Second to Fourth Years.-IX. Fifth to Eighth Years.-X. Ninth to Thirteenth Years.-XI. Thirteen Years and Upwards.-XII. Ir-

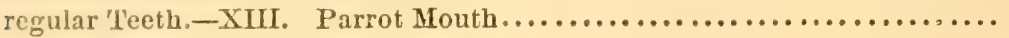

\section{CHAPTER XXV.}

DISEASES OF THE MOUTH AND STOMACH.

I. Lampas.-II. Pikes, and Paps or Barbs.-III. Wolf Teeth.-IV. Swollen Glands.-V. Choking.-VI. The Horse's Stomach and Its Peculiarity.VII. Bots.-VIII. Indigestion, or Dyspepsia.-IX. Stomach or "Blind" Staggers. $-\lambda$. Rupture of the Stomach or Bowels.................... 342

\section{CHAPTER XXVI.}

DISEASES OF THE INTESTINES.

1. Spasmodic or Cramp Colic.-II. Flatulent or Wind Colic.-III. Inflammation of the Bowels, or Enteritis.-IV. Diarrhoa.-V. Dysentery.-VI. Constipation.-VII. Hair-balls and Coneretions.-VIII. Worms.-IX. Hemorrhoids, or Piles. $-\mathrm{X}$. Hernia, or Rupture.................... 3

\section{CHAPTER XXVII.}

DISEASES OL' THE LIVEL AND SPLEEN.

I. Important Functions of the Liver--II. Organic Diseases of the Liver.III. Intlammation of the Liver, or Hepatitis.-IV. Fatty Liver.-V. Jatundice, or Yellows. -VI. Enlargement of the Spleen................ 364

\section{CHAPTER XXVIII.}

DISEASES OF THE KIDNEYS ANU BIADDER.

1. Inllammation of the Kidneys, or Nepuritis.-II. Diabetes.-III. Stoppage of the Urine, or Dysurea.-IV. Azoturea.-V. Intlammation of the Bladder, or Cystitis.-VI. Rupture of the Bladder.-VII. Spasm of the Bladder.-VIII. Stone or Gravel (Calculus) in the Bladder............... 369

\section{CHAP'TER XXIX.}

DISIASES, ETC., PLCULAR TO THE MALE.

I. Injury of the T'enis.-II. Beans,-III.-Tumors.-IV. Contraction of the Sheath.-V. Inflammation of the 'Iesticle, or Orehitis.-VI. Hydrocele. or Dropsy of the l'esticle.-VII. Varicose Veins.-VIII. Castration.-IX. Castration of the Ridgling, or Cryptorehid.-X. The Sequels of Castra-

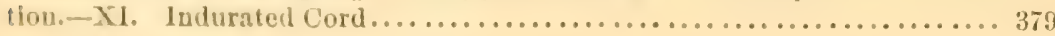




\section{CHAPTER XXX.}

DISEASES, ETC, PECULIAR TO THE MARE.

I. Rupture of the Perineum.-II.-Leucorrhœa, or the Whites.-III. Inflammation of the Womb, or Metritis.-IV. Abortion.-V. The Seven Periods of Gestation.-VI. Hemorrhage, or Flooding of the Womb.-VII. False Labor Pains.-VIII. Falling of the Womb.-IX. Nymphomania.-X. Spaying, or Castration of the Mare.-XI. Equine Syphilis.-XII. Inflammation of the Udder, or Mammitis............................. 390

\section{CHAPTER XXXI.}

\section{PARTURition.}

I. Natural Parturition.-II. Different Presentations.-III. Attention to the Mother.-IV. Attention to the Foal.-V. Difficult Parturitions in the Mare and Cow Compared.-VI. Difficulties Due to the Mother.-VII. Difficulties Due to the Foal.-VIII. Obstetric Instruments._LX. When the Foal is Born Dead, or the After-birth Retained................. 403

\section{CHAPTER XXXII.}

DISEASES OF THE NOSE AND THROAT.

I. Prevalence of These Diseases.-II. Catarrh, or Common Cold.-III. Nasal Gleet.-IV. Nasal Polypus.-V. Nasal Hemorrhage, or Epistaxis.-VI. Laryngitis, or Inflammation of the Larynx.-VII. Roaring and Whistling, or Laryngeal Paralysis................................... 411

\section{CHAPTER XXXIII.}

\section{DISEASES OF THE LUNGS.}

I. Bronchitis.-II. Pneumonia, or Inflammation of the Lungs.-III. Asthma, Broken Wind, and Heaves (Emphysema of the Lungs).-IV. Pleurisy, with Water on the Chest (Hydrothorax) ..............................

\section{CHAPTER XXXIV.}

DISEASES, ETC., OF THE HEART AND BLOOD-VESSELS.

I. Concerning Diseases of the Circulatory Apparatus in General.-II. 'The Pulse.-III. The Temperature.-IV. Foreign Bodies in the Heart.-V. Hypertrophy (Enlargement) of the Heart.-VI. Atrophy of the Heart.VII. Fatty Degeneration of the Heart.-VIII. Diseases of the Valves.IX. Tumors in the Heart.-X. Rupture of the Heart.-XI. Inflammation of the Pericardium, or Pericarditis.-XII. Aneurism.-XIII. Wounds of Blood-vessels.-XIV. Inflammation of the Jugular Vein, or Phlebitis.-

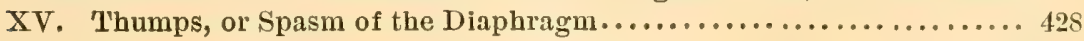




\section{CHAPTER XXXV.}

DISEASES OF THE BLOOD.

I. Boils.-II. Influenza, Distemper, or Pink-eye--III. Rheumatism.-IV. Purpura Hemorrhagica.-V. Glanders and Farcy.-VI. Strangles.-VII. Variola Equiua, or Horse Pox.-VIII. Rabies, or Hydrophobia.-IX. Melanosis, or Black Tumors.-X. Pyæmia, or Blood Poisoning.-XI. Weed or Thick Leg (Lymphangitis) .............................

\section{CHAPTER XXXVI.}

DISEASES OF THE NERVOUS SYSTEM.

I. Head Staggers, Stomach Staggers, or Brain F'ever.-II. Sleepy Staggers, Tumors in the Brain, etc.-III. Paralysis, or Palsy.-IV. Paralysis of the Lips and Tongue.-V. Spring-halt, or String-halt.-VI. Tetanus, or Lock-jaw............................................

\section{CHAPTER XXXVII.}

DISEASES, ETC., OF THE EYE AND EAR.

I. Torn Eyelids.-II. Warts on the Eyelids.-III. Entropium, or Turning in of the Eyelashes.-IV. Ectropium, or Turning Outward of the Eyelashes. -V. Filaria Oculi.-VI. Staphyloma, or Bulging of the Cornea.-VII. Glass Eye, or Amaurosis.-VIII. Inflammation of the Conjunctiva, or Conjunctivitis.-IX. Moon Blindness, or Periodic Ophthalmia.-X. Cataract.-XI. Examination of the Eye.-XII. Diseases of the Ear.........

CHAPTER XXXVIII.

DISEASES OF THE SKIN.

I. Scratches, or Cracked Heels.-II. Saddle and Collar Galls.-III. Ringworm.-IV. Mud Fever.-V. Erysipelas.-VI. Mange.-VII. Lice.VIII. Fleas.-IX. Ticks.-X. Warbles, or Woruils.-XI. Maggots.XII. Grease.-XIII. Hide-bound........................... 466

\section{CHAPTER XXXIX.}

\section{SPECIAL OPERATIONS.}

I. Many Operations Not Beyond the Farmer's Skill.-II. Anæsthetics.-III. How to Administer Chloroform.-IV. Methods of Securing for Operation. -V. Docking.-VI. Nicking.--VII. Neurotomy, or Nerving.-VIII. Trepanation, or 'Trephining,-IX. Subcutaneous Periosteotomy.-X. Tenotomy.-XI. Setons.-XII. Firing..................... 477

\section{CHAPTER XL.}

[POISONS, POISONOUS SNAKES AND INSECTS, ETC.

I. Conecrning Poisons in General.-II. The Chief Sources of Poisoning.-III. Internal Poisons.-IV. Poisonous Plants.-V. Poisonous Preparations from Plants.-VI. Poisons of the Skin.-VII. Snake-bites.-VIII. Venomous Spiders.-IX. The Centipede.-X. Stinging Scorpions.-XI.

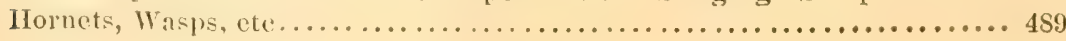




\section{CHAPTER XLI.}

Recapitulation of Remedies............................. 499

\section{THE AMERICAN TROTTER.}

BY E. B. ABERCROMBIE.

The Origin, Rise and Progress of the American Trotting Horse, with Short Sketches of the Most Celebrated Heroes of the Track and Road, and also a Set of 'Trotting Statistics at All Distances, Compiled and Revised up to

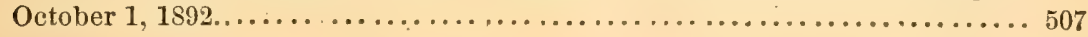

Glossary of Schentific and Important Word...................... 571 



\section{LIST OF ILLUSTRATIONS.}

PAGE.

Representative Breeds of the Horse............. (Frontispiece).

A hunter sire of 75 years ago...... 34

English hackney stallion Connaught 36

Typical English coach or post horses 37

Cleveland bay carriage horses..... 38

English shire stallion Bury Victor

Chief.....................

A typical English Suffolk stallion.. 40

English Clydesdale stallion Prince Alexander ..................

A pair of Percherons............ 45

French coach horse............ 46

Outline and points of the thor- 48 oughbred...................

Outline of draft horse and points...

The English thoroughbred (run-) ning horse) $. . . \ldots \ldots \ldots \ldots \ldots . . .6$

A typical trotting horse in condition

A breeding stallion (draft horse) ready for light exercise........

The modern Cleveland Bay horse.. Starting for the walk............ Received interpretation of the walk. Exceptional mode of starting.......

Action in the true trot............

The canter...................

Received interpretation of the gallop

Correct view of the gallop.........

Norman or French draft horse......

The leg-strap, No. 1............ 102

Cruiser, the vicious, with leg-strap and sureingle on.............

The leg-strap, No. 2............ 103

Ready for the final struggle....... 104

The horse bounding on his hind legs 105
Page.

$\left.\begin{array}{l}\text { The horse on his knees, about to } \\ \text { fall on his side................ }\end{array}\right\}$

The horse tamed............... 108

Rarey's halter and breaking-bit.... 111

Mechanism of the fore and hind limbs 114

Head of racing horse............ 119

Head of trotter................ 119

Thin-necked................... 119

Ewe-necked..................... 119

A neck bad and awkward.......... 120

Shapely for labor............... 120

A treacherous head.............. 120

Stubborn head................. 120

The idiot................... 121

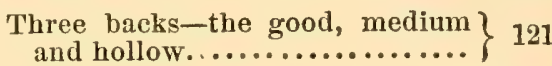

Good and bad shoulders.......... 122

Hip formations............... 122

Good form.................... 123

Not so good.................. 123

Bad form.................... 123

Crooked limbed.................. 123

Good hind limbs.............. 124

Bad to malformation............ 124

Fore limbs (two cuts)........... 124

Fore limbs (six cuts)........... 125

Front presentation (three cuts).... 126

Plan showing construction of 128 stable for sixteen horses........

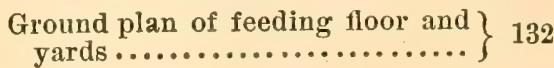

A model barn (northeast view) as 134 built and in use in Pennsylvania

Common ass and foal........... 137

Sunning himself.............. 138 $\left.\begin{array}{l}\text { A modified Spanish jack of the } \\ \text { United States................. }\end{array}\right\} 140$ 
$\left.\begin{array}{c}\text { Pagk. } \\ \text { (viewed from the right side) } . . .\end{array}\right\} 145$

Frame-work and outline of the 149 horse (from the left side)...... 149

Horse's foot and ankle........... 153

The skin—greatly magnified....... 155

Plan of the eirculation........... 159

The heart, aorta, etc. (The chest) opened on left side)........... 164

Horse's hoof.................. 166

Inside view of the hoof .......... 167

Sectional view of the horse's head.. 168

Sectional view of the eye........ 173

Organs of the neck and ehest (opened on the left side)......

The horse's stomach, as it appears upon dissection..............

The intestines of the horse........ 184

Male generative organs (the abdo-)

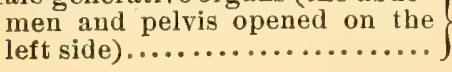
189

Generative organs of the mare (opened on the right side).....

Veins of the neck and face........ 195

Grooved director................ 197

Abscess lance.................. 198

Fleam for bleeding.............. 202

Pin suture................... 202

Sore $\operatorname{shin} . . . . . \ldots . . . \ldots . . . . .204$

Caries of the upper jaw.......... 205

Bone scraper................. 205

Splinter forceps............... 206

Cancer of the lower jaw-bone..... 20s

Bone tumor of the lower jaw (from

a photograph)...............

Bone chisel.................. 209

A severe case of big head......... 211

Fistula of the withers.......... 219

Bandage for the withers......... 220

'Three diseased hocks, illustrating)

bone spavin, bog spavin and 221

blood spaviu (three euts)......

A sound hock.................222

Bone spavin................. 223

High splint................ 224
PAGE.

High ring-bone................. 226

Low ring-bone................ 226

Large side-bones.............. 227

Simple fracture of lower jaw...... 228

Fracture that has united.......... 229

Sling for horse with broken leg.... 232

The lower jaw.............. 236

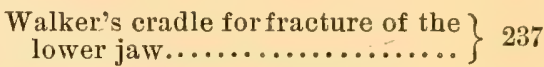

Fracture of the spine........... 23s

The ribs, vertebræ, etc......... 238

Bandage for the hip........... 240

Ankylosis of shoulder-joint........ 241

Stiff or ankylosed knee.......... 241

Shoe with iron extension......... 242

Fracture of the hock........... 243

Sage knife................... 245

A case of quittor............... 249

Sand-crack ................. 251

How to pare a cracked hoof....... 2 อั2

False quarter ................ 252

A foundered horse trying to walk... 255

'The result of chronic founder..... 256

Section of the foot, and pastern 258

The shoer at work............. 260

Section of the horse's foot........ 264

$\left.\begin{array}{l}\text { The coronet, or small pastern (dif- } \\ \text { ferent faces-three cuts)....... }\end{array}\right\} 265$

Coffin or pedal bone............ 265

Side view of coffin-bone......... 266

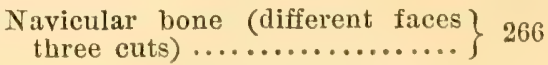

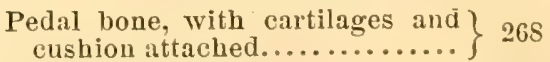

View of foot from above......... 268

Vall, or crust, of the foot........ 270

Section of the hoof............. 271

Sole and frog of the foot......... 272

Jay-Eye-See................ 276

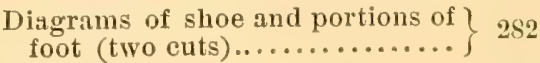

Hoof knives.................. 284 
Diagrammatic side-view of foot.... 286

Two forms of calkins............ 290

Side-view of shoe.............. 291

Hind and front shoes for carriage horses (two cuts).............

Hind and front shoes for hunters, etc. (two cuts) ................

Sectional views of shoe and point of foot (three cuts)...........

Section of the Charlier shoe....... 297

Section of the seated shoe........ 297

Dislocation of the stifle-joint...... 301

Thorough-pin and bog spavin..... 305

Bog spavin truss.............. 305

A case of knuckling of both fetlocks 307

Apparatus for deformed fetlock.... 308

India-rubber syringe............ 310

Seton needle................. 312

Muscles on back part of fore leg.... 314

Neck cradle.................. 316

Capped elbow, or shoe-boil........ 316

An ill-shaped hock.............. 318

A case of badly contracted tendon.. 319

Proper mode of bandaging the leg.. 320

Knot for stopping bleeding........ 324

Interrupted suture............. 325

Twisted suture................ 325

Different kinds of veterinarian's $\} 326$

Needle holder................. 326

Palate and teeth of the upper jaw.. 330

Toothache.................... 332

The teeth at about one month old.. 334

Rising three years (front view).... 334

Rising four years (front view)...... 335

Rising four years (from above).... 335

Five years................... 336

The nippers (incisors) at six years.. 336

Seven years old (side view) ....... 337

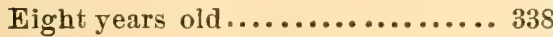

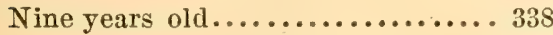

Eleven years old............... 339
Fifteen years old.............. 339

Nineteen years old.............. 340

Thirty years old................. 340

Tooth rasp................... 340

Pair of tooth-cutters............ 341

Parrot mouth (side view) ........ 341

Lance for cutting the gums........ 343

Probang for removing obstruction ? of the œsophagus (gullet)...... 345

Bandages for the front and sides of ? the neck...................

Bots and gad-flies, with eggs of the latter.................... 347

Effects of chronic indigestion...... 348

The sign of heart-burn.......... 34 S

Where to tap for blind staggers.... 350

The first signs of colic........... 351

Hypodermic syringe........... 352

Trocar and̄ canula.............. 354

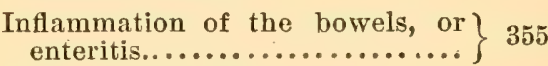

A sufferer from constipation....... 358

An intestinal concretion. . . . . . . . . 359

Abdominal hernia in mare with foal 363 An approved dreuching horn...... 366

Balling-iron ................... 367

The way to hold a pill........... 368

Inflammation of the kidneys....... 370

Diabetes.................... 371

Sectional view, illustrating the use $\} 373$ of the catheter...............

The slings in position........... 375

Calculus, or stone, from the bladder 377

Swollen penis................. 379

Testicle supporter.............. 381

Dropsy of the testicle (hydrocele).. 382

Colt thrown for castration......... 383

Castrating knife................. 384

Side lines for casting a colt. . . . . . . 384

Wooden clamps................. 385

Clamp on the testicle............ 385

The ecraseur.................. 356

Russian method of casting......... 386 
PAGE.
The ridgling cast on his back,.... 387
Round vagiual speculum ......... 391
Advancing symptoms of abortion... 393
Vaginal speculum............. 396
The position of the organs of the
mare.....................

Torsion forceps...............4400

Recumbent position............ 404

Head presentation............ 405

Tail presentation.............. 406

Right transverse position......... 407

Sharp hook................... 410

Blunt hook..................4 410

Steaming bag................. 412

Mouth speculum.............. 413

Throat bandage............. 415

Bronchitis ....................4 418

Pneumonia, or lung fever........ 420

A severe case of broken wind...... 423

A simple muzzle.............4 424

A case of pleurisy.............425

Hydrothorax, or water in the chest

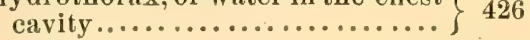

The heart and its vessels......... 428

Blood-vessels, etc., of the head..... 429

Dropsy from heart disease........ 432

Veterinarian's forceps........... 434

Tying an artery $\ldots . . . \ldots \ldots \ldots \ldots . . .45 \tilde{5}$

Balling-iron ................ 436

Diagram of boil (sectional view) .... 437

Catarrhal form of influenza (pink-) 439

Side-rod.................. 441

Purpura hemorrhagica.......... 442

Simple form of strangles........ 446

Poultice for strangles............ 447

Lymphangitis, or big leg.........450

Lymphangitis of the head.......450

The convulsions of mad staggers.... 452

Sleepy staggers............... 453

Right-sided paralysis of lower lip \} and tongue..................

Paralysis of both sides of lower lip. 455

'Tetanus, or lock-jaw........... 457

The eye in lock-jaw........... 457

Entropium................. 458

Bulging of the cornea..........459

Amaurosis, or glass eye........ 460
PAGE.

The eye bandage............. 461

Complete cataract.............. 463

The eye opener................4 465

Ear bandage................ 465

Bandage for the back..........4467

Ringworm ................ 467

Bandage for the top of the neck... 468

The mange insect (very highly 4470

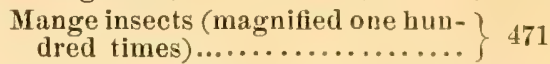

'T'he common tick (greatly magnified) 473

Bandage for the croup.......... 473

Chronic grease................ 474

Chloroform bag.............. 478

Hobbles for the horse.......... 479

Horse secured on the operating 480

Fore leg secured..............480

Docking knife................ 481

Nicking knife................ 483

A useful knife for nerving, etc..... 484

Bad results following high nerving. 484

Where to trephine............. 485

Circular trephine............. 486

Sharp-pointed bistoury.......... 486

Probe-pointed bistoury.......... 487

Convex-edged iron............. 488

Pointed iron................ 488

Various designs in firing.......... 488

Imported Messenger............. 508

Rysdyk's Hambletonian.......... 510

Lady Suffolk, $2: 261 / 2 \ldots \ldots \ldots \ldots . . \ldots 516$

Flora Temple, $2: 193 / 4 \ldots \ldots \ldots \ldots$...... 51s

Maud S., $2: 083 / 4 \ldots \ldots \ldots \ldots \ldots \ldots . . \ldots 27$

Sunol, $2: 081 / 4 \ldots \ldots \ldots \ldots \ldots \ldots . .529$

Phallas, $2: 13 \frac{3}{4} \ldots \ldots \ldots \ldots \ldots \ldots . \ldots 52$

Axtell (3 years), $2: 12 \ldots \ldots \ldots \ldots .535$

Nelson, $2: 10 \ldots \ldots \ldots \ldots \ldots \ldots \ldots . . \ldots . \ldots \ldots$

Palo Alto, $2: 083 / 4 \ldots \ldots \ldots \ldots \ldots \ldots 541$

Arion, $2: 103 / 4 \ldots \ldots \ldots \ldots \ldots \ldots .54$

Nancy Hanks, $2: 051 / 4 \ldots \ldots \ldots . .546$

H. B. Winship (trotter) and run- ? ning mate, $2: 06 \ldots \ldots \ldots \ldots \ldots . . .6551$

Westmont (pacer) and rumning mate, $2: 013 / 4 \ldots \ldots \ldots \ldots \ldots . .655$

Little Brown Jug, $2: 11{ }^{3} \ldots \ldots \ldots \ldots$.... 56

Direct, $2: 06 \ldots \ldots \ldots \ldots \ldots \ldots \ldots$.......... ฮ 60 


\section{THE AMERICAN FARMER'S HORSE BOOK.}

CHAPTER I.

HORSES FOR LABOR.

I. WHENCE OUR HORSES CAME.-II. TIIE HUNTING HORSE.-IIT. THE HACKNEY, - - IV. CARRLAGE HORSES.—V. ENGLISH DRAFT HORSES.—VI. THE SUFFOLK PUNCII.-VII. THE CLYDESDALE HORSE.—VIII. THE ENGLISH CART-HORSE.- IX. THE FLEMISH HORSE.-X. FRENCH DRAFT HORSES. -XI. THE PERCHERON HORSE.-XII. THE FRENCH COACH HORSE.XIII. HANOVERIAN AND GERMIAN COACH HORSES.

\section{Whence Our Horses Came.}

The British Isles have undoubtedly given to the world among the most excellent breeds of horses for all uses, save only the trotting horse. This class is distinctly American, and the only distinctive breed we possess; nevertheless, all the English, French, Belgian and German breeds, when brought and bred here, are, as a rule, capable of greater effort than in their original home, unless it be France, and perhaps Germany-for nowhere else is there a country whose climate seems so naturally adapted to the full development of the horse as in the Western States of the Union, including, of course, the Pacific States. There may be four divisions or classes of horses named and described among hor'ses for labor. These are the Hunting horse, a distinctly saddle horse; the Hackney, used for light driving; the Coach or Carriage horse; and last, but not least, the Draft horse. Of course, all these were originally from England and the continent of Europe. American horses superior in all these classes, whatever the country they may have originated in, have been produced by thousands, and of the most superior breeding that money could buy, until now, with our unapproachable trotting and road horses, no country in the civilized world can show better specimens than may be found in the United States. 


\section{The Hunting Horse.}

The Hunter, as he exists in England and also in the United States, is simply a modified thoroughbred, capable of carrying weight on his back, of undoubted bottom, and courage. He is generally threequarters bred, or eren higher. In the United. States trotting bred horses, many of them, make admirable hunter's, becoming extraordinary leapers, and of a courage that shrinks at nothing, when under the direction of an expert rider. Mr. Charles $W$. Tindall, in a late article on this class of horses in England, from which we make a few isolated extracts, says: "The reason why we hear so much about the

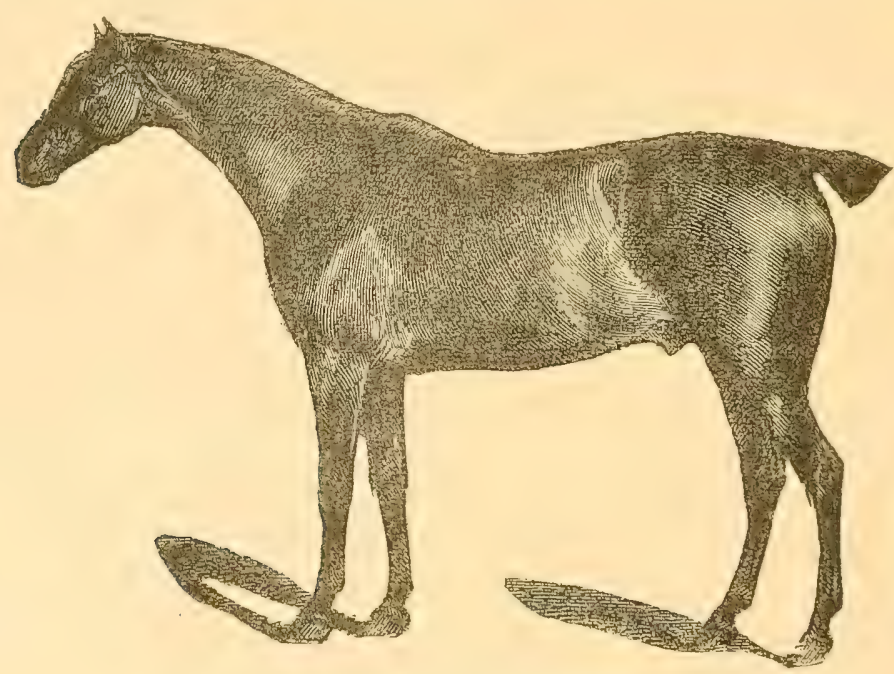

A IIUNTER SIRE OF 75 YEARS AGO.

breeding of IIunters not paring, is that, up to now, we have had no fixed type or principle for producing them. Can any one imatrine that hunters need be the only breed of horses that does not reproduce itself? Against any other class of horses we cannot make the same acrusation. In light horses, for example, from the thoroughbred to the shetand pony, or in the hearier hreeds (such as shires, Clydesdales, and Suffolks), they all reproduce themselves to type in the truest degrene. The thoroughbed moloubtedly is, and through the influence of the Turf will be, from a pecuniary point of view, the most valuable breed, and surely that of the Hunter ought to be the next in value. It will be said that Hunters have to carry different woights moler varied ciremustances, and comscruently have to be of 
so many sizes. Tes, but this equally applies to hackneys, which, although they have different degrees of strength, are still of one type.

"Hunters have, up to the present, been bred in every conceivable way; the dam bred no one knows how, the sire in most cases being a thoroughbred. Some adrocate the putting of small thoroughbred sires to light draught mares, whilst others adrise putting the small active cart-horse to a thoroughbred mare. The result of this haphazard mating is that not one in twenty-five animals designedly bred for hunters, answers the expectations, pays the breeder, or passes life in the occupation for which it was originally intended.

"Those who have for years been trying to breed valuable hunters from weight-carrying mares, crossed with thoroughbred horses, have failed to attain their object. I contend that the weight-carrying preminm mares will not produce stock able to carry weight, if mated for two generations with the light thoronghbred stallion. I believe that not five per cent of the premium mares so mated will produce progeny likely to be successful premium-wimners, but that their stock will decrease in size and substance each generation.

"To remedy this we should treat the horse in the same way as the mare, and breed from Hunter sires as well as from Hunter dams, and so fix a type. For that purpose select a stallion the true type of a Hunter, able to carry to hounds 196 to 212 pounds, with at least two erosses of thoroughbred blood in his veins, and whose dam was bred equally well, and also capable of carrying weight.

"I am not in favor of a large sire for the breeding of half-breds, but contend that the Hunter sire should certainly not exceed 16 hands, with form, substance, action, and be able to carry 196 pounds to hounds. If this be done in future, we shall then hear less about losses in Hunter breeding. To bring about such a reform I hope to see the Hunters' Improvement Society offering premiums for such sires. This would give a great impetus to breeding, and a practical result would follow."

\section{The Hackney.}

The IIackney of English blood is comparatively new in the United States, but has grown into favor in our large cities. They are certainly a most admirable class of horses, as now carefully bred in England, Yorkshire being their native home. Object lessons often teach more than pages of print, and hence the illustrations given in this work will be from the best English and American examples. 
The Hackney Stallion here shown is Connaught, the Champion at the London, Royal and Great Yorkshire shows. There is a regular Hackney Society in England, and also in America, in which is recognised only "full registered stock." During 1891 animals of this breed were imported into America as follows: New York, Connecticut, Vermont, Pennsylrania, Massachusetts, Ohio, Wisconsin, Illinois, Indiana, Colorado, Nebraska, Minnesota, and in the Dominion of

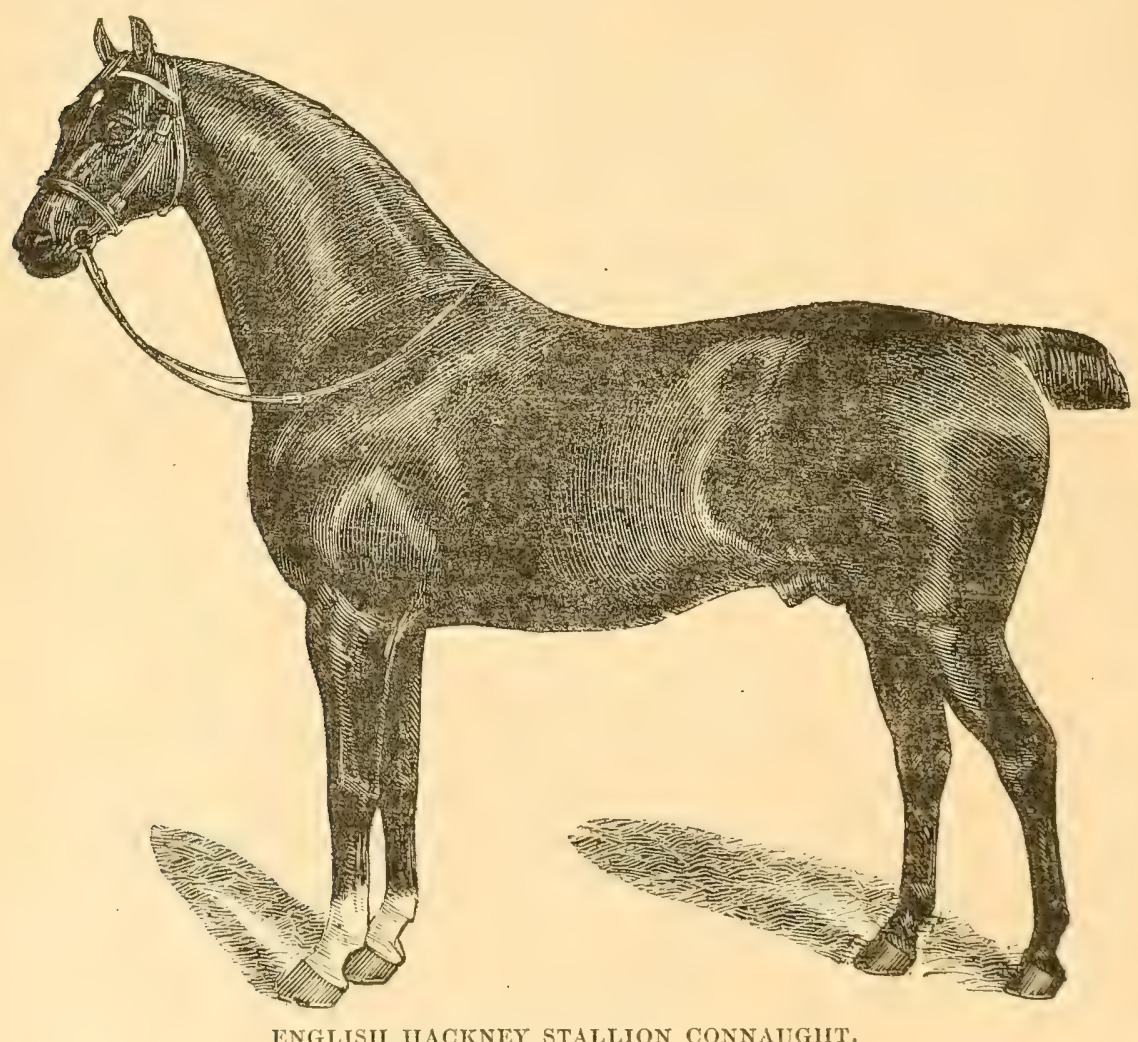

('anala 10 Queber, Ontario, Manitoha, and the Northwest Territory.

\section{Carriage Horses.}

In England there are two distinctly defined classes of carriage horses. These are the Cleveland Bay, and the Yorkshire Coach horse, both admirable for the uses intended. This elass of horses should range hetweren fifteen and three-tuarters hamds to sixteen and 
a half hands. The Cleveland Bay, as now bred, is certainly magnificent both as to style and action, and fitted for all classes of light draft, including, of course, the carriage. There are many large studs of these admirable horses in the United States, principally in the West, and they are yearly becoming better and better liked. As illustrating the advanced form both of Cleveland Bays and of the English Coach and Post horses, as they are now defined, we present accurate likenesses from original English sources of late date. On page 60 the reader will find depicted the "Modern Cleveland Bay Horse" (American).

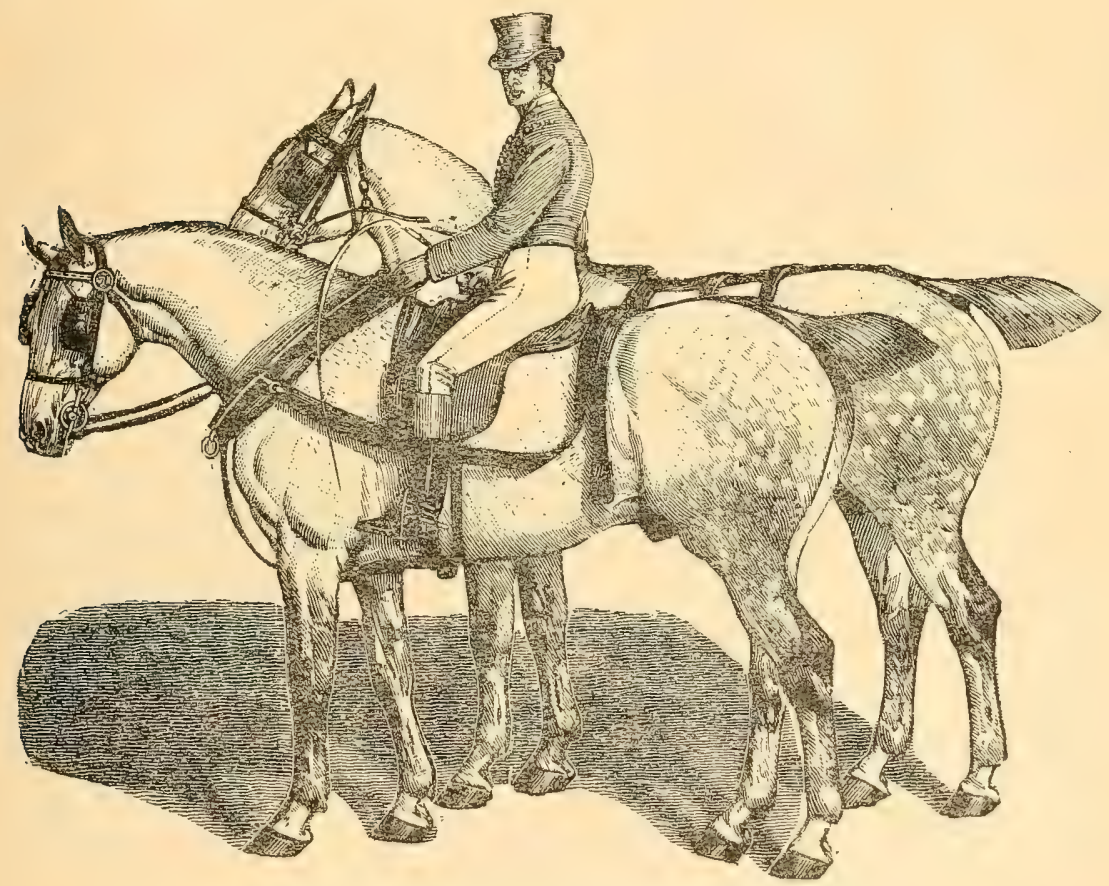

TYPICAL ENGLISIY COACH OR POST IIORSES.

The Cleveland Bay.-The Cleveland Bay, as it originally existed in the last century and early part of the present, was undoubtedly a horse bred between the old English Cart-hore mare (or, perhaps, the Flemish mare) and the thoronghbred. The Cleveland Bay of today is a far higher bred animal and a better, and one adapted to all purposes of light draft where a stylish, speedy horse is required. Hence the reason they came so quickly to be appreciated in the United States. As to the Yorkshire Coaching horse, it is simply a modifica- 
tion of the old English Post-horse, an animal now largely in disuse, but better bred now, as the illustration given of them shows, and producing arood models of horses well adapted for the family carriage, and the general work of the farm. Our cuts of the Cleveland Bay will give a good idea of this excellent horse, as now used in England and America.

The French Coach Horse.-Another candidate for public faror, and one fully competing the palm with the Cleveland Bay, is the French Coach horse, a modified Percheron, produced by crossing roomy, . modern bred French mares with the thoroughbred. They now carry

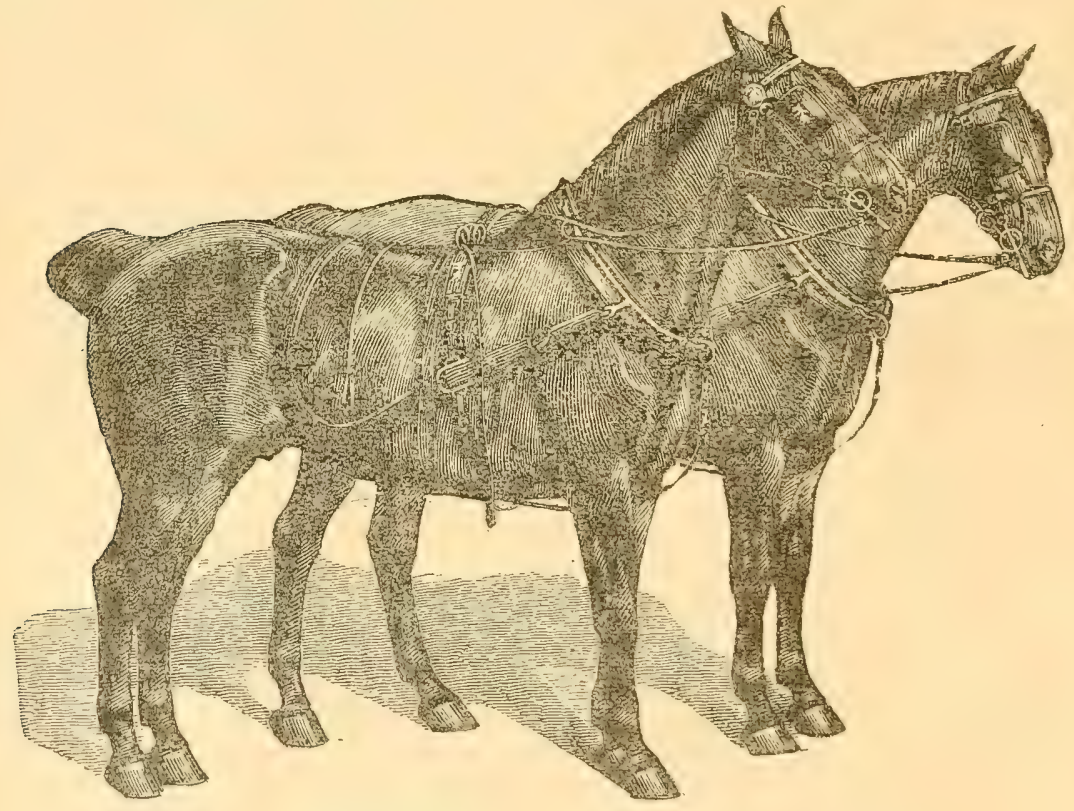

CLEVELAND BAY CATRIAGE IIOTSES.

distinctly solid colors, are stocky, elegant, high-headed, active, magnificent, able animals in every respeet, as bred in the United States. Though not as yet generally disseminated here, they are growing in faror year after year. The engraving on page 46 is a good representation of this admirable breed of French horses.

\section{English Draft Horses.}

The Shire Horse. - This haviest. and, to our mind, best of the English I raft horses, is whont doubt desended from the old English Cart-horse. Compared with his ancestors, while losing no 
weight, he has been refined and improved in every respect. The word Shire has been used in England since early in the sixteenth century. The origin of all the so-called great horses of England, as

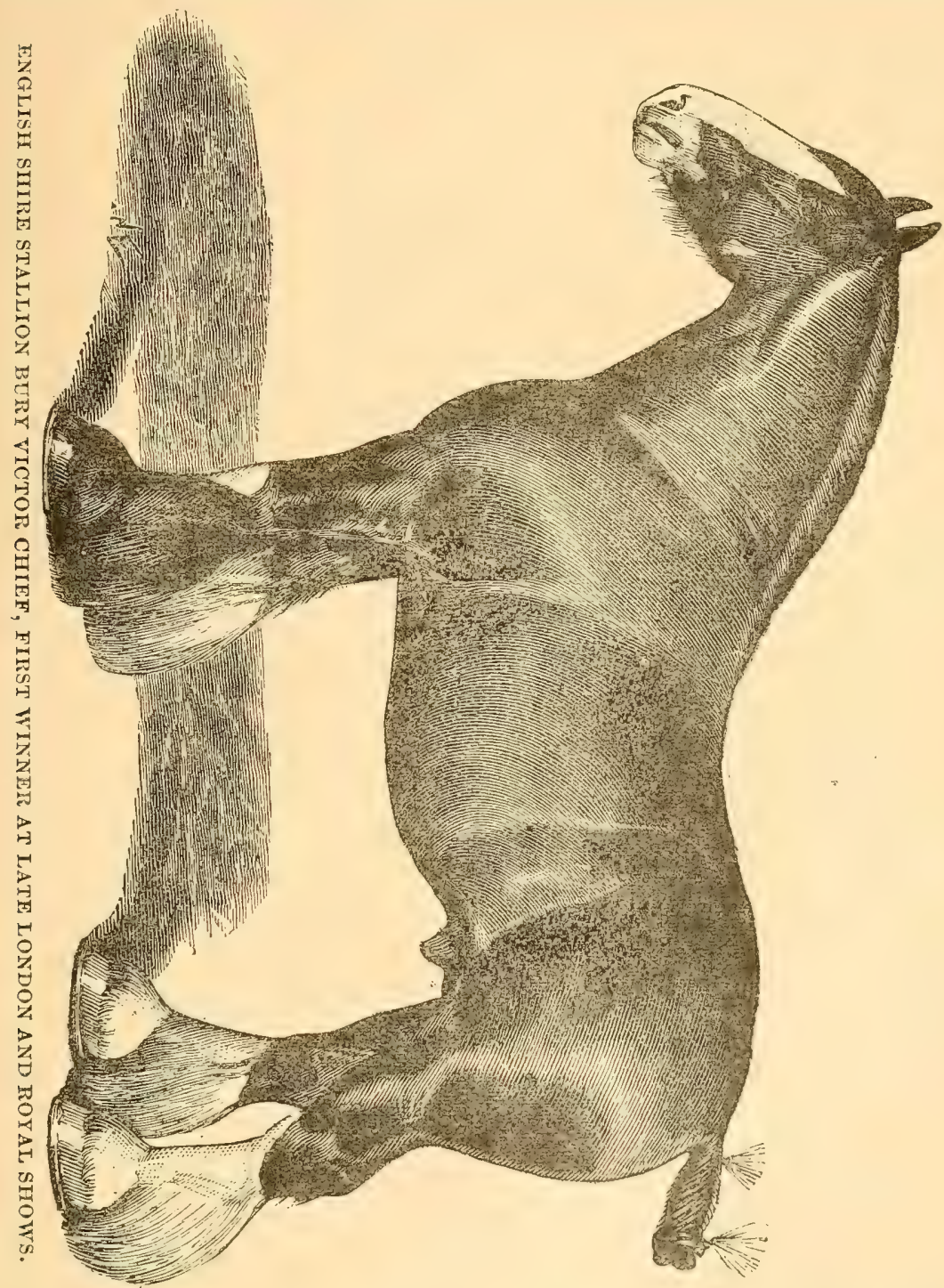

distinguishing size, lies, without douht, on the one side, with the Flemish mares introduced to Great Britain in the eleventh and twelfth centuries, and described as for the most part black, with white markings on face and feet, frequently with all the legs white to the knees 
and hocks; tall, rangy, muscular, well developed in vital points, with limbs broad, flat and cordy, strong-jointed, and with a fringe of long hair from the fetlocks to the cannon bone. They have been known since that time as the War horse, the Great horse, the old English

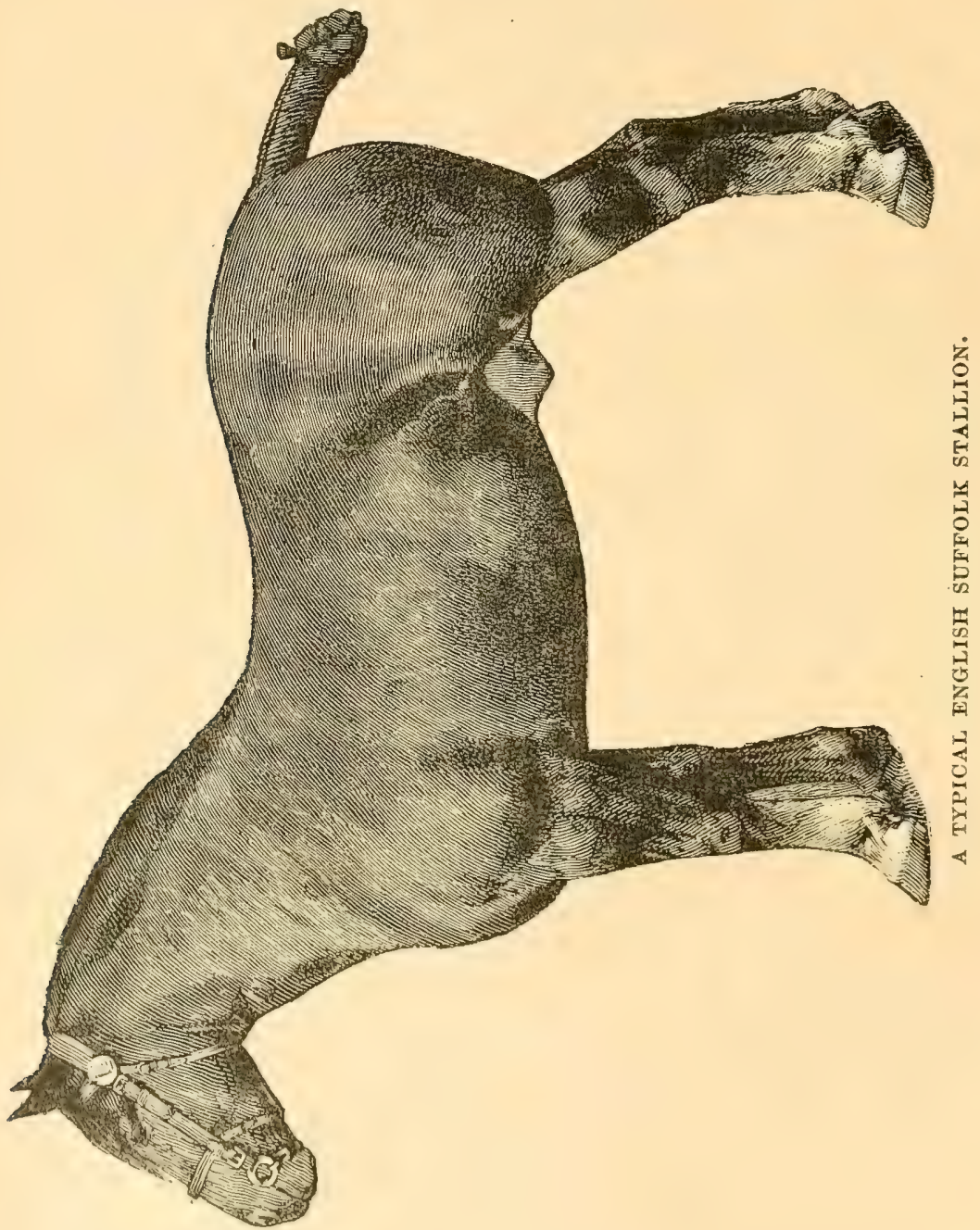

Black horse, or the Shire horse, and in latter years have been refined without impairment of vital power, so that to-day they stand as the peer of any draft horse on carth. The illustration shows the English Shire stallion Bury Victor Chief, first wimner at the late London and Royal Shows. 
sively introduced into the United States, and with general satisfaction. They are honest at a pull, and with the courage to keep trying until the load comes. While not so heavy as the Shire, as a rule they are heavy enough to take anything that comes. They have been famous in Great Britain since the middle of the fourteenth century, and are supposed to have been brought to perfection in Lanarkshire. The origin of the Clydesdale, like that of the Shire, lies in the Flemish horse, and since the early part of the eightecnth century they have been most carefully bred. Bay, brown and black have been prevailing color's, but latterly gray and chestnuts and some distinct sorrels have been bred. As with the Shire, white markings on the face, legs and feet are characteristic, as also the long, glossy hair from the knee and hock to the fetlock. All these features are regarded as marks of blood and high breeding. The illustration gives a good idea of the Clydesdale horse of to-day from the standpoint of English experts.

\section{The English Cart-horse.}

The Old English Cart-horse is not worthy of mention here, except as the foundation upon which the great draft horses of England and Scotland have been reared. They were black, heavy, and comparatively misshapen according to "Stonehenge," who, in his unique way, describes them as follows: "From time immemorial this country has possessed a heavy and comparatively misshapen animal, the more active of which were formerly used as chargers or pack horses, while the other's were devoted to the plow, and, as time wore on, to the lumbering vehicles of the period of Queen Elizabeth and her immediate successors. In color almost invariably black, with a great fiddle-case in the place of head, and feet concealed in long masses of hair, depending from misshapen legs, he united fat sides, upright shoulders, mean and narrow hips, and very drooping quarters. Still, plain as he was, he did his work willingly, and would pull at a dead weight until he dropped. This last quality was necessary enough at the first introduction of wheel carriages, for the roads were so bad that the wheels were constantly buricd up to their inaves in the deep ruts in the roads at the bottom of every hill, or wherever there was not a clear course for the water to run off. 'True pulling was, therefore, considered the first and most essential attribute of the cart or heavy carriage horse; and as without it the traveler or carter would be constantly left in the 'Slough of Despond,' it is not to be wondered at that such was the case." 


\section{The Flemish Horse.}

No less valuable in the building up of English draft horses has been the Flemish horse of the Continent, and in fact the impress of this animal is found originally in all British breeds, even in that of the thoroughbred, and especially does this apply to the Suffolk and the Cleveland Bay. These two latter, indeed, only exist in the improved and modified form. The Lincolnshire horse originated in a cross between the Black Cart-horse and the Flemish, and the French and German horses also are indebted to this mighty horse for size and stamina. So the Conestoga horse of Pennsylvania, now extinct, owed much of his value to the original Flemish blood, modified by crossing with German horses, and again with the then mixed blood of the United States in the early part of the present century. Of this wonderful horse a standard English writer says:

"The Flemish horses have long enjoyed a high reputation, and to them we owe many useful crosses among our dray and heavy agricultural draft horses. Both their light and heavy breeds are remarkable for high crests, small heads, somewhat narrow across the eyes, heary shoulder's, and round, powerful, but rery drooping quarters. Their hocks are comparatively small, but clean, and their legs light and free from hair. Their worst point lies in the feet, which almost always have flat and thin soles, unfitting them for fist work on hard roads. Just prior to the introduction of railroads, the English system of coaching was introduced into Belgium, and I have sat behind several teams of mares drawing a heary diligence more than ten miles within the hour. Almost all were bay with black points, and their leg's were nearly as clean and free from hair as those of our thoroughbreds. They were extraordinarily good tempered, and suffered their attendants to 'put them to' all together, being all attached to a splinter-bar, which was turned over the quarters of the wheelers. All that was necessary was to pull up nearly close hehind the four hor'ses standing ready for the change, then unhooking the bar of those just come in, it was turned over their quarters, and they were taken forward till they cleared the pole, when they were in a body turned on one side. The four fresh horses were then quickly backed to their places, a wheeler passing on each side the pole, the har was dropped to its place and hooked, the reins in the meantime being taken out of the territs by the coachman, and the change was effected in less than a minute." 


\section{French Draft Horses.}

There are two distinct types of draft horses in France, the principal difference being in the relative size. Both of these types have obtaincd great celebrity in the United States within the last thirty years, but are now so blended together that they really constitute a single class. The Flemish horse, the old Norman, and the Arab and Barb, introduced into France, after the victory of Charles Martel over the Saracens in the long ago of the 8th century, having been the prime integers in originating the French horses, later careful breeding has brought them to their present state of celebrity. The old Norman Cart-horse is described as having been large, powerful, active and hardy, with a heavy head and long cannon bones, but highly valued in the days when knights were clad in armor, as a war horse. Within the last fifty years, by wise selection and careful breeding, the horses originally called Normans and Percherons have been so blended, that, while having great weight, vigor and substance, they now combine the added and necessary qualification of elegance of earriage, and, unlike many of the great draft horses of England, have wonderfully good hoofs. The illustration on page 83 of the oldfashioned Norman horse will give a good idea of the size and almost colossal power which made it so famous.

\section{The Percheron Horse.}

The late J.H. Klippart, of Ohio, who made a most careful study of this breed about forty years ago in France, said: "The Percheron is a gray horse. In fact, everywhere in Perche every gray horse is called a Percheron. Every year thousands of fillies are brought there from Bretagne, a very great number undoubtedly the offspring of Boulonnais; from Flanders to Pidardy, where thee rery distinct rarieties of heavy and powerful draft horses are reared. Then there are the offspring of mares in the country of very diverse stallions." Mr. Klippart wats not impressed with these hories als at that time coming constant in form or other characteristies, exeept that they were wenerally gray. That they were, as a class, wonderfully active and courageous at a pull with a heary load on difficult roads, up hill and down, is a matter of history, and this it was that gave the Percheron or diligence horse of France his well deserved celebrity.

Sine Mr. Kipplat wrote, both the hearier and lighter horses have been most carefully bred, and Stud books have been established. 
They have been increased in size, style and weight, running from 1,500 up to 2,000 pounds each, and with the continued care, breeding and feeding and management in the United States, within the last twenty-five years, they undoubtedly constitute to-day the best and most valuable draft horses in the world, whether they be called Percheron, Norman, Norman-Percheron, or French Draft-horses-for by all these names they have been designated in the United States within the last twenty-five years. There are now two classes in the United States,

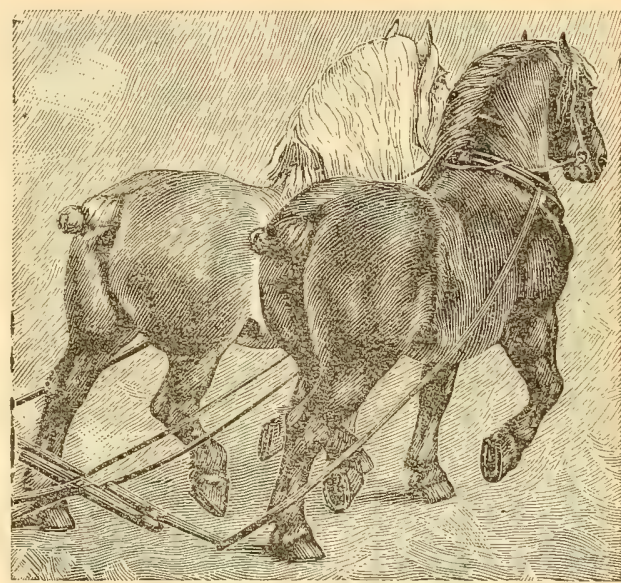

A PAIR OF PERCHERONS.

denominated one as Percheron, and the other as French Draft, and two Stud Registers.

\section{The French Coach Horse.}

This magnificent horse is a modified Percheron, having been given a sufficient amount of thoroughlned blood to increase the style and elegance, by rendering them more rangy and with higher crests, and with finer and cleaner limbs, and superb action in harness. They are of different colors-grays, bays, brown and black, and even some sorrels. The darker color's, however, are preferred. There are no poor or weedy horses among them, and hence those not good enough for stylish carriage horses, are always in request for fancy draft horses in our large cities. Notwithstanding their high breeding, they are as honest at a stiff pull as their close relations, the Percheron and French Draft horses. A good specinen is shown on the next page.

\section{Hanoverian and German Coach Horses.}

Within the last few years a class of horses have been brought to the United States known as the Hanoverian or German Coach horse. They are less in weight than the French Coach horses, and with higher erests and ereater flexion of the nerk, very elean-limbed, highactioned, nervous horses, showing careful breeding. As yet, however, they are rare. Nevertheless, an association of these breeders 
has been established, and a Stud Register of record printed. These horses are of solid color-bays, browns and blacks. It remains to be seen whether the elegant Cleveland Bay, the magnificent French Coach, or the stylish German Coach hor'se will become the favorite

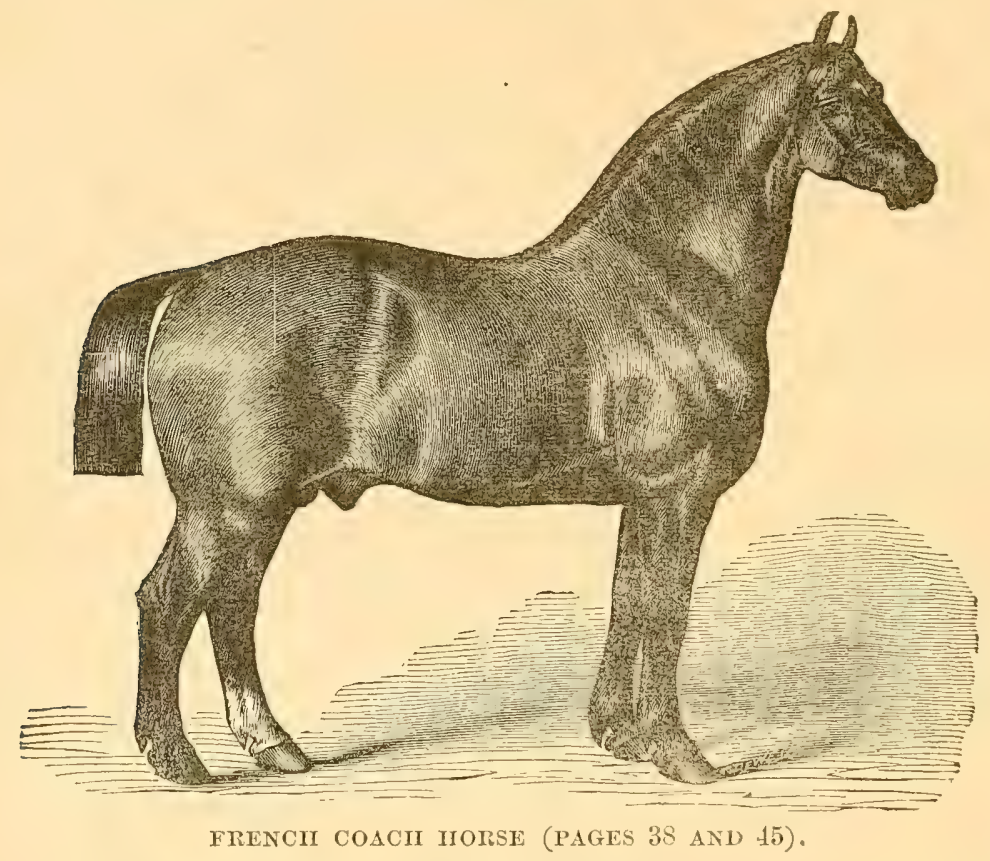

carriage horses of the constantly increasing number who willingly pay high prices for perfectly matched teams to pull the family carriage, the coach, drag, tally-ho, and other heary rehicles of our well-to-do class of citizens who have money to spend. 


\section{CHAPTER II.}

\section{THOROUGHBREDS AND TROTTING HORSES.}

I. THE THOLOUGHBRED A COMPOSITE HORSE.—II. EXTERNAT POINTS.—-III. VARYING STANDAID FOR DIFFERENT BREEDS.—IV. THE HEAD AND NECK. - V. TIIE FORE QUARTERS.-VI. TIE THOTTING HORSE THE ONLY BREED DISTINCTIVEY AMERICAN.—VII. WIDE DIFFLSION OF IIIS BLOOD. - VIII. HISTORY OUTLINED.—IX. TROTTING EVENTS IN THE PERIOD OF DEVELOPIENT.- $X$. BREEDING AND TRAINING TIE KEY-NOTE.

This work does not contemplate giving an extended history of the horse, nor any further descriptions of the several breeds than the average farmer will care to have. As for the breeder, he can easily procure a separate and more elaborate work on almost any breed he may be interested in.

\section{The Thoroughbred a Composite Horse.}

There is no doubt that the thoroughbred is a composite horse, but for centuries bred in England, and for more than one hundred years in America. Bred for speed and endurance, he will, when properly trained, pull a heavier load for his weight, and at a faster speed, than any other horse extant. Although the thoroughbred has not the weight to make him available for heary draft, the many admirable qualities he has become possessed of, and his wonderful power of transmitting valuable qualities to other breeds, when crossed thereon, render him to-day the most valuable of the various breeds of horses in England or America.

\section{External Points.}

Hence it will be well to study the external points as given in the annexed cut, with the proper term for each. 


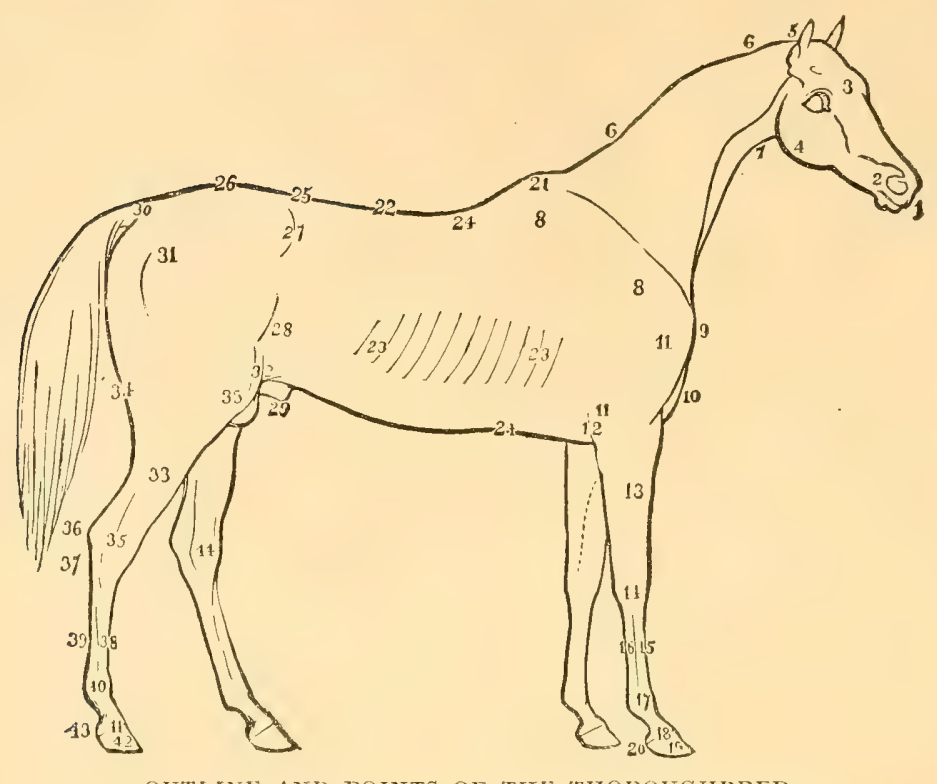

OUTLINE AND POINTS OF THE TIOIOUGHBRED.

1. Minzzle.

IIEAD.

2. Nostril.

3. Forehead.

4. Jaw.

5. Poll.

6. 6. Crest.

7. 'Thropple or windpipe.

$$
\text { BOLE QUARTER. }
$$

8. 8. Shoulder-blade.

9. P'oint of shoulder.

10. Bosom or breast.

11. 11. 'rue-arm.

12. Elbow.

13. Fore-arm (arm).

14. Innee.

15. Camnon-bone.

16. Back sinew.

17. Fetlock or pastern-joint.

18. Coronet.

19. Hoof or foot.

20. IIeel.

13OI)Y OR MIDULEPIECE.

21. Withers.

2.2. Back.
23. 23. Ribs (forming together the bar, rel or chest).

24. 24. The circumference of the chest at this point, called the girth.

25. The loins.

26. The eroup.

27. The hip.

28. 'The flank.

29. The sheath.

30. The root of the dock or tail.

TIIE MIND QUARTER.

31. 'lhe hip-joint, round, or whirlbone.

32. 'The stifle-joint.

3i. 33. Lower thigh or gaskin.

31. 'The quarters.

35. 'The hock.

36. The point of the hock.

37. 'I'he eurb place.

3. The cannon-bone.

39. The back sinew.

40. Pastern or fetlock-joint.

41. Colonet.

42. Foot or hoof.

43. Heel.

41. Spavin-place.

A Comparative View.-As a companion to the alowe we give an outline view of the draft horse, figured consecutively to correspond 
with that of the blood horse. As object lessons, the study of both these portraitures will be found instructive.

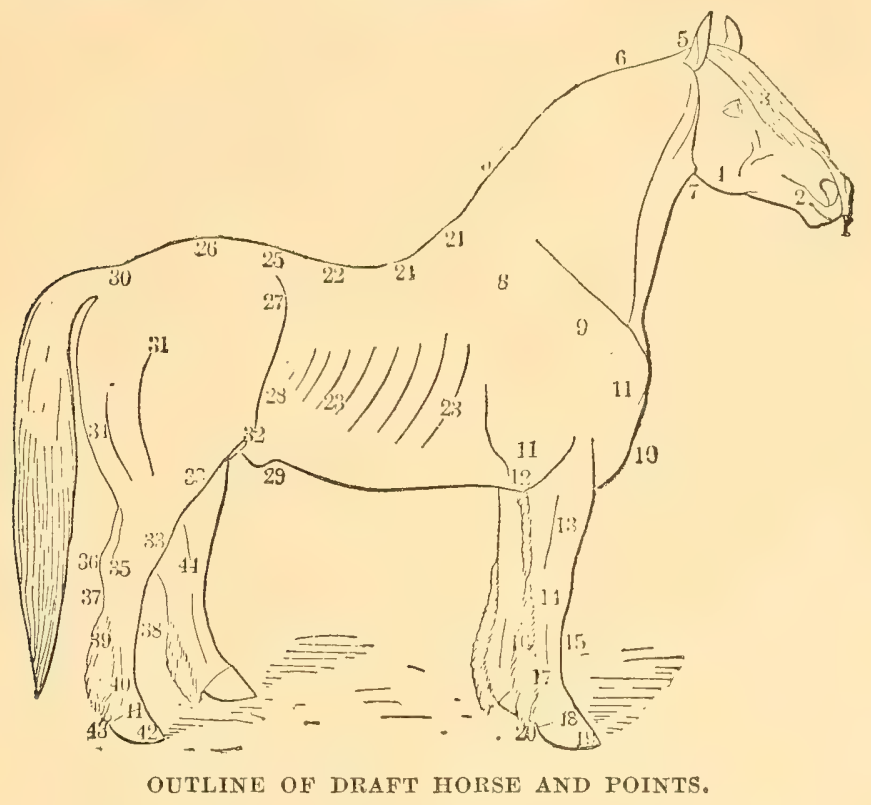

III. Varying Standard for Different Breeds.

The relative proportions of, and exact shape desirable in each of the points figured above, vary considerably in the several breeds. Thus, when speed and activity are required, an oblique shoulder-blade is essential; while for heary harness it can scarcely be too upright, enabling the pressure of the collar to be more easily borne, and allowing the animal to exert his strength at right angles to its long axis. Many good judges of Hunters and Hacks are almost wholly ignorant of the qualities desirable in a coach or cart horse. There are some elements, however, which are wanted in any horse, such as big hocks and knees, flat legs with large sinews, open jaws and full nostrils. We will next give the points which are always to be attended to, as being of importance in any kind, whether used for racing or hunting, for the road or on the farm.

\section{The Head and Neck.}

It should be known that the volume of brain contained within the head determines the courage and other mental qualities of the indi- 


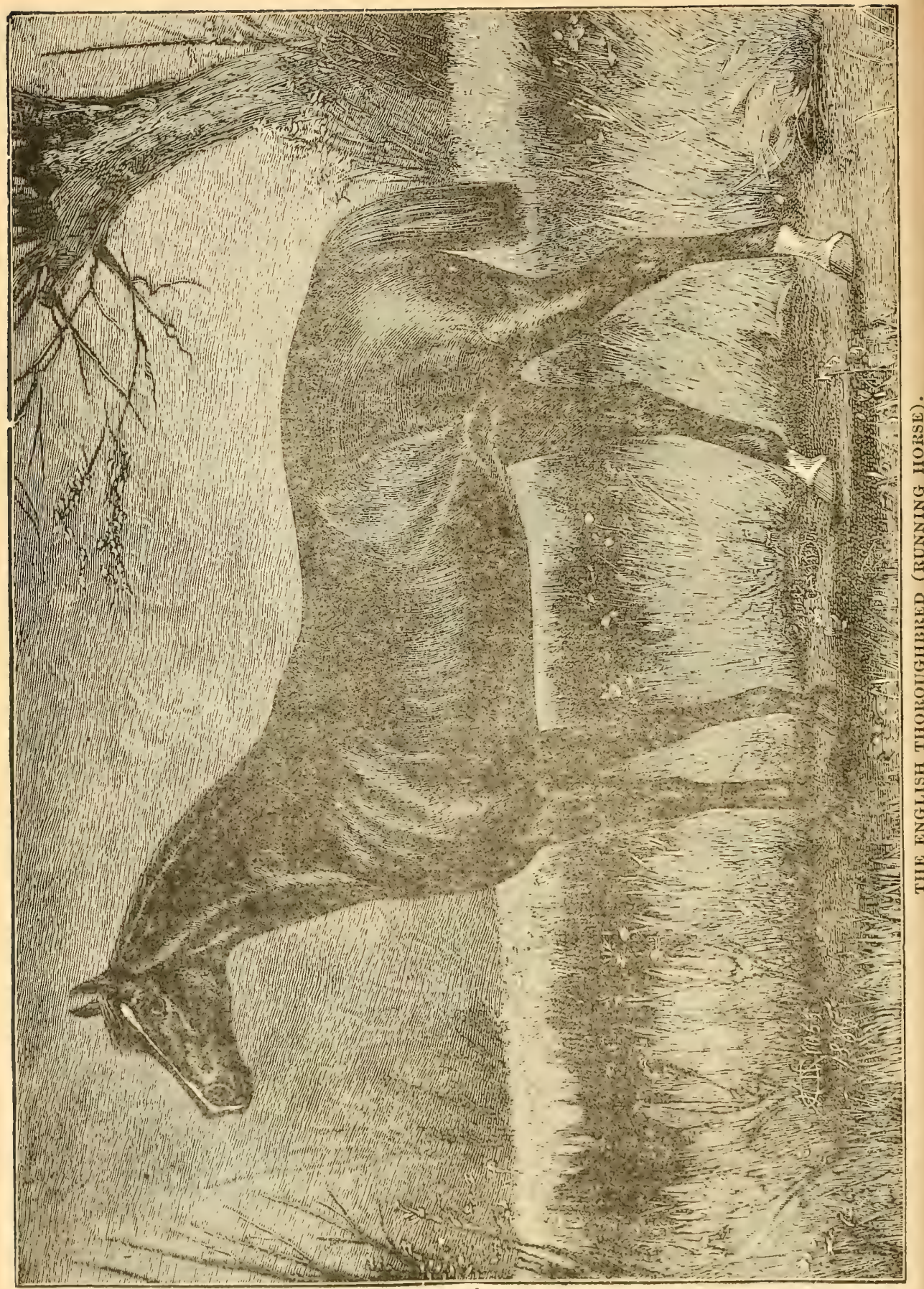


vidual. Without a wide forehead (which part marks the seat of the brain), you camnot expect a full development of those faculties known as courage, tractability, good temper, etc. The size of the muzzle is partly regarded as an element of beauty, and partly as a sign of high breeding. Hence, in the heary draft horse, a coarse jaw and thick muzzle are not regarded. A large and well-shown nostril cannot be dispensed with in horses intended for fast work, and should be desired even in the cart-horse, for in drawing heavy loads on a hot day, his breathing may be rendered almost as laborious as that of the highly-tasked race-horse or hunter. So also with the jaw, if there is not ample width between the two sides for the development and play of the larynx and wind-pipe, the wind is sure to be affected, and, in addition, the head cannot be nicely bent on the neck. A defect in this last point is the usual cause of that straight and inelegant setting on of the head which is so common, and which the practiced horseman avoids, as alike unsightly and prejudicial to the wind and the mouth; for a horse which cannot give way to the pressure of the bit is sure to become dull in his mouth, and, therefore, unpleasant to ride or drive.

The Eye and Ear.-The eye is to be examined with a two-fold purpose: firstly, as an index of the temper, the nature of which is marked by the expression of this organ; and secondly, in reference to its present state of soundress, and the probability of its continuing healthy. A full and clear eye, with soft, gazelle-like cxpression, is scarcely ever associated with a bad temper, and will most frequently continue sound, if the horse is managed as a horse ought to be. The ear should be of medium size, not too small nor too large, nor should it be lopped, though many lop-eared horses have heen known, and some very superior breeds, like that of the celebrated Melbourne, are notorious for this defect.

The Neck.-The neck should be of moderate length, all beyond a certain dimension being waste, and even a moderate-sized head at the end of an extremely long lever being too much for the muscles to support. It should come out full and muscular, with a sweep between the withers and the bosom, and should gradually diminish till it rums into the head, with an elegant bend just behind the ear. A very narrow throat suddenly hent at the upper part, marked as the thropple, is apt to be connected with roaring, and on that account objected to by horsemen. 


\section{The Fore Quarters.}

In the fore quarters there are several points to be attentively exanined, and, among these, the shoulder is regarded as of most consequence, when the horse under consideration is intended for the saddle. It is evident that, unless there is length of the blade, and also of the true-arm, there cannot be a full surface for the attachment and play of the muscles, nor can there be the same amount of spring to take off the jar which follows each footfall. The straighter the angle formed by the long axis of each of these hones, the less spring there will be. So, also, if the angle is not sufficient, the muscles of the shoulder-blade will not thrust forward the true-arm, nor will the latter be sufficiently clothed with muscles (without being loaded) to act on the fore-arm, more commonly known by horsemen as the arm. Hence it is found, that with an upright shoulder, not only is the stride in all the paces short and the action stumpy, but there is not that elastic movement which enables the horse to carry his body along rapidly and evenly, without rising alternately behind and before, and thereby jarring himself or his rider. On the other hand, the upright shoulder, loaded with a thick mass of muscles, is useful in the cart-horse, and to a certain extent, also, in the carriage-horse, in both of which the pressure of the collar requires a steady and comparatively motionless surface to bear it.

Concerning the Hind Quarters. - If the fore ruarter's are good, the hind ones should be, and generally are, the same. That excellence in the latter is just as important as excellence in the former, is indicated by the fact that the hinder parts are the real propelling machinery of the horse, no matter what his breed or his work. This subject will, therefore, be taken up in another chapter, deroted to a study of the standing and conformation of the horse, and showing, seriatim, every part of the body and limbs in detail. (See Chapter IX.)

\section{The Trotting Horse the Only Breed Distinctively American.}

The Trotting horse has become an distinet and well dereloped a breed here as was the Thoroughbred originally in Great Britain. In fact, he is the sole survivor of distinctively American breeds of horses, which at one time inchuled the Morgan, the Vermont Draft horse, the Conestoga horse of Pennsylyania, the Canadian pony, the wild Mustang of the plains, and its wiry little relative, the Indian pony. 
The Mustang of Spanish Origin.-The Mustangs were descended from the Spanish horses of an early dily in Central America, that escaped from domestication, and finally reverted to the wild state, and in time occupied Mexico and Texas, and the great plains of the Southwest and California. They are virtually extinct, like their old companions, the buffalo, and have given place to better types, bred from the best blood of both the Old and New World. The Conestoga horse above named has likewise had his day, never to return. The vast railway system of the United States has rendered these once valuable breeds no longer useful. Instead, there has been called into existence the American Trotting horse.

\section{Wide Diffusion of this Blood.}

The less valuable of this race are used for fast driving on the roads, by every class of citizens to whom speed and staying qualities are of value; so that now, among the more wealthy farmers of the country, large numbers of horses, in whose veins flows the blood of the best trotters, crossed on suitable mares, are annually raised. Meanwhile, the stamina of the real trotting horse has been so improved by special breeders for the turf, that these horses are now songht by the wealthy of every civilized nation, just as we still reinforce our racing blood occasionally from the best thoroughbred horses of England.

The Pacing Horse.-Nor should the pacing horse be ignored. He stands in point of speed between the trotting horse and the thoroughbred. Pacers are not liked for the buggy or carriage, but are easy under the saddle and undeniably fast, and the time made by the pacer, Hal Pointer, at Chicago, while this book is being printed, has lowered the pacing record to 2:051 which shows wonderful increase of speed. Whatever may be said about the equine race and pnenmatic tires to sulkies, it is evident that any owner having a horse that he thinks can beat this, may drive to the same kind of sulky.

\section{History Outlined.}

The trotting horse of America has been developed within the last fifty years, the Morgan being the first departure in this direction. Then came in an infusion of Canadian blood, and from various horses of Western origin that showed trotting stamina. Among these were the Gold Dusts of Kentucky, which owed their superior style, courage and speed to the Horgans in a good measure, as foundation stock, buit really much more to some fortunate crosses of thorough-blood. Later, the wonderful blood of Messenger, Duroe and Bellfounder, through Hambletonian and other sires, completed the genesis of the 
American Trotting horse, and at this day the greatest performers almost universally trace back to some combination of these strains, but principally to the get of the mighty Hambletonian. Tre can say that, as a breeder of descendants of Messenger and Bellfounder many years ago, we never had a disappointing colt. They were mighty driving horses, of great bone, muscle and sinew, of great lung power, and, of course, of great endurance.

\section{Trotting Events in the Period of Development.}

It will interest many of our readers to trace the development of the Trotting horse, as shown by the leading events of the American turf during rather more than thirty years up to 1856 .

In 1824, G. M. Giles trotted his horse 18 miles in one hour and fifty-seven seconds. The same year Topgallant and Betsy Baker were matched to trot three miles in harness for $\$ 1,000$ a side. The race was won by Topgallant by 40 yards, in 8 minutes, 42 seconds. Topgallant also trotted 12 miles on the road in 39 minutes. The "Albany Pony" did a mile in 2 minutes, 40 seconds. The Treadwell mare did one mile in 2:34; and Boston Blue trotted 18 miles within the hour. Boston Blue is reported to have been the first horse that trotted a mile in three minutes; it having been done in 1818. So that it will be seen that the Treadwell mare in 1824 had reduced the time to 2:34. Yet for many years after, a 2:40 horse was considered extraordinary, as also was any horse capable of going on the road in 3 minutes. In fact three minutes on the road is better than $2: 30$ on a first class, modern track.

In 1827, on the IIunting Park Astociation course of Philadelphia, Serewdriver won two heats of two miles, heating Butsy Balker in $8: 02$ and $8: 10$, the third best time on record. Dutchman afterwards accomplished the same distance in $7: 32 \frac{1}{2}$, and Lady Suffolk in $7: 40 \frac{1}{2}$.

In 1840, on the Long Island course, Jerry beat Whalebone in a three-mile trotting race, in 8:23 the first heat, and $8: 15$ the second. The best time for tro-mile heats that year was $5: 22,5: 21$; for 3 miles, $8: 26,8: 27,8: 41,8: 56$. On long distances Sweetbrier aecomplished six miles in 18:52.

In 1834 Edwin Forrest, as yet an unentered horse, trotted his mile in $2: 31 \frac{1}{2}$, beating Sally Miller. The course was 1 mile and 10 yards in length.

In 1835 Dutchman made four miles, under the saddle, in 11:19 and 10:51, and J)olly, hy Mosisenger, out of a thoroughbed mare, five miles to wagon, carrying two men, weighing 310 pounds, in 16:45; and immediately was started again to do 10 miles more, which she 
accomplished in 34:07. The same year the horse Daniel D. Thompkins, under the saddle, trotted three-mile heats in $7: 59$ and $8: 10$.

In 1842 Ripton beat Lady Suffolk, at three miles in harness, in $5: 07$ and $5: 17$.

In 1843 Lady Suffolk made mile heats in $2: 28 \frac{1}{2}, 2: 28,2: 28,2: 29$ and $2: 32$, which was not again equaled until 1854, when this record was covered by Tacony.

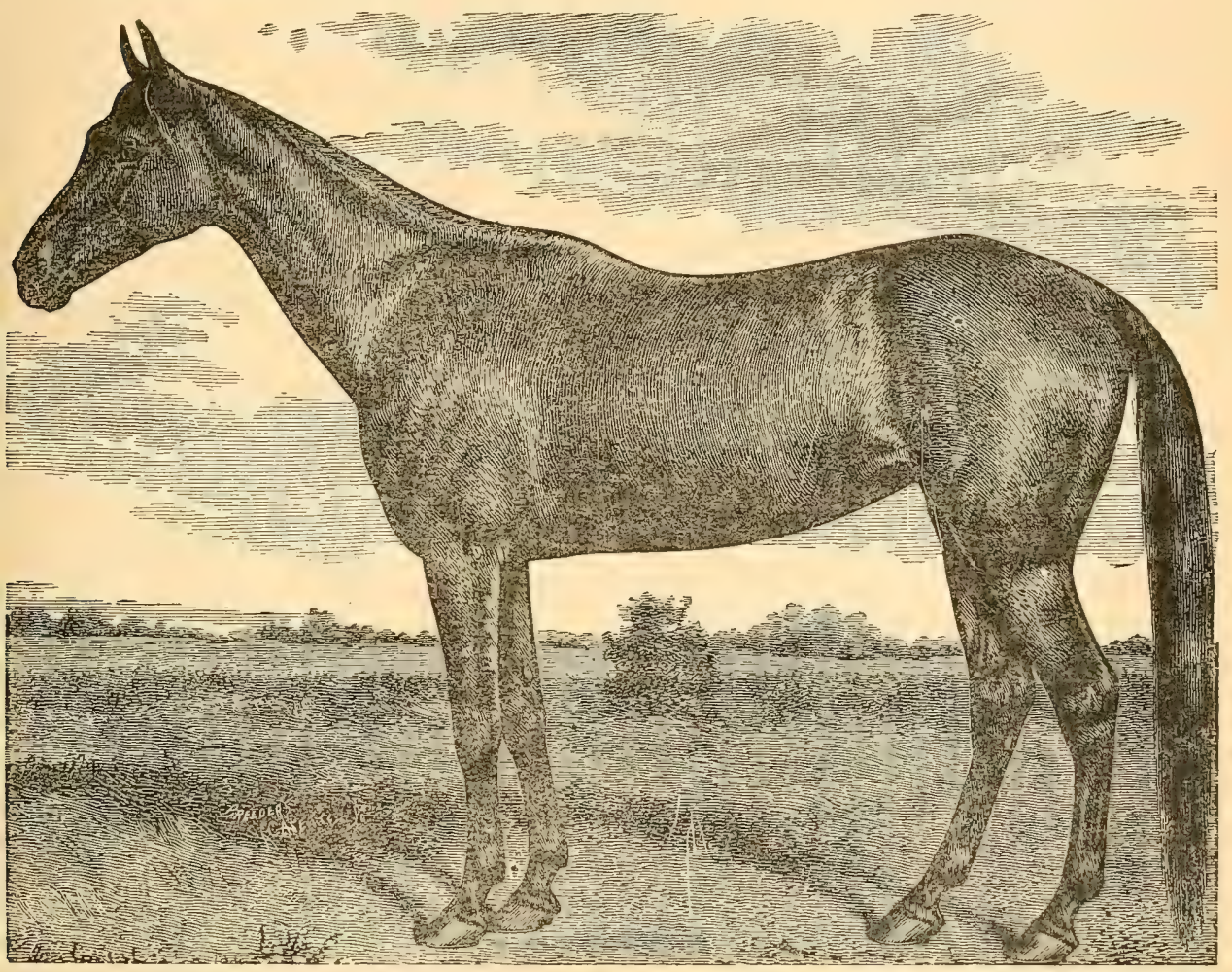

A TYPICAL TROTTING HORSE IN CONDITION.

In 1844 Cayuga Chief made the first half-mile of a lace in 1:15, the fastest yet made in pullie; and Famy Jenks accomplished 100 miles in harness, in 9 hours, 38 minutes and 34 seeonds. The slowest mile was done in $6: 25$ and the fastest in $4: 47$. At the end of the race this mare was driven an extra mile in $4: 23$.

In 1849 Lady Suffolk trotted 19 times and won 12, beating Gray Eagle and Mace twice, Pelham five times, Latly Sutton twice, Trustee four times; also beat Blake IIawk, (iray Trouble, Plowboy and other horses. In this yealr a Canadian mare, fly, is said to have been driven 
from Cornwall to Montreal, ninety miles, in 8 hours and 15 minutes. Fanny Jenks made 100 miles in 9 hours, 38 minutes and 34 seconds. Fanny Murray trotted 100 miles in 9 hours, 41 minutes and 23 seconds.

In 1852 Tacony won 12 races, beating all the best horses of the day, making a single mile in 2:26; two miles in 5:02, and was beaten only twice. As a 3-year old, Ethan Allen trotted this year in $3: 20$. Flora Temple this year won her first purse, on the regular turf, in $2: 41$.

In 1853 the entire sporting interest was centered in Flora Temple and Tacony. Flora this year beat all the best horses of the day, winning seventeen times. Her best time at mile heats was 2:27, $2: 28$, and at two-mile heats, $5: 01 \frac{1}{2}, 4: 59$. This year Tacony trotted a mile in $2: 25 \frac{1}{2}$.

In 1856 the contest lay principally between Flora Temple and Lancet. Flora made 11 races, winning 9, beating Lancet four times in harness, and Tacony three times in harness, Tacony going under the saddle. This year Flora Temple lowered the one-mile record to $2: 24 \frac{1}{2}$.

Trotting Achievements of To-day.-The trotting history of our own times is given at ample length, and in style most interesting, at the close of this rolume, by E. B. Abercrombie, of New Tork City, editor of the "Spirit of the Times." There is no higher authority on this subject than Major Abercrombie.

\section{'x. Breeding and Training the Key-note.}

It is clear that if the English thoroughbred has now lost the trotting faculty, it is not because it was never in him. It is really because, in England, the racer was never trained to trot, nor allowed to use his faculty therefor. It was left to "saga(ious Americans to develop this wonderful power in the Trotting horse of America," as the English writer, Herbert, so happily expressed it. Few horses could gallop far or fast without special training. No horse ever won a great race without previous special tests of his powers of endurance, after careful training. So no horse ever made an honest and fast trotter without the special blood of horses with the heredity of trotting sires, supplemented by long years of careful breeding and selection, and the most careful training, when of proper age, for the turf. And we repeat, the faster the horse, the faster must be his speeding to fit him for his best efforts. 


\section{CHAPTER III.}

\section{THE BREEDING OF HORSES.}

I. HOW EXCELLENCE IS ATTAINED.-II. MIPORTANCE OF EXERCISE TO BREEDING ANIMALS. - III. THE LAW OF SMIMLARITY.—IV. CAREFUL STUDY THE KEY TO SUCCESS.— V. BREED TO THE END SOUGHT.—VI. ABOUT FORM AND PROPORTION.-VII. THE POINTS TO BE STUDIED ARE MANY.-V-VII. IMPORTANCE OF ACCURATE KNOWLEDGE.—IX. STONEHENGE'S LAWS OF GENERATION.

\section{How Excellence in Breed is Attained.}

As preliminary to this subject, it may be well to state that the idea is prevalent among the masses that any person can produce a new breed by crossing animals of two different types. Nothing could be wider of the mark. It has taken one hundred and fifty years to bring Short-horn cattle to their present perfection. The English breeds of sheep have special habitats, and have had for many generations in England. The great, or rather the final, improvement in all noted breeds, including the thoroughbred horse, has, indeed, been made within the last two hundred years, and especially within the last fifty years. It has been accomplished by starting with a good foundation, careful selection, and as careful breeding to line, or to animals having the precise characteristics intended to be perpetuated; but before all this had come very many years of gradual hereditary improvement. The wonderful transmissive power's of the Percheron horse is due, in our opinion, principally to the fact that entire horses are largely used in France for labor. Hence the ease with which animals of great stamina may be selected for sires. Then, again, the breed, whatever may have been their origin, is kept pure, and not only are the horses but the mares kept steadily at work.

\section{Importance of Exercise to Breeding Animals.}

We hold to the idea of giving stamina to breeding animals. It is essentially necessary that all animals destined for labor have constant and long continued exercise, and, webelieve, none the less necessary that every breeding animal should be in full vigor, though the exer- 
cise must be different with different animals, according to the use for which they are intended. Some of our breeds of eattle and hogs are notably impotent, from lack of proper exercise of the sires and dams. To come back to the horse, our best breeders have come to recognize that both the stallion and the mare must have exercise in proportion to the work the colts are expected to perform. It is the fact that they appreciate that full exercise for the stallion, during the season of copulation, is absolutely necessary to insure vigor in the get. It is no less important to the mare while carrying the foal.

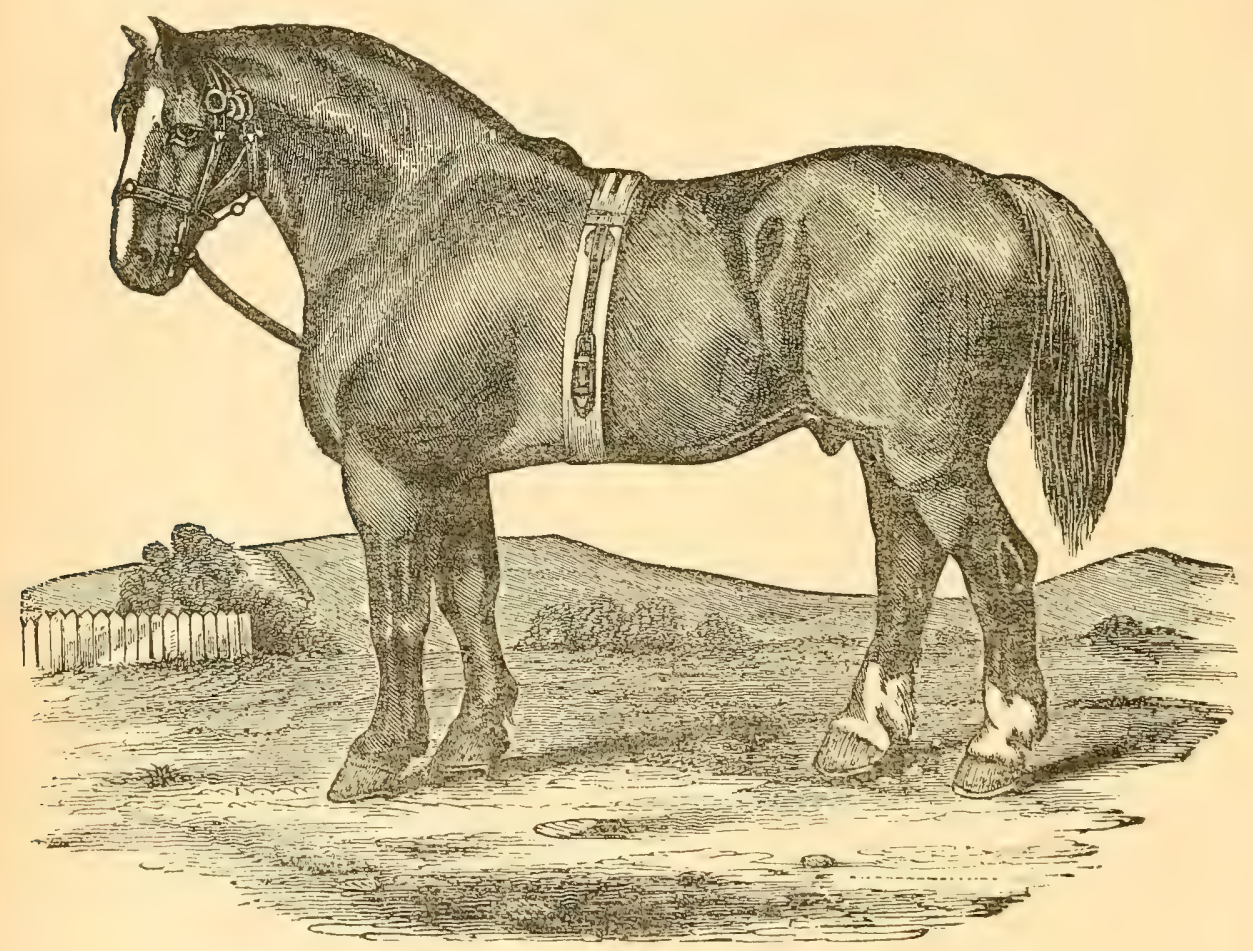

A BREEDING STALLION (DRAFT HORSE) READY FOI LIGHT EXERCISE.

III. The Law of Similarity.

It is difficult to make the arerage man believe that his judgment is not as good as that of any other man. Hence, the many mistakes of breeders. They all elaim to breed only from the best, which is what the law of similarity teaches. But judgment errs. Why? Because the judgment is not edueated to the true perception of similarity. To illustrate:- The microsene, hy enlarging an object, reveals feat- 
ures not apparent to the unassisted rision. Yet, to the uneducated eye, the microscope shows only one fact, the enlargement. The glass is said to have penetration, yet this penetration really lies in the education of the eye as much as in the clearness of the lenses. To the uneducated eye the animal fat from full feeding, sleek and glossy, seems perfect. The uneducated person hears experts speaking of an animal's fine handling. He, howerer, sees little or no difference between any two fat animals. The expert judge most surely sees a difference, whether the beast be lean or fat; the handling is entirely different to the sense of touch, as the lean and fat are essentially different to the eye. These are points that cannot be learned by reading alone. Nor can they be learned simply by experiment and continued observation and reflection, except through an immense expenditure of time and labor.

\section{Careful Study the Key to Success.}

By reading and comparing competent authorities, by giving attention to actual differences, and the explanations of them, by acquiring an accurate knowledge of the animal structure,-by processes of this kind, the anatomical and physiological differences as between the superior and inferior become clearly apprehended, because the judgment has been educated especially thereto. The mind has acquired powers of penetration, just as the eye of the accomplished microscopist acquires penetration by the aid of the microscope. To the latter all is clear, however minute. He discriminates at once the blood globules of one animal from those of another, wool from hair, one integument or substance from another, all simply through education in this particular direction. Similarly, the careful thought and study of the breeder will enable him to determine whether a particular sire or dam will be apt to throw certain peculiarities or disabilities; much more surely, at least, than the individual who has only studied the animal economy from a superficial standpoint, no matter how critically within his narrow range.

Again, an animal will show weakness to the eye of an expert, not recognized, not taken in, by the eye of a merely superficial observer. That is to say, an animal will show weakness to his educated senses that would pass entirely unobserved by one who had not critically studied the animal ceonomy, in its scientific aspects as well as those more ordinarily apparent. Thus, to be successful, the breeder must carefully study the best works relating to hygiene, sanitation, the pairing 


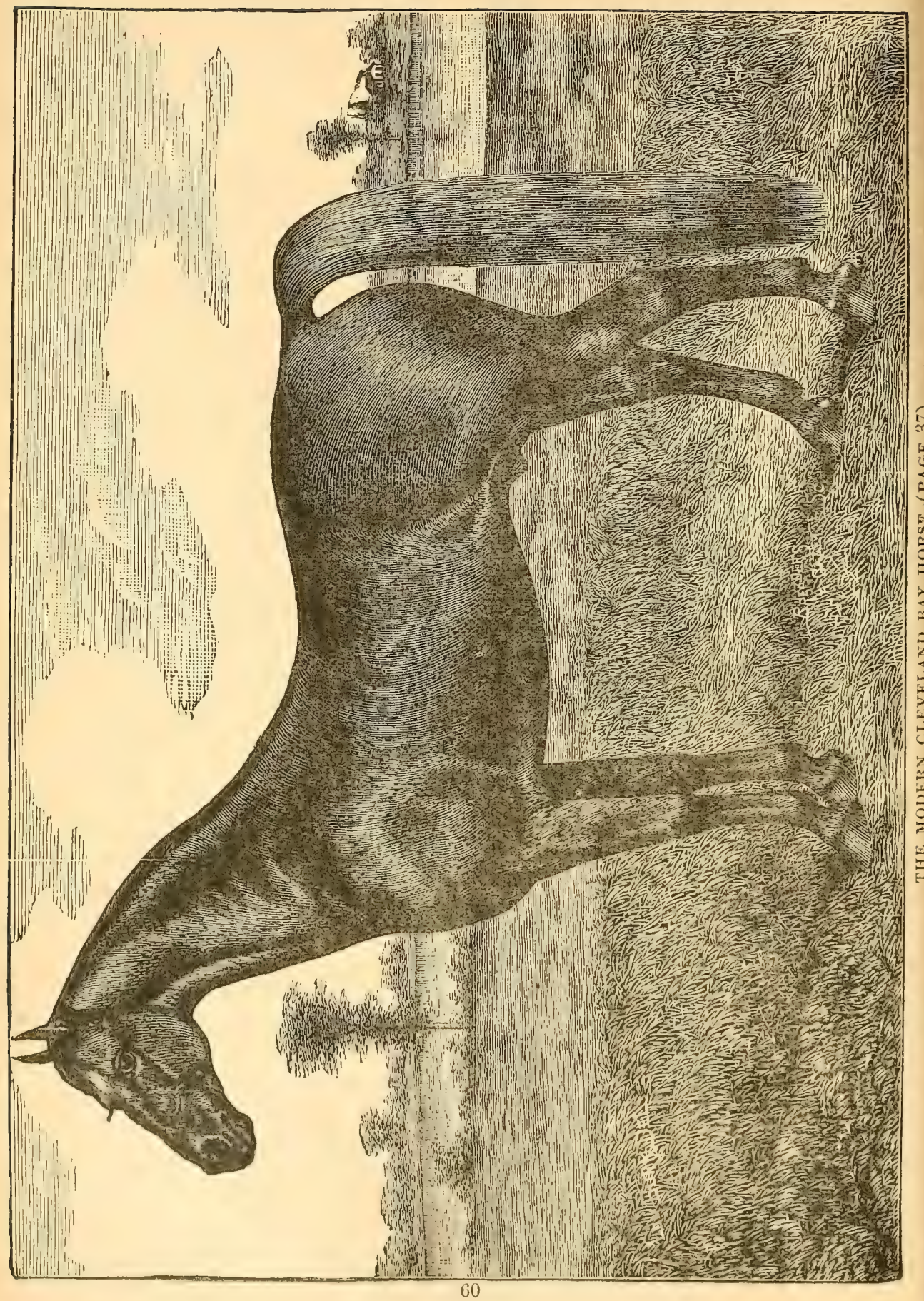


of animals, the proper foods, and all the various elements of integrity in the animal economy. While it is impossible here to go into the subject exhaustively, let these principles become fixed in mind and made the constant guide. A careful study of the various breeds, as illustrated in this work, will assist materially, so far as outward conformation is concerned, as a careful study of the best living anjmals will assist no less in penetration.

Points to be Remembered-While a correct knowledge of the animal structure and animal economy is especially necessary to the breeder, he should bear in mind that each animal must be judged, in many respects, by a different standard. Still, there are certain points always to be looked to. In the horse, style, bone, muscle and constitution, all are important, as indicating ability to perform labor. Quality is indicated by a rather thin skin, short, fine, smooth hair, and a lighter mane proportionally to the tail. On the other hand, a big-headed horse, for instance, with heavy-matted mane, may be set down as a low bred, coarsely constituted brute, unworthy of much regard, no matter what the labor it may have to perform.

\section{Breed to the Fnd Sought.}

We have always held it as an axiom that the individual who undertakes to breed up from an inferior foundation stock, begins at the wrong end. In fact, he is going over the same ground that has so laboriously been gone over by the breeders of horses for the last five hundred years; for it has taken fully that length of time to secure hereditary characteristics, that now come measurably constant. The rule will apply to all other animals, as well as the horse. The most intelligent breeders, within the last one hundred years, have spent much labor in weeding out sires and dams subject to disease and disabilities, keeping in mind the impressive declaration of Youatt, written fifty years ago, that nine-tenths of the ills to which the horse is subject, are the result of hereditary influence. Only since the truism that "like produces like," and hence "breed from the best," have come to be acknowledged, has steady improvement in breeds become the rule.

Keep the Breed Intact.-There is still another fact that should be kept constantly in mind, which is that when a breed has been brought to a high state of perfertion, it repuires as high skill to continue it on this high plane as it did to bring it there. The breeder who forgets this will learn to his cost how true it is. 


\section{About Form and Proportion.}

In breeding, a critical study must constantly be made of form and proportion in the horse, and their relations to the qualities to be developed or kept intact. This is an absolute condition of success. The horse is an animal solely of labor, whether fast or slow. Hence a different standard must be adopted for each and every breed, according to its particular use-for instance, power in slow draft, or, as in the carriage horse, elegance in style. Not so much in these broad distinctions as in minuter yet highly important ones, does the modern breeder display the mastery of his art. For example, great muscular development, to speed him over the ground, is necessary to the running and trotting horse alike; yet the peculiar derelopment requisite in the one is not precisely the development to be sought for in the other. Hence the best and most perfect types of the several classes of horses should be studied as models.

\section{The Points to be Studied are Many.}

Not every man is capable of doing what we have recommended, for only a comparatively few persons in each generation have the eye to detect minor defects in form and carriage, and especially what are, to the many, the hidden disabilities of the animal organism. But these are far from the only points which the skillful breeder will consider. Any breeding horse or mare, to pass muster with him, must have, for instance, good digestion. The heart atetion and that of the lungs must be as perfeet as possible; the bones hard and tough; the sinews tense, and the hoofs sound; the muscles firm, large and proportioned for the work to be done; and no less will the intelligence of the animal be looked to. Even the manner of getting up and lying down will be scrutinized and noted.

The Arab Maxim.-The Arab maxim is that the foal follows the sire. In the breeding of half-bloods for market, the mare whose foals bear the stamp of the sire is invaluable. It will, therefore, be well to bear in mind Rev. W. H. H. Murray's six rules in breeding.

Murray's Six Rules.-They are: first, pedigree; second, size; third, color; fourth, health; fifth, temperament; and sixth, speed. Now again, in relation to speed, this is a quality quite as valuable in the draft horse as in the racer; for the horse that will pull a given load at a faster walk than another is altogether the more valuable animal. Another thing in this connection should be kept in mind, and that is a bad feeder never can be a superior horse. The horse which 
eats a full feed slowly, not greedily-unless very hungry-is generally a horse of perfect digestion.

\section{Importance of Accurate Knowledge.}

We might pile up statistics without number, showing how heredity affects animals and human kind, generation after generation, not only as regards diseases inherited, but also vices, lack of courage, and every disability which the race is heir to, and this sometimes after several generations have passed during. which heredity has apparently remained latent. To gather in a nut-shell what may be applicable in the entire range of breeding, the sixteen rules of Stonehenge will prove most valuable to every brecder, whether of the horse or any other animal. They are as follows:

\section{Stonehenge's Laws of Generation.}

1. The union of the sexes is, in all the higher animals, necessary for reproduction; the malo and female each taking their respective share.

2. The office of the male is to secrete the semen in the testes, and emit it into the uterus of the fomale, in or near which organ it comes in contact with the ovum of the female-which remains sterile without it.

3. The female forms the ovum in the ovary, and at regular times, varying in different animals; this descends into the uterus, for the purpose of fructification, on receiving the stimulus and addition of the sperm-cell of the semen.

4. The semen consists of two portions- the spermatozoa, which have an automatic power of moving from place to place, by which quality it is believed that the semen is carried to the ovum; and the sperm-cells, which are intended to co-operate with the germ-cell of the ovum in forming the embryo.

5. The ovum consists of the germ-cell, intended to form part of the embryo, and of the yolk, which nourishes both, until the ressels of the mother take upon themselves the task; or, in oviparous animals, till hatehing takes place, and external food is to be obtained. The ovum is carried down by the contractile power of the fallopian tubes from the ovary to the uterus, and hence it does not require automatic particles like the semen.

6. The embryo, or young animal, is the result of the contact of the semen with the orum, immediately after which the sperm-cell of 
the former is absorbed into the germ-cell of the latter. Upon this a tendency to increase or "grow" is established, and supported at first by the nutriment contained in the yolk of the ovum, until the embryo has attached itself to the walls of the uterus, from which it afterward absorbs its nourishment by the intervention of the placenta.

7. As the male and female each furnish their quota to the formation of the embryo, it is reasonable to expect that each shall be represented in it, which is found to be the case in nature; but as the food of the embryo entirely depends upon the mother, it may be expected that the health of the offspring and its constitutional powers will be more in accordance with her state than with that of the father; yet, since the sire furnishes one-half of the original germ, it is not surprising that in externals and general character there is retained a $f a c$ simile, to a certain extent, of him.

8. The ovim of mammalia differs from that of birds chiefly in the greater size of yolk of the latter, because in them this body is intended to support the growth of the embryo from the time of the full formation of the egg until the period of hatching. On the other hand, in mammalia the placenta conveys nourishment from the internal surface of the uterus to the embryo during the whole time which elapses between the entrance of the orum into the uterus and its birth. This period embraces nearly the whole of the interval between conception and birth, and is called utero-gestation.

9 . In all the mammalia there is a periodical "heat," marked by certain discharges in the female, and sometimes by other remarkable symptoms in the male (as in the rutting of the deer). In the former it is accompanied in all healthy subjects by the descent of an orum or ova into the uterus; and in both there in a strong desire for sexual intercourse, which never takes place at other times in them (with the single exception of the genus Bimana).

10. The semen retains its fructifying power for some days, if it is contained within the walls of the uterus or vagina, but soon ceases 10 be fruitful if kept in any other vesiel. IIcnee, although the latter part of the time of heat is best for the union of both sexes, because then the ovum is ready for the contact with the semen, yet if the semen reaches the uterus first, it will cause a fruitful impregnation, because it remains there (or in the fallopian tubes) uninjured, until the descent of the ovum. 
11. The influence of the male upon the embryo is partly dependent upon the fact that he furnishes a portion of its substance in the shape of the sperm-cell, but also in a great measure upon the effect exerted upon the nervous system of the mother by him. Hence, the preponderance of one or the other will, in great measure, depend upon the greater or less strength of nervous system in each. No general law is known by which this can be measured, nor is anything known of the laws which regulate temperament, hodily or mental power, color or formation, of the resulting offspring.

12. Acquired qualitics are transmitted, whether they belong to the sire or dam, and also both bodily and mental. As bad qualities are quite as easily transmitted as good ones, if not more so, it is necessary to take care that in selecting a male to improve the stock he is free from bad points, as well as furnished with good ones. It is known by experience that the good or bad points of the progenitor's of the sire or dam are almost as likely to appear again in the offspring as those of the immediate parents, in which they are dormant. Hence, in breeding, the rule is that like produces like, or the titieness of some ancestor.

13. The purer or less mixed the breed the more likely it is to be transmitted unaltered to the offspring. Hence, whichever parent is of the purest blood will be generally more represented in the offspring; but as the male is usually more carefully selected and of purer blood than the female, it generally follows that he exerts more influence than she does; the reverse being the case when she is of more unmixed blood than the sire.

14. Breeding "in-and-in" is injurious to mankind, and has always been forbidden by the Divine law, as well as by most human lawgivers. On the other hand, it prevails extensively in a state of nature with all gregarious animals (such as the horse), anong whom the strongest male retains his daughters and grand-daughters until deprived of his harem by younger and stronger rivals. Hence, in those of our domestic animals which are naturally gregarious, it is reasonable to conclude that breeding "in-and-in" is not prejudicial, because it is in conformity with their natural instincts, if not carried further hy art than nature teaches by her example. Now, in nature, we find ahout two eonsecutive crosses of the same blood is the usual extent to which it is carried, as the life of the animal is the limit; and it is a 
remarkable fact that, in practice, a conclusion has been arrived at which exactly coincides with these natural laws. "Once in and once out," is the rule for breeding given by Mr. Smith in his work. on breeding for the turf; but twice in will be found to be more in accordance with the practice of our most successful breeders in the founding of distinct breeds or varieties.

15. The influence of the first impregnation seems to extend to the subsequent ones. This has been proved by several experiments, and is especially marked in the equine genus. In the series of examples preserved in the museum of the College of Surgeons, the markings of the male quagga, when united with the ordinary mare, are continued clearly for three generations beyond the one in which the quagga was the actual sire; and they are so clear as to leave the question settled without a doubt.

16. When some of the elements of which an individual sire is composed are in accordance with others making up those of the dam, they coalesce in such a kindred way as to make what is called a "hit." On the other hand, when they are too incongruous, the result is an animal wholly unfitted for the task he is intended to perform. 


\section{CHAPTER IV.}

\section{THE HORSE AT REST AND IN MOTION.}

I. THE hORSE'S ATtITUDE IN STANDING.-II. MODE OF PROGRESSION.-III. THE WALK.-IV. GOOD AND BAD WALKERS.—V. THE TROT.-VI. THE CANTER.-VII. THE HAND GALLOP.-VIII. THE EXTENDED OR TRUE GALLOP, - IX. HOW TO JUDGE A HORSE.

Concerning the attitude of the horse when at rest, and his action in motion, nothing better has ever been written than by Stonehenge. Space is lacking here to quote all that he has written on these subjects, nor is it necessary. We present a sufficiently full synopsis to completely cover his ideas.

\section{The Horse's Attitude in Standing.}

Standing may be considered under two heads, the first comprising the attitude naturally assumed by the horse when inclined to rest himself, and the second that forced upon him by education, for the sake either of appearances, or to keep him ready to start at a moment's notice, as in the cavalry horse. When standing free or naturally the horse always rests one leg, and that generally a hind one, changing from one to the other as each becomes tired in its turn. In the forced attitude all four are on the ground, and each supports its share of the superineumbent weight. In either case the different joints are kept from bending, by the almost involuntary combined action of the flexor and extensor muscles, which will keep him standing even in sleep, in which respect he differs from the human subject. The oblique position of the pasterns affords a considerable aid, but without the semi-involuntary support afforded by the museles the stifle and hock joints behind, and the shoulder and elbow before, would inevitably give way.

\section{Mode of Progression.}

In moving forward, whatever the pace may be, the hind quarters are the main propellers, and thrust the body forward on the fore legs, which serve as imperfect segments of wheels, each in its turn making 
a revolution forwards and backwards through a segment of a circle, like a pendulum. This forward motion is either effected by one hind leg at a time, as in the walk, trot, amble and rack, or by the two, nearly if not quite synchronously [at the same moment], as in the canter, gallop, and leap. In any case, the hind legs (or leg) must be drawn forwards under the body, or the body thrust backwards upon them, when a contraction of various muscles tends to straighten them, and as they are fixed upon the ground, which acts as a fulcrum, the body must give way, and thus passes forward with a speed and force proportionate to the muscular power exerted. In the various paces this mechanical action is differently effected in detail, but the principle is the same in all those contained in each class alluded to. In the first, the weight is borne by the hind and fore quarters between them, while propulsion is effected by one side of the former; but, in the second, it is taken at intervals by the fore and hind limbs, the latter propelling it with great force, and the former serving as props to it when it comes to the ground from the air, and also causing it to rebound for another interval of time. All these points will be made clear by the illustrations we give.

\section{The Walk.}

In examining the order of sequence in which the feet are taken off the ground, it appears to me that a rery simple matter has been conrerted into a complicated one; for this is a question that has led to discussions without end. No one with a grain of observation can dispute that all the four legs in this pace move separately, and not, as in the trot and amble, by twos of opposite or the same sides.

Any one who examines the action of the feet of one side only will have no difticulty in pereeiving that the hind foot is raised from the ground and moved forward for half its stride before the fore foot is disturbed, the same order being observed on the other side in suecession. Hence, if the horse is started from the standing position with all the feet on the ground, it follows that he mest begin with a hind foot, beciulse with whicherer of the sides he starts he lifts the hind foot half a pace hefore the fore foot, als is admitted by Percivall himsclf, for he says, "the latter (fore foot) would often get struck by the former (hind foot) did it not quit its place immediately prior to the other heing placed upon, partly or entirely, the same ground." It is very diflicult 10 convey a correct idea of this fact by illustration, because the eye has become accustomed to the erroneous view which 
is conventionally received by artists. However, we are enabled to present the following engraving, which, though apparently awkward and ungraceful, is literally correct. Here the near hind foot (1) is just about to be placed on the ground, on the spot which the near fore foot (2) has just left. The off hind foot (3) will follow next in succession, and lastly the off fore foot (4) will complete the cadence. But if each fore foot leaves the ground just as the corresponding hind foot is finishing its stride, it follows, as a matter of necessity, if the action is carried on throughout in the same way, that in starting from a point of rest the hind foot of one side or other is the one to

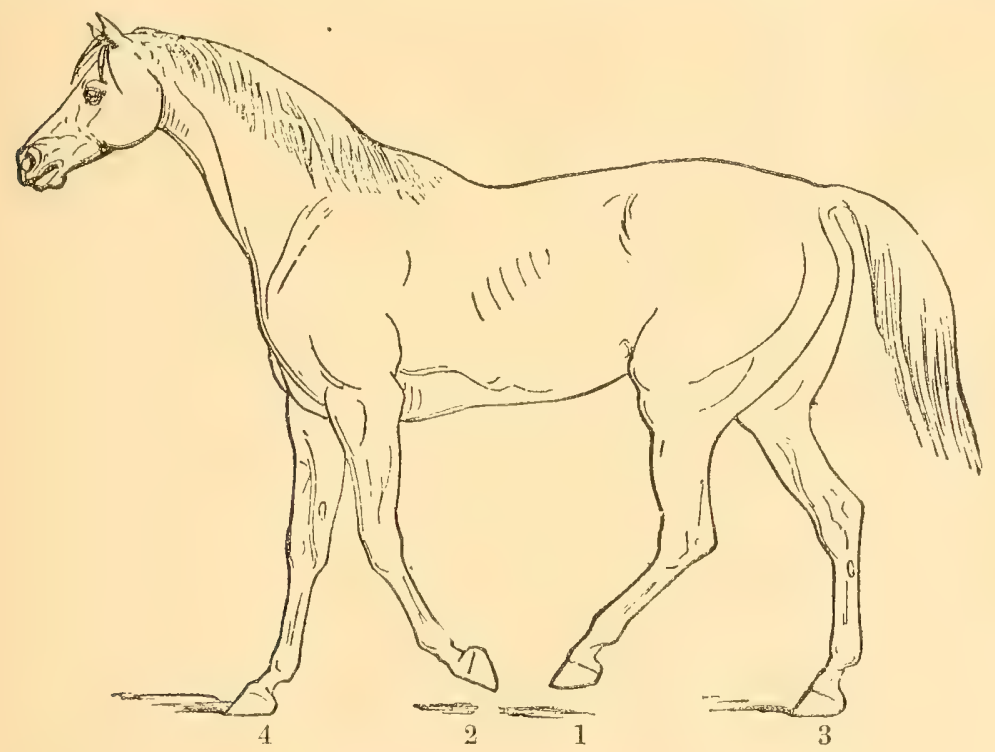

STARTING FOIR THE WALK.

begin the walk. Next follows the fore foot on the same side, then the opposite hind foot, and lastly the fore foot of the opposite side. The order of progression, be it observed, is the same, whether the description commences with the hind or fore foot, and the aroument is, after all, of little consequence; but the truth is really, as was observed by Borelli, that the hind foot is the first to move when the horse starts into a walk from a state of rest in which all four feet are placed as in ordinary standing. There may be positions in grazing where the fore foot advances first; but then the pace camnot be considered as the customary walk. 
In the cut, "Received Interpretation of the Walk," the horse is represented in the manner ustally accepted by artists, with the near fore foot (2) in the air, and apparently leading off. But as the hind foot must of necessity start first, although this engraving affords to the eye of the observer the most graceful and striking position which is taken up in the walk, yet it is not the one with which the horse commences that pace. Here the near hind foot (1) has already been brought forward and placed on the ground, on or near the spot oceupied by the fore foot, which is in the air; the hind foot (3) is just about to leave the ground, having expended its share of progressive

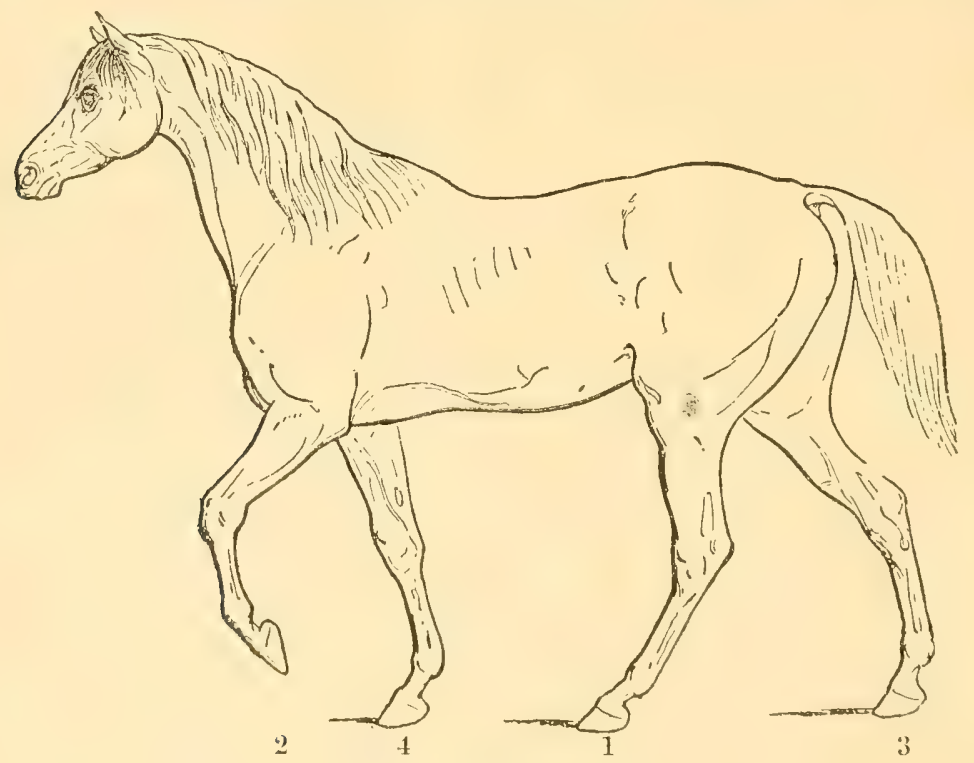

RECEIVED INTERPRETATION OF TIE WALK.

force, and the weight of the body is borne by the off fore foot and the near hind one. Whenever a fore foot starts first (which, as already remarked, may occasionally occur, as, for instance, in grazing, or when the weight is unnaturally thrown upon the fore quarters), the attitude is most constrained, and the proper sequenee, or cadence, if the animal is forced into a quicker pace, is not fallen into without a most grotesque degree of rolling, which conveys to the eye a full idea of the foreed nature of the pace.

I have thus endearored to show (and it is the most simple mode of describing the pare ) that, ats a ruke, when the horse is starting from a 
state of rest into a walk he commences with one of the hind feet, the particular one chosen being that which at the time bears the least weight of the body upon it. Next follows the fore foot of the same side, then the opposite hind foot, and lastly the fore foot also of the opposite side. When once it is shown that the hind foot almost touches the heel of the foot which precedes it, before the latter is raised, of which a moment's observation will satisfy any careful observer, the order of sequence becomes clear enough, and, as I set out with observing, a subject which is generally made extremely complicated becomes as simple as possible. In nine hundred and ninety-nine

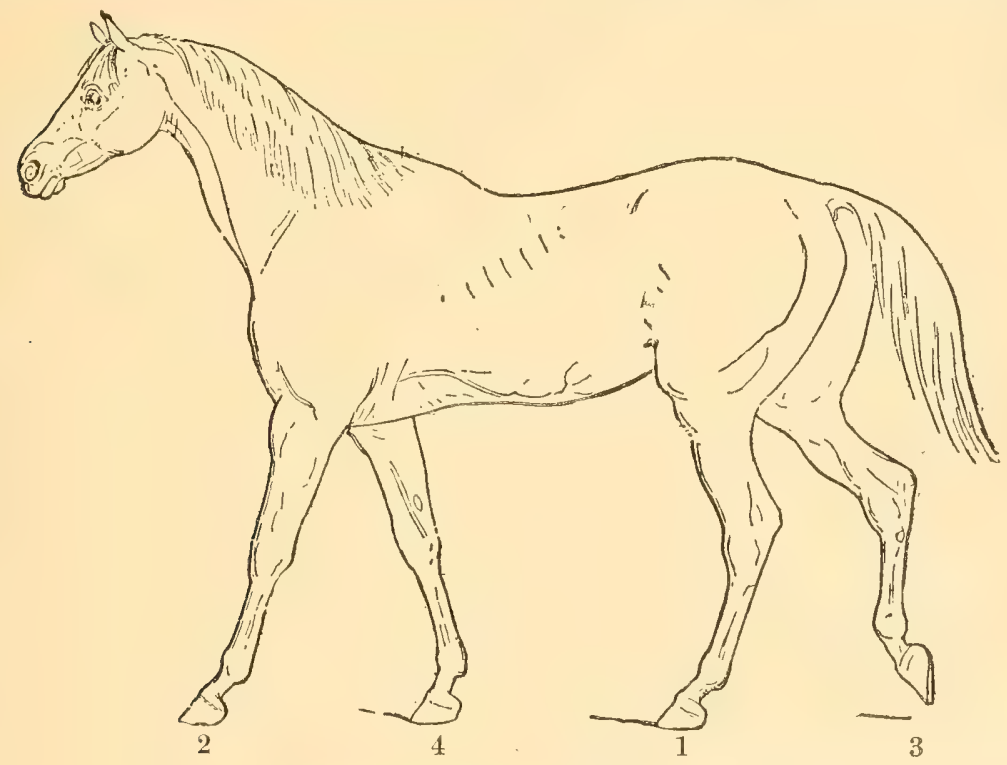

EXCEPTIONAL MODE OF STARTING.

cases out of a thousand the horse starts on a walk with a hind foot, and the only exception is when he is, from circumstances, at the time in an unnatural attitude.

\section{Good and Bad Walkers.}

Writers on the horse divide each morement of the leg into three acts, consisting of the lift, the swing, and the grounding. In the first act, the foot is raised; in the second, it is thrust forward; and in the third, it is firmly but lightly deposited on the ground. But these may severally be well performed, and yet the hor'se be a bad walker, because his body is not well balanced on the leas in contact 
with the ground while the other or others are moving. A good walker should take short quick steps, with his hind legs well under him, and then he will be able to plant his fore feet firmly but lightly on the ground in succession. If his stride is too long, his hind legs cannot be always well under him, because they must be wide apart when both are on the ground; and the hody cannot then be balanced sccurely, because there is too long an interval elapsing while the one hind leg is paswing the other. Hence, in such a horse, there is a raddling morement from side to side, so often seen in the thoroughbred horse, whose full tail shows it very manifestly, but whose rider feels the inconvenience much more clearly than it is seen by the uninterested looker-on. The clever hack, on the contrary, moves forward without his hody deviating a hair"s breadth from the line in which it is progressing, neither undulating to the right and left, nor up and down. The rider of a first-rate hack should be able to carry a full glass of liquid in his hand for any distance without spilling a drop; and if the action on the walk is not smooth enough for this, it cannot be considered as approaching to perfection.

Many horses step short and quick, yet do not walk well, because their shoulders have not liberty enowgh to thrust their arms forward while swinging the leg; and hence the pace is stow, for the foot is put down very near to the spot whence it was lifted. In choosing a good walker, therefore, see that his feet are lifted smarty; that they are well threst forward, and placed tirmly hut lighty on the cromed. Look at him well from behind, and observe whether he hits himself on the fetlock joints as one foot passes the other; and at the same time examine whether, as he lifts his fore feet, he turns them out, or "dishes," which is a very serious fault, in consequence of the loss of time which it oceasions. In most horses the hind foot orersteps the place from which the corresponding fore foot has been removed: but in a good hack this should not exeed an inch, or the pate will not he smooth and smart, as I have already observed. Very few walker's actually touch one foot with the other, as in the trot, nor do they overreach with violence so as to injure their heels; the only objection, therefore, is to the leneth of stricte, which I have shown to produce an uneasy effect upon the rider. But whenerer the horse appears to move as if his fore feet are in the way of the hind, he will rarely, even with the best tuition, beeome a pleasant and safe hack. 
The Rate of Walking.-This is very seldom five miles an hour, though horses are to be found which will cover the distance in that time, or even less. Many will do a mile in twelve minutes and a half; but to get beyond this is a very difficult task. Indeed, there are few horses which in their walk will bear pressing to the utmost speed of which they are capable, without breaking. It may, I think, be assumed, that the average pace of good walkers is alsout four miles and a half to four miles and three-quarters per hour.

\section{The Trot.}

This pace may be described under three heads, namely, the jog trot, the true trot, and the flying trot. In all three the diagonal limbs more exactly together; but in the first, the time during which each foot is on the ground, is much greater than that in which it is in the air. In the second the contrary is the case; while in the third the horse is carried completely off his leg for a considerable space of time, between the several bounds which are made by the two feet of opposite sides as they touch the ground in succession. The jog trot seems to come naturally to the horse when he is first mounted; and as long as he is fresh and fiery, the colt will maintain this pace, unless he is permitted to exceed it. He will prefer it to the walk for a long time; and it is only by good hands, combined with patience, that a spirited colt can be made to walk; for he can generally jog quite as slowly, and often much more so. Farmers are very apt to accustom their young horses to the jog trot, because they find by experience that it does not injure their legs or feet; but to a rider unaceustomed to this pace, it is by no means an easy one. 'In the true trot, as exemplified below, the feet are on the ground a comparatively short space of time, the body being carried so rapidly forward that they are moved off almost as soon as they are deposited on it. By examining this outline, it will be seen that the position of the fore and hind limbs of the two opposite sides exactly correspond, and this will be the case, whatever may be the period of the action in which the observation is made.

Trotting Action. - Very fast trotters are rough in their "feel" to the rider, and are not suited for the purposes of pleasure. Indeed, no one would mount one of them from choice; but when they possess good mouths, they are pleasant enough to drive. In examining trotting action, regard should be paid to the plane through which each limb passes, for if this is not parallel with that of the medium 
line of the body the action is not true and smooth, and there is great risk of one limb cutting the other. This is best seen by watching the trot from behind as well as before, which gives an opportunity of investigating the movements of both pairs of limbs. Every horse should be so made that, when the stands, his fore cannon bones should be quite parallel; but in order to be so, as they stand closer together than his elbows, they must form a slight angle with the arm at the knee; and hence, as this part is bent, there is always a slight tendency to turn out the foot, the exaggerated form of which is called "dishing.' The observer will, therefore, do well to ascertain the extent

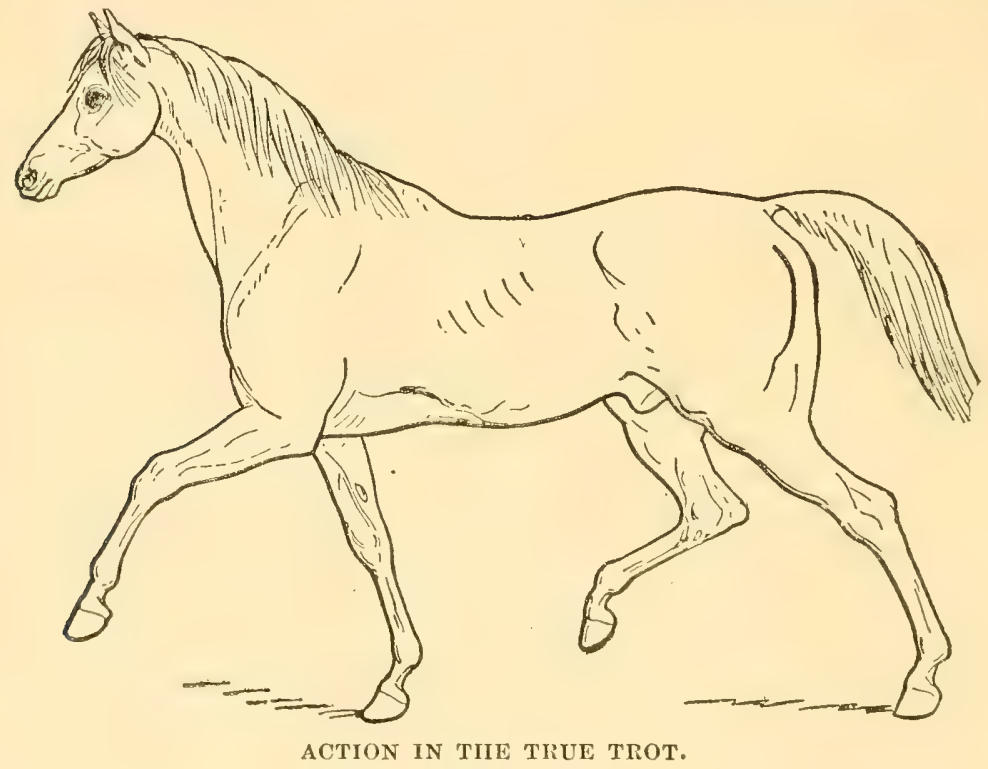

to which this should be carried, or he will be apt to condemn a per fect goer as a "disher," from finding that he turns out his toes in bending the knee, though enly in the tritling degree ordained by nature. If, in bending by the hand the fore foot to the elbow, the inner heel of the shoe is in contact with the outside of the arm, there will not be too much turning out of the foot, and the purchaser need not be afraid of this defect existing in the horse he is examining. Provided the fetlocks and cannon bones are not actually touched or "hit" in trotting, the fore legs "ammot he moved too closely together; but if they pass very near to one another in a fat dealer's horse, it may be suspected that when he is redued in flesh to a proper working 
condition, boots will be necessary. A practiced eye is required to judge of this correctly, and, if there is any doubt, some one of experience had better be consulted.

\section{The Canter.}

The canter is a thoroughly artificial pace, at first extremely tiring to the horse, and generally only to be produced in him by the restraint of a powerful bit, which compels him to throw a great part of his weight on his haunches. It is very difficult to describe or define this pace, either in a pen-and-ink sketch or by the aid of a painter. Sometimes the carriage is extremely elegant, the hind legs well under

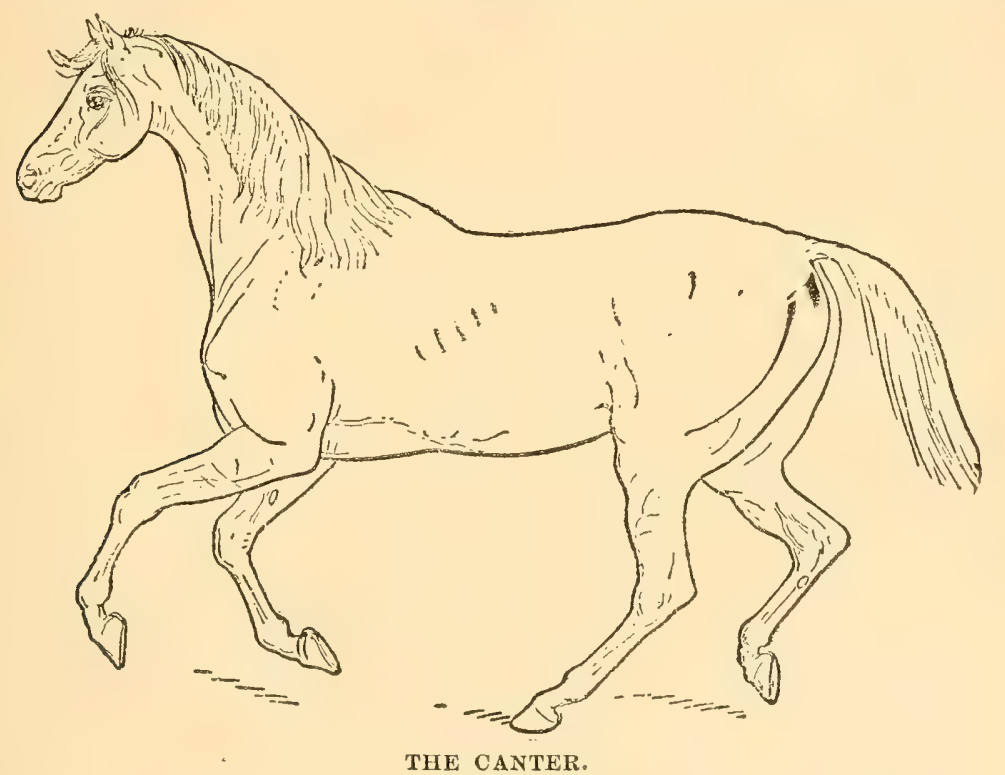

the body, and all moving like clockwork, with the head bent on the neck, and the mouth playing lightly on the bit. When such a pace is performed with the right leg leading, the canter is exactly adapted for the female seat, in which the right shoulder is of necessity slightly advanced, and it is, therefore, the object of the breaker to obtain it. But it is only in those horses which combine a free use of their limbs with fine temper and good mouth, that such a pace can be developed, and if any one of these qualities is deficient, it is useless to attempt to teach them. On the other hand, the pony will often canter without throwing any extra weight on his hind legs, with a loose rein and 
extended neck. This kind of pace may be detected by the ear on a turnpike road, by the quick pat-ter-ring sound which is evolved. It is extremely easy to the horseman, but is not so well adapted to female equestrianism, as it jerks the body in an ungraceful manner. The cut gives a graphic idea of the attitude of the horse in this gait.

\section{The Hand Gallop.}

Between the canter and the true gallop there intervenes a pace which may be easily confounded with either. The pace is merely a slow and measured gallop, in which, for a very short period, all the legs leave the ground, but in which the propulsion is steadily given, and not with those snatches or jerks which are necessary to develop the high speed of the extended gallop. The hody, also, is not nearer the ground than in the act of standing, and this may be considered as one of the best distinctions between the hand gallop and the extended stride of the faster pace. The French writers distinguish between the two by asserting that in the hand gallop there are three beats, while in the flying gallop two only are performed; but in practice there is no such variation.

\section{The Extended or True Gallop.}

Not a Mere Succession of Leaps.-Acenrding to most observers, this pace is a succession of leaps, smoothly and rhythmically performed, but Mre. Pereivall has shown that there is a comsiderable difference between the two actions. He says: "In galloping a horse, in hunting, for example, the rider need no person to tell him of the moment when his horse is taking a leap, howerer trifling it mat be; his own sensations inform him of every grip or furrow his horse leaps in his course, and should he have oceasion to malke a succession of such jumps, the rider's sensations in his saddle are of a very different-very uneasy-kind, compared to such as he experiences during the atet of galloping. This arises from two causes, from the spring or movement of the body necessary to produe the lealp being more forcible or sudden than that repuired for the gallop, and from the latter beingereated and eontinued rather by the suressive atetion of the two hind feet at one moment, and of that of the two fore feet at the next moment, than from the synchronous efforts of either biped, as happens in the leap. The two great propellers of the animal machine-the hind feet-are in the leap required to act simultamensty, to make one grand propulsory effort: not so in the gatlop, 
that being a movement requiring maintaining, not by simultaneous exhausting efforts of the hind feet, but in swift succession, first by one, then by the other; and the same as regards the office performed by the fore limbs, which latter probably amounts to little more in effect than the sustentation of the fore parts of the body. The vault into the air required for the leap is only to be effected by extraordinary subitaneous effort, but the stride of the gallop, requiring frequent repetition, does not exact this effort-amounts, in fact, to no more than a sort of lift from the ground, multiplied into a reiteration of forcible bearings forward, maintaining, increasing, or diminishing the momentum of speed, effectuated by throwing the hind feet as far forward underneath the body as possible, plunging them one after the other with inappreciable rapidity into the earth, and

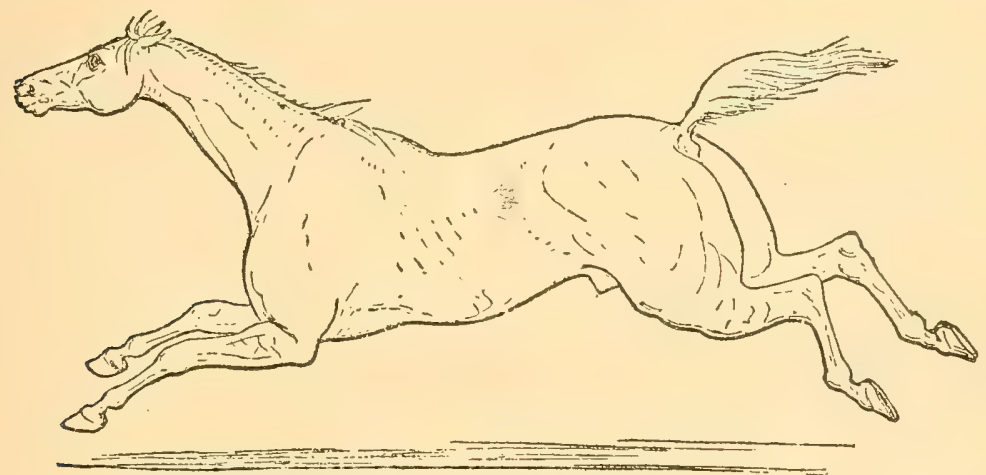

RECEIVED INTERPIETATION OE THE GALLOP.

thus by two strenuous thrusts against the gromel, one in aid of the other, working the animal machine in its fleet-almost flying-course. In the gallop as in the trot, no sooner is a certain momentum acquired, than by each successive propulsion of the hind feet the body is sprung or lifted off the ground, flying as it appears in the air, and the greater the speed, the more this rolitation becomes apparent. Hence the appellation given to the pace, manifestly the utmost speed, of flying gallop. Even this, however, according to my judgment, is an action different from leaping. Then a horse leaps or jumps in his gallopwhich he will do sometimes when he is quite fresh and has just emerged out of his stable-he is said to buck, because his action then resembles that of the deer, in whom the gallop might, with a great deal more propriety, be called a succession of leaps; even the deer, 
however, cannot continue this bucking action after being driven into his speed, or in a state of fatigue, showing that in him it is to be regarded rather as a gambol than as his proper working onward action. And that the hind and fore feet in pairs are not grounded synchronously, I think, admits of a demonstration in two ways: first, by the position they assume one in advance of the other in the gallop; secondly, by the clatter the steps of a horse in the gallop are known to make upon hard or resonant ground, and which may be heard either by a spectator or by the rider himself. Whence we probably derive the phrase, a rattling gallop.

Pictorial Misrepresentation.-To represent the gallop pictorially in a perfectly correct manner is almost impossible. At all events, it has never yet been accomplished, the ordinary and received interpretation being altogether erroneous. When carefully watched, the horse in full gallop will be seen to extend himself very much, but not nearly to the length which is assigned to him by artists. To give the idea of high speed, the hind legs are thrust backward and the fore legs forward in a most unnatural position, which, if it could be assumed in reality, would inevitably lead to a fall, and most probably to a broken back. It is somewhat difficult to obtain a good view of a horse at his best pace, without watching him through a race-glass at a distance of a quarter of a mile at least, for if the eye is nearer to him than this, the passage of the body by it is so quick that no analysis can be made of the position of the several parts. But at the ahove distance it may be readily seen that the horse never assumes the attitude in which he is generally represented, of which an example is given. When the hind legs are thrust backwards, the fore feet are raised and more or less curled up under the knees, as it is manifest must be the case to enable them to be brought forward without raising the body from the ground. In the next act, as the hind feet are brought under the body the fore legs are thrust straight before it; and so whichever period is chosen for the representation, the complete extension so generally adopted must be inaceurate. It may be said that this is meant to represent the moment when all the feet are in the air, and theoretically it is possible that there may be a time when all the feet are extended; becanse, as in the fast gallop, the stride is twenty-four feet long, while the horse only measures sixteen from foot to foot, it follows that he must pass through cight feet without touching the ground, and during that time, as of necessity, 
his legs must move faster than his body, the fore legs may change their position from the curled up one described above to the extended one represented by all painters as proper to the gallop. Observation alone can, therefore, settle this question.

As to the Leg that Leads.- As in the canter, so in the gallop, a lead is always made of one leg before the other, and as one tires the other changes places with it. A good, true, and strong galloper will seldom require this relief; but a weak one, especially if not completely broken, will effect the change continually. Sometimes this causes the loss of a race, for it cannot be done without interfering with the action, and consequently with the pace. A good horseman prefers that his horse should not confine himself to one lead, but he does not like him to change after he has once started, for the

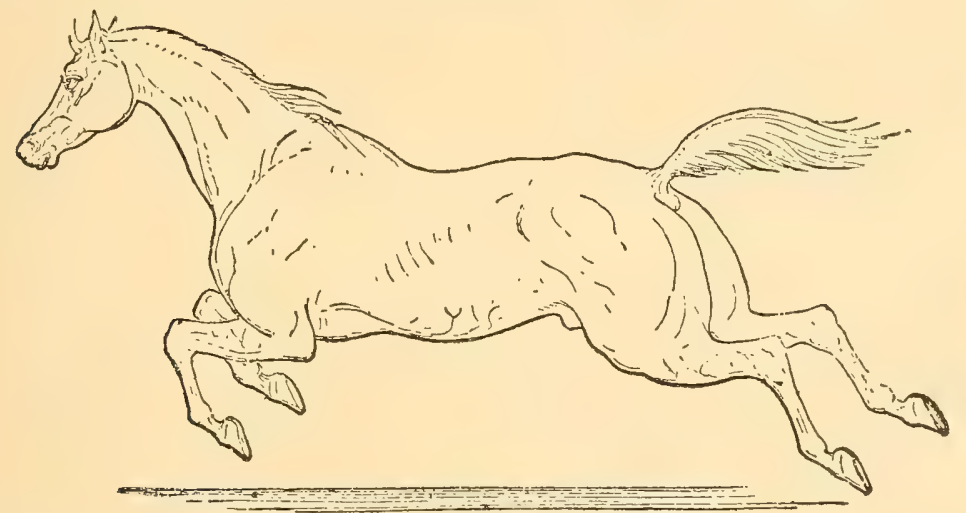

CORRECT VIEW OF THE GALLOP.

above reason. The right $\log$ in front is more easy even to the male rider than the left, but not materially so, and, except for female equestrianism, no horse should be taught to lead invariably with the right leg either in the gallop or canter. In the change the truth or harmony of action is often disturbed, and the horse jerks himself and his rider in a disagreeable manner, which is another reason why the change of legs should not be encouraged.

Length of the Stride.-There is a great variation in the length of the stride, and in the rounding or bending upwards of the foot under the knee. Sometimes even in a fast gallop the distance between the prints of the same feet will be no more than sixteen feet, while in others it will measure twenty-four, twenty-five, or even twenty-six feet. The first is too short for any race horse; but a moderately 
whort stride enables the horse to get off with a quicker start, and to ascend and descend hills better than a very long one. Where, however, a distance of level ground is to be covered, a long stride tells, and a horse possessing it has a great adrantage over one whose gallop is short, however quick and smart it may be. For this long stride there must be length of limbs, especially of the two hones meeting at the stifle joint. [The trotting stride of Nancy Hanks, who, within twenty-four hours of the time we read the proof of this chapter, became Queen of the turf, is ninetcen and three-quarters feet.]

\section{How to Judge a Horse.}

A very carefully considered scale for judging horses at fairs was adopted by the state Agricultural Society of Maine in 1892. The total number of "points" is 100 , distributed as follows:

Eyes-Prominent, clear, intelligent and expressive.......... Head-Wide apart between the eyes, ears well apart, of fair size and indicating energy, clean-cut jorvl, large, delicate nostrils,

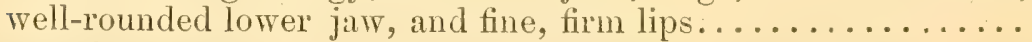
Neck-Symmetrical in length and proportions, graceful and clean

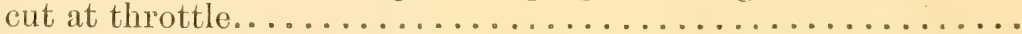
Shoulders-Fat and oblique for drivers, well-rounded and straght for draft, strong at base and well finished at withers........ Chest-Deep, full and prominent, good width............ Forearm-Well formed, strong and muscular............... Barrel-For driver's, deep and well-rounded, with long, springy ribs; round, with short ribs for draft, deep through the loms,

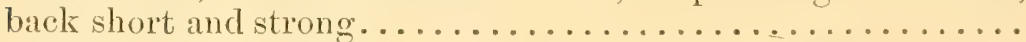
Corrpling-Smooth, strong and extending well forward over the

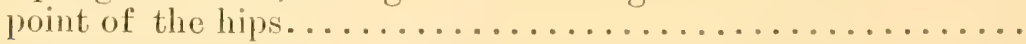
Quarters-Symmetrieal, not toosloping, well rounded and muscular. Tail-Long, full, bone straight, well set, and fine in quality.... Stifles and Gaskins-Museular, with goud lenglh of bone between joints for drivers, and short for draft.

Hock-Sound, strong, not too great an angle, free from meatiness.

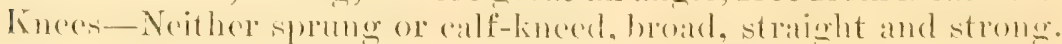
Cannons-Flat, broad, smooth, fine quality, yet abundant substance. Pasterns-Muscular, good length, sound, and for drirers at an angle of forty-five degrees; for draft shorter and stronger......

Feet-Medium height, round, free from contracted heels, of good

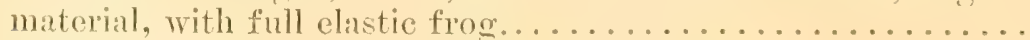

Color-Solid bay or seal brown, the standard.............. Size-15 to 16 hands and well proportioned, the ideal standard. Coat-Glossy, fine and short.

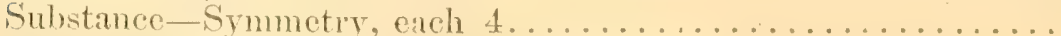

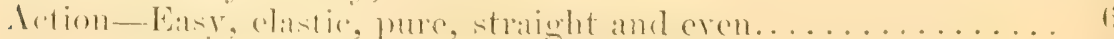

Style-Position when standing, and carriage when in motion...

Total structure.......................100 
CHAPTER V.

HYGIENE, FOODS AND EXERCISE.

I. PRACTICAL VALUE OF HYGIENIC KNOWLEDGE.-II. ABOUT PERFECT FOODS AND SHELTER。-III. THE HOLSE'S STOMACI AND DIGESTION.-IV. OATS. -V. HAY.—VI. STRAW.-VII. GREEN FORAGE.—VIII. CORN.—-IX. ARTIFICIAL AND CONDIMENTAL FOOUS.- $\mathrm{X}$. WHAT CONSTITUTES GOOD CARE. -XI. GOOD SHELTER IS TRUE ECONOMY.- XII. EXERCISE IS INDISPENSABLE.-XII. COMFORTABLE BEDDING. - XIV. CLEANING THE HORSE.XV. KEEP THE STABLE CLEAN.

\section{Practical Value of Hygienic Knowledge.}

The physician's art consists in saving life and mitigating suffering. It is wise economy to have him use all possible means to effect these ends, and to bring about a healthful reaction as quickly as possible. In the ordinary routine of farm life, so far as affects the care and condition of stock, all methods-not merely medicines, but all changes in the food, etc.,-should have a similar object in view. All means used to revive the animal integrity after exhaustive labor; conditionpowders, gruels, mashes, grooming, exercise, foods, discrimination in the use of animals at labor, clothing, warmth, cleanliness in the stable-all these are strictly hygienic topies. Drainage, ventilation, deodorization, disinfection, fumigants and other practical means employed for either preventing or curing disease in the stable,-these, while truly belonging to hygiene, are generally treated of in its special division of sanitation.

Scientific is also Practical Wisdom.-Just as in medicine, all diseases may be classed as curable or incurable, so likewise may they be in veterinary affars; and, inasmuch as the proportion of curable ailments may be much increased through hygicnic and sanitary measures, and by manual and artificial appliances, an accurate knowledge of these things is at once scientifie and practical wistom of the highest value. The term "scientific," by mány uncultivated persons is looked upon as synonymous with "impracticable," as properly attaching only to mere theorizer's, to book-worms, or the abstrusely learned. This is a false conception entirely. Science is as practical 
as it is noble. In fact science consists, is made up, of simple, proven facts, properly grouped and classified.

Artificial Life Promotive of Disease.-In a state of nature, the man (savage) and the animal (wild) are subject to only a few diseases. Both die more often from the want of food, from exposure, and the disabilities thence arising, than from all other causes combined. It is artificial life and its surroundings that multiply the forms of disease both in the human and the brute. It is the pride of the physician to combat and cure disease acquired by infringement of natural laws, and of the surgeon, by mechanical art and scientific manipulation, to heal both outward and internal injuries from violence. But it is certainly a step in advance, if we may be able to reduce the liability to disease and injury by preventive measures. We believe this may be done hygienically with animals, equally with humanity.

\section{About Perfect Foods and Shelter.}

Two of the most important subjects connected with hygiene are the questions of perfect foods and proper shelter from the weather. As regards the former, milk is a perfect food, that given by nature for the sustenance of all animals in the early period of life. In the rearing of all young animals, the adaptability of the food must be carefully considered. The nutrition must be well sustained. If not, the digestive functions soon become disordered, and the young animal pines, or if his mistreatment continues may even die. As he grows, he must not be confined to one single food, else all parts are not properly nourished, but as the frame becomes mature, foods containing more fat in proportion to the nitrogen may be more and more largely used, especially with those whose flesh is intended for food. Fortunately the cereal grains, in comnection with grass and hay, contain all the elements necessary. It will be of great advantage to any farmer or stock-raiser to understand these simple facts, and take scientific principles-that is, the laws of nature-for his guide.

The protection of animals against cold is another consideration too often slured over. For animals confined altogether in stables, except when in service, proper stable-drainage and ventilation are of prime importance. They should, in fact, be studied by every person who has farm animals under his charge. Hence we shall devote a special chapter to the construction of stables a little further on. 


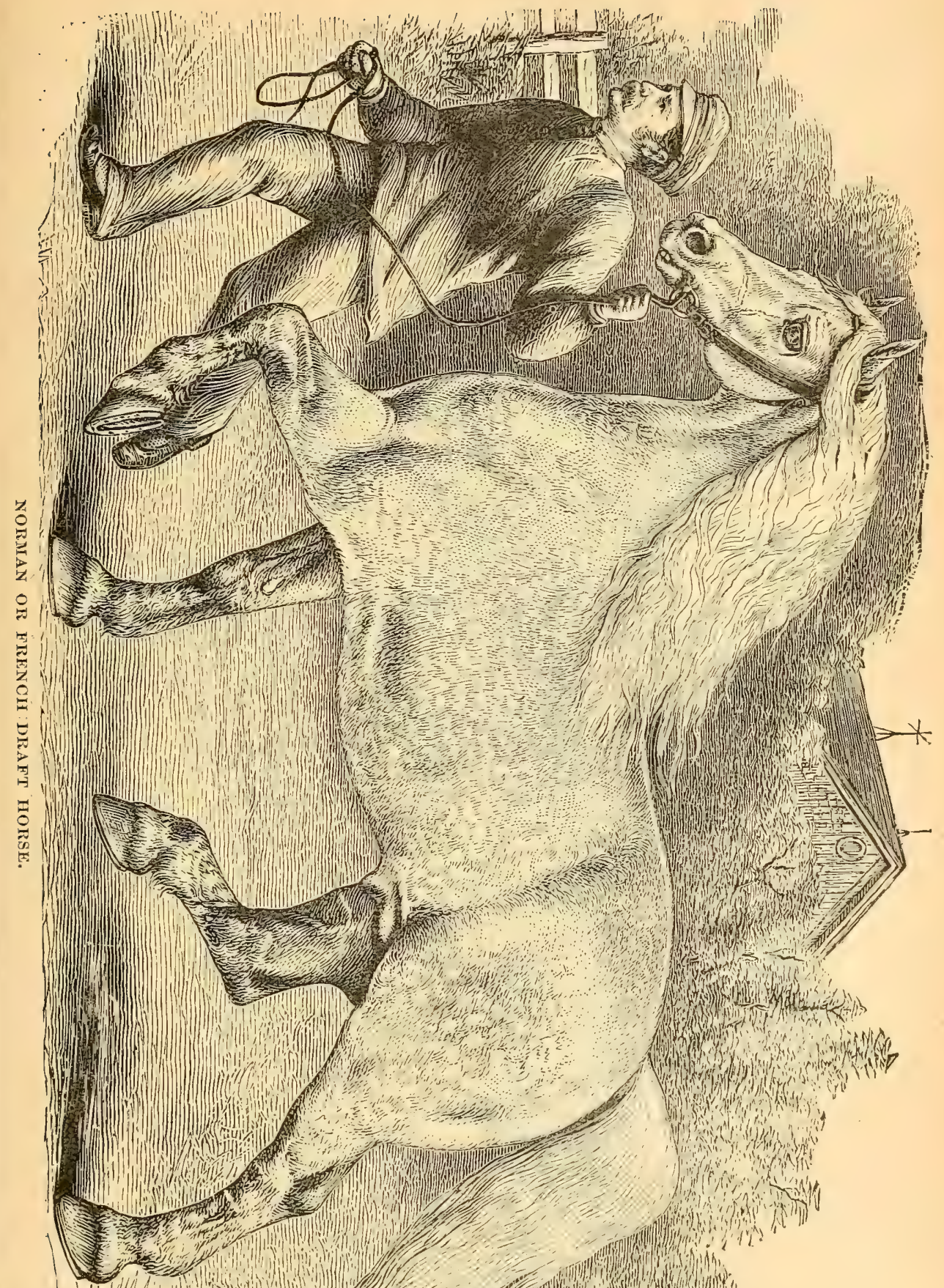

$111 / 2\left(m_{1}\right.$ 


\section{The Horse's Stomach and Digestion.}

A knowledge of the various qualities of food, and the forming of perfect foods, should constitute another of the acquirements of the breeder and feeder. Improper feeding is one of the gravest evils connected with the care of horses. The horse has a small stomach for an animal so large, usually holding fourteen or fifteen quarts. The stomach of Eclipse held but sixteen quarts, though the largest yet measured by scientists. Is it any wonder that, fed a peck of dry oats at a meal, often in the morning when the stomach is partially filled with hay, the horse should suffer agony from undue distension of the stomach through the swelling of the grain? Must it not plainly be seen that by giving large quantities of water immediately after heavy feeding with crude food, the latter will be washed far into the intestines, causing serious complications, often death? Digestion in the horse may go on continually, and when doing fast or exhaustive work he may profitably be fed four or five times a day. When on grass, the animal must needs be eating a large part of the time, to properly supply his system with nourishment. The rapidity of a horse's digestion is only equaled by his power of assimilation. He has the bile-making gland, but no means of storing it. Hence it is poured directly into the stomach, that digestion may continually go on, as well as assimilation.

To Know Sound Foods. - It is worth much for the horse owner to know how to distinguish sound from unsomd food. In the care of the horse, except in city stables, he is nearly always fed on whole grain and hay not chopped. Hence it is well to know the characteristics of the ordinary foods of the horse.

\section{Oats.}

Let us first take oats. If good, they are clean, hard, dry, sweet, have almost a metallie luster, and, when poured down on the floor, ratthe like shot. The pressure of the nat on a liernel will be strongly resisted. When pressed between the teeth, the kernel should not mash or tear, but chip. The skin should be thin, and here it may be remalied that white oats generally have a thimner skin than black oats. Bearded oats have an exeess of husk. Short outs are plumper than long oats, but oats are not necessarily bad because they are bearded, or thick-skimned; yet they contam less nutriment to the measured hushel. Good oats are without smell, exeept that new oats have an earthy odor. The flour has a taste of milky sweetness. 
Damp oats are objectionable; soft at first, they at length get musty. Musty oats are totally unfit for food, often poisonous from fungus growths formed on the inner skin. The same may be said of mouldy oats. In their case, decomposition has already taken place.

\section{Hay.}

For horses in ordinary work twelve pounds of hay per day is sufficient. It is commonly thought that horses at hard work should be limited in regard to hay; but if such work horses are every day allowed as much oats as they will eat, it is unnecessary and injudicious to put an arbitrary limit on their hay. Practically it will be found that horses, which are not linited in regard to oats, will not usually consume above six pounds of hay per day. Good upland hay should be moderately fine, somewhat hard, sweet smelling, and well saved. The color should be green, and should convey an idea of newness. Very little heating or fermentation should have taken place in the stack. Some slight heating is, however, almost unavoidable if the crop is cut early, as it ought to be, whilst the juices are still in the grass; or, in other words, before it has run to seed. The slight heating will prevent the best early-cut hay from being very green.

\section{Straw.}

Straw may be economically used as a part of the daily ration when clean and bright. Wheat and rye straw are best; next, oat straw. Its chief use, however, is as bedding. Long straw looks nicely, but straw broken up somewhat by tramping, is better. Horses should have a bed at least six inches thick. This is economical, too, since no more is soiled than when little is given.

\section{Green F'orage.}

Green forage is laxative and cooling, and, therefore, well suited for sick or young horses, especially when first taken up from grass. The quantity given to the latter should be gradually diminished, as the system becomes accustomed to more stimulating diet and the warnth of stables. Green forage, for horses in fast work, is very liable to cause bowel complaints. From its bulk and laxative action it militates against the hard condition necessary for fast or full work. It is not, however, objectionable for horses whose work is slow; yet it causes even these to sweat unduly.

\section{Corn.}

The supposed danger to stock, especially young stock, from feeding on corn, has been a favorite hohby of some writers. It is doubt- 
less true that young animals fed wholly on corn would show lack of bone and muscle, and especially impaired digestion. But it is equally true that bad results would follow an exclusive diet of grain. Oats, when used in connection with hay, are undoubtedly the best grain that can be fed to horses; but while oats are so much more costly than corn, as they generally are, throughout the Central and Western States, in these regions they can never be their main article of diet. It is, therefore, a satisfaction to know that ordinary farmhorses are not injured by having a good deal of corn in the aggregate of the year's feed. The point to be watched is to see that their corn diet is not too nearly exclusive, or too continuous, but that it is combined, or at frequent intervals is varied, with grain, or mashes, green forage of some kind, or a run at pasture. For colts, and old horses that have lost many of their teeth, corn ought always to be ground. For horses in their prime, and in good health, our experience has been that it does not pay to grind when corn is selling at less than about sixty cents a bushel, as such animals masticate their food pretty thoroughly.

\section{Artificial and Condimental Foods.}

All food, to be useful, must supply the special nutrient materials required by the particular animal. For most horses the ordinary articles of food, hay and oats, answer best. Some animals, however, have delicate digestions, others are troubled with want of appetite. Stomachies mixed with the food of the one may assist digestion, and tonies may be useful to the latter. In animals, as in men, it sometimes happens that there is some want of nutrition in some part of the system, which must be supplied before the animal will thrive or put on flesh. A harsh coat, for instance, indieates a want of oily material in the system, which maty often be beneficially supplied by giving boiled linseed. In other cases the special want may be of fibrinous material in the blood, and then doses of iron will be useful. These instances will suffice.

After a severe debilitating illness, when the system is thoroughly exhatusted, nothing will be found to amswer better than a quat of strong beef soup daily, either given as a drink, or mixed with the feed. The same recipe will in some cases, but not in all, answer in putting flesh on a horre, which, though in good health, remains persistently thin.

Most of the artilicial or patent foods advertised are compounded of a great number of stimulating and fattening ingredients, hy means of 
some one of which the special need of the system may very possibly be supplied. But it is well to remember that most artificial stimulants cease to have any effect after a time. The chief objection to the use of artificial foods is the first cost. Condimental foods should be compounded by the veterinarian, or under his direction. Thus purity is secured, and, more important still, you know of what they are composed.

\section{What Constitutes Good Care.}

What we have to say under this head will apply to animals generally. In the case of farm animals, there are three principal integers in good care, viz: 1. Kindness. 2. Shelter from storms. 3. Exercise which stops short of over-work. The neglect of any one of these is sure to entail loss. The most important, after selecting the breed intended to be perpetuated, is kindness in the management. It may be repeated that no brutal man ever gets the best results from his investment, neither does the slipshod man. Cruelty keeps stock excited and fearful, provokes combativeness as the result of fear, and impairs digestion and assimilation. Under such conditions, no animal will fatten, nor cow give a full flow of milk, nor horse perform a maximum amount of work for the food given.

\section{Good Shelter is True Economy.}

If the animal be not kept comfortable, the food given it will fail to perform its office in just proportion to the extremity of the cold. In a still atmosphere, the animal carries an envelop of heat from the body within the hair. A blanket assists in this conservation of heat. In proportion as the animal is exposed to storms, and especially to the force of the wind, will this bodily heat be lost or carried away. In severe exposure, it is only a question of time when the system must succumb, and death ensue. Not that the open air in winter is necessarily against the health of farm stock. Protection against wind being provided for, they will go nicely through even severe weather. A barn where every draft of air blows through is worse than a tight shed open on one side, if the direct pressure of wind therein is provided against. Why? The immates can move about freely, and thus keep up the circulation of the blood. But, of course, a warm yet well ventilated stable will be found the most cconomical throughout the whole West and North, and particularly no as we go far north.

\section{Exercise is Indispensable.}

The third requisite, exercise, is no less important, for without it the digestive organs soon berome inactive. But the standard of ex- 
ercise for one class of animals by no means applies to all. The horse requires the most exercise, sheep come next, and then cattle, while the animal requiring the least exercise is the hog. Dairy cattle require more exercise than fattening cattle; the horse of fast work more than the draft horse; breeding stock of all kinds more than fattening animals.

Amount of Exercise.- Without exercise the system is never up to the requirements of the owner. No driving horse should have less than five miles of exercise every day. Then he will be able to respond to the calls of his master on the road, allowing that his driving is pretty regular, say three or four times a week. For fast driving, the exercise must be correspondingly fast; but so far as exercise is concerned, the animal never need be put to his speed, except under the care of an experienced driver, who, of course, will be an experienced horseman.

\section{Comfortable Bedding.}

There are three other integers in the care of stock that it will be pertinent to mention: a soft bed to lie on, grooming, and the absence of animal odors in the stable. In regard to the first, if an animal does not lie easily, it cannot thrive, and to allow comfort he must have plenty of bedding. Nor is anything lost by this. The liquids are the essence of the manurc. Plenty of bedding takes this up and holds it. No more will be defiled with heary bedding than with light bedding. If material is scarce, the moist portions may be dried by exposure to the air, and thus the power of absorption be regained. It is, therefore, unwise economy to stint the bedding. Try lying on a board yourself, as compared with a soft mattress or feather-bed, and see how it feels. The animal is no less susceptible to comfort than yourself. Notice how, when choice is permitted him, he will always seek a soft, warm place to lie on in winter, and a smooth, elastic turf in summer. To promote his comfort is not only a question of merey, but also of direct profit in dollars and cents.

\section{Cleaning the Horse.}

Grooming will be considered in detail in the next chapter. It is absolutely necessary when animals are confined in stables. Where they are thus liept, the hair does not acpuire extreme length. Grooming cleanses the skin, excites the capillaries to action, and induces cireulation of the blood to the surfare. The animal economy is, therefore, kept intact. If allowed to run constantly ont of doors, the hair becomes long. Nature provides a scurf at the surface which forms 
an air-cushion, in connection with the long hair, to prevent the dissipation of animal heat. Sometimes toward spring this scurf may be seen rising above the skin; in the end, it is cast off with the old coat. Exercise, in a measure, compensates grooming, as it keeps the pores of the skin open, and promotes circulation at the surface, though not to so great a degree as by grooming in the stable. It is found that the grooming of animals kept constantly in the open air is not to their advantage. There they have the chance to rub, which they are sure to do whenever there is clogging of the pores, the itching being accompanied with more or less irritation of the skin. This condition is constantly seen in swine and other loose-haired animals.

Misuse of Cold Water.-Cold water in cleansing the horse from dirt and sweat is generally misused. We have many times seen a brutal stableman dash pailful after pailful of cold water over a horse's limbs to wash off the dirt, lead him to the stall, and leave him still dripping. We have seen a horse, reeking with sweat, dashed with cold water orer the back, and the suffering brute placed in a draft of air to cool off. And why? Simply because the human brute was too lazy to scrape him off, lightly blanket him, and lead him ahout until properly cooled.

\section{Keep the Stable Clean.}

The absence of odlors in the stable touches strongly on hygiene, as, in fact, do all the topics of this chapter, for hygiene simply means whatever tends to conserve the health and integrity of the animal. It is well known that the excreta of any animal, and the odors thence arising, are offensive to it, and hence inimical to its health. The animal excrement should, therefore, be removed frequently, and covered up or deodorized. The putrifying of any animal or vegetable substance in a close atmosphere favors the development of bacterial germs that may cause hlood diseases or blood poisoning. Hence, the only safe rule is to destroy all offensive odors in the stable.

Cheap Deodorizers.-Gypsum (ground land plaster) sprinkled liberally about will absorb and deodorize liquids. A solution of sulphate of iron (copperas) will destroy offensive odors. Both are cheap. Their use, in connection with a thorough cleaning of the stable daily, and with plenty of bedding, will do the work. As remarked previously, there is no better place for loose straw than under the horse as bedding. It will soak up) and retain much liquid matter. And here it may be remarked that no wise farmer will allow the liquid portions of manure to go to waste, for it is the soluble portions that are far the most valuable in all manures. The other portions are chiefly valuable when converted into mold (humus). 


\section{CHAPTER VI.}

\section{STABLE CARE, WATER AND MANAGEMENT.}

I. THE USE AND ABUSE OF WATFR.-II. HORSES IIKE CLEAN WATER.- III. USE COMION SENSE.--IV. CLEANING TIIE LIMBS.- V. CURRY COMB AND BRUSH.—-VI. CLEANLINESS OF TIIE SKIN.—VII. LOOK WELL TO THE EXHAUSTED HORSE.—VIIT. TEMPERATUIRE OF THE STABLE.-IX. SADDLE HORSES.- $\mathrm{X}$. PACERS.

\section{The Use and Abuse of Water.}

As to the water which the horse drinks, its quality and quantity, and the time when given him, are matiers of great importance. Water, as naturally drank by animals, is that of pools and rumning streams. When obtained from such sources it is measurably soft, or at least does not contain nearly as much mineral (inorganic) matter as that of wells and springs; for the results of numerous experiments show that ruming water is constantly diluting the organic and inorganic remains taken up by the water of percolation. Such water is vastly better for animals than that of any artificial reservoirs that may be contaminated by drainage of yards or sewige. Te also know that the water of artesian or other wells from which surface drainage is excluded, and also of natural springs, is nearly always excellent.

Oux opinion is that more of the every-day disabilities of farm animals arise from abuse of the use of water than from any other one cause. Let us take the horse. His stomach holds almost four gallons, or an ordinary pail-full. If he drinks more at any one time, he drinks too much; yet when kept from water till very thirsty, he will sometimes drink three pailfulls. If he hat water whenerer he wants it, which is the ideal method, one or two gallons will suffice. If he is thirsty and be wiren water after eating, the quantity not necessary to properly moisten the food will be passed beyond the stomach. carrying with it the undigented food. Every famer"s boy linows the distressing consequences that are apt to follow.

Chill from Drinking.-There is less risk of chill from drinking cool water when the body is still adively wam than when the system has begun to thag. When the horse is thoroughly tired out, the water 
should be made slightly tepid, or a bucket of warm gruel be given instead. In such cases, there may not be sufficient vitality to raise a large quantity of cold water to the temperature of the body, and there is danger that he will become chilled, and his bowels deranged; and if this experience is often repeated, his coat will stare, and further serious results may ensue at any time.

\section{Horses Like Clean Water.}

It is very commonly but erroneously supposed that horses prefer muddy to clean water. The fact is the horse prefers soft water to hard, and will drink indifferent soft water in preference to what is clearer looking but hard. But he will never choose bad soft rather than good soft water, nor bad hard than good hard water, exeept in so far as all hard water becomes more or less soft by standing and exposure to the air. Hard water, containing an excess of saline and mineral substances, does not, as a rule, agree as well with horses as the soft water of a river or pond, because it tends to produce irritation of the mucous membrane of the bowels. A change from soft to hard water is pretty sure to cause intestinal derangements. This explains why, in the case of valuable turf horses, water is often carried about with them in moving from place to place. If bad water is boiled before being given to the animals, it will generally prevent injurious consequences. Horses liable to scour should never be given full drafts; the rule for them should be small quantities and frequently. The reason for this is that the smaller quantities of water lessen the secretions of the intestines, and to that extent decrease the tendency to purgation.

\section{Use Common Sense.}

As a rule, three times a day is sufficient to offer water to a healthy horse in winter. Some persons think that twice or eren once a day at that season will do just as well, but in this practice they are running unwise risks; the horse drinks too much, and if the water is at or near freezing point, the system becomes chilled, often producing serious difficulties.

The Summing Up.-To sum up the whole matter of watering horses, the rational practice is to let them have the opportunity of drinking sufficiently often to prevent their becoming very thirsty and drinking to excess. In hot weather, and during active exertion, horses enjoy, and are the better for, a draught of water at intervals 
of two to four hours. On their return from work, they should have the opportunity of drinking, and unless abstinence has been protracted, or they are much fatigued or orerheated, or constitutionally delicate, there is no need to restrict them. Cold water does not harm them, except in cold weather, when a proportion of hot water should be run into the horse's trough, or the water, in buckets, first placed for several hours somewhere that will take the chill off. Refreshed by his drink, the horse will feed better than if he proceeds to his meal thirsty and languid. Water him first, and feed him afterwards. To postpone watering until after feeding has the serious disadvange, before adverted to, of washing the recently-swallowed, imperfectlydigested food with abnormal rapidity onward through the large end of the bowel, called the blind gut, or cul de sac, thus checking digestion, and giving rise to irregular fermentation, and inducing colic and other ailments. Although he may advantageously have a few sips after feeding, a horse should not then be allowed to gulp unlimited quantities of water, and, indeed, will not care to do so, if his thirst was quenched before he began his meal. For horses, as well as their masters, the best arrangement is to have water accessible for use in reasonable amount at all times.

\section{Cleaning the Limbs.}

We do not hesitate to say that more distress and disability is occasioned in the North by the use of cold water in washing the limbs of horses when muddy, from Norember to $\Lambda$ pril, thin by any other one abuse. Many persons suppose that, as the limbs are alleady wet, more water can do no harm; but it should be remembered that, though the limbs are muddy, they are not necessarily wet or cold at the skin. Indeed, they seldom are. How, then, are we to clean the limbs? Our practice always has been to place the horse in the stable, loosely bandage the limbs when wet, and when dry, clean thoroughly with straw wisps and brush. When a horse is once accustomed to the use of a rather stiff broom, this forms an excellent addition to the implements for eleming. Most horses, howerer, seem nervous over its use upon the limbs at first. For removing sweat and mud, a short-handled broom is almost indispensable.

\section{Curry Comb and Brush.}

The curry eomb, should never be used about the limbs, unless by a very soft hand, for no other can use it withont danger or inconveni- 
ence to the animal. Its place may well be supplied by the use of a broom-corn brush. The sole uses of the curry comb are to lightly raise and loosen the sweat and scurf of the fleshy portions of the body, and as a means of cleaning the brush, the latter being the real instrument of utility in cleansing the body. The curry comb should be laid flat and carried lightly in a succession of curves, until the dust and scurf is free, and then the brush will thoroughly cleanse the body and hair. The final operation is to wipe the coat with a slightly dampened cloth, and then polish with a dry one. The head, limbs and other hairy parts must be more lightly brushed. No two horses can be handled precisely alike in cleaning, and the stableman should be instructed to understand and humor the peculiarities of each animal. The skin of the horse is peculiarly sensitive. If the grooming is conducted without pain, the horse soon comes to enjoy the operation. Especial care, tact and delicacy are necessary in grooming nervous, high-strung animals. They will fight against pain, and what is more natural? Half the vices of horses, we believe, are contracted by a want of intelligent treatment in the stable.

\section{Cleanliness of the Skin.}

In regard to the skin of the horse and its proper care, we quote some excellent remarks by General Sir F. Fitzwygram, one of the latest and best British authorities.

"Giooming, or, in other words, cleanliness of the skin, is not, as many suppose, a mere matter of appearance, or of a rough or smooth coat; it is essential to the general health and condition of the domesticated animal. By work, and especially by fast work, the secretions of the glands of the skin are enormowsly increased. Furthermore, the horse which is worked hard must be fed on highly nutritious food; and from this cause, also, the secretions of the skin are largely increased. Nature must be assisted by artificial means to remove these increased secretions, or the pores of the skin will become clogged and the health will be deteriorated.

"The greater the action of the skin, the greater must be the attention paid to it. As long as the horse remains in a state of nature, taking only the exereise required for gathering his food, and feeding only on laxative diet, grooming is not needed, because the démis of the food and the excretions of the sytem are carried off mainly by the action of the bowels and kidneys. The horse, whose work is slow, can get on with comparatively little grooming. The horse of 
fast work, on the other hand, whose whole system is developed to the utmost, reyuires much more grooming than is necessary for carriage and ordinary riding horses.

Perspiration.-- It has been said, and probahly correctly, that a horse in hard condition and hard work gives off through the pores of the skin, or, in other words, by means of the sweat glands, during the twenty-four hours, an amount equal to that excreted as dung.

"Excretion of worn-out materials through the skin, of course, goes on in some degree in the horse in a state of nature; but the full development of these glands is only produced by hard work, high feeding, and grooming; they are then excited to a greater degree of energy than exists or is required in a state of nature; artificial means, or, in other words, means greater than those supplied by nature, must be put in action by man in order to maintain the health of the skin."

\section{Look Well to the Exhausted Horse.}

In the country, when the horses are put in the stable, perhaps wet and muddy from a storm, or sweating and exhausted with hard driving in the winter, the farmer is apt to think that they should be cleaned at once. But this is well nigh an impossibility. The most that can be done is to make them comfortable. If they are sweating or wet with rain, serape the body, blanket them, put on the hood, lightly bandage the limbs to prevent chill, and if signs of exhanstion are present, give a light stimulant, to be followed later with a warm mash, or the usual feed, as circumstances may dictate. Thus the animal will generally be recuperated by morning, and ready for his grooming:

Under all cireumstances, the owner should study to keep his horse comfortable. He ought to know how to do this, or, in other words, be educated as to the animal's proper care. For instance, a horse driven until heated, should not be left, eren in the summer, without a cover, and never in a draft of air. In cold weather he should never he allowed to stand in the free air without wam clothing, and after brisk driving should be covered as completely as possible.

\section{Temperature of the Stable.}

The horse is a native of a warm elimate, and both thrives and puts up flesh in warmth. Ilis food will go further, and his coat will look better, in a warm than in a cold stable. In spring, autumn and win- 
ter a stable should be kept as comfortably warm as possible, without making it close and offensive. Warmth is good for horses, but purity of air is more essential. Good air must never be sacrificed to warmth. Cold air will but produce a staring coat, whilst foul air is the ready parent of disease. The best test of the purity of air in a stable is the sensation felt on first going into it from the external air; and the best time for testing the sufficiency or otherwise of ventilation is the early morning, before the stable has been cleaned and aired.

\section{Saddle Horses.}

Our saddle horses should not go unnoticed. There is a constantly increasing demand for elegant horses of easy and trained gaits. The thoroughbred sire here again is the basis of excellence. They are produced by thoroughbred sires elegant in form and light in the forehand, upon roadsters and pacing mares not fast enough for the trotting ring. They bear the same relations to our tastes that the English hunter does to that of the gentlemen in England. There will be a constantly increasing demand for this class of horses, the stouter for gentlemen's use, and the lighter and more elegant for ladies. The increasing wealth of the country will demand this class of horses more and more. To-day they are among the highest priced horses we have, outside the fast ones of the turf.

\section{Pacers.}

The last eight or ten years has produced a wonderful impetus in the breeding of pacing horses. We believe pacing to be more a matter of training than anything else, although the hereditary inclination to pace is too distinctly marked in breeds, or rather strains, in various countries, and even in some wild horses of the plains, to doubt its hereditary character. Fast trotters have been made fast pacers by training, but the evidence is still stronger which shors that a pacer may be also made to trot fast. The pacing gait is the fastest gait of the horse except running, as is evidenced in the time of Little Brown Jug and his successors; wonderful indeed when we consider the small number of pacers in comparison with that of trotters. (See Major Abercrombie's tribute near the close of this work.) 


\section{CHAPTER VII.}

\section{TRAINING AND RESTRICTIVE MEASURES.}

I. CONCERNING THE EMPLOYMENT OF FORCE.—II. THE LESSON OF SUBSERVIENCY:- II. DOCILITY TIIROUGII TRAINING.—-IV. USE THE WHIP WITH DISCRETION.—V. INTELLIGENT IRESTRAINT. - VI. ANIMAL LANGUAGE. -VII. GENTLING AND TRAINING THE COLT.—-VIII. USE OF THE VOICE AND OF SIGNALS. - IX. SPECIAL MODES OF IIORSE TAMIAG.—X. RAREY'S TIREE FUNDAMENTAL PRINCIPLES.—XI. RAREY'S APPARATUS.XII. THE STRUGGIE DESCRIBED,—XII. TIE TAIRE'S VICTOIX,-XIV. DR. WAISI'S SUMMING UP.—XV. RAREY'S FAVORITE HALTER.—-XVI. A BIT OF HISTORY.

\section{Concerning the Employment of Force.}

It has taken our race a long time to understand that the inferior creation can be managed by more intelligent means than hy the employment of brute force, acting upon the terror of the animal. Even to-day, more than three-quarters of our domestic animals are subdued through the power of fear alone, rather than by the superior mind force of man over the brute, or, in other words, than by the exercise of the former's superior intelligence. That force is necessary, the force of mechanical appliances, we all admit and act upon. It is the brutal use of mechanical force that is to be deprecated.

The original idea conceived by man seems to have been the use of the tail as a means of draft, and probably clubbing or goading from one side or the other when the anmal deviated from the proper line. Then the loop around the jaw was invented, and the bridle of to-day is the result. Iet the horse in fully as eapable of understanding the wislies of his master as the dow. In fact some nations, an in Norway, cmploy the voice almost solely, and the Arabs depend more upon the voice than upon the bit. Shall we, then, discard our appliances and introduce these other methods of mamagement? By no means. They would not subserve our requirements. Yet we may combine other intelligent means with those we have. Neither spur nor whip is needed to cause the horse to exert his ntmost power. This is shown in many cases well authenticated. It is seen continually in the 
best management of our trotting horses, and occasionally in the handling of horses of very nervous temperament by some mildmannered man, who has redeemed animals so frantic under torture as to render them, for the time being, insane.

\section{The Lesson of Subserviency.}

To render an animal perfectly subservient to the will of man, he must never have been allowed to know that his strength is superior to man's. To do this, he must be taken in hand while young. The fable of the woman who practiced carrying the calf every day, and was thus enabled to still carry the animal when it had grown to be a cow, is but an illustration that it is simply training, education, that conquers. The colt taught to walk quietly by the side of the trainer by means of the simple halter, always remains in quiet subjection.

There are plenty of persons to-day who hold that no handling of a horse should occur until of an age suitable for continuous labor. They are mistaken. The intelligent trainer knows that the animal's education should commence while it is yet running with the dam. The principal reason why dogs are so tractable and amiable, so devoted to their masters, is that they are, in a sense, made the companions of man while yet very young. Their dependent familiarity becomes hereditary, and a strong part of the animal nature. This indication is shown in the horse of the Arab, which is dependent, and familiarly so, on the master. The Indian horse is the reverse. To the Arab the horse is the best gift of God, and its docility is the result of many generations of careful care and attention, while the Indian management of the horse is simply a counterpart of what he sees in the conflict of savage animals.

\section{Docility Through Training.}

The humane treatment of animals under training will more and more promote their complete subservience to man; and in respect to docility through training, the horse is really the most intelligent of the domestic animals. The vicious and stubhorn characteristics shown by some horses are more the result of heredity through generations of cruel mismanagement than of original inherent viciousness. In fact, we can trace it thus, if we choose, as between the Arab and the Indian horse, and as between the English and the American colt. The greater tractability and freedom from vice of the American over the English horse, is due to the fact that here the horse is handled 
from colthood up by the boys of the family, while in England the colt is the scape-goat of ignorant servants. There are many honorable departures from this in the latter country, just as there are brutal exceptions among us; but the rule holds good. American colts are early taught to lead by the halter. The boys play with and exercise them. It is not unusual to see them lolling on the colts, feeding them choice bits, or eren mounted on their backs. When the time for real service comes, there is no fear, and they go about their business with but few struggles to escape, unless their fighting qualities are aroused by cruelty of some kind or other.

\section{Use the Whip With Discretion.}

We believe the whip is a valuable instrument in restraining all animals, but we also believe that a single blow only should be given at one time, to be followed up, however, with another and another, but always with marked intervals between, until the animal submits. It may be necessary to repeat the blow, but a greater or less interval should elapse, and the reason made clear to the animal, if possible. Like the infant, he reasons slowly. Give him time. Once subdued, return to the law of kindness.

A good horseman uses the whip but seldon. The animal is simply made to know it is an implement of power. In training, he soon comes to understand that the slight taly gives no pain, but refusal brings the stronger blow. Its principal use should be to prevent injury to the trainer in the case of refractory animals. One stinging cut of the whip is sufficient to cause the animal to forget his other impulse. The stroke should not be repeated, unless a similar condition reproduces the idea of resistence. With each recurring punishment, the impulse becomes less and less, until it ceases altogether, so far as the trainer who has conquered him is concerned.

\section{Intelligent Restraint.}

There are certain persons who have extraordinary power over the lower animals. It is called by many names. No person of violent temper, or rather, no person who gives way to his temper, is fit to be entrusted with the control or traning of animals. Such a man is not fit to have the ordinary care of dumb beasts; his brutal incapacity is pretty sure to be shown in their actions. If a horse is uneasy in his stall at the approach of a stranger, it is a fair indication that he fears abuse. If he shows timidity or nerrousness at the approach of 
the stableman, the evidence is against the man; in other words, that man should be watched. A horse made vicious by abuse had better be gotten rid of from the stable, for the continual wrangle to produce obedience will surely infect his companions. The man who cannot manage a stable of horses without the use of the pitchfork should be discharged at once. He is a coward, whose only idea of controlling his dumb charge is through fear. The ordinary stableman can hardly be expected to show himself a deft trainer, when so often he cannot even clean a horse with comfort to the animal, nor even measurably perfect as to the finish.

\section{Animal Language.}

Every animal has its own language. We should make it a part of our business to study not only the language of his signs, but that of the voice as well. Thus we may know instantly what the play or slant of the ears means, what a glance of the eye signifies, and come to understand the meaning of a particular arch of the neck or movement of the tail. These movements all have their meaning, and are well understood by each animal of a given species. The cry of pain, the whinney of expectation, of solicitation or of satisfaction, the shriek and grunt of extreme pain, the outcry of fear, the peculiar vibrations of the body, and the attitude when standing still, - these should be made the study of all who own horses. An extension of observation in other directions would enable dealers in horses to assist their patrons to understand these signs and vocal languages, to their great advantage; most persons do not possess this knowledge, because of the lack of opportunity of observation in a sufficient number of cases.

Here, again, one may show the animal that the superior intelligence of the human is more than a match for his own brute force; and once he knows you understand and can outwit him, your ascendeney is established. The key to the whole mystery of the power which certain individuals exert over brutes, is that they understand them.

\section{Gentling and Training the Colt.}

Haltering.-The colt that has been haltered and taught to lead quietly, is half broken. In haltering the colt for the first time do not hurry, or show signs of nervousness or fear. Taking the halter in both hands, hold it out toward the colt until he will touch it with the nose. This is the final means by which the horse satisfies himself that an 
object is not dangerous. Once his fear of the halter is allayed, slip it on the head and fasten it. If he shows no serious fear, tie him up at once, but have every part so strong that it cannot be broken. If fear is still expressed, allow the colt to wear the halter until he grows accustomed to it, and quiet.

Teaching to Lead.-To teach a colt to lead, take him in a small yard and allow him to play about at the length of a ten or twelvefoot strap. When he ceases to play, approach him gently, take the halter by the nose-band with the left hand, while holding a whip by the right and under the arm. If he rears, support yourself by grasping the top of the neck to keep the colt down. Use no undue violence. Do not strike him. When he gets through floundering, pet him, let him taste a small lump of sugar, and little or no difficulty will thereafter be experienced. To lead him, take the halter at the caveson in the right hand, and bid him go. If he refuse, tap him gently with the whip, under the belly, until he moves. If he rears, subdue him quietly. So continue until he moves forward. Then reward him with a caress, and talk to him. He will soon come to enjoy his lessons, especially if an occasional lump of sugar or other delicacy is added.

Teaching to Back.- In teaching the colt to back, stand in front of him, take the halter or bridle with both hands, and with the word, "Back!" press square upon the bit, rather firmly but steadily. The colt must have time to understand what is wanted.

\section{Use of the Voice and of Signals.}

In all training, the voice must be the chief reliance, but signals by motion must also be employed. The signal by sound should always precede the signal by motion, and the check of the strap or rein should always precede the tap or, when necessary, the blow of the whip. That is to say, always give the word of command first, and sceldom in a loud voice, which is unnecessary, the hearing of horses being acute. The child is taught to walk, leap, run or speak through the power of imitation. The same means must be used with animals, and accordingly the same word, as also the same signal, should alway be used for the same particular action:-Whoa! Back! Go on! Come here! ete.

\section{Special Methods of Horse Taming.}

Now as to the modes of training flamingly advertised every few months by certain specialists, these pretentious individuals are, as a 
rule, mere fakirs, and their methods of no account to the ordinary trainer. For controlling high-strung, belligerent horses, there has never been anything better than the means originally employed by Rarey, and whence their excellence? Because founded on common sense. Hence, we here introduce the description of the famous Rarey methods, given by J. H. Walsh, F. R. C. S., of England, with some of his comments thereon, and illustrations to serve as object lessons. Dr. Walsh became well acquainted with Rarey in England, and studied his methods carefully; he was most favorably impressed with them, as was the writer of these pages at that time.

\section{Rarey's Three Fundamental Principles.}

"In his public demonstrations, Mr. Rarey always commenced by some introductory remarks on the natural history of the horse, in which there was nothing to impress the auditor with any great respect for his powers. At the end of this act, which was evidently intended to kill time, we were put in possession of the three fundamental principles of the new theory of the proper management of the horse, namely:

"First, "That he is so constituted by nature that he will not offer" resistance to any demand made of him which he fully comprehends, if made in a way consistent with the laws of his nature.'

"Secondly, "That he has no consciousness of his strength beyond his experience, and can be handled according to our will without force.'

"Thirdly, 'That we can, in compliance with the laws of his nature, by which he examines all things new to him, take any object, however frightful, around, over, or on him, that does not inflict pain, without causing him to fear.'

\section{Rarey's Apparatus Described.}

"The apparatus which is required is, first of all, an ordinary snaffle or straight bit in the mouth, without which nothing could be done with any vicious horse; and if any animal is to be 'Rareyfied,' the preliminary operation is to get this into the mouth. Stafford was brought to Mr. Rarey with the aid of guide-ropes, which were fastened to his head and held by grooms on each side. In him, therefore, this first essential point was accomplished. Cruiser also had a halter, strengthened with iron, and in him also there was a means of laying hold of the head, which was eagerly seized by the operator. 
The plan adopted in his case was to fix an iron staple to the doorpost, and then rumning through this a strong leather strap, to which a spring-hook was attached, the opportunity was seized when the horse came open-mouthed to the door, and he was securely laid

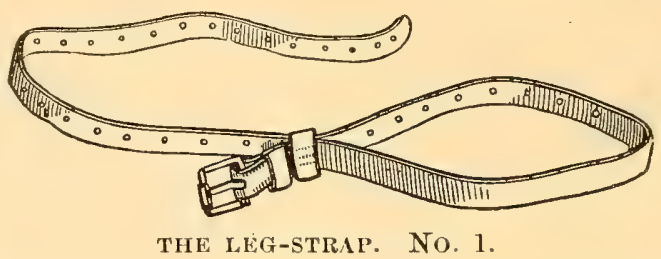

hold of and drawn up to the staple, so as to compei him to allow the introduction of a bit. The grey colt at Mr. Anderson's was bitted; but the zebra was loose in his cage, and I do not at all know how the gag in which he was exhibited was forced into his mouth, but I be-

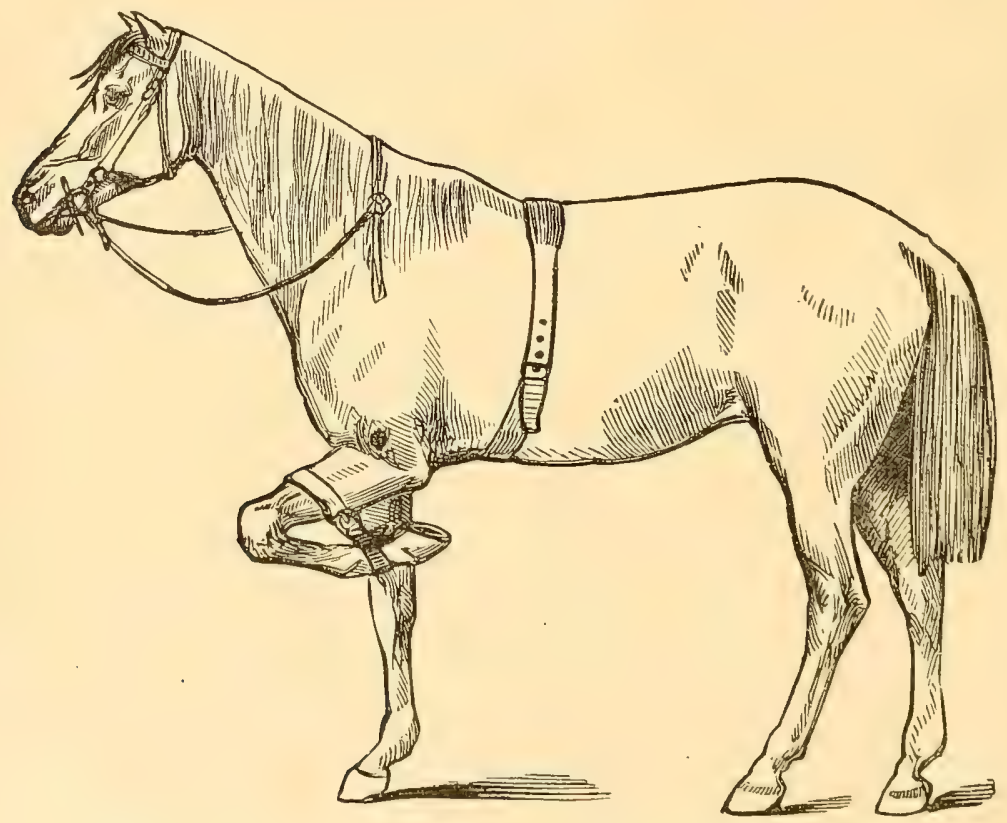

CRUISER, TIE VICIOUS, WITII LEG-STLAP ANU SUIRINGLE ON.

lieve it wats effected by a rope thrown round his neck and drawn up) to the bar's of his cage.

"The second part of the apparatus is the leg-strap for the near fore leg, being very similar to a stirrup-leather, which, with the addition 
of a strong loop, ean be made to answer the same purpose very well. Before applying this strap, which at once makes the horse harmless for offense, he must be rendered approachable, which, in ordinary animals, is effected merely with the aid of the bridle. As soon as this is done the horse is innocent of all mischief except with his teeth, for he cannot kick on three legs, and even his mouth may be kept away from the operator by drawing on the off rein. To bring him speedily to submit to the power of the operator, the other leg must also be confined, which is effected by first buckling on a surcingle, as represented on the opposite page, and then catching the off fetlock in the running noose of leg-strap No. 2, which is made in the annexed form. Provided with this second strap in his pocket, and having already applied the leg-strap No. 1, and the surcingle as shown above, the subject under manipulation is either induced to drop his off foot into the noose, or it is slipped round his ankle, while the off rein is

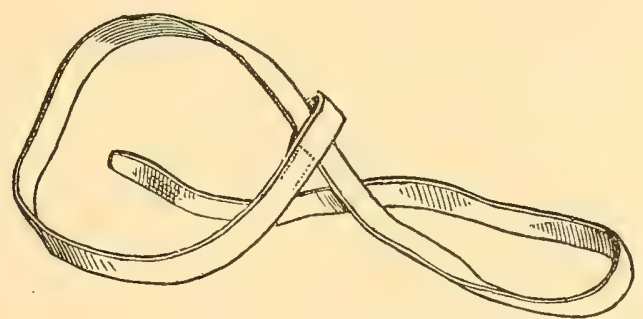

THE LEG-STRAP. NO. 2.

held by the other hand to keep the teeth off the operator. As soon as this loop is firmly drawn round the leg, the other end is slipped through the surcingle under the belly, and entire control of the hor'se is only a work of time. The arrangement of these straps is exhibited in the next engraving, where the horse is shown ready for the final struggle. Up to this time, almost every horse will be tolerably quiet and unresisting, some squealing when any approach is made to their elbows to tighten the surcingle, and others when the strap No. 2 is slipped through it. Few, however, plunge much; and if they are made to hop on three legs, they are able to go on for so long a time, without producing the necessary amount of fatigue, that the operator would be tired before his pupil.

\section{The Struggle Described.}

"It is at this stage-that is to say, with the use of the leg-strap No. 1-that the predecessor's of Mr. Rarey stopped, and they conse- 
quently failed to gain the absolute control which he has invariably obtained with the slight but really important additions which he has made, and which he uses in the ingenious manner which I shall now describe. It may be observed that, with a violent horse, it is always better to let him feel his want of power for doing mischief with the near fore leg strapped up, and the slight degree of fatigue which a few minutes' hopping will produce, before the second strap is called into platy, especially if the operator has not acquired great skill in the use of the apparatus. When this is done, and the second strap is ap-

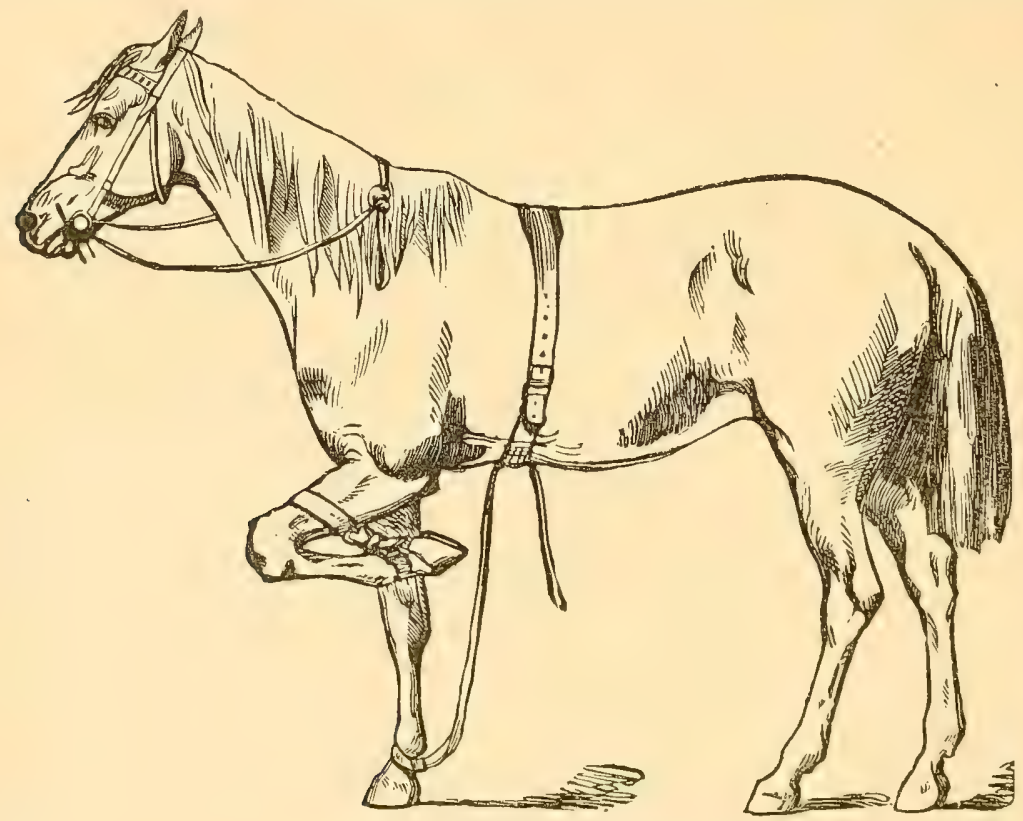

READY FOR TIIE FINAI, STRUGGLE.

plicd, and slipped through the sureingle, as shown in 'Ready for the Final Struggle, taking eare to put a stout glove on the right hand, the left rein is taken in the left hand, and gently jerked-using, if necessary, the usual slight stimulus with the tongue, to make the horse nore, which he can only do by raising the off fore-leg off the ground in the action known as hopping.

"The moment this begins, the right hand firmly draws the off leg up to the sureingle, and keeps it there, when the horse must either bound into the air on his hind legs, or he must go down on the 
ground, supported from falling on his side in the attitude of knceling. To avoid mischief, therefore, the loose-box or yard where the operation is carried on should be thickly bedded with straw; for no knee-caps are stout enough to protect the joints from injury on hard ground; nor, if they escape being bruised, will the shock to the body on falling be at all safe. Even straw can hardly be relied on, if the floor beneath is of brick, stone, pobbles, or hard natural soil; for it is apt to give way during the struggles of the horse, and allow the knees to reach it without the intended protection. When, therefore, there is no tanned riding-school, or other similar surface, at com-

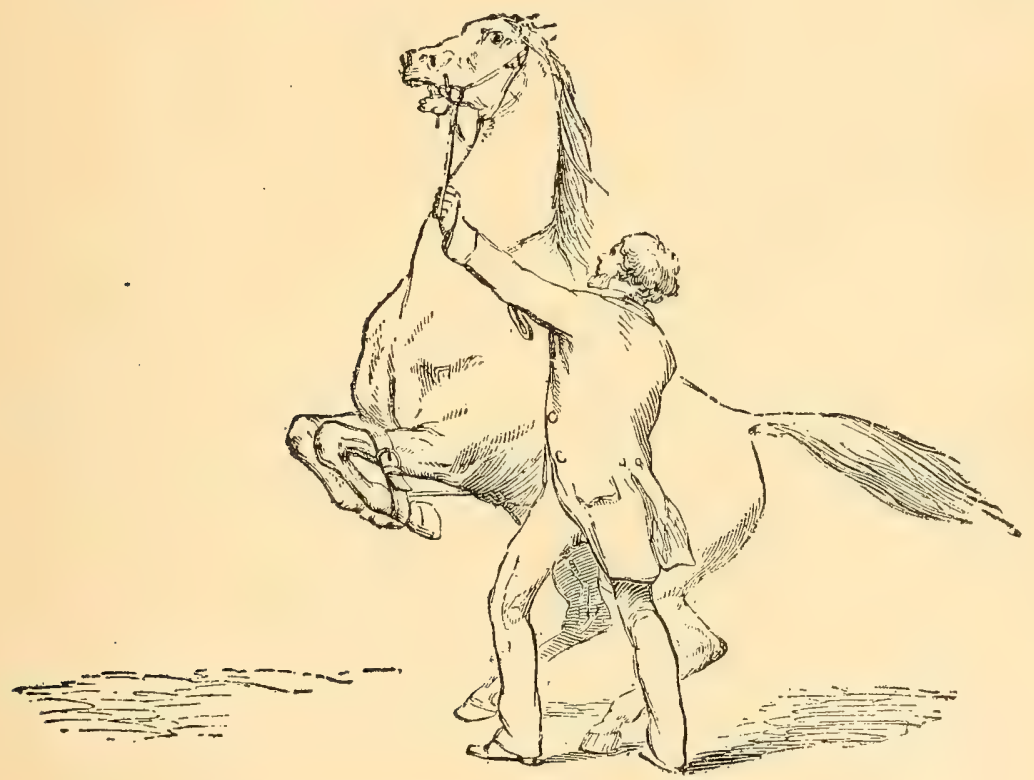

THE HORSE BOUNDING ON IIS HIND LEGS.

mand, a good solid bed of manure (which is always to be had wherever horses are) should be spread a foot thick at least, and over this clean straw may be laid.

"To return to the subject of the operation, whom we left with the alternative of bounding in the air on his hind legs, or falling on his knees in the annexed attitude, the chief art in managing this part of the process is to keep firm hold of the strap attuched to the off lig close to the surcingle; the hand being protected by the glove, can easily prevent it from slipping through during the strugeles of the horse, and at the same time serves as a point d'appui for the operator, 
so that he can follow the movements of the bounding animal in whatever direction he may progress. The operator must on no account attempt to stand away from his patient, nor must he advance before the girth-place; but keeping close to this, he is in no danger, provided he has the sense and the ability to give way if the horse should throw himself down towards his side. The rein, being still held in the left hand, prevents the horse falling away from the operator, and is also used by him as a means of guiding the animal, if he happens to progress in a direction which is not desired.

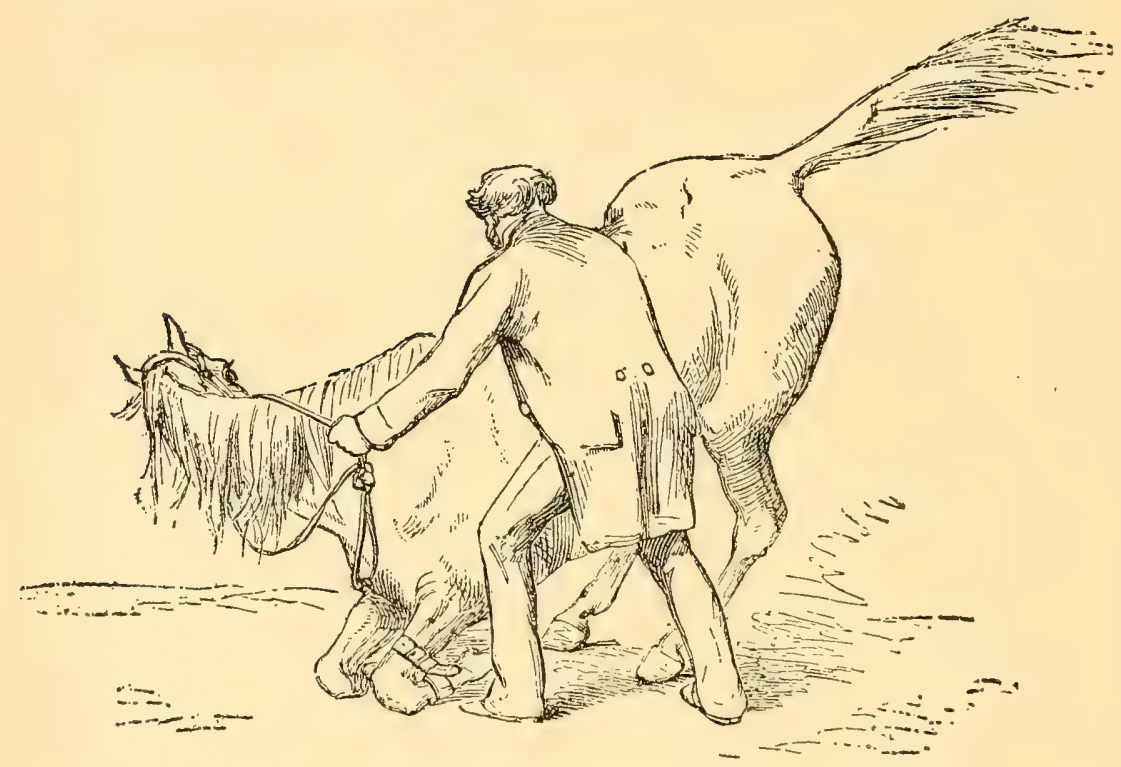

THE IIORSE ON HIS KNEES, ABOUT TO FAIL ON HIS SIDI.

"Nothing else is to be attempted till the horse has (quite exhausted all his energies, which those possessed of high courage will soon do; but low-bred animals are very apt to turn sulky, and, refusing to plunge, remain on their knees, in spite of every kind of stimulus which can be given them short of severe punishment with the whip, which is to be avoided, as opposed to the prineiples on which the whole process is fomded. By taking time with these brutes, they may always be made to tire themselven, for the kneeling position is rery irksome to them, and the most stubborn will give a plunge now and then to reliere themselves, thomgh they will not follow up one with another as speedily as a thoroughbred. 
"Sooner or later" (the time varying from ten minutes to two or three hours), the tail begins to tremble, the flanks heave, and a profuse perspiration breaks out, which are signs that the horse of himself desires the recumbent position, and will lie down of his own accord, if not pulled over by the right hand of the operator. Mr. Rarey, in his public exhibitions, has never, as far as I am aware, waited for this to take place, but, perhaps to prevent wearying his audience, has always pulled his patient over on his side as soon as he could accomplish the feat. In many cases, this impatience has led to a partial failure; the horse, not being tired out, has refused to submit, and it has only been after repeating the process once or twice that complete control has been obtained. Those gentleman, therefore, who wish to try the experiment for themselves, will do well to avoid any risk of a repetition, which they may not be able to manage with the dexterity of the great American tamer. Let them wait till the horse is thoroughly tired, and then only interfere to such an extent as to keep him leaning towards their side, by laying hold of the right rein instead of the left, as shown in the engraving, 'The Horse Bounding on His Hind Legs;' and drawing the head away from themselves. $\mathrm{Mr}$. Rarey generally used the right hand for this purpose, when he wished to throw his patient before he was exhausted, because he could in that way employ more force; and, at the same time, his dexterity was such that, if a bound was made, he was always ready to hold the strap attached to the off foot before the horse could get fairly on his hind legs. In whichever way the task is accomplished, the effect is apparently the same-the horse lies extended on his side, panting and sweating, in the most exhausted condition; but, of course, showing more of these symptoms of distress the longer he has been kept resisting the restraints put upon him.

\section{The Tamer's Victory.}

"Now comes the test of the practical ability of the operator; for whereas before he had only plain directions to carry out, he has at this stage to judge how far his efforts are successful. If he takes off the straps too soon, the patient is patient no longer, but rises rapidly, and perhaps rewards him by planting a severe blow on his ribs. It is here that Mr. Rarey displayed his great skill to perfection. Apparently by intuition, he knew when his pupil was mastered; but, as he was always ready to explain, it was really by two symptoms that he judged whether he had gained the mastery or not. One of these 
was the expression of the eye, which it would be difficult to describe, and which experience alone could adequately convey to those who wish to understand it; but the other, being readily tested, is within the reach of every one. This consists in the entire flaccidity of the muscles of the neck and limbs; and until this is ascertained to have been obtained, the straps should not be entirely removed.

" $\mathrm{Mr}$. Rarey's plan of proceeding at this stage was the following: A second or two after the horse went down, he let him raise his head, and then dragged it down again to the ground by the mane. On repeating this once, twice, or thrice, the animal would give in as far as

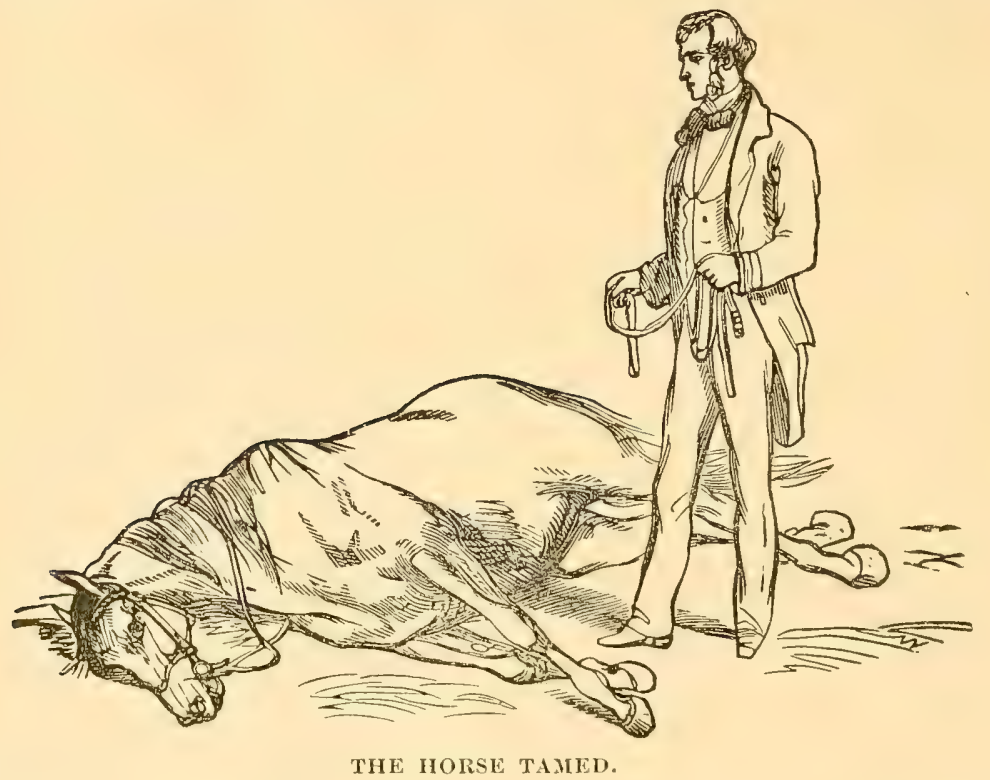

that part was concerned; and heing rewarded with a pat of the hand, the head remained still on the ground, and that part was 'gentled.' Next removing the leg straps, the fore legs were separately gently rubbed downwards; and on being lifted, and let fall, as if deat, they also were passed as in a similar satisfactory state. The operat or then going round by the back, proceeded to gentle the hind limbs ; and though, in vieious horses, he sometimes had narrow eseapes of being kicked, yet, by his great activity and elever mode of seizing his opportunity, he always succeded in keeping out of harm's way. Finally, the operator passed in front of the legs, and performed all the 
usual 'clap-traps' of putting his head between them, knocking the hind and fore shoes together, standing on the body, etc.

"While in this state, the horse lies in the attitude and with the expression which is very well represented in the accompanying sketch, and there he will gladly lie as long as he is permitted to do so. But he is not to be allowed to recruit his powers; and as soon as he had gone through the tricks which I have described, Mr. Rarey made him rise, and then showed that the power which he had gained was not lost as soon as the animal stood on his legs again. Calling for a saddle, it was in every case shown to the horse, and put first on his head, then on his neck, and finally in its proper place. The animal then always submitted to be mounted, and even allowed the dangerous plan recommended and adopted by Mr. Rarey, of standing close to the hind-quarter while putting the foot in the stirrup, to be carried out without kicking, which before the 'Rareyfication' most of the vicicus brutes operated on in public would probably have done.

\section{Dr. Walsh's Summing Up.}

"By this plan, it is indisputable that any active man, of good temper, but possessed of firmness and courage, and accustomed to deal with horses, may gain such a control over even the most vicious, that he can do what he likes with them in-doors. No one who has examined into the matter can doubt Mr. Rarey's power, nor can he refuse him the merit of improving upon the old system of controlling the horse, by the addition of the second leg strap, which adds so much to the power of the human arm that the most violent and muscular horse has no chance whatever. The secret lies in two essential features; first, that the horse must never be coerced or resisted unless the man is certain of success in controlling him; and, secondly, that when the former is thoroughly convinced of his powerless condition, and his muscles are tired out, the latter interferes and relieves him of his trammels, 'gentles' him, gives him kind words, and at length encourages him to rise. The effect is marvelous-the nost vicious brute, who would previously tear any man to pieces, after he is thus first coerced, and then 'gentled' and relieved, appears to grow fond of his master, and follows him about like a dog. Clearly, therefore, Mr. Rarey may be considered as having been eminently successful in propounding a system of horse-taming, but it by no means follows that his process is equally, or even at all, useful in horse-breaking. 
"There appears to be strong evidence that, if the operator gives occasionally a very slight reminder of his powers, the effect of one, two, or three lessons, repeated at short intervals, will continue for at least a year or two. There are numerous instances which have come to my knowledge of horses resuming their vicious habits within two or three months of receiving such a lesson from Mr. Rarey that they would allow him to do what he liked with them; but in the case of the savage Cruiser, there is reason to believe that he never once rebelled against his master from the time that he first gave in. The evidence in favor of the lasting nature of the controlling power, when exercised by the operator himself, is too strong to be gainsaid.

"Does the vicious horse which has been subdued and gentled by one man, show the same absence of vice towards others? Here the evidence is all the other way; and on putting Cruiser into the witnessbox, he would tell us that he has several times turned against his groom, and put his life in danger. Still, it must be remembered that, prior to his treatment by $\mathrm{Mr}$. Rarey, no man dared enter his box; and on comparing his two states, before and afterwards, it may be truly said that, though not absolutely cured of his vicious propensities, he is comparatively so. Probably the same conclusion may be arrived at in those cases which are related of relapses from virtue to vice; but, at all events, such instances are numerous enough, and attested in a manner so respectable, that every possessor of a coerced horse should be always on his guard.

"Whether" or not the horse is injured by the operation, is somewhat difficult to answer, because the injury, if real, is not apparent. The chief means of testing the effect is on the powers of race-horses, several of which have felt Mr. Rarey's straps, and been controlled by his master hand. And I believe there is no instance of a horse which had gone through the operation doing any good subsequently on the turf.

"On the whole, it may fairly be concluded that Mr. Rarey's plans are well adipted for the control of vicious horses, supposing they are not subsequently wanted for the turf, in which case the utility of the process is very questionable. Ilow far is all this useful in breaking colts for general purposes? My own belief is that it aets by producing in the horse a compound feeling of fear and gratitude, the former being the result of his fruitless efforts to get rid of the controlling hand of man, and, the latter being established, from finding that hand relieve him of his straps and then caress and 'gentle' 
him. If, therefore, any horse, even without vice, is required to exhibit to his master or mistress any relations more intinate than those which are usually practiced in this country, great advantage will result from the establishment of this fear and gratitude. I think the use of Mr. Rarey's straps most valuable."

\section{Rarey's Favorite Halter.}

The annexed engraving represents the halter recommended by $\mathrm{Mr}$. Rarey for all purposes, with the addition of his ordinary breakingbit. The halter is of leather, and made like an ordinary head-stall, but rather lighter. A leading-strap being buckled to the nose-band, either before or behind, anything may be done with the colt short of mounting. The method by which this halter is converted into a very useful breaking-bridle is quite simple, consisting merely in attaching any bit which may be selected to the rings connecting the checkpieces to the nose-band. The attachment is made by means of two small billets and buckles, as shown in the engraving.

\section{A Bit of History.}

The "Rarey Method" derives its name from the fact that it was first carried to perfection and given a world-wide celebrity by the late Mr. John S. Rarey, of Groveport, Franklin county, Ohio, although it

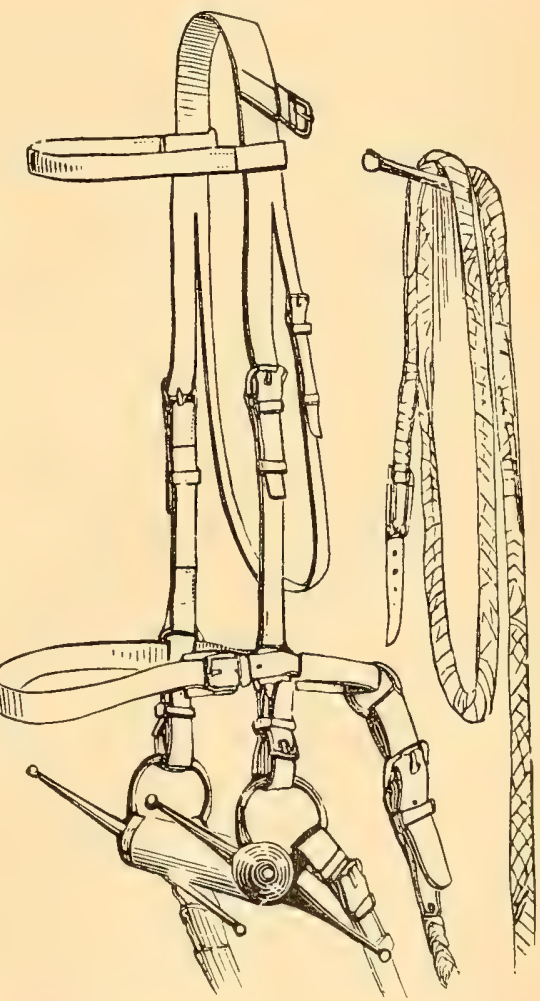

RAREY'S HALTER AND BREAKING-BIT. was not wholly original with him.

That gentleman's experience in training young colts, and in taming the vicious of a larger growth, was quite extensive and very successful in our own country. In 1858 he went to England, and created such a furore there that it is said the gross proceeds of his exhibitions,

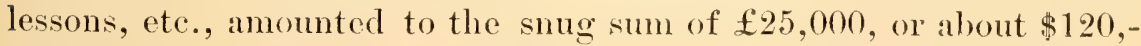
000. His most famous conquest, and the one so often referred to by Dr. Walsh, was Cruiser, a stallion of extraordinary ferocity. Mr. Rarey has been dead many years. 


\section{CHAPTER VIII.}

\section{HOW TO BUY A HORSE, AND HOW TO SELL.}

I. TIE WARRANTEE.-II. AN UNQUAlified WARRANTEE. III. THE CONDITION OF UNSOUNDNESS.—IV. VICE.—V. BLEMISHES.—VI. DIRECTIONS FOR BUYING.-—VII. LOOK OUT FOR DISABILITIES AND TRICKS.VIII. DIRECTIONS FOR SELLING.

\section{The Warrantee.}

The man who seeks to sell a horse by using deceit never succeeds, except with a class of men who do not read, but, nevertheless, think they know it all. This is the class of men who are taken in by fakirs and sharpers of every kind. If not competent yourself to judge, on careful trial, of vices or disabilities and positive unsoundness, get some competent person to examine the animal for you (as, even if you should have to pay a capable veterinarian for his skill in this direction, it would be true economy ), or exact a warrantee from the seller, it being known that his warrantee is good. That is to say, the seller must be known in the community to be solvent as a business man. If you trade with the mere traveling horse peddler, you are pretty sure to be beaten.

The warrantee should be good for not less than six weeks, and it is only good for what it specifies. If, however, there is admitted to be any defect in the horse, the exceptions must be included in the warrantee. The horse, gelding or mare should be particularly described, including the exact age in years, color, height and peculiar markings. With these reservations, the following form will cover the case of a full guarantee for soundness and vice, both in the stable and out, the reservations to be added if the case so requires.

\section{An Unqualified Warrantee.}

$\$$.... Received of (name, address and date), the sum of $\$ \ldots$ for (name of horse, and whether stallion, gelding or mare), warranted to be sound in every respect, free from vice and blemish of whatsoever kind, and quict to ride or drive.

(Signature of seller.)

Attest: (Signature of witness.) 
If the horse is very valuable, it will be well to have the attestation of a notary public added.

The reason why it should be stated in the receipt, bill of sale, etc., that the animal is free from vice, and quiet to ride or drive, is that an animal perfectly sound may be vicious, blemished, balky, or otherwise not worthy, and in the common acceptation of the term is really not a sound horse, fit for a lady or gentleman to drive. In the following descriptions we give a careful synopsis of what constitutes unsoundness, vice, disabilities, etc. Valuable object lessons in this connection are given in Chapter IX, to which the reader is further referred.

\section{The Condition of Unsoundness.}

Strangles, Colds, etc.-A horse recovering from ordinary disease is not necessarily unsound; but he must not be warranted as sound if the disease is such that unsoundness may ensue later, as, for instance, in a case of supposed strangles, when glanders, malignant tuberculosis, or blood poisoning is liable to follow. In this category, we place, besides strangles, any running from the nasal sinuses, colds, etc., that possibly may yet permanently disable the animal.

Knee Sprung. - When this exists to any considerable degree, it is unsoundness. In the case of a cheap horse, knees slightly sprung would be considered simply a blemish.

Defective Shoulders. - In the draft horse, this would not constitute unsoundness, but in horses for fast work, either in harness or under the saddle, where upright shoulders cause stumbling, the horse is unsound. The horse with the shoulders not properly sloping, should never be bought for fast work. The locomotive mechanism of the horse is shown in the diagram presented on the next page.

Knuckling - This consists of the pastern joints of one or both fore legs being abnormally perpendicular, instead of sloping maturally back, and is especially objectionable in the horse of fast work. If this is the result of overwork, if it be occasioned by strains, or by pumice foot or navicular disease, the animal is unsound, whereas, if the knuckling be natural, the animal being at rest, it is a defect but not unsoundness; yet an animal that knuckles orer is unsound, because the deformity interferes with his action and use.

Pumiced Sole.-If this is occasioned by disease of the lamina attaching the inner to the horny covering of the foot, it constitutes unsoundness. 
Unsound Eyes.-If the horse has perfect eyes, he seldom shies unless from having been beaten by a brutal groom. Any disease of the eyes, near-sightedness, or defective eyes of any kind, should constitute unsoundness; but total blindness is not necessarily an unsoundness calling for mention in a warrantee, and for the reason that it may be easily detected.

Capped Knees.-If the enlargements, or calloused surfaces, interfere with the action of the limbs, it is unsoundness; if they do not thus interfere with the action, they are simply blemishes.

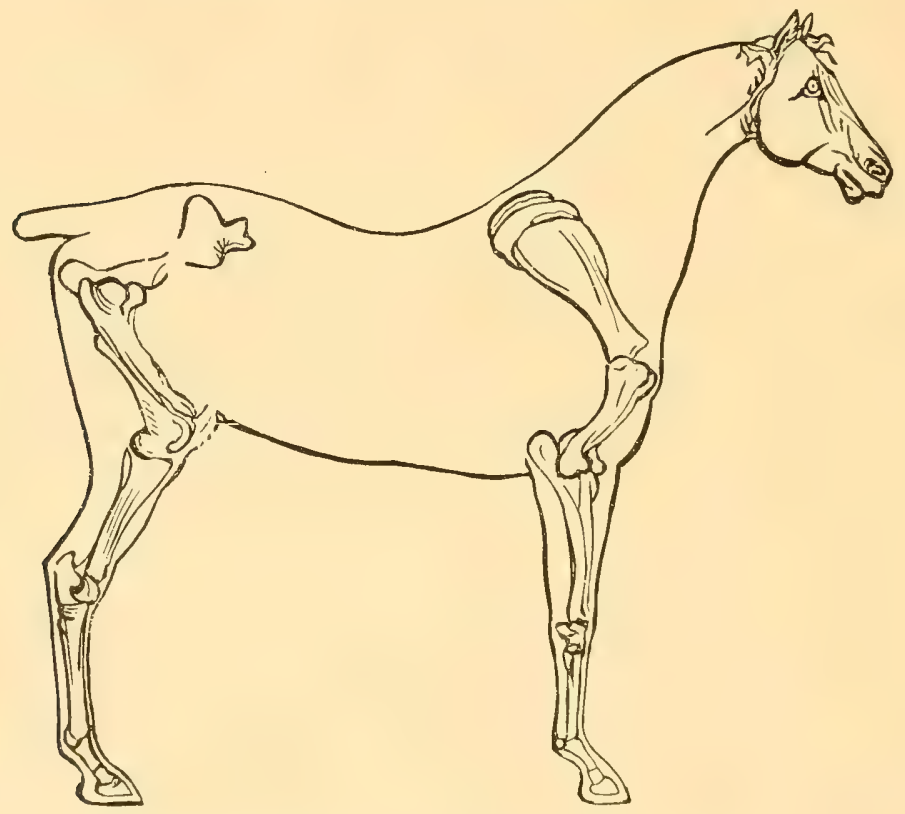

MECHANISM OF TIIE FORE AND IIIND LIMBS.

Corns.-The animal is unsound if the corns produce lameness. This will be a question for the reterinarian to decide. Corns usually oceur in low-heeled, brittle, flat-footed horses.

Sand Crack,-This is a fissure, grenerally on the inside quarter of the fore foot, having its original start just bolow the coronet, and extending towards the bottom of the hoof. While it exists, the horse is unsound. When eured, it may or may not be a blemish.

False Quarter-A horizontal fissure in the inside of the hoof is called false quarter. When apparent, it constitutes unsoundness. 
Thrush.-This constitutes unsoundness when it is caused by severe contraction of the hoof. Slight thrush is curable. Thrush degenerating to canker is certainly unsoundness.

Bone Diseases.-Ring bone, splints, spavin, curby hocks, curbs of any kind, capped hocks, or any disability causing lameness, constitutes unsoundness.

String-Halt.-If occasioned by an inflamed nerve, is unsoundness. If not so, it is a blemish.

Hipped.-A fractured hip makes the animal unsound, if he goes lame. When recovered, it is a blemish.

Grease.-Grease, cracked heels, swollen legs, or any joint disease, until cured, is unsound. When cured, it may or may not be a blemish or disability.

Wens.-When situated at the upper part of the windpipe, or near a main artery or vein, may or may not constitute unsoundness. Wens on the hock or elbow not causing lameness are blemishes.

Unnerved.-A horse having had the operation of neurotomy performed, should be considered unsound, since the separation of the nerve, while it may not cause the animal to go lame, does not prevent the previously existing cause from bringing on lameness.

Wind Broken, Roaring and Whistling.-The first named disability is indicated by a peculiar suppressed cough when the horse is exercised or after eating. Roaring is a chronic disease of the windpipe, whose principal sign is a grunting or roaring when the horse is suddenly agitated. In whistling, the horse, when sharply galloped, emits a peculiar wheezing. All these, when chronic, constitute unsoundness.

Asthma - Recognized by a short, soft cough on going out or coming into the stable, and more pronounced in winter than in summer, is unsoundness.

Crib Biting.- Seizing the manger and emitting a peculiar grunt, and wind-sucking, so-called, which is a parallel disability when the crib or any projection is not seized, is unsoundness.

Chronic Cough.-Any chronic cough should constitute unsoundness. Of such an animal beware.

Disease in General.-Any disease, while it lasts, constitutes unsoundness.

Shying.--The horse given to shying is unsound, since the habit is dangerous to the rider or driver; but this, as well as running away and starting suddenly, is generally termed a vice. 
Enlargements.-These, of whatever kind, including bog, blood, bone spavins, curbs, thorough pin, when causing lameness, constitute unsoundness.

Cutting.-When from malformation, the horse cuts himself in moving, he is unsound.

Overreaching.-When this defect is so pronounced as to be liable to pull off a shoe or to cause falling down, the horse is unsound.

Low Action.-When produced by strain of the muscles or sinews, the animal is unsound.

Stumbling.-This constitutes unsoundness.

Indigestion.-Chronic indigestion, causing bloating or a tucked up condition of barrel, or a general washy condition, the animal is unsound.

Wounds.-Wounds, or even severe abrasions, constitute unsoundness while they continue.

Paralysis - This, or the loss or disability of any limb or function, constitutes unsoundness.

Going Wide.-A horse that goes wide behind, from being stiff or diseased in the hocks, is unsound.

Swelled Glands.-A horse with swelled glands of the throat, especially if stiff at the setting on of the head, is unsound.

Contraction of the Hoof.-This constitutes unsoundness, when it interferes with the free movement of the horse.

IV. Vice.

Vice is any habit, whether acquired or inbred, that renders an animal not amenable to the control of the humane driver. We say humane driver, for a horse that becomes uncontrollable from the abusc of a brutal driver is not for that to be called vicious. Under the head of vices may be enumerated the following:

Eating the Bedding. - When confirmed, or attended by any inconvenience.

Kicking, in or out of the stable.

Shying, whether eaused by nerrousness, or inveterate as a consequence of misuse by a brutal stableman.

Balking, Bolting, Rearing, Backing.-All these, as well as rumning away, come under the category of vices. Playfulness is not a vice, but it may degenerate thereto through bad management. Skittishness is a vice, though it may be the result of bad eyes; so maly val- 
rious other vices, which, if from constitutional debility, become unsoundness.

Biting is a vice, when not from mere playfulness.

Stopping.-Any horse that stops suddenly when under way, or if he balks, is vicious, unless it be the result of insanity or disease. It is then unsoundness.

\section{Blemishes.}

We deem it needless to go particularly into the subject of blemishes. Any wound that leaves a scar; wall eyes; glass eyes-that is, horses that have eyes abnormal in any way; the result of curbs, spavins, splints, upright shoulders, knuckling, or, in fact, any outward disability that reduces the value of the horse or that renders him unsightly-each of these constitutes a blemish.

\section{Directions for Buying.}

One of the first things to be done is to examine the horse critically as to soundness, vices and blemishes. Examine him as he stands, front, sides and rear. Pass your hands carefully over all the limbs to detect spavins, curbs, splints, puffs of any kind. Bring the horse from a darkened stable suddenly to the door and the light. If there is anything wrong with the eyes, it will certainly be shown.

Notice whether the animal stands quietly to be mounted or dismounted from either side when saddled, and in sadding whether he shows nervousness; once mounted, observe if he stands quietly for the word to move forward. By this, we do not mean that the eagerness to move forward is a disability. On the other hand, this may show careful training if the animal is amenable to the wishes of the rider or driver, for the same rule will apply to driving, the getting in and out of the vehicle, etc. In starting, there must be no rearing, plunging, seizing of the bit firmly between the teeth, shaking of the head, undue switching of the tail, nor dancing about, and especially throwing of the tail over the lines, when driving, and hugging down of the tail. Let the seller exercise the horse to show his paces under the saddle, and his manner of travel in harness. Stand in front of the horse when coming toward you, and when past also scrutinize his manner of going, especially his manner of placing the feet, and the action of his limbs. If not perfectly free, note the faults.

VII. Look Out for Disabilities and Tricks.

Paddling-called round action-in front; too close action behind or before, causing liability to cutting of the limbs; straddling-going 
very wide behind-all these indicate constitutional weakness. The manner of holding the head, the flexibility of the neck, showing perfect control by the bit, should be carefully observed. In fact, everything about the animal should be carefully scrutinized, however perfect the warrantee may be.

By all means, drive the horse yourself before buying, and in so doing give him full chance to display tricks, if he has them in him, for a rogue may be perfectly safe under the driving of one he knows to be master, and yet not so under that of a stranger; but do not fall into the error of supposing an aninal in the hands of a stranger will be as perfect as under those of one whom he knows perfectly well to be his master. Then if vice shows later, trust to the warrantee; the trial should in no case be understood as abrogating the warrantee.

\section{Directions for Selling.}

On this subject less need be said. It is the business of the owner to sell the animal, showing him to the best advantage, conceding no fault that may not be asked about, never giving a full warrantee if not demanded, and so wording the warrantee that as little advantage can be taken of it as possible. As a rule, actual deceit always causes discomfiture to the seller, except in the case of the traveling horse fakir, who can suddenly disappear. The regular dealer, who has an abiding place and character to lose, hardly ever willfully deceives the purchaser. The same rule of common honesty is to be practiced, and generally is practiced, as by the honest seller of any other goods or commodities.

Fat Horses.-There is one thing important to be inderstood. In buying a fat horse, do not expect him to perform well either hard, slow or fast labor at first. The moisture and superabundant fat must first be removed. The man who knows a horse, will pay more for a horse in proper flesh, in condition for work, than for a fat one, but not every one who thinks he knows a horse does really know when a horse is in proper condition for the work expected of him. A fat lubber of a horse is in no condition for anything, except such limited exercise as will keep his digestion fairly good. 


\section{CHAPTER IX.}

\section{OBJECT LESSONS IN CONFORMATION.}

I. THE HEAD AND NECK.—II. THE BACK.—II. THE SHOULDERS.—IV. THE HIND QUARTERS. - V. LINES OF DIVERGENCE.-VI. THE HIND LIMBS. -VII. THE FORE LIMBS.—VIII. DO NOT INVEST IN FAULTY LIMBS.

I. The Head and IVeck.

In buying a horse, something that should never be slighted is to examine carefully the general appearance of the animal as to contour. First may come a study of the head and neck, and as illustrations will teach far better than even elaborate explanations in print, we give two companion pictures, one of the thoroughbred, the other of the trotting form.

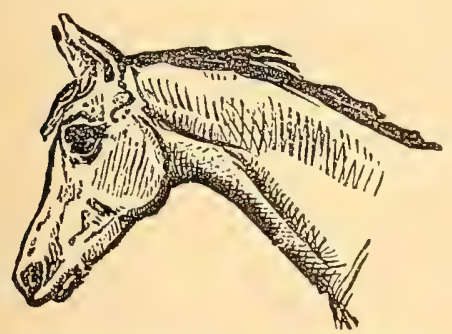

FIG. 1. HEAD OF RACING HORSE.

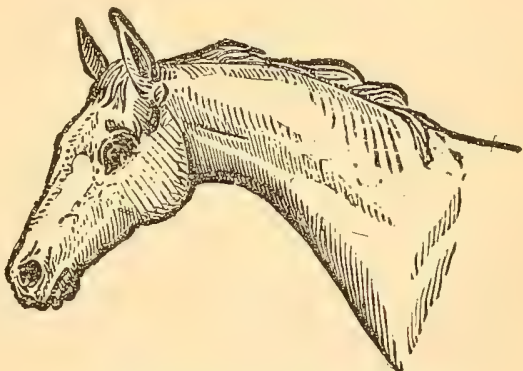

FIG. 2. HEAD OF THOTTER.

Fig. 1 shows the clean-cut head and neck of the racing horse, and Fig. 2 the head and graceful neck of the trotting horse.

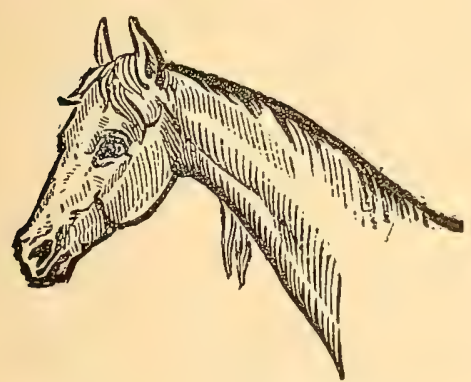

FIG. 3. THIN-NECKED.

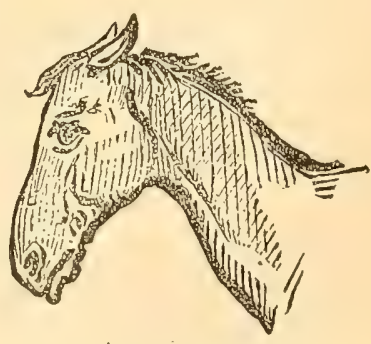

FIG. 4. HWE-NICKED.

Fig. 3 shows a fairly good head, but a nock thin and deficient in strength. Do not, however, confound the neck in Fig. 1 with 
this. The moderately thin neck of the former is flexible, yet sufficiently strong; this one is weak.

Fig. 4 shows an ewe or sheep-necked brute. Such an animal should be discarded altogether. He is an eye-sore.

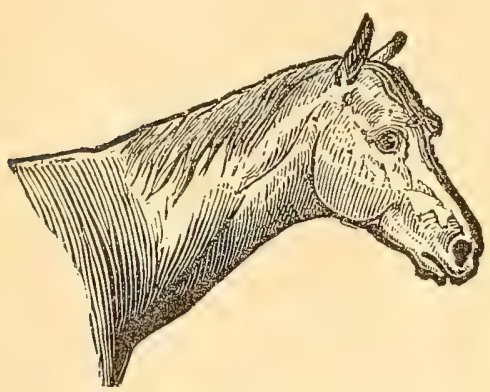

FIG. 5. A NECK BAD AND AWKWARD.

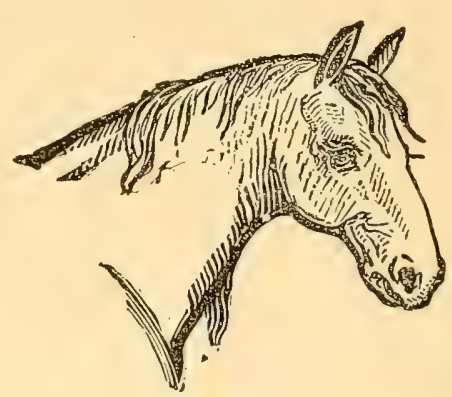

FIG, 6. SHAPELY FOR LABOR.

Fig. 5 shows another bad form, often found in ill-bred draft horses, as well as in very many farmer's horses in the country.

Good Muscular Head and Neck.-Fig. 6 shows the shapely head and muscular neck of a good draft-horse, whatever the breed may be, though, of course, the contour will be more or less modified in certain breeds, as the Shires, Clydesdale and Percheron; but the draft-horse, of whatever breed, should carry his head well up.

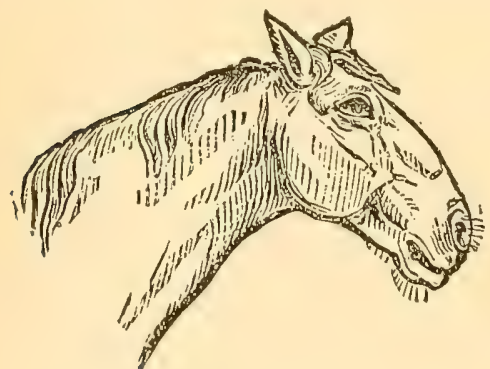

FIG. 7. A TREACHEROUS IIEAD.

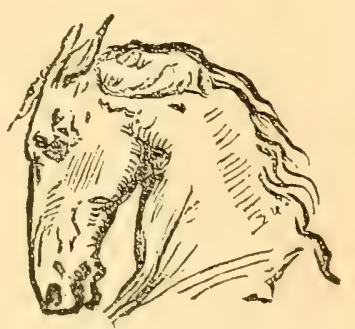

FIG. S, STUIBBOIN IIEAD.

Muscular Heads and Bad Necks.-In the line of muscular necks but utterly bad heads, Fig. 7 shows a treacherous, dangerous rogue, and Fig. 8, the stubhorn and willful brute, that is liable to run away upon any and every occasion. Never buy either, is our advice; but if you do, never drive except beside a trusty horse. Even then you never will know when he may get awaly with the honest one. 
The Idiot.-One more delineation, Fig. 9, and we are done with heads. It is the head of the fool, idiotic in every respect. Never buy anything approaching the bad forms we have shown. They will be bad bargains at any price.

\section{The Back.}

Coming now to the body of the horse, the back should be fairly straight, and not too long. The fairly straight back is the strong one; the hollow back is always weak. Horses originally straight-

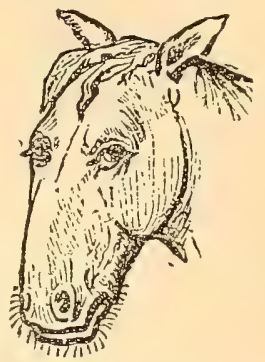

F1G. 9. THE IDIOT. backed, with old age become more and more sway-backed. This

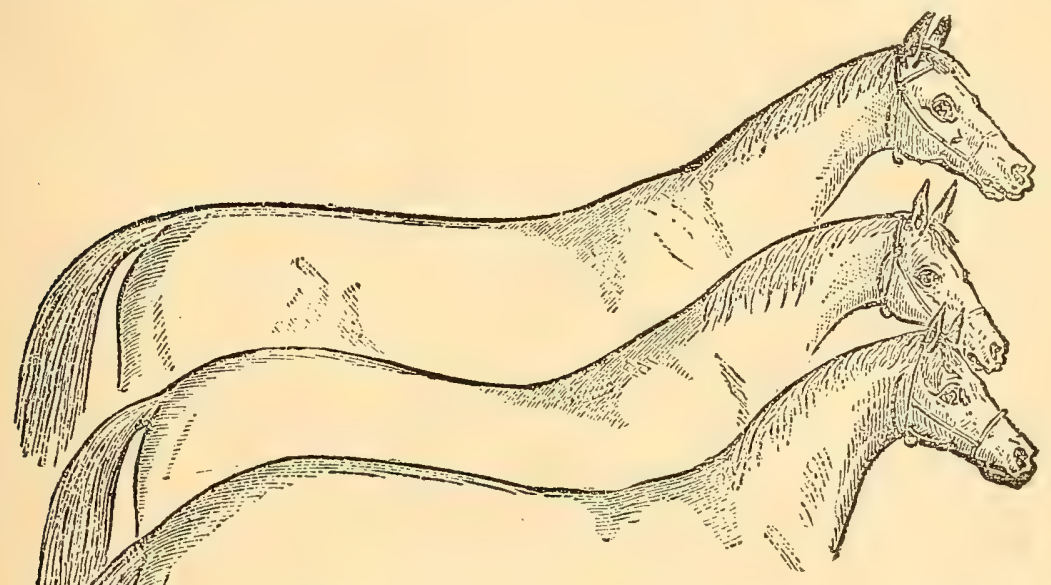

THREE BACISS-THE GOOD, MEDIUM AND HOLLOW.

is largely due to the ordinary mechanical effect of weight on a given line, to which the gradual wasting away of the muscles in advanced age affords less and less resistance. The horse sway-backed when young, with age becomes almost or quite valueless. As regards the length of the back, shortness is an element of strength, but is incompatible with speed. A very shortbacked horse camnot get his hind legs sufficiently under him, his motion is a "chopping" one to his rider, and the chances are four out. of five that he will over-reach; in fact, he is certain to do this, unless his shoulders are much more oblique than in most horses put together as he is, and unless his action as a whole is unusually good. 


\section{The Shoulders.}

No less is the conformation of the shoulders important. In the cut the figure on the left shows a good conformation; that on the

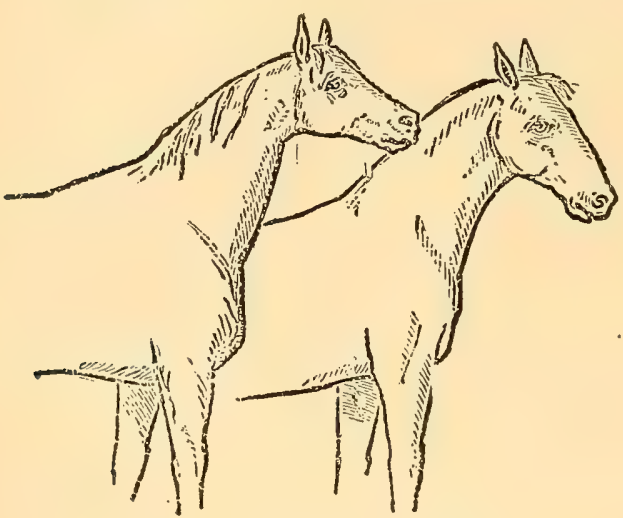

GOOD AND BAD SHOULUERS. right is bad. In the first the chest is full, the shoulders sloping, the neck rising grandly from the shoulders. The neck is flexible, and yet strong, and the head well set on. In the figure to the right the chest is hollow, the limbs are weak, and the neck and head coarse and ill-shaped. As to the degree of obliquity that should characterize the shoulders, see page 52 and elsewhere in this work.

\section{The Hind Quarters.}

As emphasized elsewhere, the hind quarters are the propelling power of the horse. They should be scrutinized closely before buying.

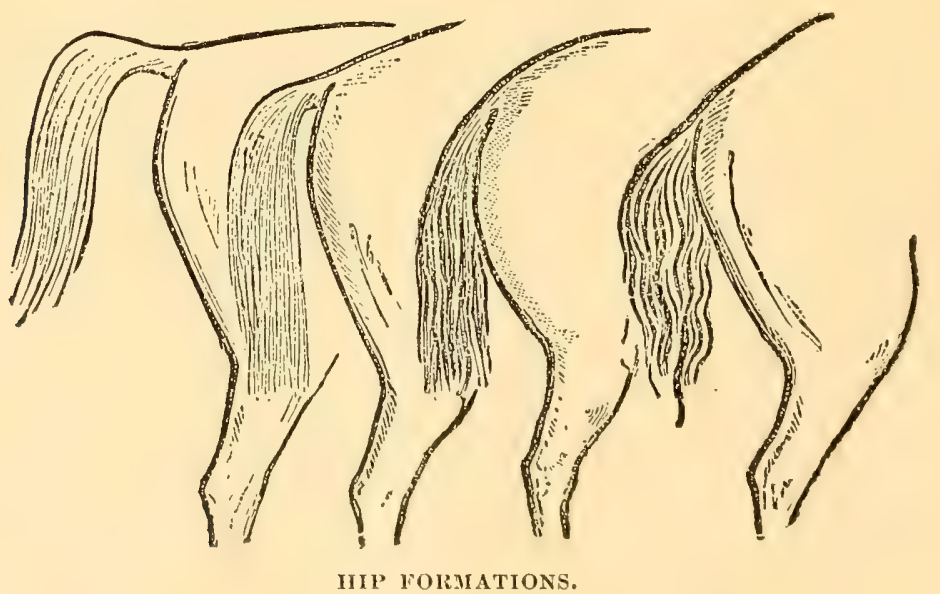

The perfect hind quirter, viewed sideways, behind, is long, deep, fully rounded and well placed, as shown in the second figure from the left in our engraving "IIip Formations." That to the left is carried too high to the rump, and the tail is set on too high. The third from the left is too round and too short from the loin, and that to the right is altogether bad and ont of shape. 
V. Lines of Divergence.

All this is shown in another and striking way in the annexed series

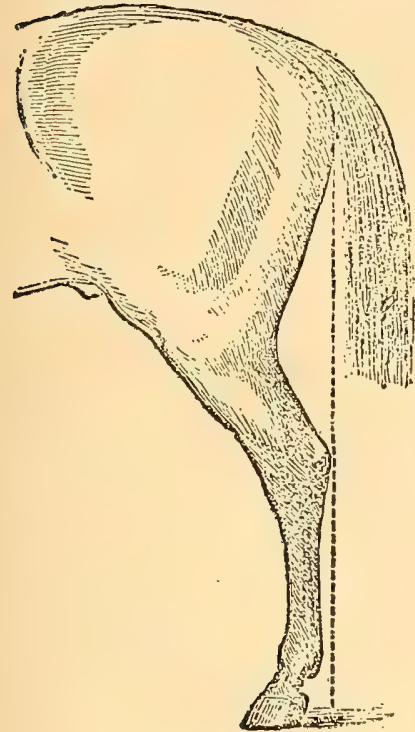

GOOD FORM. of euts. To the left is the perfect form. The line dropped from the rump just touches the hock and runs evenly down the leg, just outside the fetlock. In the second figure the line drops too far behind. In the figure entitled "Bad Form" the leg is still farther out of line from the root of the tail, while in the companion

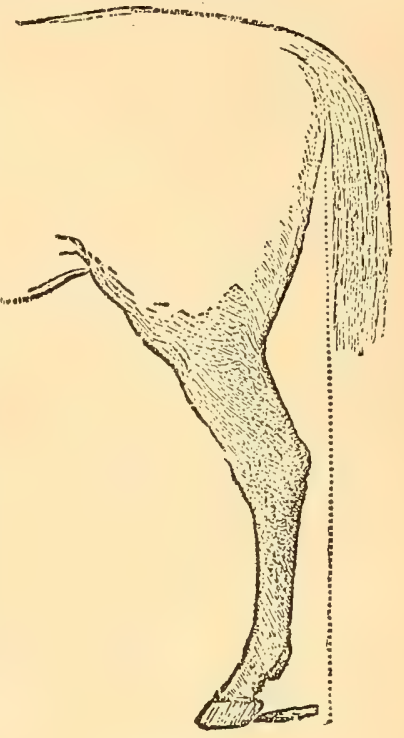

NOT SO GOOD.

figure the horse may simply be called crooked-limbed,- that is malformed. In the figure "Good Form"' it will be seen the leg is crooked,

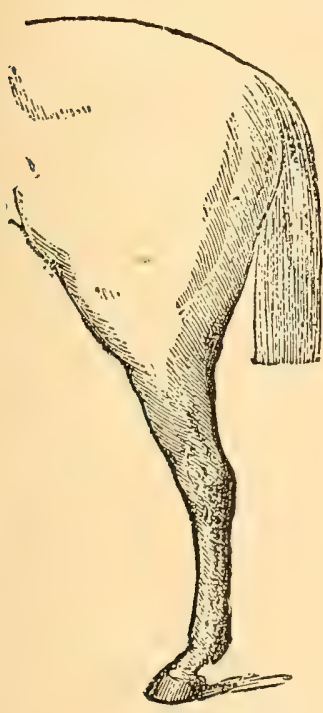

BAD FOIRI. but naturally and flexibly so, as seen in the best examples of the horse. This kind of curve of course is seen more prominently in the horse for fast work than in the draft horse, and it is never ungraceful. Speaking of graceful appearance, a tail well set on is a great ornament to a horse. The Arab carries it almost straight out in a line from the spine. In the underbred animal the tail is usually set on low down, possesses no muscular power, clings to

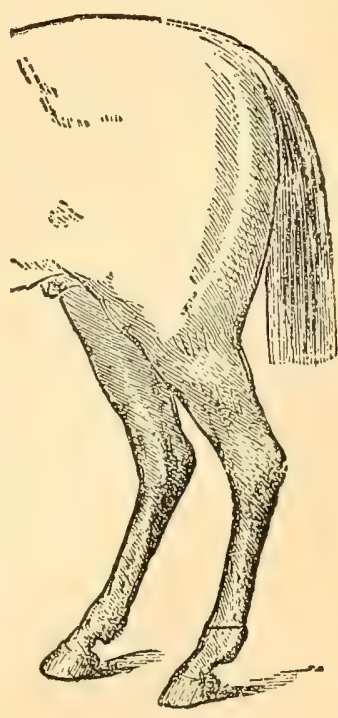

CROOKED LIMBED.

the hind quarters, and altogether looks mean. In the well-bred horse the tail is carried firm and well away from the hind quarters. 


\section{The Hind Limbs.}

Two more cuts will complete our object lesson on the conformation of the horse's hind quarters. These are here viewed from behind. The

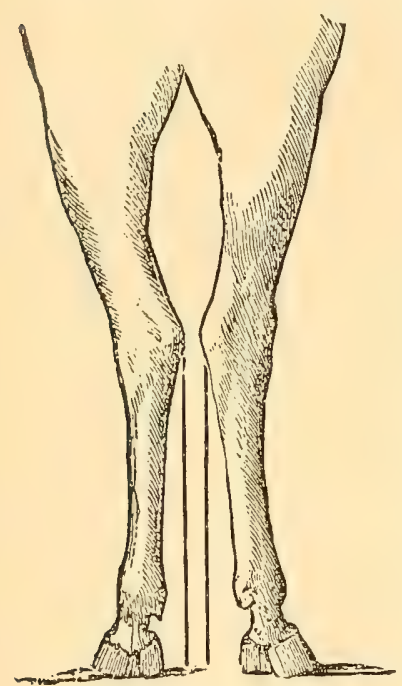

GOOD HIND IIMBS. first shows the horse standing naturally, when of a good conformation. The second has the toes turned in and the hocks out. The latter is exaggerated, and deliberately so, the better to show the difference. In the first, the left leg stands just right; the right is slightly out of line. In the second, the left limb is turned unnaturally

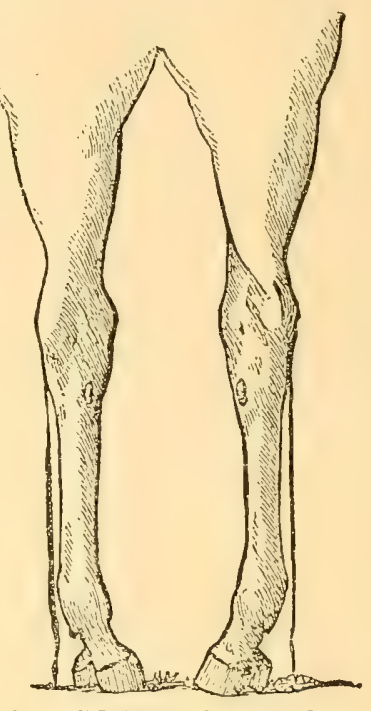

BAD TO MALFORMATION.

in, and the right is still more out of line. With perfect truth the latter might be termed positively malformed.

\section{The Fore Limbs.}

Resuming our study of the fore quarters, the annexed Fig. 1 shows the front limb at the left perfectly in line. The right limb is thrown

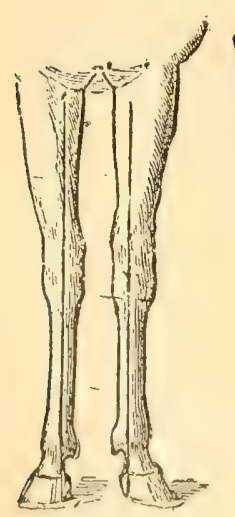

FIG. 1 .

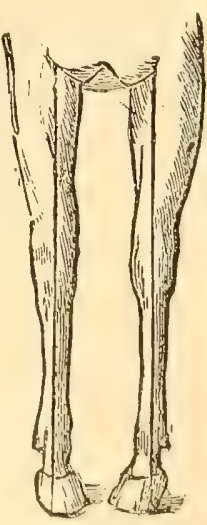

FIr. 2. slightly out. Both limbs should stand aligned as in the former. In Fig. 2 is shown the parrot-toed horse; both limbs are turned too far in. It is impossible that an awkward creature like this should have good action, as to either speed or gracefulness. In fact, the horse with bad fore limbs is apt to be more objectionable on the score of safety than one with bad hind quarters. Nothing is more annoying, when out driving for an airing, or on a trip to the village or post-oflice, than to find yourself behind a horse that keeps stumbling every half mile or so, and deppling to his knees, or perhaps tumbling oceasionally clear over on his side. 
Side View.-In continuation of this subject, we present three additional figures. Fig. 3 shows by the line running down the perfect conformation of the limb. Fig. 4 shows the limb slightly out of line, that is to say, too straight. Fig. 5 shows the limb, and especially the fetlock, too much flexed, and necessarily weak, because too long and inclined too much forward. Figs. 6 and 7 show the limbs as resting clear back of the proper line, while Fig. 8 shows weak conformation in every respect. Fig. 6 is not es-

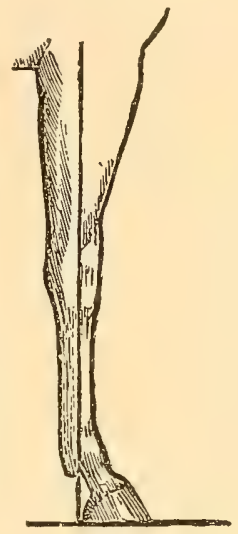

FIG. 3 .

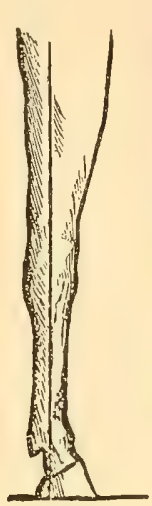

FIG. 4.

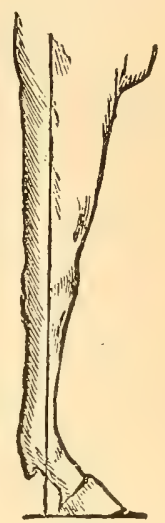

FIG. 5 . sentially bad in a cheap horse, but as shown in Figs. 7 and 8 , the animal would scarcely be worth his feed.

\section{Do Not Expect Perfection.} Right here we want to give the inexperienced buyer a bit of advice that may save him hours of indecision and mental disquiet. It is this, not to expect perfection at all points in any animal. There never was a horse that might not be criticised, to greater or less degree, in some of his points. The thing to do is, first of all, to determine the precise uses you will put your intended purehase

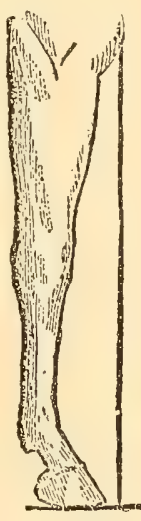

FIG. 6.

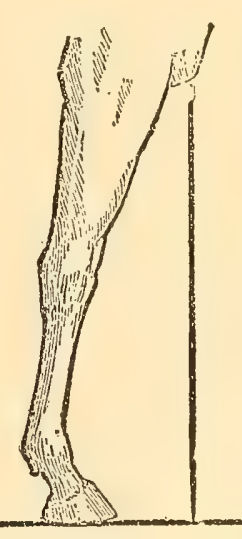

FIG. 7 .

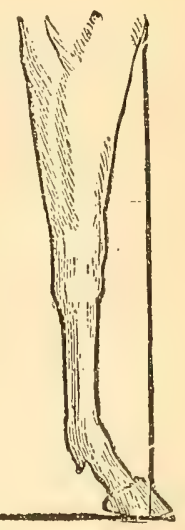

FIG. 8 . to; and, next, to settle in your mind the characteristics essential to his proper discharge of the service in view. If you can suit yourself as to these essentials, you can afford to overlook a little divergence from the ideal standard in details that for your purposes are minor ones. "Act well your part; there all the honor lies," says the poet in his "Essay on Man;" similarly the horse that well fulfills the requirements of his service, whatever that may be, is a horse not to be 
despised. The most that can be expected is a horse with many good points, few indifferent, and no decidly bad ones. In buying a horse examine particularly for the weak points. If these are pronounced, refuse him for any service. In the draft-horse we look for wellsprung ribs, breadth of chest, and necessarily fore legs wide apart. In the race-horse, trotter, or fast driver they are faults. Hence we repeat, study the horse for the purpose for which you intend him.

Front Presentation.-To return to the front presentations of the fore limbs, Fig. 9 shows the perfect-limbed horse. Fig. 10 is what

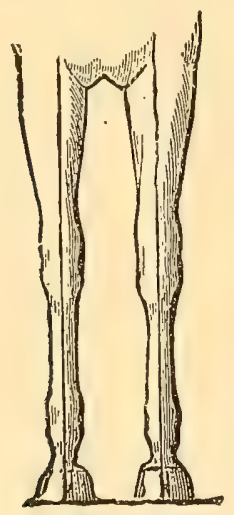

FIG. 9 .

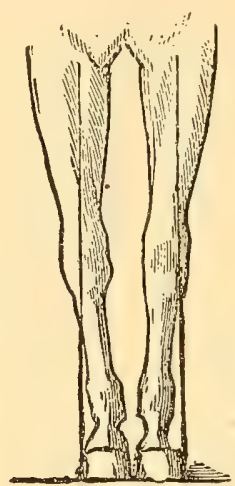

FIG. 10 .

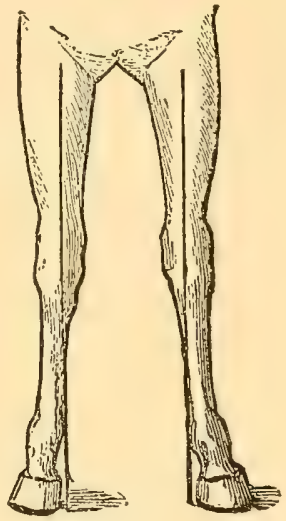

F1G. 11 .

might be called bandy-legged, the hoofs standing too near together. Fig. 11 is downright splay-footed.

\section{Do not Invest in Faulty Limbs.}

Avoid the two latter specimens, and hold fast to the first example. In short, do not permit yourself to be satisfied with any of the decidedly bad conformations exhibited in these valuable object lessons. If you study this chapter carefully, in relation to the vices and disabilities and unsoundness described in Chapter VIII, you should not go far astray in making up your mind as to what constitutes a good horse. And in this comnection we reiterate that without sound limbs and good hoofs, no horse is, or possibly can be, a really good horse. 


\section{CHAPTER X.}

\section{THE CONSTRUCTION OF STABLES.}

I. A SIMPLE AND EXCELLENT HORSE STABLE.—II. TRUE PRINCIPLES OF CONSTRUCTION.-III. LOUVRE BOARDS FOR VENTILATION -IV. PAVING FOR STABLES.—V. STABLE FLOOR HIGHER TIIAN THE GROUND OUTSIDE.- VI. SLOPE OF STALLS.—VII. SITE OH STABLES.—VIII. LIGHT.—IX. MODIFYING A FARM BARN.—X, A MODEL BARN.-XI. THE HOR.E STABLES. -XII. THE CATTLE STALLS, ETC.

\section{A Simple and Excellent Horse Stable.}

Every farmer or breeder has his own ideas as to the construction of harns and stables, and, as a rule, these ideas meet the special cases fairly well. Here, however, we have to deal simply with the construction of stables for horses. In this line we have seen none more simple than is contained in the volume of General Sir F. Fitzwygram, whose plans combine about all the modern improvements. The "plan" which we give explains itself. It shows a sixteen-stall stable, a window in front of each double stall, and the horses standing tails together, with an ample passage way between. Though the plan is drawn for a sixteen-stall stable, the same style of construction is equally available and suitable for a less or greater number of horses.

In elucidation of this whole subject, we will quote some extracts from Fitzwygram's excellent work, "Horses and Stables," that we are sure our readers will agree with us in considering instructive and practically valuable. It will be seen that the painstaking writer has in mind a brick stable; but all his suggestions as to "air-bricks," etc., can easily be carried out in the frame stables used. almost universally on American farms, by sawing out small openings, each provided with a little leather-hinged or sliding door for closing it when needed, as in stormy or severely cold weather.

\section{True Principles of Construction.}

From the peculiar properties of heated air, there need be but little difficulty in getting rid of it. The real difficulty lies in providing for the admission of fresh air in quantities sufficient to maintain the purity 


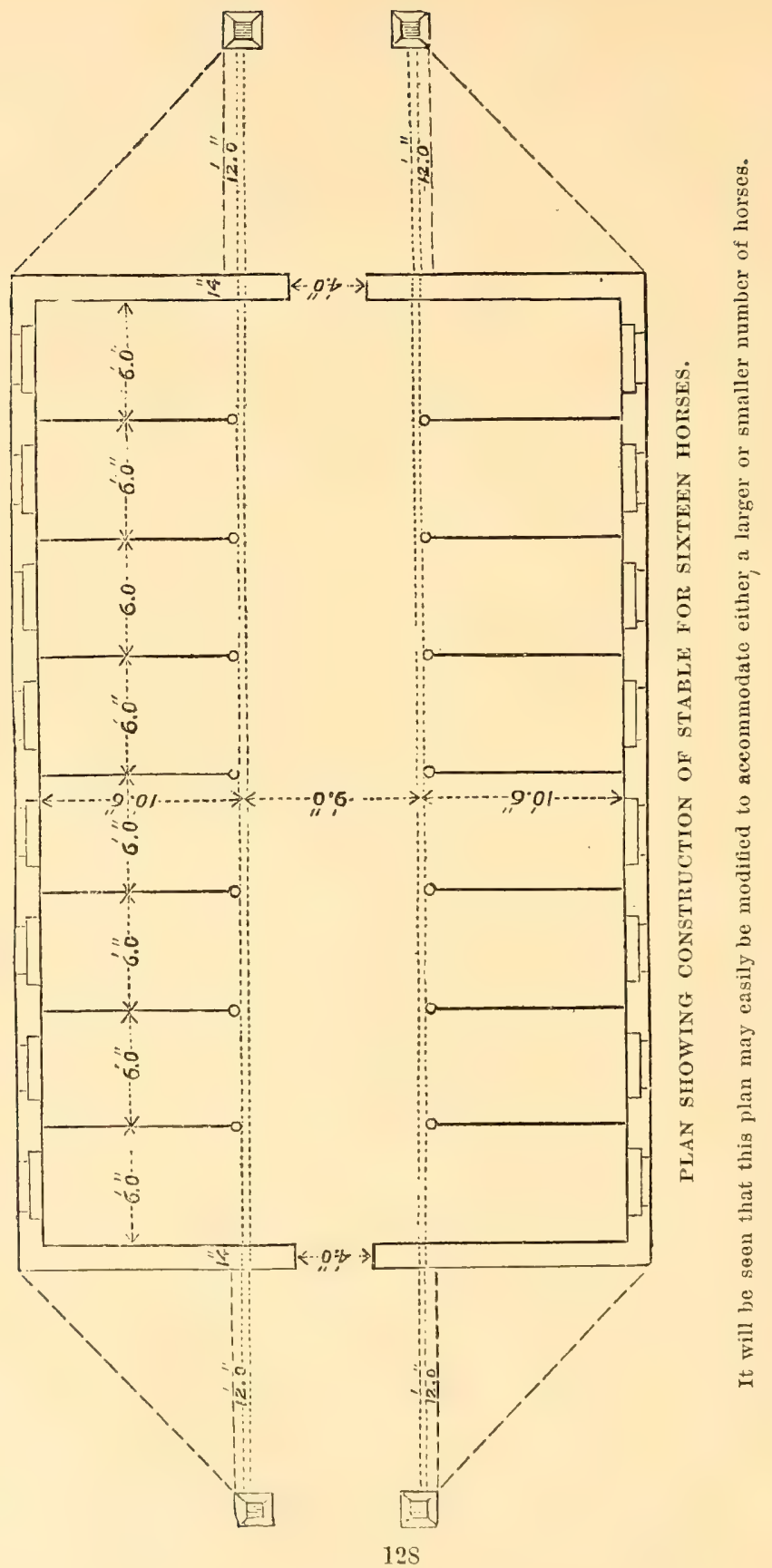


of the stable without causing in some part or other a sensible and inconvenient draught. This difficulty, however, or, in other words, the danger of draught, decreases in proportion as the air has a less distance to travel before it is presented to the nostrils of the horse.

With this view it is essential, as a primary rule, that no more than two horses should be placed between the opposite sources of air. In all stables the windows should be placed on both sides along the length of the stable. (See our "Plan.") It is then immaterial, as regards vertilation, how many horses the stable is constructed to hold. The air has no greater distance to travel than the breadth of the building. There should be a window over the head of each horse two feet six inches in width and three feet in height.

Ventilators Above and Below the Windows.-Windows may, however, under certain circumstances, require to be almost entirely closed. Therefore, above the windows, immediately under the eaves, and running the whole length of the stable on both sides, a row of air-bricks should be placed. The air entering through these numerous but minute apertures will be considerable, but it can never amount to an excessive draught. It will also be sufficient at most times, when the windows are closed, to maintain the upward current of the air, and thus prevent an excessive down-cast current from the ridge apertures recommended hereafter for the escape of the foul air.

Below each manger, about fourteen inches above the floor of the stable, a line of air-bricks should be placed. The height of fourteen inches is recommended in order that the apertures may not be choked by the bedding. By means of the air-bricks so placed a gentle and scarcely perceptible stream of fresh air will be supplied almost directly to the horse's nostrils when he is lying down. The air entering at this low point is also of great use in keeping in motion the air in the lower part of the stable, where it is otherwise especially apt to become stagnant.

The amount of air entering under these arrangments will undoubtedly be considerable, but at no one point will it be so great as to create a sensible and unpleasant draught. It will be gracdually, gently, and constantly diffused through the whole stable. Traversed openings are objectionable. They are very apt to get choked, and it is very difficult to clear them out. 


\section{Louvre Boards for Ventilation.}

For ready means of affording exit for foul air, no construction offers so great facilities as an open roof with louvre boards at its ridge running the whole length of the stable. In double-line stables the depth of the louvre should be sixteen inches, which will afford a rentilating outlet of about four feet for each horse. In stables in which the horses stand in a single line or row, the depth of the louvre may be reduced one-half. For reasons almost similar to those which have been urged in regard to the admission of fresh air, it is very essential that the foul air should have an exit along the whole length of the stable, instead of merely by holes, pipes or funnels in one, or two or three places.

Louvre boards are often objected to on account of their admitting rain, wind, and snow. When they admit rain, or an excessive amount of wind, the fault lies in the architect or carpenter. If each board is made wide enough to overlap well the board below, and if the pitch is sufficiently steep, no serious inconvenience will be felt.

\section{Paving for Stables.}

The material required for really good paving must be non-absorbent, water-tight, easily cleaned, durable, and not slippery. It is not easy, however, to find a material which combines all these requirements. Iost materials, in proportion as they answer the first-named requirements, fail in the last. All paving, whatever the material used, whether scpulre-cut stones, bricks, or wooden blocks filled with gravel and tar, must be laid in cement.

No paving, whatever the material employed, will be really sweet and dry unless the whole of the bedding is remored from the stable at the morning stable hour and turned ontside. The paving must then be swept thoroughly clean, and left to the drying and purifying influence of the air until the horses are dressed after their return from the morning exereise, when they may be bedded down again. Every door and window in the stable should be set open whilst the horses are at exercise.

\section{Stable Floor Higher than the Ground Outside.}

The floor of a new stable should be made eighteen inches higher than the ground outside. We name this very considerable clevation, partly because it facilitates natural and surface drainage, and in some degree secures the stable from dimp, partly on account of the ten- 
dency of new floors to sink, and still more on account of the probability of the soil outside becoming higher from constant gravelling or repairs. It is a fact easily to be observed that the floors of most old stables are lower than the ground outside, though it is improbable that such was the original construction.

\section{Slope of Stalls.}

Horses undoubtedly stand most comfortably on a perfect level, and any slope more than absolutely necessary for drainage purposes is decidedly objectionable. Any great degree of slope is positively injurious, because it throws an undue stress on the hind quarters and also on the flexor tendons of the fore legs, by reason of the toe being more elevated than the heel. Where stalls have underground drains in the centre, the floor should slope from all four sides to the centre, and the horse will practically stand on a level.

Where surface drains are used, the upper third of the stall may be level, whilst the rear part will require a fall of one in eighty towards the main drain. The floor should also be made to slope in the rate of one in forty from both sides of the stall towards the drain down its centre.

\section{Site of Stables.}

The site of every stable should be deeply thorough-drained. The soil selected should, if possible, be gravel. The situation should be moderately high, open, and with facilities for natural drainage. Bleak situations are not desirable. Buildings in the immediate neighborhood, if high, are objectionable. The ordinary English custom of erecting stables and coach-houses round four sides of a square is bad. The air always hangs more or less in any such enclosed space, and thorough ventilation is impossible.

A northern aspect is cold and cheerless, whilst a southern aspect is often unduly hot in summer. In stables with windows on both sides, east and west aspects will, as a general rule, be found most advantageous. The one side will have the morning, and the other the afternoon sun. There should be a door at each end or in the middle on each side, as may be most convenient to the particular locality. Either door can then be used according to the circumstimces of the weather and wind. If the stable is very large, it is desirable to have doors both at the sides and ends. 


\section{Light.}

Ventilation, drainage and sufficient cubical space, will render it possible to obtain almost perfect purity of air both by day and night. But light, and constant, intelligent supervision are likewise necessary in order to ensure cleanliness and the best stable management. The general directions, given in the preceding pages, for a stable built of brick, may easily be modified to suit, where, as is usual in the United States, they are built of wood. The principles laid down are certainly admirable.

\section{Modifying a Farm Barn.}

Many farmers have barns that may be easily altered to accommodate horses, and for such cases the stable plan next presented will be found very suggestive. This ground plan, with the corresponding elevation, which was given to the public through the Bureau of $A g-$ riculture not long since, is not a fancy sketch; it is an accurate representation of a complete Pensylvania barn, and stables for all stock,

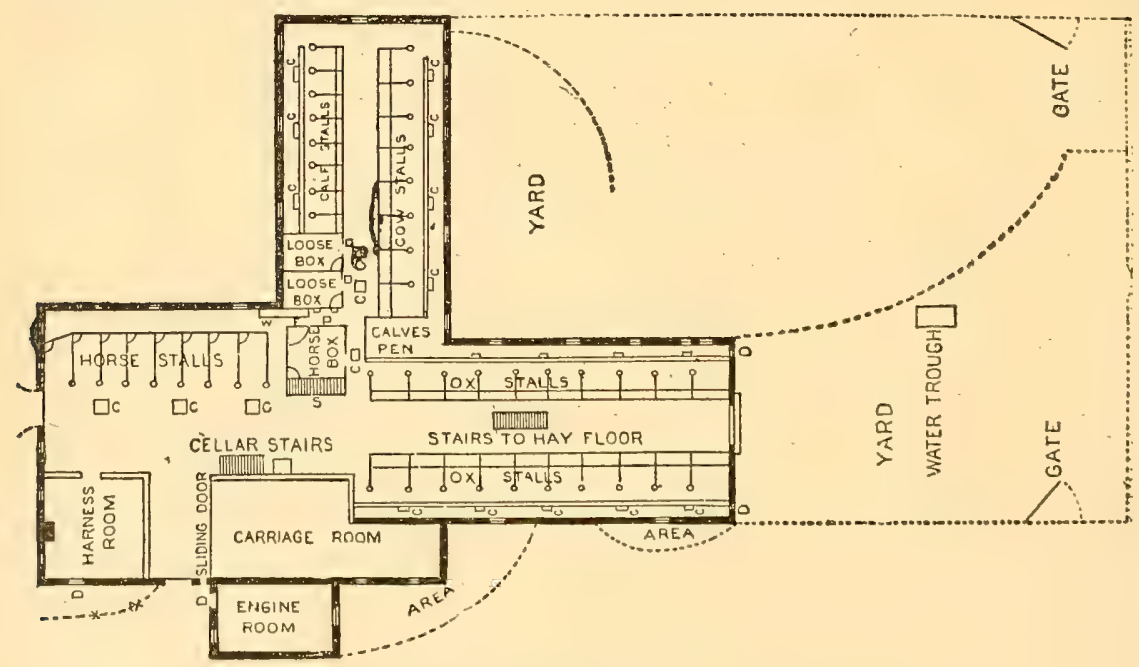

GROUND PLAN OF FEEDING FLOOR AND YARDS.

actually built and in use. The illustrations reruire no explanation, as everything in the stable is plainly lettered. Nevertheless, the general description which originally accompanied it will interest the reader, and facilitate his making the necessary modifications to suit his particuhiir requirements, in case he wishes to use this plan. 


\section{A Model Barn.}

The engraving shows elevation, northeast view. On the southwest side the yards are attached. The northwest side contains the principal embankment for reaching the second floor, with room for power for raising and carrying fodder, and also the horse stable and entrance. The diagram or "Ground Plan" shows plan of stock floor, yards, etc. The barn stands upon a side-hill sloping east. There are three distinct floors, and the barn consists of a main building and two wings, with dimensions as follows: Main building is fifty-five by eighty feet; the east wing is fifty-six feet long and thirty-one and a half feet wide; the south wing is fifty-six feet long and thirty-five in width; total length from north to south, 136 feet. In the view from the northeast is shown the east wing, and the cellar or basement wall, with the doors and windows communicating with the hog-pen, etc. The doors (D) are suspended upon rollers upon which they slide. The windows are suspended by hinges from the top, and swing open inside. The approach to the cattle door of the east wing is not as steep as it appears in the drawing.

Circular tanks of boiler iron are filled with constantly flowing water in each yard. The rail fence and gates shutting off the cellar from the yard are movable; the posts at either end being stepped into sockets, like mortices, left in the wide bases of the brick piers. Two men in a few minutes will remove them all and throw cellar and yard together, thus giving the cattle shelter in either winter or summer. Any portion of the cellar may, in the same way, be fenced off or opened to the yard. Horse power may be used for threshing and sawing, hay and stalk-cutting; but the plan is to employ steam power as the most economical, the waste of steam to be used for steaming hay and roots, and to this end the location of the engine-room, contiguous to and below the threshing floor, is exactly right.

On the storage floor, all the hay, grain, straw, and stalks are stored. Two threshing floors, sixteen feet wide, cross the building, being entered from the west. On one of these is a hay scale, and there is abundant room upon the other for a horse power and hay cutter, by which most of the coarse fodder is chopped up before being delivered at the feed trough on the floor below. Each grain and meal bin communicates by a chute with the feeding floor, where its contents may be drawn off. The greater part of this floor is occupied by the immense hay mows through which pass the four great ventilators 


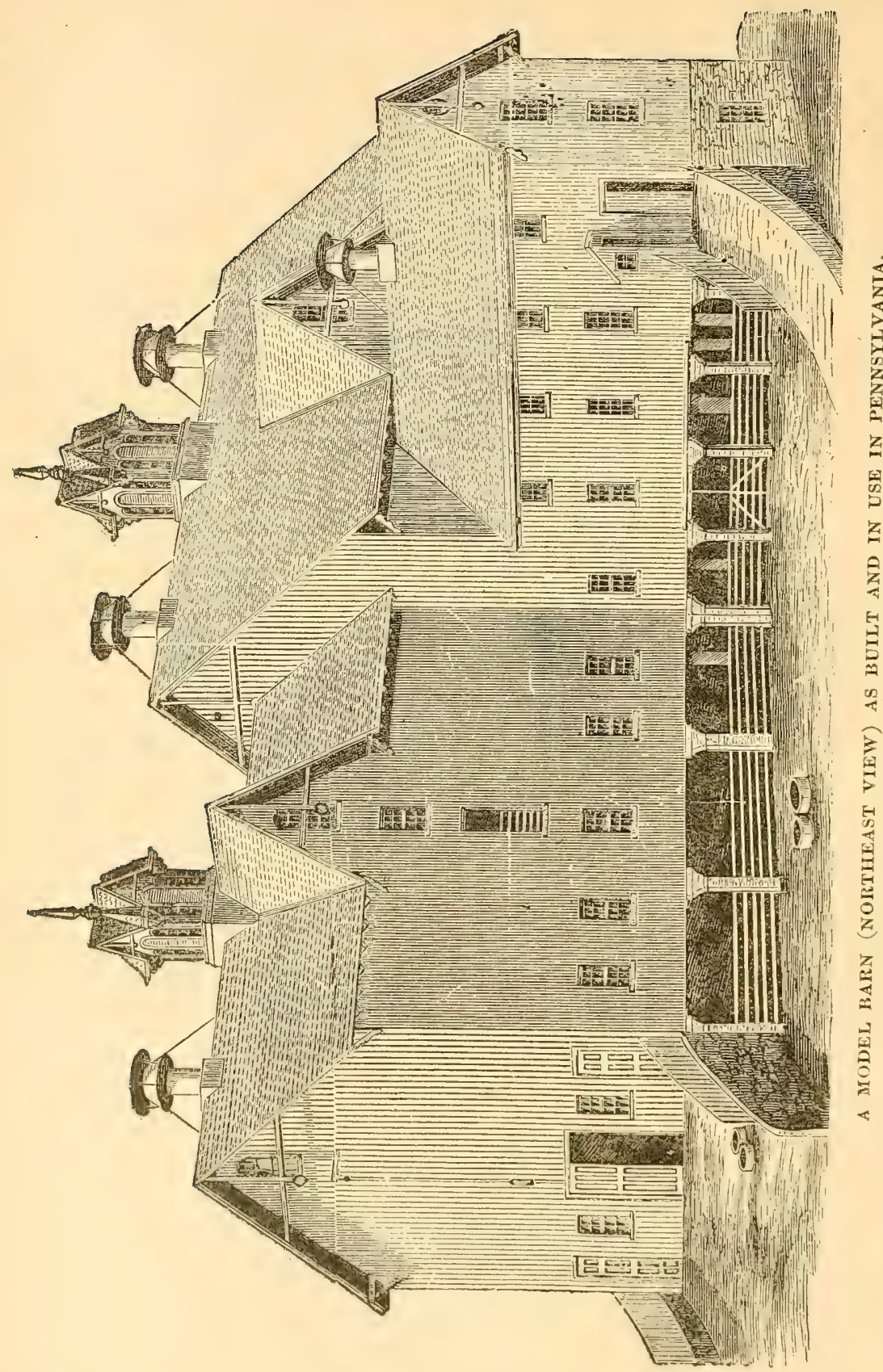


coming from the feeding floor. Doors open into the ventilating trunks at different heights, so, when desirable, hay, straw, oats in the sheaf, etc., may be thrown down to the stock. From this floor there are stairs which ascend to the cupola or observatory.

\section{The Horse Stables.}

The horse stables throughout the bain are airy and roomy. There are three loose boxes, as shown in the "Ground Plan ;" one twelve feet square, for horses, and two somewhat smaller, which are used for horses, or as lying-in stalls for cows. The horse stalls are models of convenience and excellence. Each has the following dimensions: ten feet from front to rear, five feet one inch wide, nine feet four inches high. The stalls are separated by plank partitions four and a half feet high, surmounted by strong woven-wire cloth extending two feet higher. The same style of partition forms the front of the stalls. The hay rack is of iron, in one corner, and an iron feed box is in the opposite corner, accessible from the passage way in front of the stalls by a small door in the wire cloth. There are two floors, the lower one being laid of two-inch chestnut plank, with cleats, half an inch thick, covering the cracks between the planks. Upon this watertight floor is another made in three parts; for two feet at the upper end the floor is of white oak plank nailed fast; the rest of the floor is formed of narrow oak plank fastened together by strong oak cleats let in flush so as to form two doors, as it were, hinged at either side, so as to be lifted and set up, as shown in right hand stall of the cut, for the perfect cleansing of the lower floor. A channel at the rear carries off the urine, and the solid manure is thrown into the cellar through the trap-door seen open in cut. Between the cattle-stalls in the south wing there is a passage way ten feet wide, through which carts with green food, roots, ete, may be driven, making a complete system of soiling in summer practicable and convenient. The passage way through the east wing is not quite so wide, but might easily be used in the same way.

\section{The Cattle-Stalls, etc.}

All the cattie-stalls are made upon the same principle as the horsestalls, though of different sizes, for fattening cattle, milch cown, and young stock. The feeding boxes are two and a half feet wide, the floors five and a half feet from the feeding trough to the gutter, which is fourteen inches wide, and the passage in the rear is three feet, 
making in all about twelve feet for the stalls. The stalls are six and a half feet wide, arranged for two animals, which are fastened by a neck-strap or chain attached to a short chain and ring, playing up and down upon a rod bolted to the partition between the stalls. A perpendicular rack is in front of the manger, and a shutter is hinged below it, and when open is held in an inclined position by a chain. This affords space below for a good forkful of hay between the shutter and the rack. Great economy of space is thus secured, for the encroachment upon the gangway is rarely of any inconvenience, and when carts are driven through it is easy to close the shutters.

Light and Air.-Light and air are abundantly provided for the stock, as one may see by a casual inspection of the plans. In fact, these are the first features that impress one. The ventilating trunks are four feet square, and rise from the feeding floor directly to the roof, where they terminate in ventilators of the largest size. The current of air caused by one of these is at all times perceptible, and usually amounts to a considerable flow. The windows on the stock floor are numerous, and are each provided with two glazed sashes, hung by weights, so that any one, or all, may be opened to any degree desired, making the floors cool and airy in the closest weather. 


\section{CHAPTER XI.}

\section{ASSES AND MULES.}

I. THE WILD ASS.—-II. GENERAI, WASHINGTON'S JACKS.- - III. TIIE SOUTII IS THE JACK'S CONGENIAL HONE.-IV. USES OF THE JENNET. AND WHAT IS A MULE? - V. LONGEVITY OF TIIE MULE. - VI. VALUE OF MULES FOR LABOI:-VII. A HEALTHIER ANIMAL, THAN THE HORSE.-VIII. DR. STEWAR'T'S TESTIMONY.—IX. THE BREEDING OF MULES.

The ass was probably subjected to domestication at the same time with the horse; at least, mules seem to be of the earliest antiquity. In passing, we must remark the wise provision of nature, by which the hybrids of two species of any genus are always infertile, since, were it otherwise, the earth would have been filled with monsters of every conceivable kind.

\section{The Wild Ass.}

The wild ass is essentially an inter-tropical animal, said to have been indigenous to Arabia Deserta, and the regions of ancient Babylonia. Four distinct races of the wild ass are mentioned in Scripture, one of them, according to the book of Jol, of the most wonderful swiftness. There is still a breed found wild in the hill regions of Northern India, that are said to be so fleet that no horse can overtake them. Nor is the modern European jack the imbecile, ignorant creature that travelers would have their readers believe. They only see the degenerate and diminutive scabs of the peasantry of Great Britain and the Continent, an unfortunate race of animals, which apparently have had inbred into them the idea that sub-

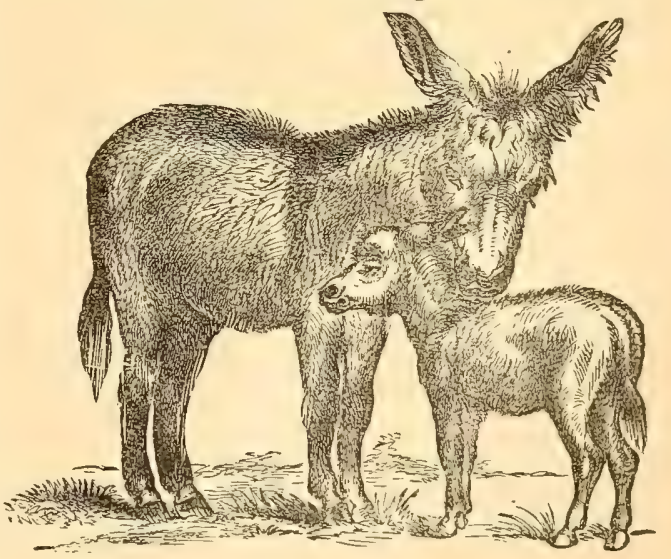

COMMON ASS AND FOAL. servience to blows and other ill-usage saves them from risk of mistreatment in other ways more cruel still; for not all brutes walli on 
four legs-some go on two. It was not so with the ass in olden times, when he was used by the very highest classes, and prized as an animal easy to ride, swift, surefooted and untiring.

\section{General Washington's Jacks.}

Of the earlier jacks introduced into the United States as far back as 1787, were those presented to General Washington-Royal Gift (as also a jennet named Gift) by the King of Spain, and the Knight of Malta by the Marquis de Lafayette. The former was a huge and ill-shapen animal, sixteen hands in height, with a big, ugly, coarse head and uncouth body, and clumsy in the limbs. He was, of course, of no account. The Knight of Malta, on the other hand, was an animal of great courage, large, but not inordinately so, clean-limbed, of great activity, and said to be so ferocious under restraint that he could only be managed by his regular groom. His mules partook of his characteristics, being active, courageous, full of spirit and serricable when bred to large mares. From the get of this fine ass on good jennets, came a most celebrated series of mules, unexcelled in their day for size and activity.

\section{The South is the Jack's Congenial Home.}

The breeding of jacks and jennets is confined almost entirely to the South, and for the reason that these mimals are peculiarly sensitive to cold. The writer of this, when engaged, thirty years ago, in the

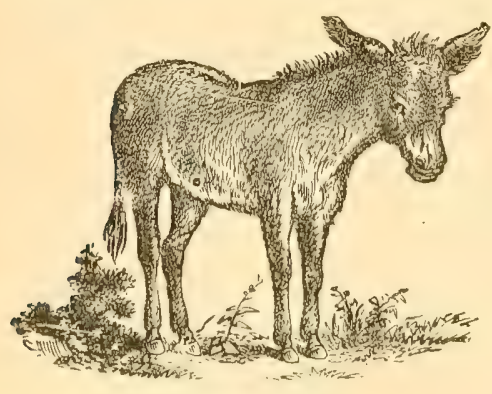

SUNNING MIMSELI. breeding of mules in Illinois, always kept his jack in a stable warmed by artificial heat in winter. As showing the difference, in this respect, between the mule (a hybrid ass) and the horse, no one who has worked them together much but has noticed how. when relieved from labor on a mild summer day, the mule will from choice take the sunny side of the barn, at the same time that the horse goes round to the other side for repose in the shade; and there he will lie, or roll, wiving every cridence of satisfaction.

\section{Uses of the Jennet, and What is a Mule?}

The jennet is a she-ass, and in this country is only kept to perpetwate the breed of jacks. The breader of jack for mule gretting should 
select the jennet with the utmost care, for it must be remembered that in all breeding the maternal parent is supposed to impart vigor as to the internal organs and viscera, as well as to increase the size of the progeny, through the laws of heredity.

As just intimated, the jennet is never bred now to a horse, at least not in the United States. This was formerly done to a limited extent, but the offspring were found to be an inferior race, and the only hybrid between the horse and ass that is now commonly known is the produce of the jack and mare. This hybrid constitutes the true mule.

\section{Longevity of the Mule.}

Why does the mule live so much longer than the original progenitor on either side? A divine once gave it to the writer, as his opinion, that it was because the laws of nature had been violated. Our reply was that it might be an ontworking of nature's law of compensation, as a set-off to the fact that a hybrid is incapable of reproducing his life, so to speak, in the life of a successor. Be the reason what it may, the longevity of the mule is proverbial. It was a common saying during the Civil War that "a mule never died;" he might sometimes be knocked over by a shot, but if one ever died a natural death the army wags refused to credit or record the fact.

Pliny gives an account of one, taken from Grecian history, that was eighty years old. Dr. Rees mentions two that were seventy years old in England. Mr. P. S. Skinner says: "I now own a mare mule twenty-five years old, that I have had in constant work twentyone years, and can discover no diminution of her powers; she has within a year past often taken upwards of a ton weight in a wagon to Boston, a distance of more than five miles. A gentleman in my neighborhood has owned a very large mule about fourteen years, that cannot be less than twenty-eight years old. He informed me, a few days since, that he could not perceive the least failure in him, and would not exchange him for any farm horse in the country. And I am just informed, from a source entitled to perfect confidence, that a gentleman near Centerville, on the eastern shore of Maryland, owns a mule that is thirty-five years old, as capable of liabor as at any former period."

\section{Value of Mules for Labor.}

It is beyond dispute that mules will continue to labor for at least donble the period of the usefulness of the horse. They endure ex- 
treme heat better, but are pinched with cold. It is a mistake to suppose that the mula will subsist on far less food than the horse. In proportion to size, they require about the same quantity; but, weight for weight, they will draw a heavier load; and, for the reason that they take little notice of what is going on about them, do not fret and seldom scare. As pack-animals, they are far superior to the

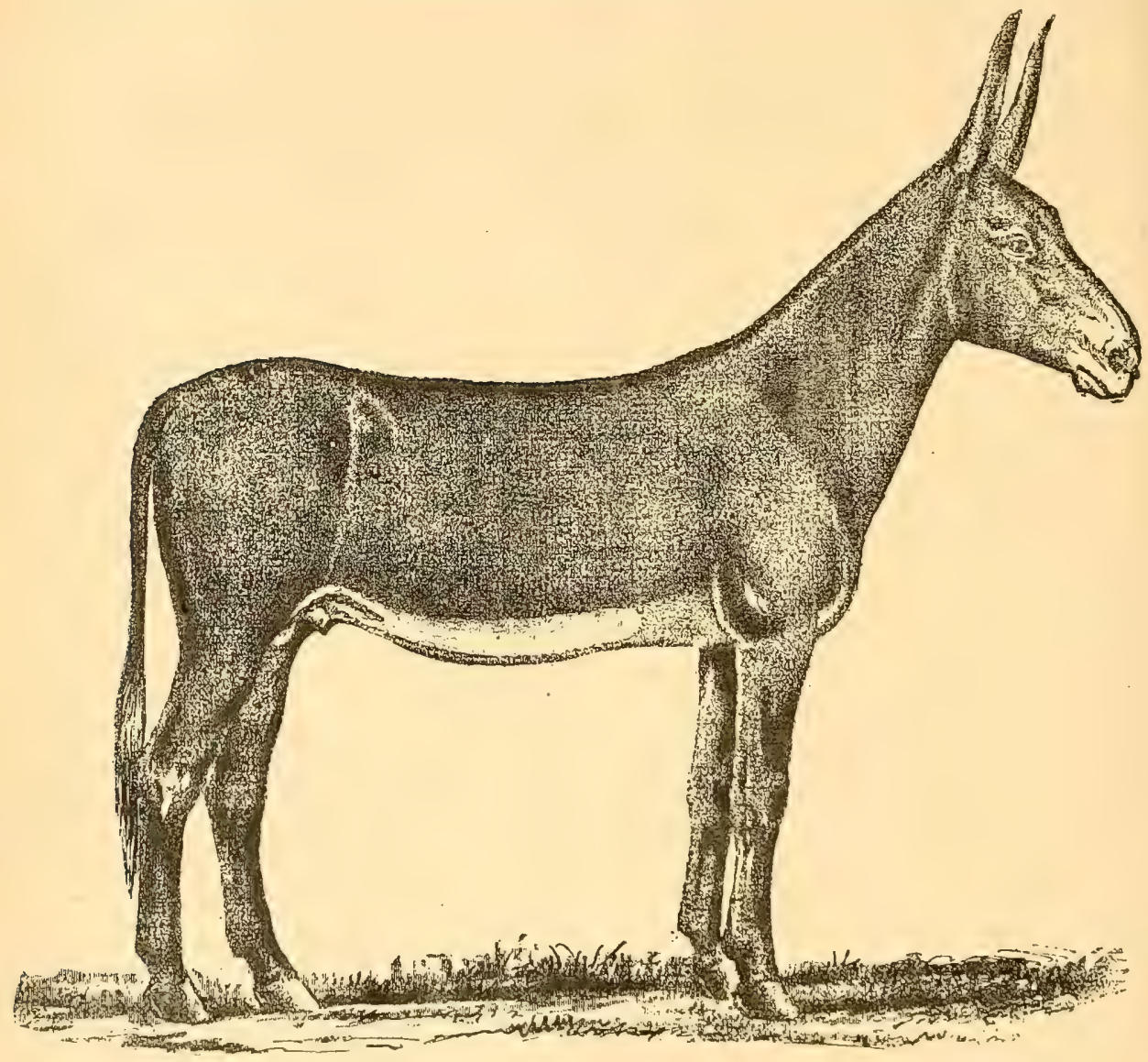

A MODIFIED SPANISH JACK OF THE UNITED STATES.

horse; while, in sure-footedness and comparative freedom from disease, they greatly excel them.

At the South.-They have been found much better suited to the requirements of the eotton plantations than horses. They work freer and with less trouble, are more hardy, stand the climate better, and 
are not so easily affected by the neglect and cruelty of the negroes or others that use them. On the score of economy, also, they deserve all the favor that has been awarded them in those sections, and vastly more than they commonly receive at the North. The mule, being smaller, does not eat more than three-fifths as much as the horse, which, when feed is high, is an item of importance. He is especially preferable also for the movement of machinery. Here his superior powers of enduranee give him such an advantage that in these services, it has been claimed, he will often last nearly as many years as the horse will months.

Mules are Not Vicious. - The common belief that the mule is naturally vicious, is a mistake. He is resentful, and never forgets an injury; but, on the other hand, no animal is more susceptible to kindness, or will exert himself more strenuously for a kind master. He has a most perfect means of offense and defense, namely, his heels, which he knows how to use to far better purpose than does the horse. They are not used, however, except under the impulse of fear or revenge. If kindly used, the mule will be found to be tractable, and willing to perform any due amount of labor. On the contrary, if illused, he becomes sullen, vicious and often balky in the extreme.

\section{A Healthier Animal than the Horse.}

Though not wholly exempt from disease, the mule is incomparably a healthier animal than the horse, particularly on the Southern plantations, where most of the latter race were originally brought from other latitudes. As to his capabilities for service, not only is he the equivalent of horse power, but he will last more than double the number of years that his more pretentious congener will. The average period of service of the horse is about ten years, beginning at the age of three, and, although some horses last considerably longer than this, there are quite as many that fail before completing their thirteenth year. The average period of service of the mule is nearly, or quite, twenty-five years. He sometimes begins to fail at twenty years old, and in other cases remains as good as ever until nearly thirty. Few of his race are worth much after that age. One mule, then, in his lifetime, will ordinarily do the work of more than two horses, at an expense each year of from thirty-five to forty per cent less in keeping. 


\section{Dr. Stewart's Testimony.}

"That the mule is much less liable to disease than the horse is undeniably true, and a fact to which we are fully prepared to add our corroborative testimony, from a long experience with both. Yet we have known the mule to be aftlicted with a large majority of the ailments to which horse-flesh is heir, and have had occasion to treat him for them. When the ravages of big head were at their highest in Western Tennessee and Northern Mississippi, during the years from 1848 to 1850 , inclusive, thousands of mules in that region were numbered among its victims, and many similar cases occurred in other sections of the Southern States. We have repeatedly seen them suffering from spavin, ring-bone, narrow heel, founder, fistula, colic; diseases of the lungs, of the skin, of the glands of the throat, of the urinary organs, etc. Perhaps they are not much less subject than the horse to certain constitutional diseases, such as distemper, farcy, and glanders. But even here one striking advantage remains with the mule-disease yields much more readily to treatment than when it attacks the horse."

\section{The Broeding of Mules.}

A mare that has once brought a mule colt, should never afterward breed to the horse, as her progeny in the latter case will he noticeably inferior. By precisely what physiological laws this matter is gorerned cannot be easily explained, but the fact is indisputahle. Fine hlooded mares, of superior size and form, should always be bred to the horse, and all others that are bred from at all should be reserved for the purposes of mule-raising. One fact that commends the employment of the jack to some owners of inferior mares is that there is a less marked difference thus in the value of the progeny. In other words, they consider that a scrub of a mare may be utilized to advantage in raising a mule colt, when her foal by a horse would amount to very little.

In the breeding of mules, as of all other animals, attention must he paid to the use for which they are intended. If for packing in the mountains, small, compact mules, such as are bred from small fine spanish jacks, are required. These are at once agile and surefooted. For work on southern plantations medium-sized mules are most sought. These are bred from mares of ordinary size, by woodsized jacks. In breeding mules for the road, and for heary teaming, 
large, roomy mares are served with the largest jacks, and at three years old command, when well matched, from $\$ 300$ to $\$ 600$ a span. The mule colts should be handled young, gently treated, and made completely subordinate to the will of the master. At two years old they may be broken. They should be carefully harnessed, without frightening then, and hitched to a strong wagon, when they will generally move off without much difficulty. Thereafter they may do light work until they are four years old, when they may be put to full labor.

The Breeding of Jacks. - The breeding of jacks and jennets is confined in this country to but few hands, principally in Kentucky and Tennessee, though this interest is by no means unrepresented in Missouri, Illinois, Indiana and Ohio. This industry was an important one up to the breaking out of our Civil War, the jacks produced being distributed all orer the Western and Southein States. For somc years after the war it languished, owing in part to the breaking up of many of the great breeding studs, but still more to the diminished demand for mules. Of late years it has revived, and, as there is reason to believe, revived permanently. The South is the most favorable field for this branch of the breeding industry, and there the agricultural interests are steadily improving, and a constant advance is noted in the quality, as well as the numbers, of the live-stock. 


\section{CHAPTER XII.}

\section{OUTLINE OF THE HORSE'S STRUCTURE.}

I. TRUE METHOD OF TREATING THIS SUBJECT.—-II. THE IIORSE'S FRAMEWORK.-III. STRUCTURE AND CLASSIFICATION OF THE BONES.—IV. THE MUSCLES.- V. MUSCLE VERSUS FAT.—VI. THE TENDONS.—VII. THE MEMBRANES.—-VIII. THE SKIN AND ITS THREE LAYERS.—-IX. APPENDAGES AND FUNCTIONS OF THE SKIN.-X. THE PORES AND PEISPIRATION. -XI. THE HAIR.—XII. THE BLOOD.—XIII. PLAN OF THE CIRCULATION.-XIV. TIE CIRCULATORY SYSTEM.—XV. THE CIRCULATORY PROCESS DESCRIBED.—XVI. THE HEART.-XXII. THE FEET.

\section{True Method of Treating This Subject.}

In discussing this subject, we propose to depart from the method usually followed by anatomists in their divisions, classes and descriptions, and to present the whole subject briefly in two preliminary, illustrated chapters, and in a natural, consecutive order. The classification of the horse among other animals in natural history, and his relations to them, are matters of no practical moment to the farmer and stock breeder. To them the subjects of chief importance are the horse's own peculiar history; his adaptation to the service of man, and the best modes of training him and fitting him for that purpose; the general laws of health, and the means of its preservation; and the discases to which he is subject, with their proper treatment, and means for their prevention as well as cure. It will be sufficient, in a work like this, to communicate a general knowledge of his structure, so that, in the treatment of disease, the part affected may be readily known, and the remedy intelligently applied.

Our plan of discussion will be similar to that of the carpenter in building a house, which concerns, first, the frame-work; next, the braces and pins that hold it together; then the covering, and, lastly, the inside finish. In the same manner, we will consider, first, the bones, which constitute the frame-work of the horse; next, the muscles and tendons-the braces which fasten the former together; then the skin and hair, the hor'se's covering; and, lastly, the internal finish - the entire vaseular arrangement of lungs, heart, intestines, urinary orams, blood-vessels, capillatries, and pores, with the whole glandular and nervous structure. 


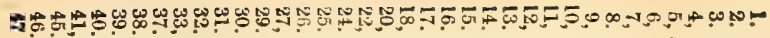
울대

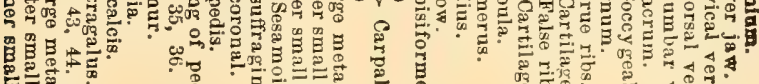

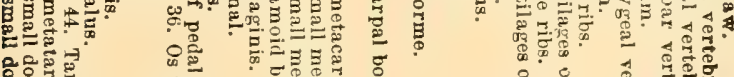

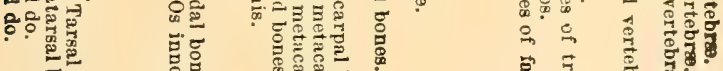

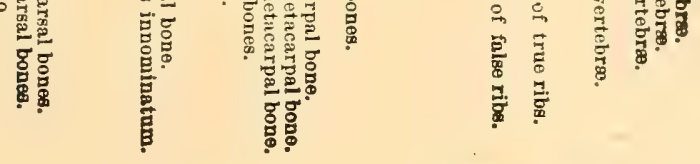

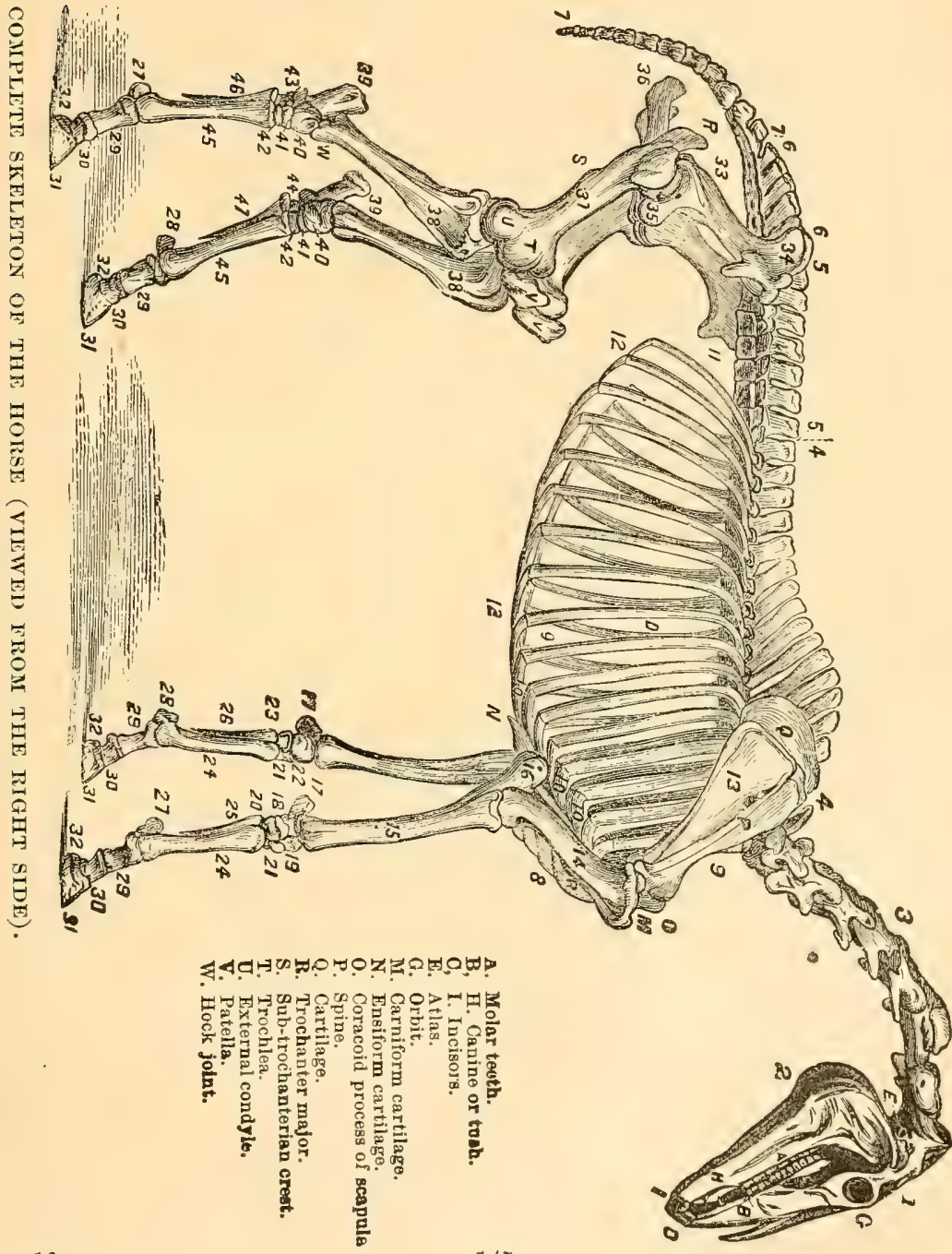




\section{IJ. The Horse's Frame-work.}

Our limits allow, and our purpose requires, but a short space for the discussion of each of these divisions. We begin with the general frame-work, and present the engraving of a very perfect skeleton, accurately indexed for reference or investigation.

The Skeleton.-The skeleton is composed of two hundred and forty-seven separate bones, which are united by joints to form the spine, thorax, pelvis, tail, and fore and hind extremities. The spine is finished anteriorly by the head, which is divided into the cranium, or skull, and face, and contains the teeth. Suspended from the head is the os hyoides (bone of the tongue), which completes the number of bones; thus:

THE SPINE consists of 7 cervical, 18 dorsal, and 6 lumbar vertebræ. Total... 31

'IHe Thorax is made up of the dorsal vertebræ, with 18 ribs on each side, and

the sternum in the middle. Total................................ 37

The Pelvis comprises 2 ossa innominata (or illium, ischium, and pubes), and

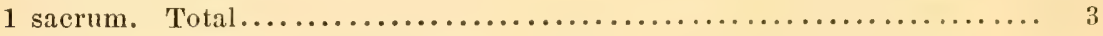

Tre Tarl contains, on the average, 17 bones. Total................. 17

The Fore ExtrentTy is made up on each side of the scapula, bumerus, os brachii, and 8 carpal bones; 3 metacarpal, os suffraginis, os coronæ, os pedis, os naviculare, 2 ossa sessamoidea. Total on both sides................. 40

The Hind Extremity has the femur, patella, tibia, fibula, 6 tarsal bones, 3 metatarsals, os suffraginis, os coronæ, os pedis, os naviculare, 2 ossa ses-

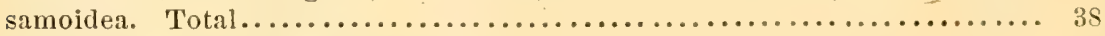

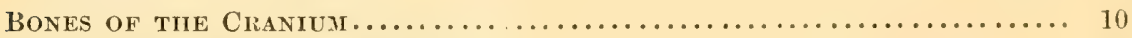

Bones of TIIE FaCE AND Lower Jaws........................ Is

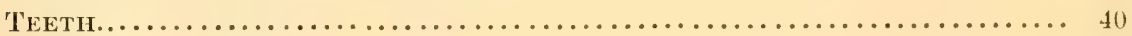

Bones of the Internal Ear, four in each organ................... 8

Os Hyoldes, or Bone of the 'l'ongue, made up of five sections.......... 5

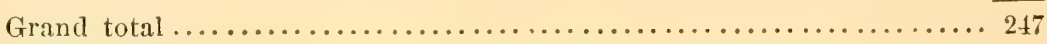

Bones of the Hoof.-The hoofs are the mud-sills of the framework, each holding-coflin-like-within its cavity the coftin-bone (os pedis), which is the first bone in the leg. Between the wings of this bone, behind, and fitting elosely in the space, is a small bone of a peculiar shape, called the navicular-literally, ship-shaped-or shuttlebone (os naviculare). This extends bakward, and forms the projection of the heel. Next above this is the lower pastern bone, resting in the hollow on the top of the coftin-bone.

Bones of the Fore-leg.-Next in order is the upper pastern-bone, upon which rests the shank bone, with the sessamoid bone, which articulates with the ankle-joint, and laps over the point of junction of the shank and upper pastern-bone. The knee-joint is composed of 
seven bones. Sometimes a small, floating bone is found at the back of the joint, making eight in all. Back of the knee, and just below it, are a pair of small, thin bones, extending down the back of the shank nearly its entire length, and denominated the splint-bones of the fore-leg. Above the knee is the main bone of the leg (the radius), known among horsemen as the arm. It is the longest and largest bone of the fore-leg. Above the arm is a bone of peculiar shape, named the ulna (elbow). Still higher up is the humerus, the upper bone of the arm, sometimes rather vaguely termed the shoulder-bone.

Upon each side, at the shoulder, is a bone called the scapula, the shoulder-blade. This unites, at its lower extremity, with the humerus, from its articulation with which it spreads out and becomes very thin, with a ridge like the letter " $T$ " running through its middle. It extends upward to the back-bone, to which it is united by muscle alone. This completes the bones of the fore-leg.

Bones of the Hind-leg.-In the hind-leg, the bones are precisely similar, until we reach the hock-joint, which is composed of six bones. The point or projection of the hock is called the os calcis, or heel-bone. Above this is the tibia (flute or pipe-bone), the largest bone of the whole structure. Behind this, and fitting closely to it, is a small bone called fibula (signifying a clasp or buckle). The stifle-joint is formed by the tibia and the femur, or thigh-bone, which is next above. It is covered in front by the patella or knee-pan. The six bones of the haunches or hips, three on each side, complete the bones of the hind limbs. Upon the four legs, which serve as posts, rests the superstructure.

Bones of the Head and Neck. - The most noteworthy of these are the superior and inferior maxillaries, or upper and lower jaw-bones. In these are set the teeth: 24 molars, or grinders-6 on each side, both above and below; 12 incisors or front teeth-six above and six below; and 4 canine teeth, or tushes-one on each side, above and below, which, however, are generally missing in the mare.

The bones of the skull are thin plates, curved so as to give the head its shape, and locked together by saw-like or dove-tailed edges, to prevent displacement. The principal ones, from their several positions, are respectively called the frontal, nasal, and occipital (eye) bone. Underneath the two former are innumerable little scales or sheets of bone, some of them entirely unconnected with the others, but most of them united to the several bones of the head. These are 
so arranged as to form many irregular cavities, technically designated sinuses.

On the top of the head, and at the beginning of the neck, is a double and yet united bone on each side-the temporal bone-to which the first bone of the neck (the atlas) is attached by that peculiar ligament, commonly known as the whit-leather, which is found nowhere in the whole body except here and at the top of the shoulder.

Bones of the Spine and Tail.-Here begins the line of the vertebræ forming the spine. This consists of thirty-one bones linked together by lock-joints. The seven joints of the neck are called the cervical vertebre, and those of the back proper, the dorsal vertebræ. The latter are eighteen in number, each having an upward projection, varying in length at different parts of the back. At the shoulder this projection is never less than three inches, and in some horses is as much as four or five. It becomes less toward the middle of the back, at which point it is not more than from an inch and a half to two inches in length. The six lumbar vertebræ, or bones of the loins, comes next, and complete the spine proper. The spinal column, however, is continued by the sacrum (literally, the sacred bone), and the bones of the tail, whose number is not uniform in different animals, but averages about seventeen.

Many anatomists, among whom is Strangeways, adopt a slightly different classification as regards the bones of the spinal column. They consider the sacrum to be made up of five bones, which are denominated the sacral vertebre. Some writers state that the bones of the tail vary between 13 and 20, a great length of this part being called a "long dock." It is a very frequent practice to dock or cut off a great part of the tail to make an imaginary improvement in the looks. This has long been the "fashion" in Europe, and apparently is becoming the same in America.

The Ribs.-The ribs-eighteen upon each side-are so arranged as to give form and strength to the body, and protect the vital organs from injury. The sternum, or breast-bone, is composed of six or seven pieces, and constitutes the floor of the chest. It is a long, spongy bone, fixed between the ribs on either side, serving as a sirpport for the eight true ribs-the forward ones-which closely articulate with it.

We have thus given a sketeh of the horse's entire frame-work, with all the bones that compose it, and the principal oftices they perform. The diseases of the bones will be considered elsewhere. 
Another View.-We present another view of the skeleton (from the left instead of the right side), showing also the outline of the horse's form, as some of our readers will doubtless prefer. Its explanation is as follows:

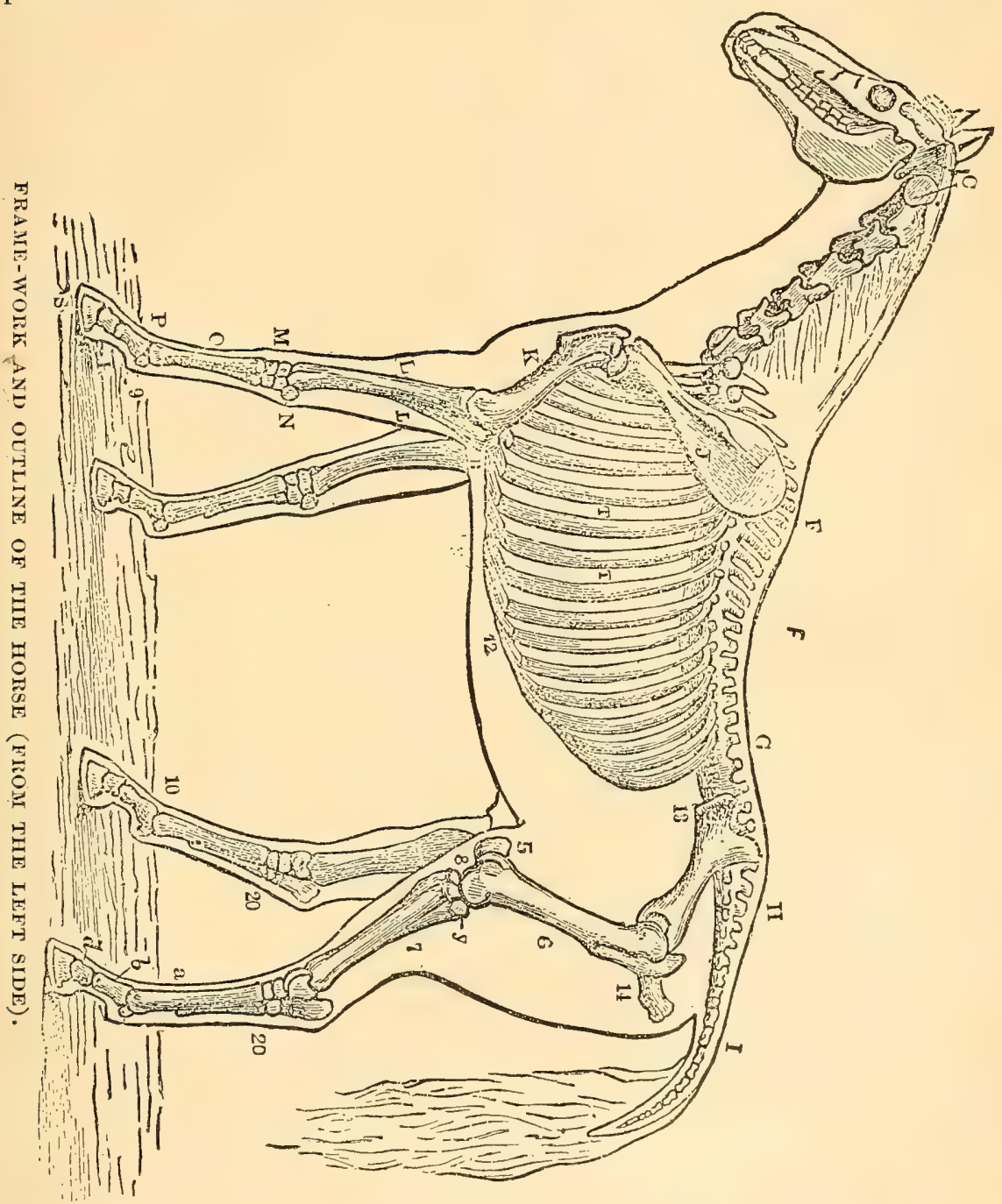

Commencing at the head, $\mathrm{C}$ shows the atlas; $\mathrm{F}$ the withers and below the dorsal vertebre, the withers being formed by spinous processes of the anterior dorsal vertebræ; G, lumbar vertebræ; II, sacral vertebre; I, cocygeal vertebre. These constitute the jointed pro- 
cesses respectively of the neck, back and tail. $J$ is the scapula, or shoulder blade; K, humerus; L, radius, or bone of the arm; M, carpus or knee; $\mathrm{N}$, trapezium; $\mathrm{O}$, metacarpal bones, or bones of the leg; P, os suffraginis, or great pastern; R, os corone, or small pastern; S, os pedis, or coffin-bone, the outline being the hoof outside the bone; $\mathrm{T}-\mathrm{T}$, the ribs.

Coming now to the figures, 4 shows the pelvis, cansisting of three parts; 13 , the ilium; 14 , the ischium, and the pubis, hidden in the illustration ; 5 is the patellat ; 6 , the femur ; 7 , tibia ; 8 , stifle-joint ; 9 , sesamoid bones; 10, fetlock joint; 11, ulna or point of elbow; and 12, the costal cartilages, or cartilages connecting the true ribs. The small letters show at a, the great metatarsal bones; $b$, the great pastern of the hind-leg; $d$, the small pastern; $f$, the dorsal vertebræ, and $y$, the fibula.

\section{Structure and Classification of the Bones.}

The bones are composed of two kinds of textures. The outer or compact tissue is hard and ivory-like, while the inner or cancellated is spongy, porous and soft. Examine a section of compact bone under a microscope, and you will see a great many little openings, surrounded by a lot of rings. These openings are exceedingly small, only 1-200 to 1-2000 of an inch across, but they are sufficiently large to allow the veswels that feed the bone to pass through. The small hlack spots and lines act as reservoirs and canals for the nourishment of the bones. They are called respectively lacunce and canaliculi.

The bones are divided into the three classes of long, flat and irregular, each class being specially suited for different parts of the body and their special uses. The long bones are found principally in the legs, and are very strong, being the weight supporters. They are composed of the two tissues already spoken of, and contain a hole in the center in which is found the marrow. The flat bones have the same structure as the long, but, as a rule, have no central cavity, though in a few of them is a cavity containing air. They are found protecting the vital organs. The bones over the face and brain, and the scapula and ribs over the heart and lungs are examples. The irregular bones are the bones not included among the other two classes. They are very strong, and of all sorts of shapes, being found generally near joints, as the knees, hocks, vertebral column, and in the skull.

The marrow which is contained in the central cavity of the bone, is a soft yellow fat, containing a quantity of blood ressels and other 
textures. It disappears to a large extent during disease. Birds have air, instead of marrow, in the center of their large bones. The covering of the bones is called the periosteum. It completely invests their external surfaces, is very tough and inelastic, and has the power of forming bone from certain little bone-cells which it contains. When inflamed, the periosteum becomes the seat of great pain, owing to its inelasticity; so, also, when any kind of bony tumor forms beneath it, pushing it out and stretching it, as in splints and spavins. Where two or more bones come in contact or articulate, there is always found a layer of cartilage or gristle, thus permitting friction of the parts without injury. Gristle is destitute of blood vessels, but its nutrition is maintained by the parts around. It is made up of small cells, and is elastic in character.

\section{The Muscles.}

The entire movements of the body and limbs, with a few trifling exceptions, are effected by the agency of that peculiar substance known in our butcher's' shops as flesh, and by anatomists as musculir tissue. The museles are of two kinds, voluntary and involuntary. The former are under the direct control of the will, while the latter are not.

The voluntary muscles constitute the chief bulk of the soft parts outside the three great cavities of the body (the cranial, thoracic, and abdominal). They possess great power of motion, being composed of numberless little strings, or fibers, each of which has a contractile and elastic power of itself, the whole being so arranged as best to serve the purpose intended. Thile each fiber has an independent elasticity, it acts, at the same time, in conjunction with all the others in the muscle of which it forms a part, so that their united power becomes very great. This may be realized when we consider that it is they which give to the horse his immense strength. Each muscle terminates in a more solid, compact, whitish substance, commonly called a cord. Such it really is, acting with reference to the joint in the same manner as the cord to a pulley.

The tissue which constitutes the involuntary muscles is found distributed throughout the digestive tract, and the various organs, as the bladder, glands, skin, and blood vessels. These fibers differ from the voluntary in not ending in tendons. Botle kinds of muscles receive very liberal supplies of blood, and contain many nerves. 
The muscles possess but a limited degree of sensibility. When the flech is eut by any sharp instrument, comparatively little pain is experienced after the skin and subeutaneous tissues are passed through. They are but seldom the seat of disease, except such as proceeds from external injuries. Sometimes, however, ulcers establish themselves within the muscular tissues, which occasion great swelling, and discharge immense quantities of matter.

\section{Muscle versus Fat.}

Among horse dealers it is a common remark, in discussing the qualities of a particular horse, that "he has muscle." This, of course, refers not to the number of the muscles, but to their size and power. One horse has as many muscles as another. It is only in their size and quality-in their flexibility and elasticity-that any difference can occur. Here, however, it is very great; and hence one important reason for the extremes which are found in the market value of different animals. A horse's power depends much less upon the amount of his muscle than upon its quality. The superior strength and quickness of some horses are principally owing to their muscular fibers being stronger, more elastic, and possessing greater power of contraction than those of others.

Fattening an animal does not increase his muscles or his strength; nothing but the adipose (fatty) matter is increased. This gives to the parts a full and rounded appearance, so much admired in the horse, and also covers up many serious defects. Excessive accumulation of fat becomes an obstruction to muscular action. A full, rounded form is not an evidence of fine qualities, nor leamness of a lack of them. The horse which is thin in flesh, but in good health and well fad, possesses more muscular power and action, and especially greater endurance, than one very fat. Besides this, the latter is much more liable to disease. While these are facts known to every horseman, it is equally true that a certain amount of adipose matter, with regular and proper exereise, is essential to the possession of the highest degree of vital energy and strength.

There are an immense number of minute glands in the skin, secreting an oily substance, which, oozing out at the pores, oils the entire surface of the skin. Thus the latter' is liept soft and pliant, the hair smooth and glosisy, and to the horse is imparted one of his chief beauties. This is Nature's own mode of adornment. 


\section{The Tendons.}

Of these there are a great many, but the limits of our work will not permit us, any more than in the case of the museles, to attempt to classify them, or make any further mention of them than simply as they come within the scope of our purpose-the history and treatment of the diseases of the horse. Most of the muscles end in tendons, and by these are attached to the bones, principally at the joints. To borrow a figure from mechanics, the bones may be considered the pulleys, the tendons the ropes, and the muscles the power pulling at the end of the ropes. Though, in general, nonelastic, the tendons possess great hardness and toughness, and serve an important purpose in the animal

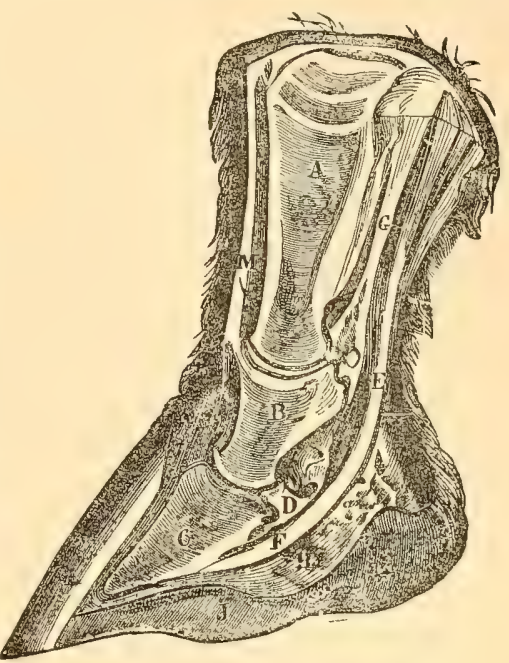

HORSE'S FOOT AND ANKLE. economy. Every joint, of course, is the tendons that move the foot are shown provided with them, since it is only at $\mathrm{G}, \mathrm{E}$ and $\mathrm{F}$. by their assistance that motion is obtained at all. They are liable to diseases of various kinds, which are not always easily cured.

\section{The Membranes.}

The membranes are of two different kinds, the mucous and the serous. The former line all the cavities of the body which communicate with the air, as the digestive tract and its appendages, the lungs, bladder, nose, ete. The serous membranes, which line the closed cavities, as the abdominal, chest and brain cavities, form a double covering for the different organs, and the material which they secrete lubricates their surface, so as to allow their free movement. If such secretion is suspended, from disease or injuries, friction of the parts will cause inflammation.

The membranes have received different names, according to their locations and the parts which they invest. The prefix peri, signifying over or covering, is used in connection with nearly all the more important of them, and, when thus employed, it designates the mem. brane which is over, or which incloses, the particular organ or part. 
Thus the periosteum invests the bones; the pericranium lines the skull; the pericardium is the sack in which the heart is placed; the peritoneum is the strong investing membrane of the external surface of the bowels, and covers the walls of the entire abdominal cavity. A notable exception to the usual nomenclature of the membranes is afforded by the pleura, which envelops the lungs, and lines the cavity of the thorax, or chest. Every farmer and butcher's boy is familiar with the smooth, glossy appearance of the serous membrane throughout the regions of the lungs and bowels, and elsewhere, in the anatomy of the various domestic animals.

The use of the serous membranes is to protect the organs which they inclose. This membrane is very thin, yet hard and tough. It is cut or penetrated with more difficulty than any other part of the body, except the bones. From its smooth surface, hurtful foreign substances readily glide off, unless the force with which they strike is very considerable. One striking peculiarity of this membrane is its insensibility: It is too thin itself to contain nerves or blood-vessels of much size. Yet a large number of these lie immediately beneath it. It is liable to diseases, and may, of course, be torn or ruptured.

\section{The Skin and its Three Layers.}

The skin is the roof and covering of the horse's entire structure. The hair forms an essential appendage of the skin, and is most appropriately considered in connection with it. This is the elothing of the horse's body, renewed by Nature once a year. We extract from Youatt's excellent work the following interesting description of the skin and its functions:

"The skin of the hor'se resembles in construction that of other animals. It consists of three layers, materially differing in their structure and office. Externally is the cuticle-the cpidermis, or scarfskin-composed of innumerable thin, transparent seales, and extending over the whole animal. If the scarf-skin is examined by means of a microseope, the existence of scales, like those of a fish, in readily detected. In the action of a blister, they are raised from the skin beneath in the form of pellucid bladders, and, in some discatsen, as in mange, they are thrown off in hard, dry, white scales, numerous layers of which are placed one above another. In every part of the body the searf-skin is permeated by immumerable pores, some of which permit the passage of the hair; through others the perspirable matter 
finds a passage; others are perforated by tubes, through which various unctuous secretions make their escape.

"There is, at all times, a singular change taking place in the outer covering of the animal. There is a constant alteration and renewal of every part of it, but it adheres to the true skin, through the medium of the pores, and also numerous little eminences or projections, which contain prolongations of the nerves of the skin. The cuticle is itself insensible, but one of its mostimportant functions is to protect and defend the parts beneath, which are so often exposed to a morbid sensibility.

"Beneath the cuticle is a thin, soft substance, through which the pores and eminences of the true skin pass. It is

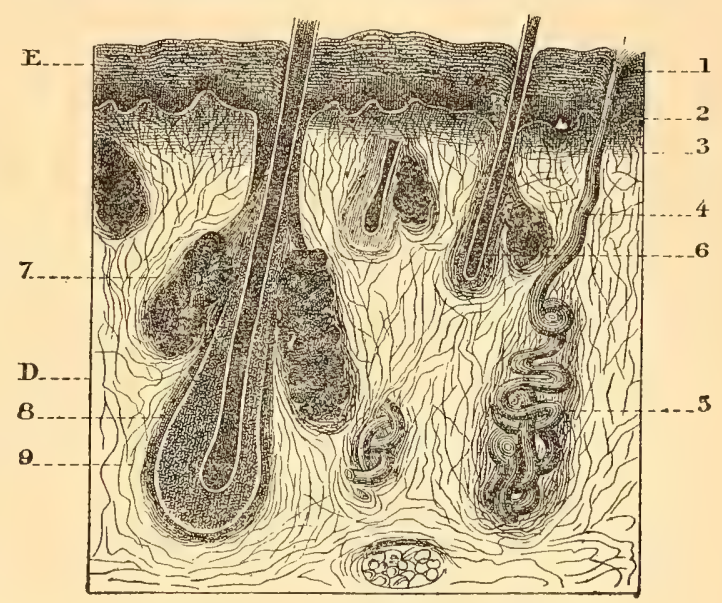

THE SKIN-GREATLY MAGNIFIED.

$$
\begin{aligned}
& \text { E-Epidermis, or Outer Skin. } \\
& \text { D-Dermis, or True Skin. } \\
& \text { 1-Opening of Sweat Gland. } \\
& \text { 5-Sweat Gland. } \\
& \text { 6-Hair. } \\
& \text { 7-Sebaceous or Oil Gland. } \\
& 8 \text { and } 9 \text {-IIair and its Coats. }
\end{aligned}
$$

termed the rete mucosum, from its web-like structure, and its soft, mucous consistence. Its office is to cover the minute vessels and nerves in their way from the cutis to the cuticle. It is also connected with the color of the skin. In horses with white hair, the rete mucosum is white; it is brown in those of a brown color; black in the black, and in patches of different colors with those the hue of whose integument varies. Like the cuticle, it is reproduced after abrasion or other injury.

"The cutis, or true skin, lies beneath the rete mucosum. It is decirledly of a fibrous texture, elastic, but with difficulty lacerated, exceedingly vascular, and highly sensitive. It is the substance which is converted into leather when removed from the body, and binds together the different parts of the frame. In some places it does this literally, and clings so closely to the substance beneath that it searcely admits of any motion. This is the case about the forehead and the 
back, while mpon the cheeks, the sides, and flanks, it hangs in loosened folds. In the parts connected with progression it is folded into various duplicatures, that the action of the animal may admit of the least possible obstruction. The cutis is thinnest and most elastic on those parts that are least covered with hair, or where the hair is altogether deficient, as the lips, the muzzle, and the inside of the flanks. Whatever is the color of the rete mucosum, the true skin is of a pale white. In fact, the cutis has no connection with the color of the hair.

\section{Appendages and Functions of the Skin.}

"Over a great part of the frame lies a muscle peculiar to quadrupeds, and more extensive and powerful in the thin-skinned and thinhaired animals than those with thicker hides. It reaches from the pole over the whole of the carcass, and down to the arm before, and the stifle behind. By its contraction the skin is puckered in every direction, and if it acts strongly and rapidly, the horse is not only enabled to shake off any insect that may annoy him, but sometimes to displace a great part of his harness. This muscle also assists the skin in bracing that part of the frame which it covers, and, perhaps, gives additional strength to the muscles beneath. It is called the panniculous carnosus (fleshy pannicle), or sometimes the fly muscle.

"The skin answers the donble purpose of protection and strength. Where it is necessary that the parts should be bound and knit together, it adheres so tightly that we can scarcely raise it. Thus the bones of the knees and the pasterns, and the tendons of the legs, on which so much stress is frequently thrown, are securely tied down and kept in their places. *** $*$ Of its strength we have abundant proof, both in the living and dead animal. Its fibers are interlaced in a most curious and intricate manner, so as, when living, to be scarcely lacerable, and converted into leather after death.

"It is, while the animal is alive, one of the most elastic bodies with which we are aequanted. It not only perfectly adapts itself to the slow growth or decrease of the hody, and appears equally to fit, whether the horse is in the plumpest condition or reduced to a skele1on; but when a portion of it is distended to an extraordinary degree, in the most powerful artion of the muscles, it, in a moment, again contracts to its usual dimensions.

"It is principally indebted for this clasticity to almost innumerable minute rands, which pour out an oily fluid that softens and supples 
it. When the horse is in health, and every organ discharges its proper functions, a certain quantity of this unctuous matter is spread over the surface of the skin, and is contained in all the pores that penetrate its substance; and the skin becomes pliable, easily raised from the texture beneath, and presenting that peculiar yielding softness and elasticity which experience has proved to be the best proofs of the condition, or, in other words, the general health of the animal. Then, too, from the oiliness and softness of the skin, the hair lies in its natural and proper direction, and is smooth and glossy. When the system is deranged, and especially the digestive system, and the vessels concerned in the nourishment of the animal act feebly, those of the skin evidently sympathize. This oil is then no more thrown out; the skin loses its pliancy; it seems to cling to the animal, and we find that peculiar appearance which we call hide-bound."

\section{$\mathrm{X}$. The Pores and Perspiration.}

The pores are the openings of the deep-seated glands of the skin. These glands are of two kinds,--the sudorific or sweat glands, which secrete the perspiration, and the sebaceous or oil glands, which secrete an unctuous fluid for softening the skin and hair. The secretion of sweat is more plentiful in some parts of the body than in others. "Besides the avenues already mentioned, through which proceeds the unctuous fluid that supples and softens the skin, there are others more numerous, by means of which a vast quantity of aqueous fluid escapes, and perspiration is carried on. As in the human being, this actually exists in a state of health and quietness, although imperceptible; but when the animal is excited by exercise, or labors under some stages of disease, it becomes visible, and appears in the form of drops.

"This process of perspiration is not, however, so far under the control of medicine as in the human being, but there are a few drugs that will certainly produce it. Warm clothing seems occasionally to effect it, but this is more in appearance than in reality. The insensible perspiration cannot escape through the mass of clothing, and assumes a visible form. *** Of the existence of absorbent vessels on the skin, or those which take up some fluid or substance, and convey it into the circulation, we have satisfactory proof. A horse is even more easily salivated than the human being." 


\section{The Hair.}

In some parts of the horse's body-especially at the neck, where the mane appears, and from the dock, whence depends the tailgrows a peculiarly coarse, strong, stiff hair. This is the horse-hair of upholsters and housekeepers, and is never shed. If it is plucked out or rubbed off, it grows out again, although slowly. The long hairs found on the muzzle, and known as "cat hairs," are very sensitive, as the endings of sensory nerves are enclosed in their bulbs.

But what chiefly interests us in this connection is the general coat of hair which Nature has not only bestowed upon the horse as clothing, but has so arranged that it adapts itself to the extremes of heat and cold of the varying seasons. In the spring the old coat of thick, coarse hair comes off, and discovers a new one, about half an inch in length, ready to supply its place. This coat is finer and much thinner than that which has just been shed, and is admirably adapted to the change in temperature. When the horse is in health, it has a smooth, glossy appearance, and is soft and downy to the touch. As the season again changes and the cold increases, a new suit of hair begins to show itself, much thicker and coarser. This is in addition to the finer summer coat, and together they form a dense covering of hair, capable of shielding the animal from great degrees of cold.

The oft-repeated assertion that the horse becomes much weakened and unhealthy during the process of shedding is not borne out by the facts. If any animal exhibits any such unfarorable symptoms at this period, the causes may be much more reasonably set down to the change in the seasons, and the change from the stable, with its confinement and dry, unnatural diet, to out-door life and grass.

Each hair consists of a root, shaft and point. The root has an enlargement at its end which fits into a little papillix at the bottom of the pore from which the hair issues. Into these pores the sweat and oily secretions are poured from the glands, and from here they easily find their way to the skin. The shaft has two coats, central and external. The central coat generally contains coloring matter. There are oily secretions in the skin, as already described, which in health pour out, and, spreading over the hatr, give it the beautiful, glosis appearance all so much admire; but when disease is at work, these fountains are often closed, the coat assumes a rough, raged look, and the hair stands out stiff, dry and bristling. The cut on page 155 is a greatly magnified view of a minute portion of the skin, containing two hairs, with sweat and oil glands. 


\section{The Blood.}

The blood is composed of two elements, the corpuscles and the liquor sanguinis. The corpuseles are likewise of two kinds, the red and the white, the former being far the more numerous. They owe their red color to a peculiar coloring substance called hremoglobin, containing some iron, and forming about ninety per cent. of the corpuscle. The white corpuscles are larger than the red, and of an irregular round shape, and they have a certain amount of independent movement. They are seen in great number in inflammation of the different parts, and are also more plentiful after eating.

The blood of the horse differs but slightly from that of the human being. The important function which the vital fluid discharges in the animal economy, is sufficiently indicated by the character and variety of its constituent elements, all of which are needed to repair the waste and decay of the system, and which the blood is constantly carrying to every part. In studying the blood of the horse at any particular season, we are studying his general condition; and to keep the blood pure is the secret of maintaining the animal in health.

\section{Plan of the Circulation.}

The arrows indicate the direction in which the blood flows in the different vessels. The vessels (arteries) that convey the pure or oxygenated blood, are indicated by the absence of all shading; and those which convey impure or venous blood are represented by heavy shading.

$A-$ Capillaries on the general surface in all parts of the body, forming the intricate net-work of minute vessels by which the veins and arteries are connected.

$B$-One of the vena cavæ, which are the two great veins through which all the venous blood in the body is finally returned to the right auricle of the heart.

$C$-The right auricle, from which the venous blood passes into the right ventricle.

$D$-The right ventricle, from which the venous blood passes into the pulmonary artery.

$E$-The pulmonary artery, which carries the still impure or venous blood to the lungs.

F-The capillaries of the lungs, spread out over the immense extent of surface afforded by the air-cells. In these

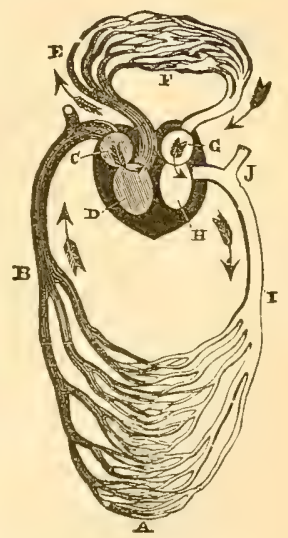

PLAN OF TIIE CIRCULATIUN. the blood is purified, by the processes of decarbonization and oxygenization. They unite and form the pulmonary veins, one of which is indicated in the cut, near the uppermost of the downward-pointing arrows, but is not lettered. 
G-The left auricle of the heart, which receives the now purified (oxygenated) blood from the pulmonary veins, and from which it passes to the left ventricle.

$I I$-The left ventricle, the contraction of whose powerful walls forces the blood out through the aorta and the successive subdivisions of the arteries to all parts of the system.

I-The aorta posterior, dividing and subdividing into smaller arteries, which finally unite with the capillaries at $A$, where begins onee more the venous circulation. The aorta posterior is the great artery which supplies the abdomen and all the hind extremities with blood. The latter is now freighted with nutrition extracted in the intestines from the food, and conveyed into the general circulation through the thoracic duct (not shown in the eut) and the anterior vena ceva.

$J$-The trunk of the aorta anterior, the great artery which supplies the contents of the thorax, or chest, and all the fore extremities, etc., with the pure and nutritious blood. It ramifies and terminates in the same manner as the aorta posterior.

The circulatory process in animal life suggests the comparison of a pond or lake, first fed by a few considerable streams, which have been formed by other and smaller ones, and these, in turn, by a multitude of little rills, originating in drops of water oozing almost imperceptibly from the earth; then the lake is drained by other channels, which divide and subdivide into innumerable rivulets and trickling streams, until, at last, all become absorbed and lost beneath the surface. Yet from the reservoir, hidden in the bowels of the earth, the water finds its way to the surface, where it again oozes out in drops, which accumulate in streamlets and rivers, to feed the lake as before. Again the outlets spread out upon the other side, and ramify, until they are swallowed up beneath the surface. Thus the round continues indefinitely.

In a similar manner the functions of circulation are carried forward. The heart is the reservoir; the veins, the feeding streams; the arteries, the streams that flow away upon the other side.

\section{The Circulatory System.}

The circulatory system of the horse, like that in the human body, consists of the arteries, veins, and capillaries. The arteries are the vessels which convey the red oxygenized or pure blood from the heart to every part of the body. The eapillaries are the net-rork of minute vessels which ramify through every organ and part, and, though generally spoken of ats constituting a distinct system of blood-ressels, are properly to be regarded as simply the termination of the arteries and the eommencement of the veins-the comnecting links between 
the arterial and venous systems. The veins are the ducts through which the blood, now become of a dark color from the presence of effete materials, returns to the heart.

The Arteries.-Each artery has three distinct coats. The outer one is of a cellular structure, and is capable of great distension; that upon the inside is a serous membrane, presenting internally a smooth surface, which serves to diminish the friction of the blood as it rushes on. The middle coat, largely composed of muscular fibers, is highly elastic. In it resides the power-without which circulation would be all but impossible-of equalizing the flow of blood, and accelerating it when considerably removed from that great central force-pump of the system, the heart.

The Veins.-Although made up of the same number of coats, the walls of the veins are much thinner and weaker. These vessels are much more numerous than the arteries, notwithstanding which their ramifications may be described, in general terms, as corresponding with the latter. Their internal area is nearly double that of the arteries. They are, of course, much less directly affected by the action of the heart. Hence, their pulsations are never perceptible except in disease, and the blood flows through them more slowly. A feature peculiar to the veins is the existence of valves, of various construction, which prevent the blood from returning upon its course, and assist in impelling it toward the heart. These are sometimes single, at others double, and occasionally are arranged in three or four folds around the interior of most, though not all, of the large veins.

Pulmonary Circulation.-Thus far we have considered only the general circulation. When we come to the beautiful process known as the pulmonary circulation, a portion of our description must be exactly reversed-the pulmonary artery conveying the impure, dark blood from the right ventricle of the heart to the lungs, where it is oxygenizea , or purified, and thence returns to the left auricle of the heart, through the pulmonary vein, possessed of a scarlet brightness. Interesting phenomena occur in connection with what physiologists term the portal circulation (pertaining to the liver), but they are exceptional and local. We must pass on to consider the general plan of the circulation, which has been already anticipated in some measure.

\section{The Circulatory Process Described.}

After the purified blood has been returned to the left auricle of the heart, by the means just indicated, it passes into the left ventricle, 
whose thick, muscular walls contract with immense power, and force it out, through the proper valves, into the aorta, the great artery of the whole body. This, after proceeding about two inches, divides into two large branches. The smaller branch is extended, by a multitude of subdivisions, to every part of the head and fore extremities; the larger one, in a similar manner, throughout the body and hind extremities.

The blood is now freighted with the varied elements necessary for repairing those losses, by natural decay and wear and tear, which every tissue in the whole body is constantly undergoing. This reparative process is what physiologists call nutrition. It is conducted in the capillaries, the minute and hair-like vessels in which the arteries ererywhere terminate. Although the capillaries vary greatly in their modes of ramification, according as they minister to gland, membrane, or muscular fiber, their offices are the same in all locations. Their services include, beside nutrition, the gathering up of the wornout, worthless particles of matter which the organs of excretion are continually throwing off, through the circulation, in all parts of the system. In the performance of these duties, capillary action changes the color of the blood from a scarlet to a brownish red. It also develops animal heat.

The veins now receive this dark blood at their origin amid the network of the capillaries, and convey it back to the heart. As they approach that organ, they continue to unite, and grow larger, and at length they pour their entire contents through the two rena carer, the verns which eorrespond to the great arterial branches of the artal, into the right auricle. Only a thin wall of muscle now separates the blood from its starting-point, at the outlet of the left ventricle, upon the other side of the heart. But through this partition there is no passage; nor is the blood ready to pass to the other side, if there was one. Before it can be sent forth again to minister to the needs of the body, it must be purified. Not only must the particles of effete, cast-off matter, which it has accumulated from erery part of the system, be eliminated and thrown off; but the chyle also-the substance into which the nutritive elements of the food have been previously converted by digestion-must be submitted to yet another process before it becomes fully prepared to afford the means of nutrition to the constantly disorganizm g tissues of all kinds. (The chyle, it must be understood, empties into one of the rena carce through the tho- 
racic duct, and mingles with the venous blood which is returned to the right auricle, freighted now with the materials of nutrition.)

These objects are accomplished through the pulmonary circulation already mentioned. The lungs, composed of two lobes, are of a spongy texture, and filled with innumerable little air-cells. They are furnished with an exceedingly fime net-work of capillary vessels, distributed on their walls, and throughout the surface of all the air-cells also. The impure venous blood, as it circulates through the capillaries, is submitted to the agency of atmospheric air under extremely favorable circumstances. It absorbs the oxygen of the air, and, at the same time, gives off large volumes of carbonic acid gas, this being the form in which the accumulated impurities of the blood now exist. The wonderful rapidity with which this process is carried on may be understood, when it is considered that the extent of surface upon which the minute capillaries ramify in the lungs is estimated to be ten or twelve times that of the skin.

Ramifications and Importance of the Process.-Having been thus purified, the blood regains its bright red, or scarlet, appearance, and is again propelled forward, through the heart and arteries, upon the same excursion as before. It reaches every part of the body, perfectly ramifies throughout every organ, and permeates every muscle, tendon, ligament, bone, and even to the skin itself, and every hair upon its surface. There is no part, however minute, remote, or unimportant, to which it does not find its way, by means of the divisions and innumerable subdivisions of the vessels which convey it. There is no tissue anywhere in the entire system which does not receive from the blood the elements essential for its development and health-the materials, in fact, of which it is composed. After its work is done here, the blood becomes the scavenger of the body, collecting the impure and deleterious excretions, and returning with them to the heart and thence to the lungs, there to be exhaled in the breath, as already described. The importance of the arterial flow can hardly be estimated. Without it no function could be discharged, and, in fact, life itself would be extinct. Yet it may be made the sure means of disease, by forcing into it harmful and poisonous substances. Great and constant attention should be exercised in regard to the materials introduced into the stomach, either as food or medicine, since they so surely and speedily find their way into the blood. 


\section{The Heart.}

Of the heart much has necessarily been said in the preceding sections. All that now remains to be added is a description of its different parts, and their functions. It occupies the space between the lungs denominated the mediastinum, and is invested by a double membrane of its own, called the pericardium. This forms a little sac, whose

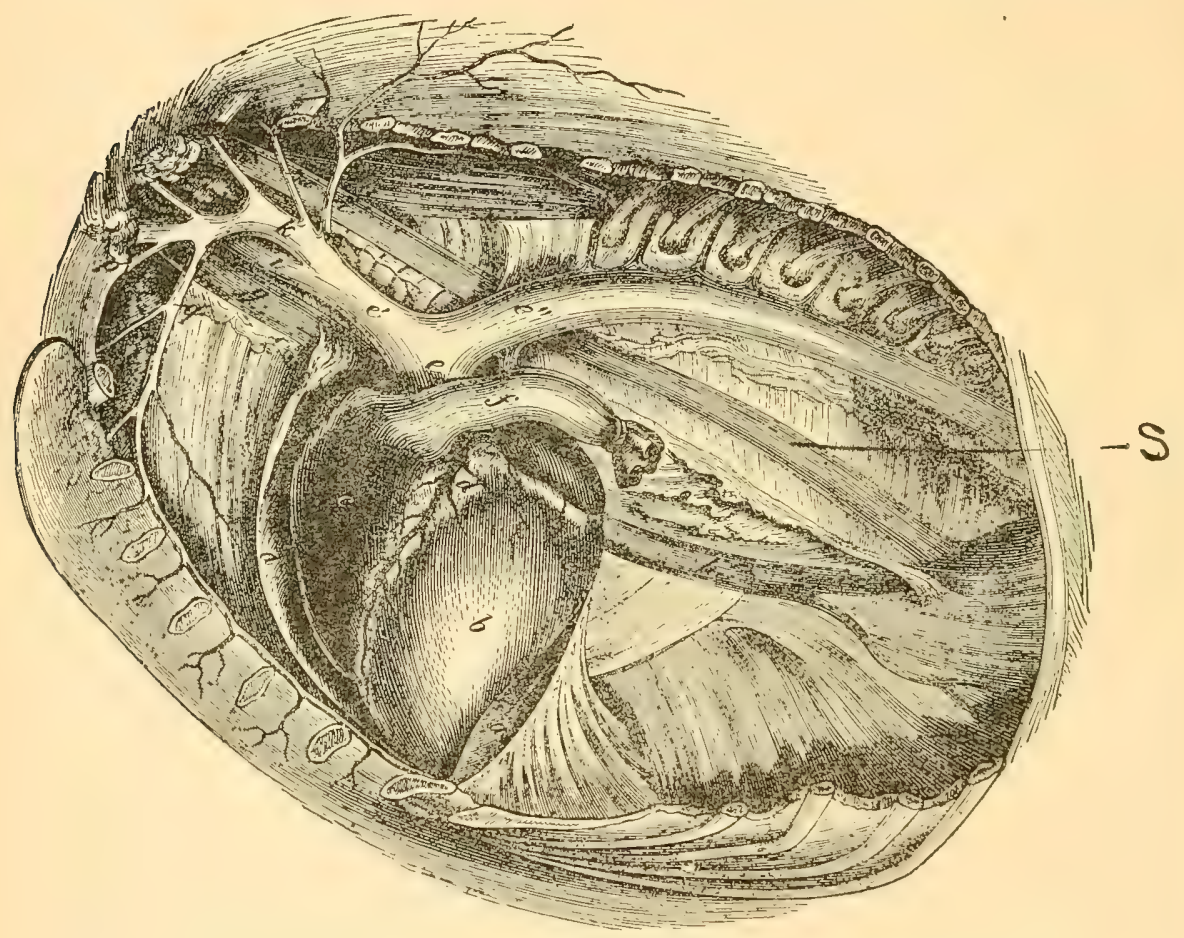

THE HEART, AORTA, ETC. (THE CHEST OPENED ON LEFT SIDE.)

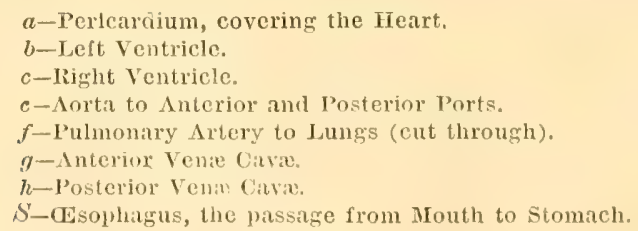

office it is to support the heart in its natural position, and prevent friction between the heart and the surrounding parts.

Four cavities occupy the spaces within the walls of the heart-two ahove, called aturides, from their fancied resemblance in form to the 
ear, and two below, called ventricles. The walls of each ventricle are much thicker than those of the auricle upon the same side, and also in the left ventricle than in the right. Why this difference is quite plain, from the uses of these several parts, as explained in the last section. The ventricles are in that part of the heart toward its apex.

Into the right auricle open the two vena cavæ and the coronary veins,-those which supply the heart itself with blood. The right ventricle communicates with the right auricle by an orifice provided with a valve. From it arises the pulmonary artery, through which the venous blood is forced to the lungs by the contraction of this rentricle. After being purified in the lungs, the blood is carried back to the left auricle of the heart by the four pulmonary veins (eight in number when they leave the lungs), which thus carry arterial blood. From the left auricle the blood passes, by the mitral valve, into the left ventricle, whose powerful walls contract and force it out into the aorta, the great arterial trunk, from which diverge, by successive subdivisions, all the other arteries in the body.

We have seen that there is no communication through the muscular partition separating the right and left sides of the heart. This mode of structure gives greatly increased power to the contraction of the heart, which is simultaneous upon both sides, and separates the impure blood on one side from the pure blood on the other.

The Pulse.-The blood, then, is forced through the arteries by successive impulsions, which are caused by contractions of the heart. When an artery of considerable size comes near the surface, these successive impulsions may be distinetly seen through the skin and coats of the artery, or they may be felt by laying the finger upon them, at any spot where they pass over some bone, which explains the pulse felt in the human wrist, and that on the jaw of the horse. Similar pulses are found in other parts of the body, but none so plain and distinct. We say the pulse is slow when the heart acts sluggishly; and fast when, from disease or excitement, its action is heightened. The beats of the pulse simply indicate so many impulsions of the blood from the heart.

\section{The Feet.}

Volumes might be written in regard to the feet, so peculiar is their construction, so important their uses, so severe their service, and so numerous the diseases with which they are afllicted. Many of the latter are among the most obstinate and serious of all the ailments to 
which horse-flesh is heir. In the veterinarian's descriptions, as in h: practice, a large proportion of his time must be devoted to the feet.

The hoof is the horny crust or wall that incloses the sensible or lifing portion of the foot. It extends from the hair downward to the edge that rests upon the ground. It is longest in front, where its extreme point is called the toe. Behind, it is open, and the crust terminates in a thick, porous skin, divided by a seam at the back part of the foot, and presenting two convex, lateral extensions, which to-

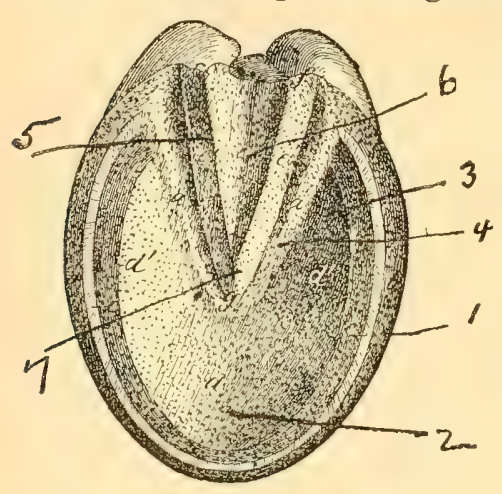

HORSE'S HOOF.

1 - Wall.

2-Sole.

3-Heel.

4-Bars.

5-Frog.

6-Cleft of the Frog.

7-Point of the Frog. gether are called the frog. At the top of the crust, where it unites with the hair, is the coronary ring. This is a thick, spongy substance-soft hoof, in fact, in process of formation. It is to the horse's feet what the roots of the nails are to the human fingers and toes. Another crust, less brittle, and more elastic, extends under the foot, forming the sole, and presenting a somerhat concave surface to the ground. At the back part of the foot is a horny projection in the shape of a letter $V$, with its opening toward the heel. The two sides of this projection, which should unite at an angle of about forty-five degrees, are called the bars. What horsemen call the inside quarter of the foot is that part without the bars, next to the opposite foot. The outside quarter lies upon the other side of the foot. Within the bars is the frog. This is of the color of dark Indiatrubber, which substance it resembles in its degree of toughness and hardness, but possessing lesis elasticity. The entire crust of the frog is insensible, but at the depth of about half an inch is found the sensible or living portion, execedingly tender, and tilled with innumerable little nerves and blood-ressels.

Inside of the hoof are two spongy bones-the coffin and shuttlebones (os pedis and os naviculare) -which are, at times, the seat of most olstinate disease. These oceny little more than one-half the space within the hoof; the remander is tilled by cartilages, tendons 
and tissues, through which ramify a greater proportionate distribution of little nerves and blood-vessels than can be found in any other part of the body.

We herewith present another view of the hoof. This is a portion of the horse's anatomy that cannot be too well understood; for, as we have said before, no horse can possibly be a good horse whose feet are not sound.

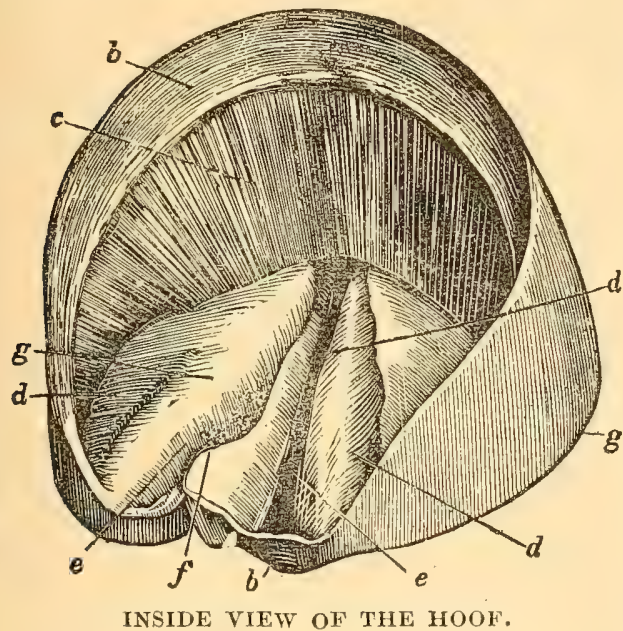

$a$-The external crust seen at the quarter.

$b$-The corouary ring.

$c$ - The little horny plates lining the crust.

d-The same continued over the bars.

$e$ e-The two concave surfaces of the incide of the horny frog.

$f$-That which externally is the cleft of the frog.

g-The bars.

$h$-The rounded part of the heels, belonging to the frog.

There are two very important tendons (the flexors), extending from the back part of the knee down to the foot. They pass down together under the hollow of the heel. One, dividing into two parts, is inserted into the wings of the coffin-bone above the heels; the other passes under the navicular or shuttle-bone, which rests on i:, and immediately above the elastic frog it is attached to the under surface of the coftin-bone, about its middle. Hence any injury which the frog may sustain, will be likely to involve both this lower tendon and the shuttle-bone. 


\section{CHAPTER XIII.}

\section{OUTLINE OF THE HORSE'S STRUCTURE (Continued).}

I. THE BRAIN AND ADJOINING PARTS.-II. ANATOMY OF THE BRAIN.-III. THE NERVOUS SYSTEM.—IV. ANATOMY OF THE EYE.- V. THE EYE'S PRINCIPAL PARTS AND TIEIR FUNCTIONS.—VI. PHYSIOLOGY OF RESPIRATION.—VII. THE LUNGS.—-CVIII. OTHER RESPIRATORY ORGANS.—IX. GLAND, SECRETION AND EXCRETION DEFINED.-X. GLANDS OF THE MOUTH AND THROAT.-XI. THE GULLET AND DIGESTIVE APPARATUS.-XII. THE STOMACH.-XIII. THE INTESTINES.—XIV. THE LIVER. - XV. THE PANCREAS, OR SWEET-BREAD.—XVI. THE SPLEEN, OR MILT.—XVII. THE URINARY ORGANS.-XVIII. MALE GENERATIVE ORGANS, - XIX. GENERATIVE ORGANS OF THE MARE:

\section{The Brain and Adjoining Parts.}

The cut represents a section of the head, and shows not only the location of the different parts of the brain, with the cranial bones which inclose it, but also gives the anatomy of that entire member, and of the neck. It will be found exceedingly useful for reference, in connection with several other sections of this work.

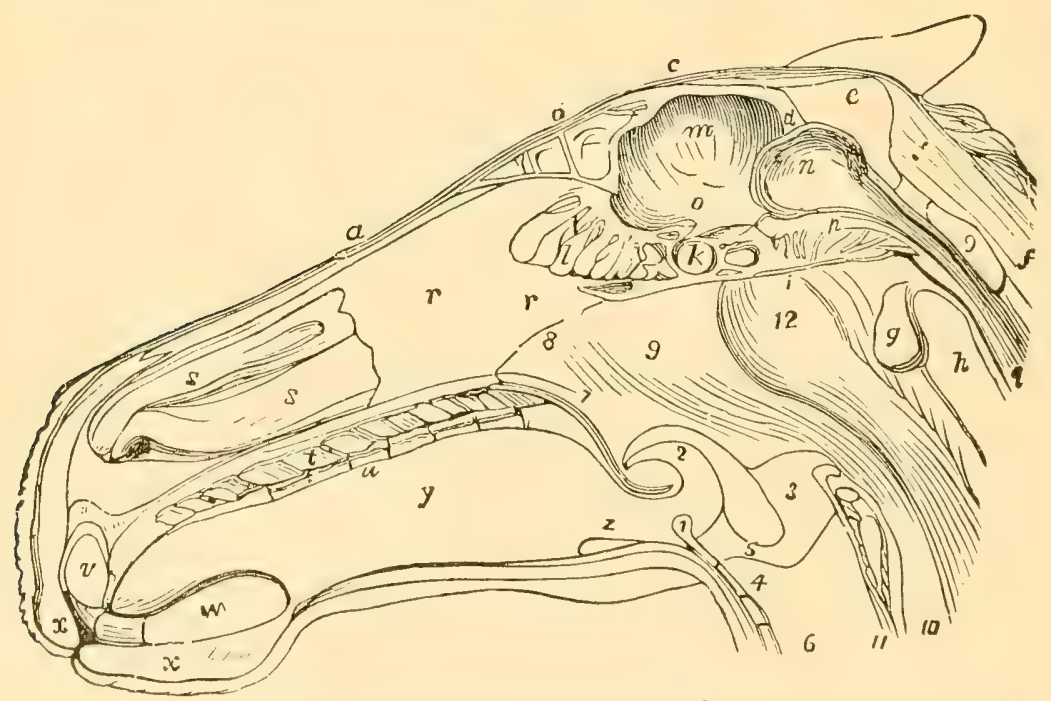

SECTIONAL VIEW OF THE HORSE'S HEAD.

a-The nasal bone, or bone of the nose.

b-The frontal bone. The cavities or cells beneath are called the frontal sinuses. $c$-The erest or ridge of the pariotal bones. 
d-The tentorium, or bony separation between the cerebrum and cerebellum.

$e$-The occipital bone.

$f$-The ligament of the neck-the whit-leather or pack-wax-by which the head is chiefly supported.

$g$-The atlas, sustaining or carrying; the first bone of the neck.

$h$-The dentata (tooth-like) or second bone of the neck.

$i$-The cuneiform or wedge-shaped process, or base of the occipital bone. Between it and the other portion of the occipital bone $e$, lies the great fortmen, or aperture, through which the prolongation of the brain-the spinal marrow-issues from the skull.

$k$-The sphenoid (vedge-like) bone, with its cavities.

l-The ethmoid (sieve-like) bone, with its cells.

$m$-The cerebrum, or brain, with the appearance of its cortical and medullary substance.

$n-$ The cerebellum, or little brain, with its beatiful arborescent appearance.

o-A portion of the central medullary (marrow-like) substance of the brain, and the prolongation of it under the name of the crus cerebri (leg of the brain), and from which many of the nerves take their origin.

$p$-The medulla oblongata-the prolongation of the brain after the medullary substance of the cerebrum and cerebellum have united, and forming the commencement of the spinal marrow. The columnar appearance of this portion of the brain is represented, and the origins of the respiratory nerves.

$q$-The spinal marrow extending through a canal in the center of the bones of the neck, back and loins, to the extremities of the tail, and from which the nerves of feeling and of motion, that supply every part of the frame, except the head, arise.

$r$-The septum narium, or cartilaginous division between the nostrils.

$s$-The same cut off at the lower part, to show the spongy turbinated (turbanshaped) bones filling the cavity of the nostril.

$t$-The palate.

$u$-The molar teeth, or grinders.

$v$-The superior maxillary bone, containing the incisor teeth, or nippers and molars.

$w$-The inferior maxillary, or lower jaw, with its incisors and molars.

$x$-The lips.

$y$-The tongue.

$z-$ A portion of the os hyoides, or bone of the tongue, like a Greek $u, v$.

1-'The thyroid (helmet-shaped) cartilage of the larynx, inclosing and shielding the neighboring parts.

2-The epiglottis, or covering of the glottis, or aperture of the wind-pipe.

3-The arytenoid (funnel-shaped) cartilage of the larynx, having between them the aperture leading into the trachea or wind-pipe.

4-One of the chorda vocales, cords or ligaments concerned in forming the voice.

5-The sacculus laryngis, sac or ventricle of the larynx, or throat, to modulate the voice.

6 -The trachea, or wind-pipe, with its different rings.

7-The soft palate at the back of the mouth, which in the horse is so constructed as to prevent the possibility of vomiting.

8 -The opening from the back part of the mouth into the nostril.

9-The cartilage covering the entrance into the eustachian tube, or communication between the mouth and internal part of the ear. 
10-The csophagus, or gullet.

11-The cricoid (ring-like) cartilage of the larynx, below and behind the thyroid. 12-Muscle of the neck, covered by the membrane of the back part of the mouth.

\section{Anatomy of the Brain.}

A Wonderful Organization.-All the agents concerned in the existence and movements of animal life would be utterly inert and powerless, had they not been combined with some motive porver to excite and regulate their action. Such a motive porver the Creator has provided in that wonderful organization, the nervous system, consisting of the brain, the spinal cord, and the nerres.

There are many things difficult to be understood in regard to the nervous system and its operations. Some of these are too deep for the wisest and most learned to fathom, much less to satisfactorily explain. But the careful reader can get a good general idea of the structure and oflices of its different parts by means of the descriptions which we shall give, aided by the foregoing cut. We can do no better than to quote from Youatt:

The Human and Equine Brain.- "The brain of the horse corresponds with the cavity in which it is placed. It is a flattened oval. It is divided into two parts, one much larger than the other-the cerebrum, or brain (see $m$, in cut), and the cerebellum, or little brain (see $n$ ). In the human being, the cerebrum is above the cerebellum; in the quadruped it is below; and yet in both they retain the same relative situation. [This arises from the fact that in man the head surmounts the body perpendieularly, while in quadrupeds its position is relatively slanting.] He, who for the first time examines the brain of the horse will be struck with its comparatively dininutive size. The human brain is by far the largest in comparative bulk; then the brain of the dog, the horse, the ox. Thus would they be classed in the order of intelligence.

The Two Substances of the Brain.- "Then the brain is eut, it is found to be composed of two substances very unlike in appearance ( see $m$, in eut); one, principally on the outside, gray or ash-colored, and, therefore, called the contical. (barli-like), from its situation, and cineritious (asken), from its color; and the other, lying deeper in the brain, and from its pulpy nature, called the medullary substance. Althongh placed in apposition with each other, and seemingly mingling, they never run into the same mass, or change by degrees into one another, but are essentially distinet in construction as well as in function. 
"The medullary portion is connected with the nervous system. The nerves are prolongations of it, and are concerned in the discharge of all the offices of life. They give motion and energy to the limbs, the heart, the lungs, the stomach, and every part connected with life. They are the medium through which sensation is conveyed; and they supply the mind with materials to think and work upon.

"The cineritious or cortical part has a different appearance, and is differently constituted. Some have supposed, and with much appearance of truth, that it is the residence of the mind, receiving the impressions that are conveyed to the brain by the sensitive nerves, and directing the operation and action of those which give motion to the limbs. In accordance with this, it happens that, where superior intelligence is found, the cineritious portion prevails, and where little beside brute strength and animal appetite exist, the medullary poltion is enlarged. There is, comparing bulk with bulk, less of the medullary substance in the horse than in the ox, and in the dog than in the horse. The additional bulk of brain is composed of cineritious matter."

Before passing to the next section, we must not forget to mention the membranes of the brain. These are three in number, each completely investing it. The outer or upper one is called the dura mater, and is fibrous in texture, and quite strong. The middle one, called arachnoid, is a serous member of the ordinary character. The inner one, denominated the pia mater, is full of vessels, and is by far the most tender. Being next the brain, howerer, it is less exposed to injury than the others. The pia mater penetrates into every depression, lines every ventricle, and clothes every portion of the brain.

\section{The Nervous System.}

"From the medullary substance (resumes Youatt), proceed certain cords or prolongations, termed nerves, by which the animal is enabled to receive impressions from surrounding objects, and to connect himself with them, and also to possess many pleasurable or painful sensations. One of them is spread over the membrane of the nose, and gives the sense of smell; another expands on the back of the eye, and the faculty of sight is gained; and a third goes to the internal structure of the ear, and the animal is conscious of sound. Other nerves, proceeding to different parts, give the faculty of motion, while an equally important one bestows the power of feeling. 
Nerves of Involuntary Motion.-_"One dirision of nerves (see $h$, in cut), springing from a prolongation of the brain, and yet within the skull, wanders to different parts of the frame for important purposes connected with respiration or breathing. The act of breathing is essential to life, and were it to cease, the animal would die. These are nerves of involuntary motion; so that, whether he is awake or asleep, conscious of it or not, the lungs heave, and life is supported.

Spinal Cord and Ganglia.- "Lastly, from the spinal cord (see $q$, in cut), a further prolongation of the brain, and ruming through a cavity in the bone of the neck, back, and loins, and extending to the very tip of the tail, other nerves are given off at certain intervals. The spinal cord is composed of six distinct columns or rods, running through its whole length, three on either side. The two upper columns proceed from those tracks of the brain devoted to sensation. Numerous distinct fibers spring abruptly from the column, which collect together, and passing through a little ganglion, or enlargement (an enlargement of a nervous cord is called a ganglion), become a nerve of sensation. From the lower or inner side-a prolongation of the track devoted to motion-proceed other fibers, which also collect gradually together, and form a nervous cord, giving the power of motion. Beyond the ganglion the two unite and form a perfect spinal nerve, possessing the power of both sensation and motion; and the fibers of the two columns proceed to their destinations, enveloped in the same sheath, and, apparently, one nerve. They are united, yet distinct; they constitute one nerve, yet neither their substance nor their oflice is confounded.

The Sympathetic Nerves.-_"All these nerves are organs of sensation and motion alone; but there are others whose origin seems to be outside of and below the brain. These are the sympathetic, so called from their mion and sympathy with all the others, and identified with life itself. They proceed from a small ganglion, or enlargement, in the upper part of the neck, or from a collection of little ganglia in the abrlomen. They go to the heart, and it beats; and to the stomach, and it digests. They form a net-work around eateh blood-ressel, and the current flows on; they surromd the rery minutest ressels, and the frame is nomished and built up; they are destitute of sensation, and they are perfectly beyond the control of the will." 
IV. Anatomy of the Eye.

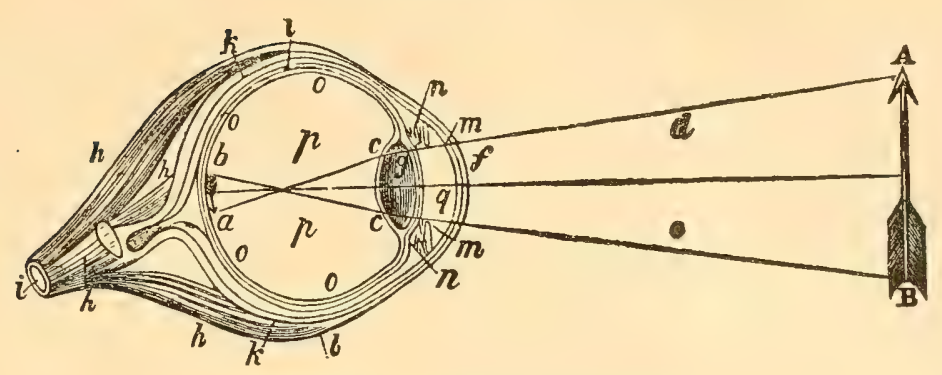

SECTIONAL VIEW OF THE EYE.

The above is a sectional view of the eye, exhibiting its different parts. It also shows in what manner the sensation of sight originates.

A B-A supposed object viewed by the animal, and an inverted image of which' $a, b$, is thrown on the retina at the back of the eye.

c. $c$-The points where the rays, having passed the cornea and lens, converge by the refractive power of the lens.

$d e$-The rays proceeding from the extremities of the object to the eye.

$f$-The cornea, or horny and transparent part of the eye, covered by the conjunctiva, uniting different parts together.

$g$-The crystalline (crystal or glassy) lens, behind the pupil, and in front of the vitreous humor.

$h \quad h$-Muscles of the eye.

$i$-The optic nerve, or nerve of sight.

$k$-The sclerotica (hard, firm coat) covering the whole of the eye, except the portion occupied by the cornea, and being a seeming prolongation of the covering of the optie nerve.

l-The choroides (receptacle or covering), or choroid coat, covered with a black secretion or paint.

$m m$-The iris, or raiubow-colored circular membrane under the cornea, in front of the eye, and on which the color of the eye depends. The duplicature behind is the uvea, so called from being colored like a grape. The opening in the center is the pupil.

$n$-The ciliary (hair-like) processes, which are folds or plaits of the choroid coat, reflected from the side of the eye to the edge of the crystalline lens.

o o-The retina, or net-like expansion of the optic nerve, spread over the whole of the choroides as far as the lens.

$p$-The vitreous (glass-like) humor filling the whole of the cavity of the eye behind the lens.

$q$-The aqueous (water-like) humor filling the space between the cornea and the lens.

\section{The Eye's Principal Parts and Their Functions.}

We shall be better able to understand the various diseases of the horse's eye, if we can first get a correct idea of its structure and the 
functions of its different parts. With the help of the foregoing cut, this will not be difficult.

The Eye's Three Coats.-The eye has three distinct membranes, or coats, and also three humors. The sclerotic coat (see $k$ ) is that upon the outside, covering about four-fifths of the globe of the eye. It is strong, firm and inelastic, by which qualities it is admirably adapted to its office of protecting from external injury the delicate organ which it incloses. It is of a white color, and constitutes that membrane which is seen when the "white of the eye" is exposed. In the human being, this is very conspicuous; but in the horse it is rarely visible, unless the animal meditates mischief, when he turns his glance outward or backward as far as he can, and thus shows a little patch of the selerotic coat.

In front-this being the part over which the sclerotica is not extended-is the comea (see $f$ ). This is a perfectly transparent coat, set in like a watch-crystal in its case, under the circular edges of the sclerotica. It is the outer membrane upon the front of the eye.

The choroid coat (see $l$ ) comes next, nearly similar in its extension to the sclerotic. It is an exceedingly fine membrane, filled with a net-work of blood-vessels, and corered upon the inside with a peculiar secretion, a hlack pigment or paint, which absorbs such wandering rays of light received within the eye as might dazzle or confuse the vision. Opposite the pupil (which will he described shortly) it has a beautiful, greenish-white lining, whose reflection, although not visible in the glare of day, may be seen quite plainly in the gray of twilight.

The inner coat of all is the retina ( see o), the beautiful expansion of the optic nerve spread over the internal surface of the eye. This receives the impressions conveyed by the rays of light, which, when they fall upen it, trace on its delicate and susceptible expansion a wonderfully minute yet perfect image of the object in riew from whence the rays have proceeded. By the optic nerve the sensation thus experienced is instantly communicated to the brain, the seat of intelligence, and in this way the animal is conscions of seeing.

Three Humors. - The three humors of the eye are the aqueous and vitreous, and the crystalline lens, which comes between them. Anatomists do not always call the lens a humor, but such it really is.

The aqueus (watery) humor (see q) occupies the spare between the cornea and crystalline lens. It is a perfectly transparent and limpid 
fluid, secreted by the lining of the chamber in which it lies. If the attenuated walls of this chamber are punctured, so that the humor escapes, Nature rapidly renews it, and the sight is restored.

The crystalline lens (see $g$ ) consists of a number of concentric layers, arranged like the coats of an onion. It has a jelly-like consistence, and in shape is double-convex, as represented in the cut. It is the chief agent in so modifying and refracting the rays of light, which are continually proceeding from every object within the range of vision, as to cause those rays to clearly trace the miniature image upon the retina. Without this lens sight would be impossible.

The vitreous (glass-like) humor (see $p p$ ) fills the great bulk of the globe of the eye. It is a limpid fluid, but, being bound up in a network of transparent cells, it has the appearance and consistency of a thin jelly.

The Conjunctiva.-In addition to these three membranes and three humors, there are three other important things to be mentioned in our description of the horse's eye. The first of these is the conjunctiva, which is the very delicate membrane covering the whole front part of the eye and the inside of the eye-lids. It is perfectly transparent when in health, but becomes blood-shot or filmy when inflamed, which it is extremely liable to become.

The Iris.-Another noticeable part which remains to be described is the iris (literally, the rainbow), so called from the beautifully intermingling hues which it displays. The cut, being a sectional view, does not show the iris any further than to imperfectly indicate its location at $m m$. It is a most elegant and delicate curtain, outstreched in the space between the cornea and crystalline lens. Its office is to moderate the light entering the eye, according to the intensity of the rays. This is the membrane that gives color to the eye, so variable in different animals and in the human species. In the horse its color is generally brown, or verging upon it.

The Pupil.-But this curtain is not a continuous one; if it were, the imner chamber of the eye would necessarily be in a state of entire darkness. There is an aperture in the center, forming the pupil, which is the last thing we now have to describe in connection with the eye. The substance of the iris is composed of contractile tissuc. When the glare of a noon-day sun, or other bright light, falls on the retina, the iris contracts, and the pupil is made smaller; but when the light which falls upon the retina is fecble-as it is at twilight, for 
instance-the iris relaxes and the pupil is enlarged, in order that all the rays possible may be admitted. The difference in the size of the pupil may be plainly seen by examining the eye of a sound horse, first in the stable, and then in the bright sunlight. One's own eyes (if a looking-glass be used), or those of a friend, will show similar changes, in this respect, when exposed to different intensities of light.

\section{Physiology of Respiration.}

The important function of respiration is carried on through the lungs and the nasal cavities, and the tubes by which these are brought into communication, with the assistance of the respiratory muscles and the system of respiratory nerves. The physiology of respiration

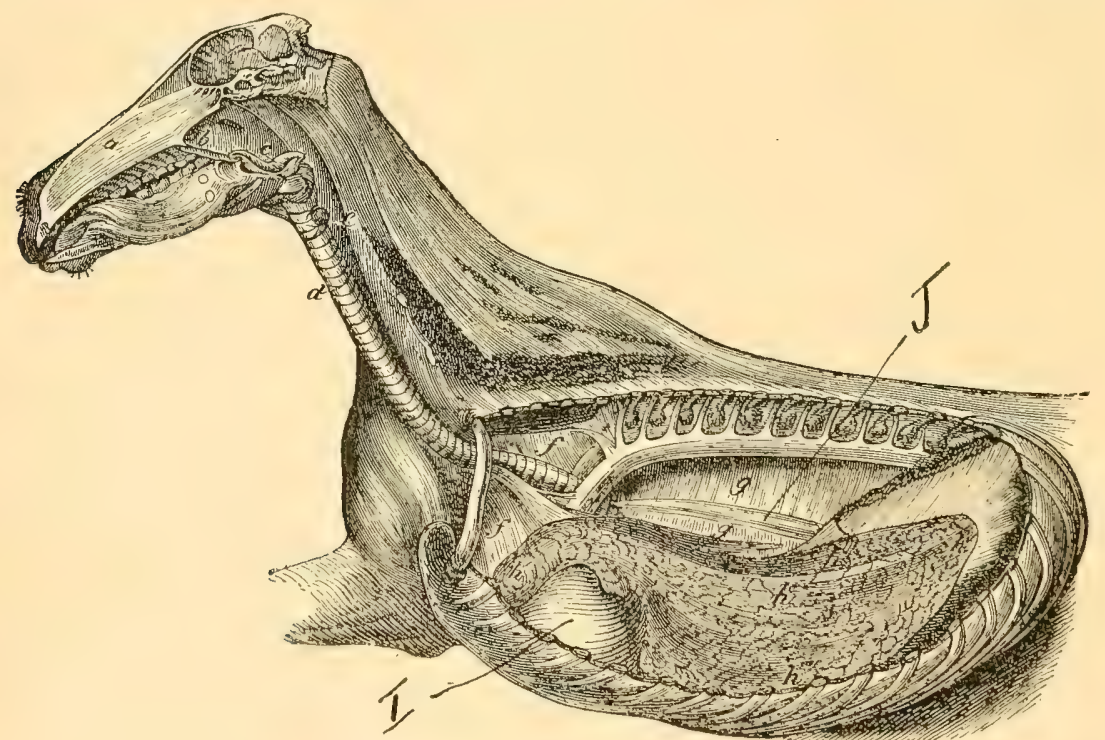

ORGANS OF THE NECK AND CHEST (OPENED ON THE LEFT SIDE).

c-Larynx.

d-Trachea, or wind-pipe.

$h$-Left lung.

I-Heart.

$J$-Esophagus, the passage to the stomach.

we have already explained in connection with the circulation. The lungs operate on the same principle as a pair of bellows. By the action of the respiratory muscles-situated on the thorax and abdomen-the cavity of the chest is expanded, when the air rushes in to 
fill the vacuum. The muscles then contract, and the air, laden with its foul gases, is forcibly expelled. They are under the control of the will, but only for a very short time.

\section{The Iungs.}

The lungs are invested by the pleura, a serous membrane, which is reflected or doubled back upon the walls of the thorax, or chest. They consist of two conical, spongy bodies, called the right and left lobes of the lungs. They are divided from each other by a doubling of the pleura and a space called the mediastinum, which is occupied by the heart, great blood-vessels, nerves, and glands. The right lobe is noticeably the larger; the heart being placed more towards the left, makes that lung smaller. By this arrangement the lungs are better adapted to the form of the chest, and enabled more perfectly to fill it. In consequence of their extremely cellular or porous structure, they are capable of great expansion and contraction during the operation of breathing.

The substance of which the lungs are mainly composed is the pulmonary tissue, termed the parenchyma. This, in the healthful subject, has a beautiful pale-rose color. It is very delicate, yet resists external violence with sufficient strength as not to be easily broken. When minutely examined, it is found to be composed of a countless number of very small, irregularly-shaped compartments, called lobules, each entirely distinct, and all without any communication one with another. What is known as broken wind is occasioned by the rupture of the walls of some of these little compartments. Each lobule receives one of the terminating branches of a bronchial tube, and is again broken up into a cluster of air-cells, resembling a bunch of grapes, on the walls of which the capillary branches of the pulmonary arteries and veins are spread out. The innumerable aircells are lined with a thin, attenuated membrane, through which the blood, in passing through the lungs, appropriates the oxygen, the life-giving principle of the air, and gives off the poisonous carbonic acid gas which the venous circulation has brought back from all parts of the system. Carbonic acid gas is highly destructive to animal life, and is that element which chiefly makes the exhaled breath so peculiarly offensive. 


\section{Other Respiratory Organs.}

Nostrils.-The nasal cavities subserve the purposes of respiration, by modifying the condition of the impure air, so as that it may be taken into the delicate air-cells of the lungs without injury. They warm the air, if it is too cold; they moisten it, if it is too dry. In the horse, the nostrils are remarkable as furnishing the sole means of admitting air to the lungs, such being the formation of his soft palate that breathing through the mouth is impossible; yet he is enabled, by considerable effort, to expel the air through the mouth in the operation of coughing. The nostrils are lined with what anatomists term the Schneiderian membrane, whose appearance, and especially its color, is an invaluable test for detecting the presence, and tracing the course, of fever in the system.

From the nostrils the air passes first into the larynx, or throat; thence into the trachea, or wind-pipe; and, finally, through the bronchial tubes into the lungs.

Larynx.-Besides its services in respiration, the larynx (see 4 and 5 , in cut on page 168) forms the vocal sounds uttred by different animals, as well as those produced by the human voice. In the horse, however, these vocal sounds are few, so that this function is not an important one. The larynx is situated immediately behind and below the nasal cavities. It consists of five strong cartilages, united together by ligaments. One of these cartilages is that remarkable little valve-like appendage called the epiglottis (sce 2, in cut). This somewhat resembles a heart in shape, and is so attached that, when the animal swallows, it shuts downward and backward, so ats to entirely close the opening to the larynx. Thus the food and water, in their parsage to the stomach, are prevented from entering the lungs, but go onward into the osophagus, or gullet (see 10, in eut), after which the elastic muscles of the epiglottis in an instant throw it back to its original position, and the wind-pipe is open again.

Wind-pipe.-Next helow the larynx comes the trachea, or wind-pipe (see 6 , in eut), which is a flexible tube, made up of about fifty incomplete, cartilaginous rings, comected together by a strong, elastic membrane. It terminates in the bronchi, or two bronchial tubes, of which the right is the more capacious, corresponding with the difference in size of this lobe of the lungs. These tubes again divide and subdivide, like the branches of a tree, into lesser tubes, still called bronchial, which tinally open into the air-cells of the lungs. As they 
thus continue to divide, they diminish in size, of course, until at last their diameter is only the one twenty-fifth part of an inch.

We now pass to consider the numerous and highly important organs concerned in digestion.

\section{Gland, Secretion and Excretion Defined.}

"A gland may be defined to be an organ whose office it is to separate from the blood some peculiar substance, which is poured out through an excretory duct, whose internal surface is continuous with the mucous membrane or skin.

"By secretion is understood the process of separation of various matters from the blood, the term being also applied to the products of the process, such as saliva, bile, etc., which are commonly known as secretions. These are all removed from the blood for one of two purposes; first, in order to be employed for some ulterior object in the various processes going on in the body, either for its own preservation or that of others; or, secondly, as being injurious to its welfare, and, therefore, to be discarded."

It has been customary to distinguish this function according as it has for its object one or the other of the purposes above indicated. By this distinction, the term secretion is limited to the former action, while the latter receives the name excretion. These are the senses in which the terms are used in this work.

\section{Glands of the Mouth and Throat.}

The throat is a part of the horse's frame that is plentifully supplied with glands. It has three sets of these, throwing out their secretions of saliva to form the spittle of the mouth. In the horse, although there is comparatively less of this discharge than in the human being, its quantity is surprisingly great, not less than four or five yallons in every twenty-four hours. The principal use of the saliva is to moisten the food during the process of mastication.

The most important of the salivary glands is the parotid. This is placed in the hollow that extends from the root of the ear to the angle of the lower jaw-bone. It is composed of numerous small glands, uniting in one common duct, that discharges its contents into the mouth opposite the third upper molar tooth. The quantity of fluid secreted by the parotid gland alone is estimated to be not Iess than one pint per hour, and, during mastication, nearly twice as much. It is generally affected in all throat diseases, and in distemper is nearly always found swollen, hot, and tender. 
Occupying the space between the two bones of the under-jaw, is found the set of submaxillary glands, which also empty through one common channel into the mouth, at the roots of the tongue, and a short distance from the front teeth. In severe colds, the submaxillary gland often enlarges, the little kernels of which it is made up swelling so as to be distinctly felt when pressed upon by the hand.

The sublingual gland is the smallest of the three. It is situated between the middle of the tongue and the lower jaw, and opens into the same part of the mouth as the submaxillary, by a number of minute orifices under the tongue, whose terminations resemble little folds of skin, or tiny bladders. Thewe sometimes become inflamed, and then have the appearance of little sores, or ulcers. This is soon corrected by the efforts of Nature alone, in nearly all cases; but, if it should be thought best to attempt any treatment, the horse's mouth may be washed with the solution of golden seal, or chlorate of potash.

Besides these glands there are smaller ones in every part of the mouth, the checks, the tongue, the lips, and several other portions of the throat. They all pour out secretions, which enter into the composition of the saliva.

\section{The Gullet and Digestive Apparatus.}

Although concerned in digestion simply as the passage from the mouth to the stomach, the oesophagus, or gullet, will be appropriately considered in connection with the digestive apparatus. It is a fumncllike tube, or bag, of muscular structure, and is lined with mucous membrane, the same in general character as that which is spread over the inside of the mouth and nose. It extends from the pharynxwhich is simply a contimuation of the extreme back part of the mouth -to the stomach, in its course traversing the whole length of the chest, and passing through an opening in the diaphragm, or midriff. It is, at first, placed behind the laryux, and with reference to the trachea is situated to the left.

The digestive organs of the horse are so important, as regards both their aggregate size and their functions, and are so extremely liable to sudden and severe attacks of discase, that crery farmer and horseman should be at especial pains to get a correct notion of their strueture, and the oflices which ther severally perform. The reader of this work will derive material assistance in fixing its descriptions in his mind hy carefully studying our illustrations. To aid him in this we shall frequently refer him thereto. 
The stomach of the horse is very small, when compared with the great bulk of his entire body, or with the relative size of the same organ in man. Its average capacity is about three gallons; while the stomach of man, whose weight is hardly one-eighth of that of the horse, contains frequently three quarts. As the regetable diet, however, upon which the horse subsists, yields a smaller proportion of nutritive matter than animal food, and that proportion with greater difficulty, it is necessary that the animal should be provided with a digestive apparatus of greater extent and perfect efficiency. What seems to be wanting in the stomach of the horse, we accordingly find made up in the formation of the intestines, which are long, large, and complicated. We will consider them presently.

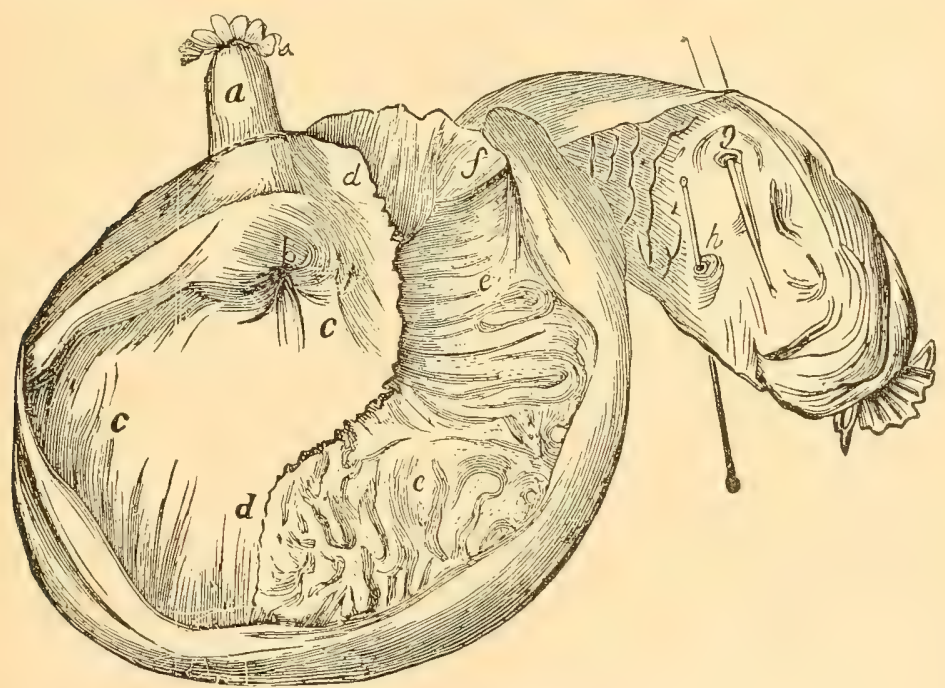

THE HORSE'S STOMACH, AS IT APPEARS UPON DISSECTION.

$a$-The œesophagus, or gullet, extending to the stomach.

b-The entrance of the gullet into the stomach. The circular layers of the muscles are very thick and strong, and, by their contractions, help to render it difficult for the food to be returned or vomited.

c c-The portion of the stomach which is covered by cuticle, or insensible skin.

d d-The margin, which separates the euticular from the villons portion.

$e$-The mucous or villous (velvet) portion of the stomach, in which the food is principally digested.

$f$-The communication between the stomach and the first intestine.

$g$-The common orifice through which the bile and the secretion from the pancreas pass into the first intestine. 'The two pins mark the two tubes here united.

$h$-A smaller orifice, through which a portion of the secretion of the pancreas enters the intestines. 


\section{The Stomach.}

Two openings and two lining coats form the features one would be most likely to notice first in examining the stomach. The upper opening is the connection with the osophagus. It is called the cardiac orifice, and in the cut of the stomach is shown at $b$. The cosophagus enters the stomach in a somewhat curved direction. It runs obliquely through the muscular and cuticular coats for some distance, and then its fibers arrange themselves around the opening into the stomach. Close observation has shown that they arrange themselves into segments of circles, interlacing each other, and, by their contraction, plainly and forcibly closing the opening, so that regurgitation of the food (vomiting) is almost impossible.

The other opening is that which communicates with the intestines. It is called the pylorus (literally, door-keepers), or pyloric orifice. In the cut it is imperfectly represented at $f$. At the lower, or pyloric orifice, the muscles are also increased in number and in size. These are arranged in the same manner as around the cardiac orifice, and are continuous with those of the intestines, with sufficient power to retain the contents of the stomach until they have undergone the digestive process.

Similar names have been given the two parts-the cardiac and pyloric. The division of the stomach into these two parts is not uniformly marked in different horses, but is generally indicated, more or less plainly, by a constriction. It is shown in the cut by $d d$, the jagged and heavily shaded line between $c c$ and $e e$. The cardiac part is simply a space for the food, while the pyloric is the real digestive stomach.

The Stomach's Three Coatings.-The stomach is composed of three coatings. The outer coat is a serous membrane, and simply a continuation of the peritoneum, which lines the entire abdominal cavity. Next to this is the muscular, or middle coating, consisting of three sets of fibers crosing each other transversely and oblicuely, which give to it a considerable power of contration and expansion. By this means a gentle vibratory motion is imparted to the stomach, and all its contents are properly mingled together and carried forwark. The internal coating is not the same in the two parts of the stomach. In the cardiac sac it is commonly called the cuticular (skin-like), or insensible coating (see c c, in cut); in the pyloric, the mucous or villous (velvet) coating (see $e e$ ). 
The cuticular lining is a continuation of that of the œsophagus. It is whitish brown in color, tough, and comparatively dry. It covers only about one-third of the internal area of the stomach-in the upper part, of course, next the gullet. In structure it is web-like, with a somewhat loose attachment to the muscular membrane, from which it may be easily separated after death. When washed and cleaned, it has the appearance of gauze, or fine net-work. The villous coating of the stomach is of a brownish red, marbled with lighter tints of the same color, and possesses a delicate texture, so as to be easily torn; yet it has an exceedingly limited degree of sensibility, since, were it otherwise, many common articles of the horse's food could not be digested without great pain.

Gastric Fluid and Chyme.-Numerous little capillary tubes have their outlet upon the villous membrane, and pour out a peculiar secretion, which continues the softening process already begun in the mouth by the saliva. This is the gastric fluid. It acts not only as a solvent, but also contributes other materials-especially what is called pepsin-that greatly facilitate digestion. By these agencies the food is converted into the substance called chyme, which passes out through the pylorus into the intestines, there to be still further digested, its nutritive particles taken up and transferred to the general circulation, and its waste matter duly voided.

\section{The Intestines.}

The intestines, to which we have now come in the natural progress of our descriptions, constitute a lollow tube, with many windings and convolutions, nearly ninety feet long in an average-sized horse. In diameter the tube varies exceedingly at different parts. The intestines have three coatings-the same, indeed, as the stomach, with only this difference, that they nowhere exhibit the cuticular lining. These membranes, however, are not precisely identical in their several arrangements and uses throughout their entire length.

The muscular coating of the intestines is composed of two sets of fibers, crossing each other at right angles, and each rumning the full length of the bowels. In certain intestinal diseases of the horse it is subject to fearful contractions, producing what are called strictures. In the mucous or internal membrane are seated myriads of little capillary vessels, which have their mouths in little papille upon its surface, and are constantly taking up the nutritive extracts of the digested food and conveying them into the blood. The point of the 
finest needle could not be put down anywhere upon the mucous surface on which these vessels are distributed without resting upon one or more of these little mouths. From the effects of severe ill-usage, as well as of certain diseases, these absorbents sometimes cease to act. Should they remain inactive, the horse, with his supply of nutrition thus cut off, is soon reduced to a famishing condition.

Only two natural divisions are found in the alimentary canal. These are the large and small intestines. Anatomists, however, have divided each of these parts into three sections. This subdivision is particularly arbitrary in regard to the small intestines, between whose three sections it is impossible to discover any defined boundary lines. Hence in the cut of these organs we have not attempted to index the

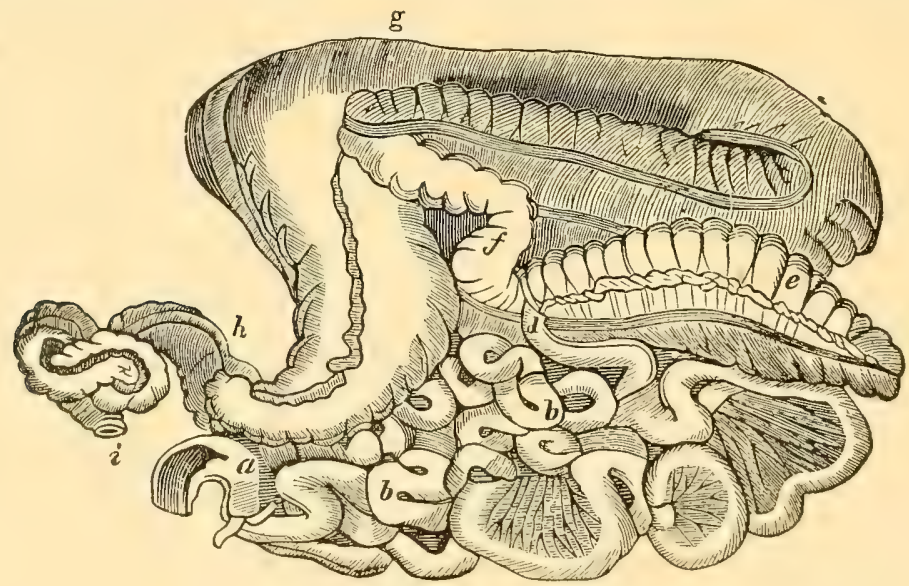

THE INTESTINES OF THE HORSE.

a-The commencement of the small intestines. The biliary and pancreatic ducts may be seen a little below.

$b \quad b$-The convolutions $0 r^{\circ}$ windings of the small intestines.

c-A portion of the mesentery, a fold of serous membrane, which hangs over the greater part of the intestines, and is thickly inlaid with fat, designed to protect the included organs from cold and violence, and to facilitate their movements.

d-The small intestines, terminating in the crecum.

$e$-'The crecum, or blind gut, with the bands running along it, puckering and dividing it into numerous sections.

$f$-The beginning of the colon.

") "/-The continuation and expansion of the colon, divided, like the cacum, into sections.

$h$-The termination of the colon in the rectum.

$i$-The termination of the rectum at the anus. 
different portions of the small bowels. Their continuous series of convolutions, however, are represented very naturally at $b b$.

Small Intestines.-The small intestines occupy rather more than two-thirds of the whole length of the alimentary duct, being between sixty and seventy feet in length. From their comparatively small diameter, however, they will contain only a little more than one-half as much as the large bowels. When fully expanded, they will hold about eleven gallons; the others about nineteen. Adding to these amounts the three gallons which represent the measure of the stomach, and we find that the entire capacity of the digestive tube is the enormous aggregate of thirty-three gallons.

The three sections into which anatomists divide the small intestines have received the names of the duodenum, jejunum, and ileum. Duodenum is a Latin word, signifying twelve. It is thus applied, because this part of the bowels in man is about twelve inches long. In the horse, however, its length is about twenty-two inches. It extends from the pyloric orifice of the stomach to the entrance of the biliary and pancreatic ducts. (See $\alpha$, in cut.) The jejunum-from the word jejune, meaning empty-is so called because it is nearly always found quite empty after the animal's death. This is in consequence of the great rapidity with which the food passes through it. It is of smaller diameter than the duodenum, and floats more loosely in the abdomen. Last of the small intestines comes the iteum, whose walls are more muscular and thicker than those of the jejunum.

Large Intestines.-The ileum terminates in the cacum, or blind gut, the first of the large intestines. Its entrance is not into the end of this, as would naturally be expected, but near the head, or outlet, as shown in the cut, where the cacum appears prominently at $e$. It follows, from this arrangement, that the food which passes into this blind pouch must twice traverse its whole length, on its return from the closed end of the pouch passing directly by the mouth of the ileum, where it is prevented from re-entering by a peculiar valve. In the crecum, as is supposed, the larger proportion of the process of absorbing the nutritive elements of chyle is conducted. Nearly all the water which the horse swallows passes at once into this gut, without any delay in the stomach and small intestines.

The cæeum is connected with the next intestine, the colon (see $f$ $g g$, in cut), by a considerably larger neck thim with the small intestine. The colon is very large, and occupies two-fifths of the abdom- 
inal carity. It is generally found filled with the alimentary substances. Its contents are made up of the coarser parts of the food, and become hard and solid. Being deprived of nearly all its moisture and nutrition, the food reaches the tapering portion of the colon, which is divided into sections, or compartments, by a number of circular bands surrounding and puckering it. By these the freces is separated into balls, upon which they contract, their absorbents extracting the last remaining nutrition, when, by a further contraction, each ball is forced onward to the rectum, whence it is discharged.

Terminating in the anus (see $i$, in cut), is the next and last intestine, the rectum (see $h$, in cut). Its name signifies straight, which it much more nearly is than the other bowels. It is much shorter than the colon, with less than one-fourth the capacity. As no portion of digestion remains to be carried on here, its mucous lining is not exactly the same as in the other parts of the intestines, and is entirely destitute of capillary absorbents. The rectum forms a capacious reservoir for the excrement until evacuated. This is retained in its place by the curious circular muscle at the anus, called the sphincter muscle, until the horse, by a voluntary effort, expels it. By these means is prevented a constant and disagrecable dropping of the freces.

The Mesentery.-A doubling of the peritonem, called the mesentery (see $c$, in cut), forms the means by which the intestines are chiefly retained in their relative positions. It includes within its folds all the intestines, extending along their entire length. It is furnished with a large artery and a laroe vein-each called the mesenteric-and is everywhere filled with innumerable small vessels, that supply the howels with blood, and others which conver the extracted nutriment from the intestines to the general cireulation.

The Caul.-The omentum, or caul (not shown in cut), is a twice doubled fold of the peritoneum, thus consisting of four layers of it, which are placed between the intestines and the sides of the belly. By some it has been supposed to answer the purpose of a soft padding, to relieve the violent concussions and prevent the injuries which rapid motion would be likely to produce. It is unusually short in the horse.

\section{The Liver.}

In the horse the liver undoubtedly performs the same offices as in the human being; but these are involred in much obscurity. It secretes the bile from the renous blood (supplied to it by the portal 
circulation), which, if retained therein, would poison the whole system; but which, when mingled with the chyme, is of the highest service in the operations of digestion. It is by far the largest gland in the whole body.

The liver is situated in close contact with the back of the diaphragm, and is divided into three lobes, with a color peculiar to itself. Its structure is also most peculiar. The bile is said to be secreted from little capsules which are innumerable, and act in the same way as a filter. In most animals the bile is stored away in a reservoir, called the gall-bladder, to be used as occasion may require; but the horse has no gall-bladder, so that the bile, as fast as it is formed, flows directly into the small intestines. These it enters through the hepatic or biliary duct, a few inches below the pyloric orifice. (See $a$, in cut of the intestines.) It is of the greatest importance in the work of digestion, sin, by the aid of certain peculiar properties which it possesses, it keeps the bowels regular in their action. The whole system suffers if its secretion and flow are interrupted or retarded. Should they cease altogether, not only would the blood be poisoned by its retention, but the animal would presently starve for want of nourishment.

This organ is much less subject to disease in the horse than in the other domestic animals, or in man. It is occasionally the seat of inflammation and some other affections, whose symptoms, however, are always obscure. Sometimes, where its functions are deranged, a condition is produced much resembling that of jaundice in the human being. This may be detected, without difficulty, by the yellow, pale color of the membrane lining the nose, and of the lips, the month, the tongue, and especially by the jaundiced appearance of the eyes.

\section{The Pancreas, or Sweet-bread.}

The pancreas is a gland placed between the stomach and the left kidney, being what is commonly called the sweet-bread. It secretes the pancreatic fluid which flows through its own duct into the small intestines through a valvular opening common to the hepatic and pancreatic ducts. (See $g$, in cut of the stomach.) In its uses, the pancreatic fluid is of very great importance to digestion, changing fats to a more easily digested form; it also has important actions on meaty substances, and changes into sugar any starches which the saliva has failed to change. This fluid contains a large proportion of albumen and some alkalies. 


\section{The Spleen, or Milt.}

This organ has no excretory duct, and hence is called a ductless gland. It lies along the left side of the stomach, to which it adheres very closely. It is long; at one end broad and thick, and at the other tapering almost to a point. In color it is of a bluish-brown. It has a spongy consistency, being composed of numerous cells, over which are spread thousands of minute vessels. Physiologists were long unable to positively demonstrate the uses of this organ. It was believed, however, "to perform the office of a reservoir for the blood required by the stomach, with which it is closely connected by a set of vessels, and also to effect some change in the blood itself." But it is now admitted to be the place where the white corpuscles of the blood are made; the red corpuscles, it is thought, are here tested, and, if weak, are destroyed.

\section{The Urinary Organs.}

These embrace the kidneys and the bladder, with the different ducts and passages that are connected with them. They are well shown in the next two engravings, those of the generative organs.

Kidneys. - The kidneys secrete the urine. They are two glindular organs, whose function it is to rid the system of the element called urea, which is that principal constituent of the urine that, if not excreted, would act as a deadly poison in the hood. In the horse they are of immense size, and are situated under the loins, the right kidney lying under the liver, and somewhat forward of the left, which is placed back of the stomach. Each of them is supplied with a large artery, which furnishes blood not only to the kidneys themselves, but likewise to all the urinary organs. Like all other glands, the kidneys abound in minute capillary vessels, where the functions of excretion are carried on. This, like the excretion of the bile from the liver, is also a sort of filtering action; the blood-drop passing through a little sack leaves the urine in a separate tube, whence it gradually passes to the bladder. The amount as well as the quality of the urine which they secrete varies greatly, at different times, in all animals, but in the horse more, perhaps, than in any other. As fast as it is collected in the kidneys, the urine passes down to the badder through the long excretory ducts called the ureters, of which there is one for each kidney. 
Bladder and Urethra.--The bladder is the oval, membranous bag, which serves as a reservoir for the urine. Here it accumulates, until its quantity begins to occasion inconvenience, when the animal, by a voluntary effort, expels it. Thus the great annoyance of a constant dribbling is prevented. The bladder has three coatings. The outer one is an extension of the peritoneum, but covering only a part of the bladder. Next to this, and upon the outside of the bladder for a great part of the latter's surface, is the muscular coating, composed of two sets of muscles, crossing each other transversely, as in the intestines. The internal coating is the mucous membrane, which lines

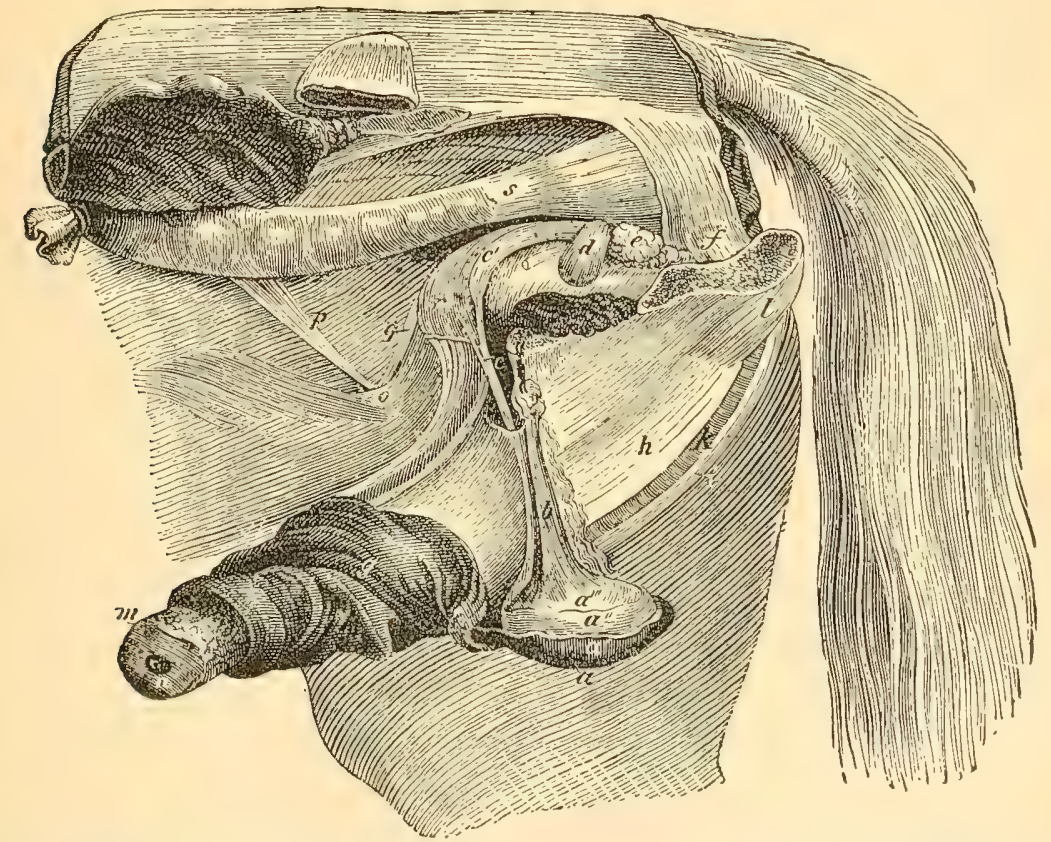

MALE GENERATIVE ORGANS (THE ABDOMEN AND PELVIS OPENED ON THE LEFT SIDE).

$a$-Testicle and its coverings.

$c$-Left vas deferens.

d-Left vesicula seminalis.

$e$-Prostate gland.

$g$-Sheath.

$h$-Penis, with cavernous tissue.

$k$-Urethra, the canal for the urine.

$n$-Opening of the urethra.

$r$-Bladder.

s-Rectum. 
all the hollow viscera. The urethra has its origin at the neck of the bladder. It is the canal which carries off the urine. Its orifice can be entirely closed, at the horse's pleasure, by the contraction of the porverful muscle which surrounds the neck of the bladder, and which is called the sphincter of the bladder.

We will now give a short description of the organs of generation in the horse and mare, together with two illustrations, designed to make this very important portion of the anatomy as plain and concise as possible.

\section{Male Generative Organs.}

The esscntial organs of the male, the two testicles or seeds, in the fœtus are found in the belly behind the kidneys, whence before birth they descend into the scrotum or bag, carrying with them the different membranes already spoken of as lining the abdominal cavity and covering the bowels. These coverings contain the vessels and nerves, and help to support the testicles. The latter are two glands divided into a great many little compartments, each having a duct to carry away the spermatozoa. These ducts join together to form the epididymis or duct from the gland, which may be seen as a ridge on the upper part of the testicle. This duct carries the sperm to a reservoir on the back part of the bladder, where it remains until nature calls for it.

The penis, the organ of copulation, is perforated by the canal for the sperm. This camal also serves for the passage of the water, but separates into two above the bladder. The penis is composed of a peculiar erectile tirsue, which is something like a sponge in its capability of being greatly dilated, and contains elastic tissue in its walls. During excitement the blood flows into this spongy tissue, which causes enlargement and rigidity, or, in other words, the condition of erection. After excitement has subsided, the blood is removed by the veins. The penis is suspended from the bones below the anal opening, and is supported by the sheath.

The spermatozoa are the secretion of the male glands, mixed with a whitish, viscous fluid. They are so small as to be visible only under the microscope. They have an oval head and long, wavy tail, and possess the power of moving to a certain extent; when in contact with the female orum, or egg, they pierce and fertilize it.

\section{Generative Organs of the Mare.}

The female organs are the ovaries, or the essential organs, the uterus, or womb, in which the fortus lies: the vagina, a cavity com- 
mon to the urinary and generative organs; and, lastly, the vulva, or lips, externally. The ovaries have a function analogous to the testicles in the male, but are of smaller size, and suspended by ligaments in the abdominal cavity, a little behind the kidneys. It is in the ovary that the ovum, or female egg, is formed, paising thence to the uterus, mixed with a secretion which lubricates the way. This egg is a very minute thing, only measuring 1-150 of an inch across. In structure it somewhat resembles the yolk of a hen's egg. Pierced by

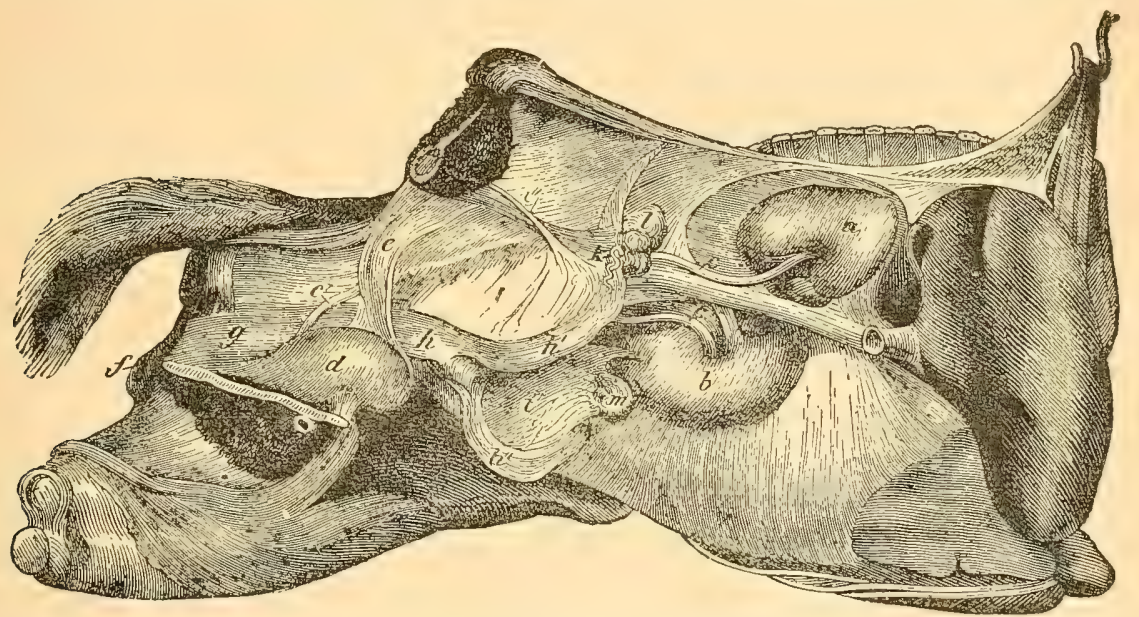

GENERATIVE ORGANS OF THE MATE (OPENED ON THE RIGHT SIDE).

$a b$-Right and left kidney.

c-Ureters to bladder.

$c^{1}$-The ureter entering the bladder.

d-Bladder.

$f$-Lips of the vulva.

g-Vagina.

$h$-Body of uterus.

k-Fallopian tubes.

$l m$-Right and left ovaries.

the male sperm, it commences to grow, receiving its nourishment from the part in which it settles, normally the uterus.

The uterus, or womb, is a muscular organ lined by a mucous membrane, and placed between the rectum above and the bladder and intestines below. It is made up of two horns with the ovaries on the end, a body in which the fœtus grows, and a neck of thick, round and hard tissue closing and separating this part from the next, into which it projects in the virgin animal. The vagina, which is the 
chief organ in contact with the stud, is of muscle and membrane internally. The opening of the bladder is on the floor of this space about three inches in from the external lips. The vulva, or lips, complete externally the organs of the urinary and generative systems. It is constituted of muscle, lined internally by membrane, while externally is a soft covering of skin. In young animals there is usually some fat here, making the lips more prominent than during old age. The space between the upper border of the lip and the anal opening is the perineum. In "gill-flirted" mares this space is ruptured. The hymen is a thin band of membrane found in the virgin animal just back of the urinary opening. The clitoris which can be seen just within the lips on the floor of the vagnia, is of spongy tissue similar to the male penis, and undergoes erection when sexually excited.

Mammary Glands.-Closely allied to the generative organs, though distinct from them, are the mammary glands, whose office is to secrete milk for the nourishment of the young. In the mare there are two of these, placed side by side between the thighs. Their structure is like that of glands in general, being composed of innumerable cells capable of secreting the milky fluid, which is thence carried by canals to a large central space in the gland or teat, where it may be retained for a moderate length of time without inconvenience. Passing by a number of small canals to the free extremity of the teat (the nipple), it is there freed. 


\section{CHAPTER XIV.}

\section{THE FROCESS AND EFFECTS OF INFLAMMATION.}

I. CONCERNING INFLAMMATION IN GENERAL.—-II. CAUSES OF INFLAMMATION. -III. THE SYMPTOMS OF INFLAMMATION,—IV. TERMINATION BY RESOLUTION.- V. EFFUSION AND SUPPURATION.-VI. ABSCESSES.- VII. ULCERATION.-VIII. INTERSTITIAL DEPOSITS.—IX. MORTIFICATION OR GANGRENE.- $\mathrm{X}$. TREATMENT OF LOCAL INFLAMMATION.— XI. BLISTERS. -XII. TREATMENT OF GENERAL INFLAMMATION.—XII. BLEEDING.

\section{Concerning Inflammation in General.}

In entering upon this subject, it should be remembered that the majority of diseases are, more or less, of an inflammatory nattre; whence it follows that a correct knowledge of the inflammatory process is essential to the proper study of disease in general. Every structure of the body which is supplied with blood-vessels and nerves is subject to inflammatory disease, and whether it be in the bones, muscles, tendons, lungs, nerves, or whatever other important organ, the inflammatory process in all answers to the same general description, and in each the sequence is precisely similar.

Kinds Defined - Inflammation, as regards its location, is of two kinds, namely: 1st, local, and 2d, general or diffuse. In the first we recognize the action as being confined to the vessels at one particular part, and that a small one, of the animal's body; the second is understood to comprise acute febrile action, the result of inflammation in large and important organs, as the lungs, bowels, womb, etc., and including, of course, the diseased process within those organs. As to character, inflammation is regarded under the other two heads of acute and chronic. In the former the tendency is to progress with great activity or vigor; the nature of the soft parts of the body, as muscle, etc., from their elaborate organization, being highly favorable to the process. Chronic inflammation, on the other hand, is slow and tardy, eventuating in much destruction of tissue, while at the same time reparation of the parts is attended with difficulty, or sometimes totally impossible. 


\section{Causes of Inflammation.}

As inflammation involves so many different organs and parts of the body, and in many cases parts that are very remote from each other, it is to be expected that a great variety of different causes may be concerned in its origin. For the sake of clearness, it will be convenient to distinguish three classes of causes: 1 st, mechanical; 2 d, chemical, and $3 \mathrm{~d}$, vital. Under the first named are included blows, friction, pressure, cuts, tears, bruises, etc., all of which destroy or disturb the nervous power of the part, and by its withdrawal living tissues become as dead animal matter, the blood in these cases often circulating in the part no longer. The next class, chemical agents,strong acids, caustics generally, the hot iron, etc.-likewise destroy the part, and the same results are brought about. Again, under the more complex causes termed vital, we must recognize the same effects, namely, a withdrawal of the controlling and harmonizing nervous power, with more or less disorder of other organs or functions. Long continued cold depresses and destroys the tone of nervous power; poisons generally do the same; and the lack of pure air for respiration brings about a long train of diseased conditions.

Life may be viewed as a collection of harmonious functions working with and for each other. Every agency which destroys or temporarily interferes with that harmony, at the same time calls forth a warning proportionate to the extent and power of its own baneful influence. The most common result is local inflammation, which may, perhaps, be slight, or, on the other hand, so extensive that the whole of the vital functions become fatally impaired, and life is finally extinguished. In both cases-the mild and the severe--there is established a diseased process which is essentially the same, differing only in the extent and operation of the disturbance.

\section{The Symptoms of Inflammation.}

The physical signs of inflammation are four: heat, pain, redness, and swelling. The redness is generally less easily seen in animals than in man, on account of the thick covering of hair, though even if this were removed the dark pigment of the skin would still suffice to conceal it in most animals.

Heat.-Of the various signs indicating the presence of inflammation, probably none is so remalkable as heat, that is, the increased animal temperature. Whether the morbid action is confined to a 
small space or has become general (as in most cases it does become), an elevation of temperature in the affected part is the inevitable result. The source of increased heat in these cases is exactly the same as under healthful conditions of the system, the process being accelerated, gencrally, by wide spread influence on the assimilative functions, through the nervous system, and locally by the same process upon the circulation of the part affected. Then comes about increased blood formation, increased quantity of blood in the part, and as a result increased combustion, or production of animal heat. During the existence of inflammatory action, of whatever kind or character, the thermometer proves a safe guide as to the intensity,

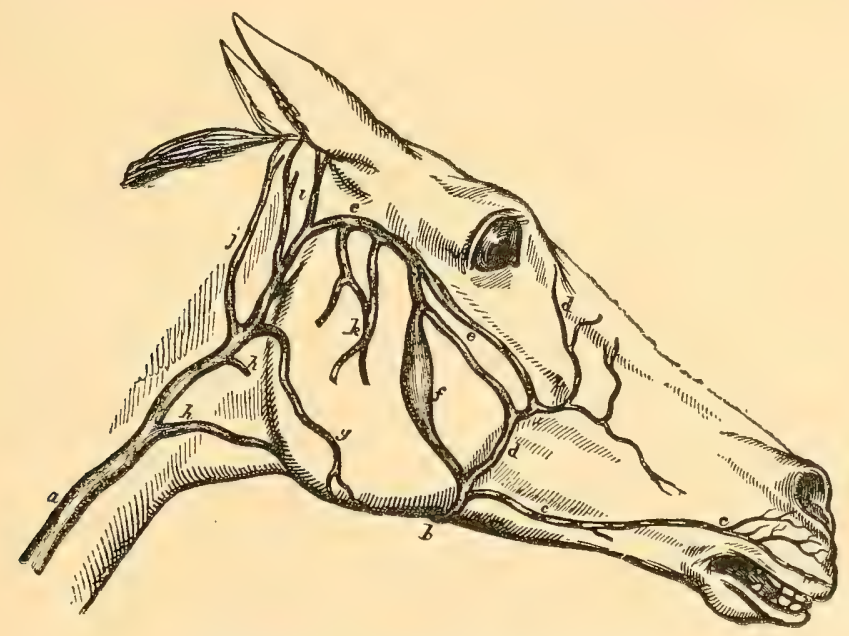

VEINS OF THE NECK AND FACE.

To illustrate Bleeding (page 202). The jugular vein is shown at $\boldsymbol{c}_{\text {. }}$

rise or decline, which is demonstrated by placing it on the part, if externally situated, or within the rectum when general. If no thermometer is obtainable, the sensation of heat, as conveyed to the hand, will give a fair idea of the temperature, the hand being placed upon the part, or, in case of general inflammation, by feeling the ears, legs and mouth.

Pain.-This symptom is the result of pressure, consequent upon the increased quantity of blood in the part. The blood-vessels are distended, and the nerves, already acutely sensitive through influences of a morbid character, perform their office under greater pressure and irritation. The sensation of an inflamed part is doubly acute, as is 
evident upon the slighest touch in some animals, and so it continues to the end of the morbid process. Coarse-bred animals exhibit this in a less degree than high-strung, nervous ones.

Redness.-For the reasons already mentioned, this is less conspicuous in the horse, as in nearly all animals, than in man. Nevertheless, in the case of general inflammation, the visible mucous membranes exhibit this characteristic to the fullest extent, revealing with a good degree of accuracy what is going on within. The redness here spoken of is the redness which the blood exhibits when viewed in man. During the distension of blood-vessels from inflammation, the increased quantity of the vital fluid coursing through them is plainly visible through the walls, which have now become attenuated (thin) through internal pressure and stretching. The redness characteristic of inflammation is due, then, to the color of the blood as seen through the semi-transparent membranes constituting the affected tissues.

Swelling.-This is not always observed. When internal organs are affected, it is impossible that it should be, except under rare conditions; and eren when it exists to a considerable degree locally, it may be altogether hidden by the nature of the part affected, or by the covering it possesses. Thus, when a ligament, tendon or bone, is involved, swelling is often not observed at the time. So also, though the feet are suffering intensely from inflammation, the encasing hoofs effectually bind down and hide everything from view. Whenever it can be detected, swelling is a sign ummistakable, furnishing evidence of a reliable character. The swelling of inflammation is due to a congestion of the blood in the discased part. Some of the fluid portions of the blood, leaving the ressels, pereolate through the tissues, and the blood still pressing from behind produces the swelling.

\section{Termination by Resolution.}

The result of continued severe inflammation are effusion, suppuration, ulceration, interstitial deposits, and mortification or gangrene. But first we will consider its natural or healthful termination by what is termed resolution. This is said to occur when the symptoms subside, and the parts resume their normal functions, which may occur suddenty or gradually, though oreasionally the trouble re-appears in another part. Resolution is effected in two different ways. The first is by the remoral of the irritant that cansed the inflammation, and while the part is still soft, the reins and lymphatices carrying off the exudation. The second occurs when the process has gone a step 
further, and the exudation turned to a low form of fibrous tissue, which ultimately breaks down, and is remored in the same manner as in the first.

\section{Effusion and Suppuration.}

That result of inflammatory action known to medical science as effusion is seen as an accumulation of fluid in different parts of the body-for example, water in the chest, dropsy of the abdomen, etc. Suppuration is a common result of the conditions we have been considering, when the irritation is more intense than in the lighter forms, its action at the same time being generally prolonged. It is a frequent termination also of the other forms. Suppuration may be either acute or chronic, and in either case appear either as a circumseribed abscess, or in a more diffused form in the substance of a part, or on a free surface. It is Nature's own "heroic" way of getting rid of some deleterious substance or matter that its ordinary processes are unable to cope with.

Grooved Director.-The simple instrument so called is shown in the annexed cut. Its use is to insert in a sinus, as of an abscess,

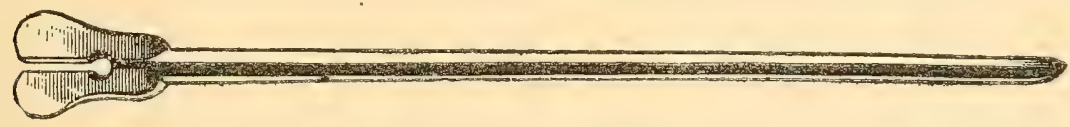

GROOVED DIRECTOR.

fistula, etc., and guide the point of the knife in cutting open. This it does by means of the groove in the center (indicated by the dark line) running its entire length.

\section{Abscesses.}

A circumscribed collection of pus in any part of the body is termed an abscess. This is the product of an inflammatory process, due to the presence of a minute organism, called a "cocci." Abscesses are of two kinds, namely, acute, and chronic or "cold."

Acute Abscess.-This is the more common kind. It is invariably preceded by constitutional signs of inflammatory ferer (generally including in man a distinctly marked "rigor" or chill), and is aceonpanied by the usual local phenomena of heat, pain, swelling, ete. As it continues to develop, these local symptoms increase. The swelling shows a tendeney to localize; a soft, and possibly a tender, spot shows itself, the covering of the skin becoming thin and weak at the most susceptible part. The abscess is now coming to a "point," and pres- 
ently, through the gradual thinning of its covering, it discharges or "bursts." After the pus is gotten rid of, the cavity either heals or contracts into a narrow canal, called, in technical language, a fistula. When the pus is deep-seated and bound down by strong ligaments, tissues, etc., it may "burrow" a great distance from the original seat of the disease, usually, of course, in the direction where it encounters the least resistance.

Chronic or Cold Abscess.-Cold abscesses form very slowly, and give rise to few symptoms, outside of the swelling. In the horse they are of most frequent occurrence on the front of the shoulder, and next in frequence along the chest and belly. In some cases the pus may be absorbed, the vessels removing the fluids, and the remaining cells withering away, or even the entire collection mily be removed, restoring the part to its natural functions. This, however,

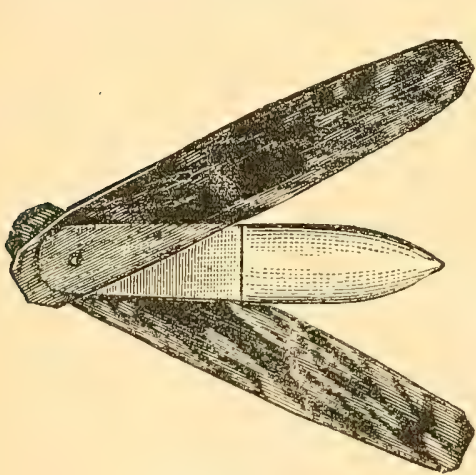

ABSCESS 1.ANCW.

is not the common procedure; usually a chronic abscess, no less than an acute, calls for skillful treatment.

Treatment.-In treating an abscess, it is first necessary to bring it to a head by poultices or a blister. Our Absorbent Blister No. 11 will be found excellent for this purpose. After coming to a point, it should be opened in such a way as to allow of free drainage, which is done by puncturing the most dependent part in which any fluctuation can be felt. The secondary treatment will consist in nsing the following Antiseptic Lotion No. 1, and preventing the opening from closing until it has healed thoroughly within.

No. 1 .

Carbolic acid, 1 part.

Pure water, 40 parts.

Mix, and wash two or three times a day.

When a fistulous opening is discovered, it will be necessary to ascertain if any dead bone, or other irritating substance, is at the bottom of the cavity, and if there is, to at once remove it, which will allow the healing procens to proceed. The injection of the following solution, which may easily be accomplished with a glass syringe, will close these canals:

No. 2.

Corrosive sublimate, 1 part.

Alcohol,

$S$ parts.

Mix, and inject a little every three-days. 


\section{Ulceration.}

At times, owing to low condition of the body, or of an organ, there is left, after the abscess has burst, a slow-healing, unhealthy sore. This is called an ulcer, which is really neither more nor less than the death of a part in small particles. Treatment will consist in remoring the cause, freely scraping all diseased parts away, and using powdered naphthaline, dusting it on the wound once or twice daily. In some cases, where the ulcers heal slowly, it is necessary to touch the edges with caustic, to stimulate their growth.

\section{Interstitial Deposits.}

If the distension of the blood-ressels in the inflammatory process is great, the albuminous portions of the blood may pass out through their coats, and fibrin be formed in the cells of the tissue. The material so generated is known as lymph. Its more fluid parts are soon absorbed, and the lymph then becomes firm and solid. Lymph, when the result of a weak inflammation, has a tendency to become rapidly organized, and take a permanent place among the living structures of the body. None of the other fluids derived from the blood under such circumstances are capable of this change. This, in the wise provision of Nature, is the material by which wounds are repaired, broken bones joined, and new parts of the body built up. But while, in some cases, lymph is most useful as a means of repair, in others it may be formed in structures where, from its adhesive qualities, it becomes a source of great mischief, as in the lungs and its covering, and many other parts; or, again, it may be deposited in excess of the quantity required for repair, and in this way, when consolidated, may work unsightliness and real injury, producing such enlargements of parts as are well known to all.

\section{Norification or Gangrene.}

This differs from ulceration thus: in ulceration the tissue dies in small pieces, while in mortification a large part is involved. It ensues upon a stoppage of the circulation going to or coming from the injured part, and unless the dead tissue is promptly removed, there is great danger of blood poisoning. This is the danger which, in medical practice, so often prompts the physician to lose no time in resorting to surgery, whenever the part affected admits of amputation. 


\section{Treatment of Local Inflammation.}

The treatment of inflammation is only secondary, the first thing being the removal of the cause. We will first describe the proper treatment for local inflammation.

As this is generally due to the presence of some irritant or other, that should be sought for and removed as quickly as possible. In the acute stages, the various lotions to cool and relieve pain are first indicated. After using these, the part may be supported by a bandage, if the legs are the parts affected. The following are soothing and cooling lotions of approved excellence:

No. 3.

No. 4.
Tincture of opium, 1 ounce.

Sugar of lead, 1/2 ounce.

Water (pure), 1 pint.

Mix, and bathe two or three times a day.

Muriate of ammonia, 2 ounces.

Common salt, 2 ounces.

Nitrate of potash, 1 ounce.

Water,

1 quart.

Mix, and apply three times a day.

Hot or cold application of water, lasting for half an hour at a time, are frequently of very great benefit.

Poultices.--Poultices are frequently helpful, and, where convenient to apply, may be used either hot or cold, but when the hot ones are used they must be changed regularly to be of benefit. It will not do to simply make the part warm at intervals; it must be kept warm continuously. Cold poultices do not need so frequent remorial, changing twice a day, to prevent souring, being sufficient. The substance composing the poultice is a matter of choice. Linseed meal and bran, in equal parts, makes as good a poultice as any for the most of cases. Of patent preparations there are many, some good, some poor.

Stimulating Liniments.-These are serviceable after the first acute pains have left the parts. Two good formulas are appended.

No. 5 .

Strong water of ammonia, 1 ounce.

Soap liniment,

Pure water,

Mix, and apply two or three times a day.

The strength of the above may be increased by adding ammonia, or, on the other hand, diluted with water. No. 6 is much stronger.

No. 6.
Strong water of ammonia, 1 part.

Water,

1 part.

Oil of turpentine,

2 parts.

Olive or linseed oil, 4 parts. 
This liniment may be diluted by adding oil, or its strength increased by more ammonia.

Tincture of iodine, painted on swollen places, very frequently removes the swelling, but should only be used after the soothing lotions have been tried.

\section{Blisters.}

Counter-Irritants. -Counter-irritants are used principally in chronic cases. They comprise blisters, setons, and the actual cautery or hot iron. Rowels are not used at the present time. Setons are pieces of tape passed beneath the skin, or through an abscess, etc., from one point to another. They will be amply treated of in our chapter on Operations, and so will be the actual cautery by the hot iron.

Blistering.-In applying blisters to the horse, the part is first washed clean and thoroughly dried, the hair removed, and the blister applied a little at a time, carefully rubbed into the skin, and finally a light layer of the ointment smeared on. We give some approved formulas for blisters of different strength.

$$
\begin{aligned}
& \text { No. } 7 . \quad \begin{array}{l}
\text { Powdered Spanish flies, } 1 \text { part. } \\
\text { Lard or vaseline, } \\
\text { Mix. }
\end{array}
\end{aligned}
$$

The above should be prepared by melting over a very slow fire and frequently stirred.

No. S.

Powdered Spanish flies, 3 ounces.
Olive oil,
Oil of thyme,

Melt the flies and oil over a slow fire in the "water bath" for six hours, then add the oil of thyme, and keep in a stoppered bottle.

No. 9.

$$
\begin{aligned}
& \text { Powdered Spanish flies, } 2 \text { ounces. } \\
& \text { Powdered euphorbium, } 1 / 4 \text { ounce. } \\
& \text { Spirits of wine, } 40 \text { ounces. } \\
& \text { Mix, and set aside for a week. }
\end{aligned}
$$

This last is a sweating blister. It may be used without clipping the hair or leaving blemishes. Blisters should never be applied to a very large surface, as they are liable to be taken into the system and cause serious damage. After blistering, keep the head tied high, so as to prevent the horse from biting the blistered surface, and thus also perhaps injuring his mouth severely. After three days the part should be washed with warm water and soap, thoroughly dried, and then a little grease applied.

\section{Treatment of General Inflammation.}

This it will serve our reader's purpose far the best to have described under the different diseases involved. The classes of rem- 
edies here called for are: Sedatives, for lowering the heart's action; stimulants, for weak and debilitated conditions; diuretics, acting through the kidneys; diaphoretics, through the skin; and purgatives, through the bowels. The three last mentioned are generally used to aid a weak part in its functions, by drawing away surplus blood.

\section{Bleeding.}

At the present day bleeding is rarely resorted to by educated reterinarians. In times past bleeding was the "main hold" of medicine. It was bleed for everything, regardless of the strength of the sufferer, or any other element of the prognosis. In many debilitated cases, a half gallon of blood was removed, when the same quantity should have been injected; and, taking it all together, the number of needless deaths caused by the practice can hardly be computed. Still, the practice should not be entirely discarded, as in the case of robust patients, with a full, strong pulse, and at the commencement of inflammatory trouble, the removal of several quarts of blood may aid in changing the course of the disease. It is also beneficial at times in such ailments as brain fever, acute founder, etc.

How to Bleed a Horse.-The life-like illustration on page 195 shows the position of the jugular vein in the neck, which should be carefully located. By placing the finger firmly over the vein it can be made to fill, and it may then be opened by using a fleam and

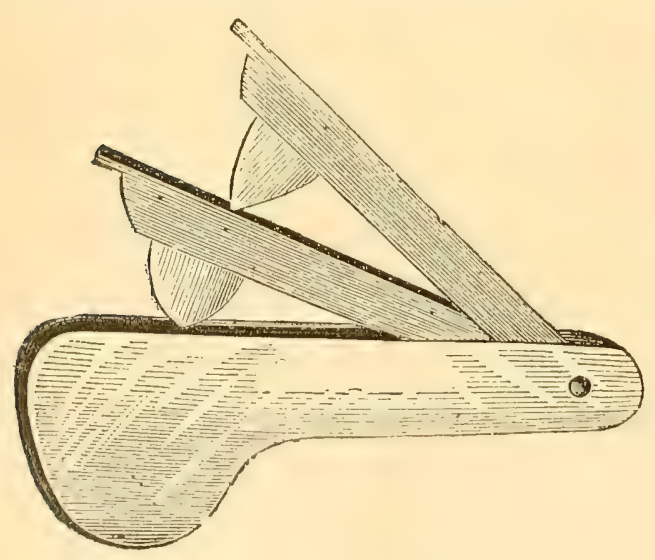

FI.EAM HOR HLEEDING. blood-stick; or, in an emergency, an ordinary sharppointed knife will do. The fleam is placed over the enlarged vein, and firmly and quickly tapped with the bloodstick, thus the oper:ation is performed before the animal has a

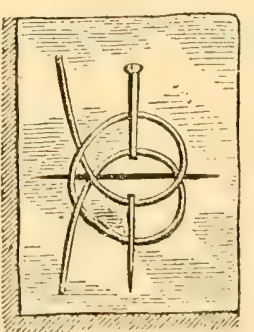

PIN SETURT.

chance to object. After removing the desired amount of blood, the outer skin opening should be closed by inserting a pin through its two edges, and winding a piece of thread, in figure 8 form, over the ends, as shown in the cut of "Pin Suture." The results of bleeding will be consiked chewhere, along with explantion of the reins. 


\section{CHAPTER XV. \\ DISEASES OF THE BONES.}

I. INFLAMMATION OF THE BONE AND ITS COVERING.-II. SORE SHINS.-III. CARIES, OR ULCERATION OF A BONE.-IV. NECROSIS, OR MORTIFICATION OF A BONE.——. NASAL GLEET, -VI. LUMPY JAW.—VII. BONE CANCER.-VIII. BONE AND CARTILAGE TUMORS.—-IX. BIG HEAD.—X. DR. STEWART'S REMARKABLE ACCOUNT OF BIG HEAD.-XI. FORMER INHUMAN MODES OF TREATMENT. XII. WHAT BRINGS ON BIG HEAD?-XII. SYMPTOMS, AS DESCRIBED BY STEWART.-XIV. DR. STEWART'S METHOD OF TREATMENT.

\section{Inflammation of the Bone and Its Covering.}

The bone and the dense fibrous membrane that wraps it round and nourishes it, called the periosteum, are so intimately connected that rarely does inflammation of one fail to include inflammation of the other. In the extent of surface involved, there is a great difference; in some cases it is a very small spot, in other's the whole of the bone. It ends in one of two ways-in exostosis, or the formation of a bony substance, or else in suppuration, which sometimes is very extensive.

Causes.-The causes are various. It is most commonly the result of injuries,-bruises, cuts, concussion from galloping and trotting on hard roads, etc.; yet it may occur as the sequel of certain diseases.

Symptoms.-Lameness, which is the most prominent symptom, may at first be but slight, but the part is very warm and tender to the feel; the swelling becomes more marked, and unless relief is had, exostosis may ere long ensue.

Treatment.-Remove the shoes, have the feet leveled, and place the horse on a good soft bed. In a very severe case, the slings may be necessary. As to medication, in the acute stages use Liniment No. 3 or No. 4. For chronic cases more vigorous measures are necessary, and then blisters will be the proper recourse, to be applied as directed in Chapter XIV. Our No. 8 will usually be suitable, though in certain cases the following will be found better still.

$$
\text { No. } 10 .
$$

Red iodide of mercury, 2 parts.

Powdered Spanish tlies, 1 part.

Lard,

Mix.

6 parts. 


\section{Sore Shins.}

This is a common disease, often seen in young race-horses, and again in old, hard-worked draft horses. New bone forms abnormally

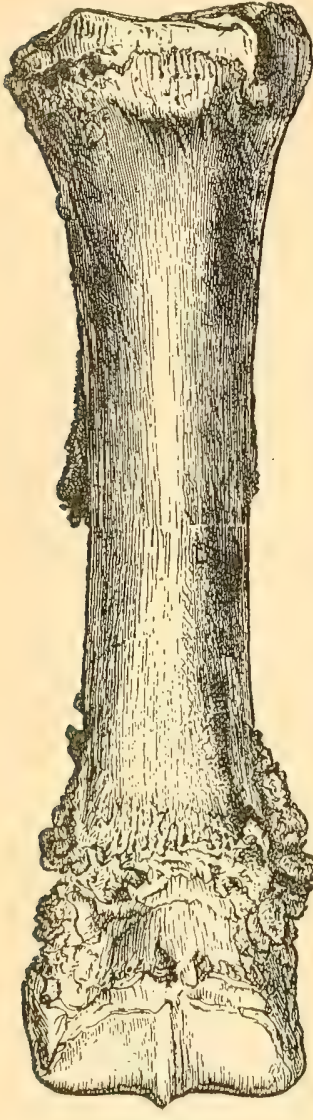

SORE SHIN. on the cannon bone and upper pastern, sometimes in one shape and sometimes in another. In some cases the outgrowth assumes the appearance of large, warty excrescences; in others it is merely a thin layer, rough like lioar frost, or any one of a great variety of shapes between these two.

Causes.-In young animals its antecedent is nearly always some strain on the soft bones; in old ones, it is the result of continued overwork, without the proper intervals of rest between.

Symptoms.-Restlessness; changing from one foot to another; stiffness of movement; knuckling of the fetlock, or bending of the knees.

Treatment.-This cannot be undertaken with much confidence of success as to a cure, though the trouble may be checked, and the suffering greatly mitigated. Remore the shoes, place on a soft floor, and keep on a low diet for awhile. Clip the hair from the shins, and rub in the following absorbent blister:

No. 11 .

Red iodide of mercury, 1 part.

Lard,

4 parts.

Mix.

Rub thoroughly into the skin; after three days wash the shins, and apply a little grease. The eautery or hot iron may, perhaps, be used to adrantage, but this is to be determined by a competent reterinarian alone. After the more aretive treatment is dropped, let the animal rum on soft pasturage for a few months.

\section{Caries, or Ulceration of a Bone.}

This is seen affecting the bones of every part of the body, but more frequently in cattle than in horses. "The plocess of which it consists 
is the counterpart, precisely, of ulceration of the soft parts, described in Section VII of the preceding chapter.

Causes.-These are very varied,-anything, in fact, that is capable of wounding or bruising the different parts of the body; or it may be simply the extension of some obstinate disease from an adjoining part.

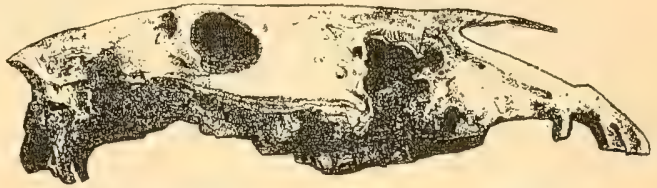

CARIES OF THE UPPER JAW.

Produced by disease of the teeth.

Symptoms.-There is generally a sinus or canal, from which proceeds the odor of dead bone. The presence of decomposed bone may be easily detected by the black discoloration it produces on any article made of silver. There will also be a most sensible difference to the touch; the bone will feel rough-perhaps, in places, almost like saw-teeth, whereas in health it is smooth. The parts most affected are the jaw and teeth, the sinuses of the head, and the poll, withers, ribs and tail.

Treatment.-Remove the decaying bone, by scraping with any blunt surface, or with a bone scraper, the instrument which is shown in the cut. Various acids will remove a slough, and leave a healing surface. Hydrochloric and nitro_ muriatic acids are among the number. On account of their great strength, these must be applied with caution, by means of a small pad, and only to the decaying spots. Under appropriate treatment wounds of the jaw heal especially easily. In this disease, whenever the bone is exposed, it should be protected from the air by the use of cotton batting.

\section{Necrosis, or Mortification of a Bone.}

The difference between necrosis and caries is, that in the former there is death of a large part, or sometimes the whole, of the bone, while in the latter there is a gradual decay of only a small surface. This corresponds, as will be seen, to the difference between mortification and ulceration, as discriminated for the soft parts of the body a few pages back.

Causes.-Necrosis generally comes from bruises and injuries

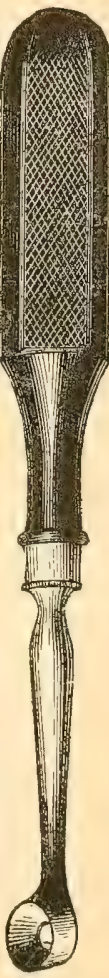

BONE SCRAPER. of various kinds. It may also be the after-effect of some debilitating disease or other. 
Symptoms.-There are usually several openings, from which issues a discharge of very offensive pus, with small pieces of bone. In this disease Nature's reparative power is wonderfully exhibited in the formation of new bone outside of the old, during the progressive decay and gradual discharge of the latter, through the openings seen on the surface. A thickening of the bone naturally results from this process.

Treatment.-This disease takes a very determinate course, that toward the construction of new bone, while at the same time getting rid of the old. The only specific treatment will be to aid Nature, by

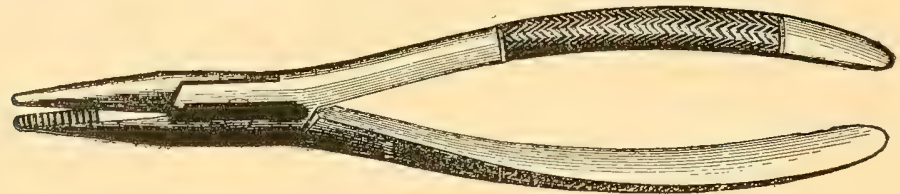

SPLINTER FORCEIS.

removing with the splinter forceps, which are figured in the accompanying cut, any loose bone that can be felt with a probe, afterwards cleansing the wound by syringing with any good antiseptic solution, such as No. 1 or No. 13. Of course, the patient's comfort should meanwhile be provided for in every suitable way.

\section{Nasal Gleet.}

The sinuses of the head are the carities in and between its various bones. These spaces are lined with a membrane capable of secreting a certain fluid, which in health is of a thin consistence, but in this disease turns to pus. As nisal glect is very liable to be confounded with glanders, a correct diagnosis is extremely important.

Causes.-Catarrh of the nose, influenza, etc.; also from discase of the root of a molar tooth in the immediate vicinity of some of the avities referred to; or it may appear in comnection with some disease of the bones of the face.

Symptoms. - The discharge of pus is seen from one or both nostrils, aceording as the nasal passages are involved on one side or both. The pus of natsal gleet will float in water, whereas the dincharge of glanders will sink, on atecount of being heary with dead tissues. Dead bone, decomposing food, or pus, may each give an offensive smell to the breath; hence, the diagnosis must be made with care, eren though there be no cause to suspect glanders. In nasal gleet the sinuses 
are usually filled with pus or a bloody fluid. Tapping the bones on both sides of the head with the finger is the usual way of differentiating these conditions. If there is a dull sound given forth, this indicates the presence of fluids within. Occasionally in this ailment there is a decided bulging of the bones.

Treatment.-After ascertaining that matter is surely present under a particular bone of the head, the thing to do is to remove it by the operation called trephining. But before proceeding to this, it is a good practice to first bore a hole through the bone with a gimlet, and thus "make assurance doubly sure" as regards the presence of pus. Next remove a circular piece of skin from the part to be worked on, and then, with the instrument called a trephine, remove the circular piece of bone, in the way that will be more fully described in another part of this work, under the head of Operations. The after-treatment will consist in carefully syringing with antiseptic solutions, such as the following:

No. 12.

Corrosive sublimate, 5 grains.

Pure water, 1 pint.

Shake well before using, which do every day, or every two days, according to the aggravation of the symptoms.

\section{Lumpy Jaw.}

This is a disease which develops gradually, and is much oftener seen in cattle and sheep than in horses. Its spread among the cattle in some parts of the West has of late years entailed heavy losses on many stock-raisers.

Cause.-A small vegetable fungus, called the actinomyces, found at times in the head of different grains. This fungus is supposed to enter into the system through some cut or abrasion of the membrane of the mouth, or in the skin somewhere on the face, and from thence to work its way to the jaws, tongue, skin, and internal organs.

Manifestations. - Small masses or tumors, from the size of a pin to that of an egg, which, as a rule, do not suppurate. The parts involved are the skin of the jaws, the upper and lower jaw-bones, the tongue, and the various internal organs.

Treatment.-When the lumps are in the skin, if they are cut out, the disease will often go no further. But in the case of fat cattle, the best plan is to turn them over to the butcher. The Department of Agriculture, in a circular dated August, 1892, has given prominence 
to a new method of treating this disease in cattle: "The treatment consists in giving full doses of iodide of potassium (procurable at any drug store) once or twice a day until improvement is noticed, when the dose may be reduced or given less frequently. The size of the dose should depend somewhat upon the weight of the animal. M. Thomassen gives one and one-half drachms of iodide of potassium daily in one dose, dissolved in a pint of water, until improvement is noticed, which he states is always within eight days. Then he decreases the dose to one drachm. The animals do well under this treatment, showing only the ordinary symptoms which follow the use of iodine, the principal ones being discharge from the nose, weeping of the eyes, and peeling of the outer layer of the skin. These symptoms need cause no uneasinees, as they never result in any serious disturbance of the health."

\section{Bone Cancer.}

In this disease the bone textures change to a fleshy substance, containing cells similar to those found in the human subject affected with cancer.

Causes.-Some injury or other, or it may result from ulceration of the root of a molar tooth. Some authors think it is due to a tuberculous diathesin, as upon dissection the various structures adjoining the tumor are frequently found matted together, and firmly adherent to it, whilst spots of tuber'ular matter may be found here and there scattered throughout its substance.

Symptoms. - When affecting the jaw, its outward manifestation is very similar to lumpy jaw, just deseribed. The part most usually af-

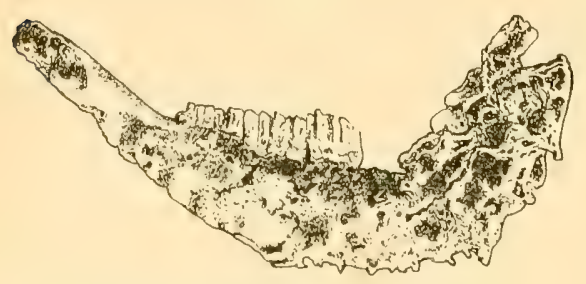

CANCER ON THE LOWEL JAW-BONE.

The worm-eatcn appearance is here platinly shown. fected is the upper jaw, which appears smaller and shows a number of openings, whence issues an offensive discharge. In many cases the teeth fall out and the bone, if exposed, has a wormeaten appearance. With the finger a fleshy mass may be felt, containing small pieces of bone.

Treatment.-Treatment is useless, as the disease is incurable; but, of course, while the sufferer is allowed to live, he should be made as comfortable as possible. Bone cancer is not at all uniform in the time required to run its course. 


\section{Bone and Cartilage Tumors.}

Bone tumors are frequently seen as exostosis on various parts of the horse's body. Our plan will be to consider them elsewhere, in connection with the diseases of those parts, because this will be at once

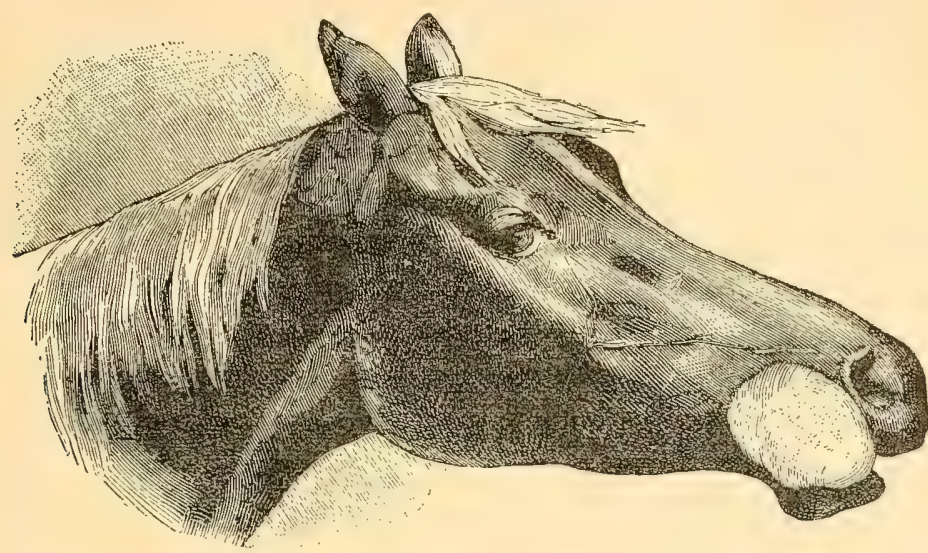

BONE TUMOR OF THE LOWER JAW (FROM A PHOTOGRAPH).

more convenient and more practical. Cartilage or gristle tumors are seen principally on the shoulder-blade, ribs, breast-bone, ete., where they seldom cause much inconvenience. Bone tumors may be found on any part of the body. Our illustration shows_one on the lower jaw.

Symptoms.-Cartilage tumors are known by their positions in the neighborhood of gristle. They feel hard, but have a degree of elasticity which readily distinguishes them from bone. No signs of inflammation are present, on account of what is scientifically called the low organization of the abnormal growth; in other words, the meagreness of its supply of nerves, blood-vessels, ete.

Treatment.-When in the neighborhood of a joint, the removal of a cartilage tumor is a very delicate operation, but in almost any other part of the body it may be removed without difficulty by a chisel or knife. Ordinarily, very little bleeding results, and they seldom return. The bone chisel in common use among veterinarians is shown in the accom- Bone panying eut. It will be seen to be a very simple instrument.

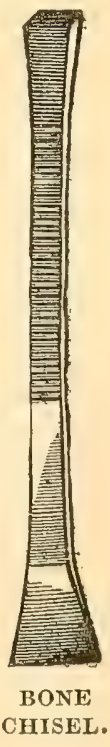

\section{Big Head.}

This is a remarkable disease of the bones among not only the horses, but also the cattle and sheep of various countries, European as 
well as American. It is known to college-bred veterinarians as osteoporosis, though some have confounded it with osteo-sarcoma, which is the technical name of bone cancer, just described. Its most common victims are young horses, between two and six years of age. In America it is a common and much dreaded disease throughout the great Mississippi Valley, and an occasional case occurs in almost every part of the Union.

Causes - The very best veterinarians have failed, as yet, in their efforts to trace this strange malady to its origin; but, as it is constantly seen in conneetion with certain well-ascertained conditions, these conditions are naturally supposed to be closely related, at least, to its causes. Thus its hot-bed, so to speak, is always the low-lying districts in which malaria abounds. Regions where there is a deficiency of the limestone formation beneath the soil constitute another of its favorite habitats. Ill-usage and hard work have been assigned by some as predisposing causes, but without sufficient reason.

Symptoms.-Big head has a very varied range of manifestations. The majority of cases have a history about as follows: The animal may appear in the usual good health, and eating heartily, when a peculiar enlarged condition of the bones of the face and one or both jaws will be noticed, and on examining the mouth some of the teeth may be found missing. As the disease progresses, the swelling of the head, ete, increases; the poor creature, more particularly, of course, when at rest, appears sleepy and stupid; the hair becomes dry and erect, the skin hide-bound, and the flanks are drawn up. The appetite, however, will continue good to the end. The lameness, which may appear at any stage of the disease, resembles rheumatism in character; it will be seen to change from one limb to another, and at the end of several weeks or months may, perhaps, have shifted several times. The bones of the legs and the joints are markedly painful, as well as swollen. Owing to the brittle condition of the bones, not infrequently they are found broken, or the ligaments of the joints break away from no apparent cause.

Treatment.-Veterinary writers have scareely noticed this discase until within the last twenty-five years, and they are all but unanimous in pronouneing it incurable. In other words, it is regarded as one of those "progressive" maladies which no remedies can reach. In the fixst stages, by allowing a lun at pasture fol some months, there may be an apparent recovery, but relief is only temporary, the trouble being certain to return. 


\section{Dr. Stewart's Remarkable Account of Big Head.}

Writing in the year 1866 , Dr. Stewart has left on record a unique account of this disease, from which we make some extracts, as likely to especially interest those of our readers residing in the regions in which he formerly practiced. It will be seen that his testimony differs materially from the standard authorities in the veterinary world. A partial explanation is to be found, perhaps, in the looseness with which the name "big head," is popularly employed. Just as "hog cholera" is used for at least four different diseases of swine, we suspect that big head has had to do duty, in common parlance, for more than one aftliction of the horse. It is a cause for congratulation that this disease is less prevalent than formerly throughout the South.

"This disease has a very peculiar history. It is exclusively American, or at least the English and French writers upon the horse have made no mention of it; and of American authorities, though all must have been well aware of its existence, but few have given it any attention, probably from a want of knowledge of either its history or treatment, or, perhaps, of both. It prevails,most extensively in the great Valley of the Mississippi-in the States of Tennessee, Arkansas, Mississippi, Louisiana, and Alabama. As we recede from the great river and its influences, it gradually diminishes; yet isolated cases may be found throughout the country, from the Eastern sea-board to the plains of the far West, and from the vicinity of the Ohio and the Potomac to the Gulf of Mexico. Its ravages appear to have been most of all destructive in Western 'Tennessee, Northern Mississippi, and Eastern Arkansas, where, at one time, it assumed the features of an epidemic. During the years from 1849 to 1858, when the author traveled extensively

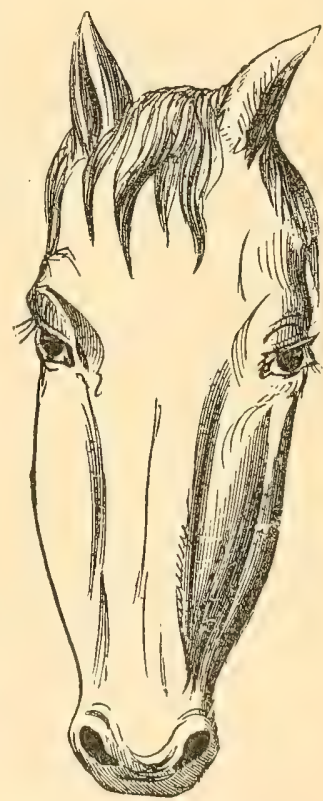

A SEVERE CASE OF BIG HEAD.

From a drawing furnished by Dr. Stewart. through those sections, and also through Northern Alabama, it was not uncommon to find, upon the smaller estates, from one to five horses and mules afflicted with big head in its worst forms, while the larger cotton plantations frequently presented the sad spectacle of twelve or fifteen utterly hopeless cases. 
Popular Ignorance.-_"At that period the most lamentable ignorance reigned everywhere in regard to this disease-its nature, causes, and treatment. Its pathology was not understood by any one. Everywhere the horse doctor was looked upon with the utmost odium, and his name regarded as a synonym for imposition and low-bred ignorance. At the very threshold of research, this terrible malady, big head, presented its most formidable front, and the curt language of the people of the country was commonly such as this: "Take that old horse with the big head, and try your hand on him. If you can cure him, you can cure any of them.' But the work was entered upon with the determination to clear up the mysteries enshrouding the subject, and, if possible, to discover some rational means of cure. That this was accomplished may now be seen, and thousands at the South will attest.

\section{Former Inhuman Methods of Treatment.}

"Among the senseless practices then in vogue for "putting back the big head,' as it was called, some were barbarous in the extreme. First in the horrible list of savageries was the practice of burning or scalding with a horn filled with a hot mush, made of ashes and boiling water, until the skin and flesh were literally cooked, so as to cause them to slough off, in a few days, quite to the bone. Another equally inhuman practice was to run a sharp-pointed, red-hot iron into the jaw, and entirely through the bone. One singular expedient, much resorted to, was the extraction of one or two of the large molars, or double teeth, by means of a large pair of tongs, alled 'tooth-pullers" about three feet long, and in shape like a pair of blacksmith 's tongs, with a shoulder near the end, so arranged as to take hold of the teeth, which wcre thus wrenched out. But the greatest enormity was the use of arsenic. The plan was to cut through the skin to the jawbone, insert a quantity of arsenic with a quill, and then close the wound. A dreadful inflammation and swelling was the inevitable result, the head sometimes becoming as lange as a half-hushel. An abscess soon formed, terminating invariably in a ruming sore, offensive almost beyond endurance. It was no uncommon thing for the flesh and skin to slough off, learing the bone exposed, when only the utmost care could save the wretehed animal from the maggot, the fly, and, at last, the merciful interposition of death.

"Other equally revolting and barbarous systems of treatment were current, but it is needless to occupy further space in describing them. 
That these practices must be described mainly as things of the past, must be a source of deep thankfulness to erery humane person. They shocked and disgusted intelligent men, even when at their height; and, as the lesser choice of two evils, many horses were given over to die, without any effort to save them. Still, no attempt was made to introduce a rational substitute, and hence the ignorant horse doctor's of that period-or 'butchers' as they were often calledhad everthing their own way. The people everywhere hailed with gladness the improved modes of treatment, and presented the author with many valuable tokens of their appreciation and gratitude."

\section{What Brings On Big Head?}

In answering this question, Dr. Stewart, after calling attention to the fact that "the water in Wrest Tennessee, Northern Mississippi, and Eastern Arkansas is not only singularly devoid of lime, but is remarkable for containing so many other minerals," says: "In grassgrowing districts the disease is rare, and even in the infected districts horses seldom have it, if they have access to good pasture. The trouble is that at the South, unless there has been a great improvement in this department of plantation management within a very few years past, the horse is seldom allowed the benefit of even the poor grazing of the dried up fields of July and onward, but, when not in service, is usually kept in the stable, or a dry stable-lot.

Corn and Corn-Fodder.-"Corn and corn-blades stripped from the stalk in the month of August and dried, constitute the principal food in the stables of the South. It is-or at least was, during the author's residence in that region-a common practice to feed nothing but these for months together, the horse, meanwhile, being kept at continuous hard labor. Corn is very heating in its tendency, and a horse which lives exclusively upon it is seldom entirely free from fever. As to corn-fodder, no common aliment is probably less favorable to the animal's health than corn-fodder, as it is harvested at the South-very dry, always dusty, and often very much injured by rains, while standing in the field; in many cases the crop is not gathered until midwinter, and sometimes not even until spring. It is no uncommon scene, in Tennessee and Mississippi, to find one set of hands gathering corn in one-half of the field, while in the other a second set are putting in the new crop. Corn that stands out a whole winter in this way must, of course, be greatly injured, and some of it actually rotten. Not only that which falls down upon the wet ground is 
damaged; but, of what remains standing, the large or stump-end of the ears are generally much softened, if not decayed. The same is true of the fodder; most of it, by standing out in shocks, becomes damp and moldy. On such food two-thirds of the horses at the South are compelled to live, and, as a consequence, more than onehalf of them suffer continually from fever."

Climatic Causes.--"In connection with water and food, climate has, undoubtedly, a powerful influence in developing big head. Cases may occur elsewhere than in malarious districts, but they are of rare occurrence, while, on the other hand, the stronger the malarious influence the more frequent is the disease. In Western Tennessee and Eastern Arkansas, portions of country well known for their unhealthfullness, it is most common and fatal, increasing as we approach the Mississippi. The whole valley of that great river, from the mouth of the Ohio to the Gulf, is low; damp, and malarious.

Plantation III-usage.- "Nor must bad treatment be overlooked in enumerating the causes of big head. No one who has given the subject any attention can have failed to notice that the horse well cared for and kindly treated is much less likely to contract the disease than one ill-used. On many Southern plantations there are no stables; and on many others it was not uncommon, a few years ago, to find the horse in the pens which were called such, half-leg deep in mud and water, at mid-winter, and in summer standing upon great steaming piles of manure. He was generally left in the sole charge of careless negroes, who neither knew, nor eared to know, much about his wants or his health; and who, after working the faithful creature hard all day, and abusing him reeklessly, thought their duty fully discharged, if at night they shut him up in these pens to gorge himself from a trough-full of corn and fodder. Nor did the poor anmal's ill-usage always end even with this. Often he was pressed into the service of some pilfering or trading expedition, conducted under cover of night; ridden at the top of his speed to the rendezrous; tied to a tree in the woods, without any protection from the weather, no matter how cold; and then, in the morning, galloped back, until he was steaming with perspiration, just in time to eat his com and be driven out to work again. Such was the treatment of thousands of horses at the South fifteen or twenty years ago. Of course, disease did a fearful work among them." 


\section{Symptoms, as Described by Stewart.}

"In its very first stage, big head may be easily detected by running the thumb up under the lip, alongside the under jaw-bone, between the lip and the teeth. The side of the jaw should be nearly perpendicular with the teeth above. Should there be any enlargement, even as much as the eighth of an inch, let the farmer beware of that horse. Any swelling of the head or upper-jaw he can see at the first careful glance. The nasal bone, which lies in a direct line from the eye to the nose, is the one that becomes misshapen and betrays the presence of the disease. The skin and muscles of the head become fixed, and will not move by pulling the lips. One of the surest indications of big head is a constant sleepiness while standing. As the disease progresses, the appearance of the poor victim becomes pitiable in the extreme. He is gaunt and drawn up, his hind and forefeet almost together; his head droops, and water runs from his eyes; the hair is erect; the joints are stiff; and the skin is dry and hard, and seems very tight. His excrement, which is hard, black, and almost entirely destitute of moisture, is voided with great difficulty.

"As has been intimated, the disease in its first stages is not percep tible to the unpracticed eye. It then presents no external evidences by which it may be known, and hence many an amateur trader in horses and mules has been deceived. The unsuspecting owner soon finds that something is wrong; the horse is stiff, and does not move with his accustomed vivacity and spirit. But his appetite is good. Very likely, indeed, he eats voraciously, and this only serves to allay suspicion. A horse with the big head continues to eat until the last moment. When no longer able to raise his head from the earth, the poor creature, lying upon his side, as well as he can, begs for corn; and strange as it may appear, corn-the undue use of which is one of the principal causes of the disease-is the only food he wants, and nothing else will he eat."

\section{Dr. Stewart's Method of Treatment.}

Dr. Stewart, like nearly all veterinarians of his time, was an ardent believer in the virtue of bleeding, nd bleeding was the first step in his treatment of big head, as of almost every other ailment. Next came the application of a strong corrosive liniment, care being taken to keep it in an earthenware cup. "It should be applied to the parts affected with a small mop, made by tying a piece of old cloth on the 
end of a stick. One tablespoonful on each side of the head and jaw will be a sufficient application, the liquid being always well shaken previously. The parts must be well wet with the liniment, which should then be thoroughly dried in with a hot iron, held near the skin, but not touching it, as actual contact would not only needlessly torture the poor brute, but would destroy the effects of the remedy. The liniment should be applied in this way, every other day, six or eight times; or, in a bad case, the treatment may be continued as long as is necessary, varied by omitting the application four or fire days at a time in every fortnight. It is important to remember that the horse's digestion, not the condition of his head and jaws, is the guide in determining what degree of success attends these efforts.

The "Jimson" Seed Remedy.--"The effects of the disease will be likely to linger in the system long after it has been checked in the parts where it chiefly manifests itself. To remove these effects will be slow work; but it must be done, or the disease will return again, in which case it will almost certainly prove fatal. To remove his stiffness, loosen his hide, and regulate his digestion, the following simple prescription should be given: One tablespoonful of stramonia seedthat is, the seed of the 'jimson weed,' as it is commonly called; or of the thorn-apple, as it is otherwise known-in some meal or bran, every other day, until three or four doses have been administered. It may then be omitted for two or three days. This medication should be repeated so long as may be found necessary.

"Many persons, supposing the 'jimson' seed to be poisonous, are at first afraid to give it. There is not the least danger, however, in using it as above directed. It has a very happy effect upon the horse's system, and especially upon his digestion. His excrement, which before was black, hard, and dry, becomes soft, and of a healthy yellow appearance. When this is accomplished, the patient is safe, and not until then, as this will not be the case until the disease is fairly broken. The use of the 'jimson' seed will do more to free him from the general effects of big head than all the other medicine which can be given him. IIundreds have been cured by it, where no other means were employed.

A Remarkable Case.--"The author recollects one remarkable case of this sort. Mr. Richard Cross, of Hardeman county, Tennessee, had two valuable horses nearly ruined with big head. He turned them into a cotton-gin lot, of two or three acres, where was growing a flourishing crop of 'jimson' weeds, determined that they should eat 
this or starve. Pressed by the gnawing of hunger, the horses first nibbled away at the leaves, then fed upon the buds, and at last devoured stalks and all. Compassion finally drew his attention to these poor creatures, and to his astonishment he found them nearly well. When turned into the lot they could scarcely drag their feet over a rail, lying on the ground; but now, the little negro who first informed him of their improvement, put the case emphatically in these words: 'Massa, I tink old Gray 'most well; he kick up his heels.' Years afterward the writer saw the same old gray horse, as well and fat as could be desired.

An Alternative Prescription.- 'In case the 'jimson' seed cannot be procured, a cuarter of a pound of sulphur may be given daily, to the amount of three or four pounds. In connection with the sulphur, the horse should have an aloes pill every other day for a week; but the 'jimson' seed should be obtained, if possible. No other remedy can be absolutely depended upon, and it is principally to his reliance upon it that the author attributes his great success in curing big head.

The Success Claimed._-"The swelling of the head and jaws will disappear very gradually, and in case it has been unusually great, the 'bunches' will always show to some extent; but it will become less and less observable each successive year. Not less than two thousand horses and mules, of which the author had knowledge, were cured by this treatment during the year's from 1850 to 1858 . The cure is radical. When it has once been effected, the horse is no more liable to the disease than if he had never had it; nor will any ugly scars remain to proclaim that he was ever unsound.

Treatment Recapitulated.-_'1st. Bleed two to six times, at intervals of six to ten days, according to the aggravation of the symptoms.

62d. Apply corrosive liniment every other day, as directed.

'‘3d. Give a tablespoonful of stramonia, or 'jimson' seed, daily, with intervals of omission as specified, as long as necessary.

"4th. In the absence of 'jimson' seed, give sulphur, and aloes pill.

After-Treatment_- "This must be judicious and careful. Unless the object is to kill him, the horse should never be worked while convalescing. When the weather is bad, he should be kept in a warm, clean stable. If pasture is in season, he should be turned upon it during the day, but during cold rains, and on chilly nights, he must be brought into the stable. Should the whether be unusually damp or cold, he should be covered with a blanket. The little blood which a horse in this condition has is very thick, and he is much more sensitive to the cold than when in health." 


\section{CHAPTER XVI.}

\section{INJURIES AND RESULTANT DISEASES OF THE BONES.}

I. POLL EVIL.-II. FISTUla OF THE WITHERS.-III. BONE SPAVIN.—-IV. SPLINTS,-V. RING-BONES.-VI. SIDE-BONES.

As will be seen from the above synopsis, the different ailments to be described in this chapter are not numerous. Yet they embrace some of the most inveterate ills to which the horse is heir, and most of them are so common as to be familiar to even the farmer's boys.

\section{Poll Evil.}

This disease is rare at the present day compared with twenty or thirty years ago, which is one, among many, of the happy results of the improvements which have come into vogue in stable management, ete. The seat of poll evil is just back of the ears over the first cervical rertebre. Poll is the old English word for head, and in popular language it is on the top of the head that this sore evil makes its appearance.

Causes.-External violence, such as striking the head on the manger, or against low ceilings or doorways, or from blows; or it may come from pulling back on the halter.

Symptoms.-There will first be noticed a swelling, the pain of which will make the neck stiff, as the sufferer cannot bear to move it. Passing to the next stage, pus is formed, which, owing to the softness of the part, will burrow in different directions, forming sinuses, or pipes. The inflammation is very great, and usually extends to the bone, producing caries, or ulceration. In old cases it is a common thing to see several openings discharging pus, which has a rery bad smell, and when the bone is affected, is offensive in the extreme.

Treatment.-At the outset of the disease, the effort should be to remove the inflammation and prevent the formation of pus, by using the Cooling Lotion No.4, or poulticing with hot bran and linseed poultice. When, however, pus has actually formed, which may readily be recognized by a feeling of softness to the touch, principally at one 
spot, more heroic measures are necessary. The swelling should be cut open, so as to prevent the pus from burrowing, and then dressed with No. 12. All the pipes should be opened to the bottom, and No. 2 injected once or twice, to remove the membrane formed. If there is diseased bone, the decaying portions will need removal by scraping, or by repeated injections of the following cleansing lotion:

No. 14.

Solution of chloride of lime, 1 part.

Pure water, 10 parts.

Mix.

After a healthy wound is secured, use No. 12, the same as for a simple case, and a cure will shortly be effected.

\section{Fistula of the Withers.}

The withers in some horses are very prominent, and for this reason especially liable to bruises by bad fitting saddles, or in rolling on stony ground, etc., resulting in a condition the same as in poll evil, but differently located.

Symptoms.-There is a painful swelling, which looks larger than it really is, from the natural prominence of the parts. Pus is presently formed, and burrows along the loose textures very readily in all directions, forming, just as in poll evil, a series of pipes or sinuses, which frequently run far under the shoulder-blade, or in other" cases affect the spines of the vertebræ (ridges of the back-bone), producing caries or ulceration.

The external view is well depicted in the en-

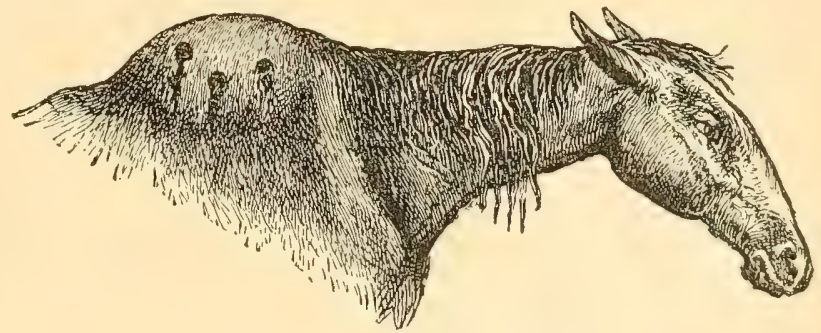

FISTULA OF THE WITHERS. graving, which shows several openings actively suppurating, and faithfully reproduces the abject, woe-begone expression of the poor animal, whose whole appearance is one of great suffering. The pus from fistulous wither's is thick and very foul smelling; when the bone is involved, the stench is sometimes almost intolerable.

Treatment.-At the outset of the disease, try the Cooling Lotion No. 4, or the Soothing Lotion No. 3, to reduce the inflammation. In slow cases the Absorbent Blister No. 11 is very beneficial, to either draw the swelling to a head or to scatter it altogether. When pus 
has formed, it will be necessary to cut down and allow of its escape; this can be freely done, as there are no important blood-vessels or nerves in this situation. The cut should be along the middle of the withers, whence any sinuses on either sides can be reached without

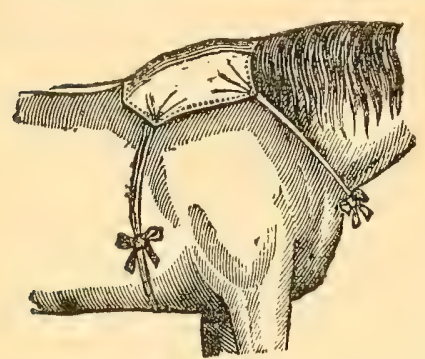

BANDAGE FOR THE WITHERS.

Showing method of securing the bandage by straps from the four cor. ners, passing below and in front. difficulty. All dead bone should be removed by a gouge, while at the same time the healthy bone should be exposed to the air as little as possible. An opening for draining off the pus should be made at the lowest part of the pipe, and a piece of tape passed through to keep it open. In a very bad case, if there is a pipe extending under the shoulder-blade, the veterinary surgeon may decide to cut through the bone, and drain it from that place.

The withers should be dressed once a day in cold weather, and twice a day in hot, with either Lotion No. 1 or No. 12. These dressings must on no account be neglected.

Caustics are frequently used with benefit to slough out the pipe, the writer's favorite for this purpose being powdered sulphate of copper wrapped in small pieces of paper, which are pushed to the bottom of the pipe. They may be removed in two days' time, learing a surface which generally heals very readily.

\section{Bone Spavin.}

Structure of the Hock.-The hock is composed of six bones arranged in two layers, one on top of the other, as shown in the cut on page 222. The external covering, or capsular ligament, is what principally binds them together; from its inner surface is secreted the joint oil, so essential for lubricating the surfaces (ends) of the bones, where they rub one upon the other. Each of the six small bones, just mentioned, has a layer of cartilage or gristle, whose important office is to reduce friction, and act as a buffer to prevent concussion. There are also a great number of short but very strong ligaments, holding the small bones in position, and binding them together.

A sparin is an exostosis (in every-day English, a bony formation), the sequel, generally, of an inflammation between the faces (ends) of these 


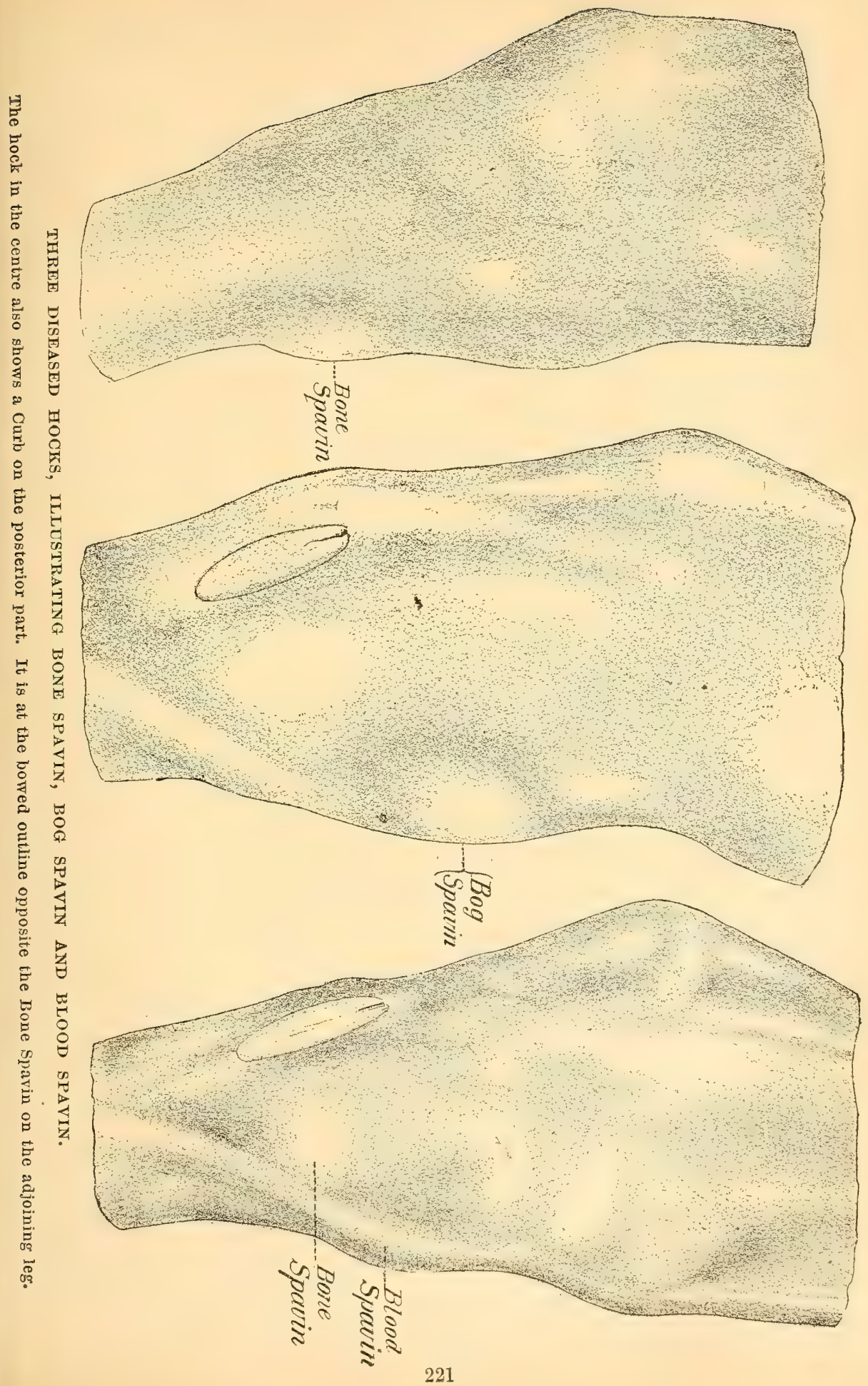


small hones we have described. It may appear anywhere around the hock, and at times is found affecting the inner faces of the bones

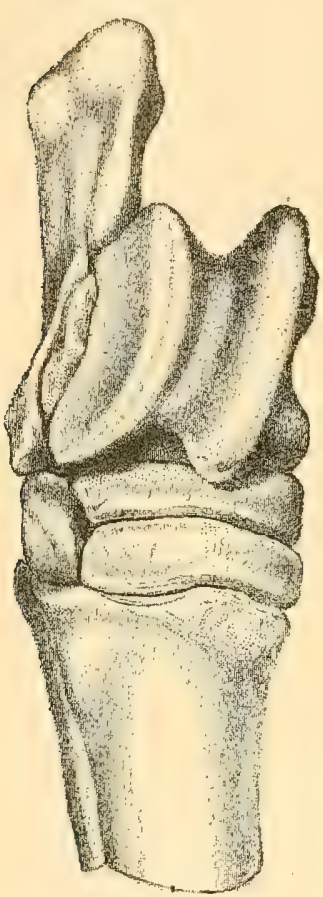

A SOUND HOCK. when no external enlargement can be noticed. Certain shapes of the hock are found to predispose to spavins. When, for instance, they are small from front to rear, and narrow and round, there is a tendency to straining of the ligaments, with extension of the resulting inflammation to the bones; and the same result may be seen in young animals, from neglecting the feet and allowing the hoof, especially at the toes, to grow too long, causing it to act as a lever on the hock. It has long been acknowledged also that spavins are hereditary, and for that reason stallions and mares so affected should not be used for breeding purposes. Other causes are bad shoeing, putting the limb out of balance; injuries of various kinds, with extension of inflammation to the bones; long rests in the stable, followed by a hard trot; and standing in stables that have too great a slant of the flooring.

Symptoms.- When not the result of injury, the lameness will come on gradually. The horse may be noticed in the morning to hop on being mored, but this quickly passes away. The leg will be favored, and the foot be rested on the toe, causing a wearing away of the shoe at that spot, and no enlargenent of the hock will be perceptible. This condition may continue for several months. There is a peculiar catch or hop in hock lameness that is characteristic. It is well seen on severely flexing the joint, when the lameness will be exaggerated; or, again, after resting from a good drive, when the manifestations are very prominent. In many cases of hock troubles the limeness is very great at first starting the horse off, yet maly disappear, or very nearly so, after driving a short distance.

While the bony enlargements of sparin may present themselves anywhere around the hock, the most common place for their appearance is on the inner and lower side of the joint, and this likewise is the location where they generally occasion the most lameness. 
They are frequent also on the back part of the outside, and in this place are usually the result of some injury, and the lameness is not so severe. Occasionally, the inside faces of the bones are diseased without any external manifestations, so that the owner is puzzled to know why his horse goes lame. This is called internal spavin.

Examination of the Hock.-In any case of suspected spavin, the hock should be examined from different standpoints, the best of which is about two feet out from the shoulder. In the healthy horse there will be seen from this standpoint a straight line from the inner side of the lower end of the tibia above to the inner splint-bone below. (Be careful not to mistake the vein, at times quite full, which passes obliquely over the hock, for a spavin. To assure yourself, press on the swelling, just below the hock, and if it is the vein, the enlargement will quickly disappear.) From the side a straight line should be found between the joint of the hock above and the fetlock below; any deviation from this will indicate disease. The joint should be examined from the rear

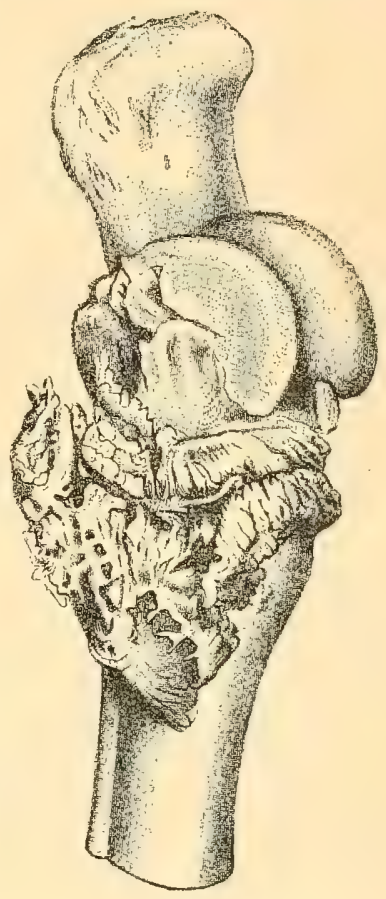

BONE SPAVIN.

In this example it is on the inside of the hock. also, and both hocks carefully compared.

Rough Hocks. - There is a difference of opinion concerning "rough hocks.". Some colts are born with them. Notwithstanding they may not, and in most cases do not, cause lameness, they are not to be trusted, and animals so affected are not sound.

Treatment of Spavins.-To speak first of prevention, no one should ever breed from a spavined mare or spavined stallion; and in young animals the feet should be kept pared down to the normal level. Truatment of a spavin is a matter of months, not of days, its ohject being to obtain an ankylosis or union of the diseased bone surfaces. This is effected more readily in animals below, than in those above, five years of age.

In the case of old horses the prospects for a cure are always doubtful. At the outset the shoes are to be removed, and the feet leveled, 
and cold applications will be in order to reduce the inflammation; for which purpose cold water, or Cooling Lotion No.4, or Soothing Lotion No. 3, will be found well adapted. The secondary treatment will consist of counter-irritation, by the use of blisters or the firing-iron. The Mixed Blister No. 10 is suitable, and should be re-applied in a month's time. It is always best to include the whole joint in the application. Afterwards place the patient in a box, with plenty of soft bedding. Firing is usually performed only over the enlargement, but we cannot endorse this limitation, as the extent of the disease cannot be measured by the external bunch. The better way, in our judgment, is to fire the whole joint, and afterwards rub in Fly Blister No. 7. For different styles of firing, see Chapter XXXIX.

\section{Splints.}

Of all the forms of exostosis, or bony growths, seen on the horse, splints are the most common, developing the most frequently while the

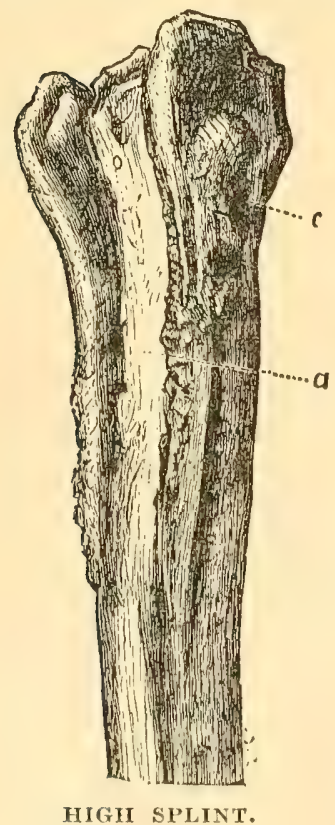

The Splint is shown at $c$. animal is young. Their situation is between the cannon and splint bones, on either the inner or outer side of any of the legs; but oftener than anywhere else on the inside of one of the front legs. Splints are distinguished as "low" and "high." Low splints are those developed at the lower part of the junction of the two bones. They are not an unsoundness when cured, unless of such size, or in such position, as to interfere with the tendons, or get knocked in traveling. High splints are found close to the joints, which are liable to be involved by an extension of the inflammation; hence they are considered an unsoundness, even when cured.

Causes.-Splints are the result of inflammation of the substance between the cannon and splint bones, the fluid there exuded gradvally turning to the bone enlargements so commonly seen. If we could trace this inflammation far enough back, we should find its origin in some injury or other, producing encussion, or clse in having the shoes and foet not level, thus altering the natural pressure on the bony column of the leg. In some instances, however, splints are a natural formation, tending to strengthen the parts. 
Symptoms.-These a:e by no means uniform. In many cases, after the bone has set, and all pain has left the part, there will be no lameness shown. At times the bony growth will be so small as to be scarcely discernible, while in other canes the effusion is large and, by stretching the sensitive periosteum, occasions great pain. When this effusion turns to bone, there is usually (not always) a passage for the tendons and ressels; if otherwise, and they be cramped for room, the lameness will be great. There is a noticeable peculiarity in splint lameness, namely, that the animal may walk all right, or nearly so, but will go very lame in trotting; in that gait there is hardly any other form of lameness that drops so low.

Treatment.-In the acute stage, when the pain amounts to severe punishment of the animal, the operation known as periosteotomy is the best recourse, and will at once afford great relief. It consists in slitting the membrane corering the enlargement, and will be described in our chapter on Operations. Otherwise, the Cooling Lotion No. 4, and the Soothing Lotion No. 3, are called for, these to be followed later by use of the Sweating Blister No. 9, or the Fly Blister No. 7, as a counter irritant. In chronic cases, the hot iron should be used (preferably the pointed iron), and Mixed Blister No. 10 rubbed in. Setons are sometimes passed over the bunch, but this is a practice that most of the best veterinarians seem to discredit at the present time.

\section{Ring-bones.}

A ring-bone is an exostosis, or bony formation, found on the upper and lower pastern bones, and most frequently affecting the hind leg. It is so called from its tendency to form a ring around the bone, particularly at the joints, though in many cases they are simply small, round knobs, either at the border of the joint or high up on the pastern bone. According to their position, they are called high or low ring-bones, both kinds being illustrated on the next page.

Causes.-As with bone spavins, so with ring-bones, there is a hereditary tendency to their formation, for which reason it must again be emphasized that mares and stallions thus affected should be discarded for breeding purposes. When not hereditary, the causes are quite diversified, but are principally sprains, bruises, the extension of disease from an adjoining part, and bad shoeing.

Symptoms.- In the acute stage, or while the ring-hone is actually forming, the lameness will vary according to the situation of the trouble. 
In low ring-bone, the joint being involved, the lameness will be severe, but less so when the trouble is higher up, in which location they also yield more readily to treatment. If, as sometimes occurs in the carly part of the disease, no enlargement is to be seen, the diagnosis becomes difficult; but even in these cases the horse will evidence pain on flexing the joint; in trotting, the heel is the part of the foot

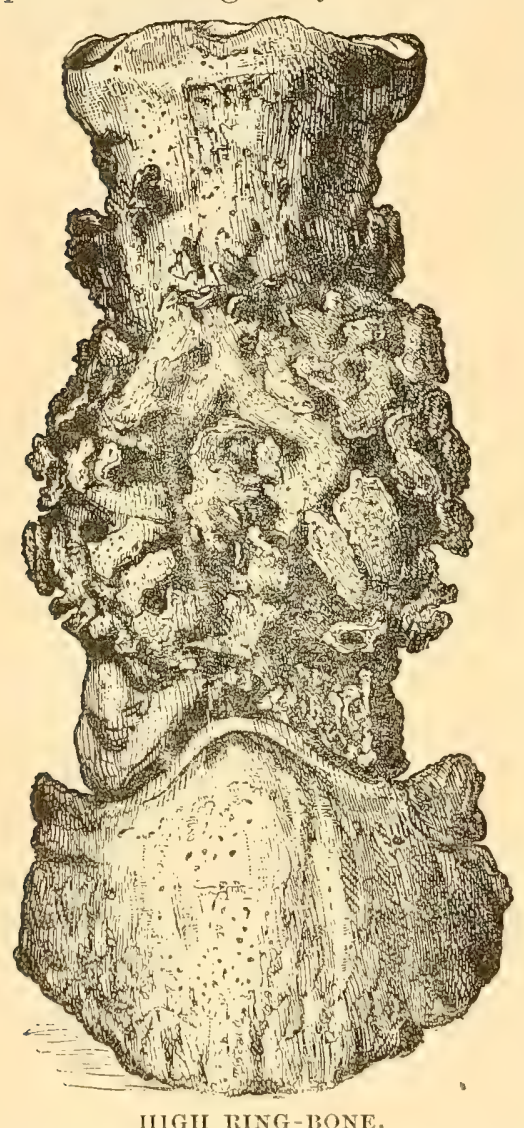

Not being close to the lower joint, the latter jo not nearly so much affected as in low ring. bone.

that he places first on the ground, and there is an unmistakable stiffness of movement shown.

The products of the inflammation readily change to bone, and there is formed a ring of callus, as seen in the repair of fractures, and then the joint becomes ankylosed, the articulating faces are $a b-$ sorbed, and a stiff joint results. Should the ring-bones interfere with themovements of the tendons, all hopes of a cure are at an end. High ring-bones, after cure, are much less liable to cause trouble than the low, which, owing to their

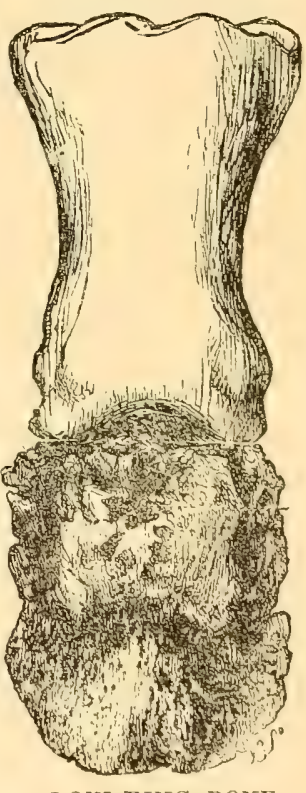

LOW RING-BONE.

Affecting the lowerjoint, which is liable to become stilf (anky. losed).

more important position, may anue trouble on the slightest provocation, by interfering with the tendons and joints.

Treatment.- Inhappily, the first stage of the discase is generally allowed to pass before treatment is thought of. At this stage all that is necessary is to reduce the local ferer, by means of Cooling Lotion 
No. 4, or Soothing Lotion No. 3. When the bone formations commence, vigorous measures, in the line of counter-irritation, are rcquired. Use the firing-iron, and afterwards apply Mixed Blister No. 10, or Fly Blister No. 7.

\section{Side-Bones.}

Side-bones are bony or limy deposits formed on the lateral cartilages of the foot. These cartilages are small pieces of gristle attached to the wings of the pedal bone. On pressing over the heels with the hand, they may, in health, be felt to bend, while in disease they are rigid, and in addition sometimes assume enormous proportions.

Causes.-This is an ailment principally found in heavy, coarse-bred horses, as a consequence of bruises or similar in-

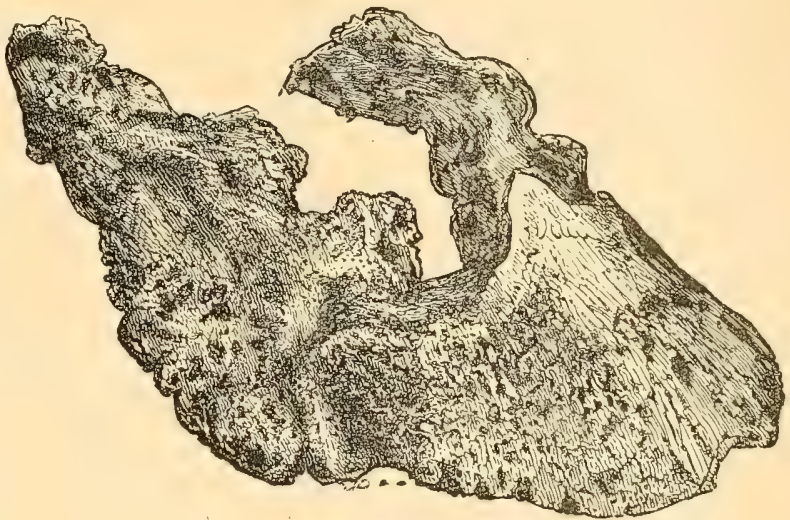

LARGE SIDE-BONES. juries. Another and very different cause is this: when the frog comes in contact with the ground, these lateral cartilages are brought into play, and kept in healthful condition, but by non-use, such as results from wearing the high-heeled shoe, they are turned to bone.

Symptoms.-Side-bones frequently appear without any outward signs of inconvenience; but in the majority of cases there will be more or less stiffness of action. Where the growth interferes with the tendons, etc, the case will generally prove incurable.

Treatment.-If there is any visible cause, such as corns, had shoeing, or the like, try to remove it as soon as possible. Reduce the local fever by cold applications, and if the lameness persists, use the firing-iron, followed by either Blister No. 10 or No. 11. 


\section{CHAPTER XVII.}

\section{FRACTURES.}

I. CONCERNING FRACTURES IN GENEIAL-CII. HOW A BROKEN BONE UNITES OR "KNITS.?"—III. BROKEN LIMBS.—IV. CONSTRUCTION AND USE OF SLINGS, ETC.—V. FRACTURE OH THE SKULL.—VI. FRAGTURE OF TIYE UPPER JAW.—VIX. FRACTURE OF THE LOWKI JAW.—VIII. FRACTURE OF THE SPINE, - IX. BROKEN RIBS.—X. FRACTURES OF THE PLLVIS.XI. FRACTUIES OH THE FORE LEGS.—XII. FRACTURES OF THE HIND LEGS.

\section{Concerning Fractures in General.}

Fractured, or in common language broken, bones are of frequent occurrence among horses. Fractures, of course, are commonly the result of external injuries, as falls and blows. There are some dis-

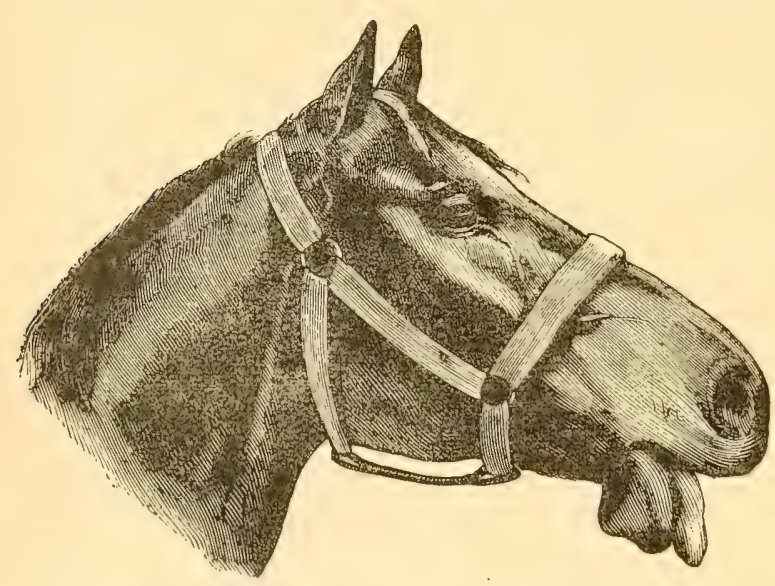

SIMPLE FRACTURE OF LOWER JAW.

(Engraved for this work from a Photograph.) eases also in which the bones become brittle, and the same injuries are-sustained from sheer in ability to sustain the natural weight of the body. The bones of the old in the brute creation, the same as in the human, are more liable to break than those of the young, owing to their larger proportion of earthy matter, and smaller share of the animal matter, which in the young, of whatever species, gives to the bones a certain degree of elasticity. Excessive muscular action is another cause of fractures, as of the back and the small sessamoid bones at the back of the fetlock joint. From just this (ause many a prominent favorite of the turf has been ruined, perhaps even condemmed to an untimely death. 
Kinds of Fracture.-Fractures are dirided into two great classes, namely, the simple, which are those in which the skin is not broken, and the compound, or those which also show an opening in the skin, produced by the cause of the fracture, or by the end of the bone protruding through the tense drawing action of the surrounding muscles, or the weight thrown on the broken limb. These two classes are found to vary greatly in extent. In a "complete" fracture the bone is broken clear across; in an "incomplete" or "greenstick" fracture, it is broken only in part, and is bent or crooked, resembling the break of a green stick. Fractures also vary in their direction, the most common forms being transverse, oblique and longitudinal, the others being of much less frequent occurrence. Besides the preceding, there are other distinctions in fractures. A "comminuted" fracture is one where the bone is broken in several pieces. A "complicated" fracture occurs when some important organ or part is involved in the injury, such as a joint, the lungs, intestines, etc.

\section{How a Broken Bone Unites, or Knits.}

The idea is very prevalent that the broken limbs of an animal do not unite as readily as in the human body, but this is erroneous. The great trouble in effecting a union of the bones in the lower animals is the poor facilities for keeping the ends in proper contact. The poor sufferer must stand, and this is not a favorable position; besides, he is apt to fret and worry at being kept in a restrained position, and in moving round to somehow undo or loosen the bandages. In the case of open wounds, in

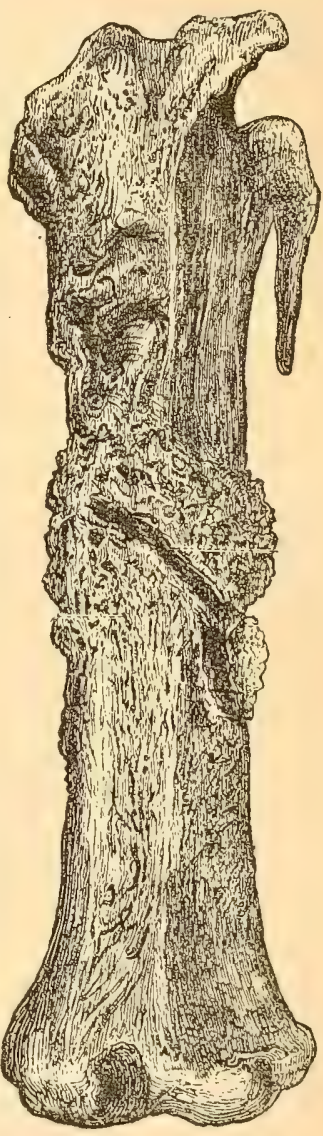

FIACTURE THAT ILAS UNITED.

Showing the callus. which the bone is exposed, the pus formed makes healing a diflicult thing, and the animal suffers severely.

After a fracture, there is an exudation of lymph from the bloodvessels into the tissues around, and this, at the end of two or three weeks, has been gradually turned to cartilage or gristle, forming a 
ring around the outside, and another around the inside of the broken cnds. This cartilage is next and gradually converted into bone, and is called a callus; it acts as a bandage on the ends, holding them firmly in position while union is taking place within. After the hones have joined, the callus being of no further use, it is absorbed by the vessels. This occurs in from six to twelve months, but there is generally some trace of the callus left, enough of it to be felt as a small ridge.

False Joints.-False joints sometimes occur. These are where the edges do not unite properly, and when the inflamed condition subsides, the limb is found to be movable at the break without any pain. Dogs are frequently seen with false joints, from their habit of eating off the bandages, allowing motion of the limb.

\section{Broken Limbs.}

How to Recognize a Broken Leg. - The limb will be noticed as hanging helpless, or very nearly so; in some cases it is shortened by the ends of the bones becoming displaced, and slipping past each other through the drawing power of the muscles. On taking hold of the limb, it is found to move in any direction. The ends of the bones will be folt to move on each other, and in most cases a harsh, grating sound can be detected, from their rubbing together. There will also be some swelling from injury of the vessels.

Setting a Broken Leg.- When a fracture has occurred, the first step is to secure the limb in a favorable position, and prevent extension of the mischief, as in some cases a simple fracture has been changed to a compound one. For this reason it is very advisable to place in some sort of a sling. (For Slings, etc., see next section of this chapter.) It is important to "sct" the bone as early as possible, as swelling maly occur, and interfere greatly with reduction. II enee, bandages and splints are always used to keep the ends of the bones together, and prevent motion. It is rery important to have the splint long enough to include the joints above and below. To apply tie splint, first wrap the leg in a layer of cotton batting, which will allow of some swelling, and keep the limb from rubbing. Then cut some strong muslin in strips of the necessary width (generally about two amb onc-half inches), and roll them into coils, at the same time thoremghly rubhing on powdered plaster of Paris. These bandages are then soaked in warm water, the surplus wrung out, and then 
they are wrapped around the leg, till a good strong support has been applied. Between the layers there is usually some stiffer and stronger substance placed, such as leather, a thin strip of wood, tin, or guttapercha. Insteat of the plaster of Paris, before mentioned, there may be used such things as starch, glue, or isinglass, if more readily procurable. When great swelling occurs, the bandage may be cut down the front, eyelets inserted, and laces used to tighten it up.

Treatment of Compound Fractures. - When the fracture is compound, the wound and its surroundings should have the hair removed and be thoroughly washed, and the wound be syringed out with Antiseptic Solution No. 1, or with the following:

No. 13.

Corrosive sublimate, 15 grains.

Pure water, 1 quart.

Mix.

Any loose bone or tissues will have to be removed. The bandages are applied the same as for a simple fracture, an opening, however, being left over the wound, as it will have to be dressed daily with solutions, as just mentioned. The wound must be closed by cotton batting and a bandage, the object being to secure a speedy union, thus turning the compound cases into simple ones.

Treatment of False Joints.-False joints are not easily cured, and should never be tampered with by a novice, as they sufficiently tax the skill and patience of the most accomplished veterinarian. The process is to set up an inflammation between the ends of the bones by inserting threads between them, or scraping the ends of the bones by some special instrument. After the bones have properly united, it is necessary to allow exercise for a few months. These cases are frequently fired with the hot iron, or blistered, but of these practices we cannot approve; they are needlessly cruel.

\section{Construction and Use of Slings, Etc.}

In this country a great many persons have never seen a horse with a broken leg, although accustomed to horses all their lives; and should this casualty befall one of their own stock, at least four-fifths of them would give up the case in utter discouragement, and suffer the animal to be killed forthwith. It is a great mistake to suppose that nothing can be done for such a horse. If the proper measures are atopted promptly, he may, generally, be saved. The sling cannot be dispensed with in treating a compound fracture, as without it (or a frame of some kind to answer the same purpose more rudely), noth- 
ing could keep the horse from lying down on his side; and even in a simple fracture he would generally do that from weariness, after standing on three legs from sixty to ninety hours. If the horse is still on his feet, and near the stable, he may be led into it, and a couple of very strong hooks put into the beam above, or into the sides of his stall, if strong enough, and the sling suspended to these on either side.

The engraving conveys a good idea of a sling complete in all its parts; but one of simpler construction will answer the purpose when one so elaborate cannot be had. It may be made of either hagging

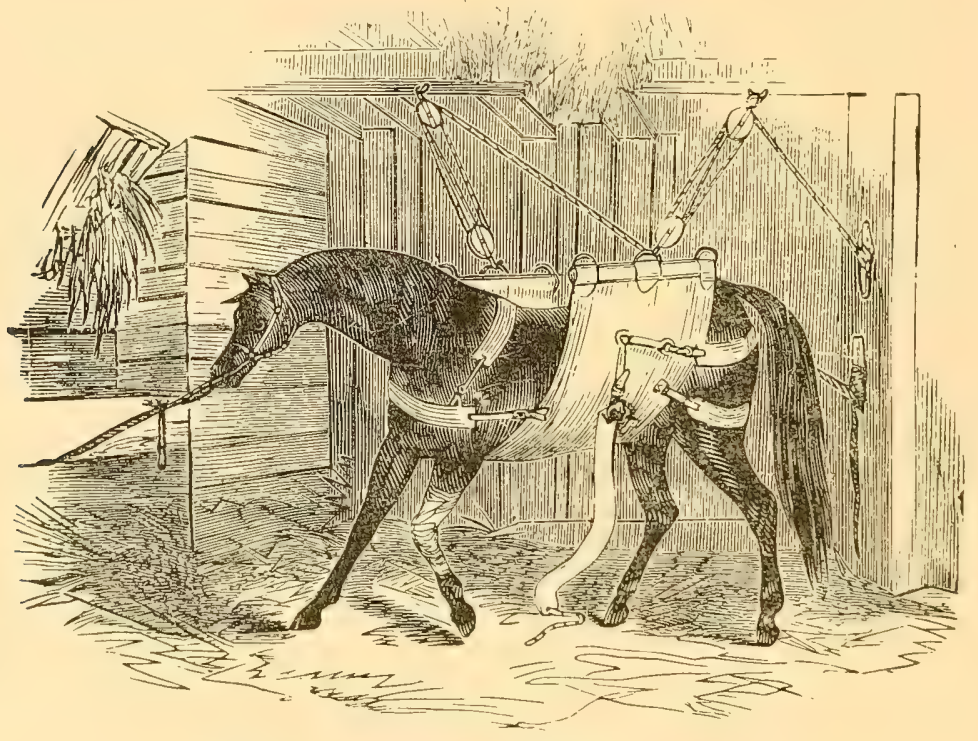

SLING FOR HORSE WITH IROKEN LEG.

In one minor particular the artist is wrong; the injured le with splint and bandages on, should be straight, insteal of bent

or sail cloth. Four yards of the cloth will be sufficient. Sew the ends of the cloth together very strongly. This, when doubled, will be about six feet in length. Get two round sticks of hard, strong wood, and put through the doth: to these attath strong propes, fastened to each end of the sticks, so that they will each have a rope extendmg from one end to the other. Each rope should be about six feot in the loop between the ends of the stick, and so tied that it annnot slide either way. Let the sling thus arranged be put under the horse, and then another rope be earried through the one attached to the ends of the stick, and through a ring on the hook at the sides of 
the stable; let the rope be carried around twice, and first drawn up and fastened on one side and then on the other, until it raises the horse's body about two inches, and yet so that he can stand on his feet. He will very soon learn to rest his body on the sling, when his fore-leg becomes very tired. He must be hitched to the front by a good, strong halter, so that he cannot pull back, and throw himself out of the sling. He will not have room to do so forward, on account of the manger. If it is his fore-leg that is fractured, he will try to throw himself backward; but if the hind one, he will incline forward. In either case he must be prevented.

The Frame,-Dr. Stewart recommends resort to the frame when the horse is found lying too far from the stable to move him into that. "A kind of gallows may be constructed very readily by locking rails or poles together, after the manner of fixing a quick gallows upon which to hang slaughtered hogs, with which every farmer is well acquainted. It will take eight poles and four chains. These must be so arranged as to stand on both sides of the horse, and in each of these couples large heary poles should be laid, which should be about fourteen feet long, and elevated about eight feet above the ground. When this frame is ready, which can be erected in some two or three hours, the assistance of five or six men will be required to raise the horse. Neighbors are always ready to assist in such a case.

"Now let the sling be brought, prepared as already described, and be placed under the horse's body, and the ropes carried over the poles, which should be about six feet apart, and so braced with other poles, lashed across the ends, that they cannot be drawn together. Let one man stand at his head and another at his tail, and at least two on each side to lift, and one at the end of each rope to hold all that is gained. It will require heary lifting to raise him, and strong efforts on the part of the men at his head and tail to keep him from pitching. Then he is raised part way up, and can begin to use his feet, he will try to raise himself, and a strong pull at the rope will quite easily bring him to a standing position. He will, in all probability, be a little restive for a time, and try to get away from his fastenings, but must be held and made fast by a strong halter in front, and a bar firmly fixed behind. A roof must be made to protect him from the weather, and a stand fixed in front, with a box on it, for him to feed in. Ditches should be dug around to carry the water awa from his place of standing, and keep it dry. 
The Rail Pen.-Still another arrangement can be made when the frame and sling cannot easily be procured. It is what Dr. Stewart calls simply "the rail pen," and recommends highly as a quick way of raising any disabled horse to his feet. He says: "All that is needed, besides the rails, is three strong planks and five or six men. The planks should be not less than one and a half inches in thickness, and at least ten feet long, and they, are to be put under the aninal's body so that they shall project equally on each side. On the planks should be spread first some hay or straw, and then an old blanket or quilt, or some carpeting, as a pad for the body to rest on. This requires especial care in certain diseases where the belly is very tender and sore. When this has been done, and plenty of rails are at hand, the preparations are complete. There should now be one man for each plank, another to handle the rails, and two to stand at the animal's head and hold him still by the bridle. Let the ends of the planks be raised on one side, and a rail laid under them about one foot from the ends of the plank, the rail being so placed that they shall be about the middle of it. Then raise the other ends of the planks in the same way. End rails can now be laid on, so as to be ready to raise the planks again.

"In this way, as the pen is gradually built up, the horse is raised along with it. When part way up, it is very likely he may struggle considerably, the position in that stage being novel and somewhat uncomfortable; but he must be held by the bridle as still as the two men at the head can hold him, and the pen raised to its proper height as soon as possible. This height, of course, sliould be such that the feet will touch the ground, and may be rested upon, if the horse is disposed to do so. The rails of the pen must be carried up still higher in front and behind, and be placed close to the hip and breast, so as to prevent the animal from surging back and forth on the planks. Lastly, heavy pieces of timber may be placed on the pen, in front and behind, to hold it firmly, and strong stakes driven down at each corner of the pen, which, by these means, will be so well secured that no movement will be posisible. The horse may be hitched by a halter to a post in front, and some planks being laid on the rails at the same place, a platform will be formed on which a feeding-box may be placed.

"Such a piece of work will cost the owner perhaps ten dollars, and consume one day of his time; but, hesides saving the horse's life, it 
will be worth fifty dollars in the practical experience gained. The contrivance may be applied in a variety of cases, which many farmers, destitute of the enterprise necessary for so simple a task, would give up as hopeless from the outset. In cases of broken legs, I have often seen this contrivance, though rude, save a valuable horse."

\section{Fracture of the Skull.}

We will now pass to what the practitioner calls special fractures; and, first, those of the skull. These are of rare occurrence, and then from falls, or it may be from hard blows on the head. They are variable in the results of treatment, according to the part and extent of the injury. When there is any depression of the bones on to the brain, the chances for recovery are very poor.

Manifestations.-There are usually some marks of injury on the skin covering the part, and a painful swelling there. When the bones are depressed, cerebral hemorrhage nearly always takes place from lacerated blood-vessels; the usual symptoms of compression of the brain follow, leading on shortly to paralysis; and in these cases there is practically no hope.

Treatment.-This will consist principally in the application of cold to the inflamed parts. Any pieces of loose bone should be removed, and the wound dressed with the Antiseptic Solution No. 1, or No. 13. When the bone is depressed, the veterinary surgeon sometimes achieves success by elevating the depressed pieces by means of a lever, to insert which he may find it necessary to cut out a small piece of the bone.

The bones of the face are oftener fractures than those of the skull, and, fortunately, the treatment is generally productive of more favorable results.

\section{Fracture of the Upper Jaw.}

The forward part of the upper jaw is liable to fracture in different directions. It may be in what is called the symphysis, or junction of the two sides, in front, or the shaft of the bone may be involved, in either of which eases the teeth may be loosened and fall out. The treatment will consist, first, in removing loose bone and teeth, and next the adoption of suitable measures to prevent morement, which is far less difficult than in the lower jaw ; it may be accomplished by binding copper wire around the teeth, and the use of bandages. 


\section{Fracture of the Lower Jaw.}

Fractures occur much more frequently in the lower than in the upper jaw, and may be in either a transverse, oblique or longitudinal direction. The teeth are frequently loosened and fall out. Our engraving will explain everything at a glance. $a \cdot a$, the median line of union, or symphysis; $b a$, line of oblique fracture: $b \quad b$, line of transverse fracture; $c$ c, line of transverse fracture.

Causes.-External violence, heavy blows, falls, kicks from other

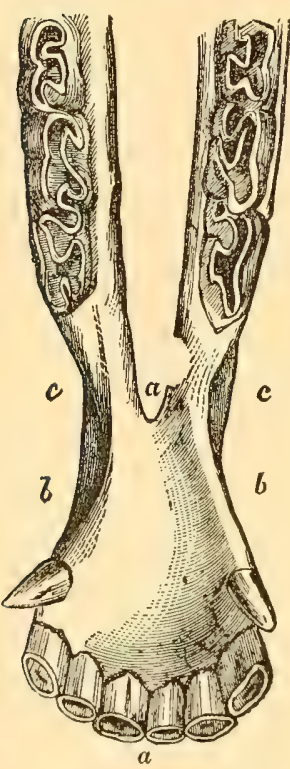

THE LOWER JAW.

The lettering indicates the different directions which fractures may take. horses, etc. They have also been seen in pulling horses.

Manifestations. - There is nearly always a dribbling of saliva, mixed perhaps with blood, from injuries of the gums. Crepitation (a slight crackling sound) may be detected from the rubbing of the bones together. In fractures through the neck of the bone, as shown in the figure on page 228 , there will be a dropping of the front part of the jaw, from loss of muscular control over it, and there will be the greatest difficulty in getting the food into the mouth.

Treatment.-This will consist in removing any broken bone and loose teeth. When the fracture is through the symphysis, it is often sufticient to wind copper wire around the front teeth (the incisors). When through the neck of the bone, it is difficult to keep the ends from moving; as a result the teeth will not come completely together, and on that account the animal will not be fit to turn on pasture. Various apparatuses have been devised for preventing motion, and among them that of Mr. Walker, V.S., the one shown in the illustration, is undoubtedly good. But the simplest method is to place a splint of gutta pereha, leather, or the like, below the jaws, and to hind up the whole head with the starch or plaster of Paris bandages, in the mamner before deseribed for setting a broken limb. In this way all movement of the jaws may be ciffectually prevented. The splint is to be left on from two to three weeks, the animal being fed, meanwhile, on fluid diet, such ats milk, gruel, etc. If the horse is mable or unwilling to take this sort of nomrishment in any other way, it will be no great trouble to inject it into the mouth or rectum by means of a syringe. 
Fortunately, a fracture of either jaw is a rare occurrence among horses on the farm. It is troublesome to feed a horse suffering from this injury, but "where there is a will there is a way." It can bo

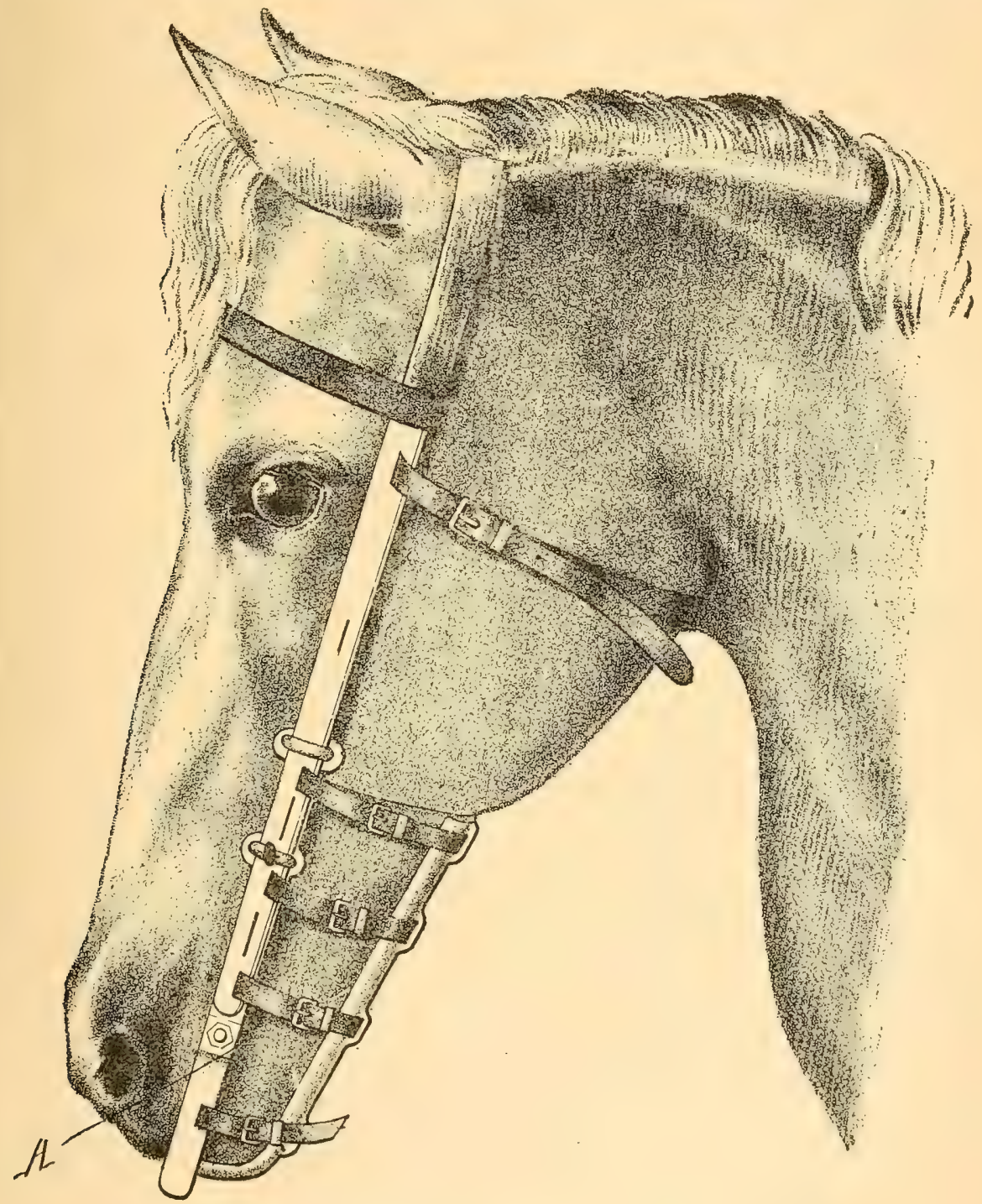

WALKER'S CRADLE FOR FRACTURE OF THE LOWER JAW.

At $A$ there is a piece. which enteris the mouth, and rests in the teeth. This greatly aids in steadying the broken bone.

done, if there is a mind to it; and the animal will often take to his diet of "slops" more kindly than was anticipated. 
VIII. Fracture of the Spine.

Fractures of the vertebral column are not of very frequent occurrence; still, many cases of old broken backs that have healed are found after death, in horses that have never been suspected as suffering from so severe an injury. When these injuries do occur, they are usually the result of falls, and are found principally in the back and loins. In the great majority of cases, the broken ends are displaced, and

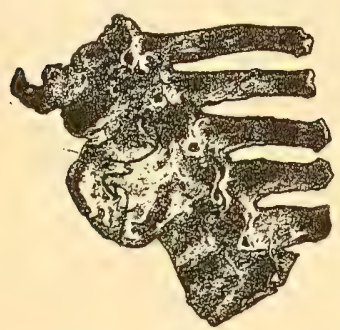

FRACTURE OF THE SPINE. press on the spinal cord, resulting in paralysis of the parts back of the injury. Oceasionally, however, there is no displacement of the bone, and the animal manages to rise and walk for a short distance, though not without great difficulty.

Treatment.-Where the bone is displaced, and the resultant paralysis is marked, no treatment can possibly avail; but there is a chance of recovery in those eases in which the horse can rise and walk a little, and for such the treatment consists in kecping him as near absolutely quiet as possible, preventing movement by securing the head, and placing the feed at a convenient level.

\section{Broken Ribs.}

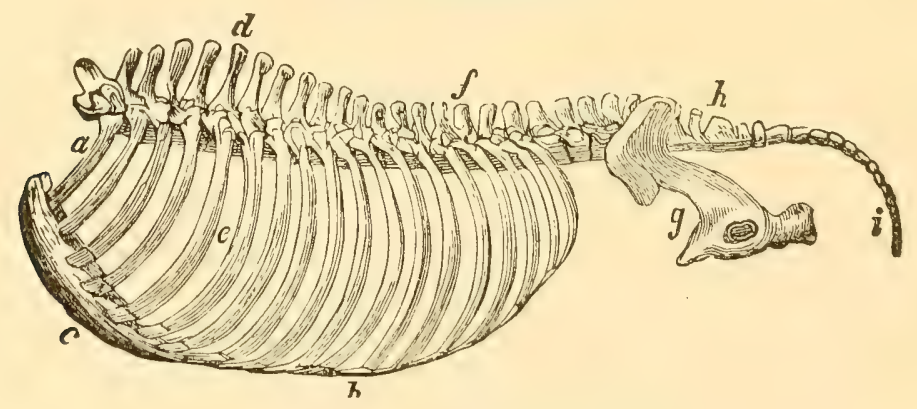

THE RIBA, VERTEBIRE, ETC.

$a$-The first rib.

$b$-The cartilages of the eleven hindermost, or false ribs, connected together, and uniting with that of the seventh or last true rib.

c-The breast-bone, or sternum.

d-The top, or point, of the withers, which are formed by the lengthened spinous, or upright, processes of the first ten or eleven bones of the back. 'I'he bones of the back (dorsal vertebra) are eighteen in number.

c-'The ribs, usually eighteen on each side; the first seven united to the breastbone by cartilage; the cartilages of the remaining eleven united to each other, as at $b$. 
$f$-That portion of the spine where the loins commence, and composed of six bones (the lumbar vertebra).

$g$-The bones forming the hip, or haunch, and into the hole at the bottom of which the head of the thigh-bone is received.

$h$-The portion of the spine (the sacrum) belonging to the haunch, and consisting of tive pieces.

$i$-The bones of the tail, usually seventeen in number.

The ribs are liable to fracture, from blows, falls, collisions, and similar violence; more especially the ribs just back of the shoulderblade, these being the more prominent ones, and, therefore, more exposed.

Manifestations.-The effects of a broken rib are very variable. In exceptional cases, it may give rise to no manifestations by which it may be recognized, the animal performing his usual work; but as a general thing there is at least some swelling, with pain and difficulty of breathing. Where there is displacement of the ends of the bone, the complications are apt to prove serious, and very frequently fatal. In these severe cases, it will be found that the pleura (the membrane which lines the chest), or even the lungs, have been cut and torn by the ends of the broken bones, the result being inflammation of the acutest type (pleurisy). One case that the writer especially recalls was a horse that had been "stove up" in a collision, a buggy shaft having penetrated the chest, breaking two ribs, and allowing the escape of the contained air'; the collapse of the lung followed, and finally death inside of an hour.

Treatment.-These conditions are best treated by rest, as movement may extend the injury. When the bone's broken ends are displaced, they must be returned to their natural position as soon as possible. This is comparatively easy when the displacement is outward, but if inward, it will be necessary to use a lever under the broken ends. Bandages of starch or plaster of Paris are then to be wound tightly around the chest, and left on for three weeks. The horse must not be allowed to lie down, the head being tied high up.

\section{Fractures of the Pelvis.}

The pelvis, composed of three bones (ilium, ischium and pubis), from the prominent position which it occupies in relation to the hind parts, is subject to fractures, which, however, vary widely in degrees of seriousmess. The point of the hip (spine of the ilium) is frequently fractured by different accidents, and sometimes the neck of 
the sime bone. In either of these injuries there is a dropping of the point, with stiffness or inability to move. In some cases, on getting the horse to limp a step or two, the grating sound of broken bones rubbing together may be heard.

The pubic bone (see engraving on page 145 ) is liable to fractures, which may be complicated by injuries of the bladder, blood-vessels, nerves, ete., and are commonly very serious in their nature.

The ischium may be fractured in different parts-in some cases separated at the junction of the two halves, from slipping; this cumes an extraordinary degree of straddling, with other evidences of great pain. The prominence which may be noticed in this bone behind, is often fractured, and the cap is then said to "knocked off." The injury last mentioned is not of a serious character, but after union

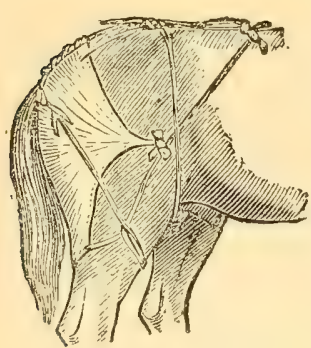

BANDAGE TOR THEIIY. there is apt to be a deformity of some sort, which may best be seen from the side, the quarter's being uneven. In some cases permanent lameness may ensue.

Treatment of Pelvic Fractures.-A goodrule to follow, when a fracture is suspected, is to place the animal in a sling, and impose perfect rest. Few cases of pelvic fractures can be expected to do very well, and if any organs or important vessels are injured, the best course is to put al bullet through the brain, and end all suffering at once. When treatmient is decided on, quiet of the part should be secured and maintained by the use of the slings, as before described in this chapter. If the injured part is back at the rear, any form of stiff bandage, similar to that shown in the above cut, will be of great benefit.

\section{Fractures of the Fore-leg.}

Broken Shoulder-blade.-The scapula, or shoulder-blade, is at times fractured from some one of a variety of causes. The spine, or prominence on the middle of the outer surface, maly be broken off by a kick or other injury; but this seldom gives any trouble in treatment. Fractures of the body of the scapula are likely to be of such a serious nature as not to repay treatment. In some cases they may inrolve the shoulder-joint, eventuating in a stiff joint after recovery. Such an ankylosed joint, as it appears on dissection, is well represented in our engraving at top of the next page. 
Broken Arm.-The humerus (see "Skeleton of the Hor'se" on page 145 ) is the strongest bone in the body, and, as might be expected,

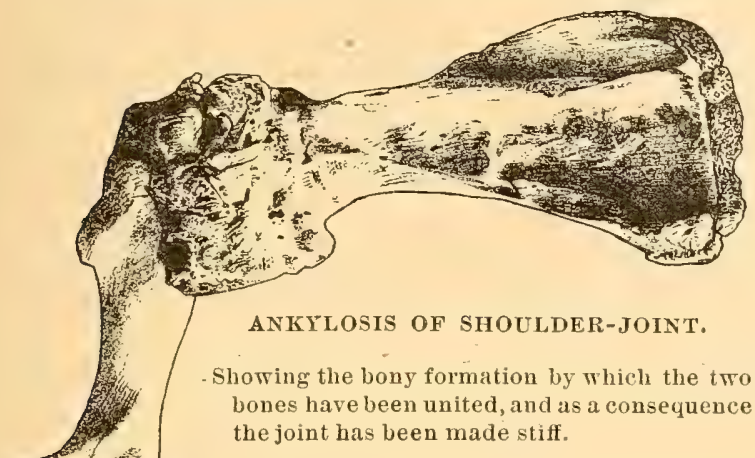

the hope of bringing and knitting them together.

has a large number of very powerful muscles attached to it; for which reason, a complete fracture of the humerus is but rarely treated, as the tense action of the muscles pull the divided ends of the bone apart, with such force as to forbid

Broken Ulna.-The ulna bone at the point of the elbow, owing to its prominent position, is subject to fractures from violence. When it is the upper part that is injured, repair may generally be effected by using splints from the foot to the shoulder. When lower down, involving the elbow-joint, the case becomes very serious, and even if the animal is saved, he is extremely likely to have a stiff joint.

Broken Radius.-Theradius may be broken, oftener than from anything else by the horse jumping a high fence. It is not very readily treated, but when handled by an expert veterinarian, the application of the splint from the foot up to the shoulder will often result favorably.

Broken Knee.-The carpus, or knee, consists of eight bones, all more or less subject to fracture, from falls, blows, etc., and usually marked by a very severe form of inflammation. This is best treated by cooling lotions, as prescribed for the treatment of inflammation in Chapter XIV. The object sought, in treating these cases, is to obtain an ankylosis of the bones involving the joint. This, when at the

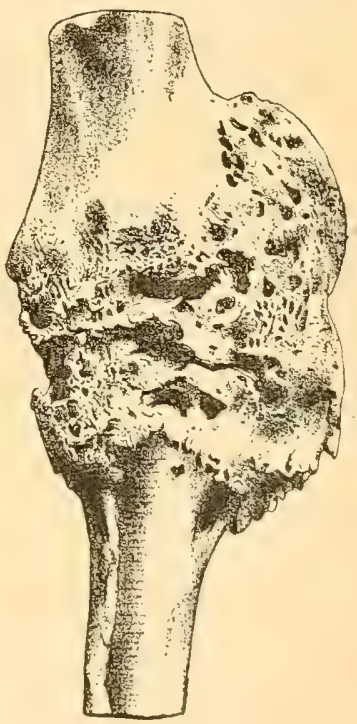

STIFF OR ANKYLOSED KNEE.

Showing the bony formation by which ankylosis has been effected. lower part, is not necessarily a rery serious result, but when high, and thus involving the true joint, stiffness is to be expected after the 
best cure possible. In this commection the reader is referred to "Open Joints," in Chapter XXI.

Other Bones of the Fore-leg.-The metacarpus, or cannon bone, is probibly the bone most frequently fractured in the whole body,

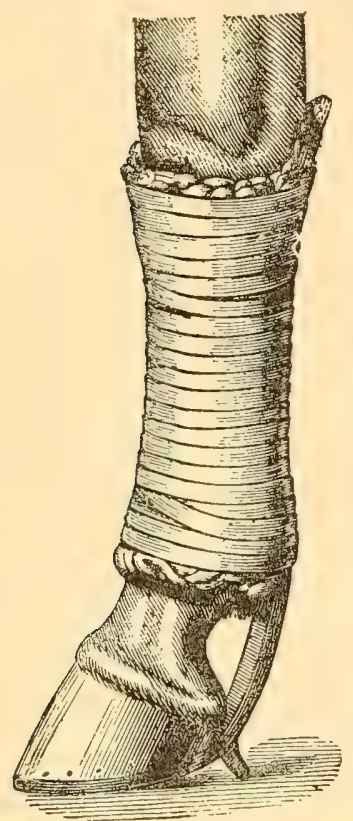

SHOE WITH IRON EXTENSION. this being due to its exposed position. When no joint is involved, there is good reason to expect success from the proper treatment, which will be to apply splints as directed for simple fractures, in Section III of this chapter.

The os suffraginis, or upper pastern, is frequently fractured, but by apposition of the ends is readily united. The same may be said of fractures of the os coronce, or lower pastern, especially in the case of young horses: The pedal bones are much less exposed to fractures; yet, by treads, the pyramidal process at the front and upper border of the hoof is at times broken. When this happens, there is commonly a wound, the joint being so superficial that it is wounded very easily. This makes a bad complication, for the treatment of which see "Open Joints," in a following chapter.

\section{Fractures of the Hind Leg.}

Broken Thigh-bone.-The femur, or thighThe extension constitutes one bone, when fractured through the shaft, is past kind of a splint.

all treatment, the tremendously powerful muscles of the leg serving to continually pull the ends of the bone apart. If, however, the fracture is of the tuberosity, or projection from the head of the femur, it is most readily repaired, by placing in slings for six or eight weeks, and allowing rest.

Broken Knee-cap.-Only rarely is the patella, or linec-alp, fractured. It may be repaired, in young amimals, by keeping the hroken parts together.

Broken Tibia.-The tibial bone, between the stifle and hock, is broken in many aecidents, and here ayain the powerful action of the muscles makes treatment diffieult, and forbids the expectation of very good results. 
Broken Hock.- The bones of the hock-joint are liable to fracture from the same causes that those of the knee-joint are. The situation as to whether high or low, is what determines the probable chance of a cure. There is strong likelihood of ankylosis, and when in the upper part the resultant stiffness is generally great. In the accompanying engraving is shown a spavin, which probably weakened the leg, and by increasing the animal's liability to slip may, perhaps, have indirectly been the cause of fracture.

The point of the hock is at times broken off, and proves a very difficult part to mend. Several conspicuously large muscles, and among the number the well known "ham-string" muscles, have their tendons inserted in this region, causing a great deal of displacement. When the break is low down on

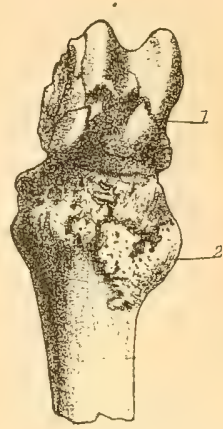

FRACTURE OF THE HOCK.

This is shown at 1 . At 2 is shown a spavin. this projection, the repairing process is very liable to leave some bony deposits that will interfere with the action of the hock-joint.

To repair these breaks, the bone must be placed in apposition, and well padded in this position with cotton first, and outside of this a cap of leather or gutta percha; over all must be used the plaster of Paris or other bandage, as already directed.

The bones below the hock are subject to the same injuries as those in the fore-leg, which have already been treated of. 


\section{CHAPTER XVIII.}

\section{DISEASES AND INJURIES OF THE FEET.}

Y. NAIL WOUNDS.—II, COINS.—III. BIUISES OF TIE SOLE.—IV. TREADS. -V. OVER-REACHING, OR GRABBING.—VI. FORGING, OIR CLICKING.VII. QUITTOR, OIR FISTULA OF THE. FOOT.—VIII. CONTRACTED HELLS OT HOOF,-IX. SAND-CRACK, OR CRACKED IOOF.—X. FALSE QUARTER. XI. TURUSH.-XII. CANKER.-XIII. FOUNDER.—XIV. HORNY TUMOR OF THE WALL, OR KERATOMA.-XV. NAVICULAR DISEASE.

\section{Nail Wounds.}

Nail wounds are of very frefuent occurrence among horses, and especially in cities, from picking up nails in traveling, or similar accidents; also from carelessness in the shoeing shop, by punching the mail holes crooked, and driving the nails poorly, so that they either enter the sensitive tissues or are placed so elose to them as to cause painful pressure from the bulging horn. Some horse-shoers can hardly put on a shoe without driving one or more nails into the sensitive part of the foot, and seem to think it all right, provided that, when the animal flinches, they are extracted and driven in almost anywhere else. Another cause of these wounds is the use of a poor quality of nails, which splinter sometimes in driving. These last are apt to be a very serious class of cases.

A nail wound ought never to be neglected. Aside from the danger of lockjaw, which none can ever feel absolutely secure against, there are serious ills lurking, possibly, in the train of even a slight injury from this cause. As illustrating the evil results of a neglected nail wound, we mention a case that we have just treated in St. Louis, while writing this book, in September, 1892. In this case a large nail entered the sole near the point of the frog, puncturing the navicular joint. The animal worked for five days, at light hauling, as usual, then became very lame, and when we were called in on the ninth day, pus tad broken out at the heel. In treating this case it was found necessary to remove the whole frog and sole, and thoronghly expose the diseased parts. The parts are growing again, and will be as sound as ever, but the navicular joint will always be stiff, from the action of filth which gained entrance to it, with the nail, when the wound was received. 
Manifestations.-The effect of a nail wound will depend on what part of the foot has been injured. A picked or gathered nail is generally found along the region of the frog, near the point of which the most serious result may be expected. As the sole just here is very thin, the nail is very liable to injure the bone, and eren the navicular joint. In wounds around the posterior part of the frog, there is very frequently no inconvenience after the nail has been extracted. At times nails apparently a great distance in the foot are found to have entered in a slanting direction, and only injured the crust.

When it is a case of poorly driven nails, the animal's lameness commonly tells the tale in a very short time, though occasionally lameness has not shown itself for several weeks. Of these dilatory cases a large proportion are those in which the toe is the part affected. After bad shoeing the foot will be found hot, and on tapping or pinching it over the faulty nail the animal will flinch unmistakably; in some cases he will try to walk on the opposite side of the foot. On removing the shoe, the faulty nail will generally be found to have discolored the horn around the hole.

Neglected nail wounds are apt to suppurate; the pus burrows in the direction of least resistance, and the outcome is a separation of the wall or sole. Ultimately the pus appears at some weak spot, generally at the coronet or the region of the frog, and then there is established a case of quittor.

Treatment.-As soon as the trouble is discovered, remove the shoes, and pare the nail wound to the sensitive parts, for which purpose the sage knife is most useful. It is shown in the accompanying cut. In many cases nothing more is required, except to pour a little turpentine into the hole. Where, however, much lameness is ev-

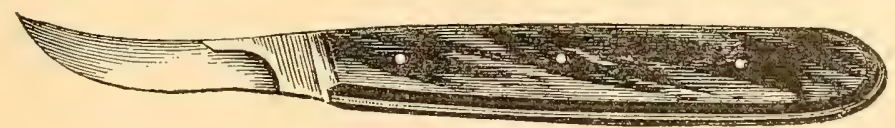

SAGE KNIFE.

idenced, soak the foot for half an hour in hot water, and afterwards apply a hot poultice, to be renewed when cooled. If pus has formed and burrowed under the sole or frog, the undermined parts must all be removed, (as they will not grow together again), and the fresh surface dressed with tow soaked in the following mixture:

No. 15 .
Blue-stone (blue vitriol), 1 part.

Oil of tar,

Mix.
4 parts. 
When the pus gathers at the coronet and bursts, then the case has become a cuuttor, and is to be treated accordingly. (See Section VII, of this chapter.)

\section{Corns.}

These are the bane of horse flesh, and it might be added that they are the result of civilization, as among unshod animals they are rare indeed. A corn is a bruise of the sensitive structures at the inner or outer heel of any of the feet, but is seen more commonly on the inner side of the front feet. It is something not to be neglected with impunity, for there is a possibility of its developing in a disease that may extend to the bones, and eventuate in caries or ulceration.

Causes.-A predisposing cause of corns in many cases is the shape of the foot, such as the flat, thin sole, or the quarter thick and straight. Among other causes the most common are bad shoeing, the shoe being put on so as to press on the heel, or the heel cut down too far, and from gravel working under the shoe. Corns are always to be regarded as constituting an unsoundness.

Symptoms. - As a consequence of the bruise, blood appears in the horn substance, staining it a red color; but the exact tinge will viry, according to the duration of the trouble, from a yellowish to a dark red color. In heels unusually perpendicular it may be necessary to cut deep down before finding any discoloration.

The weather has a great effect on a corn. In cold weather by contracting, and in warn weather by expanding, the foot, it presses upon or, again, distends the sensitive structures, and causes lameness.

The lameness of corns may ordinarily be seen in both walking and trotting; the heels are felt to be dry and hot, and pressure with the pineers, or tapping with a hammer, will elicit signs of pain. In walking, the weight is likely to be thrown on the opposite sicle of the foot; in standing the foot will be rested on the toe.

In neglected cases pus is formed, and the inflummation may extend and become as severe as to produce caries or nlceration of the bone, which makes a case well-nigh incurable. At times the disease results in the formation of quittor, or of sidebones.

Treatment.- The first thing to do in treating corns is to remove the cause, which is generally the shoe, and the next is to pare down the lom orer the bruined surface, and lower the wall at the heel, to relieve weight and pressure. If pus is suspected, a good opening must be serared for dianage. Apply barace hot laxised poultices to the entire 
foot, renewing them twice daily. Where the animal is decidedly valuable, do not think of putting him to any work until amply sufficient time has passed to allow the entire bruise to disappear. In subsequent shoeing, keep the pressure off the heels, by lomering the neighboring wall, and putting on a three-quarter bar or a full bar shoe for several shoeings.

When there is suppuration, the use of tow and tar retained by a leather sole, or the mixture No. 15, combined with the bar shoe, will generally effect a cure. Neurotomy ( see chapter on Operations) may be performed in chronic cases, the low operation being the preferable one, as it leaves some sensation in the foot.

\section{Bruises of the Sole.}

These are frequently seen, especially in thin-soled feet, as a result of stepping on stones, or of badly fitting shoes, or burning with a hot shoe in fitting, cutting too much sole off, etc.

Symptoms.-The resultant lameness is seen both in walking and trotting, and when the foot touches the ground, particularly where it is rough, there will be a great deal of dropping or bobbing of the head and front parts. The foot is hot, and pain is evidenced on pinching or tapping it. If pus should form under the sole, the resisting hoof will cause pressure on the nerves, and so severe will be the suffering that the animal will refuse his food, put his nose to his foot, and manifestly be in a general state of fever.

Treatment.-Remove the shoe, pare the sole over the tender spot; and if it is a simple bruise, by using hot poultices a farorable result is to be expected. If signs of pus are shown, a good opening must be made, and in case it is found to have undermined the hoof, all the loose horn must be removed. Then apply a hot poultice, and later use the mixture No. 15. A bar shoe may be used until the horn recovers its natural state.

\section{Treads.}

A tread is a cut or bruise of the coronet, from being stepped on by the heel of the shoe on the opposite foot, and is mostly seen on the hind feet.

Manifestations.-The cut or swelling of the coronet, combined with lameness, is the unmistakable sign. In some cases the hlood-ressels around the coronet are ent, and bleed profusely. Pus may form, the trouble having run on into quittor. The pyramidal process of the pedal bone extends, in front, up to the hoof, and, in connection with 
treads, is liable to be fractured; and the joint between this bone and the lowror pastern may be punctured, causing an open joint. These complications make the affair a very serious one.

Treatment.-If much bleeding ensues, bandige the cut with some cotton batting soaked in tincture of ehloride of iron or Friar"s balsam, or even, in a hurry, use the dry cotton. When there is simply a painful swelling, apply a hot poultice, and if the presence of pus is suspecter, open the lump immediately. The cut thus made may be healed by sponging with the following lotion twice a day:

$$
\text { No. } 16 .
$$

Sulphate of zinc, $3 / 4$ ounce.

Acetate of lead, 1 ounce.

Pure water, 1 quart.

Mix, and shake well before using.

For the treatment of open joint and quittor, see their separate headings.

\section{Over-reaching, or Grabbing.}

This consists of a cut or wound of the coronary band of the front foot, by over-reaching with the hind foot, it being produced by the inner margin of the shoe.

Treatment.-Cleanse the wound thoroughly, and when the skin is badly cut, insert a few stitches. Dress the cut with No. 12 or No. 16.

\section{Forging, or Clicking.}

This is not a disease, but the result of defective action or of bad shoeing. The toe of the hind shoe strikes against the inner side of the front shoe, either from the front foot being lifted too slowly, or from the hind feet being moved too quickly. The peculiar action that produces elicking is sometimes noticed in horses that are tired or out of condition, the same animals being free from this defect when in health.

Treatment. - Shoeing is the usual recourse, but it is worth knowing that in many cases the trouble may be remored simply by careful diring, holding the animal in hamd, and not foreing him heyond his natural gait. Shortening the front toe, and turning the toe of the shoe up, will be of service; probably the elicking may be stopped by setting the hind shoe batek and using the side chps, instead of those usually placed in front. But the horn may still strike the front shoe and be worn away. In some cases the disagreable noise will continue, in spite of almost any expedient to prevent it. 


\section{Quittor, or Fistula of the Foot.}

That quittors are not of such frequent occurrence now as in the past, is due, probably, to the better care which is taken of stock. In some parts of the country they are much mole common than in others. A comparison of the eastern cities with the West is, in this respect, greatly favorable to the latter. Quittor is a fintulous opening on the swollen coronet, communicating with some irritating substance within the foot, such as diseased bone or cartilage, or other disordered structure. Its discharge of pus is nearly continuous, and when, as is often the case, this has minute pieces of bone or cartilage mixed with it, it will have the characteristically offensive smell of dead bone.

Causes.-Wounds, bruises, filth, over-reaching, pricks by nails, burns by hot shoes, corns, and any inflammatory condition in which pus is formed under the hoof, and there retained.

Symptoms.-Lameness is an invariable accompaniment of quittor, but varying in severity, according to the parts involved, whether the bones, cartilage, tendons, or the joint. From the opening on the swollen coronet there will be the purulent discharge already spoken of. On probing the opening, it may sometimes be found to subdivide internally in several different directions; or, again, several external openings may all lead to a single centre of irritation.

Treatment.- This is similar in principle to that of all wounds, namely, a remoral of the cause. In many cases, however, this is a very difficult thing to do. If due to a corn, cut out the heel freely; if to a nail, pare down the hole. In any case secure free drainage from the bottom, if possible, and thus change the nature of the wound into a simple one.

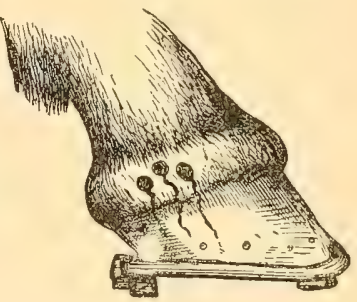

A CASE OF QUITTOR.

Showing three openings on the swollen coronet.

When dead substances act as irritants, they must be removed by the use of some application or other that will ease them to slough out. Many thing that have been employed for this purpose are very dangerous, but No. 2 is very good, when used once a week; or the following may be substituted, and injected fwo or three times a few days apart, afterwards allowing the horse a good interval of rest.

No. 17.

Chloride of zinc, 2 ounces.

Pure water, 1 quart.

Mix. 
Firing with a pointed strong wire, heated to white heat and passed to the very bottom of the "pipe," is often a very successful mode of treatment.

\section{Contracted Heel or Hoof.}

In all parts of the country there are numerous cases of contraction of the hoof, or narrow heel, as it is popularly called. The shape of the hoof is nearly round when the foot is in its natural or healthy condition; but sometimes the hoof becomes elongated, the toe extending forward, and the parts toward the heel dropping in together.

Causes.-It is a prevalent opinion that contraction is the result of defective shoeing; but this is certainly a mistake, because otherwise the trouble must occur much oftener than it does. This is not itself a disease, but merely the result of an unhealthy condition of the feet, in many cases due to a loss of moisture, with the consequent drying and atrophy of the hoof. Disuse of the frog must also take an important position as a cause of "narrow heel," - for instance, when the frog is elevated by the use of calks. In many ailments of the hoof, conspicuously in navicular disease, contraction is seen as a marked symptom.

Symptoms.--So long as all the parts included within the hoof are in their natural state, the hoof will remain natural and solid; but let disease commence, no matter how originating, and the parts shrink away, the sides of the hoof fall in, and the whole foot becomes misshapen. The hoof often assumes great irregularity of outline. One side may drop in more than the other; the lower parts of the heel turn in, or, it may be bend outward; or the toes are elongated beyond all proportion. The frog will always be found pressed in between the bars, and greatly diminished in size.

Generally, there is some lameness, though its manifestation is frequently nothing more than a constant uneasinesis and shifting from one foot to the other, and an unwillingness to exereise, with a stiff or stilty gait.

Treatment. - We know of nothing which ean properly be called a remedy; contraction will cease when the disease that caused it has been eured. Parung may, perhaps, be of some adrantage. Of all the forms of shoeing recommended, none are of any eretain benefit. The kinds most favored are the half shoc and the light slipper. The half shoe should come as far back as the anterior part of the bars, the balance of the sole resting on the ground. This is on the prin- 
ciple that frog pressure is needed. As to the slipper, it should be made narrow at the heel, and come to the point of the same; its outer part thin, and the inner edge thick, thus helping to expand by pressure outwards on the heels. Various styles of springs have been invented for expanding the heels; they are placed inside the shoe and work very satisfactorily, the greatest objection to their use being their frequent loss in traveling.

The horse's usefulness is not always essentially impaired by contraction of the hoof. Though incapacitated for rapid motion, he may still do very good slow work in the plow or wagon.

\section{Sand-Crack, or Cracked Hoof.}

This disease is called sand-crack, from the prevalent opinion that such cracks occur in sandy regions much oftener than elsewhere. Such is not the case, however. This belief has obtained from the fact that these cracks are liable to become filled with sand, when they are always very troublesome.

Causes.-Sand-crack is usually the result of a longstanding disease and feverish condition of the feet, from various causes. The hoof becomes hard, dry and brittle, losing all the elasticity and roughness that belongs to it in health, and by and by it is seen to be cracked open.

Manifestations.-The fissures may occur in any direction, in some cases extending only partially through the wall, but in others reaching clear through to the sensitive parts, which may, perhaps, fill the spaces, with the result of great pain, and more or less bleeding on any movement of the limbs. The cracks are mostly seen about the front feet, and on their inner quarters; when the

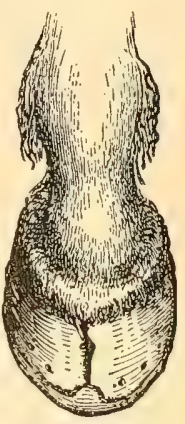

SAND-CRACK.

In this case it is at the toe. hind feet are affected, the spot is generally in the centre.

Treatment.-If the coronary substance, that which secretes the wall of the hoof, is in a healthy condition, pare the edges of the crack up to the origin, in the form of a $\mathrm{V}$, as shown in the next illustration. This will allow a solid growth of hoof. Mild blisters, as No. 11, may with advantage be rubbed on the coronet above to aid the growth, which will be pretty well completed in about six weeks. In case the crack is not in a favorable condition for this treatment, or the animal is needed for work, the use of a mechanical device is required to keep the fissure closed. Take an ordinary horseshoe nail, 
or two or three of them for a-large crack, and drive carefully in across the opening and elinch the ends. These for most purposes

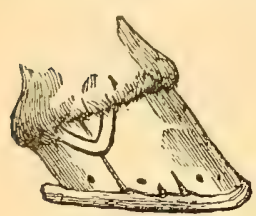

HOW TO PARE A CRACKED HOOF. answer very well. Or two nails may be driven on each side, and a wire wound around the ends. Copper plates are sometimes screwed on, but there is a drawback to their use, and that is screws are apt to be lost. Several very good styles of patented plates are likewise in use.

In shoeing, care must be taken to remove pressure from the crack, by lowering the wall; and when at the toe, have side clips on the shoe.

\section{False Quarter.}

In this, which is a disease of the coronary band, consequent on some accident, or as a sequel of quittor, treads, ete, the band, or secreting substance, secretes an imperfect horn incapable of sustaining

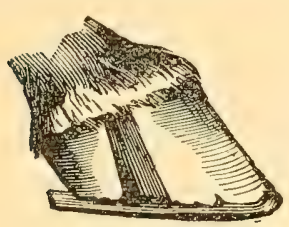

FALSE QUARTER. weight. There may be great lameness, and a raw surface, in the acute stages; but soon a sort of horny covering is formed, which fills the opening, and the animal will work thenceforward without further trouble.

Treatment.-False quarter is, as a rule, incurable, in the sense that the genuine hoof will never form again; yet a substitute horn is secreted, which will be at good protertor, and qualify the animal to be worked as usual. When there is a raw surface, tow and tar should be used to keep out the dirt, and a light blister be applied to the coronet to aid the growth. Our No. 1.1 is a good blister for this purpose. Use a bar shoe for several months to distribute the weight.

\section{Thrush.}

This disease is characterized by a continuous discharge of very offensive matter from the frog and heel of the foot. The cleft of the frog is from one-fourth to one-half an inch in depth. The exudation of purulent matter from this region sometimes continues for a long time before the inattentive owner beeomes aware of it. When thrush has an independent existence as a local disease, it is cenerally the consequence of standing in a damp, wet stable; or it may be produced by injuries of the frog. There is no disease of the horse's foot but. may he, and often is, the cause of thrush. In the great majority of 
cases it is the result of gross negligence and mismanagement; it would be a rare visitant of our stables if they were kept cleaner and dryer. We trust that to few of our readers the following advice will be applicable, but those to whom it is, cannot act upon it too promptly:-Throw out the great piles of manure that have been accumulating in your stable, and in which your horse has been so long standing, to the great detriment of his health and vigor, and, instead, give him a good bed of dry straw or sawdust. Do this, and you need have little fear of being compelled to undergo the trouble or annoyance of treating any cases of thrush or similar disease.

Treatment.-Remove at once to a clean, dry place, and administer the following purgative pill:

No. 18. $\quad \begin{aligned} & \text { Powdered aloes, } \\ & \text { Calomel, } \\ & \text { Vaseline, lard or water, sufficient. } \\ & \text { Mix, making one pill. }\end{aligned}$

Remove all filth from the frog, and pare off all ragged edges, thus exposing the diseased spot; then put on a flaxseed poultice, with a little carbolic acid in it. To dry the discharge, take a little calomel, and press it to the very bottom of the crack, and then fill in the outer part with cotton batting or tow. This should effect a cure in two or three dressings, provided the foot is kept dry. The use of No. 15, after the discharge has dried, will complete the treatment.

When the disease is the result of an impoverished condition of the system, use the Tonic Powders No. 19. In such cases the disease is very apt to return.

\section{Canker.}

This disease is not very often seen in America. It is usually the sequel of some other affection, such as neglected thrush, quittor, nail wounds, etc. The class of animals most subject to it are heavy draft horses that have been kept in filthy, damp stables.

Symptoms. - The sensitive tissues become so badly disealsed that insteal of forming healthy horn, they secrete masses of (heesy substance, or imperfect horn cells, which have furrows between, whence issues a peculiarly foul and filthy discharge. So strong is the tendency of this disease to extend and involve the whole sole, and so difficult is it to cure, that, unless the animal is valuable, it will not repay treatment. 
Treatment.-First remove all loose and diseased horn, and apply a carbolized poultice, as directed for thrush. To remove the growths use a strong caustic, such as nitric acid, corrosive sublimate, sulphate of copper, nitrate of silver, butter of antimony, or sulphuric acid. As the efficacy of most causties is apt to be impaired by frequent use, it is often necessary to change them. Whichever the one adopted, it must be applied very thoroughly, and re-applied when any signs of the growths are seen. The sole must be packed with tow and tar, using firm pressure, and careful precautions be taken to keep the feet perfectly diry.

When the animal is debilitated, or the disease is probably chargeable to a vitiated condition of the blood, change the feed to a diet easily digested, and use the following powders, and regulate the bowels with the Purgative Pill No. 18:

No. 19.

Powdered sulphate of iron, 3 ounces.

Powdered gentian, 2 ounces.

Powdered poplar bark, 4 ounces. Mix.

Divide into twenty-four powders, and give one night and morning in the feed.

\section{Founder, or Laminitis.}

This disease is known by a variety of names in different sections of the country, such as fever in the feet, water-founder, corn-founder, grass-founder, and others. It is an inflammation of the various structures that secrete the hoof, namely, the sensitive sole, the frog and coronary band, and thence extending to the bones. The hoof being a horny, unvielding box, the swollen tissues are greatly compressed, causing the most intense pain. Founder is seen in both the acute and chronic forms; in the latter there is usually more or less alteration in the shape of the hoof, and the pain is thereby rendered less acute.

Causes - Concussion on hard roads; orer-exertion; breaking lonse and over-eating, especially of feed unsuitable; drinking too much cold water after a hard drive, and throwing too heary a weight on a particular foot, on account of the opposite one being injured.

Symptoms.-There are variable. Sometimes they are well marked, the horse indieating the nature of his sufferings with ummistakable plaimness; but not unfrequently they are so obseure as to be mistaken or entirely overlooked. The first noticeable sign is the horse's 
restlessness and the frequent shiftings of the fore-feet. The pulse is quick and hard, the nostrils lave a red and florid appearance, and a condition of extreme suffering is indicated by an anxious, woe-begone look, with repeated or heavy grunts.

When the front feet are affected, the horse, as he stands, will extend them far in front, resting on the heels, meanwhile keeping the hind feet under the body to take the weight off the painful parts. When the hind feet are affected, he will also rest on the heels, but all four of the feet are then brought under the centre of the body, so as to relieve the weight from the hind parts. When backed, a foundered horse does so with difficulty, dragging the feet along the ground.

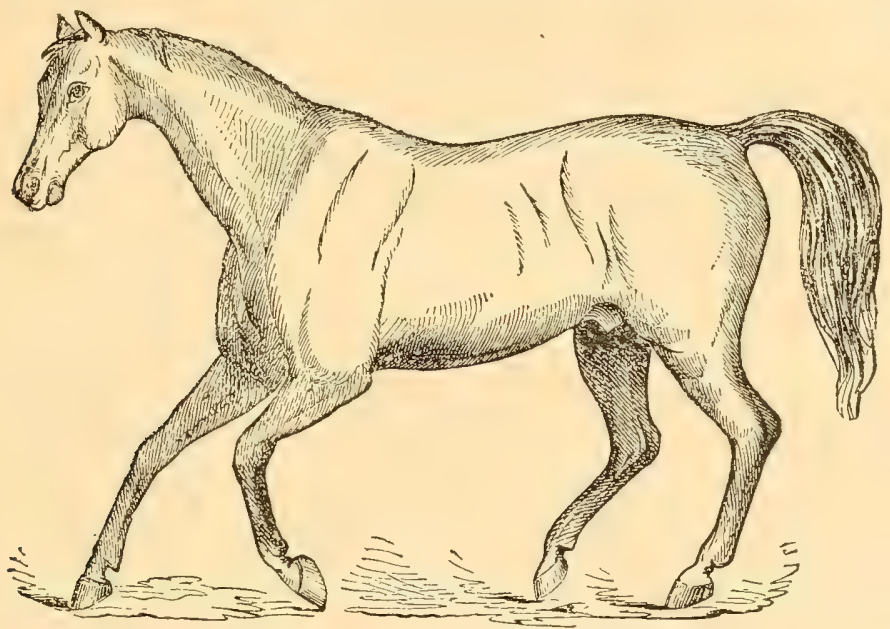

A FOUNDERED HORSE TRYING TO WALK.

Movement forward is generally much easier, but it is a quick motion, with the weight principally on the heels.

In the acute stages, the sufferer does not stand long upon his feet, and yet cannot lie down in the natural mamer; but, after maling several efforts to do so, he will rise up, turn round, change his position, and then resume his feints of lying down. Sometimes these efforts will be repeated three or four times before he accomplishes his object, which he finally does by dropping to the ground like a log. The stillness with which he lies upon his side is proof at once that the attack is not one of colic; while his changed look of relief and comparative ease declares, as plainly as words could, what his disorder really is. After a time he rises upon his haunches to get up, 
but, overcome with the pain in his feet which the effort occasions, he suddenly drops upon his side again. Putting his head around to the feet, he rests his nose upon them, as if to point out the seat of his acute pain, and to plead, as well as he can, for some relief.

In the chronic form, the prodacts of the inflammation separate the wall from the inmer parts, and the material formed presses the peral bone on to the sole of the foot, which is bulged downward, and in some cases the point of the bone is forced through. The secretion of horn is interfered with, and the wall is ringed, as shown in the illustration, the hoof becoming greatly deformed.

Treatment.-Remove the shoes, and give the following mild purgative pill:

No. 20.

Powdered aloes,
Powdered ginger,
Vaseline or lard, suflicient to mix.
Make one pill, and administer prompty.

There is a difference of opinion as to using hot or cold applications for this trouble. The writer has used, and seen used, both forms of treatment, with equally good results. In any case, it will be a good plan, if possible, to place the animal in slings, and the feet in tubs,

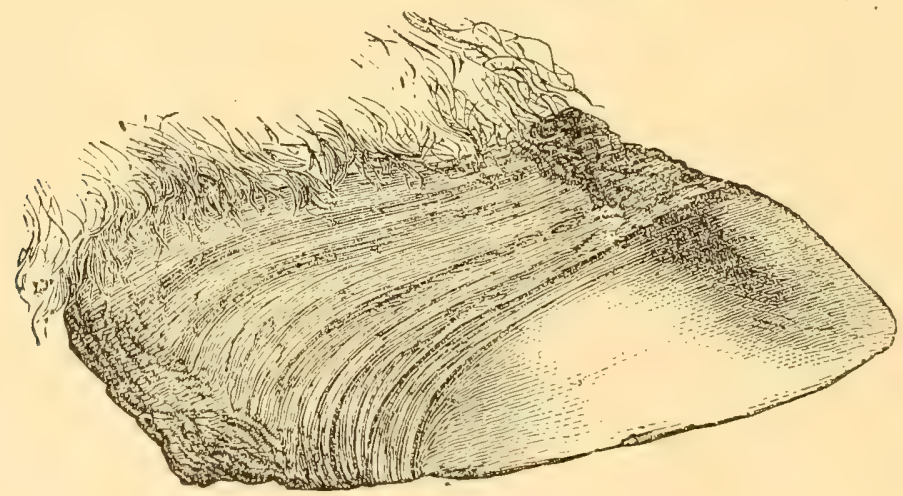

THE RESULT OF CIIRONIC FOUNDER.

containing either the hot or ice-cold water. This will give great relief. Afterwards apply large poultices of flax-seed, to be changed, as soon as the heat or the coldness (according as the hot or ice-cold treatment is the one adopted ) begins to leave them. By eneourange the animal to lie down, there will be a very decided benefit noticed, and if the feet could be elevated, the effect would be better still. 
Bleeding, both from the jugular vein and from the toe or coronet, is practiced, but only during the very first stages, and in animals decidedly robust.

For the fever give the following powders, one every four hours, on the tongue, and feed soft and easily-digested food.

No. 21.

Antifebrin, 3 ounces.

Nitrate of potash, 2 ounces.

Mix, and make into twenty-four powders.

Treatment of Chronic Founder.-The treatment of the chronic form will consist in removing the fever by cold, and afterwards shoeing carefully, in the style best adapted to the condition of the foot, using a good wide-webbed shoe, well hollowed out, to prevent pressure on the bulging sole.

\section{Horny Tumor of the Hoof, or Keratoma.}

Horny tumors, in rare cases, are found growing from the inside of the wall of the hoof. By pressing on the sensitive parts they cause lameness, and eventually maly bring about an absorption of the bone. They are most commonly seen at the toe, and may be caused by the use of toe clips, or from standing with the heel of one foot resting upon the other. The horn of the part becomes mealy, and losing its fibrous nature, is short in grain, and not of the natural color. Lameness sometimes delays its appearance until late in the disease, when it is usually very severe.

Treatment.-Remove the shoe, and follow the tumor up the wall until its origin is located; then remove it, and dress with tow and tar. In the next two shoeings, be careful to reduce the pressure on that part of the wall.

\section{Navicular Disease.}

This is also known as groggy lameness and chest founder. It is a disease which in the past was very imperfectly understood, and even at the present day there is a great deal of speculation in regard to it, with a wide difference of opinion as to the parts affected first.

Causes.-It has been pretty well settled that this disease is hererlitary. In other words, a conformation of the limbs favorable to its development is held to be transmissible from the parent to the offspring. It is also seen in connection with inflammation of the navicular joint, in consequence of nail wounds, stones bruising the frog, 17 
or sprains of the tendon passing under the navicular bone. It is a strange fact that certain colors among animals seem predisposed to it, enpecially light sorrels and hays. The most likely explanation yet offered is that color has some connection with the constitution. As before intimated, certain conformation or shapes of the limbs also show special liability to it; thus it is very commonly associated with a narrow chest, long legs and spread feet.

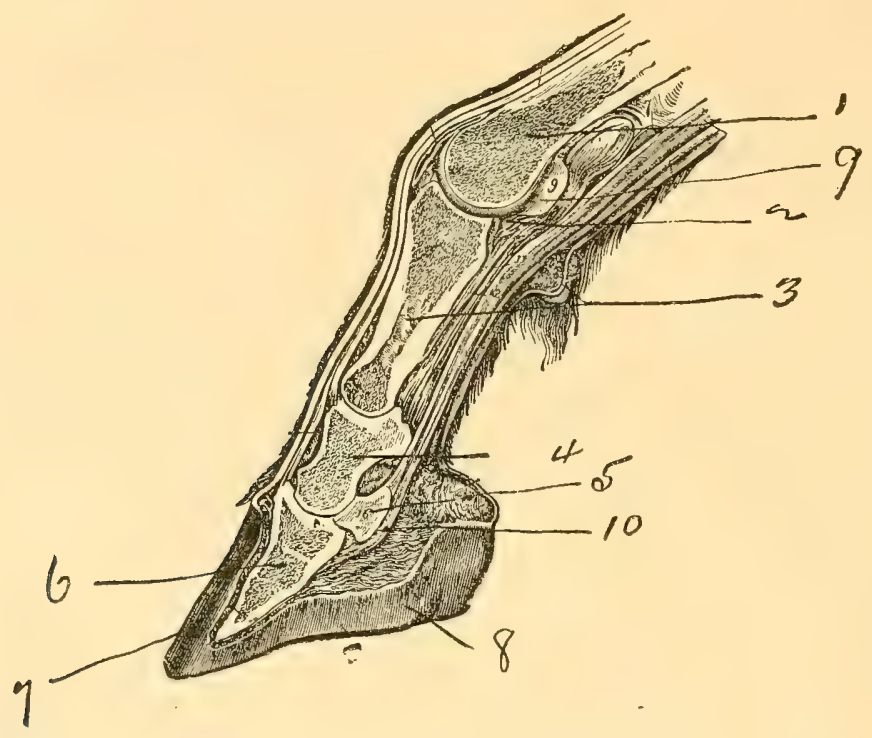

SECTION OF THE FOOT, AND PASTERN AND FETLOCK JOINTS.

This very instructive view illustrates, among other things, how easily the coftin-joint (a little to the left of 16) may be torn open by treads. The seat of navieular drsease is the tendon shown at 10.
1-Cannon or shank bone.
2-Fetlock joint.
3-Upper pastern.
4-Lower pastern.
5-Navicular bone.

6 -Coflin or pedal bone.

7 -The Hoof.

$8-$ Frog.

9 -Sesamoid bones.

10-Tendon under the navicular bone.

Symptoms.-Navicular disease rarely comes on suddenly, unless the result of an accident, and it is usually slow in progress. An uncasiness, or shifting of the feet, is the first thing noticed, the foot being rested on the toe, in wheh respect it differs from shoulder lameness. In the latter the foot is placed forward, but laid that on the floor. When taken out of the stable in the morning, or after resting from a hard drive, the animal moves off in a very stiff and stilty manner, and rery likely stubs his toe; hut in a short time the 
trouble wears off, and he goes as well as ever. Another symptom not infrequently noticed is the shifting of the lameness from one foot to another, or it mily even disappear for a time, in these ways simulating rhematism.

The hoof is dry ; discoloration of the bars is oceasionally seen from effused blood; the coronet is feverish; and pain is evidenced on tapping the foot with a light hammer, or on pressing in the hollow above the frog. The muscles of the chest will atrophy or sweeny; the foot contract, principally at the heels, and by and by the animal is found to be so crippled as to be unserviceable. When the foot of a navicular horse is dissected, the bone will be found to present a wormeaten or honey-combed appearance, and the tendon opposite will be softened and ragged.

Prevention.-Much can be accomplished in this direction by breeding only from sound stallions and mares; the disease being hereditary, anmals affected with it, should on no account be used for breeding purposes. In young animals, keep the feet properly pared down, but do not allow the shoer to pare the frog, as this will allow of bruises.

Treatment.- When a cure occurs it is through a joining of the tendon and bone together. Whenever this disease is suspected, shorten the toe, thin the sole, and apply large soft poultices. Strong blisters, such as the Fly Blister No. 7, or Oil Blister No. 8, may with advantage be thoroughly rubbed around the whole coronet. Give the patient a run at pasture for at least two months. In aftershoeing, thicken the heel and turn up the toe.

Setons through the frog are sometimes used; and neurotomy, or dividing the nerves of the foot, is performed as a last resort. (See chapter on Special Operations.) 


\section{CHAPTER XIX.}

\section{THE FOUNDATION PRINCIPLES OF SHOEING.}

I. SHOETNG A GREAT BUT NECESSARY EVIL.-II. IMPORTANCE OF ACCURATE KNOWLEUGE IN SHOEING,_II. THE TWO-FOLD OBJECT OF SHOEING.-1V. APPEARANCE VER: US UTILTTY_-V. GENERAL PLAN OF THE FOOT"S STRUCTURE.—VI. BONES OF THE SHANK AND FETLOCK.——VII. BONES OH THE FOOT,—VIII. LIGAIENTS AND TENDONS OF TIE FOOT.-IX. TILE CARTILAGES AND CUSHIONS OF THE HOHSE'S FOOT. - $\mathrm{X}$. THE SENSITIVE FOOT, OR "QUICK." - XI. THE WALL, OR CIUST, OF THE HOOF.—XII. THE SOLE.-XII. THE FROG.—XIV. AS TO MUTUAL DELENDENCE OF THE PARTS, AND SYMMETRY.—XV. STRUCTURE OF THE HOOF.-XVI. THE PRODUCTION, GROWTH AND DECAY OF HOOF.—XVII. TWO PERTINENT QUESTIONS.—XVIII. PIOPLIR RELATIVE POSITION OF FOOT AND LEG.XIX. PROPER FORM AND BEARING OF THE FOOT.

\section{Shooing a Great but Necessary Evil.}

The horse was subject to a sad necessity when shoes were first put on his feet, which was probably not done previous to the twelfth or

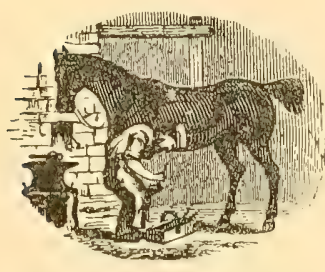

THE SHOER AT WORK. thirteenth century. Before this period he had no protection for his feet, and needed none, except that which the all-wise Creator had giventhe hard, horny hoof. This, in the early ages of the world, answered every purpose; but now, in this artificial age of unyielding, flinty roads, an artificial protection seems indispensible. Perhaps no greater curse has ever been inflicted upon the horse than this of shoeing. Ilis feet are injured-often ruined-by it. Noreorer, it frequently eauses diseases which ruin not only the foot, but other and more vital parts. But although the evils of shoeing are many, and the sufferings of the horwe often great in consequence, the world is arlvantage obviously recpures this submission of the brute to the use of man. Horses, if used at all on our present roads, must be shod. All that we hope to do, in writing on this subject, is to prevent, as far as possible, the infliction of umeeessaty evils upon the horse, by pointing out wherein they consist, and recommending a better pratefiec than is usual in the art of shoeing. 
Horse-shoeing has been discussed for ages, and hundreds have been the inventions for the improvement of the shoe; yet but little progress has been made, and the subject is scarcely better understood than it was a century ago. But the truth seems to be that the prevalent evils in shoeing arise not so much from want of knowledge as from carelessness and indifference on the part of workmen.

A practical work like this would assurerlly be incomplete, without plain directions for preparing the foot and putting on the shoe. The subject has never been more ably treated than by the English veterinarian, W. Hunting, F. R. C. V. S., from whose masterly treatise we quote at some length, believing our reader's will thank us for so doing, because of the immense importance of this subject; for the old adage, "the legs of a horse are the horse," when understood as including the feet, is almost literally true.

\section{Importance of Accurate Knowledge in Shoeing.}

"The fact that about 50 per cent. of our horses are lame, and that of these at least one-half suffer from preventable disease of the foot, is sufficient to indicate gross mismanagement, and to show the importance of a correct understanding of the foot. From colthood upwards the majority of horses' feet are submitted to ruinous influences. Animals intended for such artifical circumstances as work on hard roads and constant shoeing, should have their feet preserved in the most perfect condition. A firm, dry soil and perfect liberty render it almost certain that the hoof should acquire the desirable solidity and compactness, but how often do we find the yearling under totally opposite condition, either in a small low pasture, a loose box, or a dirty, wet fold-yard. The vitiated horn, the disproportionate, overgrown, and sometimes flat feet, due to such uncongenial situations, are incompatible with perfect equine form and action. A 'fine-topped' horse, with short legs and well-developed muscles, must have a sound hoof by nature. Yet, though it is unfair to credit the farrier with all the ills the foot is heir to, he camnot be acpuitted of frecuently aggravating matters.

"The mechanical skill brought to bear is now equal to the task, but correct principles have to be systematically arringed and cnforced. Horse shoers are not skilled specialists. They have been left in ignorance, and know no more of the structure and functions of the foot than a farm laborer knows of the intimate structure of a hedge-stake 
he is called upon to point. Horses' feet never would have been 'peeled' as they have been, unless the farriers and their veterinary master's had been very inadequately educated. Consider what is involved in the act of shoeing. A farrier not only gives to the foot a definite form, but insures the retention of that form, whether good or bad, for the time the shoe remains on the foot. In fact, the wellbeing and usefulness of the entire limb is in his keeping.

\section{The Two-fold Object of Shoeing.}

"The primary aim in shoeing horses is the preserration of the foot and the maintenance of its form in harmony with the position and action of the limb. A secondiry, though very mportant, object is the adaptation of a shoe suitable to the conditions under which an animal labors. I think no one can say that less than this is compatible with good shoeing, and yet it renders necessary an amount of knowledge seldom possessed by farriers. Failure to comply with these requisites injures the foot and leg, and places the animal in a disadvantageous position for the performance of his work. The consequences of bad shoeing are but too common-more so than is generally supposed, for immediate lameness is not alrays induced. These effects are traceable through all the varions stages of impaired action,' 'tenderness,' 'grogginess,' 'lameness.'

"Successful shoeing, then, requires something more than ordinary dexterity. A trained mind is no less necessary than a trained hand. The requirements of the foot and shoe must be known, as well as skill possessed to carry them out.

"Although it is true that no two feet are exactly alike, yet there is in all a regular conformity of type, and in each a relative proportion of parts. There is, in fact, such a similarity as to adnit of broad principles of shoeing being laid down applicable to all feet. No undeviating rules can be framed for a farrier's guidance. Each case must appeal to his judgment, and for this reason alone it is essential that the man be more than anedhanc, and that the principles of the art should be settled on a firm basis.

\section{Appearance versus Utility.}

"The present condition of farricry is deplor:able. IIorses' feet are cut and carved as if they were solid blocks. The sole object of preparing the hoof for a shoe seems to he its reduction to some regulan geometrical form with smooth surfaces. The shoe is turned to the taste of the workman or employer, and generally 'seated' in accord- 
ance with the exploded theory that the sole of the foot yields or descends at each step. That the amount of horn can affect the structures within, or that the form of the hoof can alter the position of the limb, seems either unknown or utterly ignored. The principle of most universal application is appearance first, utility next. Unluckily, modern ideas of appearance are incompatible with utility, so far as horse-shoeing is concerned. This state of things is not creditable to any one concerned; not only farriers, but veterinary surgeons and horse-owners, are each relatively responsible for it. Horse-owners should really feel that when a horse, sound or lame, is entrusted to a veterinarian with a view to its being properly shod, they are calling: into requisition higher faculties than those manifested by a smith who is asked to mend a lock or make a key. The forge suggests many disagreeable accessories, but these would be much decreased if owners would but take the trouble to visit it occasionally, and see for themselves how their horses' feet are treated.

"In the majority of London forges half the animals are shod, not on the principles held by the managers, but in accordance with directions brought with the horse; and yet, notwithstanding the extreme absurdity of some of those directions, the farrier is held responsible for the results of his work. Surely if a man is worth employing at all he may be entrusted to properly carry out that which is his special study and daily practice. Horse-owners have been deficient in interest and appreciation. A change of conduct would save them time, money and annoyance.

"'The farrier who 'pares a foot well out,' turns a neat fancy shoe, and rasps the hoof where it never should be touched, is a great favorite with men who pride themselves on their 'turn out.' Now it happens that a shoe made with mathematical accuracy may in wearing prove injurious. It is the fit, not the finish, of a shoe that shows an expert farrier. The mere making of a shoe has reached a high pitch of excellence. The attention of farriers must now be turned to the foot, for the public has lately been disabused of the idea of peculiar virtues in the form of the shoe, and is beginning to appreciate the greater importance of a proportionate foot. The simple truth is shoeing should be paid for, not shoes. Who ralues a sculptor's work by the price of the marble? No one! In farriery, however, an extra quantity of iron does obtain an extra price, whilst extra skill, save that spent on finely finishing a shoe, is altogether ignored. 


\section{General Plan of the Foot's Structure.}

"A knowledge of the foot in health is absolutely essential to its proper treatment at the forge. To gain that knowledge is, therefore, worth the mental effort of close attention to certain anatomical and other details, by which alone it can be acquired.

"The foot of the horse consists of various structures, endowed with special functions, but all mutually dependent on each other for harmonious action. A section shows us as the centre or basis, the last

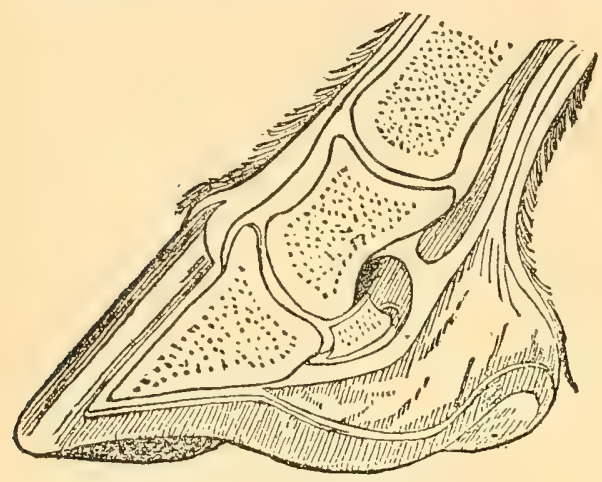

SECTION OF THE HORSE'S FOOT. three bones of the limb. These are firmly bound together by ligaments, and afford attachment to the strong tendons by which the foot is moved. On each side we have a mass of gristle, known as the lateral cartilage, whilst behind the bone is a large elastic pad-the plantar cushion. Over these is stretched a fibrous layer or envelope, - the sensitive foot. Outside of all is the horny covering, or hoof. Each of these requires a short, separate consideration.

\section{Bones of the Shank and Fetlock.}

"Below the knee and hock the bones of the fore and hind limb differ but little. Immediately beneath these joints we find the cannon or shank bones which run to the fetlock, in a direction vertically downwards, the best position for supporting columns. The shank bones, though small in circumference, are composed of extra hard and dense material; hence, strength is attained with symmetry. In addition to supporting weight, they are like all other long bones of the limbs, levers for muscular action.

"On each side of the back of the shank are the splint bones, which extend from the knee downwards to about two-thirds the length of the larger bone. The space between these two is occupied by ligatments and tendons. At the lower end of the shank-bone, where it meets the pastern to form the fetlock, are two small bones-the sessamoids. They are attached to the back of the camnon, and so arranged as to increase the joint surface, whilst their posterior surface forms a pulley for the passage of the back tendons. 
"The pastern bone, extending from the fetlock to the coronet, is placed obliquely downwards and forwards-a provision against concussion. On the proper proportion of this obliquity depends a great deal of the easy, springy action so much prized by horsemen. Straight pasterns are accompanied by a short, stilty action, and, in time, not unfrequently by a forwardness of the knee. On the other hand, excessively slanting pasterns betoken weakness; at any rate they are placed at such a disadvantage as to favor the advent of some accident or disease, as a sprain or a bony deposit. The obliquity of the pastern detracts from its strength as a supporting column, but this is fully compensated for by the strong ligaments and tendons surrounding and binding it to the bones above and below.

\section{Bones of the Foot.}

"The coronet, or small pastern, is a short, almo square, bone of great strength and solidity, resting on the coffin and supporting the pastern. It is situated partly within the hoof. Its direction is, like the pastern, directly downwards and forwards. This bone is the centre of motion for the foot. When it is a fixed point the

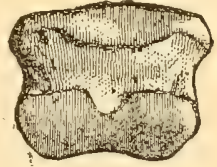

THE CORONET, OR SMALL PASTERN (DIFFERENT FACES).

coffin bone can move backwards and forwards upon it; when the foot is a fixed point the coronet moves upon the coffin in the same direction.

"The coffin or pedal bone is the lowermost segment of the bony limb. It is firmly fitted into the hoof, which it resembles in form, having a convex front surface rounded from side to side and slightly concave on its under surface. The front and sides of the bone are roughened for the attachment of the sensitive foot. The under surface, affording attachment to the same

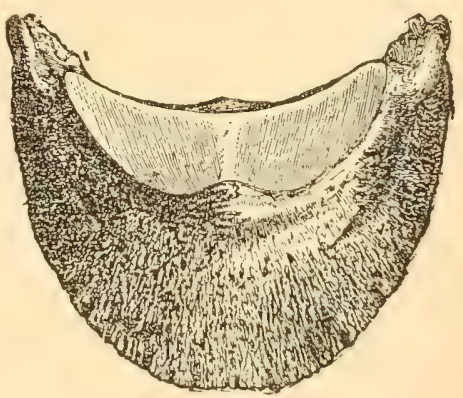

COFFIN OR PEDAL BONE. structure, is comparatively smooth. The upper part of the bone is a smooth joint surface, sloping downwards and backwards to suit the position of the coronet bone which joins it. In front of this surface, on a pyramidal eminence, is attached the extensor tendon of the foot. Behind and beneath it, in a roughened space, is in- 
serted the termination of the flexor tendon. The body of the bone only extends to near the middle of the foot; on each side, how-

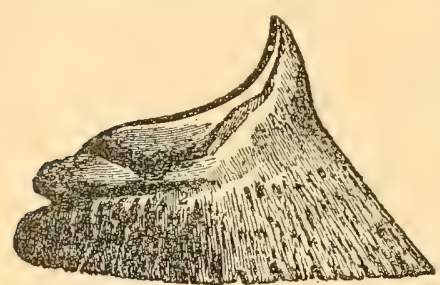

SIDE VIEW OF COFFIN-BONE. ever, is a bony projection, which extends backwards to near the heels. The pedal bone if placed on a level surface should take a level bearing on the whole of its margin. It does so in a foot which has never been shod, but many deviations are met with after a year or two of shoeing. "The circumference should not be circular, such form being due to absorption of bone at the toe; nor do I think it advisable to compare it with any geometrical figure. The bone is beautifully adapted to the wants of the foot. It is strong and light, at the same time affording extensive surfaces for attachment and bearing.

"The navicular is a small bone of a flattened oblong form. It is placed transversely across the foot, just under the point formed by the coffin and coronet bones, with both of which it articulates. Its under surface is covered by a smooth cartilaginous layer, over which panses the flexor tendon of the foot. Though firmly bound down by ligaments, the bone is possessed of a slight degree of motion; it is thus enahled easily to withstand the great force applied during contraction of the tendon. The so-called navicular joint consists, not of a bony junction, but of the passage of a tendon over smooth surface supplied with synovia, or joint-oil.

\section{Ligaments and Tendons of the Foot.}

"Each joint is supplied with its own special ligaments, of which we need only say that they are very strong and inelastic. There is,

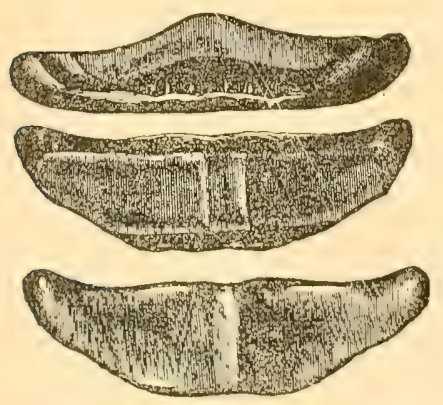

NAVICULAR BONE (DIFFERENT FACES). however, a ligamentous structure, which we must notice, as it has a remarkable action on the foot. At the back of the cannon, between the small splint bones, is situated a strong ligament called the suspensory. It arises immediately below the knee, and rums down the back of the bone, till just above the fetlock joint it splits into two branches which, diverging, take an attachment on the sessamoids behind the joint, and then passes on to be finally inserted on each side of the pastern. The use of this ligament is to preserve the relative position of the pastern and foot to the shank. When an 
animal rests its weight upon the foot, the ligament being inelastic, prevents undue extension of the pastern on the cannon bone; or, to put it still plainer, it prevents the foot being turned up in front, and the fetlock coming to the ground, an accident which really occurs in cases of its sudden rupture.

"At the back of the leg behind the suspensory ligament we have two strong tendons-the flexor or back tendons. The outermost of these, after passing with its fellow over the pulley formed for them at the back of the fetlock, terminates by two branches, which are inserted one on each side of the coronet bone. The other tendon passes down over the back of the coronet bone, then over the navicular, and finally becomes inserted on the under surface of the coffin bone. These tendons, through the action of their muscles, are both flexors of the foot, the one acting directly upon the pedal bone, the other upon the coronet. They possess, too, a mechanical action like the suspensory ligament, for a strong fibrous band passes from the origin of the suspensory below the knee to get attached to the flexor tendons about midway down the shank. Thus the back tendons, through this fibrous connection, assist the suspensory ligament in preserving the relative position of foot and leg. This connecting ligament, by the way, is the commonest seat of sprains of the back tendons. In front of the cannon bones we have two strong tendons passing down to get attached, one on the larger pastern, the other on the upper part of the coffin bone. These are the extensors of the foot. The extremities of these tendons are much fluttened and widened out, and show conspicuously a use partaken in more or less by all the tendons running to the foot, that of assisting and strengthening the ordinary ligaments of the joints over which they pass.

\section{The Foot's Cartilages and Cushions.}

The Lateral Cartilages._- "These are flattened masses of gristle situated one on either side of the foot. They arise from the processes of the coffin bone, extend backwards the whole extent of the foot and rise above the level of the horn at the heels, where they can be distinctly felt through the skin. When diseased by the invasion of bone, they become rigid and constitute side-bones. These cartilages are very extensive; they gire form to the quarters and heels, and afford a basis of attachment for the sensitive foot, where bone, from its unyielding nature, would be inadnissible. 
The Plantar Cushion.- "By this name I prefer to designate that mass of soft tissue situated behind the body of the coffin-bone, in the

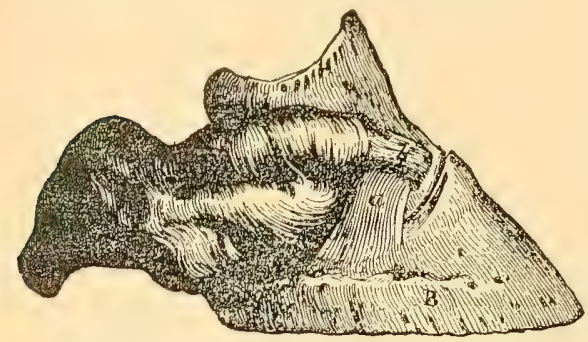

PEDAL-BONE, WITH CARTILAGES AND CUSHION ATTACHLI.

space between the cartilages. It has been spoken of as the fibrous frog, the fatty frog, and the fibro-fatty frog, according as each author regarded its structure. The use of the word frog here I consider objectionable, as likely to create confusion with the sensitive and horny elements of that name. The plantar cushion is of considerable extent. It forms the bulbs of the heels, and the basis upon which is placed the sensitive frog. It stretches across the foot from cartilage to cartilage, rising as high as the middle of the coronet; in short, it fills up the whole of the space inside the hoof be-

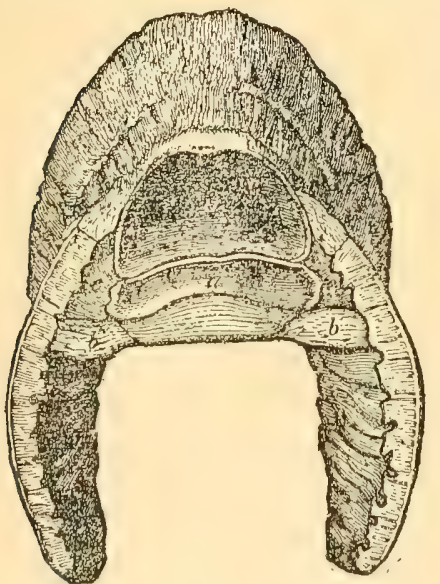

VIEW OF FOOT FROM ABOVE.

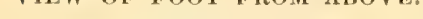

Showing the coflin-bone, cartilages and ligaments. hind the coffin-bone, save that occupied by the cartilages and flexor tendon. It is soft and yielding, being composed of masses of elastic tissue enclosed in a net-work of inelastic fibres. These fibres run, some tranversely across the foot from cartilage to cartilage, and others from above, downwards and forwards.

"This beautifully adapted cushion serves many purposes; it gives form to the heels of the foot; by filling up every interstice it acts as a pad to the cotfin joint and to the tendon passing orer the navicular bone. By its yielding properties it allows the frog to recede from undue pressure, thus mitigating jar, whilst by its transverse, inclastic bands the cartilages, and through them the sides of the foot, are tied together.

The Coronary Cushion.- "This is another mass of elastic tissue situated round the top of the foot just where the bair meets the horn. To it is due the prominence and elasticity of the coronet-a prominenee necessary as the basis on which is placed the coronary band, a structure from which is derived the wall. Its yielding properties are 
also most essential to ward off the effects of contusions on such a sensitive and vascular part. [Vascular means abounding in vessels.]

\section{The Sensitive Foot, or "Quick."}

"The sensitive foot, commonly called the 'quick,' situated just within the hoof, is a strong fibrous layer stretched over the subjacent bony and cartilaginous structures, and enclosing the coronary and plantar cushions. It is freely supplicd with nerves and blood-vessels necessary to its function as the tactile organ of the foot, and the source of the growth of horn. The superficial arrangement of the sensitive foot differs according to the local requirements. The under surface, corresponding to the frog and sole, is known as the sensitive frog and seusitive sole. The part corresponding to the wall is called the sensitive laminæ. The portion stretched over the coronary cushion, and rumning round the top of the foot, is known as the coronary band. These names are convenient for description, but the distinction is very arbitrary.

Different Parts of the Sensitive Foot.-_"The coronary band, the upper part of the sensitive foot, presents on its surface numerous little eminences, or papillæ. Each papilla forms a horn fibre, and the space between the papillæ also forms an agglutinating horn. From this source is derived the wall.

"The sensitive lamine, situated on the front and round the sides of the foot, are little folds or ridges running parallel to each other downwards and forwards. They much resemble the under side of a mushroom. They are inelastic, very vascular, and correspond to similar leaves on the inside of the hoof.

"The sensitive sole and frog, related to the corresponding divisions of the hoof, present a finely papillated appearance for the production and attachment of horn.

"All these divisions of the sensitive foot have the common function of producing and giving attachment to the hoof.

\section{The Wall, or Crust, of the Hoof.}

"We will next consider the hoof in detail, and show how each part is dependent upon the others for healthy form and action-in short, give a description of the foot in its relation to shoeing, a description which requires for its appreciation the dry anatomical details above inflicted. And first as to the hoof. This the outer covering of the 
horse is foot, is a layer of horn, moulded exactly upon the structures within. It is most conveniently described as consisting of three divisions, - wall, sole and frog.

"The wall, or 'erust,' is that portion of the hoof visible whilst the foot rests on the ground. It extends from the coronet downwards and outwards in a straight line to the ground; thus the lower circumference is greater than the upper. The front portion shows the greatest height and obliquity (about $50 \mathrm{deg}$.). Diminishing in these respects as it runs backwards, it becomes nearly upright at the guarters, the inner one more especially.

The Bars. - "On reaching the heels the wall is turned in upon itself and continued towards the centre of the foot, where it is lost in the structure of the sole. These inflexions are known as the bars; they serve two important ends. By the turning in of the wall a portion of sole is embraced on each side, which affords solidity to the posterior

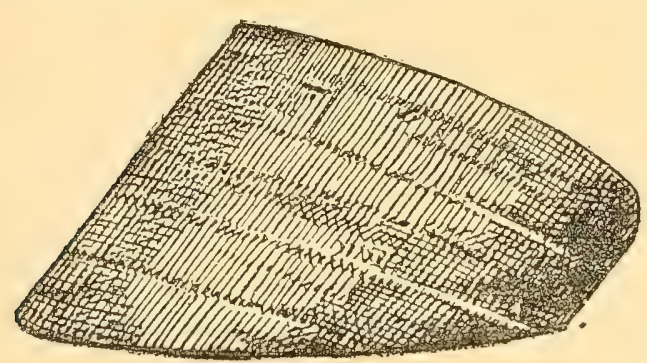

WALL, OR CRUST, OF THE FOOT. parts of the foot; they also protect the frog and sole from undue pressure, by presenting a bearing surface level with the wall.

\section{Features of the Wall. -} "By detaching the wail we are enabled to see variations in its thickness; it is thickest at the toe, becoming gradnally thinner towards the heels, thus offering strength and solidity at one part to resist wear, at another presenting pliancy to ward off concussion. A glance at any sound hoof will show that this is true in respect to both fore and hind feet. Why so many authors say that in the hind foot the wall is thickest at the quarters, I know not. They must either have examined unnatural feet or rested satisfied with the statements of previous writers. The inner surface of the wall is seen covered by a number of thin, horny plates, projecting inwards and rumning parallel to each other from above, obliquely downwards and forwards. These are called the horny lamine; they number from five to six hunded, and correspond to the semsitive laminie. This arrangenent increases the area of attachment to about twelve times its superficial extent, thus giving at once compactness and tirmmess. Round the inner and upper circumference is 
a depression, or groove, presenting innumerable small openings; this corresponds to the coronary band, the papille on which fit into the openings just mentioned.

Uses of the Wall.- "The wall, besides protecting the parts of the foot it covers, sustains the greatest portion of the weight of the animal. This it does, not because the foot is slung in it, but simply because its lower border takes the most prominent bearing.

\section{The Sole.}

"The sole may be looked upon as the floor of the foot. It is situated within the lower border of the wall, and consists of a strong horny plate, slightly arched and having its concavity downwards. The arch is imperfect posteriorly, being there divided by a space for the frog into two lateral processes, which are grasped between the wall and its inflexions or bars. The unmutilated sole is throughout of nearly equal thickness, a slight excess obtaining round the circumference for the firmer attachment to the wall. As we speak of the arch of the sole, it will be convenient to carry the simile a little further,

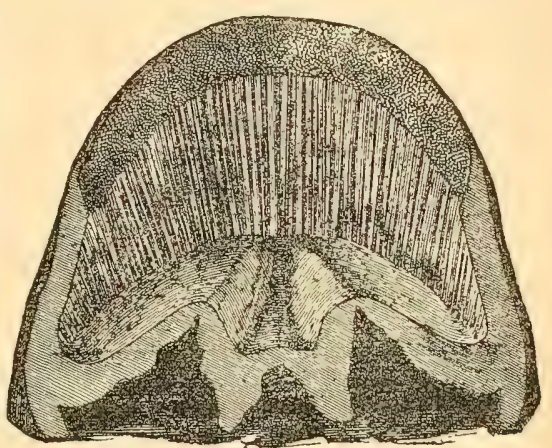

SECTION OF THE HOOF. and call its circumference or junc- Showing the lamın in streaks, or strips; betion with the wall the abutment.

low is the horny frog and sole.

"The inner surface of the sole presents a finely-fitted appearance, to correspond with the small eminences, or papilla, on the sensitive sole. This is most marked towards the toe and borders, becoming smoother as we approach the frog. The inner surface of the sole presents no line of demarcation showing its junction with either frog or wall; the whole surface of the hoof seems continuous.

Uses of the Sole.- "The sole not only protects the ground surface of the foot, but takes its share in sustaining weight. On soft ground, where the hoof sinks, this is done directly; on hard ground, where the arch takes no direct bearing, it sustains weight through its abutments like any other arch. This should be remembered, as in shoeing it is but too common to see care taken to place the whole bearing on the wall, and thus interfere with the function of the sole. 


\section{The Frog.}

"The frog is the smallest division of the hoof. It is a triangular' shaped body, filling up the space left between the bars. Its broad base is rounded and prominent, and is continued laterally by a flattened layer of horn, which binds together the heels of the foot. 'This layer is continuous, with a horn-like band rumning round the upper part of the wall, just below the hair of the coronet. By steeping a foot in water for some weeks we are enabled to remove the frog and this band entire. This structure is the coronary frog band. It is merely a cuticular prolongation analagous to that found on the under side of the human nail at its free border. It serves a useful purpose-that

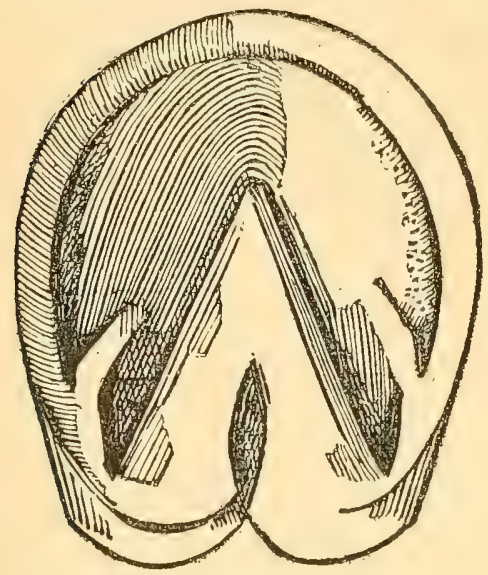

SOLE AND FROG OF THE FOOT.

Showing their appearance from below.

of protecting the young horn at its source of growth, and should therefore never be removed. Though spoken of as a band, it literally is a layer which, when not interfered with, extends down on the wall indefinitely. Probably few horsemen have ever noticed its existence, unless from the effects of a poultice it has become white, which it does by absorption of moisture.

"The point of the frog, much the harder part, extends forward to the centre of the foot, a little in front of which it ends abruptly.

"Though situated between the bars, the frog is only attached to their upper border, the sides remaining free and separate. Thus, on each side is formed a deep fissure called the commissures of the frog. These spaces allow the frog to expand laterally when compresised, without such force being continued to the heels. The frog is clastic and when pressed upon must expand slightly; if these commissures were absent, and frog and bars were in close contact, either the sensitive frog would suffer, or the heck of the foot be pressed open. Both these results are now guarded against.

Cleft of the Frog.- "The centre of the frog presents a depression or 'cleft' caused by the doubling in of the horn. Few shod fect exhibit it of natural appearance, and the term cleft, by implying a narrow and deep fissure, keeps up the false idea of its proper form. 
The cleft should be shallow and rounded. The depression causing the cleft gives rise to a prominence on the inner surface of the frog, which, by increasing the attaching surfaces, gives greater firmness to the organ. The cleft of the frog serves at least two purposes. By increasing the elasticity of the organ it reduces the amount of pressure on the structures within, and by breaking the regularity of surface must increase the foothold on soft ground.

Nature and Uses of the Frog.— "The prominence of the frog might lead a superficial observer to consider it a thick, solid mass. I believe such an idea is the cause of its frequent mutilation. It is merely a layer of horn taking the form of the structures within, which are similarly prominent. The frog is really an inverted arch, possessing comparatively little greater thickness of horn than any other part of the hoof. The frog, besides protecting its share of the foot, acts as a pad to resist shock when the foot is first placed upon the ground. Its prominence, coupled with its natural elasticity and toughness, renders it, too, a most efficient stop to prevent slipping.

\section{As to Mutual Dependence of the Parts, and Symmetry.}

"Concerning the hoof, then, let me repeat that it is divided into wall, sole, and frog; that these parts are firmly connected together; and that all possess the properties of toughness and elasticity. The hoof is thickest at the toe, and thinnest at the quarters, which are consequently more elastic. The heels, from the doubling in of the wall to form the bars, are stronger than the quarters, and yet more elastic, as cartilage is substituted for bone as their inner basis. The frog, though in itself the most elastic division of the hoof, owes a great deal of its yielding property to the fact that its point only is related to an unyielding structure. The whole body of the organ is related to the plantar cushion, an arrangement allowing of considerable upward movement. The apex being attached to the coffin bone, is the fixed point from which the two halves act. Had there been no such fixed part, the coffin joint and navicular bone would have been endangered by the undue yielding.

"In considering the hoof as a whole, we must attend more to the relative proportion of parts than to their special uses. It is true each individual part has some function of its own, but this it can only properly perform in conjunction with, and by dependence on, some other. 
For perfect action one division is essential to another, and all of them to the whole. The wall, sole, and frog are of equal importance, none being greater than another. The integrity of the sole is necessary for a perfect wall, and vice versa; or a strong sole prevents the wall from closing or contracting on the parts within, and a weak wall allows of the flattening and spreading of the sole. The frog is spoken of by some as the structure of the foot, par excellence, and yet the integrity of the bars and heels is as indispensable to its proper condition as a healthy frog is to the natural state of those parts. Should the heels become too high, the function of the frog is interfered with; it receives no pressure, consequently it wastes. If the frog and bars be destructively cut away, the heels of the foot certainly contract.

Importance also in Relation to Function.- "All the divisions of the hoof, we repeat, are equally important. Furthermore, not only the structure, but the function, of the foot requires correct relation of parts. On a hard level surface the arch of the sole takes no bearing, yet if of proper strength, pressure applied to the edge of the wall is transmitted throughout its entire extent. Suppose, however, the sole so thin as to yield under moderate pressure, this action is lost, and force, instead of being erenly distributed throughout the whole hoof, is confined entirely to the wall. Further, the whole hoof should present a normal and sufficient thickness of horn; for, whereas force applied to a cireumseribed part of a strong hoof is diffused throughout, in a weak one it is transmitted directly through to the tissues within. This direct transmission of pressure is followed by two different results. If pressure be violent, a bruise is caured, and pain attracts attention; if it be slight, but continued, we have absorption of the coffin bone, causing permanent alteration in the form of the foot-pain, howerer, heing so slight as merely to eall forth the remark, perhalps, "that the horse will not stand hard work.' Defective action is too seldom traced to the foot, and shoeing.

"Before leaving the action of the hoof, let it be fixed in mind that frog, sole and wall each sustain their share of the animal's weight. The horse is not, as some teach, suspended on his lamine, but the foot rests in the hoof, equally throughout, just as the end of a cane rests when well fitted into a thimble. 


\section{Structure of the Hoof.}

"Although the whole hoof consists of horn, we find marked difference in the quality of each division. The wall is dense and hard, and thus is well enabled to resist wear. The frog is soft and elastic, properties useful in warding off jar or concussion. The sole presents a structure of an intermediate quality.

"The horn of the hoof consists of fibres bound together by an agglutinating horny material. The fibres, in each division of the foot, run in one direction-obliquely downwards and forwards; they are most developed in the wall, smaller in the sole, and in the frog so minute as to be hardly discernible. The hoof is densest and hardest in its outer layers, becoming gradually softer as we approach the inner surface. This is due to the outer layers being furthest removed from the source of growth, and to their being exposed do the effects of friction and evaporation.

"This simple arrangement is very valuable, but frequently interfered with. By removing the outer layers of horn, either by rasp or knife, the deeper soft layers are exposed, and speedily become hard and dry by evaporation, the result being a dry brittle hoof, predisposed to sand-cracks, etc. We cannot compensate for this removal by applications of grease or water, as such agents keep the hoof soft throughout, and thus militate against its effectually protecting the structures within. A hard outer layer is well calculated to withstand wear, and preserve at the same time; it keeps the inner layers soft, and thus the whole thickness presents a beautiful combination of hardness, toughness, resiliency, and strength. Besides these physical properties, horn is a bad conductor of heat, and thus is an equally suitable protection in hot or cold climates. This property, too, is taken advantage of in the fitting of shoes, of which we shall say more hereafter.

\section{The Production, Growth, and Decay of Hoof.}

"The hoof is produced from the sensitive foot, the horn fibres grow from the little eminences called papilla, whilst the agglutinating horn is secreted by the tissue between the papillie. The sole and frog are produced by that part of the sensitive foot to which they are attached. The wall, though attached to the lamine, is formod chicfly by the coronary band. I say chiefly, because, though its main bulk grows from above, it receives from the laminæ a horny secretion as it passes over them. The product of the lamine is that light-colored portion of 


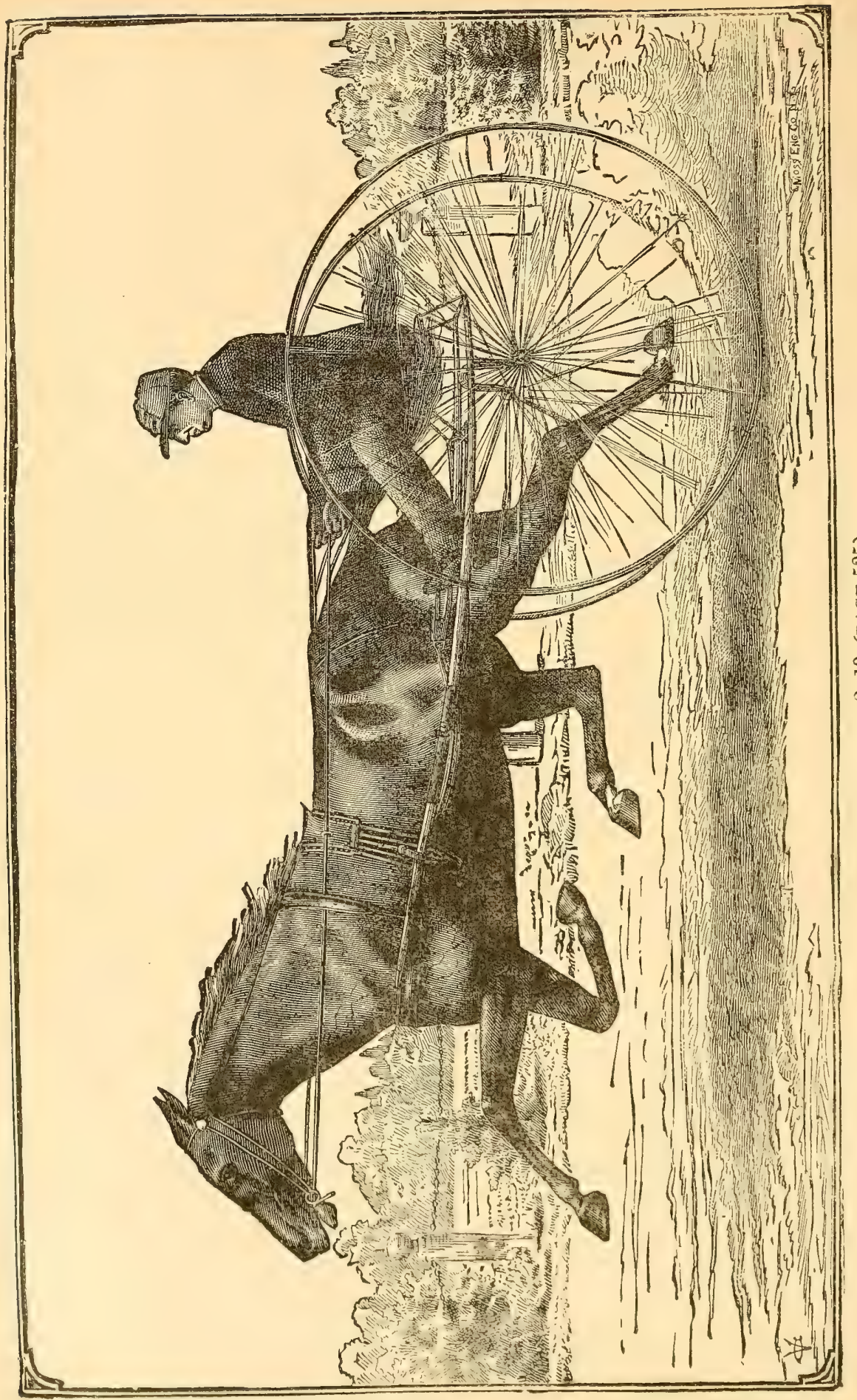

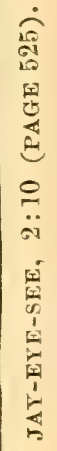


horn seen at the union of sole and wall. After an attack of "ferer in the feet' this portion of horn is often found much increased in bulk and giving rise to a bulging of the wall at the toe. The divisions of the foot are not separately formed and closely applied to each other; they are really one continuous mass of horn. Their definite form is due to the parts within, and their difference in texture is due to the relative proportion of fibrous and homogeneous horn. The hoof can be reproduced in whole or part, so long as the secreting structure remains uninjured. Like every other part of an animal's body, the hoof is constanly changing. Whilst one part decays and is removed, another receives fresh additions from its secreting surface. Thus, in a free and natural condition, the hoof is preserved of regular proportion.

"The growth of horn is slow, from twelve to fifteen months being required to reproduce the whole hoof. An average foot gains in depth of wall about one inch every three months. The rapidity of growth cannot be accelerated by any application to the horn itself. Unguents, advertised as possessing this quality, only mark the proprietor as a fool or rogue. Such a proceeding is like trying to nourish a tree through the bark instead of the roots. Everything else being right, an increased flow of blood to the source of growth determines an increased secretion of horn. We can then, by gently stimulating the coronet, accelerate the growth of horn.

"The decay and removal of horn as a natural process differs somewhat in the three divisions of the hoof. The wall when too long becomes dry, splits up in the direction of its fibres, and is broken off in irregular masses. On hard ground it may be worn gradually and smoothly down. The sole splits up and is thrown off in flakes or horizontal fragments. The frog is either worn away in shreds or rags, or else an entire layer thrown off at once. These processes may be and often are interferred with in the forge. By paring the sole thin and smooth, its natural flakes are destroyed, and nothing is thrown off till an entire layer becomes detached. If the rough surface then left behind be untouched, the natural system of decay and removal in flakes is again carried out.

\section{Two Pertinent Questions.}

"Let us now consider the action of the foot, its proper form and natural bearing surface. All these points are subjects of discussion, and all bear directly upon the practice of shoeing. 
"What part of the foot comes first to the ground? Some say the toe, other's the heel, whilst perhaps the majority incline to the whole surface coming down flat. Now it must be understood that there is only one right method of laying down the foot. It is irrational to say that this horse does one way, and that another; that one lays his foot down flat, another the heel first, and that both are perfectly natural. There is only one good natural action, whichever it may be, and any deviation from this is a defect. **** $*$ I say, then, that the horse brings the foot to the ground heel first, and this not only in the walk, but in all paces. In speaking of the natural action of a horse, I, of course, suppose a level surface and liberty. Drawing heavy loads, ascending or descending hills, are oceasions on which the horse, the sime as man, suits himself to the circumstances, altering his action to facilitate motion.

"Again, does the foot, when weight is placed upon it, spread or expand? This is an important question, as upon it depends a vast difference in the treatment of the foot in shoeing. The commonly accepted doctrine is that the foot widens or expands, as the result of pressure on the ground, and contracts again when raised in progession. My own rescarches leat me to believe that although the back parts of the foot are possessed of useful yielding properties, there is no such alternate expansion and contraction. The internal structures of the heels-the cartilages and plantar cushion-are certainly soft and yielding, but the latter structure presents transverse inelastic bands, whose special functions I take to be the holding together of the back parts of the foot. Of course, no expansion can possibly take place where the hoof is attached directly to the coffin-bone, $i$.e., at and in front of the quarters.

\section{The Relative Position of Foot and Leg.}

"Not much need be said under this head, but what is to be said onght to be remembered quite as much as anything concerning the hoof itself. A side view of the limb should show a perpendicular shank and an oblique pastern. When the heels of the foot are too high, the pasterns are straightened, and an unfarorable position given to the log for withstanding concussion. On the contrary, a long toe and unduly reduced heeds render the pasterns too oblique, and a predisposition to sprain is incurred. A front view of the leg should present such a condition that a perpendicular line should pass from the middle of the knee, through the middle of the fetlock, to the centre 
of the foot. By making one side of the hoof lower than the other, we throw the fetlock out of its true position, thus depreciating the limb as a supporting column, and incurring the risk of injury by the opposite foot. The feet and limbs of many horses are naturally not in the best relative position; but bad shoeing is capable of, and not uncommonly succeeds in, reducing the best formed limbs to an equality with the worst. Destruction of the proper relative position of foot and limbs must be accompanied by impaired action. Such cases are but too common; they are, however, usually attributed to hard work or hard roads, causes comparatively innocent.

\section{Proper Form and Bearing of the Foot.}

"The proper form of a horse's foot is a matter on which some diversity of opinion exists. There is much range in the shape of a sound foot, and mischief has been done by attempting to reduce feet to an ideal form. The farrier must endeavor, not to bring all feet to a certain standard, but merely to put into proportion whatever kind of foot is presented to him. WVe may safely say that a hind foot is smaller and narrower than a fore, more upright and more pointed at the toe, and more arched in the sole. Each pair of feet should be symmetrical, and every foot should vary in the form of its two halves, the outer circumference presenting a rounder appearance than the inner. No foot should be quite circular, and none should show a sudden narrowing of the heels. The toe of a fore foot should show an obliquity of about fifty degrees. The wall should run in a straight line from the coronet to the ground, being neither curled in at the heels, sunken in the middle, or stumped off at the edge. The ground surface should show a slightly concave, strong sole, structurally continuous with the wall, and a frog at least as prominent as the bars and wall, firm and rounded, with a small shallow cleft. To be sure that such a foot is natural, there should be no marks of a rasp on the wall, the sole should be rough, and the bars ragged.

"The natural bearing surface of a good foot is the whole lower border of the wall with the abutments of the sole. The bars and frog should also take a bearing on the ground, but in a secondary degree, $i$. e., the frog should only show such prominence that it may easily recede on moderate pressure, and allow the stronger and denser heels to sustain the main weight. The bars, though taking a primary bearing at their posterior parts, should towards their other extremity gradually recede from the line of bearing, and only transmit pressure indirectly as a part of the plantar arch of the foot." 


\section{CHAPTER XX.}

\section{THE ART OF SHOEING.}

I. PREPARING THE FOOT FOR SHOEING.-II. THE THREE REQUIREMENTS OF A PREPARED FOOT.-III. THE BEARING SURFACE.-IV. TIIE SURFACE IN SPECIAL CASES.-V. THE PROPER MEDIUM AS TO THE HORNY COVERING. -VI. LOWERING THE HEELS.—VII. DON'T PARE THE SOLE.—VIII. AS TO THE FROG AND OVER-REDUCED FEET.—IX. CORRECT RELATIONSHIP OF FOOT AND LIMB.- $\mathrm{X}$. TO SECURE A PROPORTIONATE FOOT.-XI. TREATMENT OF OVER-GROWN FEET.—XII. HAVE THE SIIES OF THE FOOT LEFT EVEN.-XII. CHARACTERISTICS OF THE SHOE. XIV. FOOT ANU GROUND SURFACES OF THE SOLE.—XV. CALKINS AND CLAWS.—XVI. THE SHOES FOI CARRIAGE HORSES, HACKS, ETC...XVII. THE NAILS AND NAILING ON. - XVIII. CLIPS AND OTHER I'RELIMINARIES TO FITTING.—XXX. - COMPARATIVE UNIMPORTANCE OF OUTLINE FITTING:- XX. AVOID WRONG SHOEING IN ANTICIPATION OF EVIL.-XXI. GOOD SURFACE-FITTING MOST OF ALL ESSENTIA.—XXII. THE FINAL PUTTING ON.-XXII. THE CHARLIER SYSTEM OF SHOEING.-XXIV. DISCARU LEATHER SOLES, PADS, ETC.XXV. WHAT IS THE PROPER INTERVAL BETWEEN SHOEINGS?—XXVI. HOW TO CARE FOR THE STABLED HORSE'S FEET.—XXVII. CARE OF TIE IIORSE'S FEET WHEN AT GRASS.

\section{Preparing the Foot for Shoeing.}

"Though there is a certain amount of truth in the expression that "the shoe must be fitted to the foot, and not the foot to the shoe," almost every foot coming into the hands of the farrier requires some alteration of form before it is ready for the shoe-it must be prepared or fitted. This is the most important step in the art of shoeing, and, I may add, the least understood. Any good worker in iron may fit a shoe to a ready-made surface, but the farrier has this surface to form, and in doing so he has no set rule, no mechanical guide. It is entirely a matter of judgment, and renires a knowledge of the correct form, relation, and uses of parts. The ability to prepare a foot so as to leave a proper bearing surface for a shoe is an essential distinction between a blacksmith and a farrier. It may he said advisedly that not one horse in fifty possesses the best attainable foot surface for his shoes. The form of a shoe may vary to suit eiremstances, hut the form of foot best adapted for a shoe is always the same, providing the organ be sound. 
"The preparation of a foot for shoeing is confined entirely to the manipulation of the horn below the level of the senstive foot. This horn is the envelope of parts extremely sensitive, and must not be treated as so much dead matter, to be cut and carved to the taste of the operator. We can, by altering its proportions, give a different form to the foot, and modify the action of an animal for good or evil. We may also, by injudicious treatment, produce. structural changes within the hoof-important changes, which, though immediately attended by no well-marked symptoms, slowly but surely impair the action, and end in lameness. It is essential, then, that a farrier should know at once, on looking at a foot, whether any horn should be removed or not, and if so, how much, and from what parts.

\section{The Three Requirements of a Prepared Foot.}

"The requirements of a foot prepared for shoeing are:-

1. An even and sound natural bearing surface.

2. A sufficiency of horny covering to properly retain a shoe, protect the foot, and harmonize with its action.

3. Correct relationship of foot and limb.

"We must endeavor to achieve these requirements with all feet, whether shod for the first time or the fiftieth. A foot brought before a farrier can only be proportionate or disproportionate. If the former, nothing is needed; if the latter, it may be overgrown, it may be excessively reduced, or it may be merely irregular. All these conditions are embraced by the requirements stated above, which will now be considered in detail, after first remarking that few irregular feet can be made proportionate at one shoeing, and that, consequently, disproportionate feet required time, as well as careful management, for their restoration to normal form.

\section{Bearing Surface.}

"An even and sound natural bearing surface is, as a rule, readily obtained by merely rasping down the overgrown wall. But we have feet in which the horn throughont is already too much reduced, yet not even. In such cases a few light touches remove inequalities, and a more extensive and better balanced surface is obtained. It is impossible to form a good even surface by means of the narrowbladed drawing knife. The bearing surface should always be made by a few sweeps of the rasp. 
"The bearing surface of the foot is by many farriers left too narrow. After rasping down the wall to its proper level, they pare out the sole, leaving a surface concave from the centre to the circumference. Thus, as bearing surface we have left a narrow ridge not half the width of the wall, and sometimes in places quite sharp. This is a serious evil. Not only is it impossible for a shoe to take a proper bearing, but there is a great probability of the wall yielding either outwards or inwards, instead of allowing the direct transmission of force. It is an evil, too, requiring time for its cure, as until more horn has grown we dare not rasp down the wall to give the needful breadth and solidity of surface. The accompanying diagrams represent transverse sections of a shoe and portion of a foot, and show the

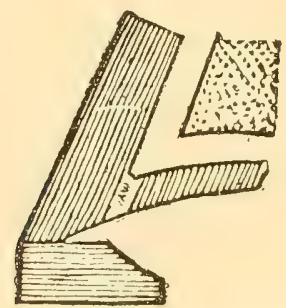

DIAGRAMS OF SHOE AND PORTIONS OF FOOT.

Narrow bearing surface, throwing all the weight, or pressure, on part of the wall.

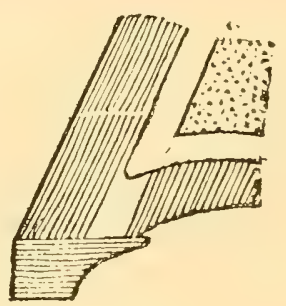

Wider bearing surface, distributing pressure throughout the entire foot.

different bearing surfaces which may be left. The extra firmness and solidity of the broader one needs no comment.

"The narrow bearing surface in many cases is due to a belief that the wall alone, and no part of the sole, should take the pressure of the shoe. This is an error, for the sole at its junction with the wall, if left strong, is capable of bearing weight on a space at least equal to the thickness of the wall. The sole requires this pressure to utilize its function-i.e., to aret as all other arches, support weight. In a foot with a broad bearing surface, consisting of the wall and the abutment of the sole, pressure is borne equally by the whole hoof, force being transmitted throughout the sole and wall.

\section{The Surface in Special Cases.}

"By not holding the rasp truly an meven surface is produced, specially noticeable at the heels-sometimes the bars being left al little higher than the wall, sometimes the opposite. Both conditions are 
objectionable, as in the first case there is a risk of the heels being compressed, and in the latter of their being violently pressed open.

"A sound bearing surface in many cases cannot he had over the whole extent of the foot, Seedy-toes, sand-cracks, corns, and, above all, fractures of portions of walls, cause inequalities in the bearing surface. Our rule in such cases must be to remove only such parts as are not strong enough to bear pressure, and to preserve other parts as much as possible. An extra amount of unsound horn is less useful than a somewhat reduced amount of sound horn. In cases, then, of a foot much broken, we should prefer to remove the unsound portions, even if we reduced the horn rather below our usual standard-believing that thus would be obtained a better and more useful bearing surface for a shoe. Not the whole foot should be reduced to the level of the most broken part. We are obliged in some cases to leave inches without any bearing, such parts being reduced to an extent incompatible with the application of a shoe. If we can, in an over-reduced foot, get a more extensive and better balanced sound surface by slightly over-reducing isolated sound parts, let us do so, rather than leave limited and irregular bearings, whose strength is more apparent than real.

"After obtaining an even surface by means of the rasp, the sharp edges of the wall should be rounded off with the same instrument, otherwise there is a great risk of its splitting, and an unsound part being produced.

\section{The Proper Medium as to the Horny Covering.}

"Too little horn will neither retain a shoe nor protect the foot; excess or irregularity will more or less interfere with the action of foot and limb. How are we to judge of the requisite medim? It is impossible to answer this question directly. It must be left to the jurgment and experience of the farrier guided by true principles. The wall is the chief part we have to attend to. Protected by a shoe it grows excessively long and requires reduction about once a month.

The growth is most evident at the toe, which becomes long; here, then, more than at other parts, we must remove the horn. It is important not to reduce the depth too much, and it is equally important to reasonably curtail the length. In all light horses this is easily effected by running the rasp round the edges of the wall at the toe. With heavy, big-footed horses, what is called a toeing-knife is used. This instrument consists of a steel blade about twelve inches long, 
and is used in connection with the hammer to chip off the hard outer edge, after which the work is finished with the rasp. The toeingknife is too often abused, the hoof being excessively reduced. This, however, may be said of all other instruments. The heels must not be neglected, as upon their due proportion depends not only the proper position of the foot, but the integrity of the frog. Overgrown heels are always accompanied by a more or less wasted frog. The freedom of the frog is the best guide to the depth of heel.

\section{Lowering the Heels.}

"The wall being at heel and toe reduced to its proper level, the bars will be seen to afford a useful addition to the bearing surface. They should never be cut away, as with the adjoining portion of sole they form a perfoct safeguard against any curling in of the wall-against, in fact, the well-known contraction of the foot. What is called "opening heels" consists of cutting out a wedge-shaped piece of horn

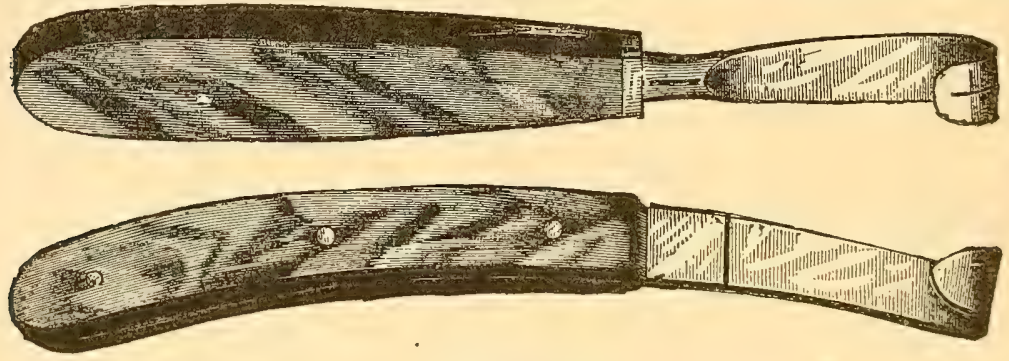

HOOF KNIVES.

from between the heels and frog. The portion remored is either a part of the wall at its posterior angle, or a part of the lateral extension of the frog to join the frog-band. It may be a piece of both. In any case the practice is useless and mischievous. Even in the contrated foot there is no active constrictive agent requiring division -merely a passive closing in of the heels for want of proper resisting body. This body is the frog and the horn between it and the wall. Instead then of "opening the heels"-which, though at the time gives a deceptive appearance of width to the foot, whilst it is productive of real evil, especially the one it is supposed to remedy-we should rest content with lowering them, whilst we preserve the bars and allow of functional activity in the frog.

VII. Don't Pare the Sole.

"The wall being sufticiently lowered will show us any superfluity of horn on the sole. For, though the sole of an mohod horse will pre- 
serve itself of a proper bulk by exfoliation, yet when shod, it, like the wall, becomes overgrown. The shoe is an impediment to the natural changes, semi-detached portions being protected and detained. These, when the wall is made proportionate, are released, and may be removed. A strong sole is necessary for protection to the foot, and that it may sustain its proper share of the weight-bearing function. But we want a sufficiency, not a superfluity, of horn; so we remove all loose portions, the presence of which does not add to the strength of the part, and which may be accounted as so much foreign matter.

"In no case should the sole be pared out. The order to "well pare out the foot' indicates ignorance of any true knowledge of shoeing. The paring of the sole presupposes that a thin sole is natural. This can only be if the theory of expansion of the foot and flattening of the sole taking place during progression be true, and I trust I have before satisfactorily refuted such a notion. By repeated parings the sole becomes hard and smooth on its surface, does not exfoliate in small flakes, but will grow until an entire layer is thrown off en masse. This event takes place in from three to six months, after which the growing sole detaches flakes naturally if left to itself. The loose flakes, then, should be broken off with the point of the 'buffer,' and not smoothly cut out. Paring the sole is productive of another evil not generally noted. Removal of horn from its central part weakens the arch, denuding the sensitive foot of its proper protection, but removal of horn from its circumference or attached border destroys the abutment and limits bearing entirely to the wall.

\section{As to the Frog, and Over-Reduced Feet.}

"The frog should be left to its natural decay. Not being protected by a shoc, it comes, or should come, in contact with the ground, and is preserved of proper bulk by wear. Although the frog is benefited by contact with the ground, and the horse's action is improred by utilizing the function of the frog, it is irrational and mischievous to over-reduce the heels with a view of hastening the contact. In a well prepared foot the frog should stand above the level of the hech in proportion to the thickness of the shoe; but the condition must be brought about gradually, not by violence.

"Insufficiency of horny covering at any part of the foot renders the internal structures liable to he injured by contusions and shatp substances, as stones, glass, nails, ete. Insufliciency of horuy cov- 
ering, where the shoe takes a bearing, may lead to acute injury by pressure, but as often allows just such an amount of continuous but slight pressure to take place as impairs the action and injures the margin of the coffin-bone.

"It is a well-known fact that bone is readily absorbed by continuous pressure, and the examination of coffin bones shows how very frequently they suffer from this cause. An over-reduced foot suffers from apparently trifling inequalities in a shoe, whilst a strong foot is capable of resisting all but the most outrageous endeavors of the farrier.

\section{Correct Relationship of Foot and Limb.}

"The bearing surface, though level, sound, and strong, may be positively injurious. We require not only a good natural bearing, but a foot in proper proportion, and in correct relationship to the limb. These conditions are obtained when both sides of the foot are even,

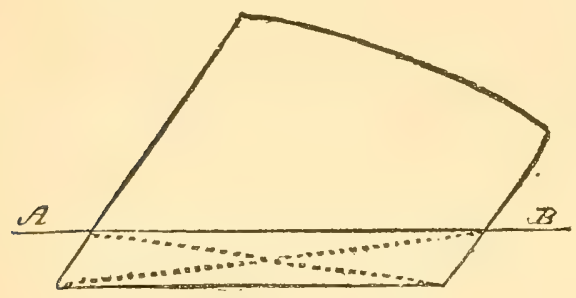

DIAGRAMMATIC SIDE-VIEW OF FOOT.

llustrating how easily a disproportionate foot may be produced. and when the horn at toe and heel is of proper relative height. The accompanying diagram, representing a sicle view of a hoof, will show better than any description how easily, in forming the bearing surface, a disproportionate foot may be produced. The outermost lines show a regular but overgrown foot. The line A B marks the lower surface of a proportionate one, and the dotted lines show how, by unduly reducing either toe or heel, a positive deformity may he produced. Between these extremes such a want of proportion may exist as to cause injury varying in degree from defective action to positive lameness. Correct relationship of foot and limb is most essential to good action. The bones of the limb are the passive organs of locomotion. They are arranged in such directions and at such angles to each other as are most conducive to ease and freedom of movement, and they are mantaned in their positions by liganchts and tendons which, when once interfered with, resume their normal conditions very slowly.

\section{To Secure a Proportionate F'oot.}

"A proportionate foot may be defined as one that has both sides even, and a proper relative height of heel and toe. As a rule a foot 
proportionate in all its parts will harmonize with the position and action of the limb. A proportionate foot, however, is not always accompanied by a well-formed limb, and a well-formed limb has sometimes an ill-shapen foot. A good farrier then should have sufficient knowledge to make allowances for natural deficiencies of form, and not endeavour to modify a faulty limb by producing a disproportionate foot. Such tricks as trying to improve the appearance of straight pasterns, by unduly lowering the heels, are irrational, and only predispose to injury. A proportionate foot cannot be obtained by following any mathematical rules. For instance, it is true that the front of the wall should run at an angle of about $50^{\circ}$, but he would commit frequent errors who attempted to reduce all feet to this standard. It has been laid down as a dogma that when the horn at the toe presented less obliquity than that just mentioned, we must attempt to reach it by lowering the heels. There are many "straight" feet in which this obliquity could not be produced if we entirely denuded the heels of horn. In approximating the relative height of heel and toe, we must be guided not only by the obliquity of the wall, but by the amount of horny covering at the heels, and bear in mind that excessive depth of wall at the toe produces the same result as deficiency at the heels.

\section{Treatment of Overgrown Feet.}

"In an overgrown foot the toe becomes long and the heels high. This entails many disadvantages, - the frog is removed from bearing; the long toe increases the difficulties of progression, puts a strain on the back tendons, and predisposes to stumbling; the whole foot is out of position as a supporting base, the centre of bearing being too far forward. These conditions are of frequent occurence in stables where the owner thinks the horse should only be re-shod when the shoes are worn out. Attendance at the forge should depend not upon the condition of the shoes so much as upon the state of the feet.

"As a horse should not be re-shod under an interval of three weeks, so he should always have his feet 'put into position' at least once every four or five weeks. By putting an overgrown foot into proportion we get a better bearing-surface, a firmer sustaining base, and a position favorable to easy and safe progression. The heels of a foot must not be left so high as to interfere with the bearing of a sound frog. They require reduction, as a rule, if the angle of horn between the wall and bars presents a line of scparation, and they should 
not he further reduced when the frog has perfect freedom. The toe should be reduced so as to leare a sufficiently strong layer of horn for bearing. It is of greater importance to reduce the length than depth of toe, and this is easily done by working the rasp round the edge of the toe. The best indications for arriving at a proper relative height of heel and toe are the obliquity of the wall in front and the freedom of the frog-the details must be left to the experience of the workman.

\section{Have the Sides of the Foot Left Even.}

"A gross evil of common occurence, for which there is no excuse, consists in leaving one side of the foot higher than the other; both sides should be of even height. This seems simple, but from the manner in which the foot is held by the farrier its reduction on one side is easice than on the other. It will generally be found that the inside of an off and the outside of a near foot are the lowest. These sides are, with the majority of men, easiest to work at with the rasp; the opposite obtains with left-handed men. One evil of this lateral inequality is, that when a shoe is attached it is apt to shift towards the highest side of the foot, producing a degree of pressure against the sensitive foot by the nails in the lower side. Another evil is, that the twist given in the foot affects the fetlock joint, throwing it out of position, thus rendering 'cutting' probable. If this lateral inequality be continued for any length of time, a more or less lasting deformity of the coronet results, the coronary band being pushed upwards on the higher side. Instead of the rule that the bearingsurface should be transverse to the pastern, it is more correct to say that the horn should be of even height on both sides of the foot. This evil camnot be remedied at once; the higher side must be reduced gradually at two or three shoeings. In some cases the lower side is very much over-reduced, and the higher side only just strong enough to support a shoe; we must then wait for the foot to grow before taking any measures for rectifying the evil.

\section{Characteristics of the Shoe.}

"The objects to be gained by any particular form or pattern of shoe are that it he light, easily and safely retained by few nails, capable of wearing three weeks or a month, and that it afford good foothold. Aceorling to the employment of an animal, certain of these objects hereme more essential than others; therefore, whilst endeav- 
oring to retain all, we give a greater prominence to the desideratum -lightness for the race-horse, stability for the hunter, and firm foothold for the draft-horse. For carriage and light draft-horses, shoes are often modified in form.

"The weight of shoes should depend upon the amount of wear required. The lighter the shoe, the better for the animal; but, as frequent removal of shoes is most injurious to the foot, we must have sufficient substance to last at least three weeks. A shoe may be heavy, and yet not a good wearer. The metal must be properly distributed, the greatest anount of iron being where the greatest wear takes place. We can increase the amount of iron either by adding to the width or thickness of a shoe. Either extreme is objectionable. A very thick shoe raises the foot too far from the ground, and throws the frog out of action. A very wide shoe does not give an increase of wear in proportion to its greater weight, and it allows the retention of stones in the foot. No shoe need be over half an inch thick, and few over one inch wide.

"The thickness should be the same throughout, so as to preserve the level of the foot. The width should be greatest at the toe, to meet the extra amount of wear at that point, and gradually lessened towards the heels, which must be narrow, to allow the shoe to fit close to the foot, and yet not impinge upon the frog.

\section{Foot and Ground-Surfaces of the Shoe.}

"The surfaces of a shoe are two: the foot-surface, which must afford the best possible bearing for the hoof, and the ground-surface, which should afford an easy tread and a firm foothold. The footsurface of well-made shoes now in use is either flat, or what is called 'seated,' i.e., flat from the outer edge for a space about equal to the width of the wall, and then sioped off or beveled to the inner edge. In both cases the bearing-surface is level; the difference is in its extent. The flat shoe takes a bearing not only on the wall, but also on the portion of sole immediately related to it. The seated shoe confines the bearing to the wall alone. Should the sole receive any pressure? By its abutment it forms a part of the natural bearingsurface of the foot, and we know that the nutrition and development of a part depends greatly upon the activity of its function. Therefore the abutment of the sole should be utilized as bearing-surface. By so doing, we obtain a stronger, more extensive, and firmer rest- 
ing-place for a shoe, and at the same time we give functional activity to the sole. We attain these advantages only by using a shoe with a level bearing-surface at least double the width of the wall.

"The ground-surface of shoes varies considerable in form. Everything else being equal, the greater the surface of iron in contact with the ground, the greater the facilities for slipping. The ordinary fullered shoe presents too extensive a surface, and consequently is objectionable. The ground-surface may be formed into ridges, grooves and notches, all of which are said to afford 'grip.'

"In short, the best shoe is one flat on the foot-surface, but concave and fullered on the ground. Such a shoe will suit all horses, if only altered in size and weight. Hind shoes may be left flat on both surfaces, and if not supplied with calkins should be of even thickness throughout.

\section{$\mathrm{XV}$. Calkins and Claws.}

"Calkins is the name given to the turned-down heels of shoes. They are used when circumstances require a very firm foothold, as

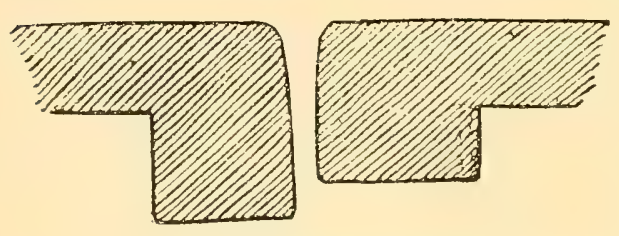

TWO FORIIS OF CALKINS.

The lower and broader of these is much the better. for instance on paved streets, or to hold back heavy loads. They are very effectual, but are open to objections. When the frog comes fairly to the ground sufficient firmness of foothold is obtained for all light work. Never, then, use calkins unless the requisite firmness of foothold cammot be obtained with a level shoe. If they are indispensable, see that they are formed in the best mamner. The higher the calkin is made, the worse for the limb and for the wear of the shoe. Let them be made low and square (see contrast in cut), and increase the breadth rather than the height if wear requires more substance. If calkins are used, have them on both heels, and let them be of equal height; the inner one may be a little narrower than the outer. A 'welge' heeled or oneheeled shoe possesses no advantages whatever, but really predisposes to insecurity of tread.

"IIeavy draught-horses require not only calkins, but a toe-piece, or, as it has been called a 'claw.' This claw consists of a piece of iron, about three-quarters of an inch square, welded transversely across the 
toe of the shoe. Armed with toe-piece and calkins, the shoe does not interfere with the level of the foot, and it gives the firmest possible foothold on paved strcets, either when drawing or backing a load, ascending or descending hills. The accompanying figure shows a side

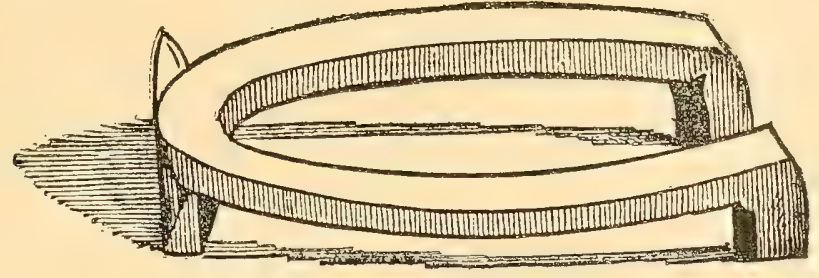

SIDE-VIEW OF SHOE.

Showing level bearing of shoc, provided with calkins and claw, on the ground.

view. It is the only rational method of shoeing heavy draughthorses for work on pared streets.

XVI. The Shoes for Carriage Horses, Hacks, etc.

"Carriage horses and those used in light vehicles never require calkins on the fore-shoes, but when the vehicle is heavy the hind
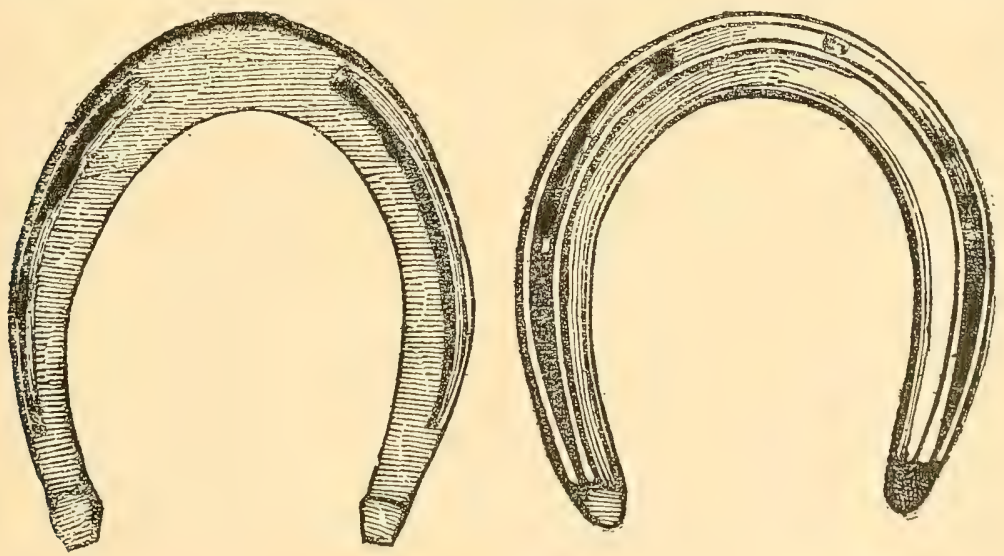

HIND AND FRONT SHOES FOR CARRIAGE HORSES.

shoes should have them, as nothing else affords the same hold in descending hills, or when 'pulling up.' Those figured above are useful forms.

"Hunters and hacks may be safely shod with level shoes all round, providing the frogs are in contact with the ground. The fore shoes 
should he concave on the ground-surface and fullered, varying in width and substance in proportion to the wear expected. The hind shoes should also be fullered, and, in the case of hunters, made con-
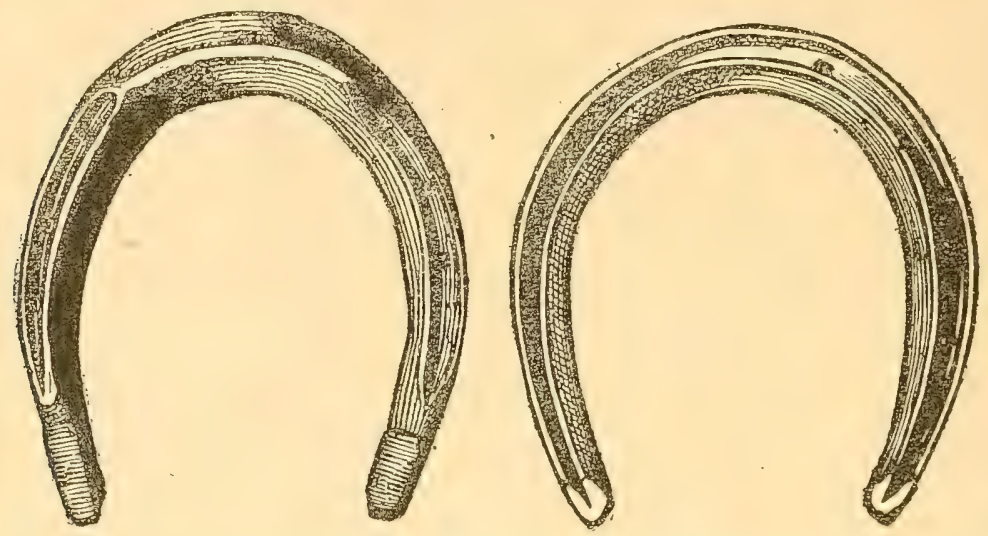

HIND AND FRONT SHOES FOR HUNTERS, ETC.

cave, especially at the toe, so as to prevent over-reaching. The figure shows this form of hind shoe pretty well.

\section{The Nails and Nailing On.}

"Space will not allow us to consider fully the nails and nail-holes, but it may be said briefly that the holes should be punched straight through the shoe, neither inclined inwards nor outwards. They ought not to be clustered all together round the toe, nor placed, if possible, behind the middle of the shoe. Each hole should be at least an inch from any other, and they should be placed so that the nails will take a firm and safe hold of the horn. The toe-nails should be coarsest the furthest from the outer elge of the shoe, and the heel-nails finest. This arrangement is needed, as the wall of the hoof is thickest at the toe, and becomes gradually thinner towards the heel. The mails should be selected so that their heads exactly fill the holes into which they are driven, consequently the size of nail-hole should be nicely proportioned to the shoe, or else too large a nail will be used. The shank of a nail shoukd be flat and broad, so as neither to split the wall, nor press upon the sensitive foot.

XVIII. Clips and Other Preliminaries to Fitting the Shoe.

"Having selected a shoe suitable for the class of horse and the condition of foot-light for a strong foot, heavier for a weak one- 
it is made hot, the nail-holes are cleared out and the clips drawn where required, preliminary to the important step of fitting. The object of clearing out the nail-holes is to allow a free passage for the nail. The too common custom of 'back pritcheling'-driving the pritchel or punch through the hole from its narrowest opening-is not conducive to such an end, as it is apt to leave a ridge in the hole, which prevents the nail-head from exactly filling it, and may cut the nick of the nail, thus causing loose shoes. Clips are thin triangular processes drawn from the outer edge of the shoe at right angles to the bearing surface. They increase the security of a shoe, and prevent its shifting on the foot. The best position for them is at the toe, where the foot presents its greatest thickness of horn. As a rule, one clip is quite sufficient, though on the hind shoes of hacks and hunter's two-one on each side of the toe-are often used. They give a little more firmness and allow of the shoe being less prominent in front when 'clacking' or over-reaching are to be feared. An additional clip on the outside quarter may be applied to shoes to prevent their shifting inwards. It is an allowable precaution with horses liable to 'cut,' and it is necessary with some horses of irregular action that twist the foot in going, or wear mostly on the outside, as when spavined. The usual practice of cutting a deep notch in the edge of the wall, into which to imbed the clip, 1s objectionable. The round edge should only be rendered flat, and the clip laid nis not in the horn. If the wall be very brittle or much broken, the clip should be large, so as to rest against sound horn. Harm is more frequently done by small than large clips.

"The next step is to approximate the length of the shoe to the heels of the foot. A shoe is always chosen a trifle longer than the foot, and the superflous portion cut off. This should be done so as to leave the extremity rounded from side to side, and sloping in the same direction as the heels of the foot-obliquely downwards and forwards. No shoe should be shorter than the foot, and the fore shoe should never be longer, as it is then liable to be pulled off by the hind foot, or to injure the elbow when the animal hes down. A hind shoe may be rather longer than the foot, and so should all shoes having calkins.

\section{Comparative Unimportance of Outline Fitting.}

"Outline fitting, or correspondence of the circumference of the shoe with the outline of the foot, is much overrated. It is an error 
to think that perfect correspondence of outline denotes good fitting. One of the worst of shoes-one too small-can, by rasping away the horn, be made to fit exactly. We do not depreciate the absolute value of outline fitting, but to guard horsemen against the idea that it is a useful criterion of the quality of work. Its value is quite insignificant when compared with the fitting of the bearing-surfaces. Shoes should be fitted slightly full on the foot, on the principle that the base should be greater than the column. Although as a rule, the shoe should follow the course of the edge of the wall, being. in fact, a direct continuation of it, there are cases in which some departure from this is necessary. When the bearing-surface is of less diameter than the wall above, as in cases of weak heels, we bring the shoe out equal to the widest part of the hoof. Again, when the foot is raised from the ground by calkins, we fit the shoe somewhat wider at the heels, believing that thus is obtained a firmer supporting base and surer foothold.

\section{Avoid Wrong Shoeing in Anticipation of Evil.}

"By way of anticipating evil, shoes are sometimes fitted on very wrong principles. Lest a horse should 'cut,' some men regularly apply a shoe straight from the inside toe to the quarter, learing a protruding portion of horn, which is finally risped off, and the foot weakened. Thus, for the prevention of a remote injury, one nearly as bad is resorted to. Doubtless, prevention is better than cure, but here the doctrine is reduced to an absurdity. With the hind shoes of hacks and hunters, a common proceding consists in leaving the shoe too short, and then with a rasp removing the horn at the toe. The foot, in fact, is fitted to what is called a square-toed shoe, an arrangement useful in some cases of 'clacking' and overreaching. We protest against these forms and methods specially adapted for alonormal conditions being acknowledged as sound common usage for all horses.

\section{Good Surface Fitting Most of all Essential..}

"Surface fitting, the adaptation of the bearing-surfaces of foot and shoe, is certainly the portion of the art upon which mostly depends the sucess of the whole operation. From toe to heel the shoe, on an sound foot, should have an even bearing, every part taking an equal share. There is a notion that the heds of a horse's foot are weaker than either quarter or toe, and it is commonly satid that "pressure on the heels causes colns.' By way of preventing this evil the shoe is 
'sprung' or 'eased' off the heels, so that the last inch or more takes no bearing on the foot. A shoe so fitted is an unmitigated evil. In addition to the loss of so much good bearing-surface it submits the foot to an increased and abnormal pressure on one spot, the quarters, where the real bearing-surface of the shoe ceases. The evil is greater in proportion to the extent of surface without a bearing, such part acting as a lever on the point where shoe and foot are firmly in contact, thus lieeping a constant strain on the last nails, and throwing an increased amount of pressure on a part of the hoof relatively weak.

"The bearing-surface of a shoe should throughout be perfectly flat across, as in Fig. 1. The seated shoe usually presents too narrow

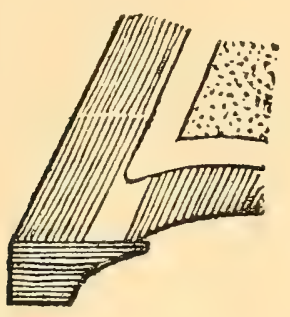

FIG. 1.

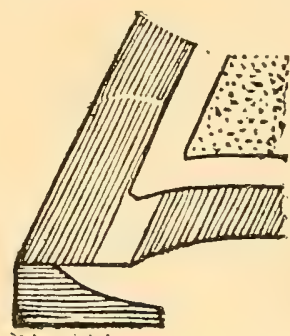

FIG. 2 .

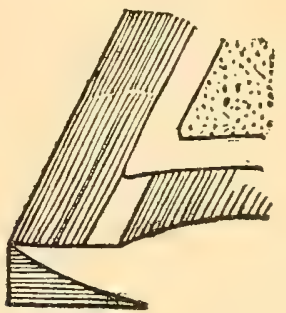

FIG. 3.

SECTIONAL VIEWS OF SHOE AND POINT OF FOOT.

a bearing-surface, as in Fig. 2, and not unfrequently we find it in a form positively injurious. When a shoe is extra 'well seated,' the surface is sloped or beveled inwards from the outer edge as in Fig. 3. Such a shoe offers no true bearing-surface, and frequently causes lameness by compressing the foot. Sometimes a shoe is fitted just the opposite to this, the surface inclining from within outwards. This form may cause lameness by forcing asunder the heels of the foot. A mild adaptation of it has long been used for the express purpose of widening the heels of the foot. It is unsafe, and achieves nothing which cannot be as surely done by a well-fitted shoe.

\section{The Final Putting On.}

"To obtain the exactness of fit so essential to good shoeing, the shoe is first taken to the foot and compared with it. It is then heated, the heels cut off or turned down, as the case may be, to the proper length, and each limb of the shoe is approximated to its side of the foot. Thus foot and shoe are brought to the same form, as near as the eye of a workman can tell; still there 
are certain to be some irregularities, to detect which the red hot shoe is applied to the foot for a few seconds, when all the points of contact are marked by the scorching of the horn. If the shoe is at fault, it is taken back to the anvil and remedied. If the foot be uneven, the too prominent parts are carefully reduced by the rasp. This operation may be repeated until there is an exact co-aptation of the two surfaces, an event ordinarily obtained by a good workman in two examinations.

Cold and Hot Fitting. - "Engineers, in fitting two surfaces, make use of some colored material to show the points of contact. If this were done by a farrier, it would necessitate the alteration of the shoes cold, which cannot be done with exactness. Fitting a shoe whilst it is hot is the only way of obtaining a speedy and perfect co-aptation of foot and shoe. It is perfectly harmless, as the shoe is only retained in apposition with the hoof sufficiently long to mark the horn, and horn is one of the worst conductors of heat. Hot-fitting is often abused, the shoe being made to burn itself a bed on the foot, even though the shoe be ill-shapen or the foot improperly prepared. For cold fitting we recognize in the Goodenough and other shoes one great advantage-a perfect level.

\section{The Charlier System of Shoeing.}

"The Charlier system consists in removing so much of the lower border of the wall as may allow a narrow rim of iron, equal in thickness to the wall removed, to be imbedded. It is claimed for this system that it simply substitutes iron for horn round the lower circumference of the foot, where alone wear is to be feared, and that thus the frog and sole are left in an unshod and natural condition. The sole advantage, we think, of the Charlier shoe is its lightness, unless we add that of the sole's being left free to preserve itself of proper thickness without artificial aid, which is but a very small matter indeed. On the other hand, it has some positive disadvantages.

"Its bearing is too limited, and thus the functions of the foot are not wholly utilized. The shoe is placed too near the sensitive parts; we are directed to file the internal angle of the shoe to prevent injurious pressure. Compare the accompanying diagrams, a section of the Charlier, and one of the ordinary seated shoe. IIorses maty and do go somnd with it, but why run the risk when we can obtain all desirable results without it? A third objection is 
that such a narrow shoe, when partly worn, is apt to spread or widen on the foot, as the result of contact with the ground, and to prevent this the heel nails are placed further back in the foot than is expedient. Finally, the narrowness of the shoe has a very bad effect on the nail-holes, which must be pitched or directed in towards the

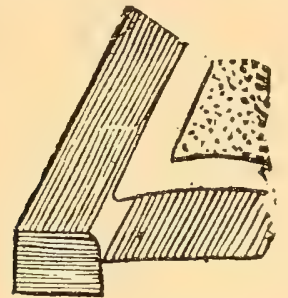

SECTION OF: THE CHARLIER SHOE.

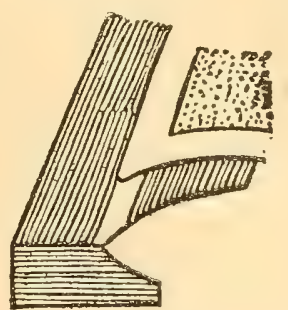

SECTION OF THE SEATED SHOE.

sensitive foot, otherwise the mails must be driven with so little hold as to risk splitting the hoof. The proper course for a nail is straight through the shoe and portion of horn which it pierces.

\section{Discard Leather Soles, Pads, etc.}

"The use of leather soles is a very injurious practice. No substance should be applied between the foot and shoe, as it necessarily interferes with the exact co-aptation of hoof and iron. Leather under a shoe yields gradually to the weight of the animal, and thus in time clinches rise and shoes get loose. When the whole foot is covered with a plate of leather, a mass of tar and tow is inserted between the horny sole and the leather. This arrangement is always accompanied by excessive paring, and is simply a patch to remedy bad work. No doubt a badly fitted shoe does less injury, sometimes, when applied with an interposing layer of leather; but a well-fitted shoe can be applied with greater benefit without leather to any foot in which the sensitive structures are not positively denuded. As to the claim that a leather sole protects a weak foot from injury and concussion, a layer of horn is surely a better protection than an equal thickness of leather, and this can be obtained on any foot by four or five weeks' growth. These remarks apply with equal force to the use of India-rubber pads, which are not only unnecessary, but injurious in many cases.

XXV. What is the Proper Interval Between Shoeings?

"The operation of shoeing should be done at regular intervals, and not left till the shoes are worn out. A broken foot from the loss of 
a shoe is only a possible injury resulting from over-long retention of shoes. There is a certain and unavoidable one-a disproportionate foot. When the shoes remain too long upon the feet, the heels become too high, and the toe too long; the frog is wasted, sometimes diseased; a strain is imposed upon the joints and flexor tendons; and tripping and stumbling are the cause of not a few broken knees. Shoes should not be allowed to remain on the feet orer four weeks; if not worn out they should be taken off, and replaced after the foot has been reduced to due proportions.

"On the other hand, it is injurious to have shoes removed too frequently. The mere act of fitting a shoe reduces the foot to some extent, and what is worse, the nails being driven each time in sound horn, a perforated and broken state of the wall is soon induced. During a frost the frequent removal of shoes, necessitated by the usual method of 'roughing,' causes injury to hundreds of feet, which is not recovered for three or four months. Shoes should not be removed under every three weeks.

"Unshod feet become overgrown and disproportionate on a soft surface. But it is mistaken kindness to remore the shoes when work will be required again in less than six weeks. By so doing great risk is incurred that the feet will be injured. If the foot be reduced to proper proportion, the wall may be broken so much as not to be again replaced in the time. On the other hand, if the foot is left long and allowed to grow, the frogs become diseased.

\section{How to Care for the Stabled Horse's Feet.}

"In the stable, the feet of a horse properly shod and regularly worked, require but little attention. In very wet or very dry weather a little nentral ointment-say tar and tallow mixed-may be rubbed orer both wall and sole. This applieation prevents wet from soaking into the horn, and checks excessive evaporation in a hot dry atmosphere. Soft soap or strong alkaline ointments should never be used. They make the horn brittle, and so does the constant application of oil. 'Stopping' the feet with clay, or dirty mixtures of cow-dung, are looked upon as escential hygienie duties in a stable. Replacing the parement of a stall or box by wet elay is also thought to be good treatment for bad, esperially flat feet. Layers of felt saturated in water are to be found in many well-conducted (?) stalbles. The whole of these are uscless experlients, founded on a misconception of the requirements of the foot. 
"The truth is that, in the stable and on hard roads, we should endeavor to place the foot in as nearly as possible the same condition as we find it in when an animal is at liberty on a hard dry surface. That moisture is not conducive to compact, well-formed feet we see in nature, the flat feet being a feature in animals bred on marshy land. That dryness is conducive to sound feet every observant horseman may easily satisfy himself, both with well and badly formed hoofs.

\section{Care of the Horse's Feet When at Grass.}

"At grass the unshod animal requires no attention, if it but have sufficient liberty to wear the hoof in proportion to the growth. Should it be intended to re-shoe the animal, a little attention is advisable about a month or six weeks before the time, so as to get the feet proportionate. It is often a question in turning horses ont, whether to remove the shoes or not. Of course, when a number are together the hind shoes must for safety be removed. Unless a horse be turned out for at least three months, I should not remove the fore shoes. If turned out with the shoes on, the feet should be attended to every month.

"Shoes applied to horses turned out for the season should be as light as possible, and cover the whole bearing-surface of the wall. Tips are a good appliance, but care must be taken to remove them regularly, as they cause greater deformity by long retention than shoes. If the shoes are removed, the foot should be made proportionate-a little greater depth of wall being left for shoeing, and, what is very important, the edges of the wall should be rounded off with the rasp, so as to reduce the chances of splitting." 


\section{CHAPTER XXI.}

\section{DISEASES AND INJURIES OF THE JOINTS.}

I. INELAMMATION OF THE JOINTS.-II. OPEN JOINTS,-III. RHEUMATIC JOINTS.-IV. DISLOCATIONS IN GENERAL.—-V. DISLOCATION OH, THE PATELLA, OR STIFLE-JOINT.-VI. BOG SPAVIN.-VII. THOROUGH-PIN.VIII. BLOOD SPAVIN.—IX. WIND-GALLS, OR WIND-PUFFS.-X. KNUCKLING, OR STANDING OVER.

\section{Inflammation of the Joints.}

Inflammation, while attacking all the different joints of the body, is most frequently seen in those especially exposed-the joints of the knee, hock, stifle, pastern and shoulder-following blows, sprains, punctures, etc. In ordinary cases, the inflammation subsides in course of time, and the joint is restored to its previous healthy state; but not infrequently the disease continues, the cartilages on the ends of the bones are absorbed, and the two ends unite, forming a stiff (ankylosed) joint; or it may be there is a bony deposit in or around the joint, eventuating in a deformed articulation, with more or less stiffness, or a lameness that proves incurable.

Symptoms. - Swelling, heat and pain; and the joint is carried so as to avoid movement, on account of the pain thereby occasioned. In many cases, and especially of open joint, the leg is kept moving, and frequently it is held up off the ground.

Treatment.- When this trouble is of recent origin, the treatment most advisable is to shower with cold water, by tring a hose orer the part and allowing the water to flow for an hour at a time, and this several times daily, afterwards using the Soothing Lotion No. 3, and keeping the joint perfectly still. When the disease shows a tendency to become chronic, more enerotic measures are needed, and then Mixed Blister No. 10 should be rubbed in thoroughly. Let the animal rest for a month or so.

\section{Open Joints.}

These constitute a very serious class of cases. Briefly described, they consist of a wound extending into the joint, thus allowing a dis- 
charge of the joint oil (synovia). This latter, in health, is a clear, strawcolored fluid, with an oily feeling when rubbed between the fingers. It is secreted by the membrane lining the walls of the joint, its important use being to lubricate the joints, thus facilitating their varied and long-continued movements, and keeping them in a healthful condition.

Symptoms.-The wound or opening into the joint is, of course, plainly visible. The secretion of joint oil is greatly increased in quantity by any inflammation in the surrounding parts, and when the inside of a joint is exposed to the air, there is a change in its character; it becomes thicker, until by and by it is mixed with pus, blood, and finally the remains of broken-down structures, such as the cartilage and the bones. In this stage the discharge will be quite offensive, and in old cases the pus may also burrow along the tissues around the joint. A fracture of the bones in connection with the joint is frequently seen in bad cases, and proves a very serious complication. In all these different forms of open joint, there is usually some sympathetic fever, which may, perhaps, be so severe as to affect the appetite and make the breathing hard, the sufferer evincing his distress by great restlessness, and, if it continues for a few days, by falling off greatly in condition.

A false open joint is frequently seen, especially at the knee, after severe falls, the cut then received opening the small sack containing the fluid for lubricating the tendons that pass these points. There is then a discharge of oil, but the case is altogether less serious than the true open joint.

The outcome of an open joint, if well and promptly treated, is often very favorable, the joint assuming its former condition. When pus forms, however, the termination, if not fatal, is either by ankylosis or by the formation of bony deposits around the articulation; and in either event there will be a stiff joint. Ankylosis will occasion the greater stiffness, but the bony growths will, besides stiffness, cause troublesome lameness by interference in the joint's movements.

To recapitulate, the farmer may recognize an open joint by its being a wound over an articulation; by a continuous discharge of the straw-colored and slippery-feeling joint oil, which discharge is decidedly more plentiful on movement; by the great pain and swelling; and in old cases by the discharge of pus, which will smell particularly bad when dead bone or cartilage is present, 
Treatment.-The first necessity is complete rest of the joint, which will best be secured by using slings. Place a plaster of Paris cast over the whole leg, learing an opening opposite the cut. Then clip the hair off around the edges of the wound, and wash it thoroughly with plenty of our prescription No. 13, or No. 1. In recent cases, with a clear discharge and a large wound, try and stitch the edges together, afterwards binding on a pad of cotton batting soaked in No. 13. This must be kept on continuously to exclude the air, thus helping to prevent suppuration; besides, the lotion has the power of coagulating the joint oil, and thus plugging the opening. This treatment must be continued until a complete union has been effecter. When the wound is small, a blister, or the firing iron, applied over the wound, is a very good expedient, as the resulting swelling will be likely to close the opening. Always, when pus has formed, the opening must be left free to allow its escape. Still, when the stage of suppuration is reached, it is a grave question whether to attempt further treatment or not; for the very best that can then be hoped for is an ankylosed, a permanently stiff, joint. The intelligent farmer will, in most such cases, probably decide to relieve the poor creature of his sufferings at once.

\section{Rheumatic Joints.}

Rheumatic joints are most frequently seen among foals, especially in the neighborhood of the sea-const; but old horses anywhere that have been hard worked, and at the same time subjected to great exposure and badly cared for, are likewise subject to them. They may also be seen as a seruel of debilitating diseases, where, owing to the imperfect discharge of some function or other of the organs, there is an accumulation of morbid products in the blood.

Symptoms.-The attendant lameness will be noticed to shift from one part of the borly to another, as, for instance, from the shoulder to the fetlock; or it may temporarily disappear, only to return in some other locality, settling ultimately in some such spot as the foot, hock, or knee. In the foot its manifestation resembles navieular disease, while in the front leg or on the hock there will he ostcophytes formed, or dropsical swellings, or in the hocks perhaps bog spavin, thorough-pin, or the like.

Treatment.- When oecurring in old horses ats a seyuel of some debilitating disease, give Purgative Pill No. 1s. change the diet to 
soft, nutritious food, keep warm, and allow moderate exercise. To counteract the disease, give either of the following preparations:
No. 22.
Salicylie acid,
Liquor ammonia acetate,
$1 \frac{1}{2}$ ounces.

Mix.

Warm the mixture and give, in form of a drench, a wineglassful in a little water, four times a day.

No. 23.

Powdered colchicum,

Nitrate of potash,

$2 \frac{1}{2}$ ounces.

Mix.

Divide into 12 parts, and give one in the feed, or on the tongue, four times a day.

If the joints are sore, rub in the strong Stimulating Liniment No. 6.

Chronic cases are very unsatisfactory to treat, especially when they settle in the foot. For such use the Oil Blister No. 8 around the coronet, and the same general treatment as for other cases.

Foals thus affected recover quicker than older animals. Give them a loose box with plenty of soft bedding, apply bandages to the legs, and for the sore joints use the Soothing Lotion No. 3. The balance of the treatment will be the same as for older horses, only reduced according to the age.

\section{Dislocations in General.}

When the articular end of a bone is displaced from its proper situation in the joint, we call it a dislocation, and this may be either partial or complete. Although very frequent among mankind, this sort of injury is comparatively rare in animals. In all dislocations, and especially in joints possessing a variety of motions, there will be found more or less laceration of the surrounding tissues. In complete dislocations the end of the bone will tear the capsule of the joint. As a sequel of this, there may be changes in the joint; a new articulation may be formed, the head of the bone, wearing a smooth surface, which acts as a socket, thus allowing of the various movements required in the natural uses of the part involved. The most common dislocations oceur at the stifle, fetlock and knee; the shoulder and hip are very rarely dislocated, and when they are, there is monally a fracture of some of the bones. The condition called "knuckling" of the fetlocks is one form of partial dislocation. Te shall consider it fully a few pages later.

\section{Dislocation of the Patella, or Stifle-Joint.}

This is altogether the most common dislocation to which the horse is subject; the stifle is said to have been slipped, or to be out of place. 
However, to "stifle," as it is called for short, is often attributed troubles of quite a different kind. Any sudden, obscure lameness of the hind parts is apt to be accounted for, among the knowing ones, by saying, "the stifle is out," simply for want of a better explanation.

Causes.-In young horses "stifle" occurs from allowing the feet to grow too long at the toes, or from grazing on billy ground, or from standing in a stall whose floor is too sloping. In all these cases the structures supporting the patella bone gradually lose their tone, the ligaments become loose, and the bone readily slips out of its socket. Debility, after a long illness, may bring on the same conditions and the same result.

Symptoms. - In the beginning, the dislocation may be very slight, the bone appearing to simply move too freely in its socket; howerer,

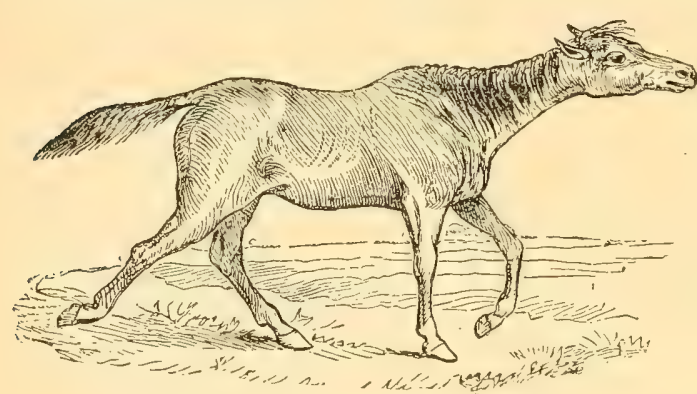

DISYOCATION OH THE STIELE-JOINT.

this trouble increases-the bone gradually slips further and further, and in time it will move out of, and then back into, the socket, producing a peculiar clicking kind of sound. While the horse is standing still, the leg may rest naturally, but as soon as he begins to move it, his control over it is lost; it will fly backwards, with the fetlock greatly flexed, as shown by the illustration. The patella bone can be felt, in the great majority of cases, on the outside of the joint, rarely on the inside. Some animals that possess great control over the muscles of the hips are able to return the leg to the gromd, but the trouble recurs again just as soon as they try to walk.

Treatment.-Place an old collar around the neck, attach a rope to the fetlock of the foot, passing it between the front legs to the collar, and in this way forcibly draw the leg forward, when by pressure on the patella it will slip in place. The leg should be held forward by the rope for some hours to prevent a recurrence of the trouble. Blisters are frequently used on the joint, in order, by the resulting swelling, to prevent movement. In old eases the likelihood of reduction is very small, as lasting changes in the joint have probably been already established. 


\section{Bog Spavin.}

This very common disease of the hock makes its appearance as an enlargement on the front and upper part of the joint. As a result of irritation of some kind, the membrane of the joint is distended by an over-secretion of joint-oil.

Causes.-Bog spavin is a frequent sequence of $c$ sprains, blows and other inflammations of the hock. It may also be seen in young, heavy-bodied colts, from over-feeding, coupled with insufficient exercise. It is a trouble far the most common in old, hard worked horses.

Symptoms.-There is very seldom any lameness in the case of young animals, in whom it generally disappears as they grow older. But in old animals,

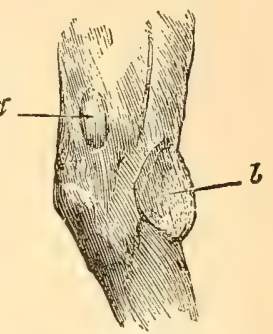

THOROLGH-PIN AND BOG SPAVIN. $a-$ Thorough-pin. $b-$ Bog Spavin. during the acute or forming stage, the swelling will be very sore, and the lameness severe, especially on starting to walk. The limb will be lifted with a hop, or catch, similar to bone spavin; and in these cases there really is a liability of the inflammation extending to the bones and causing that ailment, or some other disease of the bones. The spavin is found at the upper part of the front of the joint, extending somewhat to the inside. (See illustration on page 221.) The swelling is very soft and puffy, and, by pressure, it may be pushed through to the back of the joint.

Treatment.-For young over-fed animals, reduce the feed and allow more exercise. If the puffs still persist, apply wet bandages with pressure on the parts. There is a special and simple truss made for the purpose by instrument makers, of which the

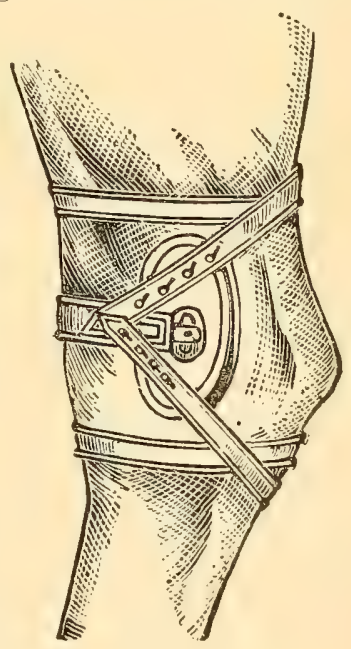

BOG SPAVIN TRUSS. accompanying is a good representation. It is a useful appliance.

In the acute or forming cases, whether in old stock or young, the cold shower treatment and Soothing Lotion No. 3, or Cooling Lotion No. 4, are indicated. If any lameness remains after the fever hals disappeared, more severe measures are called for, namely, the Fly Blister No. 7, or the Absorbent Blister No. 11. This should be 
thoroughly rubbed in all around the joint, and if there is reason to believe the bones have become diseased, the firing-iron should be used over the whole hock, and the animal given a long run at pasture.

\section{Thorough-pin.}

This is an enlargement, similar in appearance to a wind-gall, consisting of distension, by synovia (joint-oil), of the sac through which the tendons pass. The causes of thorough-pin are the same as those of bog spavin.

Symptoms.-While this condition very rarely causes any trouble, its prominent position makes it objectionable. It is always a blenish, though in most cases no more than that. The distended sac is seen and felt as a soft round swelling at the upper and back part of the hock, in the depression known as the "hollows of the hock." The swelling usually appears on both sides of the leg, and it is freely movable from one side to the other.

Treatment.-This is called for to remove the enlargement, which may be successfully done by wet bandaging (pads are the proper thing) on each side of the swelling. The philosophy of this treatment is that the pressure in time causes absorption of the synovia to take place. There is a special truss manufactured for the cure of thorough-pin, one that is very readily applied and remored, as desired. If any fever is present, adopt the same treatment for it as in bog spavin.

\section{Blood Spavin.}

This is a distension of the vein that passes over the front of the hock from below, in an oblique direction from within outward. It is shown in the engraving on page 221. The swollen condition may be a varicose state of the vein, the same that is so frequently seen in the human race, or it may be the result of some pressure preventing a free flow of the blood.

Treatment.-Treatment is hardly ever called for. Mixed Blister No. 10 may be applied with advantage.

\section{Wind-Galls, or Wind-Puffs.}

Wrind-galls are a very common form of bursal enlargement, from caluses of the same nature, and containing the same flud, as thoroughjin. They sometimes develop very quickly, especially after a hard dive.

Symptoms. - These puffs are found at a point above and behind the forlock, between the back tendons and bone. In some eases ther are 
found to communicate with the fetlock joint, and then they will be felt very hard when the weight is thrown on the leg. Where no such communication exists, they feel soft and puffy. The swelling is generally their only manifestation.

Treatment.-These puffs may be prevented by hand-rubbing and bandaging the legs after a hard drive. If the horse gives indications of pain, Lotion No. 3, or No. 4, should be used.

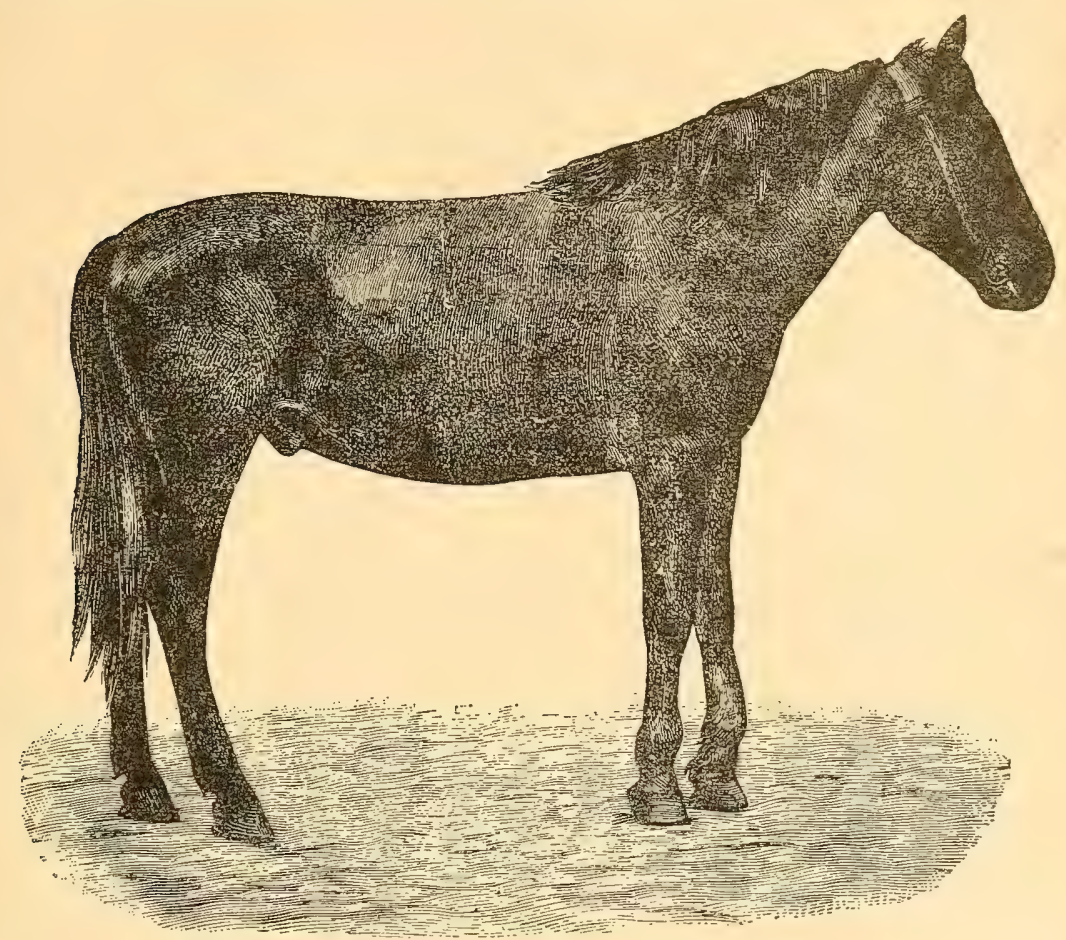

A CASE OF KNUCKLING OF BOTH FETLOCKS.

Engraved for this work from a Photograph.

To reduce the swellings, pressure with some sort of a pad, and a wet bandage tightly wrapped, will usually produce a good effect. In olxl eases, a good blister, as the Mixed Blister No. 10, or perhilps the firing-iron first and afterwards the blister, will be called for. This will promote the absorption of the oil and strengthen the part.

Where they do not communicate with the joint, wind-galls are frequently punctured, but this should only be done by an experienced veterinarian. 


\section{Knuckling, or Standing, Over.}

This is a displacement of the joint (a partial dislocation) that occurs principally in the knees, and in the fetlocks of both the fore and hind legs. When in the knees the animal is said to be "knee-sprung." Knuckling is found in intra-uterine life, but by the period of birth the limbs should have become straightened. A foal that cannot stand on its feet when three days old is not of much use.

Causes.-This condition is principally due to hard work and exposure, or, in the opinion of some horsemen, to feeding from a rack.

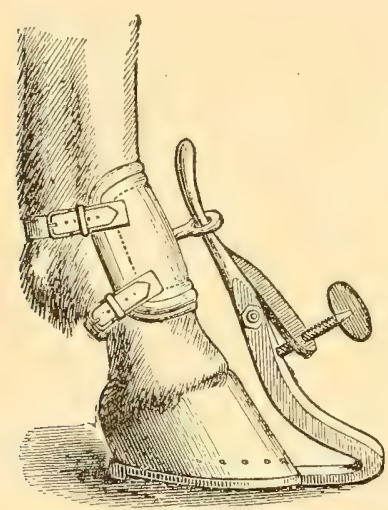

APPARATUS FOR DEFORMED FETLOCK.

It is also seen in connection with osteophyte deposits; or in other cases as a congenital defect, from contraction of the ligaments at the back of the joint; or, again, as a result of rheumatism.

Symptoms.-This is a very easily recognized trouble, the joint being continually kept in a semi-flexed shape, and in bad cases the knees will tremble and the horse look as if he would fall forward. The class of horses most affected are those used for light wagons and hacks, and in this lind of service subjected to abuses. Lameness is not ordinarily an accompaniment of knuckling, the horse working regularly, perhaps for many years.

Treatment.-In foals, bandage the legre, and allow time for the parts to gain strength. In old horses, feed from the floor or allow a rum at pasture, at the same time applying the Oil Blister No. is in at very thorough manner. When rheumatism is suspected as a cause, treat as for rheumatic joints.

The use of the apparatus shown in the acompanving illustration is pretty sure to be followed by great improrement, cspocially in young animals. 


\section{CHAPTER XXII.}

\section{DISEASES AND INJURIES OF THE MUSCLES, TENDONS AND CELLULAR TISSUES.}

I. ATROPHY, OR WASTING AWAY, OF A MUSCLE.-II. BROKEN OR CUT MUSCLES.—II. CRAMP OF THE MUSCLES.—IV. SPRAINED SHOULDER.-V. SETONS, AND HOW TO INSERT THEM.—VI. SPRAINED ELBOW.-VII. SPRAINED TENDONS.—VIII. SPRAINED FETLOCK.—IX. SPRAINS OF TIIF HIND LEG.- $X$. SHOULDER SLIP, OI SWEENY.-XI. CAPPED ELBOW, OIR SHOE-BOIL.—XII. CAPPED HOCK.—XIII, CURB.—-XIV. CONTRACTEI) TENDONS.-XV. SWELLED LEGS. XVI. SWELLED ANKLES.

\section{Atrophy, or Wasting Away, of a Muscle.}

Atrophy, or wasting away, of a muscle is of very common occurrence, both in horses and man, from want of exercise. When the muscle is in a condition of health its color is a beautiful red, which changes as soon as the wasting commences to a yellowish red, then to a fawn color, and as it gradually degenerates into a fibrous structure it takes on a dirty white hue. In very extreme cases the whole muscle has been known to turn to fat.

Causes.-Atrophy originates from such causes as "inactivity of a part, obstruction of its blood vessels, failure of its own vital energy, continued pressure on its surface, and the process of inflammation." It may come about as a sequel of inflammation in any muscle, producing the condition popularly called "sweeny," or again, as the penalty of continued disuse of a muscle or set of muscles, as is well illustrated in certain chronic disabilities of long standing, like navicular disease, spavin, shoulder-slip and paralysis, and also in old age.

Treatment.-The muscle that has once degencrated to a tissue of lower organization can never be restored to its former state; when, therefore, this change is just setting in, then is the time to treat and stop the disease. A good smart blister over the course of a muscle that is commencing to waste-such as Fly Blister No. 7, or Oil Blister No. 8-is necessary. When atrophy is consequent on other ailments, such as navicular disease, spavin or the like, the treatment should, of course, be directed to their cure first. 


\section{Broken or Cut Muscles.}

The muscles of the body are the principal agents in the important functions of movement, and for this service they are endowed, as might be expected, with great power. In some locations they are stronger than even the bones, which they are known to have broken by the intensity of their contraction. From their great number and the important part they play in locomotion, the muscles are liable, from various accidents, as wounds, bruises, lacerations and violent contractions, to be broken or cut. In bruises, as a regular thing, and in contractions, this sort of injury occurs without any external wound to betray its presence.

A broken or cut muscle is always repaired by one uniform process; that is, a new material joins the two ends of the muscle, which, by their natural elasticity, have drawn apart. In subcutaneous breaks

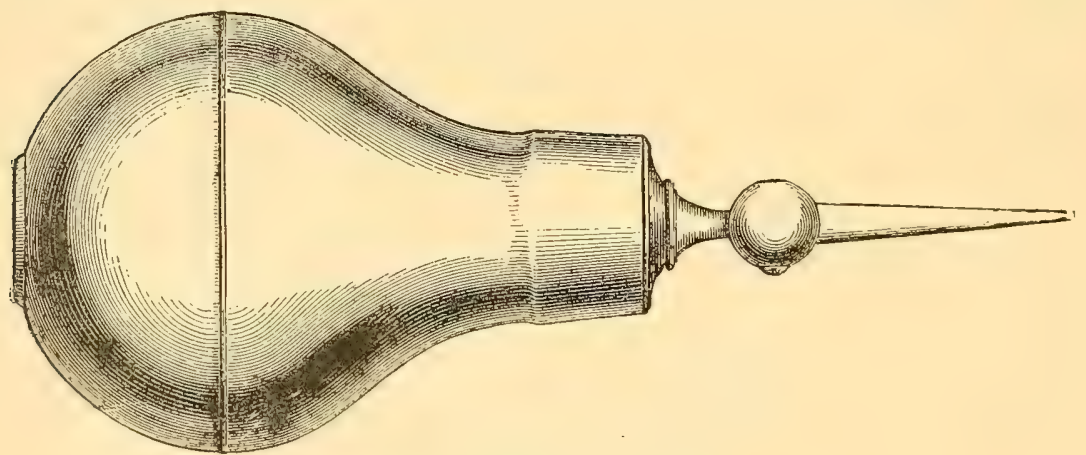

INDIA-RUBBER SYRINGE.

(those where the skin is not cut), the muscle will heal by what is callsd "first intention," the two ends being united by an albuminous substance, without the formation of pus. When, howerer, the ends are exposed to the air, the union must be by granulations, or, in other words, by a gradual growing together, and during this process there is always a formation of pus, in warm weather nearly always of pus in great quantities.

As before intimated, a broken or cut muscle is never restored by the sort of material originally composing it. The repair is effected by a red vascular substance, which lat er chamees to a dense white ecllular thssue constetuting a "cicatrix," which divides the muscle into two bellicis, and being smaller in size than the original substance, oceasions a corresponding depression in the skin, called a "dimple." 
The skin, on healing, forms a hard, irregular looking "cicatrix," or "callus" mark of a reddish color when recent, but gradually turning white and by degrees growing smaller, until in some cases it may be nearly imperceptible. On these cicatrices the hair will never grow, owing to the destruction of the hair roots, but if not large originally they may get so small, in course of time, as to be completely hidden by the surrounding hair.

Treatment.-This will consist in washing all, dirt and hairs off by means of a rubber syringe, of which most useful and not at all expensive article the one illustrated is a neat and handy specimen. The after-treatment will be the use of antiseptic solutions, as directed for wounds, in Chapter XXIII.

\section{Cramp of the Muscles.}

A few horses are subject to cramp, which is mostly seen in the hind parts. Cramp is an irritability and involuntary spasm of some particular muscle, or set of muscles, and is caused by a strain, or bruise, or in certain cases by a cause so obscure as not to be assignable. Horses whose energies have been overtaxed by severe pulling and straining during the day, and who are compelled to stand all night in a narrow stall, are very likely to suffer from cramp in the legs. When the horse tries to move, the muscles, having become stiff and inflexible, refuse to act for a while, until the nervous energy is restored; and then they exhibit a spasmodic overaction that produces cramp. The horse seems utterly powerless to control their action, and tney jerk and twitch in a most singular manner. The circulation which has been partially suspended, is soon restored by this exercise, and as the parts become warmed the muscles relax, and their pliancy and elasticity return. Cramping is very painful, and often leaves lameness and great soreness behind it. When this is the case, no pains should be spared to find the affected part, which may be done by pressing upon the muscles of the legs with the hand. The horse will wince when the tender spot is touched.

Treatment.-This will consist in dry rubbing the leg when the cramp occurs. Later the painful muscles may be rubbed with the Soothing Lotion No. 3, or the Cooling Lotion No. 4. If the cramp is found to commonly leave a soreness in the muscles, Absorbent Blister No. 11 should be thoroughly rubbed into the sore part. 


\section{Sprained Shoulder.}

The great number of muscles in the region of the shoulder, and the important part they perform in locomotion, makes this a frequent seat of sprains, from wrenches, over-exertion, and ill-fitting collars.

Symptoms.-Shoulder lameness it is not always easy to assign to the true cause. In many cases it is very difficult to determine whether the trouble is in the shoulder or the foot. But if, when standing quiet, the leg is habitually advanced, with the foot resting flat on the ground, the trouble may safely be set down as in the shoulder; for in lameness of the foot that member rests customarily on the toe. By lifting the foot, and flexing and extending the shoulder, the different sets of muscles will be brought into play, and if there is soreness in any of them, the animal will show by his flinching in which ones it is. The way of carrying the leg when walking is regarded as very characteristic of this trouble; the leg is held stiff, and brought forward with an outward swinging of the foot, so as to keep the sore muscles quiet, and thus prevent pain. A dragging of the leg and stumbling are often noticeable, but these are uncertain indications, since they also characterize lameness of other parts.

Treatment - In the beginning use hot or cold water, bathing the part for half an hour at a time. Afterwards rub in Soothing Lotion No. 3, or the weak Stimulating Liniment No. 5. Be sure to allow the horse complete rest, as atrophy, or wasting of the muscle, is liable to set in if he is kept at work.

In chronic cases insert a seton over the sore part, leaving it in place for three weeks. Wet it occasionally with a little turpentine and move it twice a day. Do not neglect this, as it is very important that pus be not allowed to collect and burrow under the skin.

\section{Setons, and How to Insert Them.}

A seton may be made of any sort of linen or cotton, but a piece of $\frac{3}{4}$-inch tape is the best. To insert a seton, the skin should be pinched up, and a small cut made with a knife, or ordinary scissors, at the

SETON NEEDLE

points above and below as required. The seton needle, holding the tape, in then passed under the skin, and the ends tied together, or two small pieces of stick tied on, to prevent the tape from coming 
out. The horse's head should be secured to prevent his biting the seton. For this purpose use whicherer is the more convenient-the neck cradle, or the side rod, as illustrated elsewhere. Firing and blistering are other expedients resorted to at times over the sprained muscles.

\section{Sprained Elbow.}

Owing to its prominence and the large muscles in its neighborhood, the region of the elbow is particularly exposed to sprains, as well as bruises. When it is cut or torn in connection with bruises, air is likely to be sucked under the skin, causing great swelling, which may even extend as far as the head; but this is readily gotten rid of by making small punctures in the skin, and pressing it out. While not all the air can thus be expelled, the remainder will be absorbed.

Elbow lameness makes the horse stand with the knees flexed, and on trotting him the parts drop a great deal from the pain it occasions, In some instances the leg is dragged in a manner similar to that in shoulder-lameness.

The treatment is the same as that just given for sprained shoulders.

\section{Sprained Tendons.}

The principal tendons that are liable to sprains are well shown in the next illustration. In the hind as well as fore leg, the perforatus tendon is external, and the perforans is in the middle, while the suspensory, the most internal, lies close to the back, at the bone. They are all subject to injury, from the horse slipping, or from hard galloping, or allowing the toe to grow too long; also from very hard pulls, and various other causes. When the perforatus is sprained, there is a great deal of swelling, the leg having a bowed out appearance. If it be the perforans that is hurt, the swelling is slight, and is principally visible at the sides; while a sprain of the suspensory tendon will, on account of its location, show no swelling; and yet by flexing the knee, each tendon will relax, and the different enlargements will be readily felt. Although the swelling of the perforatus, or the outer tendon, is very great, and a deformity maly result, still the animal will be able to perform his work. On the other hand, the slight swelling of a sprain of the suspensory tendon will mislead any one not acquainted with the important part this tendon plays in supporting the leg; for this is really an injury from which the animal rarely recovers--that is, fully recovers-and as a rule he will never again stand work. 
Following these sprains, contracted tendons are liable to result. But that condition will be treated of under another heading.

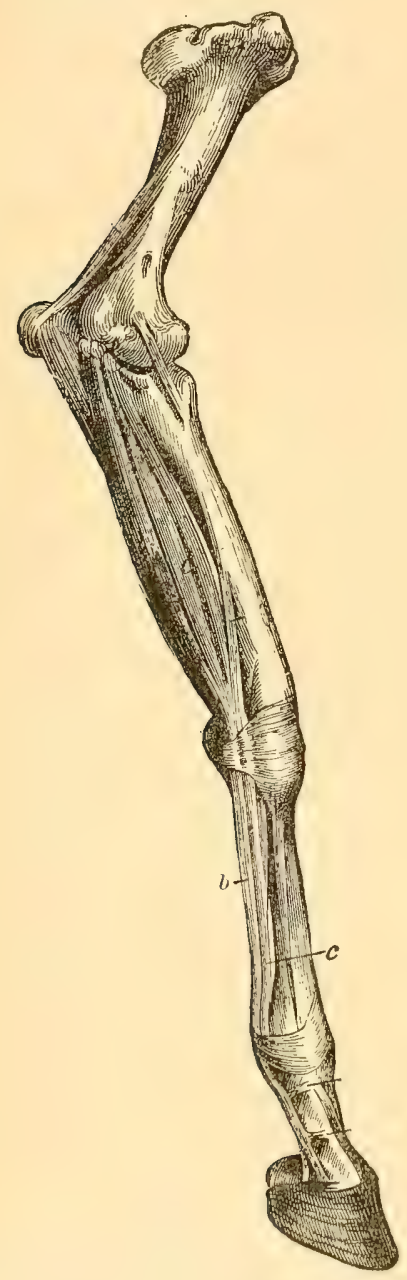

MUSCLES ON BACK PALT ON FORE LEG.

Showing their endum in the ten. dons, or "leaders."

$b$-Perforatuz tendon.

$c$-Perforans tendon.

Treatment.-Remove the shoes, and have the feet leveled. In case of a recent sprain, attach a hose to the leg, and allow the cold water to run on a bandage for several hours at a time. Afterwards bathe freely with the Soothing Lotion No. 3, or the Cooling Lotion No.4, and re-wrap the leg in a bandage. A shoe with a high heel will taka the strain off the sore tendons, but this is liable to encourage their contraction. After the fever is gone, if any lameness is left, use the Mixed Blister No. 10; or the firing-iron may first be used, and afterwards the blister. Be sure to allow a month or two's rest.

\section{Sprained Fetlock.}

From sprains and bruises there will be lameness in this particular injury, but very little swelling. The horse will stand so as to keep the joint flexed, and the whole fetlock will feel hot and tender. A frequent repetition of this trouble is liable to eventuate in a hard cartilage or gristly formation around the jomt, occasioning what has already been described (in Chapter XXI), under the head of "Knuckling, or Standing, Over."

Treatment.-This will be the same as for sprained tendons. After the pain has gone, use the Mixed Blister No. 10.

\section{Sprains of the Hind Leg.}

Sprained Hip.-The hip is not a very frequent seat of lameness, many supposed cases of hip lameness being referable to the hock or foot. In a genuine ease, however, the animal 's morements suggest strongly just where the trouble is located. As he stands, the foot is Hexed, and perhaps it may be held up from the ground; when he is 
moved, the hip is held stiff, and progression is effected by hops, in some cases the foot not being brought to the ground at all. On flexing the leg, and moving the hip, he will flinch from the pain, while the rest of the joints move freely and naturally.

The treatment essentially required is absolute rest. The use of the high heeled shoe is also advisable, to remove the strain from the muscles. Further treatment, if any, should be the same as for a sprained shoulder.

Sprained Stifle.-In this trouble the leg, when standing, will be bent, but, when in motion, it will be kept extended and stiff, so as to prevent that movement which causes pain. When walking there may, perhaps, be a swinging of the foot in a circle, the heel being brought to the ground first. For treatment, carry out the directions for sprains in other parts.

\section{Shoulder Slip, or Sweeny.}

A "sweeny," or atrophy, of the muscles may occur in any part of the body where muscle is present, but what we are here to consider is sweeny of the shoulder, which is the one of most frequent occurrence, and is more discussed among farmers and stockmen than all others put together. But it ought to be remembered that what applies to sweeny of this particular part, applies in a general way to sweeny, or atrophy, of all other parts as well. (See Section I of this chapter.) There are various sets of muscles subject to stveeny of the shoulder, but those most generally affected are the muscles on each side of the shoulder-blade and the prominent masses at the breast.

Causes. - Sweeny is the result of a sprain, followed by the usual train of symptoms, as lameness, swelling, etc. These at first may not attract much attention, and so the trouble may go on till the sweeny or wasting has gotten firm hold. The changes that occur in an atrophied muscle during its degeneration and wasting away have already been considered, and shown to be a sequel of the inflammatory process.

Symptoms.-The peculiar symptoms of sweeny are the rotating of the leg in walking, and the outward slipping of the shoulder, both indicating a greatly relaxed condition of the joint structures. Similar symptoms attend certain diseases of the feet, especially navicular disease, in which the breast muscles gradually shrink and waste away, simply from non-use. 
Treatment.-In the first stages, or immediately after the sprain occurs, allow rest, remove the shoes, and level the feet. Apply hot

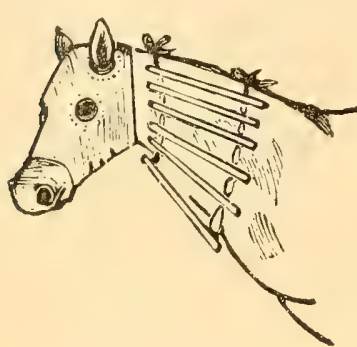

NECK CRADLE.

fomentations to the muscles, afterwards rubbing with the mild Stimulating Lotion No. 5 . A large box stall, or a paddock for gentle exereise, should be provided.

Where sweeny has unmistakably developed, a good application of the Mixed Blister No. 10 , and the same general treatment as for atrophy, will be in order. The neck cradle, a simple device which is tellingly depicted in To prevent a horse from biting our illustration, had better be used to prevent at a blister, etc. biting the blistered shoulder.

\section{Capped Elbow, or Shoe-boil.}

A capped elbow, or shoe-boil, is, as the name suggests, a swelling of the parts over the point of the elbow, from a bruise or other injury, most generally from lying on the heel of the shoe. It is of common occurrence, especially in winter, when the shoes have long calkins. It is also seen in trotters; they are apt to strike the elbow in their excessive flexion of the knee, necessitating the use of a protecting "boot."

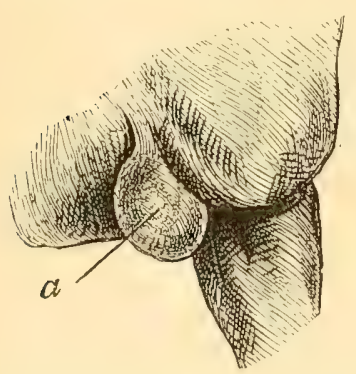

CAPPED ELBOW, OR SHOEBOIL.

It is shown at $a$.

Symptoms.-A horse put in his stall all right in the evening may produce a shoe-boil before morning, by lying on the heel of the shoe. On the other hand, they are sometimes very slow in developing. The cellular tissues around the elbow are filled with a thin serous fluid. as a result of the bruise. This will be hot to the touch, swollen and tender, in many cases attaining great size. This condition lasts for a few days, and then the fever subsides, and there will be found a sac full of thid. Now it is that the permanent mischief is done; this fluid, if allowed to remain, will, in turn, form a hard, callused swelling, or a fibrous tumor gradually forms. or possibly an abseess containing pus will develop.

Treatment. - First attemel to the shoes: have them removed and alter their style, and as a preventive of further damage place a "shoe- 
boil boot" on the ankle. These boots are made-in a great variety of forms, but nearly all on the general plan of a ring of very large size, so arranged as to buckle below the fetlock. They are made of all sorts of materials, from the rough and ready band of straw to the more elaborate one of leather, carefully stuffed with hair. They all answer their purpose very well, but the great trouble is in forgetting to put them on; a single night without the boot mily cause a return of the whole trouble.

During the very fererish stage, use hot fomentations, or cold water irrigations, and afterwards the Soothing Lotion No. 3. After the ferer has disappeared, if the sac has not been absorbed, but is still found full of fluid, it should be punctured with the abscess lance, and the wound kept open until it closes thoroughly from the inside, the hole being syringed every day or two with Antiseptic Lotion No. 1. If the ailment has progressed until the sac contains a semi-solid mass, rub frequently with the following liniment, whereupon the distended spot will either suppurate, or its contents disappear by absorption:

No. 24 .

Strong ammonia water, 1 ounce.

Olive oil, 2 ounces.

Mix.

Where a tumor is old, and absorption cannot be induced, it must be cut out. This is done by making a good long cut in the direction of the leg, and dissecting out the abnormal mass, as close to the skin as possible. Care must be taken to remove no more skin than is absolutely necessary, as otherwise the skin will contract too much, and confine the elbow in its morements. The edges may be stitched together, and the wound kept thoroughly moist by the Lotion No. 1, or No. 12. The slings are necessary to prevent lying down, as that would break all the stitches loose.

Another way of remoring the tumor is by making a deep opening into the middle of it with the sharp bistoury, and injecting some irritating solution to eat away the growth.

\section{Capped Hock.}

This is not an uncommon thing as a result of injury, especially among kicking horses, from striking the hock against the stall.

Symptoms.-This condition is similar to capped elbow; the cellular tissues are infiltrated with flude, producing a prominent round lump at the point of the hock. While usually there is no fever or lime- 
ness to hinder working, eases have been known in which the inflammation involved the whole joint, thus presenting a serious aspect, and leaving a permanent enlargement.

Treatment. - When the swelling is not large, and is of recent formation, the use of cold showers and the Soothing Lotion No. 3 often suffice to effect a cure. If the fever is severe, use the cold shower, and afterwards the Lotion No. 3, with the addition of the Purgative Pill No. 18. Should a soft sac remain filled with fluid, it has frequently been our practice to open it, and inject a little of Solution No. 25, given below. This may, perhaps, cause some swelling and tenderness, but we have never seen any permanent bad effects ensue.

No. 25. Tincture of iodine, 1 drachm.

Water, 1 ounce.

Mix.

\section{Curb.}

A curb is a sprain of the ligaments at the back of the hock, from slipping, heavy pulling, carrymg heavy riders, etc. Certain shapes

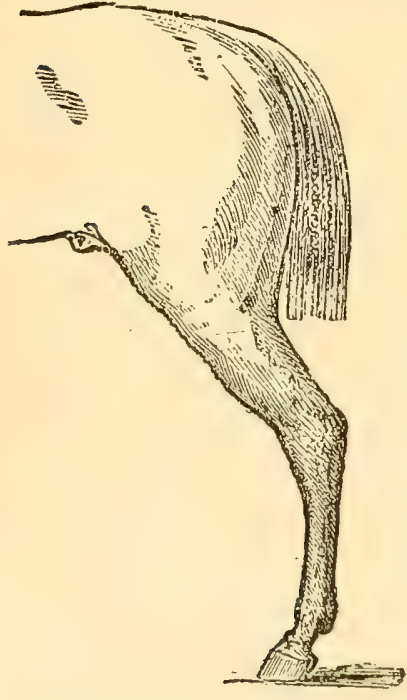

AN ILL-SHAPED IIOCK.

Such a hock is predisposed to dis. ease. of hocks are undoubtedly. predisposed to curbs; such are the sickle-shaped, the bowshaped, and small hocks.

Symptoms.-At first there will be a soft, pulpy swelling, which later will become harder, leaving the hock with a bowed appearance behind (as shown in the engraving on page 221), which will be the most apparent when the observer stands at the side. From this stand-point the difference between the curbed and the perfect leg will easily be noticed, the sound limb showing a straight line from the point of the hock to the fetlock.

This trouble is not so serious in old as in young horses, in whom there is the added danger of a tendeney to bony formations, extending to the hock.

Treatment.-Allow rest, and use the high-heeled shoe. Reduce the ferer by Lotion No. 3 , or 4 , the same as for capped hock, and afterwards rub in Absorbent Blister No. 11. In the case of romm anmals, it is best to fire and blister. Some veterinarians in doing this include the whole joint. 
XIV. Contracted Tendons.

These are frequently seen as a consequence of repeated sprains of the tendons or joint ligaments, though they may also be of congenital origin. When a sprain occurs the tendons become swollen, by effusion of fluids from the blood. This naturally shortens them, and when long continued, the effused material (which is not at all like the tendinous substance) is found to contract, and the upshot of it all is a condition in which the horse walks on his toes. The different forms of knuckling, or standing, over are very frequently brought on through contraction of the ligaments enwrapping the joints.

Treatment.-Treat the ailments that are liable to cause it promptly when

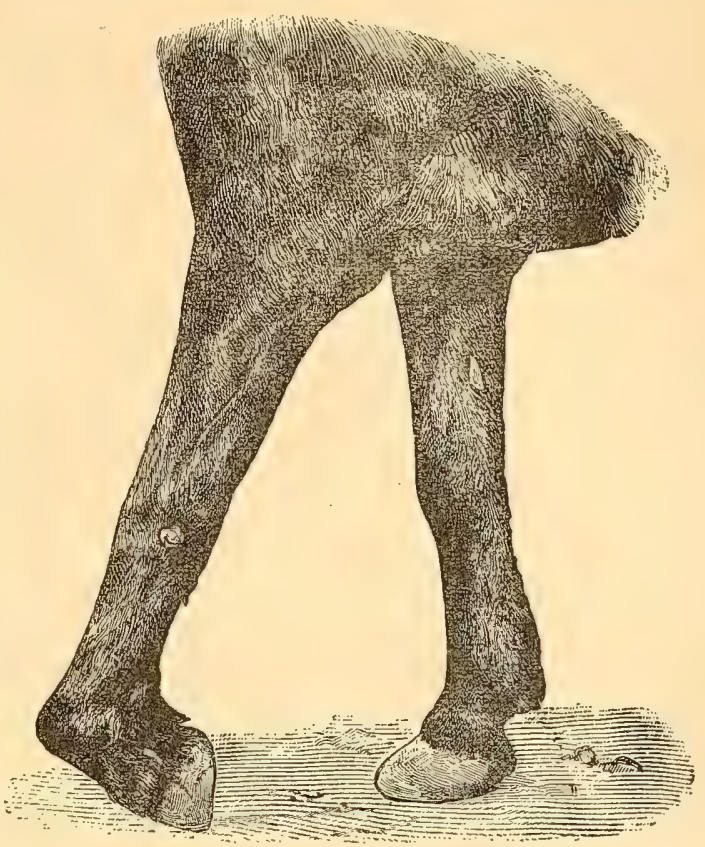

A CASE OF BADLY CONTRACTED TENDON.

Engraved for this work from a Photograph. they appear. When the condition has actually been established, there is but little hope except through the operation of tenotomy, which will be described in the chapter on Special Operations.

\section{Swelled Legs.}

The hind and sometimes the fore legs of the horse are subject to an enlargement having its origin in the cellular tissue underlying the skin. This tissue is the thin, white membrane that attaches the skin to the muscles, and extends not only around the legs, but is spread over the entire body. Nature has filled all the interstices between the fleshy parts and the outer covering of the body with minute salcs, or close cells, filled with a watery secretion. They constitute the cellular tissue, and act as little pads for the skin, which everywhere rests upon them. 
But frequently infammation is established in the cellular tissue, the leg becomes dreadfully swollen, and the skin puffs out all around the limb, as though it had been stuffed and pressed out to its utmost tension. The leg grows very lame and stiff, and, after a time, cracks appear, from which exudes a whitish-yellow, watery matter, similar in appearance to that which characterizes cracked heels.

Sometimes the swelling of the legs comes on with astonishing rapidity-perhaps in a single night-and then disappear's almost as suddenly. Such phenomena usually indicates nothing more than sympathy with functional derangement in some other part of the horse's frame. Swelled legs is so intimately associated with other diseases that, in many an instance, it is impossible to decide which is the cause and which the effect. They are continually running into and aggravating each other.

Causes.-Both local influences and constitutional tendencies. Under the first head, we include exposure, insufficient or unwholesome food, irregular feeding, hard usage, improper stable management, and a foul atmosphere; under the other, a feeble state of health, impurity of the blood, the presence of ferer, and the like. Several of these causes, acting together, cannot fail to bring on disease.

Treatment. - The first thing to do is to provide a good clean, pure stable, or if possible place in a paddock. Then attend to the disease itself; use cold showers on the legs, and afterwards apply the Soothing Lotion No. 3, or the Cooling Lotion No. 4. Afterwards apply a

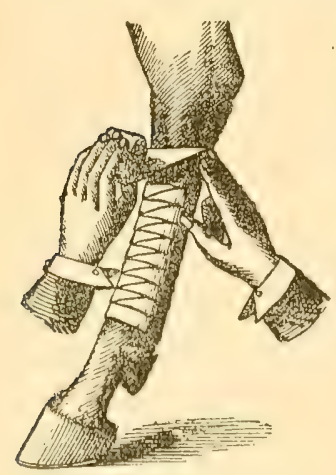

PLOPER MODE OH BANDAGING TIIE ILE. bandage to the legs, turning the bandage at each round, as shown in the illustration. The diet should be light and moist. Scalded bran, with perhaps a little oats mixed, will be the best; and if the bowels do not movely freely, give the Purgative Pill No. 18, or the milder one No. 20. The animal must be kept out of the wet, and be given well regulated exercise.

A powder as follows should be mixed in the feed three times a day:

No. 26. Powdered nitrate of potash, $1 \frac{1}{2}$ ounces. Powdered rosin, $1 \frac{1}{2}$ ounces. Mix, and divide into 12 parts.

When found in eonnection with some pronounced blood diseanse, the latter should recive spocial tratment, but the leas are, nevertheless, to be bandaged and treated as above directed. 


\section{Swelled Ankles}

This is an affection of much milder type than the preceding, and, as its name implies, is confined almost entirely to the ankle joints. It is intimately connected with swelled legs, of which it is nearly always a precursor. Some horses are extremely subject to sivelled ankles. At night the parts show no signs of enlargement, but in the morning they are much swollen, and manifest a considerable degree of heat. These symptoms disappear after exercise, and everything seems right again. This condition of the joints may last for months, and has been known to trouble some horses for years. That it is attended with great uneasiness, or even real pain, is sufficiently evidenced by the efforts which the horse is continually making to rest his feet, his disposition to lie down, and the relief which he manifests in doing so.

Causes.-In the cases above outlined, a diseased condition of the feet is invariably chargeable with these developments. Less frequently the origin of swelled ankles may be traced to disease of the navicular and lower pastern joints; and occasionally it seems to be simply the result of constitutional tendencies, - a plethoric condition, a superabundance of blood, - or in connection with hard work and severe straining. The fever and heat arising from the diseased condition of the bottoms of the feet inflame the membrane of the joint under the skin, and it enlarges while the horse is resting; but exercise restores the healthful action of all the parts, and the swelling disappears.

Treatment.-The first thing to be done is to remove the cause of the swelling by curing any disease of the feet found to be present. Examine the heels, to see if they show soreness, or any appearance of thrush. In a plethoric condition of the blood, give the Pills No. 18, or No. 20, and the same diet, bandages, exercise and medicine as advised for swelled legs. The two ailments are so closely allied, that the sume general instructions will, in fact, answer for both. 


\section{CHAPTER XXIII. \\ WOUNDS, BURNS, ETC.}

I. CLASSES OR KINDS OF WOUNDS. II. CALSES OF WOUNDS.-III. ClEANSING A WOUND.—IV. SEWING A WOUND.—V. SUTURES.-VI. BANIAGES.—VII. THE THREAUS AND NEEDLES TO USE.—VIII. NATURE'S DIFFERENT MODES OH HEALING. - IX. DRESSING WOUNDS.- $\mathrm{X}$. BURNS AND SCALDS.

\section{Classes or Kinds of Wounds.}

A wound is any breach of the skin and flesh, or any division of the soft parts of an animal's body, caused by violence or external force. This class of injuries may be conveniently considered under the six different heads, or divisions, of incised, lacerated, punctured, contused, poisoned and gun-shot wounds.

Incised Wounds - These are wounds produced by some sharp instrument or substance, giving a clean, straight cut surface. They are the simplest of injuries when superficial, but when they penetiate deeply, they are liable to cut important ressels, nerves and muscles. thus producing a serious condition. When it is remembered that, if the sources of nourishment are shut off from a part, mortification will ensue, it will readily be seen how important it is that these cases should be carefully watched and skillfully treated.

Lacerated Wounds.-Here the tissues are torn and ragged, in some cases making it mpossible to bring the edges together. The bleeding is usually small in quantity. The ressels being twisted and torn by the accident, their contraction helps to stop the flow of blood.

Punctured Wounds.-These constitute the most serious class of all, as they generally include the injury of important parts, wuch as the joints, viscera, vessels or nerres. In the foot the navicular joint, and in the chest the lungs or heart, may be injured. Foreign bodien are frequently carried inwards by the penetrating substance that inflicts the wound; and accordingly skin, elothing or hair maly be found deeply imbedded in the puncture, preventing healing. The foreign body acts as an irritant, and the pus which Nature presently forms to throw it off, may burrow into other important parts. 
Contused Wounds.-These are characterized by a hruising of the tissues, and a rupture of the minute vessels in the skin; these are followed by an escape of blood between the tissues, and consequent swelling.

Poisoned Wounds. - In these there is an entrance of poisonous matter from the wound-inflicting body; or some other variety of wounds may take on this form from unhealthy surroundings.

One of the most common sequels of this class is lock-jaw, in which the poison is generally introduced by rusty nails or other iron substances.

Gun shot Wounds.-In civil life these are seldom encountered by the veterinarian, but when they do occur, are generally of a serious nature. They frequently combine some of the other sorts of wounds.

\section{Causes of Wounds.}

The causes of wounds are innumerable, but, of course, are usually accidental. At the same time they are generally due to carelessness of some kind or other. In the stable, they frequently result from improper tying; or, from the horse's pulling back, he may injure the poll on the halter; again, he may injure the poll on certain old styles of mangers, low ceilings, or low doorways. The cheek may be injured by buckles; the eyelids, lips and nostrils are torn on nails or hooks; and the hip, hock and elbow, are frequently injured by kicks. When the animal is at work, the knees and hind parts may be injured by falls. Then there are the wounds seen from collisions with other vehicles or with cars; those from running away, or from being run into by other runaways; and from goring by cows, being staked in jumping fences, or from weights falling from the wagon onto the back, etc.

\section{Cleansing a Wound.}

In the treatment of a fresh wound, the first thing to do is to cleanse it thoroughly, removing all foreign substances, as gravel, hair and dirt. This is best done by means of a syringe, such as that shown on page 310. Plenty of clean water should first be used, followed by Antiseptic Solution No. 1, or No. 12. Of these, too much can hardly be used in the syringing out of a wound, as on its proper cleamsing depends the whole success of the treatment, and without it neither the direct union nor the union by adhesion will be possible This will be fully understood on reading section VIII of this chapter. 
When a syringe is not to be had, small sponges made of cotton batting answer very well. They should never be used more than once, and then thrown away. The regular store sponge is a very

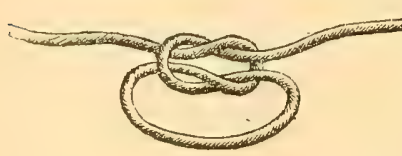

KNOT FOR STOPPING BLEEDING

Showing the proper way to tie the knot. poor thing to wash a wound with, as it readily absorbs and retains dirt, and it is hardly ever clean.

A bleeding vein or artery is to be caught with the forceps and ligatured, or tied by a properly made knot; the one shown in the annexed cut exhibits the proper mode of tying. Any oozing of blood from the capillaries may be stopped by pressure with a sponge wet with cold or hot water.

Before sewing ul a wound all the hair around the edges should be carefully clipped off, as it might retain matter, or prevent healing by getting between the edges.

\section{Sewing a Wound.}

Sewing is always advisable in wounds of any considerable extent, though it is well to leare an opening, by missing one or two stitches at the most dependent part, for the drainage of any matter forming inside, and also that through it may be injected the antiseptic solutions reconmended for cleansing wounds. The hair having been clipped off, and the wound carefully washed as already directed in Section III ahove, the edges should be drawn together with the fingers, to get an idea of the best position for the sutures. In most parts of the body any loose fragments of skin had better be trimmed off. But not so around the eyelids, lips, nostrils or tongue; in these localitics every particle of skin that by any chance can be saved should be saved. It is important to remember thin, as these are parts that need all the skin they can get, and the removal of any, especially in case of the eye, may cause serious trouble. Wounds of even a serious nature in these parts usually heal very easily,

\section{Sutures.}

The wound being ready to sew, the next thing will be to cheose the style of suture to be used. In a work like this it will be sufficient to mention only a few out of the great number of sutures that are in use. The "interupted" suture, here illustrated, is. then, the simplest and most eommonly used, being well suited to surface wounds of all kinds. It has this advantage that on any emergency, one or more 
stitches may be cut without disturbing the others. The "continnous" suture is seldom used for horses, and when it is used, princi-

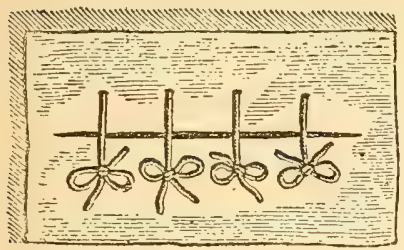

INTERRUPTED SUTURE.

pally in cases where very little matter is expected to form. It consists of one continuous thread through the edges of the whole wound, and is tied only on each end. The "quilled" - suture is placed by passing a double thread deeply through the tissues, the ends being at least one inch from the edges of the cut. A quill, pencil or other substance of similar shape, is placed on each side, and the double threads tied tightly around them. This form of suture is useful to

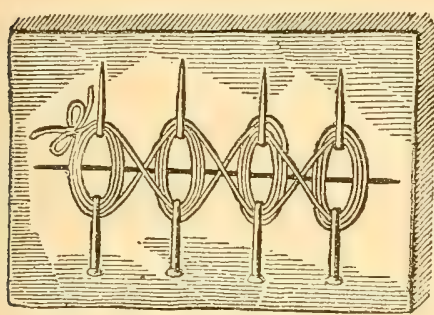

TWISTED SUTURE. bind a deep wound firmly together, but the edges are liable to be everted; to prevent this, a few superficial interrupted sutures may be needed.

The "twisted" suture is very frequently used. It is placed by inserting :one or more pins across the cut and winding thread, twine, etc., around their ends, in any form desired, which in ordinary wounds is likely to be about as shown in the accompanying illustration.

\section{Bandages.}

In the absence of sutures, bandages may be used to retain the edges of small wounds together. They are also necessary when the effort is to heal by direct union, or by adhesion.

They are of great value in all wounds, acting as a protection from dirt and flies, excluding the air, and taking some of the strain off the sutures. They are not needed when scabbing is the process of healing in contemplation.

\section{The Threads and Needles to Use.}

Threads.-Any sort of very heary thread or twine may be used for sutures. The thing necessary is to see that it is clean. Heary braided Japanese silk thread is largely used by professional veterinarians, and to a less extent cat-gut and tendons, the latter mostly for special cases. Before using always dip the thread in an antiseptic solution. Our Nos. 1, 12 and 13 are all good for this purpose. 
Needles.-These for veterinary purposes are made of all shapes and sizes, from 1 inch to 6 inches long, containing in some cases a
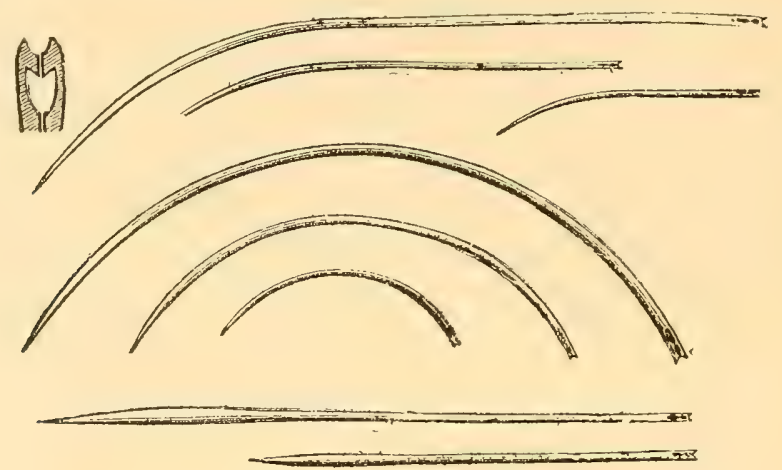

DIFFERENT KINDS OF VETERINARIAN"S NEEDLES.

double bend, for special purposes. The shapes in most common use are shown in the accompanying engraving. In the left-hand corner is seen the enlarged head of a self-threading needle. The curved needle is the style most used for superficial wounds.

The skin of the horse, on some parts of the body, is very tough and thick, making it very difficult to push the needle through, and in

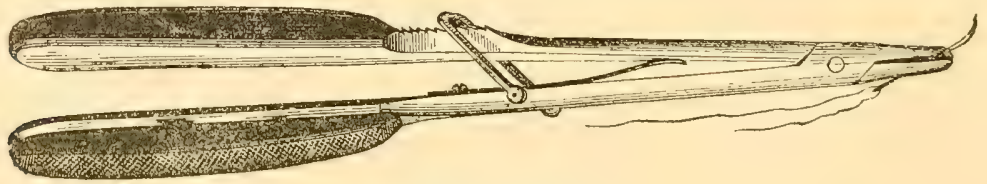

NEEDLE HOLDER.

these cases the needle holder is a valuable aid. Annexed is a picture of the needle holder in common use.

\section{Nature's Different Modes of Healing.}

There are four different ways in which a wound may heal; namely, by direct union, adhesion, seabbing, or gramulation.

By Direct Union.-This the most farorable mode of healing is very rarely procured in the horse, the surrounding being against obtaining so happy a termination. To produce it the wound must be seen immediately after its oceurrence, all foreign matter removed, and the ederes bromglat dosely together hy handages, thus excluding the air and its germs. From this union there results no appreciable cicatrix. 
By Adhesion.-This occurs in wounds of a similar nature to the preceding, but which have been left a longer time without treatment. It is characterized by a slight inflammation; a plastic fluid is thrown out between the edges that binds them together, and cam afterwards be seen as a thin, pale line. In this process of healing also bandages are necessary, and though it is a less favorable one than by direct union, it will take place in a very short time.

By Scabbing.-This well known mode of healing in the wonderful reparative provisions which Nature makes, occurs in wounds that are exposed to the air. The scal is formed by a thickening of the fluids thrown out by the vessels of the wounded surface, in this way excluding the air, and preventing the formation of pus. In case, however, that pus should form under the scab, from the irritation of dirt or fever, its accumulation will cause pain, as a consequence of the resultant pressure, and the scab will be lifted, allowing its escape. When the irritant is thrown off another scab will form, and the healing process will be resumed.

By Granulation -Granulation takes place in severe wounds, where the tissues have been torn, and thus air has gained entrance, and matter formed, making unavailable the more farorable modes of union just considered. From the wounded surface, small red elerated spots will project; these continue to form, and if the surfaces are brought in contact they join together; and if this is not done, granulation will be a slow process, and such, in fact, it often is, especially in the hot season. The substance which acts as a bond of union is a new form of connective tissue, for the original tissue is never reproduced in a granulating wound.

\section{Dressing Wounds.}

This has been referred to many times in preceding parts of this work, and hence no more will be required here than a few condensed remarks. After a wound has been properly washed and sewed, the air should be excluded by dipping cotton batting in Antiseptic Solution No. 1, or No. 12, and bandaging on the part. The bandages should be changed tiwce a day in summer; in the favorable weather of winter, they need not be changed so often. At each dressing be sure to use fresh cotton batting, throwing the old handage away.

When a wound is left free to the air, a scab forms. It should not be touched, but if matter gathers, it may be washed off daily, and 
the White Lotion No. 16 sponged on; or, instead, either of the following healing powders may be dusted on.

$\begin{array}{ll}\text { No. 27. } & \begin{array}{l}\text { Powdered calamine, } 1 \text { part. } \\ \text { Powdered rosin, } 1 \text { part. } \\ \text { Mix. }\end{array} \\ \text { No. 28. } & \begin{array}{l}\text { Powdered iodoform, } 1 \text { part. } \\ \text { Powdered naphthaline, } 2 \text { parts. } \\ \text { Mix. }\end{array}\end{array}$

\section{Burns and Scalds.}

These are occasionally seen, even on the farm, as a result of accidents. The extent of tissue involved will depend on the intensity of the heat, and the length of time of its application. Burns are classified, scientifically, under the three heads of erythema, or redness; vesication, or the formation of blisters; and mortification, or death of a small or large surface. Where a large extent of skin dies, the muscle, tendons and joints may be exposed, which, of course, is a very serious condition. In most cases of burns, the local pain will become general, the animal grows fererish, and in the case of stables burning there may be inflammation of the lungs, from inhalation of the irritating smoke or intense heat.

Treatment.-The aim in the treatment is to exclude the air from the wound, and in this way relieve the pain. For this purpose flour may be dusted over the raw parts. But a better application is that of carron oil, so much used for burns by iron workers, and made by mixing equal parts of linseed oil and lime water. When this is applied, it forms a protecting paste, over which may be sprinkled flour or some similar air excluder. Layers of cotton batting may be used alone or over the other preparations. In slight burns, such as rope burns, etc., the White Lotion No. 16 may be applied.

For the relief of pain, half ounce doses of tincture of opium may be given at frequent intervals, and if there is great prostration, any sort of a stimulant will be beneficial.

When extensive burns expose the tendons or joints, it is generally most humane to kill the animal at once. 


\section{CHAPTER XXIV.}

\section{DISEASES OF THE TEETH, AND THE MARKS OF AGE.}

I. THE TEETH A FREQUENT SOURCE OF SUFFERING.- II: THE HORSE'S TEETH. -III. TEETHING, OR DENTITION.—IV. SHEDDING THE TEETH.-V. DECAY OF THE TEETH, AND TOOTHACHE.-VI. EXTRACTING THE TEETII. -VII. THE MARKS OF AGE.—VIII. SECOND TO FOURTII YEARS.—IX. FIFTH TO EIGHTH YEARS. - $X$. NINTH TO THIRTEENTH YEARS.-XI. THIRTEEN YEARS AND UPWARDS.-XII. IRREGULAR TEETH.-XII. PARROT MOUTH.

\section{The Teeth a Frequent Source of Suffering.}

Careful observation has convinced us that the teeth of the horse are much oftener the source of suffering and disease than is generally believed. In speaking of this subject, Youatt says: "Horsemen, in general, think too lightly of dentition [teething], and they scarcely dream of the animal suffering to any considerable degree, or absolute illness being produced; yet he who has to do with young horses will occasionally discover a considerable degree of febrile affection, which he can refer to this cause alone. Fever, cough, catarhal affections generally, disease of the eyes, cutaneous affections, diarrhea, dysentery, loss of appetite, and general derangement will frequently be traced by the careful observer to irritation from teething.

"It is a rule, scarcely admitting of the slightest deviation, that, when young horses are laboring under any febrile affection, the mouth should be examined, and if the tushes are prominent and pushing against the guns, a crucial incision [that is, one in the form of a cross ] should be made across them. 'In this way,' says Mr. Percivall, 'I have seen catarhal and bronchial inflammations abated, coughs relieved, lymphatic and other glandular tumors about the head reduced, cutaneous eruptions got rid of, deranged bowels restored to order, appetite returned, and lost condition repaired.' "

Possibly the effect which this extrict is calculated to produce is hardly distinguishable from that of an over-statement, and yet few experienced veterinary practitioners would undertake to dispute the general correctness of these views. 


\section{The Horse's Teeth.}

The palate and teeth of the upper jaw of the mature horse are depicted in the cut herewith presented, showing the six incisors, or nipper's; the two canine teeth, or tushes-sometimes called bridle-teeite; and the twelve molars, or grinders. Upon one side of the roof of the mouth is a natural view of the bars of the palate, and upon the other is indicated the appearance which would be presented if the bars were

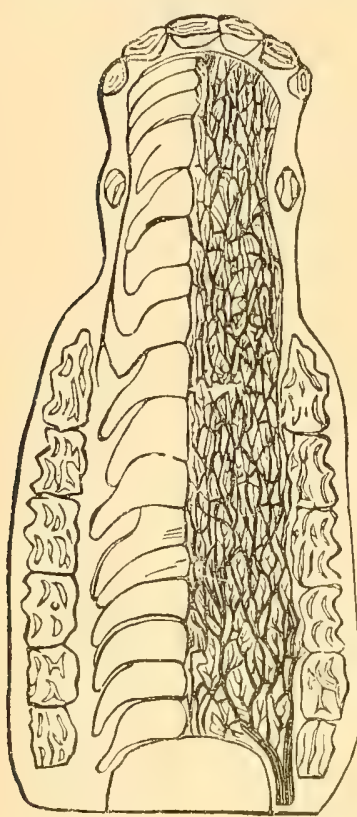

PALATE AND TEETH OF THE UPPER JAW. dissected off so as to reveal the intricate network of blood-vessels and nerves below.

The colt cuts his first front teeth when very young, which operation is known as teething. After this, at different stages of his growth, these are displaced by a new set, larger and better adapted to the needs of the mature horse. For the sake of convenience, this process is distinguished by the name of shedding.

The horse has, or should have, when fully grown, forty teeth-in each jaw six nippers, two tushes, and twelve grinders. In the mare, the tushes are either not dereloped at all, or else do not make their appearance before old age, although bony protuberances, corresponding to them, are hidden below the gums. The tush is a long, sharp tooth, occupying a position on each side of the jaw, between the nippers and the grinders, but somewhat nearer the former than to the back teeth. What a great many farmers call blind teeth, or wolf teeth, and iguorantly imagine to be the cause of almost numberlesis ills, come on the upper and lower jaw between the bridle-teeth and the grinders. (See Section III in next Chapter).

The changes which the tecth undergo before attaining their full derelopment, with the derangements which attend these changes, will first elaim our attention.

\section{Teething, or Dentition.}

When the foal is born into the world, no teeth are visible except the tirst or second grinder's, on each side, above and below, making eight in all; or sometimes these do not appear for two or three days afterwards. He euts the remaining teeth in succession, at various in- 
tervals; so that the mill-teeth-the first set-are not all developed until he is in his second year.

The cutting of nearly thirty teeth, however lightly it may be regarded by the stock-raiser, is certainly a matter of no small moment to the colt. While it is true that Nature prepares the gums, in a great measure, for this process, if any one will take the trouble to examine the mouth and gums of the colt while it is going on, he will probably be astonished to find how hot and feverish these parts are. During the period of suckling, the milk of the mother tends greatly to counteract the evil effects of teething, and, at this period, Nature will seldom need any assistance in the way of other diet, or medication of any kind. But after weaning, all through what remains of teething, and the entire process of shedding, the young animal does not fare so well, and a variety of disorders lie in wait for him.

It is undoubtly a wise and kindly provision of Nature that the colt's teeth do not all come at once; for, if that were the calse, such would be the severity of the operation that very few, probably, would live through it. As it is, the soreness and inflammation occasioned by the cutting of one pair has time to subside, and the gums are allowed time to heal over, before any more come through. It is worthy of remark, also, that dentition does not so seriously affect the horse as either the human species or the dog.

\section{Shedding the Teeth.}

Closely connected with teething, and, in the beginning, coincident with the latter stages of that operation, is the process of shedding, which is the replacement of the milk by the permanent teeth. The first set of teeth do not come out, and the lacerated gums then heal over, as is the case with children; but the second tooth comes up immediately under the first one, and lifts it entirely out of the gums. What is still more remarkable, while this is going on, the under part of the milk tooth is being gradually absorbed by the surrounding parts, so that there is but a small portion of it left by the time the permanent tooth reaches the top of the gums. As the under tooth comes up from its bed in the jaw, the gums, being lifted up with it, retain their hold upon the other until the second is noar enough through to subserve the needs of the animal in eating; then, all at once, the gums peel off from the upper tooth, which drops out, and they now sink down around the new one; their swelling and soreness subside, and all is right in the mouth again. 
For a considerable time previous to their removal, the position of the milk teeth is by no means a firm one, as they are only retained in their places by the adhesion of the gums. Every hard substance that comes in contact with them is likely to move or twist them about.

\section{Decay of the Teeth, and Toothache.}

The teeth of horses. like those of human beings, are subject to decay. In common parlance, they become rotten, which is just the same condition that the dentist refers to when he speaks of "caries" of the teeth. The horse's front teeth sometimes show signs of decay, but generally it is the jaw teeth, the molars, which are

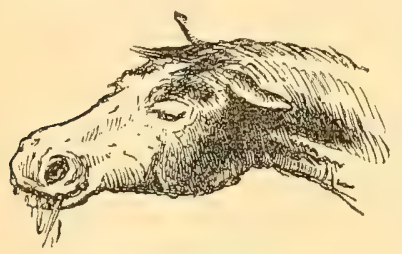

TOOTHACHE. affected. From the tooth's decay, the nerve which it contains is very frequently exposed, and the slightest cause-cold water, food getting in the cavity, and thus causing pressure while eating, etc.,-will start a violent case of toothache.

Causes.-A disordered condition of the stomach has much to do with the premature decay of the teeth. The foul gases which it gives off, when there is fermentation of the food, exert a very detrimental effect upon the teeth. Similar consequences follow the reprehensible practice of giving the horse strong mineral poisons, such as copperas, blue-stone, calomel, corrosive sublimate, arsenic, and many others. These have a tendency to destroy the enamel, and corrode and ruin the teeth. A similar deleterious process goes on when particles of food become wedged in between the teeth, and there decay.

Symptoms.-Toothache is one of the causes which so often make the horse suddenly drop the corn, or other hard feed, from his mouth while eating. The owner or attendant generally sets this down as indicating some natural disrelish for the food at that particular time, whereas the fact very often is that he has hurt his tooth. IIaring no hand to press to his mouth, the poor animal is allowed to suffer, without so much as a suspicion of what the trouble really is.

Treatment.-The horse's teeth, like those of mankind, admit of being filled when decayed, and the art of veterinary dentistry has been so improved on in the last dozen years that it is now a very common oceurence to fill a horse's tooth. 'The substance most used for this purpose is gutta percha, but other amalgam fillings may he substituted. The filling will have to be performed by an experienced 
operator, the greatest care being taken to remove all dead tooth sul, stance, and have a perfectly clean cavity before introducing the filling.

\section{Extracting the Teeth.}

The horse's teeth should not be extracted except in extreme cases, when the fact admits of no doubt that they are the occasion of acute suffering, or are past filling. The practice of driving out the teeth with a punch or hammer ought not to be countenanced, and is only justifiable in those rare instances where a proper instrument camnot be procured.

To extract a tooth a strong pair of forceps are needed, such as may be bought of any instrument maker; or else have a pair of pullers made on the principle of the old-fashioned instrument, formerly used in dentistry, but, of course, larger and stronger; and while an assistant holds open the horse's mouth, the operator can fasten on the decayed tooth and draw it. If the horse is vicious or restless, it will be necessary to fasten his head, so that he cannot move it about. The operator may stand on a bench or box, so as to work to better advantage.

The three back molars are exceedingly hard to extract. In some cases it is next to impossible to remove them, necessitating the trephining of the face above and punching them out with a probe. This, of course, is not to be attempted except by a proficient veterinalian.

\section{The Marks of Age.}

The appearance and shape of the teeth constitute what is most generally relied upon as a means of determining the age of a horse; and, in connection with other circumstances, concerning which the experienced horseman will always ascertain full particulars, if it be possible to do so, they form a quite accurate mark of age, until the animal is somewhat past his prime. The incisors, or front teeth, are those usually examined to tell an animal's age. Of these there are twelve ( six in each jaw), known as the central, lateral, and corner incisors. The three parirs thus named are indicated by the three parirs of figures, 1, 2 and 3 respectively, in the lower cut on page 336 . The lower row of teeth being situated the most conveniently for examination, are always chosen for that purpose. The upper row present the same markings, but they are somewhat slower in appearing. $W^{\top}$ e will now point out the peculiarities which generally characterize 
the teeth at different periods of the horse's life, and by which his age may be determined with considerable exactness.

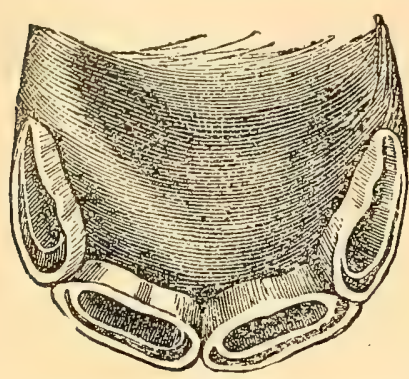

THE TEETH AT ABOUT ONE MONTIK OLD.

At Birth.-At birth, or within two or three days after that, the mouth of the foal shows two grinders on each side, above and below-eight altogether. Within the next day or two, the four central incisors-two below and two above-push through the gums. When the next four, the lateral incisors, appear, one on each side of the centrals in both jaws, the colt has attained the age of one month, or a little more. The appearance of the third set-the corner incisors in each jaw-indicates an age of about eight months.

\section{Second to Fourth Years.}

One Year Old.-At one year old the central and the second pair of

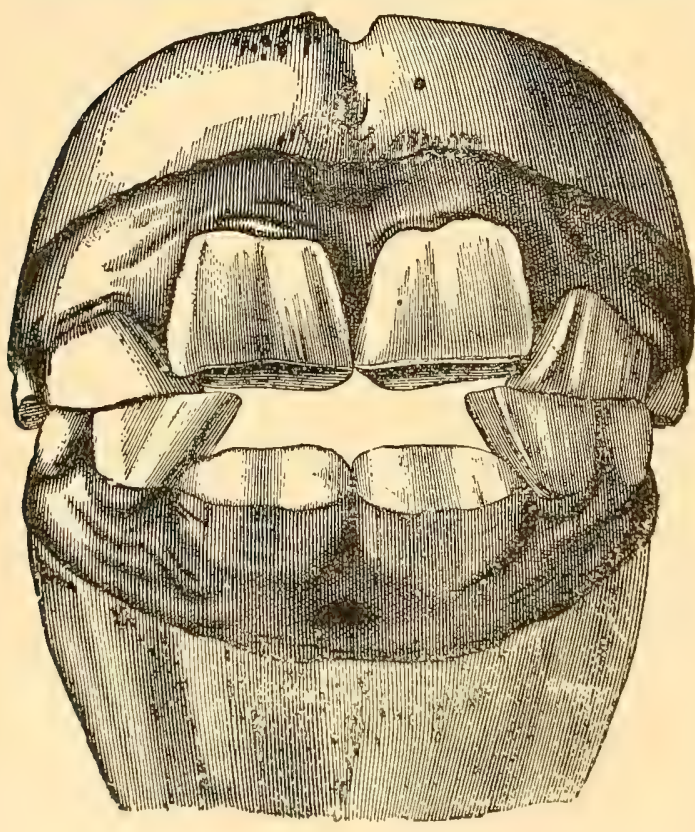

RISING TIREE YEARS (FRONT VIEW.)

Showing the failure of the new (permanent) central incisors to meet as yet.

first set with the permanent teeth. This operation begins with the first grinder-the forward onc; but as the grinders are all of them nippers are worn nearly level, and the corner tooth, which is now of the same length as its neighbor, is rapidly becoming so.

Two Years Old. - The two year old colt has the mark, or "kernel" - the dark, hard substance in the middle of the crown of the tooth-ground quite out of the central incisors. So far, the young :mimal has got along very well with his milk teeth, but now he begins to need others, not merely larger, but also of a firmer, more durable composition and setting; and this necessity nature meets by commeneing the replacement of the 
too far back in the mouth to be easily inspected, we must continue to depend mainly upon what we can discover in connection with the nippers.

\section{Three Years Old.}

-At the beginning of the third year, or sometimes a little sooner, the central incisors are shed, and the permanent teeth appear. As these new teeth do not meet together at first, the mouth will have a peculiar and characteristic appearance. The difference between the milk and temporary teeth may now be seen at a glance. The milk teeth are

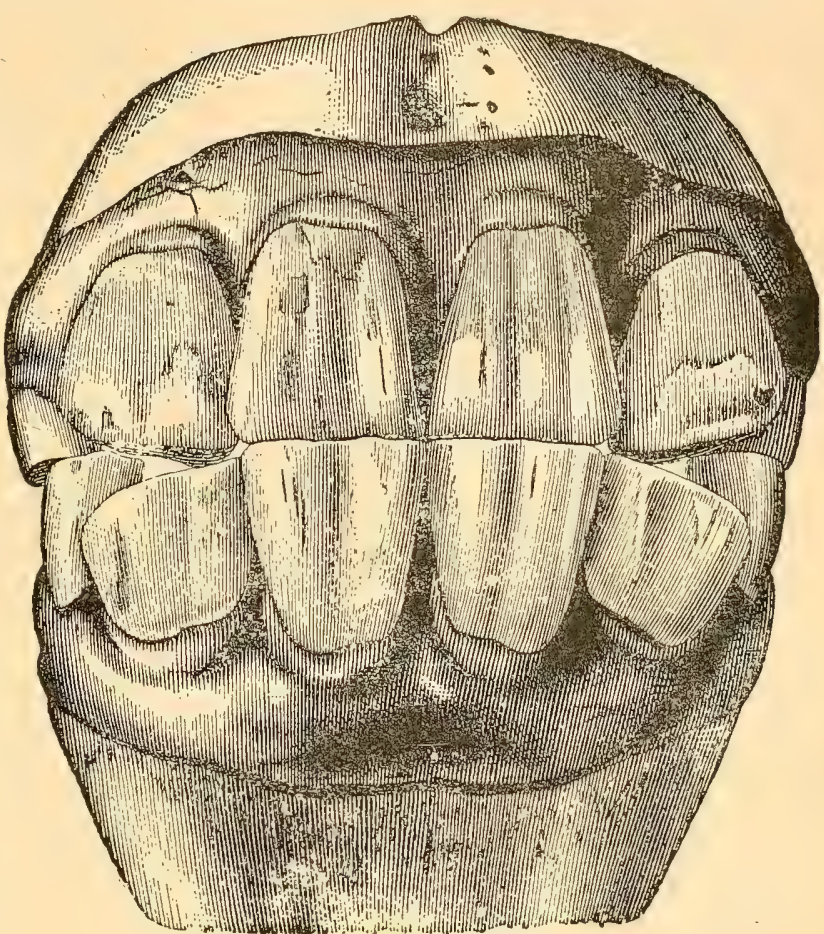

RISING FOUR YEARS (FRONT VIEW.) smaller than the second growth. They present a smooth front surface of a dull whitish color, and near the gum a constriction, or neck, appears that is not seen in the permanent teeth. The second set, the permanent teeth, are larger, and have a small groove down the front; their color is of a yellowish white.

IX. Fifth to Eighth Years.

Four Years Old.-Rising four years old, the intermediate incisors are replaced by the permanent, whereupon their appearance will be as shown in the en-

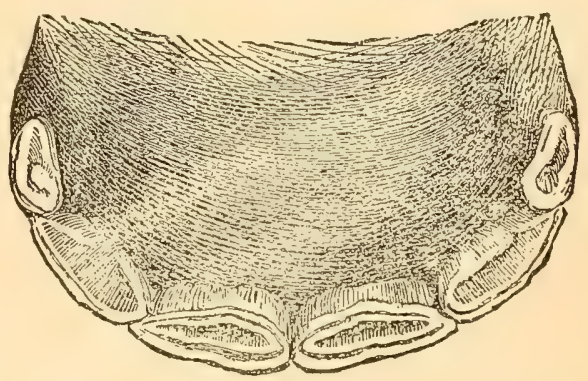

RISING FOUR YEARS (FRON ABOVE.)

Showing the cutting surfaces of the incisors. gravings above. The eutting surface (shown in the smaller engraving), will begin to wear slightly at about four years. This age is 
very readily recognized by the presence of four large permanent incisors in each jaw, with two small corner mille teeth.

Five Years Old.-Between four and five years the corner permanent teeth appear, and at five year's the anterior border of all the

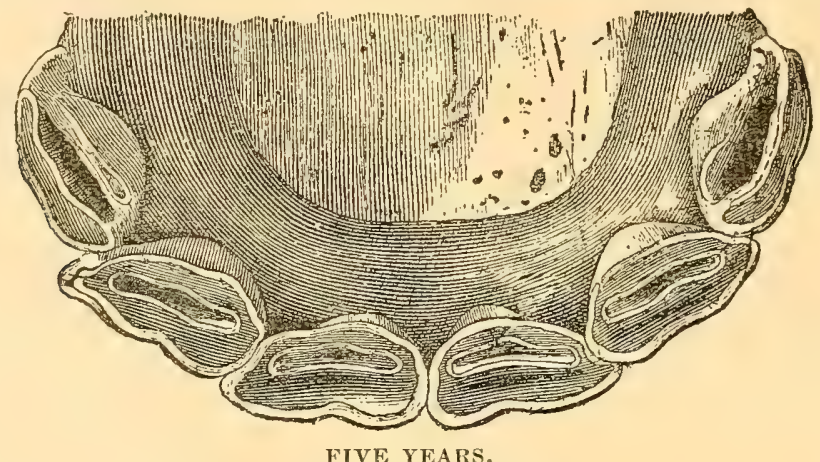

The incisors are now all permanent, and each shows the kernel very plainly.

teeth are on a level. At this period, accordingly, the mimal has a full mouth of permanent teeth. The four tushes, or eanine teeth, will also appear at this age.

Six Years Old.-The front view of the teeth is the same as at five years. From this period onward the table, or bearing surface, of the teeth, by its changes in shape, and the wearing of the black central

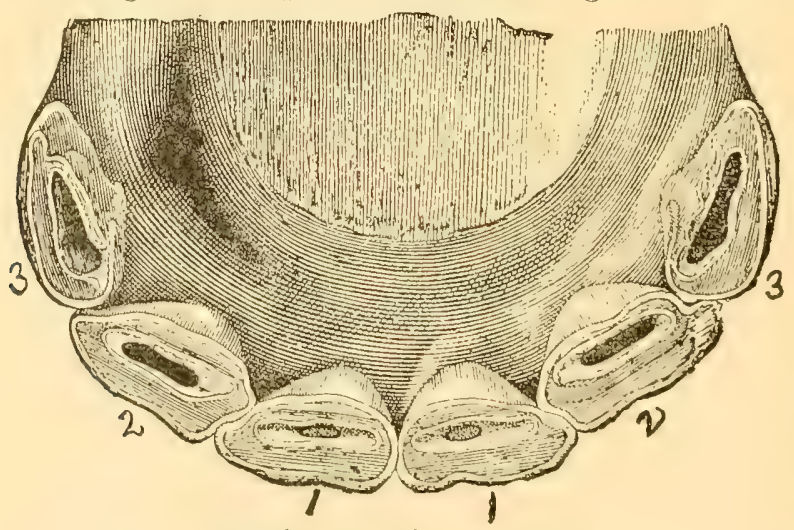

THE NIIPLIR (INCISORS) A'T SIX YEARS OLD.

spot known as the kemel, will be the best index of the animal's age. Thy this time the posterior border of the corner teeth are well in wear, and the tahles of all the teeth show an obviously worn surface. It will be noticed in the engraving that the kernel of the eentral teeth 
is not near so dark in color as that of its neighbors; and this is a sign of importance in determining the age.

Seven Years Old.-The front view of the teeth is the same as at six years; the side view shows the lower row to be narrower than the upper, in which there is a notch, as is well shown in the accompanying cut. The table shows signs of the continual wear, and the dark

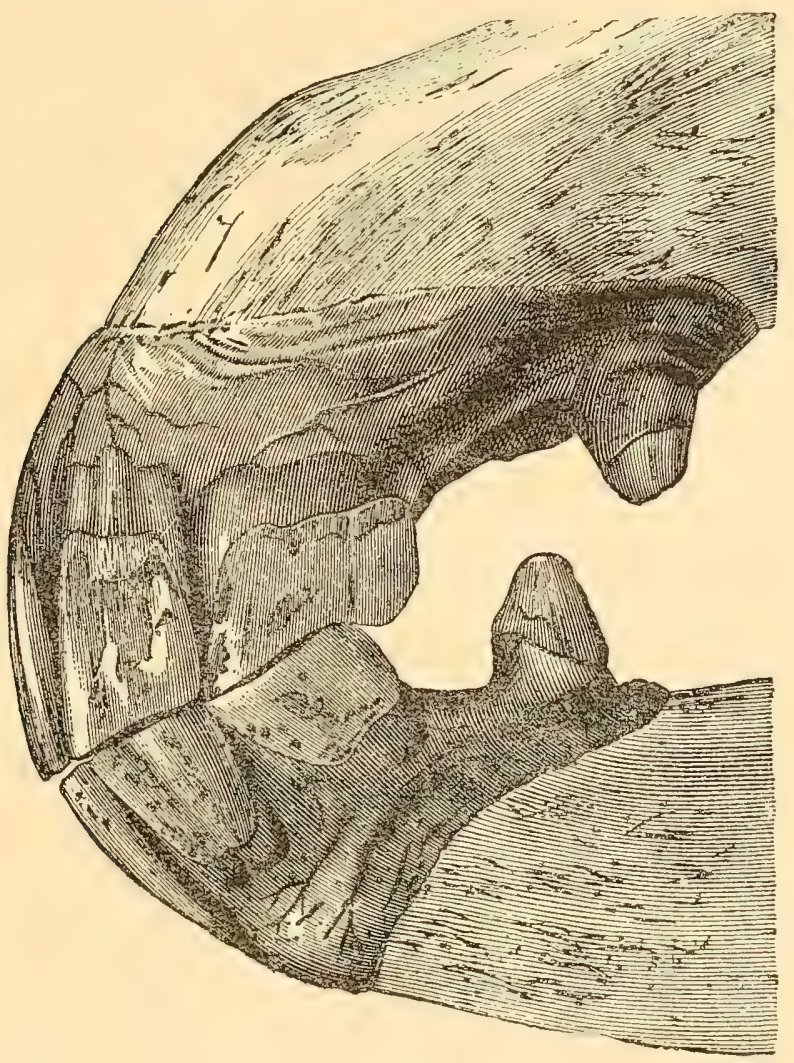

SEVEN YEARS OLD (SIDE VIEW.)

kernel of the lateral teeth is beeoming of a light color, the same as described at six years.

It should be remembered, in exmining the teeth of any horse, that feeding constantly on hard, unshelled corn is very apt to wear the teeth prematurely. Crib-biters also are almost invariably rather younger than their teeth would indicate. In these cases the corner teeth are the ones that afford the best index of the animal's age, as they are less used in grinding the food than the rest. 


\section{Ninth to Thirteenth Years.}

Eight Vears Old.-At this age the tibles show the dark kernel worn out of all the teeth, which are now of an oval form. In the illustration will be noticed a fine, wavy, black line between the kernel

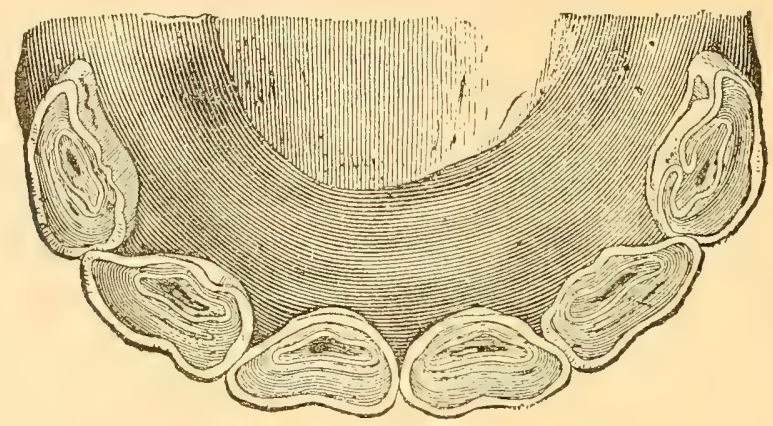

EIGHT IEARS OLD.

and the front of the tooth. This is the "dental star," which now becomes of great importance as an indicator of age.

Nine Years.-By this time the notch in the upper corner tooth has usually disappeared, and the teeth will be noticed to meet more

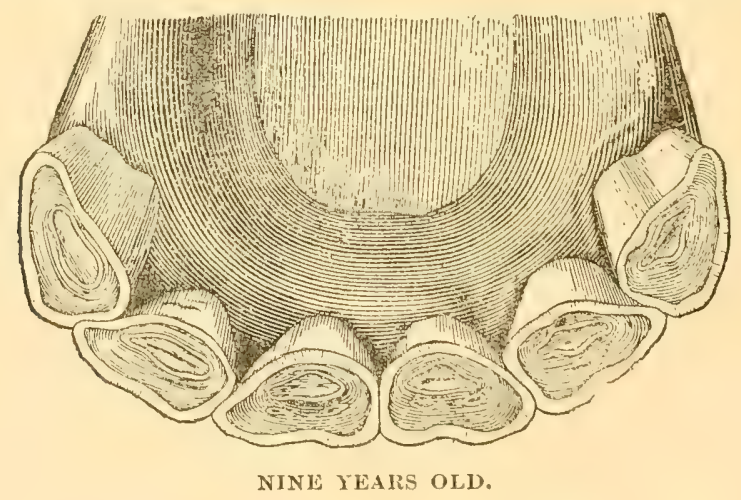

oblicuely. The dental star is hecoming mole pronounced in the central tecth, which are also changing their shape from an oval to round.

Ten Years, - The jaws are meeting still more on a slant. The bahle surfaces of all the teeth are now round, while the dental star is about in the middle of the tooth. 
Eleven Years. - There are no very visible changes at this time. The kernel is now seen as a small ring at the posterior border of the tooth.

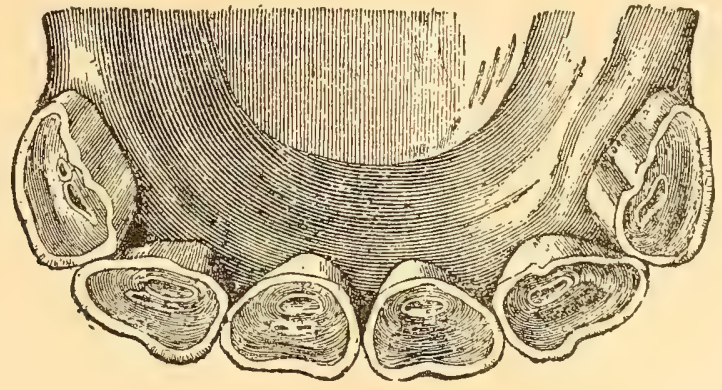

ELEVEN YEARS OLD.

Twelve Years.-At this period the kernel has disappeared from the central teeth, and in some cases from the others also.

\section{Thirteen Years and Upwards.}

Thirteen Years.-The changes by wear are seen to progress, and the angle of the meeting of the teeth is still more aeute.

Fifteen Years.-In consequence of continued wear, the central teeth are of a triangular form. The dental star is seen as a dull spot about the centre of the surface.

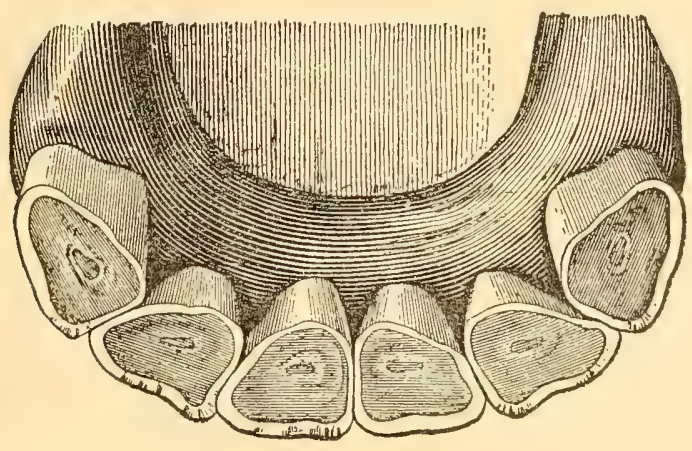

FIF́TEEN YEARS OLD.

Seventeen Years.-All the teeth have now become triangular in shape, and they are not so close together as at a younger age. 
Nineteen Years. - The jaws now form an acute angle. The separation of the teeth is becoming quite marked, and the posterior border

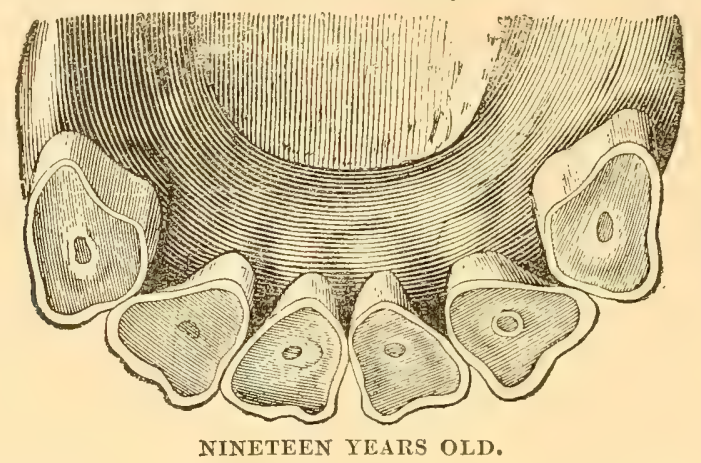

of the table is converging to a point, as seen in the illustration. In the next (twenty-first) year the notch in the superior tooth will disappear.

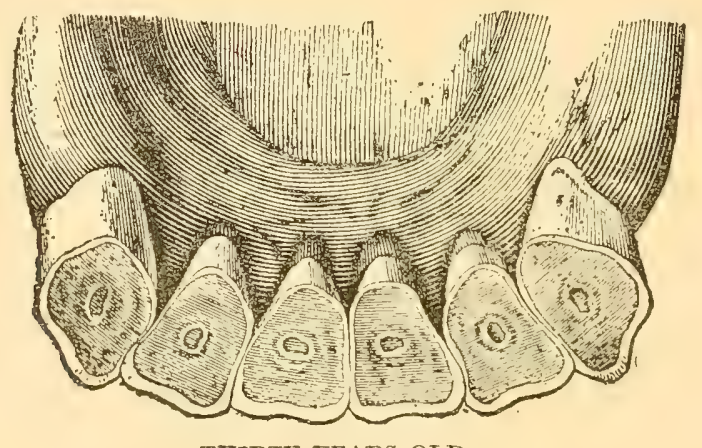

THIRTY YEARS OLD.

Thirty Years.-This is extreme old age. The teeth are now worn down very low; in some cases they may even be on a level with the gums. In shape they are flattened, as shown in the engraving.

XII. Irregular Teeth.

The molar teeth of the horse do not wear evenly. This is due to the lower jaw being narrower than the uper, whence it follows that

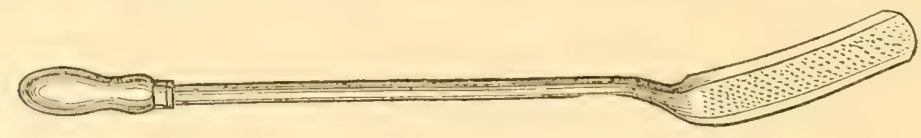

TOOTII RASP.

the outer arders of the upper and the immer edges of the lower teeth are liable to berome very shap, and in this way to cut the tongue or 
cheek. To remedy this, the teeth should be filed or rasped with an instrument of the kind shown in the preceding illustration.

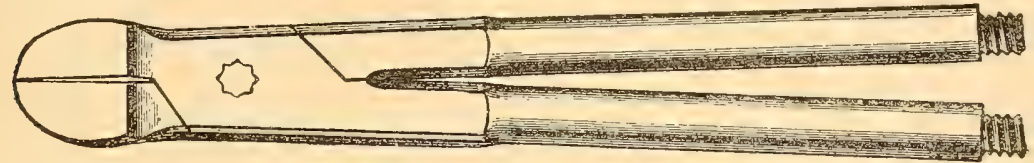

PAIR OF TOOTH-CUTTERS.

When a tooth is extracted, or wears very fast from the softness of its substance, the corresponding tooth in the upper row is likely to grow long, there being nothing that meets and wears it. To remedy this condition will require a pair of tooth-cutters, such an instrument as is above represented. The rough cut surface of the tooth may afterwards be smoothed with a rasp.

\section{Parrot Mouth.}

Parrot mouthed horses, as they are called, are not infrequently met with by veterinary dentists. In this conformation the upper jaw projects over the lower, -

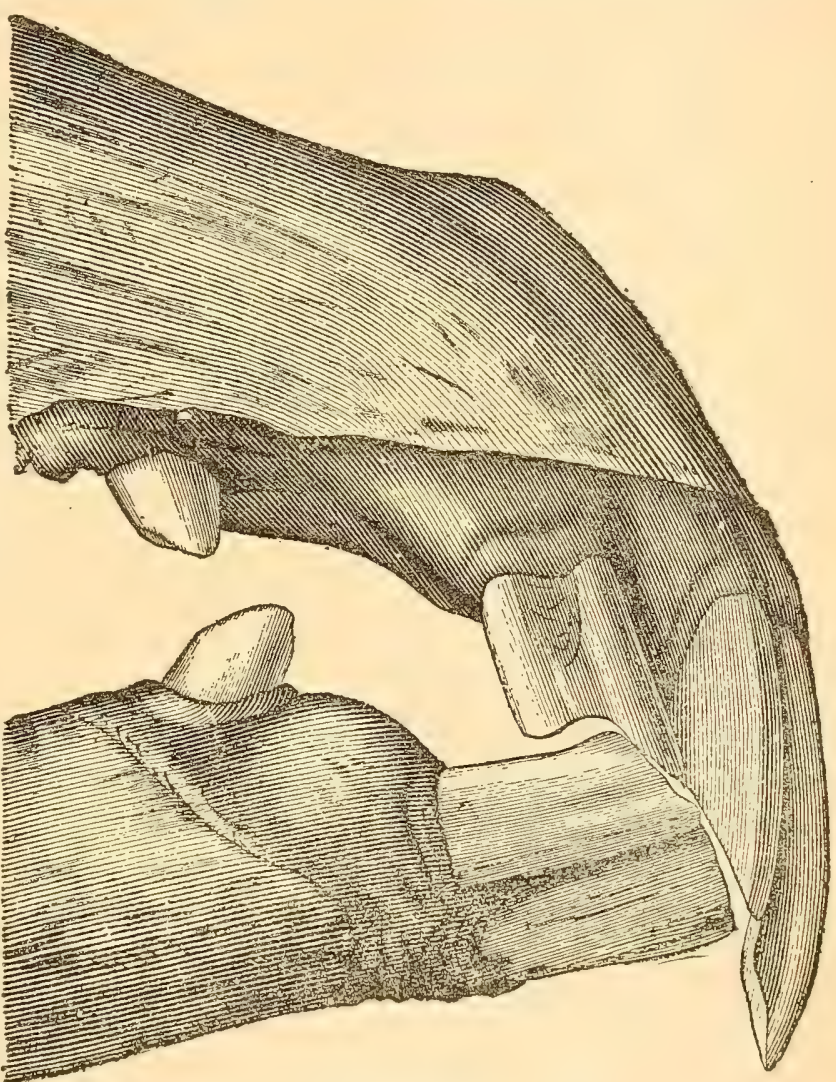

PARROT MOUTH (SIDE VIEW.) in some cases so much so that the lower lips are cut or torn. Such a mouth prevents a horse from eating grass at pasture, because, as the teeth do not come together, it is impossible for him to seize and hold the grass with them. To remedy this deformity, the teeth need to be cut down by appropriate instruments. 


\section{CHAPTER XXV.}

\section{DISEASES OF THE MOUTH AND STOMACH.}

I. LAMPAS.—II, PIKES, AND PAPS OR BARBS.—-III. WOLF TEETH.-IV. SWOLLEN GLANDS.—V. CHOKING.—VI. THE HORSE'S STOMACH AND ITS PECUliarity.—VII. BOTS.—VIII. INDIGESTION, OR DYSPEPSIA.- IX. STOMACH OR "BLIND" STAGGERS.-X. RUPTURE OF THE STOMACH OR BOWELS.

\section{Lampas.}

This is an ailment principally incident to young horses, and was an object of great alarm to the farriers of former times. It is simply an inflammation of the lining membrane in the front part of the roof of the mouth. The little ridges running across the surfice of that part are called "the bars." They are shown in the engraving on page 330 . The bars serve the purpose of assisting the tongue in moving the particles of food backward to the jaw teeth, there to be properly masticated. That portion of the membrane next to the front teeth sometimes swells, until it extends downward not only to the level of the teeth, but, it may be, even beyond them. It becomes, very sore, and greatly annoys the horse in eating, especially if his food consists of such hard substances as corn, oats, and timothy hay. He shows the pain which their pressure occasions by often dropping the food from his mouth.

Causes.-Such inflammation is apt to arise from the soreness that accompanies teething, and which is communicated to the bars in the adjoining parts of the mouth. This is the reason why the young horises are more subject to it than the older ones. But changes of some kind are continually going on in the mouth; the teeth, after the operations of tecthing and shedding are done with, begin to wear away, and, after a time, they commence to fall out, and the gums sink down around them. As a general thing, the horse is free from lampas between the ages of five and eight years; but, at the latter briod, the wearing off of the teeth becomes more marked and rapid, the sums have noticeably shrmk, and this disease is apt to appear again. 
We think there is a tendency on the part of many late writers on veterinary practice to underrate the injurious effects produced by lampas. A marked derangement of the digestive process would be no more than might reasonably be expected from the sympathy with the feverish mouth and gums; and observation plainly teaches that when horses have been long troubled with lampas, they are likely to be found in bad condition, thin in flesh, and with a staring coat of hair.

Treatment.-In many cases, lampas will disappear of itself. If not, scarification is the first thing to be done. This should be performed with the point of a very sharp knife, or, best of all, the lance here illustrated, the object being to relieve the overloaded vessels of the superabundance of blood they contain. Great care must be taken not to make the incisions too deep, or back of the third bar, just behind which an artery approaches very near to the surface, that will

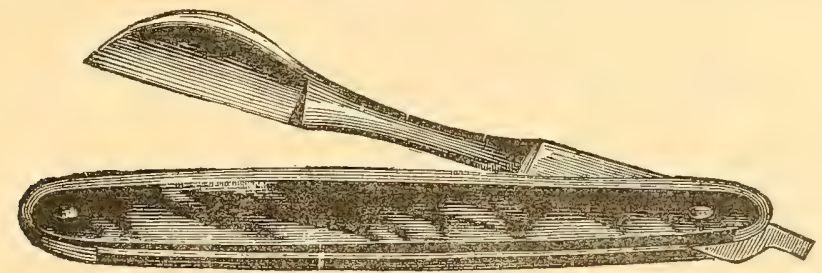

LANCE FOR CUTTING THE GUMS.

be quite difficult to close, if it should be severed in this operation. Should such an accident happen, the bleeding can be stopped by tying a strong cord around the upper front teeth, close to the gums, and drawing it very tightly. This will close the orifice, and check the hemorrhage at once; or, instead, a thick pad of tow may be bound on.

The use of some mild astringent will form the proper continuance of the treatment. Alkaline solutions will often meet the requirements of the case when nothing else will. The following mouth wash will be found helpful:

$$
\text { No. } 29 .
$$

Chlorate of potash, $1 / 2$ ounce.

Pure water, 2 ounces.

Mix.

Wash the gums thoroughly with this wash every morning.

If the general health is not good, give any of the tonic powders mentioned in this work. Sce "Recapitulation of Remedies," in Chapter XLI. 
We must add our emphatic concurrence in the condemnation expressed by all respectable veterinarians of the brutal custom of burning the bars of the mouth for the cure of lampas. The bars, as before stated, are of great service in moving the food during mastication. To burn them, therefore, is not only an act of great cruelty, but is really a permanent injury. Caustics are equally objectionable in their effect upon the mouth, and on the teeth still more so. There is not the least excuse for resorting to either of these modes of treatment, for the swelling can readily be removed by the course prescribed above.

\section{Pikes, and Paps or Barbs.}

These are the natural papilla of the mouth, which the ignorant practitioners of former times considered a sign of disease, and cut off. It is almost unnecessary to state that, being a natural formation, they should not be cut.

Paps, or Barbs.-This is another imaginary disease of the month. Below the tongue is the opening of the canal from the glands under the jaw; and this opening is protected by a fold of the lining membrane of the mouth, to prevent the entrance of food. It is this small prominence that was considered a disease, and cut off. Happily, this foolish and hurtful practice has almost fallen into disuse.

\section{Wolf Teeth.}

These are occasionally found in a horse's month just in front of the first molar teeth. All sorts of diseases are popularly attributed to them, especially weak eyes. While there is no reason to regard them as the cause of disease, it is undoubtedly true that they are of no service to the animal. Not being well fastened in the jaw, they may be extracted with a pair of forceps; or, in fact, a nail and hammer will do to knock them off with. Any part of the root remaining need cause no alarm; it will be harmless.

\section{Swollen Glands.}

The glands under the jaw, as also those helow the ear, are liable to swell in certain diseases, as strangles, lampas, laryngitis or sore throat, glanders, farcy, ete. They will be fully treated of in this work, in commection with the several diseases of which they constitute a prominent manifestation. 


\section{Choking.}

This is occasionally seen both in foals and in old horses, from trying to swallow apples, potatoes, eggs, turnips, etc., or in foals from trying to eat hay.

Symptoms. - The animal is found to have stopped feeding, and stands with the head stretched forward with an expression of suffering. There is generally a husky cough, and a dribbling of saliva from the mouth. If he tries to swallow water, it will fill the csophagus and run out of the nose on lowering the head. When the obstruction is in the neck portion, it may be felt with the hand, but if further down in the chest section, this cannot be done.

Treatment.-If the obstruction has come on from the animal's turning the neck sideways, on his returning to the customary position it will generally disappear. The passage may be lubricated and any cramp relieved, by administering half an ounce of tincture of opium in a half pint of oil. Eggs are often given whole for some internal trouble; if one of these has caused the choking, try and break it.

When medicines fail to remove the obstruction, use a probang, such as is shown in the illustration, in manner as follows: After giving the oil and opium already spoken of, extend the head as much as possible, and then pass the probang down to the obstruction, and use very gentle but firm pressure, bearing in mind that any sudden punching is likely to cause a rupture of the canal.

Esophagotomy.-When all other means fail, the proficient veterinarian may decide to perform the operation known as cesophagotomy. This consists in cutting down on the place of obstruction, and removing the

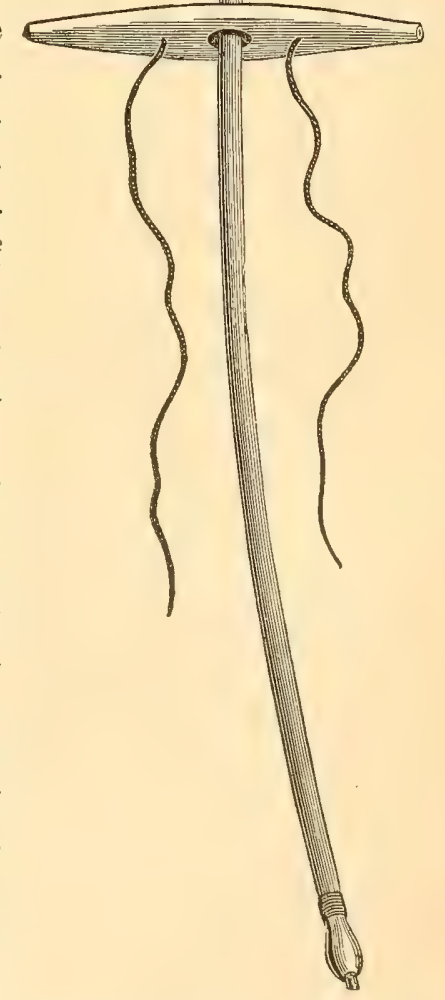

PROBANG FOR REMOVING OBSTRUCTION OF TIE CESOPHAGUS (GULLET.)

obstructing substance through the opening thus mate. This op- 
eration is likely to be followed by serious trouble from the contraction of the canal in healing; in some cases the osophagus narrows to a very serious extent. After removing the obstruction, the edges of the wound should be stitched together, and a bandage, similar to the illustration, may be used to retain the dressing in place. The

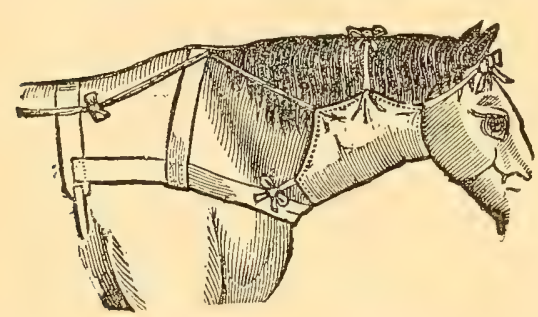

BANDAGIS FOR TIYE FRONT AND SIDES OE THE NECK. dressing will consist of a piece of cotton batting, as directed for wounds, and it will have to be renewed every day at the first, but may be dispensed with as soon as the edges of the wound have healed.

\section{The Horse's Stomach and its Pe- culiarity.}

The main function of the stomach in all animals consists in softening down the food. The remaining operations are carried on in the intestines, which, by their great length, presenting an immense extent of surface filled with absorbents, are especially adapted to their performance. A remarkable peculiarity of the stomach in the horse is strikingly indicative of its limited part in the functions of digestion. As is well known, it is the mucous membrane that is furnished with the minute absorbents, whose office it is to take up the digested particles of food, in the form of chyle, and transfer them to the general circulation. While this coating lines the entire inner surface of the intestines, not more than one-third of that of the stomach is similarly provided.

Though apparently free from bilious disorders, the horse is frequently a sufferer from various derangements of the digestive functions, some of which are liable to assume the gravest character quite suddenly.

\section{Bots.}

This is the proper place to consider this so-called disease, whose supposed frequency and fatality render it a subject of deep interest to every proprietor of the horse. It has given rise to numberless theories in regard to both its cause and cure-all strenuously urged by carnest advocates, of whom, neverthelesis, there are exceedingly few but are willing to confers they know next to nothing of the habits and oflice of the bot, or of the effects areated by the little creature's presence upon the horse's general system. Nearly all agree in this, 
however, that, in some way, the bot kills the horse. The common opinion is that he effects this by seizing hold of the stomach, from some ferocious propensity which possesses him at certain undetermined periods, and eating or cutting his way entirely through its walls; and as to a remedy, that all depends upon the speedy administration of something which will compel him to relinquish his hold before his ravenous work has produced irreparable injury.

These views are grossly erroneous. What is supposed to be the ravages of the bot is, in reality, the work of some inflammatory disease. To begin with, the natural history of the bot has never been properly understood by horsemen. This parasite is found attached to the coats of both portions of the stomach. For a mouth he has a tiny orifice, no larger than the point of a cambric needle, with which he feeds upon the food in the stomach, after it has been softened down into BoTs AND GAD-FLIES, witi EGGS of ThE chyme. This tiny mouth he can close against any sub- $a$ and $b$-The eggs of the gad-fly, adhering to the hair of stance which offends his dainty taste; and, being protected by a scaly covering,
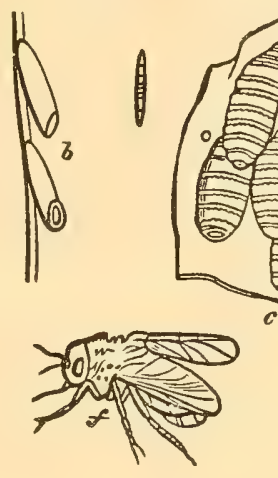

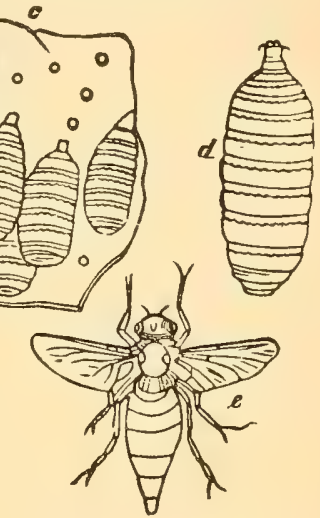
upon which no acid, caustic, or poison will operate, he is much safer from the acion of any hurtful element than the horse into whose stomach he is introduced. There is no evidence that in his normal condition he ever injures the horse's health in the least degree. The wise farmer will treat for disease, not for bots.

The Bot's Biography.-The life history of the bot is interesting. After being retained in the stomach for about one year's time, he loosens his hold, and is passed off during the months of July and August. Burrowing in the earth, he forms a chrysalis, which in turn develops into the gad or horse fly. The fly deposits her eggs on the hair, and the horse, by licking, transfers them to the stomach, where they become attached, and hatch out into the dreaded bots; then the same round is made again, and so on indefinitely. 


\section{Indigestion, or Dyspepsia.}

Causes.-Dyspepsia is the most commonly seen in old horses and foals. It may result from diseased, irregular or sharp teeth, which cut the cheek or tongue, and in this way so hurry the eating as to cause bolting of the food. Other causes are indigestible or musty food, over-work, changes of weather, or eating too much at irregular periods. It is seen in foals from trying to eat hay or fodder; or, again, when the mother having been at work, the foal is allowed to feed while she is very warm; or it may be simply from the milk being of a poor quality.

Symptoms. - The animal appears unthrifty; the coat is staring, and the belly tucked up; the skin is tight on the body, a veritable condition of "hidle-bound." In old, chronic cases, these symptoms

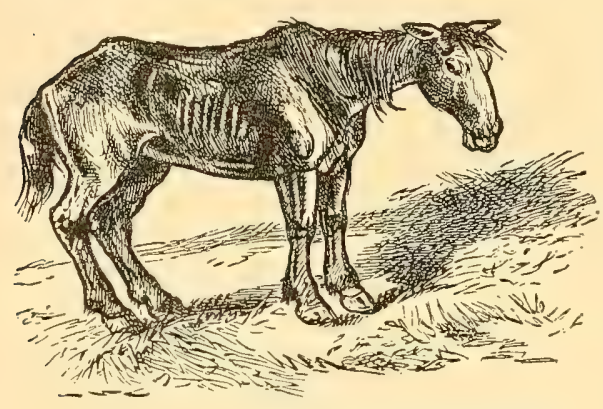

EFFECTS OF CHRONIC INDIGESTION. are all aggravated, and the emaciation is very great, as exhibited in the illustration. They will be dull at work, and bad smelling wind will be passing from them continually. When the habit of bolting the food is the cause, large particles of food will be found unmasticated and undigested among the dumg. A prominent sign denoting heartburn, which generally accompanies indigestion, or rather is one form of the trouble, consists in the animal elevating the head and turning up the lip, as shown in the accompanying cut; and many will, at the

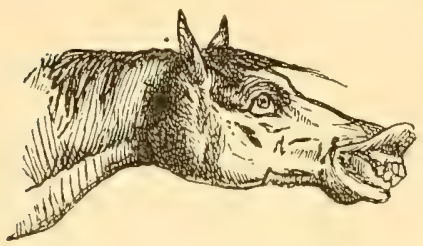

THE SIGN OF HEART-BURN. same time, form a habit of licking the wall, particularly if lime enters into its composition. Dull, griping pains may come on at any time, but they are seldom severe.

Treatment.-If the food is bolted, examine the teeth, and if necessary rasp them down. Give the mild Purgative Pill No. 20, and change the feed to bran mash and hay. If grass is in season, this also will aroatly benefit. (ive one of the following powders in the feed, three times a day:

No. 30 .

Bicarbonate of sola, 6 ounces.

Powdered gentiun, 4 ounces.

Mix, and divide into twenty-four powders. 
Follow up the above with any of the tonic powders given in our "Recapitulation of Remedies."

For foals, give half a pint of linseed oil, and see that they get their milk at regular and frequent intervals. They may be given doses of say half the bicarbonate powders above prescribed, and twice instead of three times a day.

\section{Stomach or "Blind" Staggers.}

This is also called grass staggers, as it is frequently developed from overloading the stomach and hoven with grass.

Causes.-Gorging the stomach with food after a fast, or from eating large quantities of indigestible food, such as hard, fiorous, innutritious hay, or musty hay or oats; also over-eating green food, such as clover, etc., especially after it has been long cut and wilted. On some of these aliments the gastric juice of the stomach is unable to act, while others ferment, and evolve astonishing quantities of various gases.

Symptoms.-The first thing noticed is uneasiness, parving and looking at the sides. In some cases the belly is found tucked up, while in others it is greatly distended by gas. In the latter, all the signs of wind colic will be seen, as violent rolling, walking around with the head to the ground, and frequent passages of wind by the rectum. As the disease progresses, the brain becomes affected, and the sufferer appears delirious or blind, walking right up against anything that happens to be in the way. In the last stages, he will sit on his haunches like a dog, and gas and food may even be passed through the nose and mouth. These are unmistakable signs of rupture of the stomach or bowels, and show the case to bo hopeless.

Treatment.-This disease is very rapid in its progress, and what is decided on must be done quickīy. There is not one moment to lose. Try and arrest the fermentation, and neutralize the gas with either of the following drenches:

No. 31 .

Oil of turpentine, $3 / 4$ ounce.

Oil, 1 pint.

Mix.

Give at one dose, and repeat in an hour.

No. 32.

Strong ammonia water, $1 / 4$ ounce.

Oil,

1 pint.

Mix. 
This is to be given same as the other. If much pain is present, the drench for wind colic, No. 35, may be given.

As a last resort, the veterinarian will draw the wind off, by means of a trocar and canula, the instruments shown on page - The

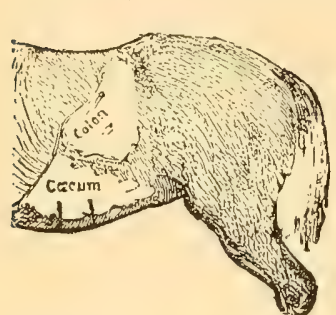

WHERE TO TAP FOR BLIND STAGGERS.

The place is as described in the text, anywhere at the upper end of the colon. place to-puncture is the right side, in the centre of the triangle formed by the point of the hip, the last rib and the back-bone. The trocar should be pushed downward, but not too much inward, as it would be likely to injure the kidney. In bad cases, the canula may be left in the gut for from six to eight hours, and the medicine injected through it.

\section{Rupture of the Stomach or Bowels.}

This is not infrequently seen as a result of either stomach staggers or wind colic. The animal becomes clammy and cold; he continues to walk, or rather to stagger, in a dazed way, running up against any object near him; sweat runs off in streams; gas is belched through the mouth and nose; the muscles of the body tremble violently. The expression of the face is haggard and pitiful in the extreme. In this state the sufferer may suddenly drop dead, or he may fall and be unable to rise, continuing to struggle, however, until death results from sheer exhaustion or from the disease.

Don't waste a thought on treatment. There is no possible chance of recovery after a rupture has once taken place. 


\section{CHAPTER XXVI.}

\section{DISEASES OF THE INTESTINES.}

I. SPASMODIC OR CRAMP COLIC.CII. FLATULENT OR WIND COLIC._-III. INFLAMMATION OF THE BOWELS, OR ENTERITIS.- - IV. DIARRHEA.- - V. DYSENTERY.—VI. CONSTIPATION.—VII. HAIR-BALLS AND CONCRETIONS. -VIII. WORMS. - IX. HEMORRHOIDS, OR PILES. -X. HERNIA, OR RUPTURE.

\section{Spasmodic or Cramp Colic.}

The small and large intestines of the horse are very subject to cramps. From some nerve irritation, the muscular coat of the gut contracts. The passage of food thus being stopped, it is likely to

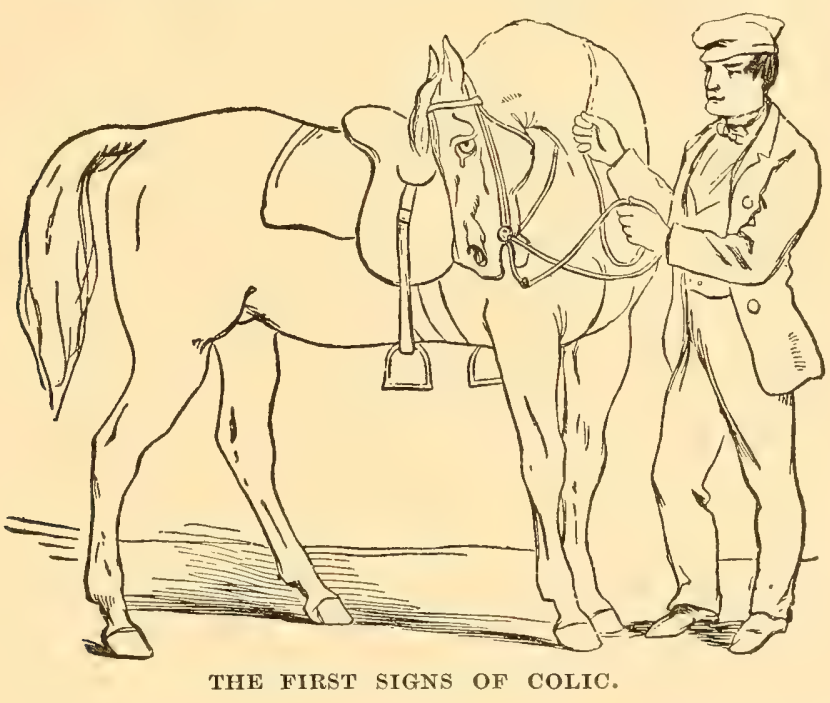

ferment, and the bowels to become distended with gas, and so the case often passes on into wind colic.

Causes.-Usually some error in feeding or watering, such as drinking cold water when very hot, thus producing a reaction of the system, or drinking water immediately after feeding, and washing the imperfectly digested food through to the large intestines. It may be seen also in connection with indigestion, or stomach staggers, in consequence of the system being unalhle to assimilate the indigestible 
matcrials which have found their way into the stomach; or, in fact, from almost any weakness or derangement of the digestive organs. Frozen roots, damp grasses, succulent foods, or too hearty a meal after a long fast, may, any of them, bring it on. Irritation, produced by worms, dust-balls, concretions, stoppage of the water, or bots on their outward passage, are frequent causes. Purgative medicines nay likewise cause severe griping, especially when the animal's system has not been properly prepared for them. In the case of a stallion, a special examination should be made for scrotal hernia. (See Section X of this chapter.)

Symptoms. - The attack comes on suddenly; the horse paws with the fore feet, kicks at the belly, looks at the flanks, and in every

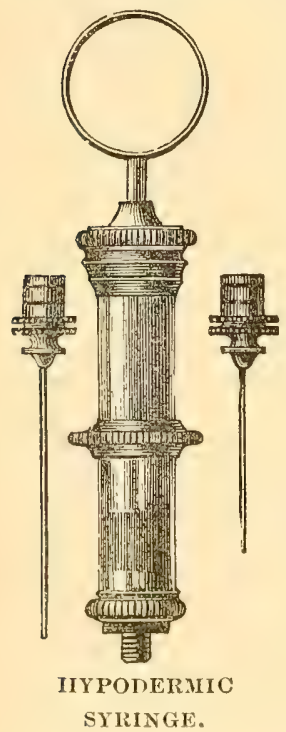
action manifests great uneasiness; he will throw himself down and roll violently about, but, rising presently, he shakes himself, and for a little while may, perhaps, appear as well as ever. But the cramps may return at any moment, and he become worse than before. Under treatment they will generally disappear, and, though returning again and again, each succeeding paroxysm will be milder than the preceding. In bad cases, it is generally all over with the poor brute in from three to four hours. Sometimes cramp colic runs on into inflammation of the bowels. How to distinguish between the two diseases will be explained in connection with the latter.

Treatment.-To relieve the cramps must be the first endeavor. Any inti-spasmodic drug, combined with a laxative, will do. Either of the following cramp colic drenches may be given, and if necessary repeated in half an hour :

No. 33.

No. 34 .
'Tincture of opium, 1 ounce.

Linseed oil, 1 pint.

Mix, and give as one dose.

'I'incture of opium, 1 ounce.

Sulphuric ether, 1 ounce.

Water or oil, 1 pint.

Mix, and give as one dose.

These should be followed, after recovery, with the Purgative Pill No. 18. 
The use of from three to five grains of the sulphate of morphia will be followed by immediate relief; the morphine is dissolved in a teaspoonful of water, and injected under the loose skin of any part of the body-generally around the neck-with a hypodermic syringe, an approved form of which instrument is herewith illustrated.

The hind bowels should be cleaned out with the hand "backraking," or by using a funnel and a piece of hose, three to four quarts of warm soapsuds and water being allowed to gravitate into the bowels through the anus. Should the cramps still continue, put hot water blankets to the belly, or rub it with mustard and water, or with turpentine.

When worms are suspected, some efficient vermifuge should be given, as, if present, they will be likely to induce other attacks. (See Section VIII of this chapter.)

\section{Flatulent or Wind Colic.}

This in many respects resembles cramp colic, of which it is often a sequel, but has the additional feature of a great formation of gases by the retained food fermenting.

Causes.-The causes are the same as those of spasmodic colic, errors of diet, and cramming the stomach with indigestible foods, being principally to blame. It is likewise associated, in many cases, with other diseases, notably with stomach staggers.

Symptoms.-At first the symptoms are identical with those of cramp colic, but, as the gas forms, the pain becomes continuous and the belly is highly swollen. The sufferer wishes to lie down and roll, but he will make many attempts before this is accomplished, being evidently afraid to do so; when he finally does get down, copious passages of wind are likely to reward his efforts in rolling. When the attack lasts several hours, symptoms similar to stomach staggers are developed, such as stupidity, blindness, continuous walking, etc. These indicate that the brain is becoming involved.

Treatment.-This will consist in using remedies to relieve the spasm and neutralize the gas, for which purposes either of the following wind colic drenches can be recommended as efficient, to be given as one dose, and repeated in half an hour if necessary:

No. 35 .
Tineture of opium, 1 ounce.

Oil of turpentine, 1 ounce.

Linseed oil, 1 pint. 


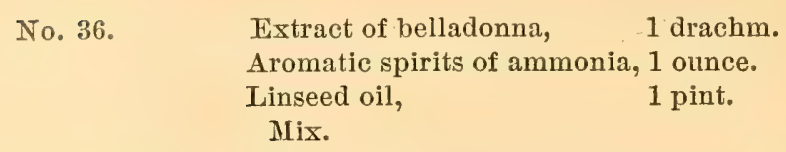

The hind bowels should be relieved by the hand, or by the funnel with soap and water, as directed for cramp colic. The belly may be rubbed with turpentine or mustard, or hot cloths may be applied.

When the medicines give no relief, and the gas continues to form, the only thing left to do is to use the trocar and canula, as advised

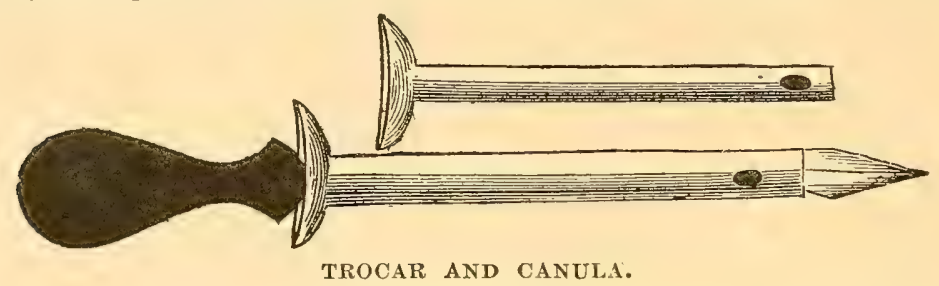

The perforation is made with the sharp-pointed trocar in position within the canula; then the trocar is drawn out by the handle, and the gas or fluid finds vent throught the now empty canula.

for stomach staggers. In bad cases the canula may be left in the gut for six to eight hours; medicine injected through it will reach the part direct, and any gas forming will immediately pass off.

\section{Inflammation of the Bowels, or Enteritis.}

Inflammation of the bowels is a vague expression on the lips of most persons, meaning any one of perhaps three different diseases; and it is so just the same, whether the patient is human or of the horse kind. But, correctly speaking, it should be restricted to a certain very dangerous inflammation of the lining membrane of the bowels, which generally extends to the other coats. The morbid changes that are here seen resemble those occurring in a muscle, bone or any other part, when inflamed,-congestion, effusion, and, in a favorable issue, resolution, or, when unfarorable, mortification and death. Any part of the intestines maly be the seat of the original attack, but it is the small intestines in the ligleter classes of horses, and the large intestines in the heary breeds, which are most generally involved.

Causes.-This is one of the most common sequels of spasmodic colic, wheh merges into it imperceptibly. 1)ust-balls, or concretions in the bowels, or worms in the mesenteric arteries of the intestines, will also cause it. Or it may result from eatme or drinking irritating substances, either by acedent or when administered for the cure of colic; or from 
drinking cold water when heated; and in very many cases the cause remains unknown.

Symptoms.-There are usually some premonitory symptoms: the horse probably is dull, the legs and ears cold, the food is not eaten, and he stands with his head down in a dejected sort of way. This being an inflammatory disease, the temperature will be slightly elevated, and the pulse and breathing quickened.

These symptoms, as the disease progresses, will be replaced by colicky pains, pawing, turning the head and looking at the flanks, and hesitating attempts at lying down. Once down, he will roll and try to remain on his back, as this position evidently gives a degree of ease. The pain is continuous, and it gradually increases, along with a quicker pulse and respiration, and presently sweat will stream off the body. Owing to the difficulty of distinguishing between this disease and spasmodic colic (a thing which it is highly important to make no mistake in doing), we have prepared

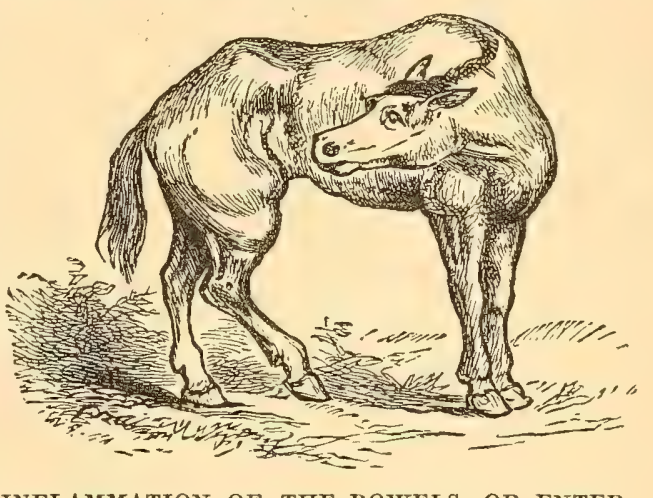

INFLAMMATION OF THE BOWELS, OR ENTERITIS. contrasted tables of symptoms, and present them herewith in opposite columns.

\section{SPASMODIC COLIC.}

Comes on suddenly.

Pain is intermittent.

Pain is violent (in paroxysms) from the start.

Pulse natural.

Temperature natural.

\section{ENTERITIS.}

Has premonitary signs.

Pain is continuous.

Pain commences as uneasiness simply, and increases.

Pulse gradually increases.

Temperature elevated.

As the disease gains the upper hand and death approaches, the temperature falls, the skin becomes cold and clammy, but the victim most likely struggles up to the last moment of life.

Treatment.-Place in a comfortable box stall, and clothe warmly to restore the superficial circulation. To combat the fever, give ten drops of tincture of aconite, in a little water, every half hour, decreasing the dose as the pulse becomes slower. Drench with No. 33, or No. 34, with plenty of oil, as directed for spasmodic colic. 
IIot blankets, poultices, mustard or turpentine, may also be applied to the belly. Morphine, as prescribed for cramp colic, is likewise of great benefit.

The bowels should be relieved at frequent intervals by means of the fumnel and soap and water, as mentioned in the two preceding sections. After recovery, this treatment may be followed by the Purgative Pill No. 20.

\section{Diarrhœa.}

This condition is said to exist whenever the frees, or dung, becomes abnormally soft or liquid. It may be looked on as an effort of nature to rid herself of some irritating substance in or through the digestive tract.

Causes.-Indigestible food; changing the feed, especially from a dry to a soft one; the action of various medicines, etc. Horses of a certain conformation, having narrow chests, thin flanks, and lone coupled, are very subject to diarhoea, and for this reason they are often spoken of as "washy horses." Such a horse is very hard to keep in condition, and is very easily upset. He cannot be expected to prove a very good worker; yet, at slow work, he may, perhaps, lay on flesh, and retain it too. Diarrhoea is also seen in advanced stages of various debilitating diseases, as pneumonia, blood poisoning, intestinal and liver disorders, etc., in these cases indicating the near approach of dissolution.

Symptoms.-Frequent evacuations of soft or fluid frees, haring the color of the substance producing it; when, for instance, from grass, they are green, bnt give iron powders and they will change to black. In simple diarrhœa there is very little or no smell, but when the trouble arises from a breaking down of the system, the evacuations will seem fairly putrid.

Treatment.-The purging being the result of some irritant, it behooves us to encourage the discharge which will remove it. True, this is contrary to the old practice of stopping the purging as quickly as possible; but it is well to remember the old axiom (sound in every syllable), "Remove the cause, and the effect will cease." Examine the feed and water, and see that they are good and sweet; and for medication, give a pint of linseed oil. This simple dose, by removing the irritant, will, in mild cases, be all that is necessary. If, however, the purging continues, give either of the following: 
No. 37.

Tincture of opium, 1 ounce.

Tannic acid, 1 drachm.

Water,

Mix.

Make one dose, repeating it three times a day.

No. 38.

Powdered catechu, 1/2 ounce.

Powdered opium, 1/2 ounce.

Powdered camphor, $1 / 2$ ounce.

Molasses or lard, sufficient to mix.

Make four pills, and give one of them three times a day.

After the diarrhœa is checked, stimulants may be used to restore the strength. For this purpose brandy is the best.

\section{Dysentery.}

This is an attenuated condition of diarrhœa that is rarely seen in horses; yet there is a liability, always, that the causes producing the one may, by an unfavorable turn, lead to the other.

Symptoms.-Great weakness, probably shivering, arching of the back, and violent straining. The fæces are fluid, composed of blood and mucous, and with a very offensive odor. There may be colicky pain, and gas may form from decomposing matter. In a severe case, death may close the scene in from three to six days after the appearance of the blood-streaked passiages.

Treatment.-First of all make the animal comfortable in a warm box, with plenty of clothing. Give a pint of linseed oil, and follow this in about four hours with astringent medicines, such as No. 37 or No. 38 ; or the following, which in some cases will be best of all:

No. 39 .

Perchloride of iron, 2 drachms.
Tannic acid, 1 drachm.
Water or milk, 1 pint.
Mix, and give as one dose.

This dose may be repeated every four hours.

When the discharge is unbearably offensive, sprinkle the place with chloride of lime, and give the following drench internally three times a day:

No. 40 .

$$
\begin{aligned}
& \text { Hyposulphite of soda, } 1 / 2 \text { ounce. } \\
& 1 \text { pint. } \\
& \text { Water, } \\
& \text { Mix, and give as one dose. }
\end{aligned}
$$

In this disease, which is very fatal when fairly established, the continuous drain on the system causes great weakness, so that the strength will need to be supported by the liberal use of whiskey, or, better still, of brandy. Beer, porter, or other malt liquors, should 
not be used, as they have a direct tendency to produce a state of diarrhoa. From ignorance on this point, mischief may be done.

\section{Constipation.}

Constipation, or costiveness, is characterized by a stoppage, more or less complete, of the intestinal movements, or a lack of peristaltic action, as it is called in the language of science. Fatal results sometimes follow.

Causes.-These are very numerous, such as feeding dry, fibrous food, like hay, for example, over-ripe when cut. Rye and barley straw are especially open to this objection, but oats straw, in a regulated feed, seldom causes this trouble. Other causes are imperfect mastification from diseased or irregular teeth; a lack of water in proper quantities; or, again, too much lime in the water habitually given. It may also be seen after diarrhoa, sometimes from Nature's excessive reaction, but oftener in consequence of overdosing with astringents, or, occasionally, from paralysis of the bowels. Hair-

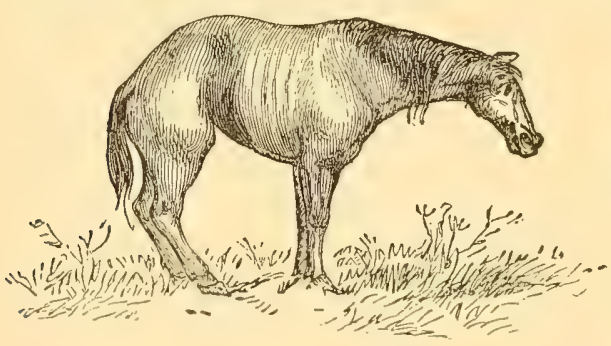

A SUFFERER FRCM CONSTIPATION.

balls and concretions also belong in the category of its causes; but these will be specially considered in the next section.

Symptoms.-The observant stableman or driver will notice that the bowels are not acting; the animal appears dull and The tucked-up belly, the attiiude, and general ex- listless; and if the ear is pression of suffering are plainly shown.

is no sound audible, such as may plainly be heard in the case of an animal in health. Pains ensue, with the uneasiness and rolling alleady described as colicky pains. Repeated and riolent straining fails of its object, and the horse paws and licks at the belly, in the vain endeavor to obtain relief. By inserting the hand in the rectum a stringy mueus will be found which is ofton mistaken for worms. When due to hair-balls and coneretions, the symptoms vary somewhat according to the part affected, a matter that will be suitably treated of on the next page.

Treatment.-Ascertin the cause, if possible, and change the food to a laxative diet, such as bran mashes, oil-calke, beets, carrots, etr. Examine the teeth, also, and, if necessary, have them attended to. 
Give a pint of linseed oil, and follow this by Purgative Pill No. 18. In addition, give the following - a wineglassful in half a pint of water four times a day:

No. 41.

Tineture of nux vomica, 1 ounce.
$\begin{array}{ll}\text { Extract of belladonna, } & 1 / 2 \text { ounce. } \\ \text { Powdered alum, } & 2 \text { ounces. } \\ \text { Water, } & 1 \text { pint. } \\ \text { Mix. } & \end{array}$

Warm injections of soap and water, by means of the funnel, as recommended for colic, will nearly always be of great benefit.

\section{Hail-balls and Concretions.}

To these are due many cases of colic and constipation, especially among old horses. Hair-balls are formed from the habit some horses have of licking one another, or from eating the sweeping of mill floors containing the beard of the grain. Pass ing to the bowels, these substances become matted together by the mucus which is secreted as the result of the intestinal irritation. Concretions are usually deposits of salts, from the intestinal juices, around some nucleus, such as a piece of nail; or they come from the matting together of sand or earth, which has been partaken of through some morbid appetite; or, instead, particles of food may be imbedded in them, the whole being bound together by the secretion, the mucus, already spoken of.

Symptoms.-Hair-balls are frequently found among the dung, having caused no trouble on their passage. But they are not always thus

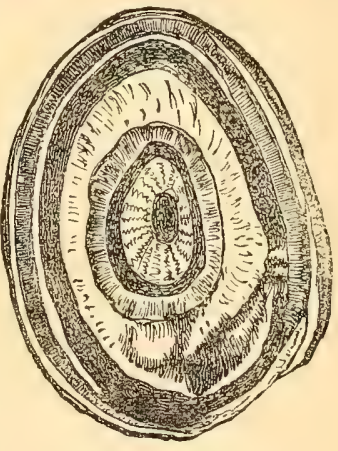

AN INTESTINAL CONCRETION.

Showing the central nucleus, and the layers of coucreted substance that have formed around it. harmless; they often cause great pain while slowly working their way through the intestinal canal. The animal may even sit on his haunches like a dog, and so continue perhaps for days, and only get relief at last by the ball shifting to some more favorable position. Later the pain may, perhaps, recur as bad as ever; at least, the liability to this will be ever present until the ball has been passed.

As to concretions, these often form in very large bodies, of irregular shape, and from long retention in the intestines malie for themselves a kind of pouch in which to lie. While undisturbed in this pouch all is well, but as soon as they shift to a new location, suffer- 
ing ensues, which is often very great. They may cause constipation by obstructing the bowels, and in these cases there is great danger of a fatal termination. Yet, small concretions have been passed without much trouble.

When a hair-ball or concretion is in the small intestines, the horse will paw with the fore feet, turn the head to the side, and stand with the fore legs stretched forward. When it is in the large intestines, especially towards the back, he will strain violently, and push back against the wall.

Treatment. - This will consist in using the remedies prescribed for' the relief of pain in spasmodic colic. Always back-rake when any obstruction is suspected, as it may be the obstruction is within reach through the anus.

\section{Worms.}

Of the many different species of worms which are found infecting the stomach and intestines of the horse, the principal are as follows:

Ascarides.-Small, white worms from one-half to one inch long. Though found in all parts of the stomach and intestines, they chiefly locate in the cæcum, a portion of the large gut. (See engraving on page 184 ).

Strongyli and Oxyuris.-These two kinds are also small, resembling the ascarides. They are found in the crecum, and colon of the large intestines, and the duodenum of the small, and also in the stomach.

Lumbrici.-These are a large, yellowish-white, round worm, tapering at each end. They are from six to twelve inches long, and are never numerous.

Tænia, or Tape-Worm.-The tape-worm rarely troubles the horse, though quite common among dogs. Each segment of this parasite contains a complete set of generative organs, this being a hermaphrodite worm, and hence unless the head is expelled, the worm will grow again.

Symptoms of Worms. - The presence of worms may never be suspeeted until they are seen in the dung. Indigestion and diarrhea are but two out of many evils traceable to them at times. The eoat, likewise, will be rough and dry, the skin is hide-bound, and the tail is rubbed from the irritation around its root. The remains of the yellow worms we have mentioned maty be seen around the anal opening, through which they have been squeezed. Horses troubled with 
worms may eat heartily, yet never gain in condition, the reason being that they are so largely defrauded of nutrition by these parasites absorbing it.

Treatment.-Prepare the patient by a soft diet for several days, then compel eight hour's' complete fasting, and give a strong vermifuge, either No. 31 or the following, in a little wet feed:

No. 42. Powdered santonin, 1 ounce. Powdered areca nut, 15 grains.

Mix, and make one powder.

The strength of the powder will have to be reduced according to age, when administered to colts.

Follow the vermifuge in an hour or two with a bran mash, and then the ordinary feed. A day or two later Purgative Pill No. 20 may advantageously be used, to carry off the remaining worms.

It may be necessary to repeat the above course once a week for a month, in order to make sure of thorough work.

As worms contain no iron in their system, and this element is to them a deadly poison, it may be used with great benefit in effecting their riddance. The following is an excellent prescription for this purpose :

No. 43.

$$
\begin{aligned}
& \text { Sulphate of iron, } 3 \text { ounces. } \\
& \text { Sugar, } \\
& \text { Mix. }
\end{aligned}
$$

Make twenty-four powders, and give one three times a day in the feed.

\section{Hemorrhoids, or Piles.}

These likewise are very rarely seen in the horse, but are more common in the dog. The swelling of the membrane around the anus, with which they begin, is followed by a characteristic dilatation of the veins, appearing as soft, prominent fingers, or tumors. They are not always external and visible; they may be internal, and noticeable only at the time of dunging.

Symptoms.-A persistent switching of the tail, for which there is no other cause discoverable, gives reason to suspect piles, as this is a natural effect from the irritation that they produce on defecation, the dung in most cases being tinged with blood. 
Treatment.-At the commencement, this will necessarily be of a soothing nature. The use of warm water is very beneficial. This may be followed by applying the following ointment:

No. 44. Powdered galls, 1 drachm.

Powdered opium, 15 grains.

Lard or vaseline, $1 / 2$ ounce.

Mix.

In old cases where the tumors are prominent, these may be tied close to the base, and allowed to drop off ; or they may be snipped off with the scissors. No after-treatment will be necessary in either case.

\section{Hernia, or Rupture.}

The commonly used word, rupture, when speaking of this trouble, is simply an abbreviation, indicating a rupture of the coats of the abdominal walls. It may be of only one of the walls or of all of them, excepting, of course, the skin. Through the opening the bowels pass, and make their appearance as a lump of very variable size. According to the part of the wall involved, the hernia is given a special name. Umbilical hernia is seen from failure of the navel opening to close at birth. Scrotal hernia is mostly seen, in foals, from a relaxed condition of the muscles that ought to have closed the opening through which the testicle has come. Ventral hernia occurs through any other part of the abdominal wall.

A hernia is said to be "reducible" when, by placing the animal on his back it disappears, the protruded bowel having slipped back to its natural place; "irreducible," when it will not do this; and "strangulated" when the protruded sac fills with food, ete., which is detained there by mechanical conditions, followed soon by a stoppage of the circulation, and eventually by mortification and death.

Causes.-In foals, besides non-closure of the navel opening at birth, hernia may come from the foal sucking at the end of the umbilical cord, or by the mother stepping on it. In old animals it is usually the penalty of violent exertion, or may come from goring by cows; in mares, the weight of a foal on a weak part of the wall may cause it, and in stallions a strain or struggling while serving a mare.

Symptoms. - There is a visible swclling, which in simple cases is usually soft, permitting the gut to be pushed back, and the opening in the wall felt. In stallions, scrotal hernia gives signs similar to colic, for which it is often mistaken. When a hernia is strangulated it auses intense pain, similar to enteritis, or inflammation of the bowels; and if not relieved, it must soon end fatally. 
In the mare, a hernia is a very serious trouble, on account of the great strain on the walls of the abdomen during delivery. The excellent engraving we here present is from a photograph. It should be studied by every stock breeder. In hernia, of whatever description, the swelling becomes larger on making the subject cough. This, accordingly, is the usual and sufficient test when any doubt exists.

Treatment.-The treatment of umbilical hernia in the foal is simple. The use of pressure by means of a bandage is usually sufficient.

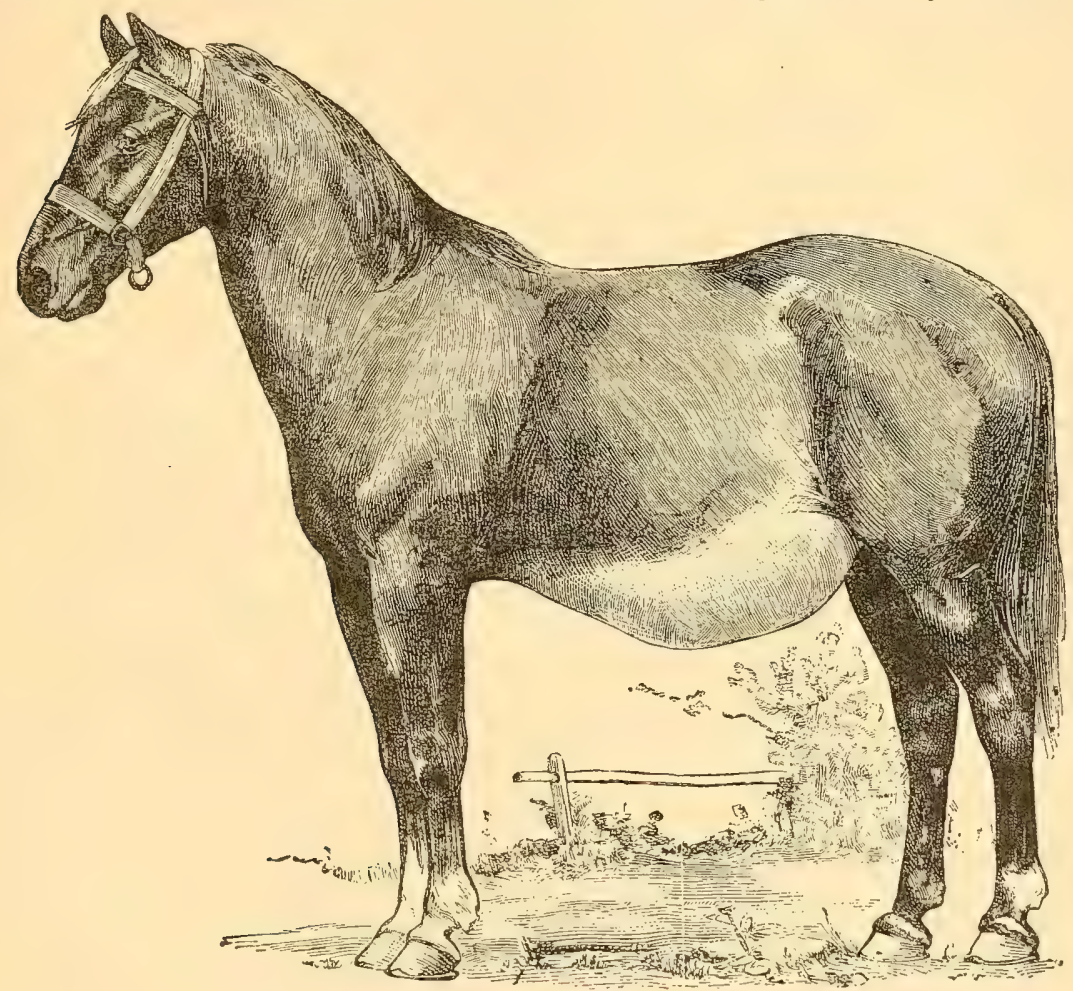

ABDOMINAT HERNIA IN MARE TVITII FOAL.

(Engraved for this work from a Photograph.)

For ventral hernia the animal is cast, the sac carefully opened, and the finger inserted to break up any adhesions that may have formed; then the gut is pushed into the belly, and two clean skewers are crossed at right angles through the skin as close to the opening as possible, and a piece of strong twine wound below these, the skewers being allowed to drop off with the slough. The treatment of scrotal hernia is very complicated, but at times by placing the animal on his back, manipulation will succed in effecting the return of the gut to its proper place. 


\section{CHAPTER XXVII.}

\section{DISEASES OF THE LIVER AND SPLEFN.}

I. IMPORTANT FUNCTIONS OF THE LIVER.-II. ORGANIC DISEASES OF THE LIVER. - III. INFLAMMATION OF THE LIVER, OR HEPATITIS. - IV. FATTY LIVER.—V. JAUNDICE, OR YELLOWS.—VI. ENLARGEMENT OF THE SPLEEN.

\section{Important Functions of the Liver,}

The purpose which the liver subserves in the animal economy is an important one, and upon the proper discharge of the functions of this organ the health of any animal is largely dependent. It is in the liver that the bile is eliminated from the blood, and hence this viseus is considered a gland, by far the largest one in the body. Using the terms excretion and secretion in the distinctive senses indicated on page 179 of this work, the action of the liver is both secretive and excretory - secretive because the admixture of bile with the chyle is essential to the healthy performance of the digestive process; excretory because if the bile were allowed to remain in the blood, it would vitiate and poison the entire circulation. These considerations will better enable us to understand how important a bearing the condition of this organ must have upon the general health.

In the horse, the bile from the liver, together with a whitish fluid from the pancreas (or sweet-bread, as it is familiarly called) enters the small intestines at the termination of the duodenum, about twentytwo inches from the pyloric orifice of the stomach. These secretions are conveyed through the biliary and pancreatic ducts, which are shown near $a$, in the cut of the intestines on page 184. The horse has no gall-bladder, so that the bile, as fast as it is eliminated from the blood, passes directly to the intestines. He is less subject to liver complaints than any of the other domestic animals, or than his master-man.

\section{Organic Diseases of the Liver.}

That liver complaints are not common among horses is a circumstance which the farmer may well be thankful for, on account of the ohscurity of the symptoms in such cases, and the extreme difficulty 
of determining precisely what the trouble is. Often it is only by a post mortem examination that the most experienced can make a diagnosis even tolerably satisfactory. Perhaps the following extract from that usually precise and reliable veterinarian, Youatt, will illustrate all that we could wish to say upon the vagueness and uncertainty which surrounds our knowledge of hepatic diseases.

"If horses, destroyed on account of other complaints, are examined when they are not more than five years old, the liver is usually found in the most healthy state; but, when they arrive at eight, or nine, or ten years, this viscus is frequently increased in size; it is less elastic under pressure; it has assumed more of a granulated or broken-down appearance; the blood does not so readily permeate its vessels, and, at length, in a greater or less quantity, it begins to exude, and is either confined under the peritoneal covering, or oozes into the cavity of the belly. There is nothing, for awhile, to indicate the existence of this. The horse feeds well, is in apparent health, in good condition, and capable of constant work, notwithstanding so fatal a change is taking place in this important viscus; but, at length, the peritoneal covering of the liver suddenly gives way, and the contents of the abdomen are deluged with blood, or a sufficient quantity of this fluid has gradually oozed out to interfere with the functions of the viscera.

"The symptoms of this sudden change are pawing, shifting the posture, distension of the belly, curling of the upper lip; sighing frequently and deeply; the mouth and nostrils pale and blanched; the breathing quickened; restlessness, debility, fainting, and death.

"On opening the abdomen, the intestines are found to be deluged with dark venous blood. The liver is either of a fawn, or light yellow, or brown color, easily torn by the finger, and, in some cases, completely broken down."

\section{Inflammation of the Liver, or Hepatitis.}

This is exceedingly rare in the horse, and is very seldom, if ever, diagnosed as a distinctive disease. The veterinarian is likely to know it only as the result of an accident.

Symptoms.-The animal is feverish, the pulse quickened, and the eyes more or less bloodshot. From the stoppage of the flow of bile, constipation presently results, the dung is dry, and like clay in appearance, and the water is high colored. The sufferer will be noticed to turn his head and look anxiously at his side, thus suggesting where the 
pain is, and on pressing there with the hand he will wince in at way that leaves no doubt on this point.

Treatment.-For the fever give the Fever Powder No. 21, or any of the febrifuges mentioned in the "Recapitulation of Remedies." Relax the bowels by a soft diet, give a pint of linseed oil, and after-

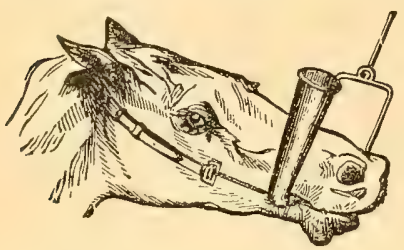

AN APPROVED DRENCHING HORN, wards Pill No. 18. For the further relief of the constipation, use the funnel, ete., or try back-raking, all in manner as laid down for spasmodic colic.

A Good Drenching Horn.--The linseed oil above described will, of course, be given as a drench. Our illustration presents a better form of the drenching horn than any of the old-fashioned kinds, making it easy to give the drench without spilling, or splashing it on the clothes.

\section{Fatty Liver.}

This is occasionally found among horses, but, as a rule, its existence can only be detected after death, or, in other words, by a post mortem examination. It mostly occurs in heavy breeds of horses that are very highly fed; they receive more oil-forming materials in the system than it is possible to assimilate. It is sometimes seen in the rapid emaciation of debilitating disease; the fatty tiswes throughout the body being absorbed into the blood, more work is thrown upon the liver than it is possible for that organ to properly perform. The oil being stored up in cells here, structural changes are brought about-the liver becomes large, soft and pale-colored.

Hepatitis is thought to be the cause of many of the sudden deaths that oceur among the large breeds of horses; and it is also supposed to cause various inflammatory disorders of the bowels by interfering with the flow of the bile.

Treatment.-As the disease is hardly ever capable of heing diagnosed, not much can be said in regard to treatment. If this condition is suspected from the presence of certain symptoms traceable to no other cause, the feed should be reduced and laxatives used; or the more active Purgative Pill No. 18 may be given. The animal should be carefully dieted, with a large proportion of laxative food, until his health is entirely regained. 
The Balling-Iron--The balling-iron ( shown in the cut) is of great service in administering pills, etc., by keeping the horse's mouth open. As many farmers have never seen one used, we will briefly describe it. The horse's mouth being open, the balling-iron is pushed into it; through the part shaped like a D lying on its round side, comes the animal's lower jaw, the points at the opposite end of the iron being outside the gums of the upper jaw. The operator's hand, with the ball to be administered, is passed through the elliptical opening between these points.

\section{Jaundice, or Yellows.}

Occasionally this is seen in the horse as an independent disease, but much more commonly in connection with other diseases.

Cause.-The cause of jaundice is the failure

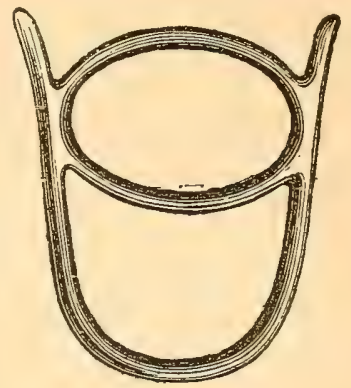

BALLING-IRON.

Another form of the ballingiron is shown at the close of Chapter XXXIV. of the liver to separate the bile constituents from the blood. This failure is sometimes due to disease of the liver which obstructs the flow of bile, while, in other cases, it seems to be closely connected with disease of the heart or other organs.

Symptoms.-The yellowness of the eyes and mouth, and of the skin where it is not covered with hair, mark it sufficiently plain. The dung is small and hard, the urine highly colored, the horse languid, and his appetite impaired. If he is not soon relieved, he sometimes begins to express considerable uneasiness; at other times he is dull, heavy, and stupid. A characteristic symptom is lameness of the right fore-leg, resembling the pain in the right shoulder of the human being in hepatic affections.

Treatment.-It is necessary, first of all, to inquire whether this affection of the liver is not the consequence of the sympathy of that oagan with some other part: for, to a very considerable degree, it is an accompaniment of inflammation of the bowels and the lungs, and disappears as soon as those diseases are subdued. If there is no other apparent ailment, an endeavor to restore the natural passage of the bile by purgatives may be made. For this purpose Pill No. 18 will be very suitable. The horse should have plenty of water and a light diet. Thin gruel or bran mash will be good for him. 
Giving a Pill.-There will be little trouble in administering a pill, if it is held in the manner shown in the accompanying eut. It is to

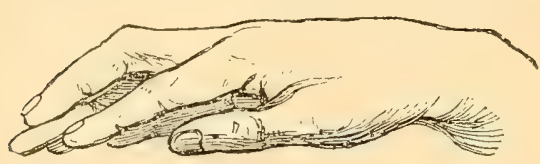

TIE WAY TO HOLD A PILL. be dropped far back in the mouth, on the base of the tongue. With the aid of the balling-iron the most unwilling patient may be readily managed.

\section{Fnlargement of the Spleen.}

What is the precise function of the spleen-or milt, as it is commonly ealled-has never been fully demonstrated. The old theory that it served as a reservoir for the storage of blood has been replaced by the better founded one that it destroys the worn-out blood corpuscles. This strange organ is subject to enlargement, but from what cause, or by what remedies to counteract it, no one seems to have more than surmised. The candid veterinarian will confess his ignorance on this subject, which he need not be ashamed to do, since every candid physician must do the same. It is, at all events, a subject of no practical moment to the farmer, the supposed symptoms being anything but determinate or reliable. 


\section{CHAPTER XXVIII.}

\section{DISEASES OF THE KIDNEYS AND BLADDER.}

I. INFLAMMATION OF THE KIDNEYS, OR NEPHRITIS.-II. DIABETES.—-III. STOPPAGE OF THE URINE, OR DYSUREA.—IV. AZOTUREA.—V. INFLAMMATION OF THE BLADDER, OR CYSTITIS. - VI. RUPTURE OF THE BLADDER. -VII. SPASM OF THE BLADDER.-VIII. STONE OR GRAVEL (CALCULUS) IN THE BLADDER.

\section{Inflammation of the Kidneys, or Nephritis.}

The kidneys are frequently the seat of disease, one of whose most acute manifestations is that of inflammation, technically denominated nephritis.

Causes.-The causes of this condition are various. Perhaps as common as any is exposure of the loins to wet when the animal stands still for a long time, especially if the atmosphere is raw and chilly, as well as damp. We know also that when certain substances are introduced into the stomach, and subjected to the digestive process, their absorption results in very marked irritation and disturbance of renal action, (renal being a word that signifies "relating to the kidneys," which were anciently called the reins). Thus, moldy feed of every kind is found to have a strong tendency to bring on urinary diseases. Many strong diuretics, of which ignorant practitioners are so extremely fond, possess the same hurtful properties in such degree as should condemn their use entirely, except in the hands of a man of known experience and caution. To this class belong all such mineral poisons as saltpetre, blue-stone, copperas and lead. Among vegetable poisons nux vomica (strychnine) has the same effect.

The application of strong fly (cantharides) blister's to a large extent of surface, in the region of the loins, or the administration of powdered Spanish flies internally, will also cause this trouble.

Severe strains, and other injuries of the loins and hips, seem often to cause inflammation of the kindeys, though the connection between the two circumstances is not very obvious; and it has been supposed that the disease, in such cases, is developed by exposure to cold 
while in a state of exhaustion, or that some branch of the renal artery or vein has been ruptured by the violence of the preceding exertion. It may, likewise, result from the extension of inflammation from any adjoining diseased part.

We believe that bad treatment of every kind predisposes to renal affections, as one of the effects of constitutional debility, and its tendency to functional derangement. For this reason, therefore, if the many stronger ones were all lacking, low, damp situations should always be aroided, and the foul air and fetid breath of many stables ought never to be tolerated. Finally, whatever produces disorder in the digestive apparatus will be quite apt to extend its harmful influence to the kidneys also.

Symptoms.-The early symptoms are generally those of fear; but the seat of the disease soon becomes evident. The horse looks

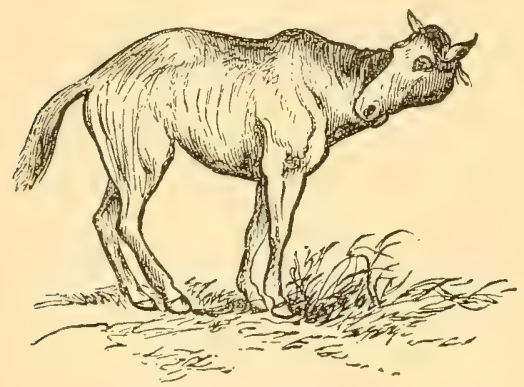

INFLAMMATION OF' THE KIDNEYS. anxiously round at his flanks; stands with his hind legs wide apart; is unwilling to lie down; straddles as he walks; expresses pain in turning; shrinks when the loins are pressed, and some degree of heat is felt there. The urine is voided in small quantities; frequently it is highcolored, and sometimes bloody. The attempt to urinate becomes more frequent, and the quantity roided smaller, until the animal strains painfully and violently, but the discharge is nearly or quite suppressed. The pulse is quick and hardfull in the early stage of the disease, but rapidly becoming small, yet not losing its character of hardness.

How to Distinguish From Inflammation of the Bladder.-These symptoms clearly indicate an affection of the minary orwans; but they do not distinguish inflammation of the lidney from that of the badder. In order to effect this, the hand must be introduced into the reetum. If the bladder is felt full and hatrd under the rertum, there is inflammation of the neck of it; if it is empty, yet on the portion of the intestines immediately orer it, there is more than natural heat and tenderness, there is inflammation of the horly of the hader'; and if the bladder is empty, and there is no increased heat or tenderuess, there is inflammation of the kidney. 
Treatment.-First relieve the fever, by means of the following:

No. 45.

Tincture of aconite, $\quad 1 / 2$ ounce.

Liquor of ammonia acetate, 4 ounces.

Mix.

Give a dessert-spoonful every two hours, increasing the interval between doses as the fever subsides. In order to carry off a proportion of those fluids by the bowels which would otherwise pass by the kidneys, give Purgative Pill No. 18. Hot blankets or poultices should be kept on the loins, and changed frequently as they begin to cool.

The diet should be light, easy of digestion, and of a mucilaginous character. For this purpose linseed tea will be best of all adapted; oat meal gruel, with a little baking soda in it, will also be soothing.

\section{Diabetes.}

In this disease, which is comparatively common among horses, there is an excessive secretion of the urine.

Causes.-Diabetes is generally due to some too stimulating element in the horse's water or food. Musty hay, oats, etc., are very apt to lay the foundation for it. At times it is produced by using certain drugs for other purposes.

Symptoms.--Intense thirst;

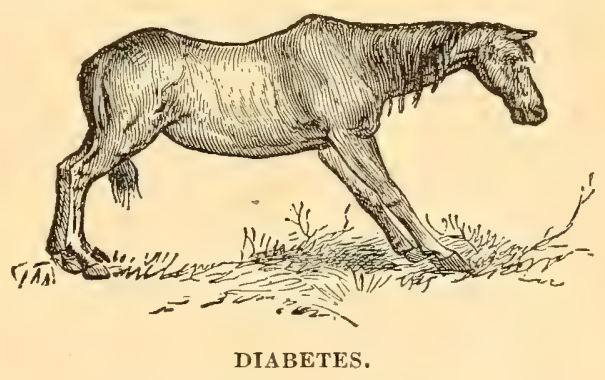

The attitude is characteristic. light-colored water passed very frequently-often almost clear; constant uneasiness, or pain in the loins, it being evident to even a casual observer that the animal wishes to pass more water. Wrakness supervenes, the coat becomes harsh and staring, and sweating appears on the least exertion. The fact is that the continual drain of fluid from the blood has brought on heart trouble along with the great debility; and if this goes on unchecked, a fatal termination is inevitable.

Treatment.-Change the food, water, medicine, or any other suspected cause.

Pipe clay, pea meal, chalk, ete, in the drinking water, are all favorite remedies, and may be used in case of a hurry; but the fol- 
lowing drench is far preferable, as it will check both the thirst and the secretion of the urine:

No. 46.

Iodide of potash, 1 ounce.

Water, 1 pint.

Mix.

Give a small wineglassful every three hours on an empty stomach, and less frequently as the trouble disappears.

Good sweet hay and pure oats will be the proper diet during convalescence. When any debility remains, any of the tonic powders prescribed in this book will be likely to answer a good purpose in restoring the appetite and strength.

\section{Stoppage of the Urine, or Dysurea.}

Causes.-This painful disorder is one of the occasional symptoms of gravel, and the presence of large calculi in the kidneys, bladder and urethra; but this, although the most common cause, is by no means the only one. The same effect may follow stricture of the urethra, fiom some mechanical injury, or from a collection of rinatter in the canal at the point of the penis. Such a collection is called a "bean," and occasionally it is found of a very large size. Stoppage may also result from the formation of tumors on the end of the organ.

The urethra, as the reader will recollect, is the canal extending from the neck of the bladder, and through which the urine is voided. On account of its being so much shorter in the mare than in the horse, stoppage of urine is a much less prominent trouble with the former. But inflammation, swelling, or spasm of the neck of the bladder, which also may obstruct or entirely prevent the urinal flow, is equally common to both sexes. From whatever cause it has originated, such a condition is necessarily productive of intense pain, especially when long continued.

Symptoms, - The principal symptom is a straining in endeavoring to palss the water, which, nevertheless, dribbles away in drops, or may he stopped completely. This uneasiness is soon followed by great pain, evidenced by looking at the flanks, rolling, grunting and stamping with the hind and fore feet, in this respect resembling a calse of colic.

When due to a bean, the latter may readily be felt at the opening of the camal; it will be recognized as a collection of soft, sticky seeretion from the surrounding glands. There will be no trouble in re- 
moving it. The presence of a calculus or stone in the bladder may be determined pretty accurately by attending to the directions therefor which are given in Section VIII, of this chapter. When the stoppage is caused by a calculus (stone), it frequently happens that by the horse rolling the stone will be returned to the pouch in which it was formed, whereupon the symptoms will all subside, the animal appearing perfectly well again. Nevertheless, such a horse is always very liable to colic, and if the stone is not removed, another or several more attacks will occur later, the result at last being fatal.

Treatment.-First ascertain the cause, and if found to be a bean, tumor, stricture, or stone, adopt the proper mechanical or surgical means to remove it, with as little loss of time as possible. The catheter (see illustration), is here of the greatest value, whether for dilating a stricture or as an aid in locating a stone. It should be well greased before introducing into the urethral canal. When refuse matter collects in the bladder, it is not easy to remove. Lukewarm water may be injected through the catheter, and perhaps some of it

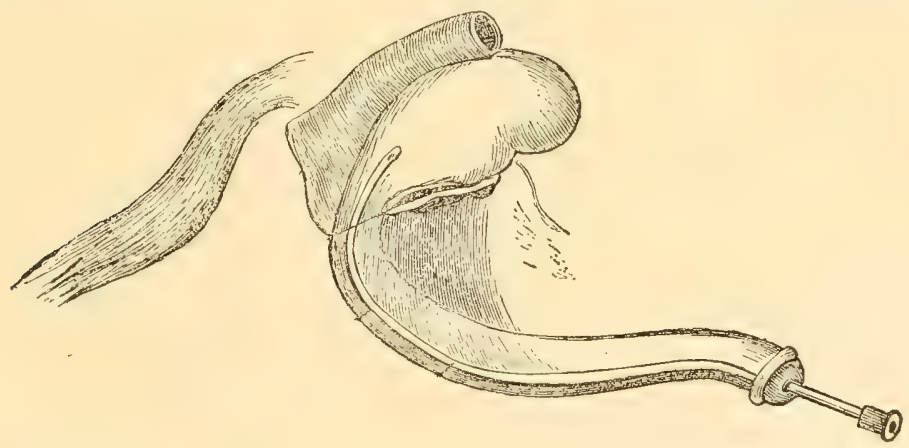

SECTIONAL VIEW, ILLUSTRATING THE USE OF THE CATHETER.

The catheter has been passed through the urethra into the bladder.

in this way washed out. There is a class of drugs, called "anti-" lithics," that have a certain power in dissolving salty concretions, and aiding in their removal. They are powerful acids, needing cantious handling. The following drench contains one of the best of them:

No. 47.

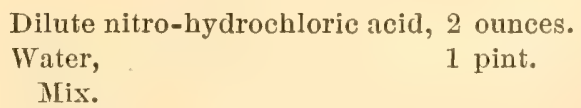

Give a small wineglassful three times a day in a quart of water, allowing the patient to drink from a bucket. 
The treatment for beans and stones will be considered a few pages later, under special headings. Tumors will have to be cut off, if there is a sufficiently skillful operator procurable, and the wound touched with a hot iron, to arrest the bleeding.

\section{Azoturea.}

This affection is also known as hemoglobinuria, or, more loosely, paralysis. It is a peculiar disease among horses, that has been generally recognized only in very recent times.

Causes.-This ailment is found almost altogether among horses that are fat, and little worked. Whenever seen, it has always been after a rest of a day or a week, or perhaps still longer. To put the matter in simple language, they are cases in which the already highly charged blood has become loaded with nutriment in excess of the requirements of the system.

Symptoms.-The manifestation of this disease is strikingly peculiar. While in the stable nothing unusual is noticed, and, in fact, the expression is often used that when put in harness he never looked better. But after proceeding for a mile, or perhaps less, stiffness appears, and a disinclination to move; then the muscles over the hips begin to swell; presently the animal staggers in the hind legs, and at last falls to the ground, control over the back parts being completely lost.

When the urine is examined, it is found to be of a dark chocolate color, and an oily or even stringy consistence. This change in the urine is a marked characteristic of the disease. As recovery progresses, the urine will gradually turn a lighter hue, and resume its normal state.

In connection with this disease, though usually in a modified form of it, the muscles around the shoulder joint may also be swollen. The muscles of the loins are often found more or less puffed, causing a stiffuess of movement. This condition readily yields to treatment, but the form of the disease in which paralysis occurs is quite fatal.

Treatment.-First draw the water with the greased catheter, as shown in the illustration on page 373. This must be done three times a day until the horse is able to relieve himself. Back rake the howels with the hand, or use the fumnel with the soap and water. These measures, in a favorable case, will give the animal the immediate relicf so necessary. The next thing will be to reduce the overnourished system, and this eam best be accomplished by using pureatives and diureties, in this way working through the two great er- 
cretory systems of the bowels and kidneys. Give the Purgative Pill No. 18, and allow nothing but bran or linseed mash for feed. Also give Powder No. 26 every three hours, on the tongue or in the feed. Or, instead, one of the following powders, composed of the latest drug, recommended and used very successfully, may be given:

No. 48. Citrate of lithium, 1/2 ounces.

Divide into twelve parts, and give one every five hours on the tongue or in the feed.

In the beginning of the disease, we believe in allowing the animal to lie down, being particular, however, to see that he is turned at least twice a day. (When placed in the slings at the start, he is likely to struggle, and complicate the disease.) But as the disease begins to wear off, and the strength of the hind parts to return, then it will be an advantage to use a sling, at the same time frequently hand-rubbing the legs briskly to restore the sluggish circulation. In some cases we have seen the slings used with benefit from the first. The slings here illustrated are somewhat simpler in construction than those shown on

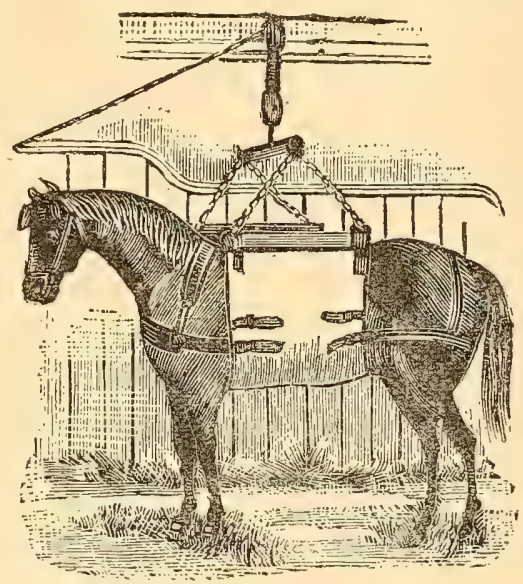

THE SLINGS IN POSITION. page 232, and are the kind now generally used.

The application to the muscles of the loins of a soothing lotion, such as No. 3, sometimes has a very good effect.

\section{Inflammation of the Bladder, or Cystitis.}

Causes.-This is frequently seen from the common practice of giving horses saltpetre, rosin, turpentine, etc., for the water. It maly also be caused by injuries, calculus or stone, or from the extension of disease from an adjoining part.

Symptoms. - The animal is feverish, and is evidently in great pain ; he kicks at the belly, looks at the flanks, and when walking keeps the legs apart. The water is passed with abnormal frequency in small amounts, and the act is attended with acute pain; in a bad calse blood or pus may be mixed with it. To make sure of the diagnosis, the hand may be passed into the rectum, on the floor of which, near the 
edge of the pelvic bone, the bladder will be felt; by pressing at this point, the pain evinced will tell its own story. Examine the bladder through the rectum, and ascertain if any calculus or other matter is present. If so, remove it in the way we shall describe in Section VIII, of this chapter. This, of course, requires the skill of a thorough veterinarian.

Treatment.-The necessary medication any farmer can attend to himself. Give the Purgative Pill No. 18, to draw the fluids off by the bowels, so far as possible, and soothing drinks, such as linseed tea or oatmeal gruel. To reduce the fever, use the Drench No.45, or any of the fever medicines given in our "Recapitulation of Remedies." Apply hot cloths to the loins, and if the pain is severe, use the Drench No. 33, or No. 34.

\section{Rupture of the Bladder.}

This occasionally occurs among mares during parturition; the fœtus being pressed against the bladder, when full, with such force as to cause a rupture. The importance of emptying the bladder before starting in to deliver a foal is thus most obvious. Rupture of the bladder may supervene also in connection with certain diseases-for instance, azoturea-the bladder being unable to force out its contents. In stallions it may also occur from the canal (urethra) being blocked by a stone.

It is needless to say no treatment can possibly avail.

\section{Spasm of the Bladder.}

This is a not infrequent accompaniment of colic. The most serious trouble, of course, is when the spasm seizes the ne is of the bladder, thus preventing urination. An attack of this kind is easily known by the animal's attempts to pass water.

Treatment.-Introduce the greased catheter, as pictured on page 373. To allay the pains, administer the Colic Drench No. 33. Hot cloths on the loins are often helpful.

\section{Stone or Gravel (Calculus) in the Bladder.}

This is a somewhat common trouble, in which the salts of the urine -principally lime-are deposited around some nucleus, such as a collection of mucus, or in the mare around a piece of iron, straw, or the like, that has been malicionsly pushed through the short canal into the bladder. A stone, such as is shown in the amnexed eut, is slowly formed. The salts are deposited in layers; when a calculus is broken in two, it shows the succession of rings exactly as in the illustration 
Symptoms. - The symptoms will vary according to the nature of the deposit, which may only be a collection of a certain fine whitish substance, or may exist as small gravel, or the larger calculus (stone). The last is nearly always round or oval, but occasionally is irreguIar in shape.

The first thing noticed to be wrong about the horse is his difficulty in making water; it comes in small squirts, accompanied with great straining. The urine is continually coming away thus, and if the animal is forced to walk it will be with the legs wide apart.

The absolute test in determining what ails him is to insert the hand in the rectum and feel the bladder, below its floor. If any stone is present, it will be readily felt resting on the edge of the bone. (Care must be taken not to mistake a pellet of dung in the gut below the bladder for a stone.) Upon introducing the catheter, a peculiar sensation of hardness is felt when it strikes the stone; the instrument may also be felt to touch the stone by keeping the hand in the rectum. This will settle the diagnosis conclusively.

Treatment.-This will naturally consist in removing the abnormal deposit, whatever Showing its appearance when cut it be, from the bladder. Any fine gravel or

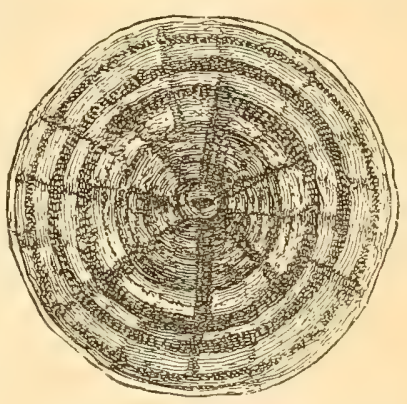

CALCULUS, OR STONE, FROM THE BLADDER. sandy deposits may be got away by passing a catheter up, and through it syringing luke-warm water into the bladder, in this way "flushing", them out. Our recipe No. 47 will aid in their elimination.

When a stone has formed, its removal will necessitate the operation called lithotomy; and for this a special forceps-to grasp the stone-is needed. In the mare this operation is commonly rery simple. The canal to the bladder is very short and possible of wide dilation, allowing the stone to be grasped by the forceps and gradually withdrawn by a rotating motion.

Lithotomy in the stallion or gelding is generally supposed to be at very serious operation; yet it is easily performed if care is taken to follow the instructions. The use of chloroform, while not absolutely necessary, is of great benefit; the animal being out of pain will not struggle, or otherwise increase the difficulty. The first step is to pass the catheter into the bladder (see engraving on page 373 ), and 
make sure of the presence of the stone. The next is to cut down onto the catheter at the point whence access to the bladder is the most easily gained. This spot is just below the rectum, where the catheter is felt to pass over the edge of the bone, on its way to the bladder. At this point a straight cut about one inch long is made, and continued inwards by successive cuts, until the catheter is exposed. The latter is now withdrawn, and the special forceps, well greased beforehand, are passed, with a slow, rotating motion, through the opening into the bladder. The forceps once in the bladder, the hand may be passed into the rectum and the stone by it guided between their blades. To withdraw the stone is a slow process and requires patience; the same rotating motion will be necessary as on the inward passage of the forceps.

Very large stones are not often found, but occasionally one is come across that is too large to extract. In such cases it will have to be broken by means of a pair of special crushing forceps (or in an emergency anything in the form of an ordinary forceps that is capable of performing this service), and the broken pieces extracted separately.

The after-treatment of the wound will consist in putting in a stitch or two at the top of the skin opening, and allowing the rest of the eut to remain open. The urine will prevent the interior wound from closing for some time, but by slightly touching the edges occasionally with a stick of lunar caustic, it will slowly heal.

The catheter should be passed in every day or two at first, and at longer intervals afterwards. This will prevent the formation of a stricture, from the contraction or growing together of the parts while healing. 


\section{CHAPTER XXIX.}

\section{DISEASES, ETC., PECULIAR TO THE MALE.}

I. INJURY OF THE PENIS.-II. BEANS.-III. TUMORS.-IV. CONTRACTION OF THE SHEATI.- - V. INFLAMMATION OF THE TESTICLE, OR ORCHITIS.VI. HYDROCELE, OR DROPSY OF THE TESTICLE.- - VII. VARICOSE VEINS. VIII. CASTRATION. - IX. CASTRATION OF THE IRIDGliNG, OR CRYPTORCHID. - $\mathrm{X}$. THE SEQUELS OF CASTRATION.-XI. INDURATED CORD.

\section{Injury of the Penis.}

This is liable to occur from kicks or blows, accidentally or otherwise, in consequence of which the organ swells, in this way preventing its retraction within the sheath, and it becomes very painful and feels hot. These injuries occasion a tendency to the collection of a dropsical fluid, whereupon the pain measurably subsides, the swelling becomes soft to the touch, and often elastic or flaccid; the organ assumes a reddish brown color, and the horse is still unable, from its size, to withdraw it within the sheath.

Treatment.-During the acute stage, the best way to reduce the swelling is by bathing with hot water for an hour, then do your best to get the or-

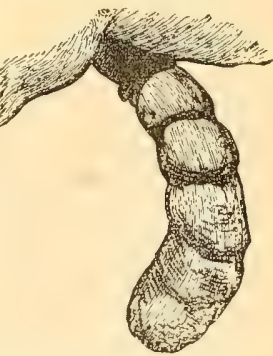

SWOLLEN PENIS. gan back into the sheath, as there it will be subject to a continual pressure, which will be highly beneficial. If this is found impracticable, suspend the organ by a bandage, but still keep up the bathing at regular intervals. Sometimes it is necessary to scarify the protruded part to aid in its reduction. In chronic cases, those in which the dropsy occurs, the swelling can be punctured at the lowest part, and the fluid squeezed out. The sheath and penis should always be kept as clean as possible. If the organ has become dry, a little oil or lard may be rubbed on, before pushing it into its sheath.

\section{Beans.}

This trouble is very common among horses, especially where the parts are not washed often enough, and kept properly attended to. 
What is called a "bean" is a collection of mucous secretion, of a firm yet sticky character, in the dilatation of the urethra, at the point of the penis. When very large it may interfere with the passage of the urine, but may be readily pressed out with the fingers.

\section{Tumors.}

Tumors occasionally form on the extremity of the penis from an enlargement of the parts, especially of a fow glands at the point of the organ. The only remedy when so large to prevent retraction into the sheath is amputation.

To amputate the penis, first pass the catheter in manner as illustrated on page 373. Then bandage tightly around, above the point to cut, in order to steady the organ and more especially to prevent bleeding. Make the cut in an oblique direction; this gives the stump a pointed end, which cannot very well be closed by any swelling that may supervene. All vessels should be tied with a piece of silk thread, as shown in the cut on page 324 , and if any oozing of blood occurs, the surface may be touched with a hot iron. In case of swelling, bathe with hot or cold water. Keep the bowels open, and let the diet be light.

\section{Contraction of the Sheath.}

Where this trouble arises it may prevent the penis from being extended, or when extended prevent its retraction.

Causes.-The causes are injuries, kicks, blows, etc. At times it is an after-effect of debilitating diseases; or it maly be traceable to want of exercise. In all these cases the loose tissues of the sheath become filled with fluid, whereby a mechanical obstruction is produced.

If this condition be allowed to continue, the swelling may stop the flow of blood, and the end of the penis and surrounding parts of the sheath will then die from lack of nutrition. While writir g Chapter XXVII of this book we had a case of this sort in a bull-dog, in which it was necessary to amputate a part of the penis and remove part of the dead sheath.

Treatment.-Reduce the swelling by frequent bathing with hot or cold water. Should the swelling prove obstinate, let it be freely punctured over its entire surface, and pressure used to reduce it in size by means of a thread band drawn tightly around the body and between the legs.

When the swelling is so incorrigible as to bring about the death of the part, the latter will have to be amputated, and a healthy surface secured hy appropriate means, as directed elsewhere for wounds. 
V. Inflammation of the Testicle, or Orchitis.

This is rarely seen in the stallion; when it does occur some injury, such as a kick from a mare, is generally to blame for it, though, possibly, it may have resulted from a strain.

Symptoms.-The testicle is swollen, hot and painful. It hangs lower than the opposite one, and the covering has a tense, shiny look. The pulse is quickened, and the whole system is fererish. The legs are kept wide apart in walking, and the steps are short. No one need mistake it for a hernia. It differs from that in its symptoms of fever, and in not increasing in size when the animal is forced to cough.

Treatment.-First give the Pill No. 20, and diet carefully. Bathe the swelling freely with warm water every hour or two, and keep the testicle supported in some way; the kind of supporter here illustrated is the best. To relieve the pain, give tincture of opium in half ounce doses every one or two hours, as required. Relieve the fever, and quiet the heart, by means of recipe No. 45. This disease is liable to bring on dropsy of the testicle, which we will

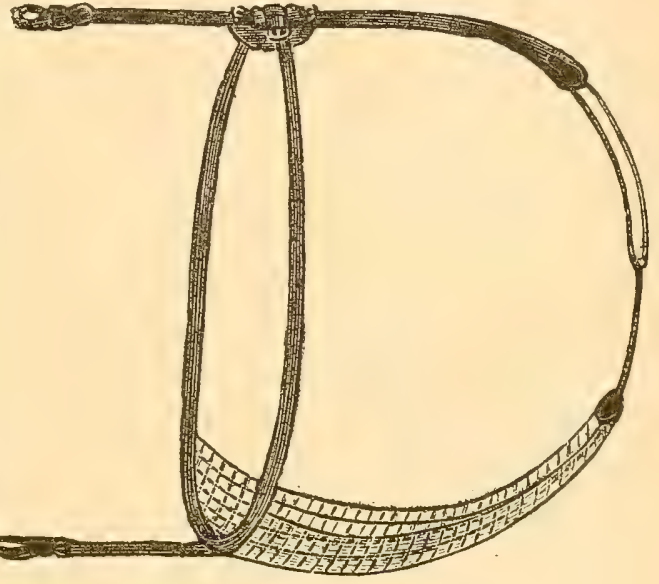

TESTICLE SUPPORTER. consider next.

\section{Hydrocele, or Dropsy of the Testicle.}

Almost any swelling or strain of the testicles may, under certain conditions, result in hydrocele.

Symptoms.-The dropsy comes on gradually, the fluid first collecting at the bottom. The sac is soft and appears full, as shown in the excellent illustration on next page herewith reproduced from a photograph. As the fluid collects, the testicles float upward, and will be found at the upper back part of the sac. The fluid is of a clear straw color, and if a light is held behind the swelling it is seen to be translucent. Hydrocele is readily distinguishable from orchitis by the absence of pain and fever, and from a scrotal hernia by its translucent 
character, and by its not increasing in size when the horse is made to cough. The farmer need be at no loss in discriminating the diseases.

Treatment - It will be necessary to draw off the fluid that has collected by mechanical means. This operation is called tapping, and the instrument employed is a trocar, with canula, the same as illustrated on page 354. Care must be taken not to plunge the instrument upward, as the testicle is in that direction. After tapping, a sufficient quantity of the following solution may be syringed into the

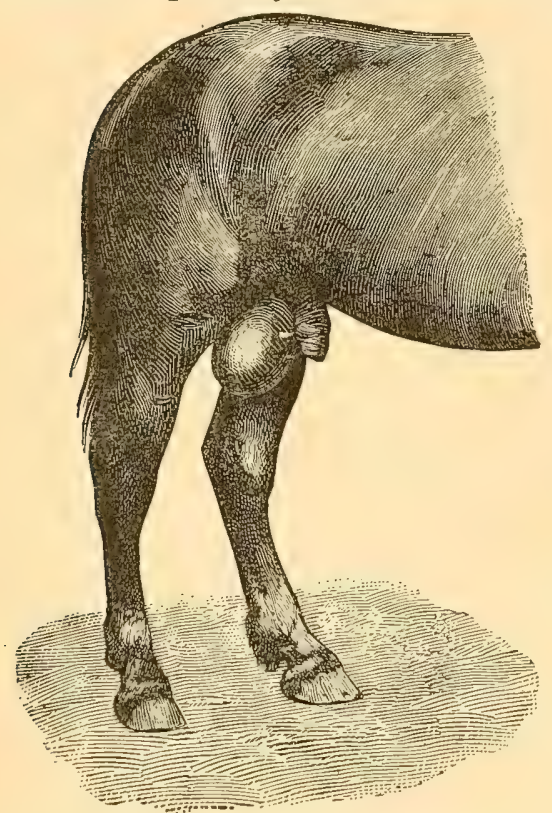

DROPSY OF THE TESTICLE (HY DROCELE).

Engraved for this Work from a Photograph. sac, and -worked around inside by manipulating the skin, the surplus being then allowed to run out:

No. 49. Tincture of iodine, 1 ounce. Pure water, 3 onnces. Mix, and inject a little.

The above may cause signs of uneasiness in the animal, but these will soon pass off.

\section{Varicose Veins.}

Varicose veins-an enlargement of the spermatic veins that carry the blood from the testicles-are of rare occurrence among horses. They ean readily be distinguished by their peculiar wormy feeling. As they cause no inconvenience, no treatment is necessary, and the only reason we mention them is to relieve the reader from any apprehension in case he should discover this condition in a stallion belonging to him.

\section{Castration.}

This consists in removing the two tosticles or seeds-the esseritial organs-from the scrotum, or sac, of the male. There is a difference of opinion as to the proper age to castrate. Some farmers do it at the same age as they do calves, or alout the fourth or fifth month. But this is a mistake; the proper age is from one to two years old. When the colt is poorly developed, he should be allowed to run until the hegimning of his third year, though there is no diffeulty in performing the operation at any age. 
As to the best time of year, this is in early summer, when fresh grass is available, and before the fly season has commenced. Good, clear and settled warm weather is essential. Rapid changes of temperature, thunder-storms, etc., are indications against operating, such as no careful owner will disregard.

The colt should be in good but not high condition. It is always

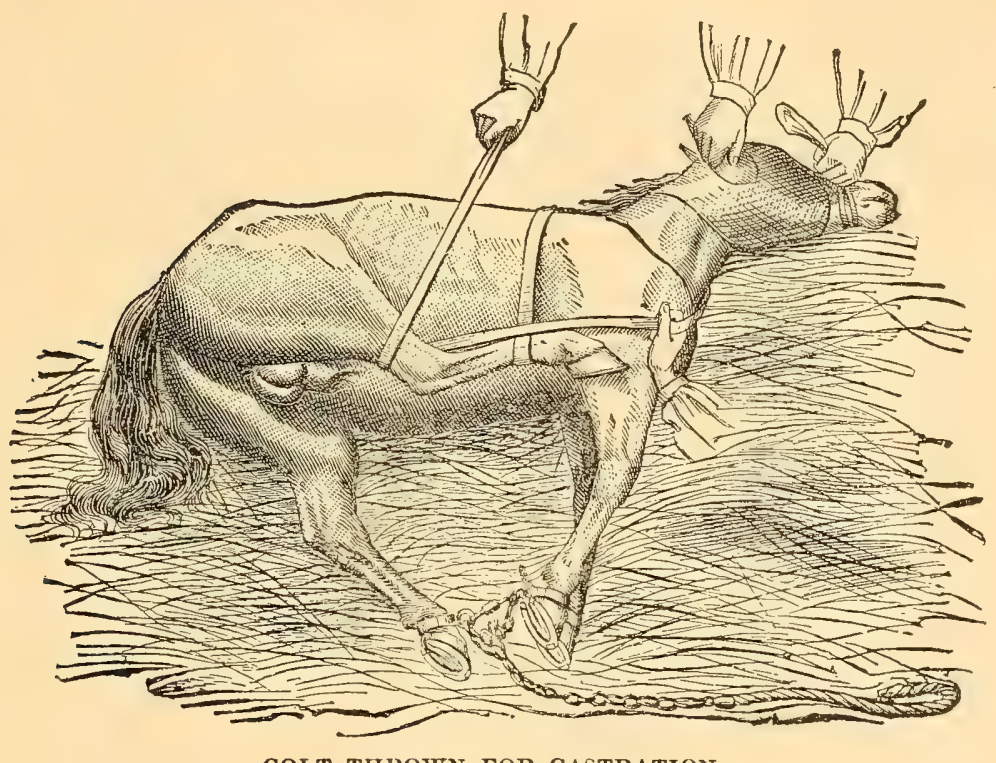

COLT THIOWN FOR CASTRATION.

well (though not considered essential) to prepare him for the operation by opening the bowels by means of a laxative diet. In case any epidemic disease is prevalent in the vicinity, it will be best to postpone the cutting, as the wound is likely to become infected.

Before commencing, the operator should examine the sac, and see that no scrotal hernia is present. If there is such, it will appear as a doughy swelling of the scrotum, that increases in size whenever the colt is made to cough.

The Standing Operation.-Castration may be performed with the animal either standing or lying down, and as each method has its advocates, we will consider both. For the standing operation, if the animal is very irritable, some soothing drug may be given ten minutes before commencing. Tincture of opium or chloral hydrate, in half ounce doses, in a little water, will, either of them, serve this purpose. 
In the actual operation the animal is usually approached from the left side. The scrotum is cut through with the castrating knife (in manner as will presently be described), or a pair of scissors may be used, and have the advantage of being quicker handled, with less

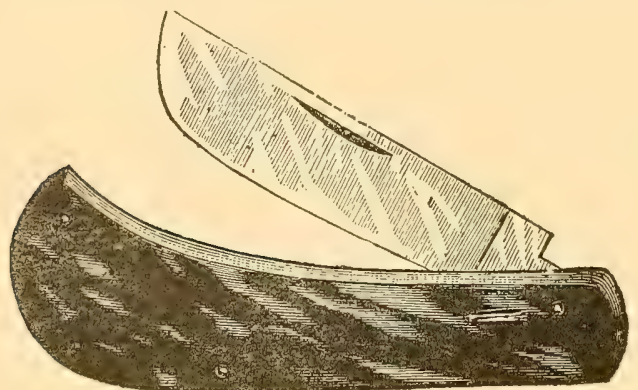

CASTRATING KNIFE. danger of injuring the testicle, which would cause great and needless pain. After severing the scrotum, the operation is finished with the clamps, ecraseur, or ligature -whichever may be preferred-as we will explain shortly.

Lying Down.-To castrate with the animal lying down, one of the various methods of casting will have to be chosen. For young animals the side lines, as shown in the illustration, are a favorite means, but the hobbles, and the straps of the Rarey method are also used. After the colt has been cast, the scrotum, or sac, and the sheath, should be washed with luke-warm water and castile soap. Then the testicle-one at a time-is grasped between the thumb and first finger of the left hand, with the skin tight and smooth, and with

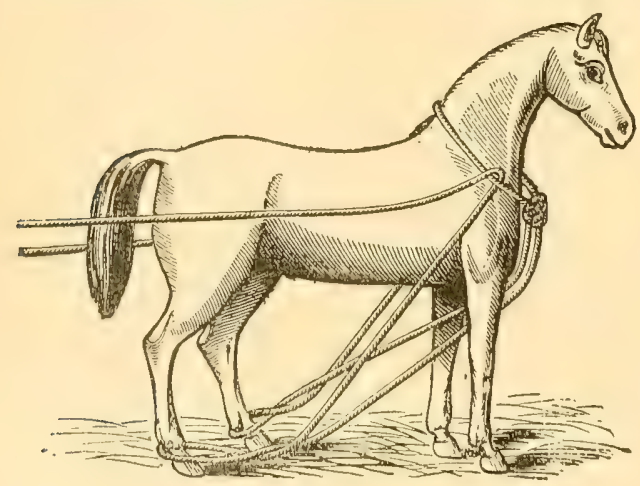

SIDE LINES FOR CASTING A COLT. the castrating knife held in the right hand, a cut from three to four inches long is made close to the middle line of the sac, which is known by the small ridge down the centre. When the cut is made in this place, it allows of good drainage of the matter that will form. The operator should be very careful not to cut the testicle, thus causing unnecessary suffering. The actual extirpation of the seed, which has yet to be acemplished, may be done with the elamps, actual eautery, ligature, scraping, or by the ecraseur. It will be best to consider these methods separately. 
Clamps.-The use of clamps is the old-fashioned way, and though now almost abandoned by educated veterinarians, it is still very extensively practiced in the farming districts. We show the best form of a wooden clamp in the annexed cut. The testicle having been exposed, the clamps are placed on the cord that hold them in position, and the ends of the sticks tightly tied with strong twine. See that the clamp is placed so as to remove the small lump of vessels along the top of the seed, as shown in the next illustration. The seed may either be allowed to slough off, or it may be cut off with a knife.

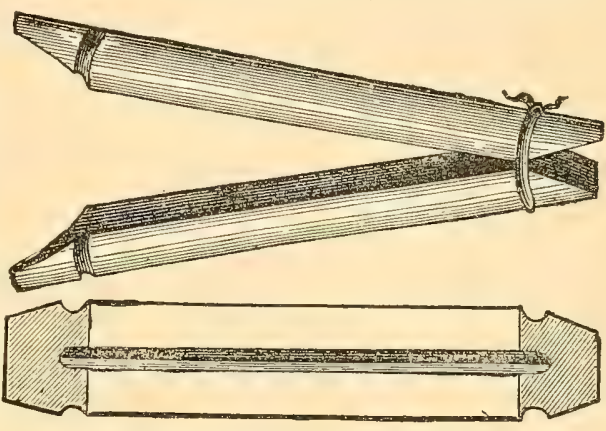

WOONEN CLAMPS.

Actual Cautery.-In this method the clamps are used as already described (their position, when tied is shown in the illustration), but the cord, instead of being left to slough away, is burned off with a hot iron. This stops bleeding.

The Ligature.-A long, stout piece of twine is tied around the cord at the same point as that at which the clamps are applied, as shown above. Then the testicle is cut or burned off, and the long ends of the twine are allowed to

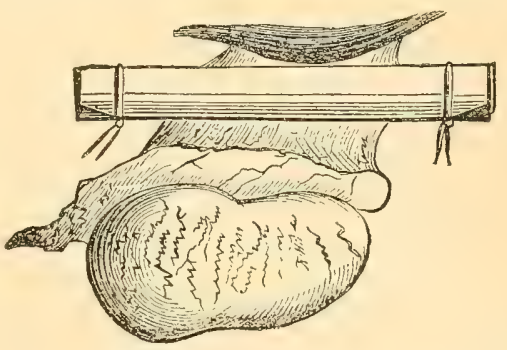

CLAUP ON THE TESTICLE。 remain until the slough removes them.

Scraping.-This consists in gradually scraping through the cord with a blunt knife. This is a very good method when the work is properly done.

The Ecraseur.-This is the simple instrument used by most veterinarians at the present time for effecting castration, which it does by gradually crushing off the vessels and cords. By this method there is hardly ever any bleeding, and after-complications are rare indeed. We show the latest and best form of the ecraseur in the illustration. By slowly turning the handle, the steel chain is gradually tightened, 
the vessels are crushed and torn apart, the ragged ends which thus result being unfavorable to hemorihage.

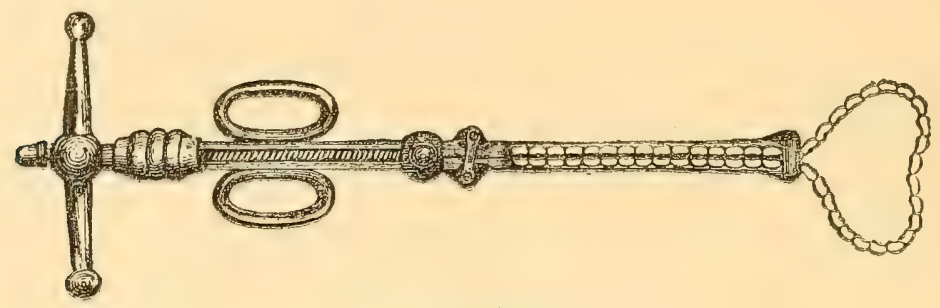

THE ECRASEUR.

Torsion.-This is a method largely used in France. The cord is held by a strong steel clamp, and the seed is seized by a pair of forceps and twisted off.

Russian Method.-In Russia, a common practice is to cut the vas

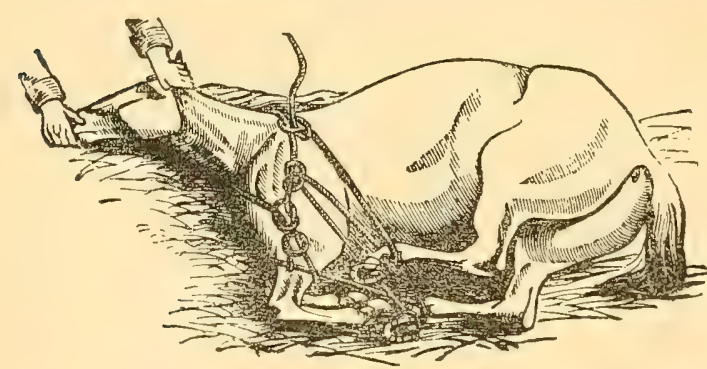

RUSSIAN METHOD OF CASTING. deferens (see engraving on page 18.9 ), the duct leading from the testiticle. This renders procreation impossible, but leaves the seed intact. In time the latter will grow somewhat smaller. This method must be held as crude and unsatisfactory.

IX. Castration of the Ridgling, or Cryptorchid.

Oecasionally a horse is found in which one or both testicles have not descended into the scrotum. Such an animal is known in many sections of the West and South ats a ridgling, and in the books ats a cryptorchid (literally, concealed or hidden testicle). Often, at one year old, one testicle will not have descended, yet it will do so during the second year.

In the most of ridglings the missing testicle, or oceasionally both testicles, are somewhere in the canal marked $C$, in the next illustration, though sometimes remaining still higher up in the abdominal cavity, as shown at $B$, intemal to the ring $D$. To castrate a ridgling reepuires considerable expertness, based, of course, on a good knowledge of the anatomy of the parts. Many operators in the country will not undertake it at all; but there is no great difliculty, when one knows how, provided the seed has passed out of the abdomen. 
The colt may be cast with the hobbles or side lines, as for the ordinary castration. The best position to get him into is on the back, as shown in the excellent engraving herewith presented.

If one testicle is down, first remove it in the regular way already described; then open the empty sac on the other side, pass the fingers inward and to the outer side, when the opening of the canal $\mathrm{C}$ will be felt. At this point the finger may be passed into the canal, and rery frequently the seed may be reached, drawn out, and removed by the ordinary method. But if it cannot be reached, the canal will have to

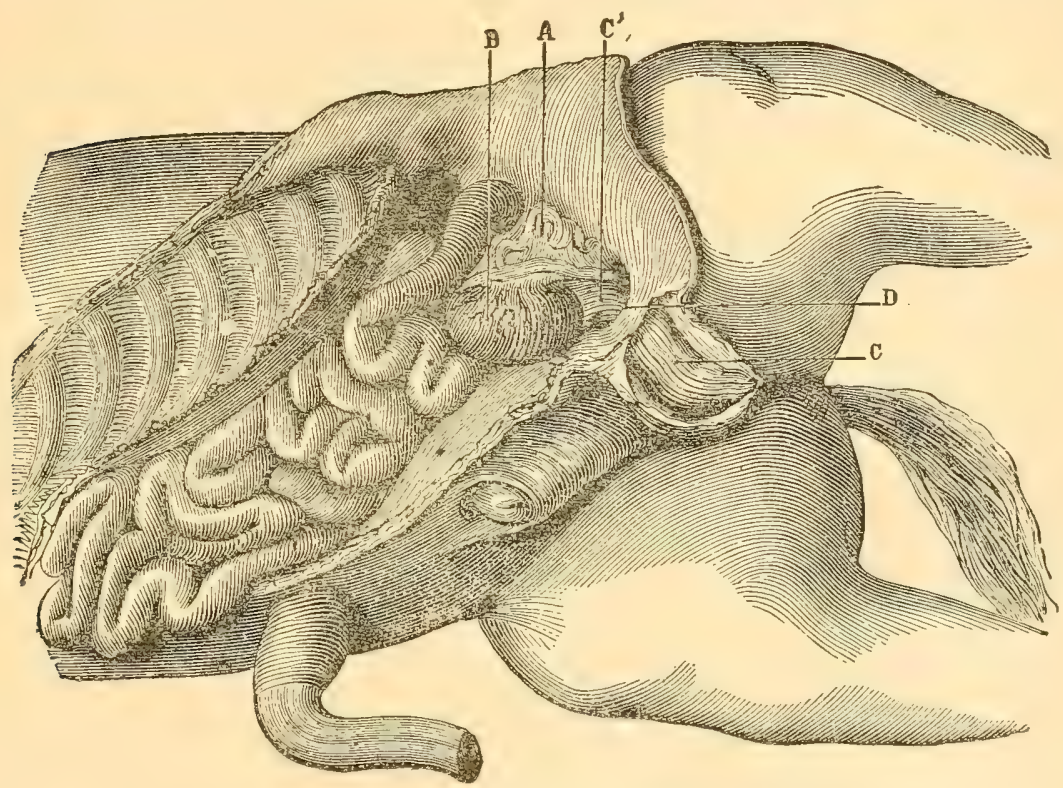

THE RIDGLING CAST ON HIS BACK.

Showing the position of the testicle, or seed.
B-The testicle.
C-The canal.
D-The ring.

be laid open with a knife, and the testicle grasped and removed the same as before.

When the testicle is still in the belly, its remoral is generally very dificult, and the results frequently fatal. The camal having been opened, the fingers are formed into a cone and used to dilate the ring $\mathrm{D}$, after which the fingers, or if necessary the whole hand, is passed into the cavity, the location of the seed, in the plurality of cases, being just in front of, and a little above, the ring $D$. The position 
is plainly indicated in the illustration at B. The seed may be gradually drawn through the ring and cut off by the ecraseur, which is the best way; or the clamps or ligature may be used, in manner as directed in the last section. A few stitches may afterwards be placed in the skin to guard against a hernia, which is always one of the greatest dangers in these cases.

\section{The Sequels of Castration.}

These, in unfavorable cases, may be hemorrhage, swelling of the sheath, hernia, indurated cord (or champignon), tetanus or peritonitis. Some of these, of course, are much more serious than others. We will consider them separately.

Hemorrhage.-This is readily stopped by bathing or showering the sac with cold water. This is mostly seen following the scraping method, and if it continues, the blood-vessel will need to be tied with a silk thread.

Swelling of the Sheath.-This is seen often; the sheath hangs pendulous, and has a shining look. Bathe it well with hot water. Open the bowels with the pill No. 20, and allow gentle exercise. If the opening has closed, break the adhesions with the finger. It may be necessary to lance the sheath in a number of different places.

Hernia. - This hats already been considered under a special heading, at the close of Chapter XXVI.

Tetanus.-Tetanus does not often appear until after recorery has taken place, or say four to five weeks after the operation. Re-open the sale at once, and remove the end of the cord, if within reach. Apply soothing ointments to the cord, such as the bellarlomma ointment, and in general adopt the same treatment as will be laid down for lockjaw in a later chapter.

Peritonitis.-Peritonitis may appear within a few hours after the operation, or at any time within two or three weeks. The symptoms are similar to colie, - the pulse hatrd and wiry, the belly tender to the touch, and the temperature elevated.

Treatment will consist in bathing the wound with warn water, applying hot eloths to the belly, and the other general treatment for colic. 
XI. Indurated Cord.

This, in the books, is also deseribed under the names champignon, schirrus cord, and sarcocele. It oftener follows castration by use of the clamps or the ligature, than the other methods. The opening in the scrotum fails to close, a slight swelling is seen, the end of the cord is enlarged, and sometimes will be found to have grown to the side of the sac. In the latter case break the cord loose, and remove the enlarged end with the clamps, or, still better, with the ecraseur. See that the opening in the sac is amply large to allow the free exit of the matter that forms. 


\section{CHAPTER XXX.}

\section{DISEASES, ETC., PECULIAR 'IO THF MARE.}

I. RUPTURE OF THE PERINEUM.- II. LEUCORRHEA, OR THE WHITES.--III. INFLAMMATION OF THE WOMB, OR METRITIS.-IV. ABOITION.- V. THE SEVEN PERIODS OF GESTATION.-VI. HEMORRHAGE, OR FLOODING OF THE WOMB.—VII. FALSE LABOIR PAINS.—-VIII. FALLING OF THE WOMB.IX. NYMPHOMANIA.-X. SPAYING, OR CASTRATION OF TIE MARE.-XI. EQUINE SYPHILIS,-XII. INFLAMMATION OF THE UDDEI, OR MAMMITIS.

\section{Rupture of the Perineum.}

This is occasionally seen among mares, from accidents in foaling or during copulation. It consists in a rupture of the skin and other tissues between the vulva and the rectum, making a common external opening for the digestive and urinary systems.

Treatment.- The tearing of the parts is so severe, and the passage of dung and urine so constant, that repair by sewing is almost impossible, and if sewing is attempted, it should be done only by an experienced man. After a time many of these animals will sufficiently recover to do ordinary work in the comntry, but they will never be able to stund driving on the crowded, hard-pared streets of a city. Mares thus injured have, in a number of recorded cases, produced healthy foals, but they are liable to receive serious injury when being served.

\section{Leucorrhœa, or the Whites.}

The discharge which gives name to this disease is the product of infammation of the ragina (see 3 , in the illustration on page 399.) It is given off at frecpuent intervals, often in linge quantifice, and is a whitish fluid, in sone cases quite fetid. When this condition continues for any eonsiderable longth of time, the animal falls off in condition, sweats very easily, and becomes unfit for work. She may become pregnant, but will very seldom carry the foetus the full time, abortion being extremely likely to oceur.

Treatment.-First thoreughly sringe ont the vagina with lukewarm water two or three times a day, then inject the Lotion No. 1, 
or No. 12. If the discharge continues, substitute the lotion following:

No. 50.

$$
\begin{aligned}
& \text { Sulphate of zine, } 1 \text { ounce. } \\
& \text { Tincture of opium, } 1 \text { ounce. } \\
& \begin{array}{l}
\text { Water, } \\
\text { Mix. }
\end{array}
\end{aligned}
$$

Use after the syringing directed above.

The Speculum.-In this, as in various other troubles of the mare, the vaginal speculum, shown in the accompanying cut, is of great advantage; the inflamed portions of the vagina will be seen, and can very readily be painted with the tincture of iodine erery second day, or with a weak solution of caustic silver. As, however, this instru-

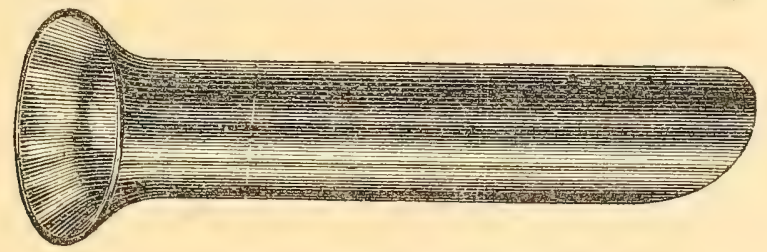

ROUND VAGINAL SPECULUM.

ment is not in general use, the treatment first mentioned will most generally be called for. The suggestion may, perhaps, be of service to some of our intelligent and thoughtful readers, that any round cylinder (even of tin, ete.,) so fashioned as not to bruise the delicate membrane, could be used instead of the practitioner's speculum.

The general health will need to be improved by good, nutritious food, and the use of the Tonic Powders No. 19 in the feed.

\section{Inflammation of the Womb, or Metritis.}

This may follow either an easy or difficult parturition, or an abortion, or may result from a hard drive before foaling, or from slipping.

Symptoms. - The mare is first noticed not to eat; the pulse is quickened, and a high fever may set in. Uneasiness, and looking round at the flanks, arching of the back, with violent straining, are all seen precisely as shown in the next illustration, "Advancing Symptoms of Abortion," and a black, bloody discharge may be forced through the vulva. On pressing over the loins, the mare will flinch and groan. These symptoms, put into connection with the antecedent of a heary drive, or some injury, will effectually determine for the farmer what the trouble is. 
Treatment.-Reduce the fever with No. 45, or any of the ferer mixtures given in the "Recapitulation of Remedies." If the pain is very severe, give half ounce doses of tincture of opium every hour.

Syringe out the womb with luke-warm water, and afterwards with No. 1, or No. 12. Place hot blankets, or poultices, over the loins, being careful to change them as fast as they cool. In spite of the best attention, this ailment, when the mare is with foal, is extremely likely to result in abortion.

\section{Abortion.}

An abortion is said to take place when the fotus is expelled before its organs are sufficiently developed to carry on the vital functions. It will be both scientific and practically convenient to consider abortion under two different heads, namely, (1) sporadic, or accidental, and (2) enzoötic, or contagious. The former variety occurs as a few scattered cases, here and there, from a number of different causes that can generally be pointed out; the latter when large numbers of different animals on a farm or in a given district are affected, evidently from the same cause, which is generally difficult to locate.

Causes.-Sporadic abortion is due to a great variety of very different circumstances, which can barely be enumerated here, such as changes of the weather; sudden chills; all sorts of indigestible foods, particularly those which are excessively dry and innutritious, or which have been frozen, or become musty; certain plants, such as ergotized grain (rye) and grasses, rue, horse tail, beet root leaves; purgatives; excessive muscular exertion; injuries, blows, or kicks in the abdomen; excitement; rarious serious internal diseases as lung fever, asthma, inflamed bowels, womb, etc. Certain odors are likewise said to cause abortion, as also debility of the stallion from excessive service. Again, when the latter is disproportionately large and powerful, the mare, as many think, is prone to abort.

The contagious form of abortion is of a very serious nature. It is very difficult to get rid of, in the sense that a mare with foul, if brought into a shed or stable where it was rife long before, is liable to it. Some veterinarians seout the contagions theory of this disease, but it is nevertheless generally accepted by the veterinarians of the present day, because it accords better than any other theory with the observed facts when generalized. The fact of one animal aborting being followed by several others in the same stable-animals not in close 
proximity-points strongly in this direction, and especially if the first abortion has occurred in a mare newly introduced there. In favor of the contagious hypothesis are a great number of other reasons, some of them as strong as this one, which space will not permit us here to discuss. In regard to the contagious form of abortion spreading through a stable, a familiar fact already mentioned, it should be added that though about all the mares in the stable maly abort, they will not do this all at once, but one will follow the other at intervals of perhaps a week or ten days.

Symptoms.-The great majority of abortions come on at night, the animal having shown no signs of the approaching trouble; often she appears bright and hearty both before and after the accident. Abortion may take place at any period of gestation. In the accidental form it generally occurs during the first four periods (to be described in the next section), but in the contagious form usually from the fourth to the seventh month.

In some cases certain premonitory signs are seen that are fre-

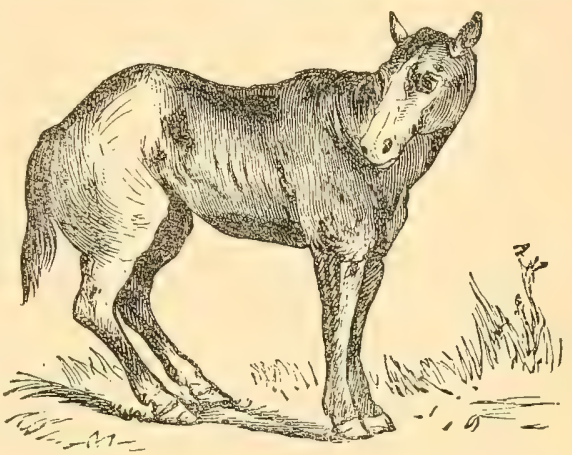

ADVANCING SYMPTOMS OF ABORTION. quently mistaken for indigestion,--loss of appetite, laziness, ferer, pawing, and a persistent switching of the tail. These are succeded in a variable time by violent straining and other well known symptoms of parturition. Happily, abortion in the mare is only occasionally followed by any very serious trouble.

Treatment.-When the food is the suspected cause, change it to an easily digested, laxative diet; when impure water, substitute the very best and cleanest that can be procured. When abortion assumes the contagious form, remove the animal that has aborted, and place her in a separate stable with a special attendant. Wash out the stall, and flush the drains, with some strong disinfectant solution. Our No. 73, or No. 74, will, either of them, be efficient.

When the mare is first observed to be uneasy, with other suspicious symptoms, ascertain if the fotus is alive, and if so give small doses of some narcotic, as tincture of opium-say a half ounce every hourwhile the signs persist. Keep the animal in some quiet, well rentilated 
place for two or three days. If the case goes on, however, until the water-bag has ruptured, the treatment must be changed immediately ; there is nothing now to do except to aid the expulsion of the fotus. (of course, the fererish symptoms that follow should be appropriately treated.

A mare that has once aborted should not be put to the stallion again for at least one year; in fact, the best plan will be to allow two full seasons to pass before so doing.

\section{The Seven Periods of Gestation.}

The question of the age of the fwetus is often an interesting or even important one to decide, in cases such as we have been convidering. We, therefore, insert a succinct account of the seren periods of gestation, as they are given in the very valuable work of Fleming. The following abstract gives all the known information on this subject.

"First Period.-Towards the second week after conception, the ovum, or germ, has passed from the ovary into the uterus; it is then ahout one-twelfth of an inch in diameter.

"Second Period.-In the third and fourth weeks of gestation in the mare, cow and pig, there appear the first traces of the embryo, and the head, body and limbs can be distinguished. Towards the 28th day the embryo of the mare measures abont six lines ( $\frac{1}{2}$ inch), and that of the cow 4 lines ( $\frac{1}{3}$ inch); that of the sheep at 25 days is $4 \frac{1}{2}$ lines, and of the bitch at 18 days is two lines ( $\frac{7}{6}$ inch).

"Third Period.-This is from the ifth to eighth week with the mare and cow ; the fifth to the serenth with the sheep and goat; and the fourth to the sixth with the pig. The embryo of the mare his now acouired a length of rather more than 2 inches; that of the cow 13 inches, of the sheep and goat $1 \frac{1}{4}$ inches, of the pig 1 inches, and of the bitch one inch.

"Fourth Period.--This is from the ninth to the thirteenth week with the mare; the ninth to the twelfth with the cow; the serenth to the eighth and ninth with the sheep and goat; and the sixth to the eighth with the pig. The length of the foetus of the mare is 6 inches, of the cow $5 \frac{1}{3}$ inches, of the small ruminants $3 \frac{1}{2}$ inches, of the pig 3 inches, of the $\log 2.1$ inches.

"Fifth Period.-This extends from the fourteenth to the wentysecond week with the mare, the thirteenth to the twentieth with the cow; the tenth to the thirteenth in the sheep and goat; and the eighth to the tenth in the pig. At this stage the fotus of the mare 
is about 13 inches long; that of the cow is 12 inches long, of the sheep and goat 6 inches, of the pig 5 inches, and of the bitch $3 \frac{1}{2}$ inches.

"Sixth Period.-From the twenty-third to the thirty-fourth week in the mare, the twenty-first to the thirty-second in the cow, the thirteenth to the eighteenth in the sheep and goat, and the eleventh to the fifteenth in the pig. The foetus of the mare by the end of this period has acquired a length of more than 2 feet, and that of the cow nearly the same; the fotus of the sheep is more than a foot; that of the pig is about 7 inches, and of the bitch 5 inches.

"Seventh Period.-This covers the remaining interval up to parturition; that is, the thirty-fifth to the forty-eighth week in the mare, the thirty-third to the fortieth week in the cow, the nineteenth to the twenty-first in the sheep and goat, the fifteenth to the serenteenth in the pig, the ninth week in the bitch, and the eighth week in the cat.

"A newly born foal measures, on an average, about 31 feet long, a calf 2 feet, a lamb $1 \frac{1}{2}$ feet, a pig 9 or 10 inches, a puppy 6 to 8 inches, a kitten about five inches long."

\section{Hemorrhage, or Flooding, of the Womb.}

This is of rare occurrence among animals, compared with the human species. It is generally the sequel of difficult parturition, abortion, or retention of the membranes, the womb or its blood-ressels failing to contract.

Symptoms.-These are not always clearly manifested. In many cases the bleeding is internal, while in others dark colored blood and clots are expelled, making the diaguosis quite easy. Where there are other symptoms suggestive that the case in hand may be one of internal and concealed hemorrhage, the uterus (womb) should be explored by the hand.

In consequence of the loss of blood, the heart becomes weak in its action, and beats irregularly. This condition is easily recognized by the quick and small, or in a bad case even imperceptible, pulse. The different visible membranes (the eye, nose, and vulva) have a blanched appearance, instead of the delicate rose color of health. Weakness and staggering come on, cold sweat breaks ont all orer the body, the ears and legs grow very cold, and finally comes on the most common of the fatal endings of hor'se diseases, - hagendrexpression of comntenance, convulsions, and death. 
Treatment.-Stop the flooding as quick as possible. To accomplish this, apply cold blankets to the loins. If there is much apparent weakness, give lurge doses of brandy. The following prescription will be of great service in checking the flooding:

$$
\begin{aligned}
& \text { No.51. Acetate of lead, } 1 \text { ounce. } \\
& \text { 'lincture of opium, } 5 \text { ounces. } \\
& \text { Water, to make } 1 \text { pint. } \\
& \text { Mix. }
\end{aligned}
$$

Give a wineglassful, in a half pint of water, every hour, as needed.

A day or two after the flooding has been checked, the womb may need to be syringed out to remore the clotted, and by this time decomposing, blood.

\section{False Labor Pains.}

These are pains that come on after foaling, the animal straining and looking around at the flanks, in the same manner as during actual parturition. Often they are due to the retention of the mem-

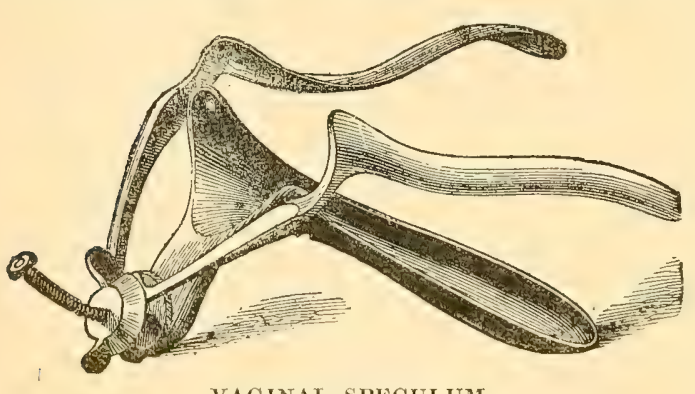

VAGINAT, SPECUI,UM. branes, or from injury of the walls of the womb or vagina. The speculum, such as is here illustrated, or the simpler form shown on page 391 , is the instrument a professional veterinarian will use, in such a case, to detect the cause.

Treatment.-Examine the uterus (with the speculum, or else the hand), and if any membrane is found to have been retained, gently remove it. Apply hot cloths to the loins, and give the Cramp Colic Drench No. 33.

\section{Falling of the Womb.}

This aceident, also known as inversion of the uterus, is not so frequent in the mare as in the cow. On the other hand, the fatality among horses, when it does oceur, is estimated at about seventy-fire per cent., while among cors, it is only about fire per cent., a difference truly surprising.

Causes.-This trouble is usually seen after parturition, and it is as common after an easy as it is after a difficult labor. Weakness, de- 
bility of the system generally, is supposed to be the superinducing cause; or, at other times, a slackness of the ligaments that hold the womb in position; violent pulling at some retained membranes; noncontraction of the womb after foaling; or any one of a host of other accidents of a similar nature.

Symptoms. - The womb may not be visible externally at first, but can be felt as a soft mass in the vagina. This soft mass is often mistaken for retained membranes, and the injury complicated by violent efforts to extract it. In consequence of straining, and the backward pressure of the bowels, it will not be many hours, however, before the appearance of the womb-externally. Sometimes it shows as a small round bulging between the vulva; at other times, much larger, even to an immense protrusion that reaches as low as the hock. This is liable to become covered with dirt by lying down, or to be torn by being stepped on, or even eaten by cats, rats or dogs. Unless help is given, the mass soon begins to smell, the circulation stops, and eventually gangrene occurs - that is the death of the protruded parts first, and later of the sufferer herself. Fever, pain and quickened pulse and breathing all appear soon after the complete falling of the womb, together indicating a serious condition.

Treatment.-Obviously this consists in adopting measures to return the organ to its place, and retain it there. If the womb has protruded no further than the lips of the vulva, the return may be effected by pressing it back with the closed fist. Sereral wraps of a rope around the body will aid in preventing straining. In case the latter is severe it must be controlled by medication; give a half ounce of either tincture of opium or chloral hydrate, dissolved in water, and repeat this dose as required by the urgency of the symptoms. The most effectual way of reducing straining, howevor, is by administering chloroform, according to the rules given in Chapter XXXIX. The hind quarter's should be kept higher than the fore, to diminish the pressure of the bowels upon the womb.

When the womb is hanging far out, covered with dirt, and swollen, it should be supported on a clean sheet; all dirt carefully sponged off, and the swelling reduced by the use of ice-cold water, used either as a spray, or else held in a bucket, and the whole mass be placed in it for ten or fifteen minutes. The expedients already enumerated for controlling the straining should be tried. If the animal is too weak to stand, some stimulant should be given, as the standing position is 
the best; if still unable to stand, the hips must be elevated with bundles of straw or soft hay, and the bedding taken from under the belly.

To return the protrusion, have it on a level with the lips of the vulva, and then commence to press the innermost part in. It is a tedi ous process, requiring both time and patience, but it must be persevered in.

During straining, the part already returned must he held firmly in position with the fist, and the replating recommeneed only when the straining disappears. When the entire organ is replaced in the vagina, the fist may be applied to the centre of the mass, to press it in further; or, when this point is reached, the organ may perhaps complete the work of replacement itself. The return haring been effected, the hand should be inserted, and all the folds that cam be felt in the uterus be smoothed out, as otherwise they will be likely to cause more straining.

The after-treatment will consist in allowing quiet and rest for two weeks or more, and keeping the hind parts elevated for several days.

\section{Nymphomania.}

This is a condition in which the mare is continually in season. She will take the stallion every day or two, if permitted, yet does not become pregnant. Congestion of the ovaries, or of the clitoris, is commonly the exciting cause. When the trouble is of long standing, the mare not unfrequently becomes dangerously wicked, the continual discharge is disgusting, and, take it altogether, she is well nigh useless.

Treatment.-The treatment usually laid down in the books is to excise the clitoris, or, if the ovaries are believed to be the reat of the congestion, to spay in manner as directed in the next section.

Our advice is that before proceding to either course, the following drench be tried for several days, as in some cases the trouble is susceptible of removal by medication.

No. 52.

Bromide of potash, 3 ounces.

Pure water, 1 pint.

Mix.

Give a wineglassful three or four times a day.

X. Spaying, or the Castration of the Mare.

Fipaying eonsists in removing the essential oreans of generation,the vrarics. It is the counterpart of castration in the stallion. When 
the mare is spayed, the object, generally, is to cure nymphomania, or some other disease peculiar to her sex. The effect of this operation upon a ferocious animal is often very marked; she soon becomes docile and easily managed. In case of the cow, if the operation is performed after the third or fourth calf (the hest time), both the quantity and quality of the milk is improved, and the flow will continue thus from eighteen to twenty-four month. Besides this, she will then readily lay on a great deal of fat; as beef, her flesh is tender and juicy, and she will bring considerably more money when

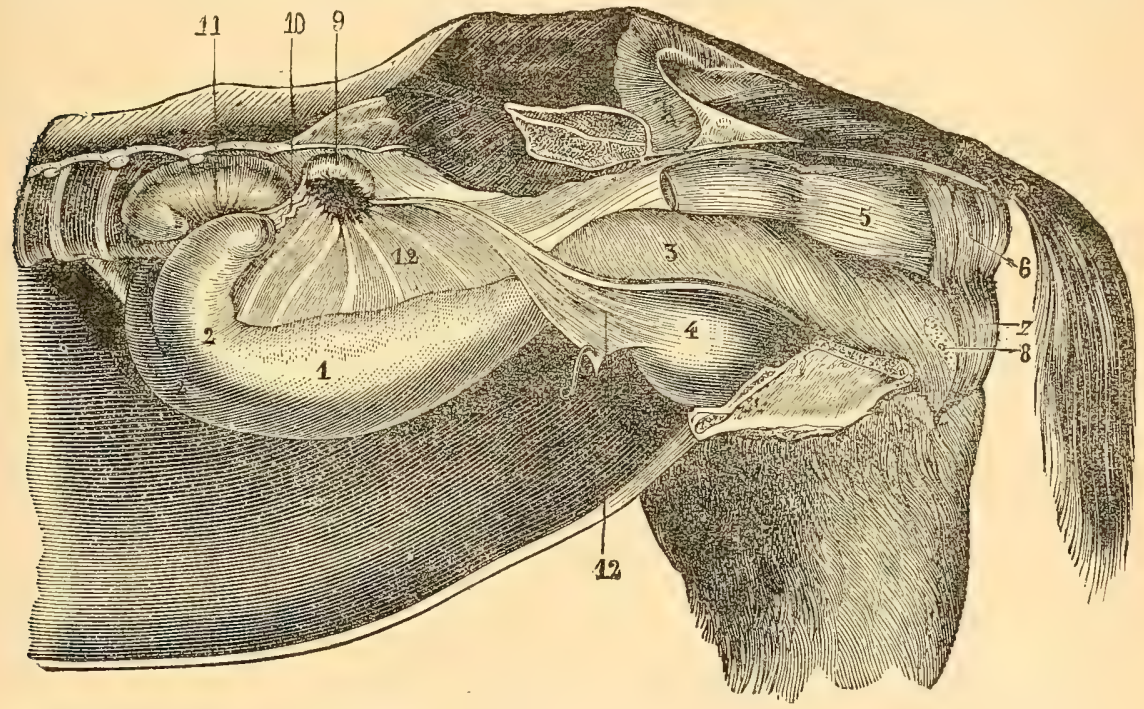

THE POSITION OF THE ORGANS OF THE MARE.

1-Uterus.

2-Horn of uterus.

3-Vagina.

4-Bladder.
5-Rectum.

7, s-Vulva.

9-Ovary.

11-Kidney.

sold to the butcher. Of course, she can never produce any more calves.

There are two methods of operating in spaying, (1) through the flank, and (2) through the vagina. The former method requires only a knife and an ecraseur ( see cut on page 386), or a linife and a silk thread for a ligature, and is the easier one, particularly so for the inexperienced operator. The animal is most easily worked on when she is in the standing position, with the feet hobbled, the head held by a twitch, and the body pressed against the wall. The left is the 
flank usually chosen.

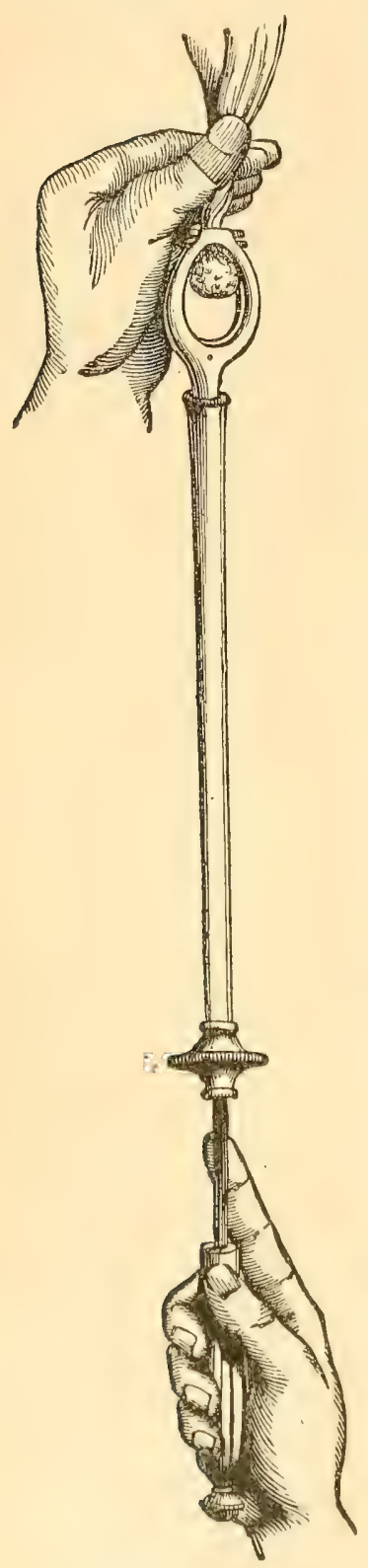

TORSION FORCEPS.

Showing mamner of holding and using them.
A vertical incision in the upper part of this region is made, sufficiently long to admit the hand, which is passed in and upwards; the horn of the uterus will be felt just below the rectum, as shown in the engraving, and, at the extremity of the horn, the egg-shaped ovary. The ovary is drawn out of the opening and removed with the escraseur, or by using a silk ligature and cutting it off with the scissors. Thus the left ovary is extirpated: The right is next to be felt for at the other horn of the uterus, and drawn out and removed in the same way.

Spaying through the vagina requires special instruments; the principal are a concealed knife, the torsion forceps shown below, or the ecraseur, or ligature. It being too difficult an operation for any one not an expert, our description of it will purposely be condensed. The place where the opening is made is the vagina, at a point just behind the neck of the womb, at the top of the cavity. The opening needs to be about two and one-half inches long, and parallel with the cavity. Through it the finger is passed, and the ovary, when secured, is drawn into the opening and twisted off with the forceps (see illustration), or crushed off with the ecrasen, or cut off with the knife and the ressels ligatured. This process is then repeated on the opposite side. There are other instruments for dilating the vagina, and for guiding to the place to cut, that we have not described; they are very costly, and of no use to the average horse owner.

\section{Equine Syphilis.}

The French name of this disease is maladie du coit. It is also known as contagious eczema, epizootic chancre, ete. It is a peculiar contagious disease affecting the stallion and mare, the callse of which is still in doubt; hut it has many symp- 
toms that closely resemble those of syphilis in the human species. It has a specific well-identified history. First found, or at least first reported of, in Russia, in 1796, it has since spread to Germany, France and other continental countries, and Africa, Egypt, ete. Though not yet known to have invaded Great Britain, Spain or Belgium, it was unfortunately introduced into America, through the importation of diseased French stallions to Illinois.

Symptoms.-The symptoms are both local and general. The general symptoms are the same for both sexes. The various mucous membranes are specially involved, the nose and eyes both discharge, and the glands around the jaw are enlarged. The appetite is good, yet the animal falls off in condition, becomes hide-bound and weak, and the sweat possesses a very offensive odor. A little later the limbs and joints swell, and lameness makes movement difficult; but this trouble may be intermittent. The back also shows weakness, and if pressed on forcibly the animal may fall. Small tumors or lumps appear suddenly in the skin; these may disappear quickly and suddenly, or last for a week or ten days. The last stage of the disease is usually characterized by paralysis of the limbs, and perhaps the lips may also be affected.

The local symptoms, in the mare, are first seen shortly after copulation; they consist of irritation and stamping, and if the membrane of the vagina is examined, it appears red and inflamed. This is followed by the discharge of a thick, vile-smelling fluid. Later the lips of the vulva, the surrounding parts and the milk glands will become swollen; the membrane of the vagina will be swollen, and show small excoriations and ulcers, its color, at the same time, being a peculiar marbled one; and the water will be passed with difficulty and evident pain. The mare very frequently aborts about the third month, or if the foal is carried the full time, it is generally born dead.

In the stallion, the only observable local sign may be a continual swelling of the sheath, persisting for months or even a year. When the penis is in a state of erection, the point may be greatly enlarged, and while the organ is naturally colorless, or nearly so, it will now show a marbled color, or have small violet spots scattered over the surface. In some cases the testicles show no signs of disease, but in others they are swollen and painful to the touch. 
Treatment.-The treatment with mercury, so very successful in the physician's practice, has no effect on this equine disease. In fact it is said, by eminent authorities, even to hasten a fatal termination. French scientists are said to have found that certain constituents of the blood-those composing the fibrin-are wanting, and these they have therefore supplied, by cooking horseflesh and dividing it up very fine, and giving about half a pound in the soup that it was boiled in, three times a day. Great success is claimed for this treatment; but it requires to be continued for an average time of about three months, and in some cases as long as six months.

The local treatment will consist in injecting the vagina of the mare, and bathing the penis of the stallion, with a solution of sulphate of zinc, one drachm to a pint of water.

The stallion or mare thus affected should not be used for breeding purposes for a number of years. In fact, some authorities insist that they should never be used again.

\section{Inflammation of the Udder, or Mammitis.}

Inflammation of the milk glands, or udder, is not nearly as common in the mare as in the cow. It is most common very soon after foaling; but may also attack mares in high condition at almost any time. It is also seen, occasionally, as a result of blows or other injuries.

The entire gland is larely involved, but usually only one part, or section, which becomes tense and painful, and has a glossy look. In a severe case the mare will be very feverish, and when walking will keep the legs straddled wide apart.

Treatment.-The ghand should he bathed frepuenty with hot water; or, instead, hot flax-seed poultiees may be frecuently applied. Rub in the following liniment three times a day:

No. 53.

$$
\begin{aligned}
& \text { Extract of belladonna, } 1 / 2 \text { ounce. } \\
& \text { Linseed oil, } \\
& \quad \text { Mix. }
\end{aligned}
$$

It will always be well to try and support the swollen udder by some sort of a suspensory bandage, which mat casily he done by pasinge it over the loins. The milk should be drawn frecuently, the teat syphon being used, if necessary, to effect this. For the fever give any of the ferer mixtures recommended and prescribed in our "Recapitulation of Remedies."

If an abscess foms it must be lanced, and the matter allowed to discharge; after that, adopt the ordinary treatment for wounds. 


\title{
CHAPTER XXXI.
}

\author{
PARTURITION.
}

I. NATURAL PARTURITION.—II. DIFFERENT PRESENTATIONS.—-III. ATTENTION TO THE MOTHEL.-IV. ATTENTION TO THE HOAL.—V. DIFEICULT PARTURITIONS IN THE MARE AND COW COMPARED.—-VI. DIFFICULTIES DUE TO THE MOTHER.—VII. DIFFICULTIES DUE TO TIE FOAL.-VIIr. OBSTETRIC INSTRUMENTS. IX. WHEN THE FOAL IS BORN DEAD, OR THE AFTER-BIRTH RETAINED.

\section{Natural Parturition.}

This branch of our subject needs but little consideration, the various phases of labor being so well known to all breeders. However, a brief outline of the different stages of lahor will not be out of place.

Preliminary Stage.-This is announced by several well marked features. The milk glands of the mare, which are naturally small, become large, tense and painful; in many instances the swelling extends to the thighs up to the vulva, and along the belly to the breast bone. The vulva becomes enlarged, soft, and its inner lining of a bright red color. There is also a discharge of sticky mucus which lubricates the passage, and when in large quantity soils the hock and tail. The abdomen sinks near the critical period, giving the croup a sunken appearance.

Fleming, in his justly celebrated work on veterinary obstetrics, says: "As parturition draws nearer, these phenomena are more marked. The animal also begins to be restless, and continually agitated; if feeding, it stops for some moments, as if listening to some sound only audible to itself, or, as if experiencing some strange internal sensation for the first time, and which may be the commencing or preparatory contractions of the uterus. Not unfrequently the animal lies down and gets up again, as if suffering from colic. Some are quite mute, though amxious and measy; while of hers, in addition to exhibiting restlessness and distress, utter a half stifled 'ry of pain, and violently whisk the tail."

The position taken during labor in the mare and cow is usually the standing one, but the recumbent position, here illustrated, is not in403 
frequent; the mare, resting on the breast bone, strains and raises up somewhat on the hind legs at the same time.

Dilatation of the Neck of the Womb.-This commenced towards the latter part of the former stage. It is marked by increased signs of pain. It is a gradual process, the pain at first lasting for a few seconds; later, when the membrames are forcibly dilating the neck, it is continuous, the womb and vagina becoming, by the dilatation, one continuous cavity.

Expulsion of the Fœtus.-The water-bag, having dilated the neck of the womb, passed outward and appears at the vulva. The serere straining soon ruptures it, allowing the feet of the foetus to protrude. The head resting in most cases as described in the next section, aids

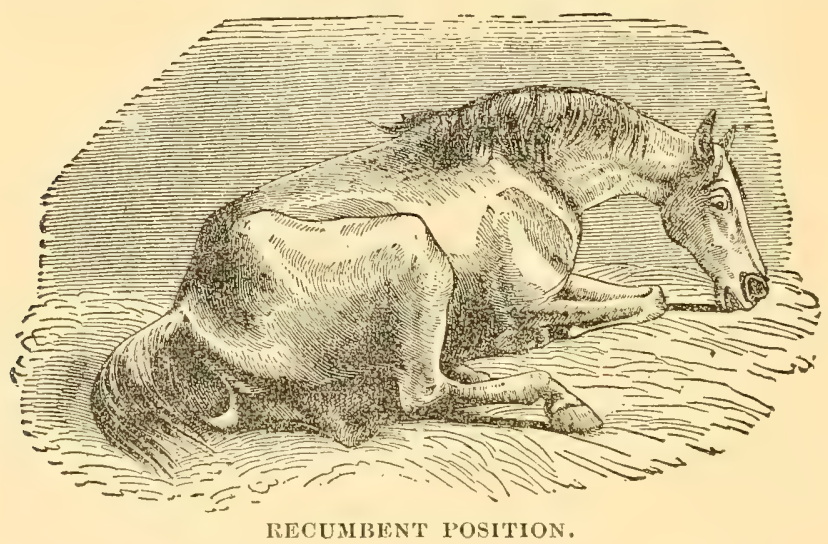

The large water-bag has just appeared.

in dilating the parts. Nature usually allows a short rest after foreing the head through, to prepare for the sererest part, the passage of the shoulders, after which all is easy. The mubilical cord is usually broken when the foal falls to the ground, and it is freed from its coverings.

Expulsion of the After-birth.-This usually takes place a few minutes after birth, but oceasionally not for a longer time. If not detached within a few hours it becomes a serious natter, as in removing it hemorrhage is liable to oceur. During and after the expulsion of the membrames, the womb rapidly eontrats and diminishes in size; the neek of the womb also grows smaller, and in a short time assumes normal proportions. 
In the cow, the placenta (after-birth) may be retained for one, two or three days without causing any trouble, owing to its formation being different from that of the mare.

\section{The Different Presentations.}

The variety of positions in which the foetus may be presented is surprising, but there are four presentations to which, because of their being by far the most frequent, we will call special attention, namely: (1) the head presenting, (2) the tail presenting, (3) the the right transverse position, and (4) the left transverse position.

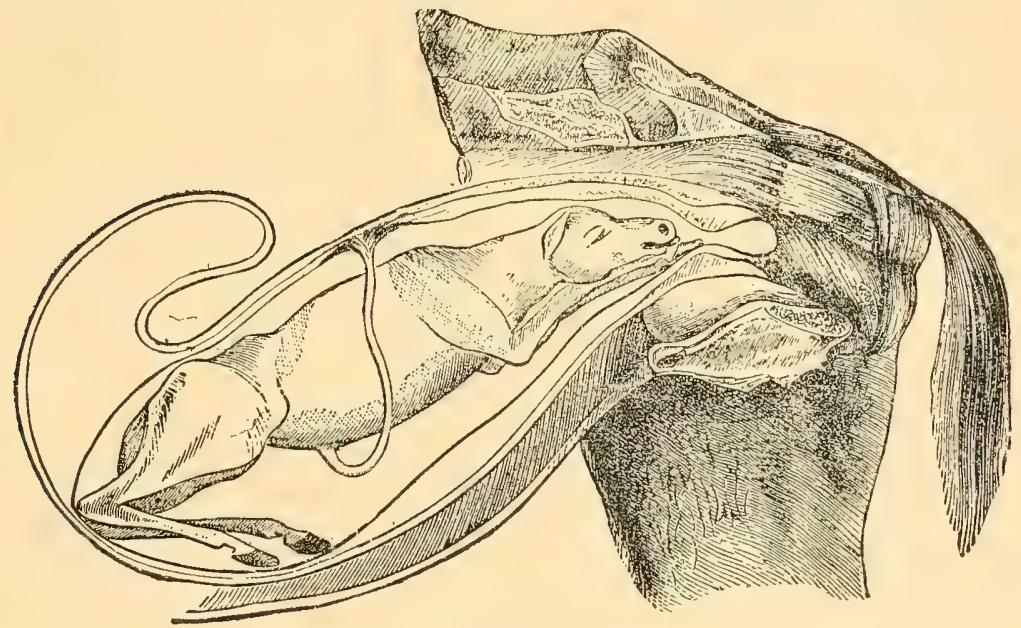

HEAD PRESENTATION.

Head Presentation.-This is the most common, and the one that is attended with the least difficulty. It is depicted with great accuracy in our illustration. The fore feet are extended, and the head rests upon them; thus they form a sort of cone, which acts as a dilator of the passage, greatly facilitating the delivery. Many authors claim this to be the only "natural" form of delivery.

Tail Presentation.-This is inother frequent form, yet much less so than the one just considered. Here the hind feet protrude, with the tail resting on them. This form of delivery is not as easy as the first, on account of there being no gradual dilatation to permit the passage of the large croup. It is easily recognized by feeling the hocks and the tail of the foetus. Our illustration of this position is of the cow, and to many of our readers will be the more useful for that reason. In the mare this presentation is exactly the same. 
Right Transverse Position.--This should not be considered a natural form (though many veterinarians think otherwise), but rather as a malpresentation. The head is turned to the right side of the mother. It may be distinguished by feeling the colt's withers, mane and head.

Left Transverse Position.-This is the reverse of the preceding. The position is head to the left, as may be recognized by feeling the colt's withers, and up along his neck.

All other presentations may, in a general way, be regarded as modifications of the four above described.

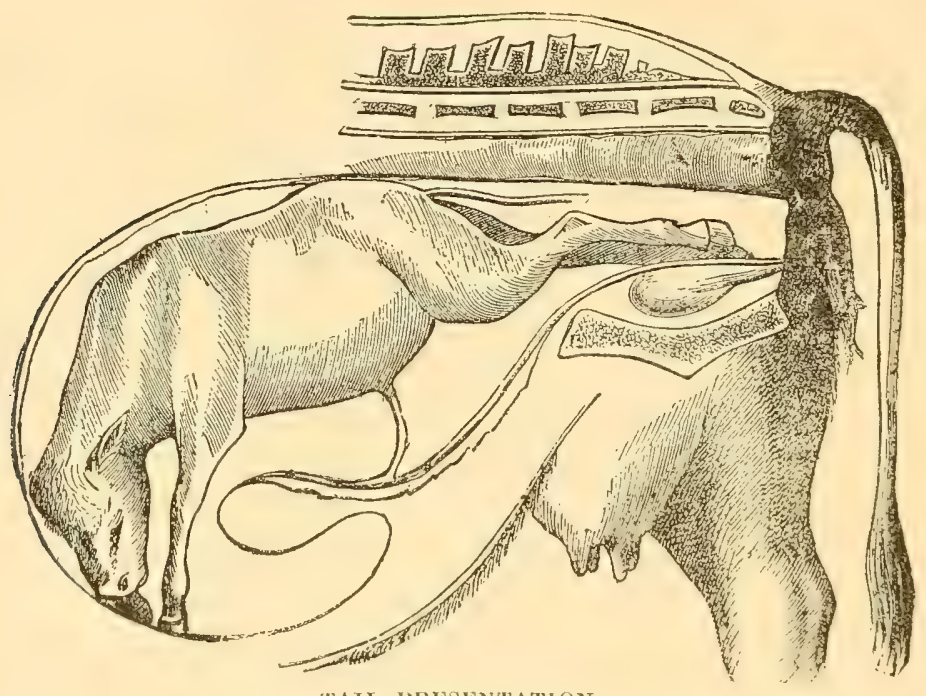

'TAIT, IRISHN'TATION.

III. Attention to the Mother.

In this section we shall simply run over a few leading itens as to the eare of the mother. For at least three or four weeks previous to the period of foaling, the mare shoukl be allowed gentle exereise, as a safeguard against abortion. As the eritical period approalches, she should be put in good condition, not positively fint, and not thin, and if her digestion is disordered, it should be treated as directed elsewhere in this work. Medieines, especially those violent in their action, are only to be used by experienced men, and even then with extreme caution.

No person should be allowed to stay within sight of a mare showing signs of foaling. Fiven the attendant should lieep in the back- 
ground, as this animal has a natural arersion to any one being present during delivery.

The stable should be warm, well ventilated, and free from drafts. A box stall is always advisable. A mare heavy with foal should never be tied in a stall, for if she should suddenly foal, she would be unable to clean the offspring, and, besides, during the labor, she might seriously injure herself.

If any marked weakness is shown after foaling, a dose of diluted whiskey is advisable. The after-birth is ordinarily passed within fifteen or twenty minutes, and while this is likely to be accompanied by additional pains of a colicky nature, they are not to be regarded as dangerous.

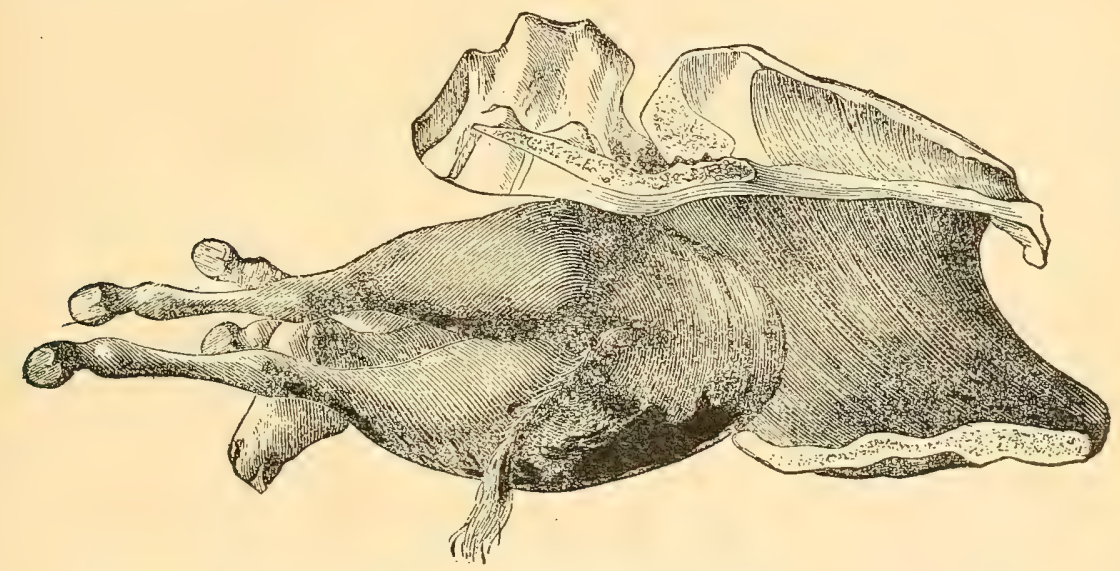

RIGHT TRANSVERSE POSITION.

\section{Attention to the Foal.}

Immediately the foal is born, the mother will clean it, and assist it to the teat. Occasionally it is passed still enwrapped in the membranes, and if these are not soon opened, it is liable to be asphyxiated. A careful inspection of the various openings of the body should be made to see that they are free; possibly the eyes, rectum, etc., mary be imperforate, necessitating eutting the skin over them.

When the mother neglects to clean the foal, it may be rubbed dry with a soft cloth, or by some similar method. If too weak to stand, support and hold it up to the teat; in many instances bandages to aid in strengthening the legs are of much benefit. Constipation is a frequent trouble in very young animals, but may readily be removed by the judicious use of a little castor oil. 


\section{Difficult Parturition in the Mare and Cow Compared.}

In the mare there is not often much difficulty in parturition. In the vast majority of instances no aid is needed to bring the delivery to a successful termination, and parturition is accomplished in a very short time, the whole process being completed within about half an hour. Compared with the cow, the mare's difficult labors have been placed by different authorities at only 1-10 to 1-25 as many. But what she gains by the rarity of her difficulties she loses in the very crious nature that they take when they do occur. Practical farmers and breeders, for whom this book is expressly written, will be interested in a comparison which has been formulated by Donnarieix, as follows:

MARE.

1. Delivery is often followed by insuccess.

2. A wound inflicted on the genital organs is generally fatal.

3. Inversion of the womb is nearly always irremediable.

4. Mares nearly always succumb to penetrating wounds of the abdomen during parturition.

5. Delivery of the most simple kind is occasionally followed by bad results. In abnormal and laborious parturitions not unfrequently mare and foal succumb.

6. Difficult parturition proves a herculean task to the operator.

7. The duration of the life of the fotus in a case of abnormal labor, does not extend beyond the fourth hour, on account of the young animal having to maintain its independent existence, as if already born.

8. The neek of the foal being very long, the head is usually found deeply buried in the flank whenever it is turned backward. 'T'he operator has very great difliculty in reaching the head with his hand; indeed, it is often impossible to bring it into its natural position. 'I'he loop slips off the neck of the lower jaw, and has constantly to be replaced; it is scarcely possible to fix a cord there, this portion of the jaw being so short, and the fotus having no teeth.
COW.

1. Delivery always terminates favorably.

2. A wound of these organs rarely causes death.

3. Inversion of the uterus is often curable.

4. This accident is generally not fatal in cows.

5. Delivery, even in the most complicated cases, generally proves comparatively easy, and obstetrical operations successful.

6. Such parturitions are not of much account to a practitioner skilled in the necessary operations.

7. Under the same circumstances the calf may live four or five days in the womb, as life is maintained by the large number of placental attachments. These differences are explained by the mechanism of fotal life in the two species of animals, as well as by the anatomy of the uterus and foetul membranes.

8. The neck of the foetus being shorter and thicker, the head is iess twisted, and the opcrator can with greater ease bring it back into its normal position; in addition there are teeth in the lower jaw, the neck of which is narrow; so that the slip-knot does not leave it, and straightening of the head and neck becomes an easy affair. 
9. When once the amniotic fluid has escaped, the introduction of the hand is difficult, owing to the genital organs becoming dry; this dryness causes an efflux of blood to the mucous membranes. The resistance made by the fotal membranes to manipulation, when made to ascertain either the position of the fotus, or for correcting the position, together with the struggles and violence of the mare, which now and then drops as if dead, are all difficulties to be overcome.
9. The genital organs are continually lubricated by a mucous fluid, which, while it facilitates the introduction of the hand, renders easy any necessary correction of position, and favors parturient operations. Besides, any movement made is not, in general, of much consequence.

\section{Difficulties Due to the Mother.}

The cause of difficult labor is not often found in the mare, but when it is the obstruction is generally of a serious character. Among the number may be mentioned fractures of the hip bones, which, by uniting badly have reduced the possible vaginal diameter; tumors on the bones; disease of the neck of the womb; twists of the womb; tumors in the womb, or the adjacent parts; stricture of the vulva, etc.

\section{Difficulties Due to the Foal.}

Ordinarily, the cause of difficult parturition is to be found in the foal. Malpresentations are, of course, the most common. Of these veterinary science has had to deal with an exceedingly large number, but principally with those forms in which the head is turned back or turned to one side, or the feet do not present properly. The head and tail presentations, both excellently illustrated by our artist, are the ordinary ones; the right or left transverse positions (see page 407) are necessarily sources of trouble. Under the head we are considering must likewise be mentioned excessive size of the foetus, its death, twins, too much fluid in the water-bag, monstrosities, deformities, etc.

\section{Obstetric Instruments.}

For the correction of a malpresentation, definite rules must be followed, and certain instruments are necessary.

When aid is given, always commence by securing the part that is presenting, with a rope; then insert the hand, to determine the cause of the difficulty. If due to the head or a foot being turned backward, bring it to a proper position before endeavoring to remove the foal. The instruments absolutely necessary are neither numerous or costly, a thin, strong, cotton rope, a sharp-pointed hook, a blunt-pointed 
hook, and a long iron rod with a cross-piece on the end, called a repeller. The last mentioned is exceedingly valuable for pushing away one part, to allow of another being secured, or to aid in turning the

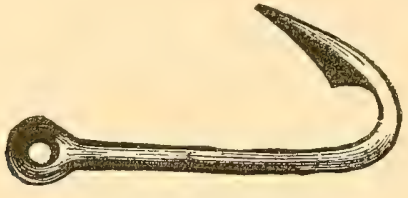

SHARP HOOK.

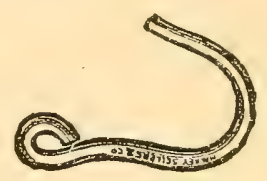

BLUNT HOOK.

foetus. The hooks are invaluable for taking firm hold of a part and helping to extract the foal; to the loop at the end a rope is attached.

IX. When the Foal is Born Dead, or the After-birth Retained.

In those cases already referred to, where death and decomposition of the foetus has occurred, or where the after-birth has been retained and become putrid, efficient antiseptic measures are necessary. Aftertreatment, such as is so prominent in the physician's practice, following difficult parturition, is never thought of in the veterinarian's. However, the copious use of lukewarm vaginal injections of a mild nature, are very requisite in the class of cases we are considering. No. 1, diluted with an equal amount of pure water, will be of signal benefit. An ordinary syringe will answer. From one to two quarts of the fluid should be injected into the vagina, whence it will graritate to the lowest parts, and render harmless the germs accompanying the decomposition. This may be repeated twice a day, for three or four days, by which time its healthy action will have become very apparent. 


\section{CHAPTER XXXII.}

\section{DISEASES OF THE NOSE AND THROAT.}

I. PREVALENCE OF THESE DISEASES.—II. CATARRH, OR COMMON COLD.-IIL. NASAL GLEET.—IV. NASAL POLYPUS.-V. NASAL HEMORRIIAGE, OR EPISTAXIS. - VI. LARYNGITIS, OR INFLAMMATION OF THE LARYNX.- VII, ROARING AND WHISTLING, OR LARYNGEAL PARALYSIS.

\section{Prevalence of These Diseases.}

Diseases of the nose, throat and respiratory organs are very common among the horses of our climate, which is so variable, and subject to such great extremes of temperature in a short time, that twentyfour hours is sometimes enough to plunge one from summer heat into the severity of winter. Perhaps the valley of the Mississippi has, in this respect, one of the least desirable climates within the temperate zone. During much of the year, also, the atmosphere is very damp, especially in the winter and spring seasons. The horse has nothing but the superior strength of his system, enabling him better to resist unfavorable influences, to entitle him to any exemption from most of the diseases of humanity, and this advantage is apt to be fully orerbalanced by the greater exposure he is compelled to undergo. Hence we find that the horse's throat and air-passages are as subject to disease as most other parts of his body, and nearly as much so as those of the human being in the same latitudes. .

\section{Catarrh, or Common Cold.}

This is the simplest and most common of the class of disorders under consideration, as well in the horse as with his master. When we consider the great and sometimes prolonged exposure of the horse, it is astonishing that he does not take cold more frequently than he does. There are many horse owners-and it is something for which every humane person must be thankful that their number is constantly increasing - who are as careful concerning their teams as the nature of their duties will permit; and who, knowing the advantages of good, sufficient, and regular feeding, of comfortable stables, and of 
warm blankets at the proper time, practically improve that knowledge in the habitual management and keeping of their stock. Such exemplify the Scriptural proverb that "a merciful man is merciful to his beast," and are repaid thrice over for their humanity in a direct pecuniary sense.

Symptoms.-The first sign noticed of approaching disease is sneezing. This is followed by dullness, and a general feverish condition, with, perhaps, more or less disinclination for food. The eyes water and a whitish discharge appears from the nose, which later turns thick and of a yellowish color. Cough is generally a prominent accompaniment, from the extension of the inflammation to the throat.

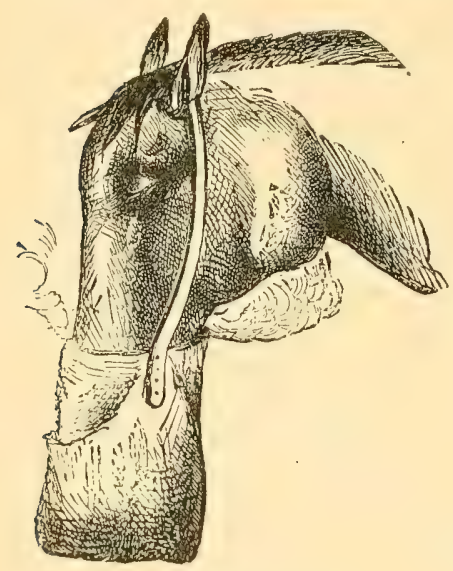

STEAMING BAG.

Treatment.-In an ordinary case this is very simple. Provide a comfortable stall, and if necessary cover the horse with a blanket. Let the diet be of soft and easily digested food. Allay the fever by administering any of the fever medicines that will be found in our "Recapitulation of Remedies." If the glands become much swollen, the steaming process which we illustrate will be very beneficial. It is easily accomplished by pouring boiling water on bran, and fastening the sack which holds the latter under the nostrils, or by holding the head orer a bucket of hot water in which some tincture of iodine

has been poured. This will afford the sufferer grateful relief.

For the relief of the cough, follow the treatment laid down for laryngitis, in Section VI of this chapter.

\section{Nasal Gleet.}

This disease has already been considered in Chapter XV. The importance of distinguishing it from glanders is too apparent to require further emphasizing.

\section{Nasal Polypus.}

This is a soft tumor that grow from the lining membrane of the nostril. Acting as an obstruction to breathing, it oceasions measiness in the horse, and produces a kind of snuflling. In time there is a discharge from the nostril, which may be tinged with blood. 
The tumor may not be noticed at first, but by its steady growth will presently become visible back of the nasal opening. This is the usual growth, but occasionally these tumors grow in the opposite direction, and extend into the pharynx; if of large size, they may even project into the larynx, making the animal seem a "roarer." Such a horse, in case of severe exertion, is liable to fall down from suffocation; but he will quickly recover, the larynx being cleared by the cough and the change of position. These things will be better understood after consulting pages 168 and 169 of this work.

Treatment.-This consists, of course, in removing the abnormal growth, which will be far less painful than most persons suppose, the reason being that the polypus is a structure of very low organization.

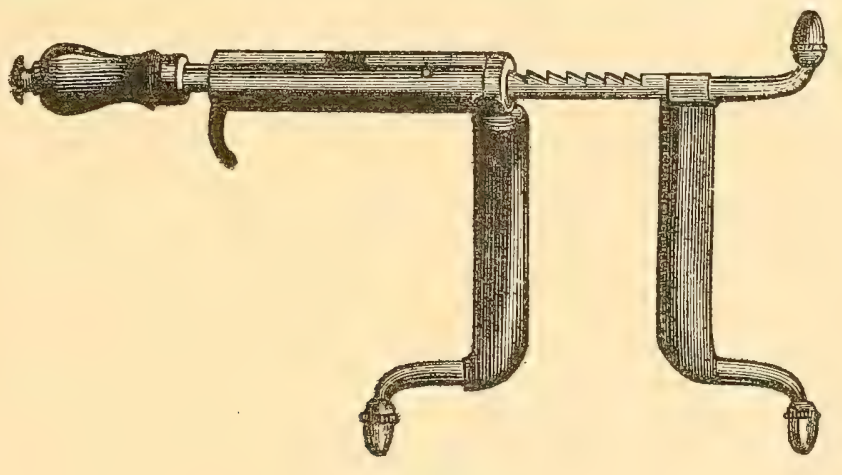

MOUTH SPECULUM.

When it projects into the nose, it may be grasped high up by a pair of forceps and gradually twisted off. When it projects into the pharynx, a mouth speculum will be very valuable in assuring the diagnosis, etc. This instrument is well illustrated in the foregoing ent. The tumor can be felt back of the soft palate. Fasten a loop of strong wire around its pediclè, and gradually pull it away.

The after-treatment will be quiet and rest for a few days, with the occasional use of the steaming bag.

\section{Nasal Hemorrhage, or Epistaxis.}

This is what is commonly known as nose-bleed.

Causes.- This may result from the rupture of a small blood-ressel in the nose, or from any injury that crushes in the bone. A ruptured vessel in a highly inflamed lung may likewise produce it; or it may be a symptom of other discases that break down the general system, such as glanders, etc. 
Symptoms. - When the hemorrhage is caused by some injury $t$, the nasal cavity, the blood usually issues from one nostril only. If the injured vessel is a large one, the flow will be continuous, but from small vessels it will collect inside, and form clots, which are sneezed or coughed out at irregular periods. When the ruptured vessel is in the lung, the blood will flow from both nostrils during painful fits of coughing, and it will be of a frothy character, from mixing with the respired air. On applying the ear to the chest, the bubbling of the blood in the air-tubes may be recognized. By noting the distinctions we have pointed out, any one can readily locate the seat of hemorrhage in the great majority of cases.

Treatment.-The use of cold applications is often of great benefit; likewise the plugging of the nostril with a picce of tow. When the hemorrhage is due to an injury and a depressed piece of bone, the latter must be elevated, or the bone may be trephined out. These processes are briefly described elsewhere, both requiring the skill and special appliances of a professional man.

When the bleeding is from the congented lungs, it is their relief to which treatment must be directed. The following drench should be given to check the flow.

No.54. Acetate of lead, 1 ounce.
Tincture of opium, 4 ounces.
Water, to make 1 pint.
Mix.

Give a wineglassful, in a half pint of water, every hour until relieved.

\section{Laryngitis, or Inflammation of the Larynx.}

This is a very common trouble anong horwes, sometimes independently, but oftener in connection with such diseases as influenza, catarrh, ete., from the extension of infammation from other parts. Occasionally, it is brought on by inhaling irritating gases.

Symptoms.-The anmal is fererish, with a full, stong pulse. In the first stages, the throat is dry, there is a painful cough, and swallowing is only aceomplished with manifost difienty. By presing on the larynx, pain is evinced and the congh is renewed. The head is usually extended, the nostrils dilated, and in many catses the eyes are very prominent, indicating intense suffering.

This dry condition of the membrane soon gives place to a moist one. It then becomes swollen, and a discharge of thick whitish, or 
perhaps yellowish, matter issues from the nose, and collects around the orifice. The cough is now noticed to be softer and of a less painful character, the nostrils are not so widely dilated, and the eyes appear less strikingly unnatural. The fever still continues, but in a less degree, and the pulse is slower and less irritable. A little soft or soothing food may be eaten, but the appetite is still poor. Should the discharge change to a greenish tinge, it indicates that the cartilage of the larynx is involved-a very serious condition.

If well treated, recovery should oceur in about two weeks. When the attack lasts longer than

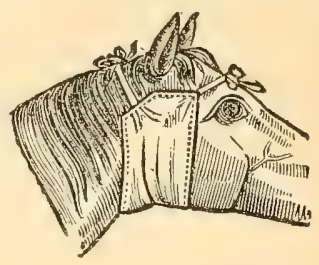

THROAT BANDAGE. this, it is liable to become chronic; the membrane of the larynx becoming thickened, keeps up a continual state of irritation, and the short, hacking cough-may last for many months.

Treatment.-First provide a comfortable box stall, with plenty of fresh air, but protected from drafts. In the stall keep a bucket of clean, fresh water, with a tablespoonful of chlorate of potash in it, and let the horse drink of it whenever he wishes. The diet must not only be easy of digestion, but of such a kind as will be easily swallowed. Oatmeal gruel, flax-seed tea, and grain boiled soft, with plenty of salt, will be excellent.

Poultice the throat with hot flax-seed, as may easily be done in the manner shown in the engraving. The poultices should be renewed as soon as they cool; as often as every two hours, at least. To combat the fever, many of the fever medicines are prescribed in this work; and to relieve the cough administer the following:

\begin{tabular}{|c|c|}
\hline No. 55 & Syrup of squills, \\
\hline & Fluid extract of belladonna, \\
\hline - & $\begin{array}{l}\text { Powdered camphor, } \\
\text { Honey, }\end{array}$ \\
\hline
\end{tabular}

Give a tablespoonful on the tongue every three hours.

Should the cough become chronic, a little of the Absorbent Blister No. 11 may be rubbed over the throat, and the following pills given: No. 56.

Powdered opium,
Powdered camphor,
Powdered digitalis,
Powdered liquorice root, $1 / 4$ ounce.
Vaseline, sufficient to mix.

Divide into six parts, roll into pill shape (nee cut on page 368 ), and cover with thin paper. Give one pill twice a day, 


\section{Roaring and Whistling, or Laryngeal Paraiysis.}

Roaring and whistling are generally considered as symptoms of the same disease, namely, laryngeal paralysis, although they may also occur from other causes, to be presently considered. The difference between them may be stated in few words.

In roaring the paralysed side-usually the left-allows the rocal cord of that side to relax, while in whistling, both cords are found to relax, and hence the production of different sounds. The unnatural sound of roaring is emitted during inspiration, never during expiration; that of whistling is generally the same, but in some horses may be heard during expiration also, though feebly.

Causes.-The hereditary nature of this disease is now generally accepted by veterinarians. It has been demonstrated that it is transmissible from a stallion to his progeny, and that certain strains of horses are peculiarly subject to it. Yet there are many special cuuses. Among them we may mention nasal polypus; broken bones closing the nostril; tumors extending downward from the posterior part of the nostrils into the larynx; tumors in the chest cavity; disease of the neighboring glands; stricture of the trachea; and the foolish, not to say barbarous, practice of reining too tightly, etc.

Roaring does not commence abruptly, but usually in an intermittent form. Very likely the animal is also noticed to be very subject to sore throats and general laryngeal irritation. These conditions may have come and gone several times without attracting much attention, till at length they reappear in an aggravated form, and the horse is found to be a confirmed roarer.

How to Detect.-To test the wind of a horse, take your position, and have him galloped up a hill or over a rough piece of ground, past you, and near you. Never allow the seller to slow him up as he approaches you, as this, in an ordinary case of either roaring or whistling, will frecuently stop it. If it is a draft horse, make him pull a heavy load for a short distance. Roarers are also generally "crunters;" that is, by feinting at striking them, they will grunt. Grunters, however, are not always roarers. Both forms of this diseasein other words, both the roaring and whistling-are considered serious unsoundnesses.

Treatment-Asectain, if possible, whether any removable cause is present, and if so, remedy it immediately. At the beginning of roaring or whistling, the use of a blister, or the hot iron, over the 
larynx has in a few cases effected a cure. But in confirmed cases treatment is useless. Even in these, however, a nose band, with two pads pressing on the affected nostril, will frequently greatly lessen the disagreeable sound, by diminishing the volume of air which enters. An operation, devised by the veterinarian Gunther, of Hanover, for the excision of the vocal cord, has been very extensively tried of late years, but with less success, in a large percentage of cases, than the inventor anticipated. It is too complicated an operation to describe here, and requires a number of special instruments which no farmer can be expected to have.

Another method of relieving this trouble is to perform tracheotomy; that is, to open the trachea, and insert a tracheotomy tube for the passage of air. This tube will always have to be worn, when the animal is at work, for the remainder of his life. No farmer will think of resorting to this method either. 


\section{CHAP'TER XXXIII. \\ DISEASES OF THE LUNGS.}

r. BRONCHITIS.-II. PNEUMONIA, OR INFLAMMATION OF THE LUNGS.- III. ASTHMA, BROKEN WIND, AND HEAVES (EMPHYSEMA OF THE LUNGS). - IV. PLEURISY, WITII WATER ON THE CHEST (IIYDIOTHORAX).

\section{Bronchitis.}

This is an inflammation of the bronchial tubes leading to the lung, having at first a dry and congested stage, followed later by the formation of a mucous secretion.

Causes.-Most commonly exposure to colds or drafts. It may also occur from inhaling irritating substances, or from food or water passing into the lungs.

Symptoms.-Bronchitis exists in the two different forms known as acute and chronic. We will consider the two forms together. The

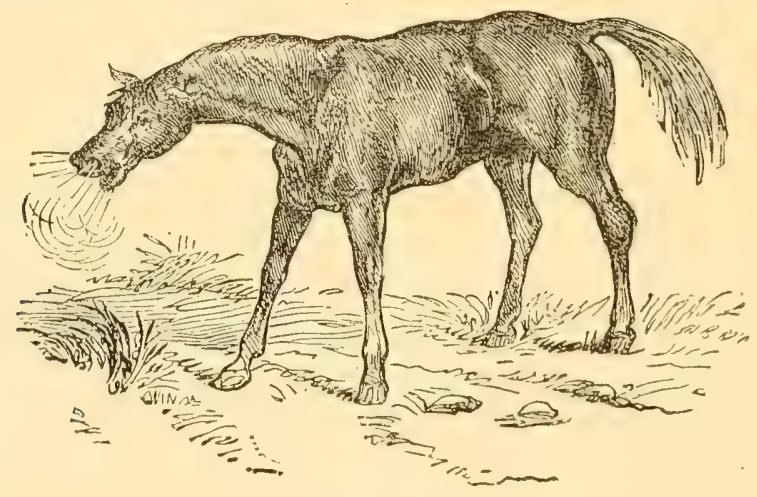

BRONCHITIS.

symptoms of hronchitis are gencrally well marked. The horse is noticed to be off his feed, appears listless, and very likely is remarked to have a cold. Soon, however, there oceurs an alarming change in the breathing, which becomes dapid and difticult, the chest and abdominal muscles being abled into foroible atetion to assist in respiration. 
There is a cough, loud and harsh, and the mucus that keeps accumulating in the bronchii is frequently forced through the nose, by an effort similar to that in sneezing. This is illustrated in the engraring herewith presented. The mouth is filled with saliva, the legs and ears are hot, indicating an increase of the temperature, or, in other words, fever. Trater is drank greedily, and the head will be poked out of the stall to secure all the cool air possible. The pulse is quick and soft, and will beat as high as sixty to seventy per minute.

Auscultation, or listening to the sound of the lungs by pressing the ear against the chest, will be an invaluable aid in recognizing bronchitis. In a healthy lung respiration is characterized by a soft, cooing murmur. This in bronchitis is turned to a loud, rattling sound over the middle of the chest, when the large bronchial tubes are the ones affected; or a high squeaking sound over the extreme upper or lower parts of the chest, when the smaller tubes are involved. Any farmer can avail himself of this method of diagnosing bronchitis. On the other hand percussion, or tapping on the chest with the finger tips, will show nothing except to the trained ear of a professional man.

As the case progresses, the nasal discharge which has hitherto been thick, and whitish or eren yellowish in color, is likely to hecome thinner and clearer, the cough is less forced and softer, and the breathing and pulse become slower. These are favorable symptoms, indicating the subsidence of inflammation, and the approach of convalescence.

Chronic Bronchitis. - The chronic form of bronchitis is characterized by similar symptoms, but the disease does not tend to such a speedy recovery. The cough has a loud, metallic ring, and may be very painful. Weakness and wasting are also frequent accompaniments.

Treatment.-The treatment of bronchitis will be essentially the same for both the acute and chronic forms. Provide a large, airy box, free from drafts; clothe the horse well; give a little light food, and keep a bucket of water continually in the stall. If half an ounce of the chlorate of potash is dissolved in the water, all the better. At the commencement of the disease, a dose (one ounce) of the tincture of opium will usually relieve the symptoms and give ease. The head should be steamed with hot water, or hot bran (see cut on page 412 ), in which some tincture of iodine, carbolic acid or creosote has been placed. The chest may be wrapped in blankets that have been 
wrung out in hot or cold water; these should be changed every hour or so. Change quickly, so the animal will not chill.

Bleeding is not advisable in this disease. The animal being debilitated already, needs to have his system stimulated and supported, instead of depleted. Give him wineglassful doses of whiskey in the drinking water every four hours. Should the fever rise to a temperature of over 104 degrees, the Fever Medicine No. 45 should be given.

In chronic bronchitis, it will be best to also apply a blister to the chest; for this purpose mustard answers very well. The following drench should also be given:

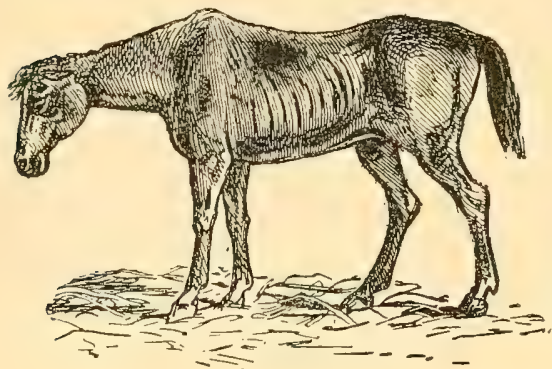

PNEUMONIA, OR LUNG FEVER.

No. 57. Iodide of potash, 6 drachms. Chloride of ammonia, 1 ounce. Water, 1 pint. Mix

Give a wineglassful four times a day:

\section{Pneumonia, or Inflammation of the Lungs.}

Inflammation of the lungs-or, as it is often called, lung feverdiffers from bronchitis in the whole of the lung substance being involved, whereas in bronchitis the lining membrane of the tubes only is involved. But a condition often exists in which both diseases are present, constituting broncho-pneumonia.

Causes.-The ordinary causes are the same as those of bronchitis, namely, exposure to draughts; chills; inhaling irritating substances, as the smoke of burning hay, straw, ete.; and the passage of food or water into the lung. It may also result from some accident, in which the chest wall is punctured and the lung injured. It is also seen as a secondary affection in some blood diseases.

Symptoms.-Pneumonia very commonly begins with a chill, which soon passes off, and is followed by increased warmth of the ears, mouth and legs. The temperature rises to 103 or 104 degrees, and the pulse becomes full and rapid, though still soft. The breathing, which at the outset appeared natural, or nearly so, very soon changes, the respirations increasing to 30 or $40 \mathrm{per}$ minute. At this stage of the disease the sufferer hangs his head, and stands with ellows turned out and toes turned in. This is faithfully depicted in 
our illustration. The appetite, very capricious at the start, is now entirely lost. Thirst is very apparent and distressing, and the mouth is filled with frothy saliva. In extreme cases, the fore legs are stretched forward and the head extended. In nearly all cases of lung disease the horse will refuse to lie down, and exhibit great reluctance to move.

Auscultation (listening to the lung sounds by pressing the ear against the chest) is of the highest value in determining the existence and extent of the malady. In the commencement a fine, crackling sound is heard, which has been well compared to the erackling of salt when thrown in the stove; this may be heard orer all the affected area. In a short time this is succeeded by a loud tubal breathing, or, perhaps, there is a total absence of sound, denoting the solidification of the lung. In a farorable case, this condition, combined with the fever, will continue for about a weck, and then will gradually subside, the mouth and ears becoming cooler, and the breathing easier, as the lung resumes its normal character.

Pereussion (tapping with the finger tips) orer the chest wall, will, to a practiced ear, show a dullness over the affected regions that is of material value in the diagnosis.

During the progress of the disease, a mucous discharge of a yellowish color issues from the nostrils; this may be so profuse as to fairly stop them up.

After a severe attack of pneumonia, great debility and emaciation may be expected, but they rapidly disappear under healthy influences, including good feeding.

We must mention that pneumonia usually affects one lung only, and frequently only in spots; yet it does sometimes attack them both at once. Observations seem to show that the right lung is oftener affected than the left.

Pneumonia is emphatically an acute disease, and runs its course rapidly. Death may occur at any period, but most frecpently during the stage of consolidation of the lung, and when the fever is at its height.

Treatment.-The first thing is to secure a good, comfortable, airy box; then clothe the animal warmly. Thirst being cxcessive, on account of the fever, keep a pail of cool water-with a tablespoonful of the chlorate of potash dissolved in it-all the time before the patient. In the early part of the trouble, and while the pulse is full 
and strong, the following drench will be beneficial, but must be discontinued if the pulse becomes small and weak:

No. 58.

Tincture of aconite, 1 drachm.

Liquor ammonia acetate, 1 pint.

Mix.

Give a wineglassful, in a half pint of water, every four hours.

When recovery commences, or earlier if great debility is shown, a stimulating course of treatment will yield far better results. Two ounces of whiskey may be given in a little drinking water every three hours; or the following stimulating ferer medicine may be substituted.

No. 59.

$\begin{array}{ll}\text { Powdered camphor, } & 2 \text { ounces. } \\ \text { Alcohol, } & 6 \text { ounces. } \\ \text { Spirits of nitrous ether, } & 5 \text { ounces. }\end{array}$

Water, suflicient to make 1 quart.

Mix.

Dissolve the camphor in the alcohol, and then add the remainder. Give a wineglassful in half a pint of water every four hours.

Local Treatment.-The local treatment of pneumonia will be to apply blankets around the chest, that have been wrung out in hot or cold water' these must be changed every hour or two, day and night, while the disease is serions. The effect of this form of treatment is generally very maked, the temperature rapidly falling, and all the principal symptoms being greatly relieved.

Mustard poultices, blisters, etc., should not be used, except towards convalescence, and then only when it has become tardy. In the acute stages of the ferer, the use of these fiery substances can do no good; they only tend to increase the uneasiness, by creating another inflammation.

As to Bleeding.-Bleeding has practically been abandoned hy reputable veterinarians in the treatment of $\ln g$ fever. If ever adrisable, it will only be at the commencement, that is, during the congestive stage, and while the pulse is full and strong. When weakness sets in, bleeding can only result in positive injury to the patient.

III. Asthma, Broken Wind, and Heaves.

These may all be considered as one form of disense; or, rather, one condition (emphysema of the lungs), which may be brought on by a variety of different diseases. The parts of the lung involved are the small air cells, the minutest ramifications of the bronchial tubes. These may be greatly distended, or clse their walls ruptured-in either 
case, forming large vacuous spaces. Having lost all elasticity, their contained air is only forced out by the peculiar mode of breathing to be described later.

Causes.-In many instances the cause is very obscure, but in the majority of these cases careful inquiry can generally trace it to some disorder of the digestive apparatus, especially over-distension of the stomach. This latter is supposed to affect the pneumogastric nerves, which also supplies the lungs, in this way inducing a sympathetic affection. This condition also appears as a sequel of many inflammatory diseases of the respiratory apparatus, such as brorchitis, pneumonia, laryngitis, etc. Furthermore, the opinion has come to pre-

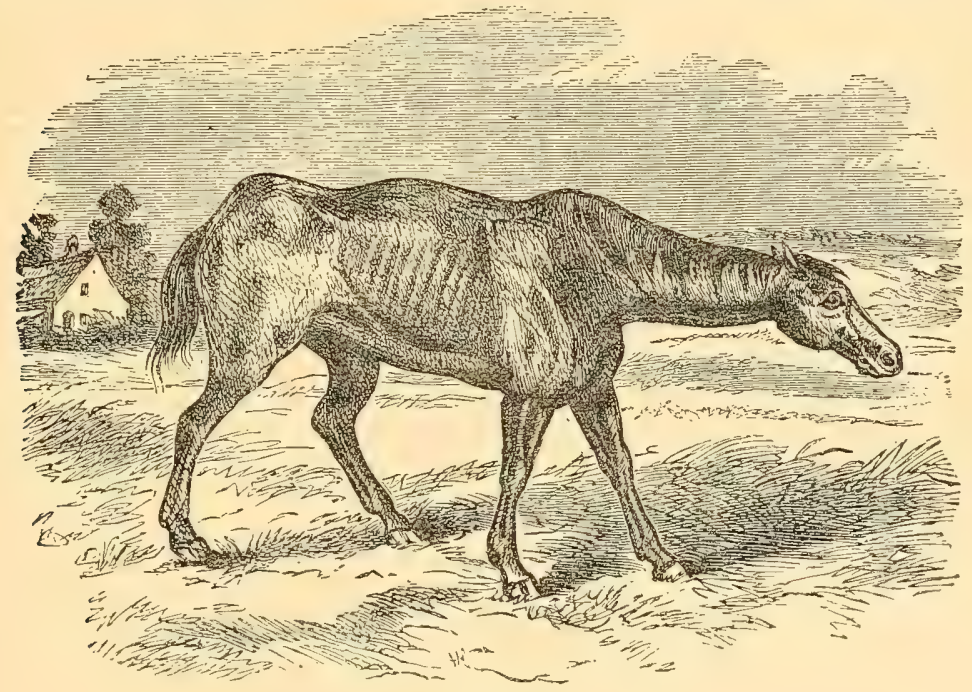

A SEVERE CASE OF BROKEN WIND.

vail, of late years, that this disease, or a tendency to it, is transmissible from one generation to another,

Symptoms.-Broken wind is a trouble that may come on very gradually, or may appear more suddenly after severe inflammiation of any of the respiratory organs. Frequently the animal is a greedy feeder, and greatly troubled with flatulence. In horses but slightly affected, the symptoms may not be noticed while at rest, but when in motion they will be quite apparent. A characteristic feature of this condition, both in and out of the stable, is the cough. This is so peculiar as to be readily recognized. It has a weak, prolonged, hollow sound, and seems to be performed with dificulty, the mouth generally open. 
But the most marked peculiarity is in the respiration. At each expiration the abdominal muscles are brought into powerful action to expel the air from the lungs, a process which is noisily effected by a double jerking movement of the muscles, altogether different from the easy simple movement of health. In severe attacks a shallow groove will be seen along the lower part of the chest, as shown in the accompanying illustration. This is due to the muscular rigidity of the chest caused by the effort required to expel the air. Auscultation, explained in the previous sections of this chapter, may reveal a bubbling or rattling sound in different parts of the lung; or, according to the severity of the case, may show an almost total absence of sound. Percussion will give a loud, hollow sound, but is of little diagnostic value, except to a trained veterinarian. The chest is generally fuller and rounder than in perfect health.

Treatment.-The diet is the first thing to be attended to. The food should be of the best, and given at frequent intervals, the ob-

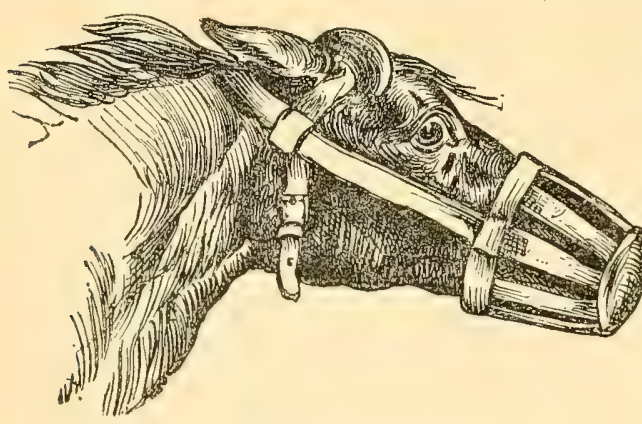

A SIMPLE MUZZLE.

This device is eflicacious in preventing biting, as well as for a greedy feeder. ject being to prevent any distension of the stomach, which is something that always seems to have a very bad effect. The hay should be limited in quantity, all dust shaken out, and chopped fine; then wet, and perhaps salted. The amount of feed given should be carefully regulated. Between meals the "greedy feeder" should be muzzled. We herewith show a strong durable muzzle, and one easily made and managed.

The bowels must be kept in regular condition, by using an occasional mash. For the same purpose regular exereise is rery desirable; but it should be earefully given, always in moderation and on a full stomach.

To relieve the distressed breathing, give the following drench, repeating it in an hour or two, if required:

No. 60 .

Spirits of ether, 1/2 ounce.

Glycerine, $\quad 1$ ounce.

Mix.

Give as one dose in half a pint of water.

The cough may be relieved by using the Pill No. 56 . 


\section{Pleurisy, with Water on the Chest (Hydrothorax).}

Pleurisy is an infiammation of the pleura, the membrane which covers the lungs and lines the chest cavity. This membrane, when inflamed, goes through the regular inflammatory changes-first a dry or congested stage, followed by an effusion of serum from the blood.

Causes.-The causes are similar to those of bronchitis and pneumonia, especially colds from exposure, ete. ; but it may occur in connection with other diseases, as rheumatism, influenza, etc. It is also seen as a result of various injuries of the chest-kicks, punctured wounds, blows, etc.

Symptoms.-Pleurisy comes on suddenly, usually with a chill. Sometimes the animal will paw and rolls, the manifestations in this way resembling colic, for which it is frequently mistaken. Before long, however, difficult breathing is noticed; the ribs are held rigid, the elbows turned out, and the breathing is nearly all done by means of the muscles of the abdomen. Along the lower side of the chest, from the fore leg back to the

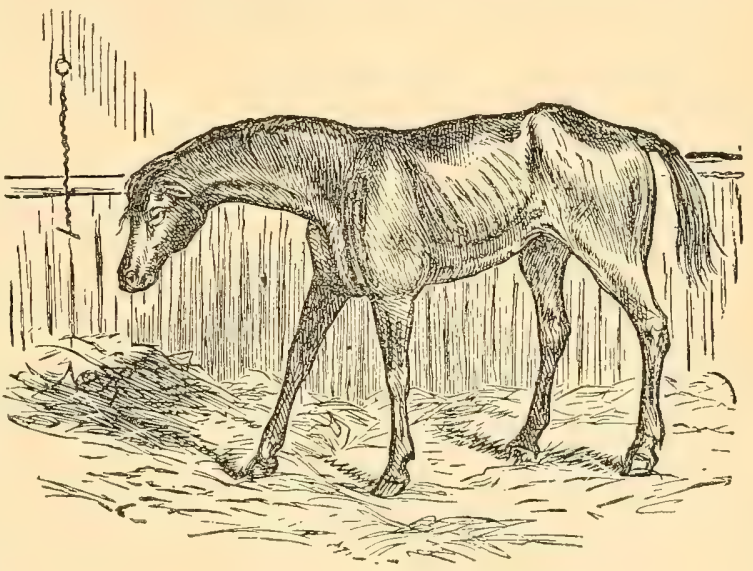

A CASE OF PLEURISY.

point of the ilium, may The shallow furrow below the ribs and up the flank is plainly be discovered a shallow shown.

furrow, marking plainly how greatly the muscles are contracted. The fever runs high, equaling that of pneumonia; the temperature ranges from 103 to 107 degrees. The pulse, of course, is greatly accelerated-from 60 to 80 beats per minute-and is hard and wiry. When a cough is present, as there often is, it causes such pain that the animal will try and suppress it. By pressing between the ribs, feinting at striking them, or making the patient turn suddenly round, a painful grunt is very likely to be elieited.

Auscultation will find the murmurous sounds within the lung about natural, and yet the sound is peculiar; there is, in addition, a sort of creaking - a noise as of harsh folds rubbing together-caused by the 
movement, one upon the other, of the serous membrane covering the lungs, and the extension of the same lining the chest wall. This is the stage of congestion, which is shortly succeeded by the stage of effusion. So now-the dry painful period having passed, and a plentiful effusion of serum being in progress-we have a case of hydrothorax, or water in the chest.

Hydrothorax.-The amount of the secretion may be small, in which cases it is readily absorbed, the disease ending in resolution, and the natural functions being shortly restored. But when the secretion is excessive, the surrounding parts are not capable of disposing of (absorbing) it, and there it continues to gather in the lower part of the chest cavity, and this, too, upon both sides, there being a communication between them. The horse which, when the congestive stage first gave place to the effusive, may have appeared nearly well again, will now begin to take long, deep breaths. There is a marked change

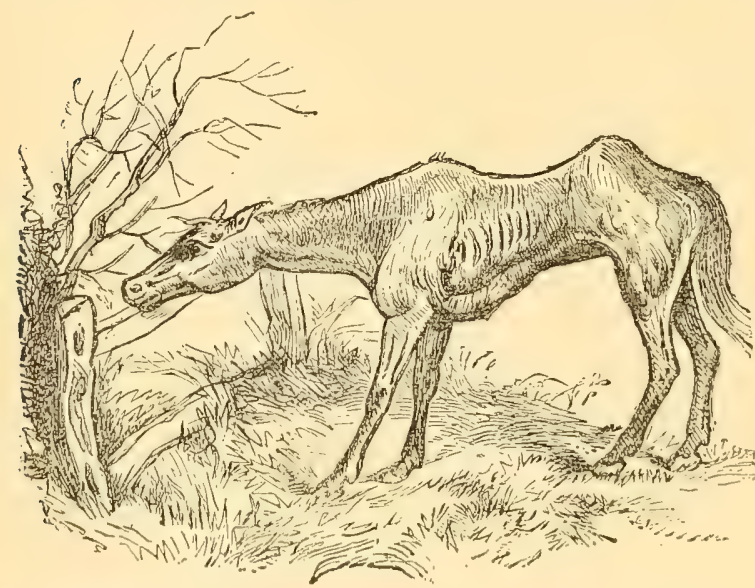

IHYROTHORAX, OR WATER IN THE CIIEST CAVITY.

This has been brought on by a bar attack of pleurisy. also in the pulse; it is small, weak and fluttering. As the amount of the effused fluid increases within the chest, it compresses the lungs more and more, and increases, correspondingly, the difficulty of breathing; the head is protruded; the countenance assumes an anxious expression; and swelling of the legs and along the belly appears. If the fluid does not inereatse very fast, the sufferer's fight. for life is prolonged; hut he will lose thesh rapidly, and appear greatly emaciated.

Pereussion with the finger tips will eall forth at dull somel as high up as the water goes, and above this at resonance that affords a marked contrast.

This condition causes great weakness. If relief is not given, death must speedily ensue. 
Treatment.-When signs of pleurisy appear, it is sometimes possible, by prompt treatment, to abort the disease. Give a dose of half an ounce of the tincture of opium in a pint of linseed oil ; this will relieve the pain and give ease in breathing. The legs should be bandaged, and the body warmly clothed. The Fever Mixture No. 45 should be given regularly, the intervals or quantity being diminished, of course, as the pulse gets slower. Blankets wrung out in hot or cold water may advantageously be bound around the chest, and covered with a blanket; this will aid in reducing the fever, and relieving the pain.

When convalescence approaches, the use of tonics will be of great benefit. Give a little whiskey in the drinking water, or, instead, any of the tonic powders. This should always be combined with a nourishing diet.

Treatment of Hydrothorax.-For the removal of the fluid, various drugs are used. These are principally diuretics and laxatives, which, by increasing the action of the kidneys and bowels respectively, tend to deplete the accumulation. This treatment does not generally suffice, and then the tapping of the chest becomes necessary. The case is now an urgent-nay, a desperate-one. Its grave character is sufficiently indicated by the great difficulty of breathing. The necessury operation can be performed only by a thoroughly educated veterinarian. The instruments required are a trocar and canula (see cut on page 354 ) and an ordinary knife.

The place to tap is at the fifth, sixth or seventh rib, about eight inches from the junction of the rib with the breast bone. The skin is pulled forward, and a small cut made with the knife; then the trocar and canula is pushed in near the anterior edge of the rib. When the instrument reaches the cavity, the trocar is withdrawn, and the fluid is allowed to escape through the canula, which remains in the opening, and serves as a spout. Care must be taken not to admit air into the chest. Among human patients it is eustomary to only withdraw a portion of the fluid; but in the horse, from which we have remored as high as twenty quarts, it is best to leare no more than a quart or two. The sudden removal of such a large cuantity of fluid is frequently followed by weakness and dizziness, requiring the prompt use of stimulants in large doses. After the operation, allow the patient perfect quiet, with a liberal, but simple and easily digested diet. 


\section{CHAPTER XXXIV.}

\section{DISEASES, ETC., OF THE HEART AND BLOOD-VESSELS.}

I. CONCERNING DISEASES OF THE CIRCULATORY APPARATUS IN GENERAL.II. THE PULSE.—III. TIE TEMPERATURE.—IV. FOREIGN BODIES IN THE HEART.- V. HYPERTROPHY (ENLARGEMENT) OF THE HEART.-VI. ATROPHY OF THE HEART.—VIY, FATTY DEGENERATION OF THE HEART.VIIT. DISEASES OF THE VALVES.—IX. TUMORS IN THE HEART.—X. RUPTURE OE TIE HEART,-XI. INFLAMMATION OF THE PERICARDIUM, OR PERICARDITIS.- - XII. ANEURISM.—XIIF, WOUNDS OF BLOOD-VESSELS.XIV. INFLAMMATION OF THE JUGULAR VEIN, OR PHLEBITIS.—- XV. THUMPS, OR SPASM OF THE DIAPHRAGM.

I. Concerning Diseases of the Circulatory Apparatus in General.

The heart and the blood-vessels-arteries and veins-furnish the various parts of the body with the blood essential for their nourishment, and equally essential for the carrying away of their effete or deleterious particles. The blood is sent to every extremity of the

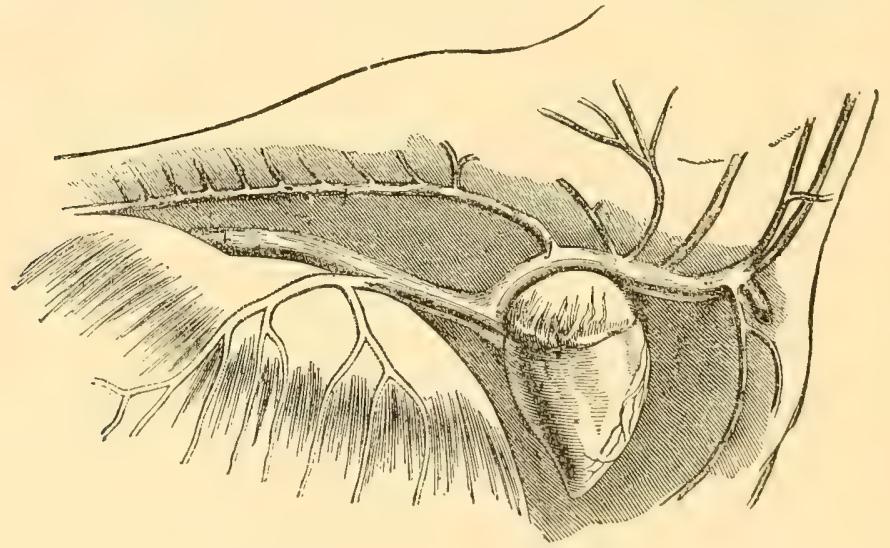

THE HEART AND ITS VESSELS.

body by the extraordinary muscular contration of the heart, whose incessant activity in health brings about its continuous purification. All this has been explained in detail in Chapter XII.

Any weakness or disease of the central pumping organ, the heart, will naturally be a very serious matter: but, fortunately, this is not 
frequent in the horse. When it does exist, it is seldom discovered until after a fatal termination, usually of a sudden character.

\section{The Pulse.}

In the diagnosis of all diseases of an inflammatory nature, the state of the heart's action is of great importance, serving to indicate the extent of the irritation, and to determine the condition of the patient, whether strong and hearty, or weak and with the vital functions depressed.

The pulse may be felt in any superficial vessel passing over a prominent bone. The most accessible place, and that to which the veterinarian always gives the preference, is where the artery passes over

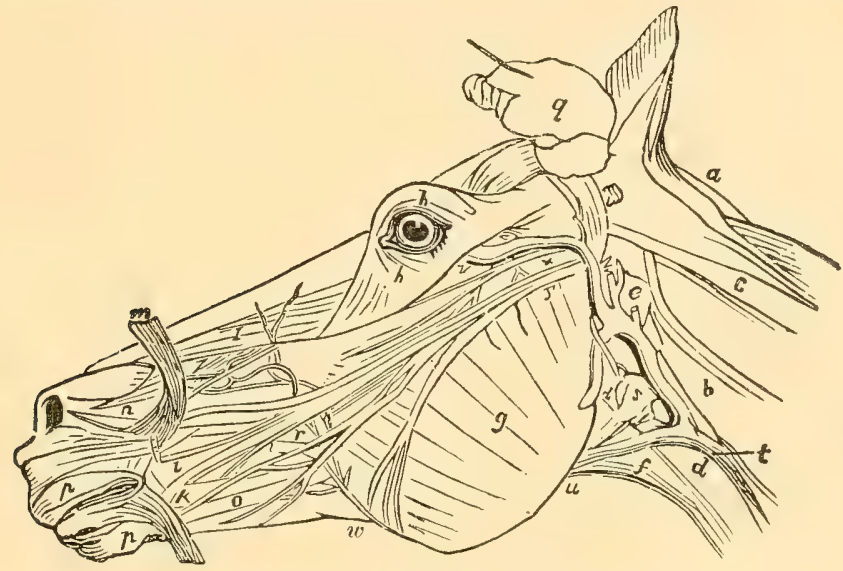

RLOOD-VESSELS, ETC., OF THE HEAD.

Where the artery passes over the edge of the lower jaw-bone is the pulse (at $W$.

the jaw-bone, in front of the masseter muscles, shown at $W$ in the accompanying illustration.

The pulse varies greatly in character, as well as frequency, under different conditions. We, therefore, present a short resume of the different kinds of pulse, as this is a practical sort of knowledge that every farmer ought to familiarize himself with. We quote from Williams, a standard authority, as follows:

"The Quick Pulse.-This is due to the mode in which the ventricles of the heart contract, and always indicates irritation and little strength; the heart makes a quick, short contraction, which differs much from the somewhat prolonged and more or less forcible contraction of real energy and excitement. 
"The Slow or Long Pulse.-This is the reverse of the preceding. It indicates a prolonged or slow contraction of the ventricles.

"An Infrequent Pulse.-This kind of pulse is often associated with slowness, and indicates diseases of the brain, or a disordered condition of the digcstive apparatus, and is often indicative of that condition of the system manifested by excessive urination (polyuria). In degenerative disease of the heart the pulse is often more infrequent than the cardiac contractions, because the impulse of the heart is too feeble to be transmitted to the arteries.

"As to the Volume of the Pulse.-The volume of the pulse may be greater than usual, in which case it is said to be 'full' or 'large;' or it may be less than usual, when it is said to be 'small.' This may be associated with 'strength' or with 'feebleness' of the pulsations. It is important not to confound a full, feeble pulse with a full, strong one. The feeble pulse is known by the weakness of the impulse, and by the artery yielding to the finger.

"The Feeble Pulse.-This, if associated with softness, the artery yielding readily to the finger, indicates debility, either general or cardiac [of the heart]. It is sometimes so weak as to give one the idea that the artery is filled with air; hence, it has been called the 'gaseous' pulse. It is not infrequent in an anæmic condition of the body.

"The Small Pulse.-This may result from aniemia; from congestion of some important organ, as the lungs; from feeble contraction of the heart; or from great tonicity [abnormal strength or stimulation $]$ of the arterial coats.

"The Hard Pulse--In this kind the artery resists pressure. It is often associated with smallness; it is then termed 'corded,' 'wiry' or 'thready.' This condition is often met with in the carlier stages of inflammatory disease, particularly during the rigor [premonitory chill] in dangerous inflammations of serous membranes, and especially in endoearditis [inflammation of the mombrane that lines the cavities of the heart, a very rare disease among horses].

"The Soft Pulse.-Of this kind of pulse sereral varieties are described. In the small, soft pulse, towards the close of progressive (xhaustive diseases, the impulse of the heart is slight, the tension of the arteries diminished, and the volume of blood sniall. It is reatily known by the fechleness of the impulse, and by the artery yielding readily to pressure. 
"The Venous Pulse.-Pulsation of the veins is often seen in the jugulars of the ox, especially during rumination, and seems to be quite compatible with health. In some forms of heart disease the jugular pulse becomes a diagnostic symptom.

"Pulsations in Health.-In a healthy horse the pulse shows from thirty-five to forty-five beats per minute, varying ten beats, or perhaps a little more, according to the size, breeding, and work performed."

\section{The Temperature.}

This should always be considered in conjunction with the pulse, in estimating the amount of fever, and general state of the patient. The clinical thermometer, a small instrument with a scale registering from 90 to 110 degrees Fahrenheit, may be had at almost any drug store, or at least ordered through it. In using it for the horse, the temperature is taken in the rectum, this being the most accessible place. In the mare the vagina may be used, but will register slightly higher than in the rectum.

The normal temperature of the healthy horse is from 99 to 101 degrees, but this is subject to a slight variation in different animals, or the same animal at different times, especially from exercise, scxual excitement, digestion, etc. What the temperature is may be approximated very handily, by putting the finger under the tongue, practice at which method will greatly develop both the sensibility of the finger and accuracy of the judgment. In many cases of fever the ears and legs are hot, and within certain limits serve to indicate the character of the disease.

A temperature of 104 or 105 degrees constitutes a high fever, and gives to the case a serious character, while a temperature of 109 degrees must, as a rule, extinguish the hope of recovery.

\section{Foreign Bodies in the Heart.}

The penetration of the heart by needles, pins, wire, etc., is of very rare occurrence in the horse, compared with the cow, these substances being swallowed with the food, and passing from the stomach to the heart.

The symptoms are very obscure, but, in general, may be said to resemble those of pericarditis, a discase soon to be described. Moaning and sighing are likely to be noticed, and there may be irregular heart-sounds and the venous pulse. These cases must be considered 
hopeless. In cows, needles have been known to work their way through the chest-walls and recovery to follow, but in these rare instances it could not be determined whether the heart was actually punctured or not.

\section{Hypertrophy (Enlargement) of the Heart.}

This condition is usually the result of some chronic pulmonary disease, such as emphysema (see Section III of preceding chapter), or of some obstruction to the circulation of the blood.

The symptoms are an increased force of the heart-beat, shortness of breath, and general incapacity for work. The treatment will be rest, and use of Heart Tonic No. 61.

\section{Atrophy of the Heart.}

This is the opposite of hypertrophy; the heart is smaller than natural. It is most commonly seen in old subjects, often as a result

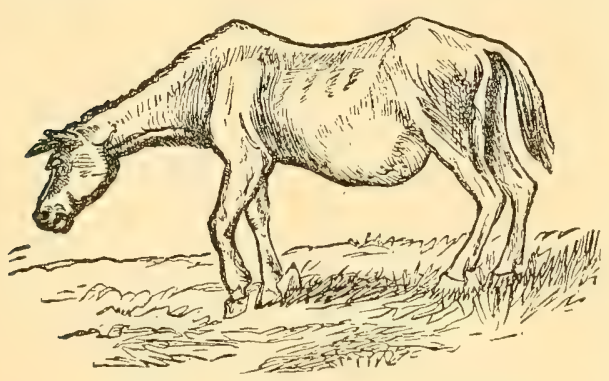

DROPSY FROM HEART DISEASE. of epizoötic and blood diseases. Pressure of fat around the heart will sometimes produce it.

The symptoms are weakness and debility, with swelling of the legs and belly, perhaps to

a considerable size. But the principal diagnostic sign is the character of the pulse-soft, weak and intermittent; it may even intermit at the same time that the heart beats regularly.

This trouble will, most likely, evade recognition until the post mortem; but if it is suspected, allow quiet and rest, and give No. 61.

\section{Fatty Degeneration of the Heart.}

This is usually found in old patients, or among animals which are over-fed and little worked.

The symptoms are great weakness of the heart, and a falling off in condition, but in a majority of cases the animal falls dead without anything wrong having been suspected.

\section{Diseases of the Valves.}

The various valves of the heart may be diseased, most commonly those on the left side of it. When the mitral valve, that which guards the opening into the ventricle, is diseased, a bellows-like murmur is 
given forth with the first heart sound; when the aortic valve, which prevents the backflow from the arteries into the heart, the bellows murmur is heard with the second sound. In both these cases there is usually a marked difficulty in breathing, dropsy of the legs, and the venous pulse. Occasionally the patient may even be attacked with blind staggers.

The proper treatment is rest, and the following drench:

No.61. Tincture of digitalis, 2 ounces.

Tincture of nux vomica, 3 ounces.

Water, to make 1 pint.

Mix.

This is an approved heart tonic. Give a wineglassful three times a day.

\section{Tumors in the Heart.}

Morbid growths are rarely found in the heart. Still, cases are on record in which a tumor was found attached to the side of the heart, or to the valves. In this position tumors are pretty certain to cause regurgitation of the blood, its flow back into the heart. They can never be diagnosed.

\section{Rupture of the Heart.}

A broken heart is no figure of speech, at least not when applied to some horses. This catastrophe in well-attested cases has occurred through some weakness of the walls of the heart, consequent on certain diseases, such as fatty degeneration, aneurism, etc. Death is instantaneous.

\section{Inflammation of the Pericardium, or Pericarditis.}

The pericardium is the thin serous membrane which encloses the heart as in a sac; it is continuous with the pleura that covers the lungs. It is liable to be inflaned from being punctured by foreign bodies, and from extension of inflammation from the lungs or the pleura.

Symptoms.-As in heart troubles generally, the symptoms are not well defined. During the first or dry stage, by putting the ear to the left side of the chest over the heart, there is heard a slight rubbing sound, corresponding in sequence to the heart's movements. Later, a similar condition to that of pleurisy comes on; the effusion of a dropsical fluid commences, which, when large in quantity, interferes 
with the heart's movements. At this stage the sounds discovered on auscultation are very dull and of a sort of churning character. At the same time, the thermometer shows the presence of considerable fever; the respiratory movements are increased; and, frequently, the legs are cold. As the fluid is absorbed, the dry, rubbing sound is again heard.

Treatment. - Provide a comfortable box and keep the patient perfectly quiet. See that the diet is light and easily digested, and if the bowels are constipated give a pint of linseed oil. To control the fever, the pulse being strong, give No. 45. If the pain is great, administer an ounce of tincture of opium, repeating with half tiis quantity every two hours while the pain lasts. When the fluid has formed, give No. 46. If any weakness becomes apparent, tone up the system with a little whiskey in the water, or diluted as a drench.

XII. Aneurism.

An aneurism is a rupture of one or more of the coats of a bloodvessel, so that bulging of its wall ensues, in consequence of the arterial pressure.

Symptoms. - When superficially seated, a soft lump is felt, that beats in time to the heart. If near the heart, the aneurism affects the heart beat, producing irregularity. When involving the chief

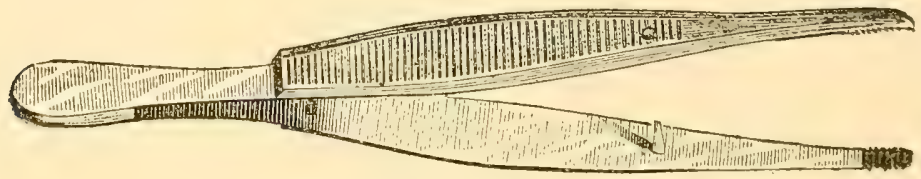

VETERINARIAN"S FORCEPS.

artery of a leg, it may give rise to an obscure lameness, with noticeable coldness of the limb; in the case of the hind legs, the tumor may frequently be felt through the rectum. When a rupture occurs through the gradual weakening and final giving way of the artery s wall, the animal bleeds to death in a few moments.

Treatment.-Aneurism of a large vesisel situated internally camnot be treated. But a superficial vessel, not of the lingest elass, maty be (aught with foreeps (a good style is shown in the cut) and tied above and below; the branching ressels will establish a collateral-as the bookis call it, a vicarious-circulation sutticient to stuply the part. 


\section{Wounds of Blood-vessels.}

The local blood-vessels are always involved, of course, in a wound of any part of the body. Whenever a vessel is cut straight across, the contraction of its coats prevents much bleeding, unless it is a large one, but when in an oblique direction, the bleeding is generally free.

To stop the flow of blood from a wound, the scientific plan is to catch the bleeding vessel with the forceps, and tie it with a thread, as shown in the illustration. Hardly any farmer could be expected to try this; so, his best recourse, ordinarily, will be to take a piece of cotton batting, soaked in some astringent solution, such as tincture of iron or of catechu, and pack it in the cut, and hold

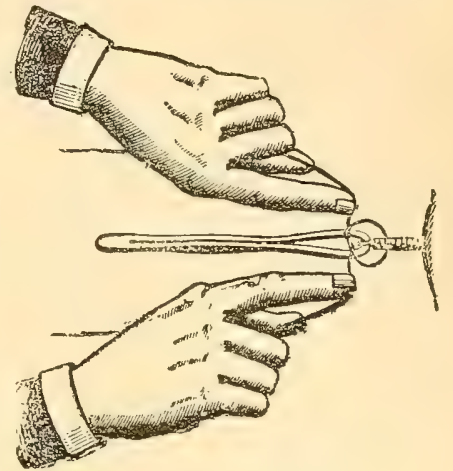

TYING AN ARTERY. it there firmly with a bandage. Another convenient way to stop the bleeding is to tie a rope tightly around the part, a little above the wound.

XIV. Inflammation of the Jugular Vein, or Phlebitis.

In the days when bleeding was the cure-all for almost any disease a horse could exhibit, this was a common trouble. It has become much less frequent since the practice of bleeding fell into comparative disfavor.

Causes.-As just intimated, phlebitis is usually the result of some bungling in bleeding, or from the use of dirty instruments, or from pinning some hairs in the opening of the wound.

Symptoms.-The first signs are generally noticed very shortly after the bleeding. The tissues swell in the neighborhood of the cut in the vein, and the swelling soon extends upwards toward the head. The edges of the wound become red and are everted (turned inside out). Presently the vein is found to contain a hard clot. A little later, if this clot could be examined under a microscope, minute vessels would be discovered begimning to ramify through it; in other words, it is becoming "organized." This process of organization continues until the vein is obliterated, and shows simply as a fibrous cord. When the clot contains unhealihy matter, pus forms, and next a number of alscesses along the nerk. If the matter ganins andision into the blood, a case of blood poisoning (pyimia) will be established. 
Treatment.-Tmmediately after the swelling occurs, and before the clot forms, re-open the wound, and wash it out with the Antiseptic Solution No. 1, or No. 12. After the clot has formed, if any abscesses begin to appear, lance them immediately. Blister the entire length of the swelling with No. 11. For the fever that always accompanies this as every other inflammatory disease, give No. 21, or No. 45. If the case becomes one of blood poisoning, treat it according to the directions given in the next chapter for pyæmia.

\section{Thumps, or Spasm of the Diaphragm.}

This is a peculiar affection of that great nuscle of respiration, the diaphragm, separating the chest cavity from the intestines. Although not a disease of the heart, we introduce it here for the reason that it is almost universally believed to be so.

Causes.-An attack of the thumps is most generally brought on by over-exertion; yet it may be seen in connection with various other diseases, and with a disordered digestion.

Symptoms - The symptoms are quite characteristic, being a peculiar, dull, thumping noise in the region of the belly, a sound which is sometimes said to be "like a hiccough." The pulse is small and

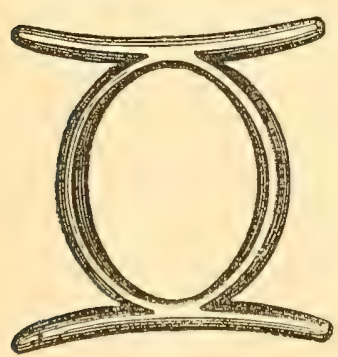

weak. On careful observation, the thumps will be found to be entirely independent of the heart, proving conclusively that they have no connection with the heart's action.

Treatment.-Clothe warmly, and give the Pill No. 20, which can easily be done by using the balling iron. Next give a good dose of whiskey well diluted, and repeat this dose in a few hours if the symptoms continue. If the spasms are BALLING IRON. another form of the ball- found to be uncontrollable by this treatment, ing iron is shown on page 367. give No. 33 . 


\section{CHAPTER XXXV. \\ DISEASES OF THE BLOOD.}

I. BOILS.-II. INFLUENZA, DISTEMPER, OR PINK-EYE.—III, RHEUMATISM. IV. PURPURA HEMORRHAGICA.—V. GLANDERS AND FARCY.—VI. STRANGLES.—VII. VARIOLA EQUINA, OR HORSE POX.—VIII. RABIES, OR HYDROPHOBIA.—-IX, MELANOSIS, OR BLACK TUMORS. - X. PYÆMIA, OR BLOOD POISONING.-XI. WEED OR THICK LEG (LYMPHANGITIS).

\section{Boils.}

Boils may make their appearance on any part of the body that is covered with skin. They are generally found in debilitated horses, or those kept in unhealthy stables; yet the class of highly-fed animals, regardless of their surroundings, are by no means strangers to them.

What a Boil is.-A boil, whether on man or beast, is an inflammation of the skin and the loose tissues beneath it. In a short time pus forms, and the abscess-for such it really is-is said to "point", on the surface. Up to this time, the pain by tension of the skin is of a throbbing character; but let the boil be opened, and the tension thus relieved, and the pain is relieved likewise. Our illustration shows a boil in section. After them atter is discharged, the sore commences to

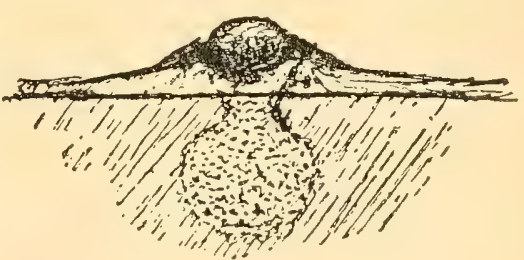
heal and the cavity to fill, beginning Diagram of Boil (SECTIONAL View). at the bottom. It is a familiar fact, which many of our readers have doubtless learned by sore experience at some time or other, that in many cases one boil heals only to be followed by another, or perhaps many others in rapid succession.

Treatment.- In the treatment of boils, the best method is to freely lance them, and this, even if the pointing has not occurred, as we may thus expect to, abort their formation. Ordinarily, no further treatment will be needed, further than simply to keep the wound clean. If, however, they show a slowness in healing, an occasional touching with lunar caustic will aid in the process. The general state 
of the health may also need attention. If there is evident debility, good food and any of the tonic powders prescribed in this work will be requisite. Cleanliness of the stable should likewise be seen to.

\section{Influenza, Distemper, or Pink-Eye.}

These are simply different names for one and the same disease. In its mild form, called distemper, it may be seen all the year round in horses fresh from the country, that have passed through infected city sales-stables. In the severer and epidemic form, it has been treated of in the writings of veterinarians from the thirteenth century down. Thousands of our readers will recall the wide-spread epidemic in America of "epizoötic," influenza, or pink-eye, in the winter of 1872 and 1873. Occasionally an outbreak of the same disease still occurs in circumscribed localities, but for the most part yields to treatment readily.

Causes.-The contagious nature of this disease is universally acknowledged. Yet the very mild form of distemper which the "green" horse contracts, does not seem to affect the seasoned veteran at his side. Certain depressed conditions of health, and unfarorable surroundings generally, are predisposing causes. The disease is well known to affect the debilitated horse sooner than the healthy one, and those kept in damp, poorly ventilated stables than those better housed and better cared for. When, however, it breaks ont as an epidemic, old and young, well-kept and ill-kept, are all similarly affected, although some withstand the infectious influence longer than other's, or succumb to it in less degree.

Symptoms.-The first thing noticed is, generally, the loss of appetite, with, perhaps, a hacking cough, and, on examination, the horse will be found to be very feverish, and show signs of great thirst. In a little while follows a discharge of milky mucus from the nostrils and eyes, and a characteristic redness and swelling of their membranes. The legs and ear's are cold, but the temperature ranges as high as 103 to 105 degrees. Each day the disease increases in intensity; the discharge from the nose thickens, and is likely to take on a yellowish tinge; the cough is painful; owing to the soreness of the throat, great difficulty is experienced in swallowing-so mueh so that, in many cases, the food is returned by the nose, giving to the mucus the color of the food. The pulse is fechle and rapid, ruming an high, probahly, as eighty beats per minute. Flesh is lost very fast, and the head hangs down, as shown in our illustration, which does 
not exaggerate the suiferer's woe-begone aspect in the least. If no complication arises, the disease runs its course, and convalescence begins, in about two weeks. The strength is rapidly regained, and often the animal lays on fat in a way that makes his owner wonder.

The greatest danger in this disorder arises from possible complications. In severe attacks, dropsical swellings are apt to appear on the chest, belly and legs. They are due to debility of the circulation, and, in themselves, are not an alarming symptom. Ordinarily, they call for no interference, as the effused fluid will be absorbed on the return of strength.

Complications.-When, however, lung, intestinal, liver, or rheumatic diseases develop in a "pink-eye" patient, the complication affords ground for great anxiety, as the death-rate under these circum-

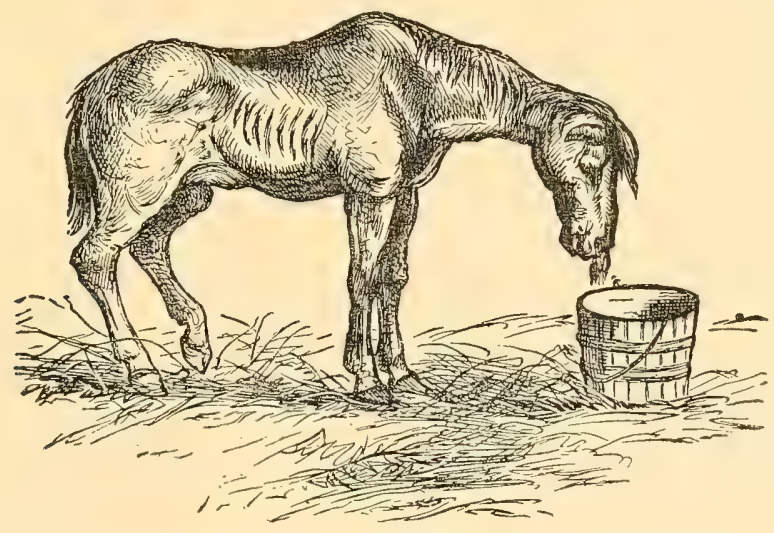

CATARIHAL FORM OF INFLUENZA (PINK-EYE).

stances is tremendously increased, as compared with the original disease alone. The treatment is sometimes a perplexing matter, but, as a rule, should be directed mainly to the disease last developed.

Treatment.-The first element in the treatment of an uncomplicated case, after attending to the sanitary condition of the surroundings, will be to provide a healthy stable, away from other horses. Clothe warmly, if the weather is cold; supply good, easily digested food, as scalded bran or oats, gruel, milk, ete. Let the patient assuage his excessive thirst whenever he wishes. To this end keep continually in the stall a bucket of clear water in which an ounce of the chlorate of potash has been dissolved. If there is much coughing, poultice the throat with flaxseed or bran. For the fever very 
small doses of No. 45 may be given, unless the pulse indicates great weakness, in which case substitute free doses of stimulants-brandy or whiskey, given in the water. Irregularities of the bowels may be corrected by a laxative diet, or a moderate dose of oil. If the eyes and nose are bathed with warm water, and the edges greased, the effect often seems very grateful to the patient. Steaming the head, in manner as illustrated on page 412, is always of great benefit in soothing the cough, and aiding a free discharge through the nostrils. The dropsical swellings, as we have already explained, call for no special treatment. As convalescence begins, the Tonic Powders No. 19 may be given, along with plenty of good food.

As to the various complicative diseases, these will be found under their own headings, elsewhere in this work.

\section{Rheumatism.}

What is Rheumatism?-The peculiar inflammatory disease which principally affects the joints and tendons of various parts of the body, and to some extent the muscles also, is one of the most familiar forms of disablement and suffering in the human race and the domestic animals alike; and yet the precise origin of rheumatism has never been satisfactorily determined. A variety of different theories exist; that which has, perhaps, the most advocates is that it is due to the presence of lactic acid in the blood.

Causes.-The predisposing causes are well known,-exposure to damp, to cold and winds. Rheumatism is a frequent accompaniment also of epizoötic diseases, especially influenza, or pink-eye.

The two well distinguished forms of rheumatism-"acute" and "chronic" - will best be described separately.

Symptoms of Acute Rheumatism.-An acute attack, in the generality of cases, comes on suddenly, being manifested by lameness and pain, with or without swelling, in a joint, tendon or muscle, and usually of that one side. But the striking peculiarity of this disease is the manner in which it shifts from one part or organ to another. The pulse is tense and fast; the condition is feverish, the temperature varying from 103 to 105 degrees. The bowels are usually costive.

Symptoms of Chronic Rheumatism.-This form ma either commence independently, or the acute form may degenerate into the chronic, in which the feverish condition disappears, the joints and bones are the parts mostly involved, and the trouble is more stationary. 
As a result of this disease, enlargement of the bones, from bony deposits and ulceration of the articulations, are not uncommon. A frequent seat of ulceration is the navicular joint, producing navicular disease, or chest founder. In young animals deformities of the limbs are a sequel not uncommon, nor is this unknown among older ones. In both man and beast, rheumatism is often an antecedent of heart diseases.

Treatment.-Provide a comfortable box and clothe warmly. Give pill No. 18, and see that the diet is good in quality, and in nature easily digested. To neutralize the "poison" in the system give No. 23, or the following:

No. 62.

Salicylate of soda, $4 \frac{1}{2}$ ounces.

Divide into 12 powders.

Give one powder every four hours.

If the local pain or swelling are great, give half ounce doses of the tincture of opium

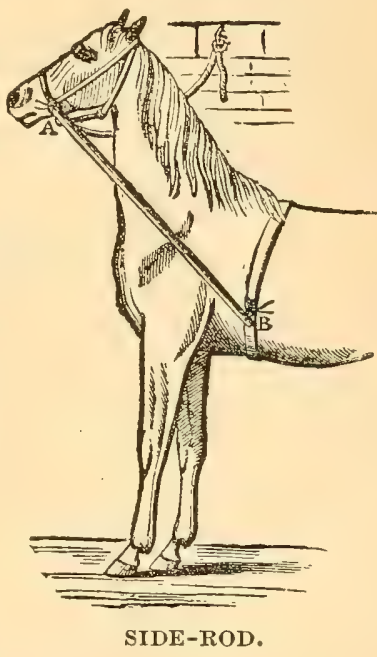
internally, and externally rub on Soothing To prevent the horse from bitng Lotion No. 3, and then bandage.

a blistered part.

Locally, if an acute case shows no signs of abating, one of the strong blisters given in our "Recapitulation of Remedies" should be thoroughly applied around the whole joint, and the side-rod or muzzle used to prevent the part from being bitten. In this way we may hope to prevent the case from becoming chronic.

In the chronic form the same internal remedies are advisable. As with master so with horse, chronic rheumatism is not very amenable to treatment, and results will often be discouraging.

\section{Purpura Hemorrhagica.}

This is a peculiar ailment of a non-contagious character, oftener seen as a sequel to some debilitating disease than as a disease itself.

Causes.-Veterinary authors are generally agreed that this ailment is of a septic (putrefactive) nature, from the absorption into the system of poisonous elements from unhealthy surroundings. Thus it is apt to develop late in the history of debilitating fevers, wherever the ventilation and drainage are bad; or, again, in healthy animals that are compelled to inhale the foul air of stables loaded down with that great product of decomposition, ammonia. 
Symptoms.-These, whether it be a successor of some other disease, or has its origin in filth, are uncertain. But among the first signs likely to attract attention will be a painful swelling of the legs, or a purple discoloration of the membranes of the nose or eye, or of the skin; this will be far the most noticeable in light-skinned horses. At the same time a sudden fever arises, the temperature going as high as 106 degrees, but showing daily fluctuations somewhat marked.

As the disease progresses, the involved mucous membranes of the whole system exhibit signs of sympathetic action. A dirty-colored or bloody discharge streams from the nostrils, and in many cases a fetid, bloody diarrhoa is also present. The swellings of purpura involve the legs, lips and dependent parts of the body generally; also

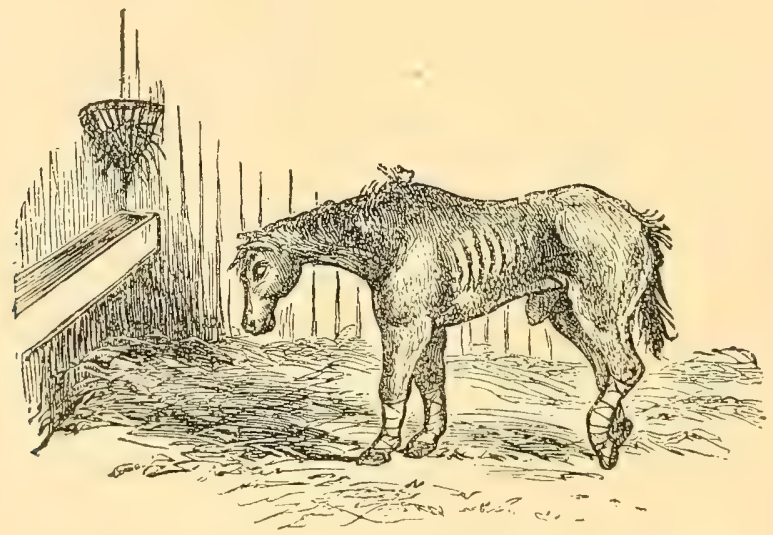

P'UIRPURA HEMORRIIAGICA.

the internal organs, as the lungs, liver and spleen, all of which become enlarged. The swellings are characteristic; they are not only tense and painful, but end abruptly at the upper side, looking "ats though a cord had been tied around the part.' Eventually, the swellings may crack at the flexures of the limbs, and a thin reddish, or distinetly bloody, discharge is established, and when the blood supply of these parts is interfered with, large patches may slough off. Swellings of the lips, face and tongue hinder the animal from seizing and manticating his food properly, and this hastens the wasting, or emaciation, which is always so marked a feature of this discase, owing to the great amount of tisue change. The extravasated blood in the tissnes beneath the skin, or in the internal organs, may undergo 
decomposition, and be discharged in the one situation externally, or in the other into a cavity of the body, and, by being absorbed into the blood, may set up a case of pyæmia, with the characteristic abscesses of that disease.

Treatment.-The very first requisite is to change the animal to a healthy stable. Clothe well in cold weather; allow plenty of clean, cool drinking water, dissolving in every bucketful daily an ounce of the chlorate of potash. To prevent the swelling of the limbs, or to aid in its reduction, give the following drench:

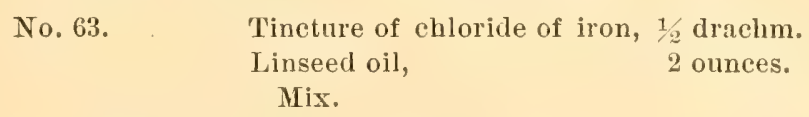

Give as one dose, and repeat it three times a day. Oatmeal gruel, linseed tea, or bran mash, will be the proper diet; if debility is a prominent symptom, a little whiskey should be mixed in the water.

As convalescence approaches, good oats, hay, turnips, etc., should be given, along with any of the tonic recipes prescribed in this work. This stage of the disease is often very prolonged, the animal remaining thin and weak for many weeks. The owner will be fortunate in this disease if recovery attends his best efforts.

Local Treatment.-This is not often called for. But occasionally the swelling around the head is so great as to interfere with the breathing, and then it must be bathed with hot or cold water, or even an astringent solution. The local swelling, in whatever part of the body, should never be opened, unless the presence of pus can be demonstrated; in that case it should be evacuated, and the sores dressed or syringed with antiseptics. If health only returns, nature will take care of the swellings; they will vanish through absorption.

\section{Glanders and Farcy.}

These are not two different diseases, as used to be believed, but two forms of one disease, affecting principally the horse, mule and donkey, and to which cows, sheep and fowls are not susceptible. In glanders the parts affected are the membranes of the nose, upper air passages and lungs, and the glands of the jarws; while farcy affects the absorbent vessels of the system which are superficially situated around the body. Horses inoculated with the glanders poison in many cases develop farcy, and vice verse; and cases of glanders, towards the latter stages, generally include the symptoms of farcy, and the case is the same as regards farcy turning to glanders. 
Causes.-This belongs to the class of contagious and infectious diseases, being produced by a very small germ, the bacillus mallei, which somewhat resembles the germ of consumption. This scourge is found accompanying such conditions as tend to lower the health, such as poor ventilation, bad drainage, uncleanliness, bad food and general neglect. For these reasons it is of frequent occurrence in places where horses are crowded together, in camps, railroad construction quarters, and other large collections. A horse may contract glanders, and have the poison lie dormant in his system until some depressed condition of the health appears favoring its growth, in the same way as is frequently seen in rabies, or hydrophobia; this is doubtless the reason why it was at one time supposed to be of spontaneous origin. After debilitating diseases, and in low conditions of the system generally, there is always a great susceptibility to the contraction of all sorts of infectious diseases.

Symptoms of Glanders.-Usually the first sign of the disease is a swelling of the glands on one side of the lower jaw ; these are painful, hard and knotty, but there is no tendency to suppurate. The pain gradually leaving, they remain enlarged. Closely following the swelling of the glands, there is a thin discharge from the nostril on the swollen side; this will become yellowish in color and of a peculiar sticky feeling; it adheres around the nose in a crust, obstructing breathing. These signs may last for weeks or months before the next change appears; good care and feeding having a great influence in retarding the development of the malady, while hard work and ill-usage hasten the acute.stage. The mucons membrane of the nose will be noticed of a very red color, and small blisters form, which burst, forming an ulcer, with an excavated look and elevated red border. The discharge may now be tinged with blood. The ulcers are supposed to form in the air-spaces of the face, from there extending to the nose, throat and lungs. The condition of the animal becomes distressing; there is weakness and emaciation, and the hair of the mane and tail is easily pulled out. Farey is at last found affecting the limos and body, the animal presenting a pitiful sight. The breathing is of a snufling sort from the collection of matter, which in some cases is so profuse as actually to cause suffocation.

Horse owners sometimes undergo needless anxiety from nasal gleet, so closely resembling in appearance (though only in appearance) the early discharges of glander's. For the same reason genuine 
cases of the latter are sometimes regarded as innocuous, until they have done wide-spread mischief. There is a very simple test for distinguishing between nasal gleet and glanders. It is given under the former head in Chapter XV.

Prevention.-In this disease it is emphatically true that "prevention is better than cure." Preventive treatment consists in keeping the stables clean and well ventilated, and in supporting and toning up debilitated animals. In suspected cases they should be isolated from the rest of the stock, and all brushes, buckets, combs, blankets, etc., used for them, should never be brought near the others.

Treatment.-Treatment for the cure of glanders is not allowed in any of the States that we know of. The loathsome nature of the disease being so well known, and its ready communicability to man, it is manifestly best to destroy the animal as soon as the diagnosis is confirmed.

Symptoms of Farcy.-Farcy generally commences with a slight fever, but the most noticeable thing is the swelling of the absorbent vessels just below the skin; these are said to be corded, and at intervals will be seen little knots, corresponding to the small valves in the vessels. When the knots appear and the vessel is not corded, it is called button farcy. These buds, or buttons, ultimately break, forming ulcers of an unhealthy appearance, from which there is a discharge of offensive smelling, dirty yellow pus, having the same gluelike qualities as seen in glanders from the sores in the nostrils. In other cases the first signs are painful swellings of the legs, with the later development of the buds and ulcers. A chronic form of farcy is sometimes seen in which there are few ulcers, and it may be months before any further changes occur, but the final termination is in some form of glanders.

Treatment of Farcy.-Mild cases have apparently been cured by using the hot iron on the ulcers, and biniodide of mercury ointment along the cords; but the disease will invariably reappear as either glanders or farcy, although it may be latent for a period as long as even a few years. At the same time other horses are liable to contract the disease from the one apparently cured.

\section{Strangles.}

This well-known disease is especially common among horses under seven years of age. The parts affected are the glands under the 
lower jaw. In the second or irregular form of strangles, the glands in the axilla (corresponding to the arm-pit in man), and the groin, and those among the internal organs, inflame and suppurate.

Cause.-The true cause of strangles is a "micrococcus," a germ which is too minute to be visible to the unassisted eye, but is recognizable uncler the microscope by its staining the pus discharged. Infection may occur through wounds, especially if they are in the mouth or interior of the throat.

Symptoms.-The simple form commences as a common catarhal

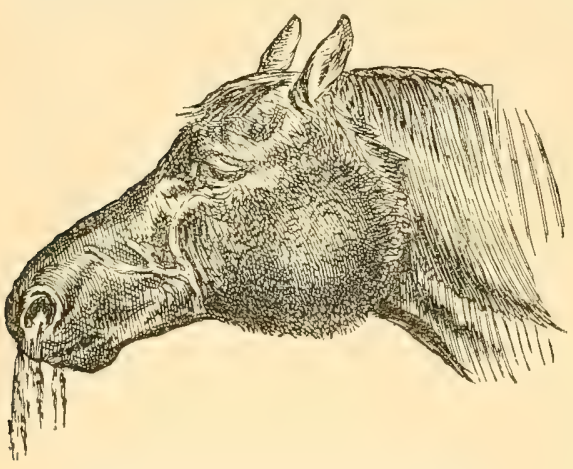

SIMPLE FORM OF STRANGLES. cold, with cough and loss of appetite. Shortly ensues a swelling of the glands on one or both sides of the maxillary space (that between the two sides of the jaw), and this may, perhaps, extend to the edges of the lips, giving the head a very ungainly appearance. There is a profuse discharge of whitish matter from the nose, which soon partakes of a purulent character. Owing to the greatly swollen condition of the parts, and at times from the extension of the disease to the larynx, a roaring noise is made during respiration. In very severe cases the difficulty of breathing may even amount to a most distresing and eventually fat al strangling process, whence the name by which the disease is known.

The irregular or batstard form of the disease generally takes a long time to develop; the animal will be noticed to be hide-bound, unthrifty, and tucked up in the flanks. These signs, combined with an occasional cough and shivering on the slightest exposure to cold, are certain forerumners of the peculiar ailment we are considering. The glands between the jaws may swell, and when opened they discharge their contents, but, as soon as healed, mother crop of swellings will be noticed in the same vicinity; and this may go on for weeks, or cven months, until the glands the whole length of the neck become involved. The glands in the axilla (arm-pit) and groin may likewise be affected. The formation of alscesses internally must be regarded as very serious, as their rupture will end fatally. 
Treatment of the Simple Form.-In this the treatment is very simple. To the swelling apply a flaxseed poultice, as shown in our illustration, and when pus is detected by the fluctuation in the swollen part, make a free opening low down in the swelling, thus assuring good drainage. A laxative diet will be necessary.

\section{Treatment of the Bastard} Form.-The treatment for the irregular or bastard form of strangles will be to give good,

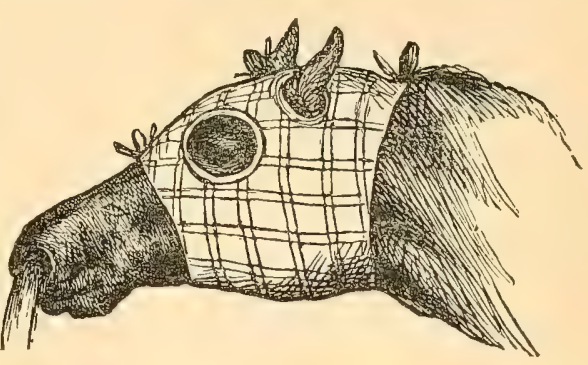

POULTICE FOR STRANGLES. easily digested food, with tonies, promptly when the first unthriftiness is noticed. Exposure to cold must be avoided. When the swellings develop, they should be opened as soon as ever pus is suspectod, and the wound washed with an antiseptic solution, such as our No. 1,12 , or 13 .

\section{Variola Equina, or Horse Pox.}

This is a contagious eruptive fever, characterized by the appearance of pustules and scabs, on the limbs principally, but also at times affecting the face, nose and other parts.

Causes.-This disease is caused by a specific virus bearing a close relation to the human small-pox. It frequently breaks out as an epidemic, especially in cities where epidemic small-pox is raging. In Montreal, two well marked outbreaks of it have occurred within a few years, simultaneously with the wide-spread ravages of small-pox among the inhabitants.

Symptoms. - The attack is generally mild in character. A feverish condition is first noticed, with a swelling of the limbs or other parts; small lumps form at these parts, and seven to ten days later pustules, which discharge a yellowish watery liquid that produces scabs, and mats the hair together. These sores readiiy yield to treatment, and when the scab is removed the surface appears red and depressed. A cure may generally be effected in three weeks' time.

Treatment.-Isolate the animal at once, to prevent the spread of the disease. All buckets, blankets, etc., must be kept separate, and only one man should be allowed to attend the patient, and he should not attend the other horses. II should be careful about sores on 
his hands, or he may be innoculated with horse-pox. An easily digested diet will be required, and if the fever is excessive, some of the fever medicine that will be found among our recipes. The disease runs a regular course, and the only treatment called for is to support the patient's system while passing through it. Locally, hot fomentations may be used for the comfort they impart. To remove the scabs and promote the healing of the sores, apply a little of the following with a brush or mop:

No. 64 .

Sulphate of zine, $1 / 2$ ounce.

Carbolic acid, 1/2 drachm.

Glycerine, $\quad 3$ ounces.

Mix, and apply twice a day.

If debility is marked after convalescence, give some of the tonics mentioned in the "Recapitulation of Remedies."

\section{Rabies, or Hydrophobia.}

This is a disease primarily affecting the canine race, but transmissible by innoculation to the horse and other domestic animals.

Cause.-The germ of rabies is a specific virus in the froth of an affected dog's mouth, which gains an entrance into the system of the animal bitten through the circulation, and may produce its effect almost immediately, or, on the other hand, may be dormant within the doomed creature for a long while.

Symptoms.-The symptoms in the horse are not characteristic. A wound may be found, or, instead, a thickening of the skin, with a scar, where a wound has healed. The first symptoms are nerrousness, with pawing and stamping of the fore feet; these increase, and then a dangerous wickedness appears, the animal struggling and biting at objects near, and if the attendants approach, they are attacked in a ferocious manner. The innoculated wound is often persistently bitten by the sufferer. In the latter stages, paralysis of the hind parts comes on, the forerunner of death, which soon follows.

Treatment.- When a wound is known to have occurred from the bite of a rabid animal, it should be deeply cauterized with stick caustic, or a hot pointed iron, or else the entire wound cut out. Medication has utterly failed in rabies. The method of immoculation introduced by Pasteur has proved a decided suceess on human patients, and innoculated animals have also completely resisted the discase, but the $t$ wo great diffeulties in making it available in veterinary practice are, first, to know that the specific wound has ocemred, and next to 
procure innoculation virus. Stiil, hydrophobia is so rare among horses that no farmer need lie awake of nights from worry over it.

\section{Melanosis, or Black Tumors.}

This is a peculiar form of a black-colored tumor that most commonly makes its appearance on old grey horses. The black pigment, when the veteran's hair begins to turn white, is deposited in the skin and internal organs, in round black masses, which increase in size and number, until, perhaps, considerable portions of the body are covered with them. Their usual seat is under the tail, around the anus and vagina, around the sheath or milk gland, and also frequently on the lips. By their size, they sometimes produce inconvenience in passing the dung, and from frictions during the animal's motion they may ulcerate and discharge. They often cause death by interference with the functions of some important internal organ.

Treatment.-When the small lumps are first seen they may be cut out, and the raw spots treated as directed for wounds. But they will most likely return in time-if not in the same spot, then in its vicinity. Old, large tumors may also be removed, but at that stage no great benefit can be expected.

\section{Pyæmia, or Blood Poisoning.}

This can scarcely be termed a disease; it is rather a sequel to some purulent disease or wound, from the absorption of pus into the blood. thus poisoning the entire system.

Symptoms.-These at first are not easily recognized. There is fever, but there has probably been fever all along. Later, however, the breath becomes very fetid, and in many cases a very foul smelling diarrhoia sets in. The animal loses flesh rapidly, and has a general haggard expression. Abscesses form in the internal organs, and often also in the glands underneath the skin.

Treatment.-Not much can be done in the way of treatment. If any matter points near the surface, the abscess should be opened, and afterwards treated as an ordinary wound. In the human subject large doses of quinine are used, but our own experience shows no success from this treatment in veterinary practice. Stimulants of any kind should be freely used to tone up the vital functions, and, of course, good healthy surroundings should always be mantained.

\section{Weed or Thick Leg (Lymphangitis).}

This is a common disease known also as "big leg," or sometimes "Mondaty morning disease." 
Causes.-Too high feeding and too little work, under which conditions the blood is overloaded with nutriment, and inflammation of the lymphatic vessels is induced.

Symptoms.-The symptoms may appear suddenly, but oftener

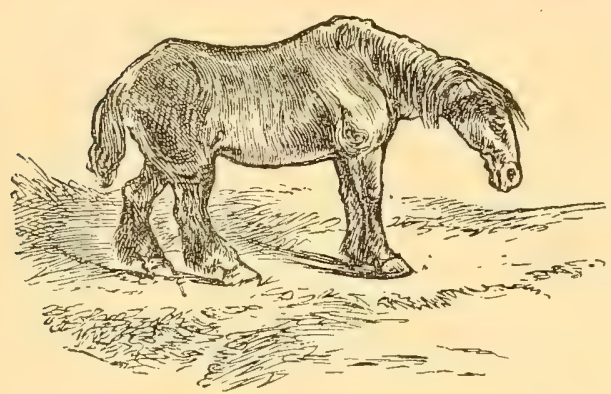
after a period of rest, especially on Monday morning. It ordinarily commences with a shivering fit, to which there soon succeeds, a hot stage; the animal remains feverish, and the pulse is hard and strong. A stwelling may presently be noticed in the groin of the hind leg, and sometimes in the axilla LYMPHANGITIS, OR BIG LEG. (arm-pit) of the fore leg. It is painful and hard; the vessels leading from it down the leg are corded and sore; and in time the whole leg will be found uniformly

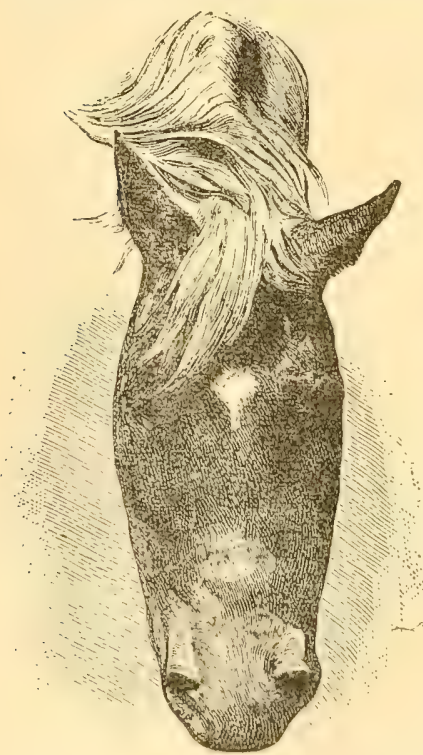

I.YMPIIANGITIS OF IIIE IEAD. Engraved for this work from a Photograph. enlarged, hot and painful. By proper treatment the pain leaves the swelling, which gradually subsides. Occasionally the leg remains permanently, though but slightly, enlarged.

The peculiarity of this disease is its tendency to recur, each recurrence being liable to leave the log larger than the previous one did. In the great majority of subjects the hind legs are the only ones affected, though the fore legs are liable to be involved also. Our illustration shows a case in which the swelling has attacked the head.

Treatment.- In the commencement of this trouble give Pill No. 18, to relieve the bowels, and change the feed to a laxative diet-bran mash. If shivering contimues, give a few doses of some stimulant. When the hot stage is reached, allow plenty of water and give No. 45. The kidneys should be encouraged to vigorous action, in order to deplete the system down to a state of health. No. 26 will be the medicine for this purpose. 
Locally, when the swellings appear, bathing the leg with hot water will encourage the swelling, and this in its turn give relief to the pain. Bandages will promote the patient's comfort. The Soothing Lotion No. 3 is often used with great benefit. After the pain has left the leg, moderate exercise will materially hasten the dispersion of the swelling, and should be given twice a day if possible.

In the chronic thick leg all forms of treatment have been tried without avail; a permanent tissue has been introduced, which it is impossible to remove. 


\section{CHAPTER XXXVI.}

\section{DISEASES OF THE NERVOUS SYSTEM.}

I. HEAD STAGGERS, STOMACH STAGGERS, OR BRAIN FEVER.—II. SLEEPT STAGGERS, TUMORS IN THE BRAIN, ETC.-III. PARALYSIS, OR PALSY.— IV. PARALYSIS OF THE LIṔS AND TONGUE.-V. SPRING-HALT, OR STRIŃG-HALT. -VI. TETANUS, OR LOCK-JAW.

\section{Head Staggers, Stomach Staggers, or Brain Fever.}

This is not a very common disease, though occasionally it will appear in a neighborhood as an epidemic.

Causes.-As to this there is great difference of opinion, but the preponderance of authority attributes it to the quality of the food. When too dry, fibrous and indigestible, the over-loaded stomach becomes inflamed, and then, by sympathy, the brain and spinal cord, with their coverings.

Symptoms. - The symptoms of this disease are not uniform; but most generally it comes on with dullness and drowsiness. Later

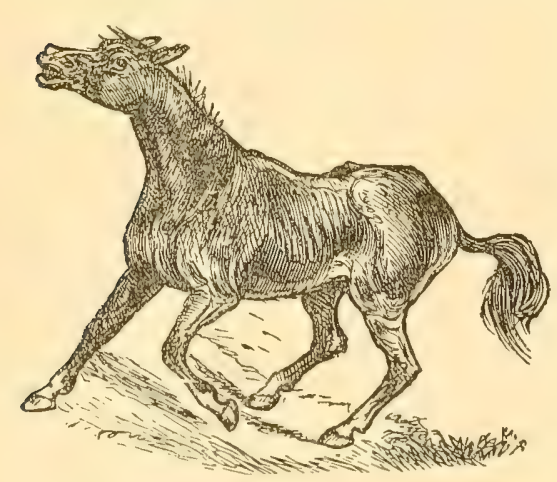

TIIE CONVULSIONS OF MAD STAGGEIR. these give way to more violent manifestations, in which convulsions are prominent. No one who has ever seen a horse thus affected - the muscles of the whole body convulsed, the tail erect and head extended-will need any description. The violent stage is usually succeeded by great weakness. If not already lying down, the patient will fall; now the struggles may recur, and the suceeding exhaustion advances rapidly, death ensuine shortly. At every stage after the first, grat nervousness is shown on the sliphtest noise, or the approale of any one. In many instances the animal goes to sleep with his mouth full of hay; or, when at patsue and smitten with the hlindness characteristic of this 
malady, he will walk right up to any obstacle in his way, press his head against it, and paddle with his feet until utterly exhausted.

Treatment.-Perfect quiet, away from other horses, is essential. A good purgative, such as our No. 18, will be of benefit, to relieve the bowels; if this does not act in twenty-four hours, repeat the dose. In the beginning of the attack, when the pulse is strong, bleeding may be resorted to with advantage, to the amount of from four to six quarts. If the convulsions are severe, give No. 33 .

When convalescence is well forward, it maly be necessary to apply blisters to the poll, or along the spine, to aid in removing any inflammatory products remaining around the nervous substance. In a mild type of this disease, recovery is very frequent, but the chances become much less when the convulsions are severe.

II. Sleepy Staggers, Tumors in the Brain, Etc.

The condition known as sleepy staggers is caused by tumors of various kind on or in the brain, or by some disease of the brain substance.

Symptoms.-Tumors in the brain sometimes attain a large size before causing noticeable inconvenience, but giving rise at length to convulsions, staggering, etc. In many cases the animal is only drowsy and sleepy; he will hold the hay in the mouth while he dozes, as shown in our illustration. If suddenly disturbed,

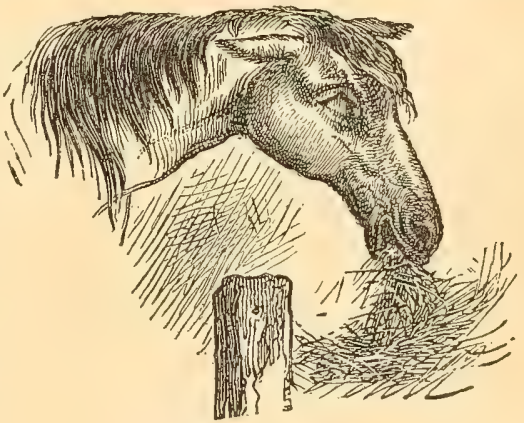

SLEEPY STAGGERS. he is very likely to tremble as if greatly frightened, and pull back on the halter. His every action shows he is not himself.

Treatment.-When due to a tumor, very little can be done; the symptoms will grow steadily worse as the tumor increases in size. The pill No. 18 may be given in connection with an easily digested diet. The place where stabled should be kept dark, and as quiet as possible. Palliative treatment is all that can be attempted.

\section{Paralysis, or Palsy.}

Paralysis may be complete or partial, and even in the latter case is to be regarded as serious, though some of such cases will respond to treatment.

Causes.-Various diseases, constipation, worms, grass staggers, azoturia, etc.; also fracture of the spine from exterior violence, the 
broken bones pressing upon the spinal cord, and in that way producing paralysis.

Symptoms.-When resulting from disease, the paralysis is rather likely to be general; yet in many cases the hind legs only are affected, the animal being able to stand on his front legs all right, while the hind parts are useless. When due to an injury, the symptoms will vary according to where the injury is located. If it is below the middle of the neck and above the withers, there is palsy of the parts posterior to this. This rule, in fact, holds good for the rest of the spinal column-the parts paralysed will be those posterior to (back of) the seat of the injury.

Treatment - When due to some other ascertained disease, treat according to the directions given for that particular disease, whaterer it be. When brought on by some injury, if the animal is valuable

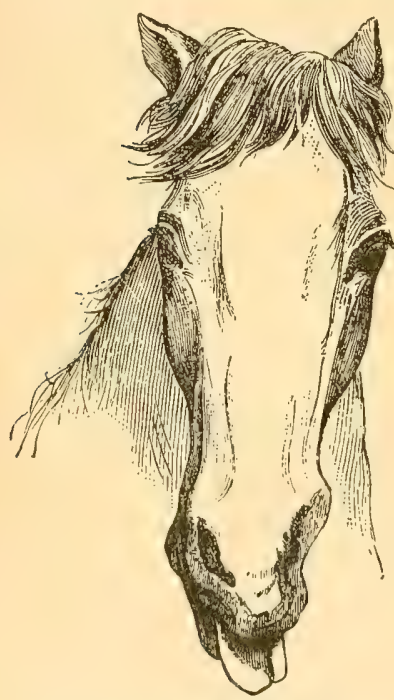

RIGHT-SIDED PARAI,YSIS OF LOWER LIP AND TONGUE.

Engraved for this work from a Photograph.

object. Horses that have the bad habit of pulling back are particularly prone to this trouble. Occasionally, as it comes with some disease of the brain, so it will go with it.

Symptoms. - When the paralysis is one-sided, the lip is pendulous, and the membrane is exposed. The tongue is frepuently included in the injury, and, when protruded, is seen to be drawn toward the and the hurt not too severe, treatment may be undertaken; but it is well to bear in mind that these can never be very hopeful subjects. Place the animal in a sling, to keep the ends of the broken bones in apposition while uniting. Regulate the bowels carefully, and be sure not to overfeed.

\section{Paralysis of the Lips and Tongue.}

Paralysis of the lips, and especially of the lower one, is much more common among horses than is generally understood. It gives to the sufferer an awkward, foolish look, besides the inconvenience in eating and drinking.

Causes.-Usually, some injury to the facial nerve at the point where it finds its exit from the cranium, below the ear. A bridle, halter, rope, or even an abscess of the neighboring glands may be the injurious 
healthy side, the same as the lip. This is well depicted in the engraving, where the right side is paralysed, and lip and tongue are drawn to the left.

Drinking is not always easily accomplished; naturally the lips are a great aid in suction, but now the water will dribble out of the mouth. Eating is likerrise greatly interfered with. Many animals in this condition, being unable to seize or gather the food with the lips, will make use of the teeth to accomplish this feat.

In complete paralysis of the lip it hangs down, and all control over its movement is lost. When the animal is in motion, it wags up and down. When the tongue is inrolved, in a bad case like this, it will be almost useless for eating; hence a not infrequent result is an emaciated condition of the whole body. Still, except as thus weakened, perhaps the animal is not at all incapacitated for work.

The upper lips are not as frequently paralysed as the lower. Possibly, however, they are paralysed sometimes without its being suspected, as the lips, although destitute of sensation, still hang against the teeth in the natural position. If the horse is suffering from general paralysis of

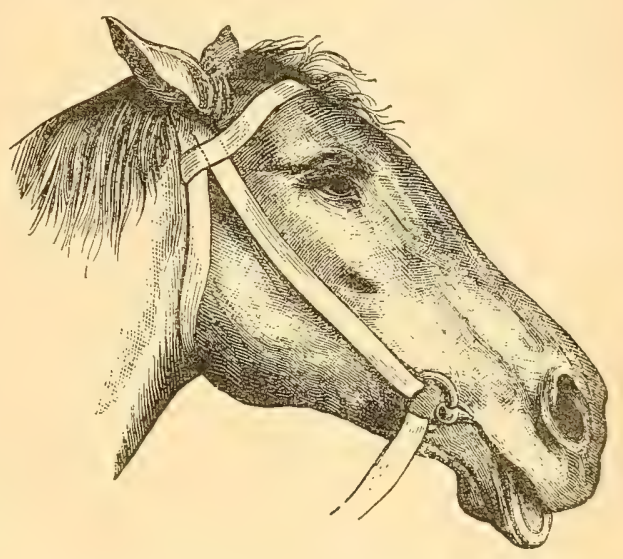

PARALYSIS OF BOTE SIDES OF LOWER LIP.

Engraved for this work from a Photograph. one side, even the upper lip will be drawn slightly toward the healthy side.

Treatment.-On the first appearance of any drooping of the lip, examine the bridles, halters, etc., and remove the pressure from the parts around the ears. If due to any disease of the glands-for example, distemper or strangles-treat such disease promptly and vigorously. At the beginning of this trouble, hot fomentations along the side of the face up to the ear, opposite the upper row of molar teeth, is generally adrisable. The Soothing Lotion No. 3 may afterwards be rubbed on, to relieve any irritation.

In case this treatment fails to relieve within a week or ten days, the use of Blister No. 10, or No. 11, along the course of the nerve (described above) will be necessury. If a galvanic battery can be pro- 
cured, let it be used faithfully-one pole placed helow the ear, and the other at the angle of the mouth. This must be tried twice a day, for at least ten days, before any observable benefit can be expected. Generally this is a very valuable adjunct to the treatment. In certain cases there is a tumor or bony growth, and these will resist treatment of any kind.

\section{Spring-halt, or String-halt.}

This is a very common, nervous disease among horses, that usually affects one hind leg only. In the human subject and in dogs, the same ailment is apt to involve the whole nervous system, producing the incessant twitching of the limbs and muscles of the body which is familiarly known as St. Vitus's dance.

Causes.-Precisely what causes this strange disorder is not certainly known ; but, besides its common association with other diseases, it is sometimes found in comnection with tumors, pressing on the nerves reaching to the affected part.

Symptoms. - Occasionally, a horse is seen with spring-halt in both the hind legs, and instances have not been wanting of a horse with one, or even both, of the front legs thus affected. The movement of the limb in spring-halt is peculiar and characteristic. While standing, nothing will be noticed amiss with the horse, but put hin in motion, and the leg will be raised with a spasmodic jerk, nearly always to a point higher than natural, and in very severe cases actually touching the belly. Unlike some forms of lameness that wear off with exercise, spring-halt is continuous. As a rule, however, it does not incapacitate the animal for service. It is mnsightly always, but for draught purposes it hardly ever impairs his working power at all.

Treatment. - This is very unsatisfactory in its results. When associated with some form of disease, spring-halt, in most cases, gradually disappear's after such other disease is cured. Various formidable operations have been devised, and adrocated with a great flomish of trumpets; but reliable, permanent suceess has eluded them all. In those exceptional cases where a tumor is discorered pressing on the nerve, its removal will generally effect a cure.

\section{Tetanus, or Lock-jaw.}

Cause.-Tetamus, as has been aseertained by late researches, is due to the small tetanus barillus, which gains entrance to the system, usually through some cut or a mail wound of the skin or hoof, or oceasionally through abrasions of the digestive tract. 
Symptoms.-Ordinarily these do not develop until the wound is nearly healed; in many kinds of nail wounds of the feet they will not appear for several weeks. The first sign, in many instances, is a stiffness of movement when working, with difficulty in turning around. This is followed by the characteristic setting, or locking, of the jaws, though in special cases the jaws may be slightly opened, or may even not be affected at all, the animal being able

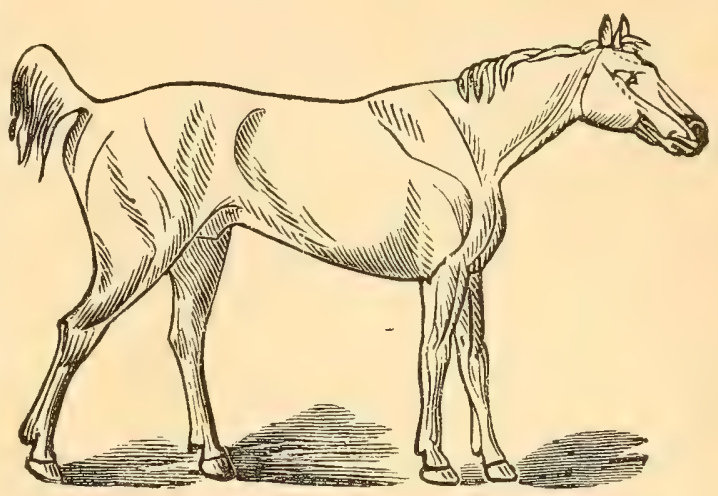

TETANUS, OR LOCK-JAW.

to eat during the whole course of the disease. The muscles of the whole body become rigid, and from being so drawn, their outline is

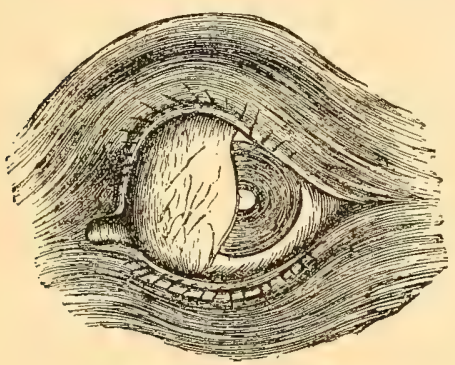

THE EYE IN LOCK-JAW. abnormally distinct; the neck is extended; the tail elevated, and moving up and down, perhaps, like a pump handle; the belly is greatly tucked up; and a deep furrow is traced from the elbow to the joint of the hip. When the jaws are locked, the horse keeps them in motion with a grating sound, and the mouth is full of ropy saliva that dribbles away incessantly.

The eye presents important symptoms in the early stages of the disease. It has a gloomy, sunken look; but, more particularly, the haw partly covers the front, or if the animal be suddenly frightened it will be protruded, as shown in the illustration.

Treatment.-This is not successful in more than two out of a hundred cases. The essentials are quiet and good nursing. If drinking is possible, give plenty of nourishing gruels. If the patient lives beyond the ninth day, and the symptoms are not very severe, he will have a chance of recovery. In this stage the slings are very useful, to relieve the weight of the body. Medicines of all inaginable sorts have been tried, but withont success. The treatment most advisable will be to poultice the wound regularly once a day (if it is still open), and attend to the general wants. 


\section{CHAPTER XXXVII.}

DISEASES, ETC., OF THE EYE AND EAR.

I. TORN EYELIDS.—II. WARTS ON THE EYELIDS.—III. ENTROPIUM, OR TURNING IN OF THE EYELASHES. - IV. ECTROPIUM, OR TURNING OUTWARD OF THE EYLlashes.--V. Filaria OCUli. - VI. STAPHYLONA, OR BUlgING OF THE CORNEA.—VII. GLASS EYE, OR AMAUROSIS.—VIII. INFLAMMATION OF THE CONJUNCTIVA, OR CONJUNCTIVITIS.-IX. MOON BLINDNESS, OR PERIOdIC OPHTHALMIA.-X. CATARACT, - XI. EXAMINATION OF THE EYE.—XII. DISEASES OF THE EAR.

\section{Torn Eyelids.}

The eyelids, by catching on hooks, nails, etc., are liable to be cut or torn. When this happens, wash the dirt off and sew the edges together with a silk thread, as described in the chapter on Wounds. On no account whatever should the torn piece be cut off, as the licl protects the eye from the entrance of dust, etc., and must be pre-

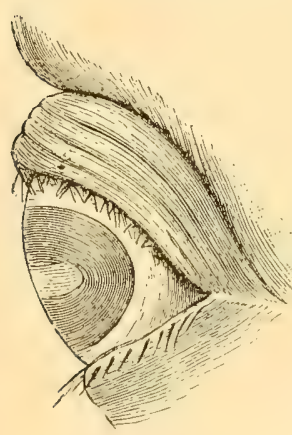

ENTROPIUM. served intact; and, besides; it is surprising how readily union will be effected in this part, even when the conditions seem desperate. The eye bandage may be used, and the Lotion No. 12, weakened by adding one-third its quantity of water.

\section{Warts on the Eyelids.}

Warts are often seen on the edges of the eyelids among horses. When pedunculated in form, they may be readily removed by tying a silk thread tightly around their base, and, if desired,

The upper lashes are the top clipped off. To remove the more diffused here turned inwards.

flat form touch with strong acetic acid; but it requires a steady hamd and great care to prevent injury to the eye.

III. Entropium, or Turning in of the Eyelashes.

This condition is ocmasionally scen among horses, but more often among dogs. When the erelashes of either the upper or lower lid project in against the cornea, the first result is conjunctivitis, and if this is long continued, the discase becomes chronie; the eye surface is thickened and opatpue, and in extreme catses it becomes dry. 
Treatment.-This consists in cutting an elliptical piece of skin out of the eyelid, close to its margin, but allowing sufficient room to insert a few stitches to draw the edges together. Healing will occur without much trouble. If there is a disposition to rub the eye on surrounding objects, put on the eye bandage.

\section{Ectropium, or Turning Outward of the Eyelashes.}

This is the exact reverse of the preceding condition. In the horse it is very rare. The eyelid being everted allows the entrance of dirt into the eye, and inflammation results, with similar consequences as in a case of entropium.

Treatment-Make a cut in the skin of the deformed lid and stretch it. At the same time carefully apply a little lunar caustic to the inside of the membrane, repeating this at intervals of four or five days.

\section{Filaria Oculi.}

This in America is an exceedingly rare disease, due to the presence of a small worm varying from one-eighth to onesixteenth of an inch long, which has somehow found its way through the circulation into the humors of the eye. In India, British veterinarians meet with it often. Irritation of the eye, weeping, dimness of vision, and ultimately a cataract, form an outline sketch of its history.

Treatment.-This consists in casting, turning the horse on his back, and carefully puncturing the cornea at the top, and allowing the fluid, and with it the worm to escape. The fluid will be again secreted,

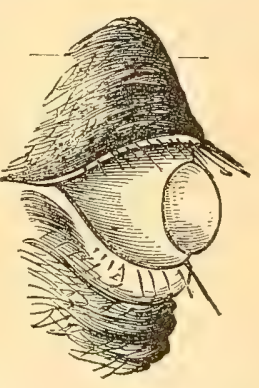
BULGING OF THE CORNEA. and if the puncture has been carefully done, no harm ensues.

VI. Staphyloma, or Bulging of the Cornea.

This, while rarely affecting the horse, is a common trouble among dogs. The cornea becomes milky, and bulges outward like a tumor in appearance; it even projects beyond the eyelids.

Treatment.-This will consist in the frequent and cautious touching of the protrusion with nitrate of silver (lunar caustic), at intervals of sufficient length (several days) to allow the scar to drop off before repeating the application. In many cases, when the tumor is solid, a needle may be passed through the bulging part, which is then earefully cut off with a knife, the hase being afterwards touched with lunar caustic. 


\section{Glass Eye, or Amaurosis.}

This is a diseased condition of the optic nerve, the one which connects the eye with the brain, and transmits the reflection of external objects. It is seen in connection with several different diseases, and from the excessive use of various poisons.

Symptoms.-The prominent symptom is a glassy stare. The pupil is widely dilated, and so remains, whether in the sunlight or in a dark

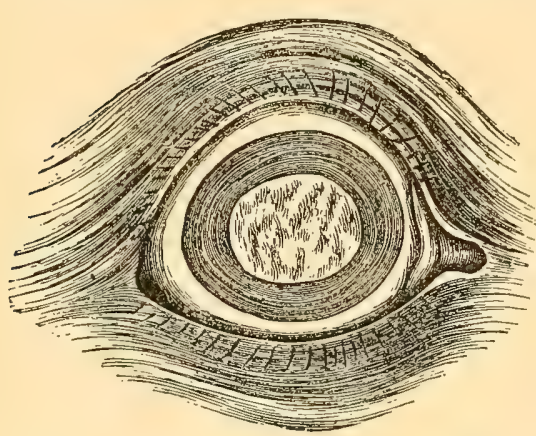

AMAUROSIS, OR GLASS EYE. stable. When both eyes are affected, which is usually the case, the horse keeps his ears in continual motion, and steps in a peculiar way. Standing at his head, if one finger is slowly advanced towards the eye, without causing any stir in the air, the cornea may actually be touched without causing the animal to wink.

Treatment.-Treat the other disease, if any such is at the root of this trouble. When proceeding from disease of the optic nerve, cure is impossible.

\section{Inflammation of the Conjunctiva, or Conjunctivitis.}

The conjunctiva is the thin, delicate membrane, lining the inside of the eyelids and the front of the eye. It is very liable to disease, as well as to injury from accidents, from being struck by a whip or stick, or from hayseeds getting under the eyelid. It is a frequent concomitant also of catarih, pink-eye, etc.

Symptoms.-First a slight weeping, with an intolerance of light, so that the eye is kept partially closed. As the inflammation increases, the eyelid is puffed and swollen, and the watery discharge becomes thick, and changes to a white or yellow color. If the eyelids are parted, the inside of the lids will be found to be swollen, and of a bright pink hue, with occasional streaks of red over the surface. The clear part of the eye-the cornea-is now dull looking, and later has a bluish scum on it; this, when the inflammation follows some injury, will frequently focus around one particular point. As recovery comes on, the swelling diminishes, and the bluish color disappears through absorption; but when the trouble has arisen from an aceident, there will at times remain a small, white speck at some particular spot. 
Treatment.-Provide a dark stall to keep the patient in. Change the diet to a laxative one. Should the disease have developed in connection with some other, treat both conditions. If it is suspected that hayseed is in the eye, use the eye opener, and make a thorough examination. To relieve the inflamed condition, use the following eye drops:

No. 65 .

Salphate of atropine, 4 grains.
$\begin{array}{ll}\text { Pure water, } & 1 \text { ounce. } \\ \text { Mix. } & \end{array}$

Put a dozen drops in the eye two or three times a day, with a feather or medicine dropper.

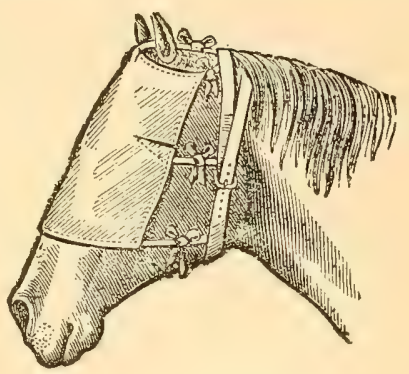

THE EYE BANDAGE.

Place a piece of sponge, soaked in the Lotion No. 53, made up with water instead of oil, over the eye, and apply the eye bandage. No caustics should, on any account, be used on the eye. Only a thoroughly skilled veterinarian should attempt such treatment for any eye disease.

\section{Moon Blindness, or Periodic Ophthalmia.}

This trouble is not nearly so prevalent now as it was fifty or seventyfive years ago, owing to the same circumstances which have so beneficially affected many other diseases of the horse, namely, the great improvement in stable construction and stable management.

Causes.-The predominant cause is to be found in the stable being too dark and badly ventilated, and, perhaps, filthy besides; or at least these conditions are great predisposers to ophthalmia. The disease is very common likervise in districts where the geological formation is of white rocks; this color, by straining the eye, produces an inflammatory condition. Hereditary weakness of the eye must also be taken into the account, although there is a difference of opinion as to the advisability of breeding from an animal affected with moon blindness. Our own observation has been that the foal of such a parent is extremely liable to become similarly afllicted, in the course of a few years at farthest.

Symptoms.-The first signs resemble those of conjunctivitis. There is a painful susceptibility to light, and a swelling of the eyelids of only one eye; tears run over the face; a cloudiness of the eye is also prominent, and as this clears off, the color of the humor is 
found to be of a dirty amber. The eye looks smaller than the opposite, on account of the muscles retracting it inward from the painful light. Occasionally a highly feverish state is seen.

In about a week the inflammation subsicles, the eye gencrally assuming its natural appearance. But in the course of a month or six weeks, the same process has again to be gone through with. Though the eye may, perhaps, have successfully resisted the first attack, so far as permanent change is concerned, the second is almost certain to leave its mark; the eye will not clear up so soon as before, the lens will exhibit a few spots of white lymph on its surface, readily visible through the pupil, and some of these may float in the humor. However, these spots are not always to be detected by the naked eye.

The frequent recurrence of the inflammation, and the concomitant deposits of the white lymph on the lens through which the light has to pass, will gradually so affect the organ as to prevent any light from passing. By this time, the condition of cataract has become established, which, in the horse, means irremediable blindness in this eye. But the disease does not stop here; it usually turns its attention to the eye that has hitherto been healthy, and in a varied length of time it, too, succumbs, through the same process as its fellow. All degrees of moon blindness are encountered by the retcrinarian from very partial to complete blindness. Cataract, in which it terminates, will be treated of in the next section.

Treatment.-In the early stages, give Pill No. 20, and place the animal on an easily digestible diet. If the stable is too dark, put in more windows, not forgetting to attend carefully to the stalls, removing all excretions, and sprinkling plentifully with chloride of lime. If a highly fererish state exists, give the Ferer Medicine No. 21 , or No. 22, until it is allayed.

The local treatment will eorisist in protecting the eye from the light by the eye bandage, shown on page 461. Reduce the inflammation with the Eye Drops No. 65 ; after using them, place a wet sponge over the eye, as directed for conjunctivitis. When a cataract is discovered coming on, treat as directed for that affection.

\section{Cataract.}

This is the sequel of moon blindness, just described. The changes in the structure of the eye have now become permanent, and from 
this defect, many valuable animals are rendered comparatively worthless. It is, however, one that can be most readily detected.

Symptoms. - A cataract is usually of gradual formation. At first only one or two tiny white specks may be seen back of the pupil, on the lens. By a recurrence of the original disease, this condition extends until the whole pupil is covered, when it is seen as a pearly white formation completely filling the pupil, thus shutting out all light. Many other changes may also be seen; the pupil becomes very irregular in form, or its beautifully colored iris, or curtain, may either bulge

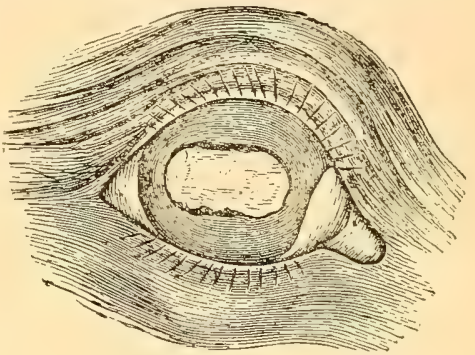

COMPLETE CATARACT. forward, or be retracted. The finger, if cautiously advanced, may be placed upon the cornea without causing winking-the eye is stone blind. The effect of cataract in producing blindness is varied according to the disposition of the animal. Usually the ears are kept continually in motion, and in locomotion the feet are lifted high from the ground. Many horses in this condition are inveterato "shyers."

Treatment.-If the sight is completely lost, treatment would only be a loss of time and money. But when the cataract is only developing as yet, the hope of success, while not great, is sufficient to warrant the owner in doing his best to save the horse's sight. In case of irritability of the eye, use the Eye Drops No. 65. The removal of the formation on the lens is to be effected, if at all, by constitutional treatment. Accordingly, use No. 46, and use it perseveringly. Success need not be expected immediately, but only after two or three weeks' time; if any benefit is to result, it will certainly be shown within three weeks at furthest.

In the human subject the somewhat formidable operation termed couching is performed for the removal of the diseased lens, but it is surrounded by serious additional difficulties in the horse. The administration of chloroform is absolutely necessary, to prevent the haw of the eye from getting in the way. The eye opener is also required to keep the eye open. Only certain subjects should be operated upon at all; a vicious or nervous animal, in conseguence of the imperfeet vision which is the best result to be hoped for', would be likely to prove a "shyer," if not a runaway. It is estimated that the 
anount of vision possible in a successful operation for cataract is never more than one-eighth of the natural.

Another method of operating on a developing cataract, is to insert a needle into the upper part of the cornea, and gently prick the lens in a half dozen places. Chloroform is absolutely necessary in this case also.

\section{Examination of the Eye.}

The importance of a thorough examination of the eye cannot be overestimated in passing upon the soundness of a horse. The inspection will comprise, first, a comparison of the two sides as to size, color and position; second, an examination of the cornea, the haw and the aqueous humor immediately behind; and, lastly, a searching scrutiny as to the transparency of the lens, and the structures posterior to it.

The cornea and the aqueous humor should be clear, and allow the iris, or curtain, and the pupil to be plainly visible. The haw should be of a delicate pink hue, and not in a prominent position. It may be brought into view by placing the thumb and fore-finger, one on each eyelid, and then drawing the lower lid down, at the same time pushing the upper lid upward and inward. By thus pressing on the eyeball, the haw is forced partly over the front of the organ. (It is always well to know how to do this, for in this way any speck of dust, hay, oat chaff, etc., is readily brought to view.)

The transparency of the lens may be tested in a moderate degree by varying the intensity of the light. Take the animal into a dark stable, and notice the condition of the pupil; then into a strong light, and see if it dilates. Or simply use the hand to cover the eye for a half minute, and on suddenly withdrawing it, notice carefully the succeeding dilatation. The use of reflections is also an important test. Where a lighted candle is used in a dark stall, in the nommal eye there will be three reflections, one from the cornea, one from the lens, and an inverted one from the retina at the back of the eye. If any of these reflertions are wanting, it indicates disease of the organ.

There is a complieated instrument greatly used by oculists for examining the internal structures of the human eye, which is also very useful to the veterinary oculist. It is on the plan of a small round mir- 
ror to reflect a light from behind the subject into the eye. In a critical examination this is of great importance.

The Eye Opener.-In any examination whatever of the horse's eye, the little instrument called the eye opener, and well shown in our illustration, is invaluable. This can best be appreciated after trying to examine. without it, the great obstacle being the protrusion of the haw from the inner side.

\section{Diseases of the Ear.}

Diseases of the ear are so rare among horses that we will not bur-

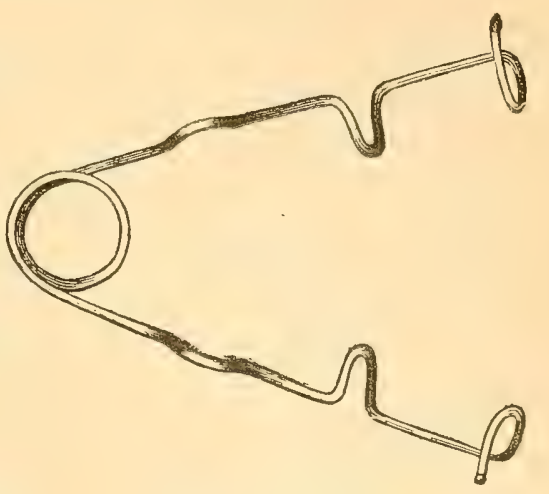

THE EYE OPENER. den the reader with a description of them. The fact is that very few horsemen ever think of looking in the ear, and would be none the wiser if they did.

An eczematous condition (resembling a breaking out) of the cartilage and around the base of the ear, is often seen from the rubbing

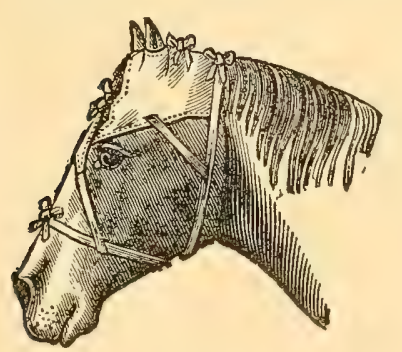

EAR BANDAGE. of bridles, halters, or the twitch. This is a very mild inflammatory condition, which is to be treated by removing the cause for the time being, and applying the following simple ointment:

\section{No. 66 . \\ Oxide of zinc, 1 part. \\ Vaseline, 6 parts. \\ Mix, and apply twice a day.}

This may be readily applied by means of a piece of cotton; or No. 16 may be used on a piece of cotton, and the ear bandage put on over it, to prevent the displacement of the dressing by rubbing. 


\section{CHAPTER XXXVIII.}

DISEASES OF THE SKIN.

I. SCRATCHES, OR CRACKED HEELS. II. SADDLE AND COLLAR GALLS. - IIT. RINGWORM.—IV. MUD FEVER.-V. ERYSIPELAS.—VI. MANGE.-VII. LICE.-VIII. FLEAS.—IX. TICKS.—X. WARBLES, OR WORNILS.XI. MAGGOTS.-XII. GREASE.-XIII. HIDE-BOUND.

\section{Scratches, or Cracked Heels.}

This is a very common disease among horses during the chilly season of the year. It is generally due to the use of water to wash the mud off the legs, but occasionally has its origin in the part being violently rubbed, or in rope burns, etc.

Symptoms.-The first noticeable symptom is a slight lameness, and a soreness on pressure in the hollow of the heel; in horses with white feet, the skin will be seen of a rosy red color. It maly stop at this stage, or it may advance until cracks are found from which pus will issue; in bad cases these may bleed at every step. After they are healed over, there is frequently a hard cicatrix where the crack was. In mild attacks, lameness will pass off after the animal has gone a few steps, but in the severer cases it will be rery persistent, so much so that the animal will have to be left in the stable.

Treatment.-To remove the cause will be the first proceeding. If due to the practice of washing the legs, have it stopped; instead, allow the mud to dry, and afterwards powder it out of the hair. (See pages 89 and 92.) Give the pill No. 20, if the bowels are not already open. The local application of No. 66, or of the following, will assure a speedy recovery, if the animal is taken care of:

No. 67 .

Liquor plumbi acetate, 2 ounces.

Olive oil, 6 ounces.

Mix.

Apply twice daily on cotton, with a bandage.

When the discance is of long stameling, it may be necessary to touch the surface with lunar caustic, or to apply a blister, such as No. 11 , afterwards using the above prescription. 


\section{Saddle and Collar Galls.}

These are exceedingly familiar troubles to all who have to do with any class of work horses, and thousands of patent nostrums are on the market for their cure.

The symptoms of chafing or galls are too common to need any description. When in the neighborhood of the withers, they must be promptly attended to, unless the owner wishes to have a case of "fistula" on his hands.

Treatment.-When the gall is unimportant, the use of a little padding on the harness will remove the pressure, and allow work to be continued; but if the gall be a large one, humanity demands that the animal be exempted from work till

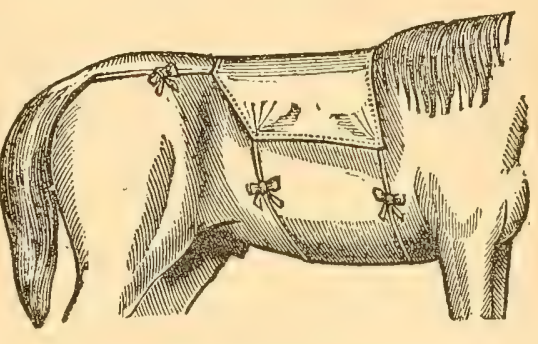

BANDAGE FOR THE BACK. cured. As a healing application to these galls, any of the following: preparations will be suitable: No. 16 , No. 17, No. 27, No. 28, No. 64 ; but No. 66 is probably the best of all. When possible, especially during fly time, the ointment or lotion should be put on a piece of cotton, and this bandaged on. Our illustration shows how easily this may be done.

\section{Ringworm.}

This is a contagious disease, not only transmissible from one animal to another, but even to mankind.

Cause.-The cause of ringworm is a small vegetable fungus that attacks the hair follicles of the skin, and eventually destroys the hair. It is most likely to be seen among poorly kept animals, as in such it finds a ready field for growth.

Symptoms.-The first sign will be an itching of the skin, to relieve which the animal will be continually rubbing himself. This is followed by an eruption of yellowish matter, which glues the

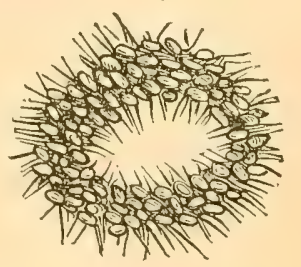

RINGWORM. hair together, and, on leaving presently, forms a circular scab, whose centre contains none of the disease. The fungus attacks the hair, and it falls out, leaving bald patches, which are permanent. Ringworm may appear on any part of the body, but the neck is the favorite spot, and next after that the shoulders and face. 
Treatment.-The only way to eradicate the disease is to kill the fungus. For this purpose a variety of medicines have been employed. Tincture of iodine will be rery good, painted on once a day; or the following may be applied with a mop every second day:

No. 68 .

Corrosive sublimate, 1 part.

Alcohol,

50 parts.

Mix.

After the skin gets sore, the mercurial ointment (to be had at any drug-store) may be placed on cotton and bandaged on once a day.

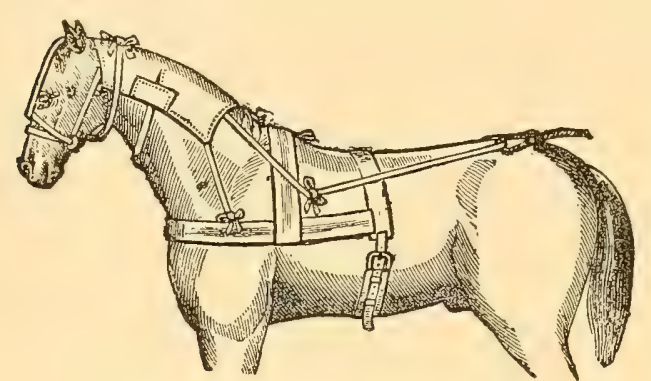

BANDAGE FOR TOP OF THE NECK.

It may, perhaps, be necessary to pull out the diseased hairs with a pair of forceps before any cure can be effected.

\section{Mud Fever.}

This is a severe inflammation of the skin of the legs, which may involve the whole leg and belly. It is a pro*.. duct of cold, rainy weather, combined with ignorance or laziness on the part of the stableman. Like scratehes, it is very frequent among horses whose legs are washed to remove the mud, and very rare among those which are allowed to stand until the mud is dry, and then brushed off.

Symptoms. - The legs are sore and somewhat swollen, the hair is rough, and, as recovery occur's, is shed in patches. In very severe esses there maly be some scabs about the parts. Considerable sympathetic fever is also to be noticed.

Treatment.-Stop the use of water on the legs, and rub No. 67 on the parts twice a dily. Give Pill No. 20, and if the ferer is high use No. 21, or No. 58, until it subsides. Allow gentle walking exercise, and keep the diet low.

\section{Erysipelas.}

This is an affection similar to that so common in the hum:an race. But the skin of the horse is of such a color and so thick, that the red coloration which gives rise to the vulgar names of the "rose" and "St. Anthony's Fire," in him is not visible.

Cause.-The cause is some unknown change in the condition of the blood, usually following a wound, sometimes even a slight one. 
The infection is connected with debilitating surroundings. The parts affected are the skin, and in the severer form the tendons and muscles, or even the bones.

Symptoms.-Within a few days after the horse receives a wound, it will be noticed that the part is swollen and tender. This condition rapidly extends; sometimes, where a leg is involved, it will extend the full length of the limb in only a few hours, and cause great lameness. The swelling is peculiar in this, that if occurring at a part where the skin is loose, it seems spongy, and pits on pressure with the finger. In consequence of the intense swelling, the skin around the joint is liable to erack; and then a yellowish fluid exudes.

There is a more severe form of erysipelas, in which the swelling is hard, tense and exceedingly painful. This is less common thin the preceding, but much more fatal; the swelling is very frequently followed by the formation of abscesses along the leg, and these may extend into the joints, which constitute it a hopeless case.

In both varieties of the disease, but especially the latter, the feverish condition of the system is very marked, and although the animal may urinate but little, he will drink immense quantities of water with obvious relish. The pulse is not only very fast, but also hard or wiry.

Treatment.-At the beginning of the attack give the Pill No. 18, and diet on easily digested food, if he will eat it. Reduce the fever with No. 58. Also give No. 39, to relieve the swelling and counteract the poison in the blood. The local treatment will be to bathe the part about four times a day with hot water, afterwards rubbing in the Soothing Lotion No. 3 , and then bandaging the part. If any wound exists, let it be treated as directed in Chapter XXIII. All abscesses that "point" must be opened, or they will extend into deeper and more important parts.

\section{Mange.}

This is a disease of great though repulsive interest to all lovers of the domestic animals, none of which are exempt from its rarages. It is contagious, and is generally transferable from one animal to another, and even to man. It is designated by various other names in different animals, such as itch, scabies, etc.

Causes.-Mange is caused by a minute animal parasite, a kind of which there are several varieties affecting the horse, some of them barely large enough to be seen with the naked eye. This parasite has a 
number of legs, as shown in the illustration, with mumerous fine hairs, and at the extremity of some of them very small suckers, as will be noticed in the highly magnified picture. The females, which are wreatly in excess of the males, lay almost incredible numbers of eggs, and thus the insects are hatched out at an immense rate.

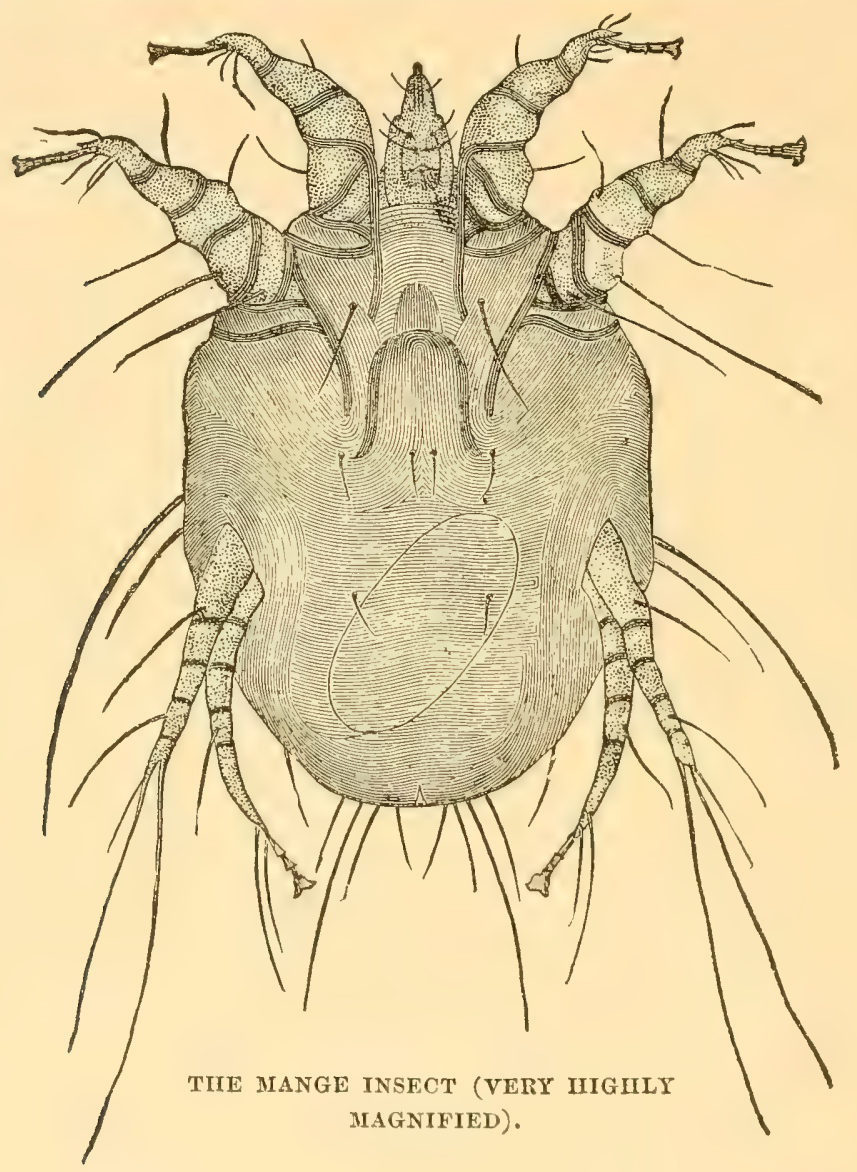

Symptoms. - In the horse, the first noticeable sign is an itching of the part affereted, which in some instances is so distresing as to malie the animal uneontrollable. The irritation is especially serere towards evening. If the skin is of a light color, some redness will be secn. The hair is generally rough, and either partly falls out, or is rubbed off; but after a cure has been effected, a new glowth quickly alperars. usually longer than the original, and of a slightly darker color. The 
irritation begotten of the insects burrowing in the skin causes scales and scabs to form. They will dry, and may be rubbed off, but only to be followed by another crop. The parasite is somewhat particular in "locating his claim." Not every part of the animal's body is equally favored; his choice is principally the neck under the mane, the withers, the root of the tail, and the legs.

Incredible Fecundity of the Mange Insect.-The manner in which the eggs are hatched is a study. The female, after biting through the horse's skin, commences laying her eggs, and gradually works her way inwards; so that the eggs first laid are nearest the surface, and being first matured, the young insect readily escapes, and thus makes room for the next below it. As an object-lesson in the extraordinary fecundity of the female insect, we here show a section of these burrows, (very greatly enlarged). This cut gives a clear idea of the hatching process. The female, after laying all her eggs, dies at the bottom of the hole she has burrowed. Gerlach has calculated that, starting with a single pregnant female, the number of eggs hatched within ninety days will reach the enormous number of $1,500,000$ !

Treatment,-Owing to the contagious nature of the disease (from mechanical contact), isolation will be essential. The patient's brushes, combs, blankets, etc., must be kept exclusively for him, and after he is cured, these articles should be thoroughly boiled in a mixture of soap, carbolic acid and water before using them in common. The harness and wagon shafts must also be washed with the same compound to remove scabs which may shelter the insects. The stall should be thoronghly cleaned, and brushed with a hot mixture of one pint of crude carbolic

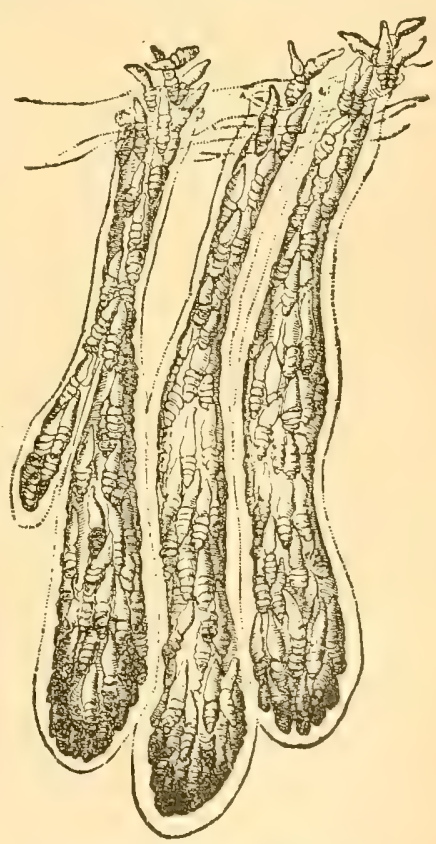

MANGE INSECTS (MAGNIFIED ONE HUNDRED TIMES).

They are seen developing in the openings of the skin. acid in a pail of water; after this has dried, the use of whitewash will complete the renovation. Care must be taken to keep the animal away from the posts or other places where he has been aceustomed to rubbing himself. 
As the disease is entirely local, no internal treatment is necessary, further than to regulate the bowels. As a local application, the following is excellent:

No. 69 .

$$
\begin{aligned}
& \text { Powdered stavesacre, } 2 \text { ounces. } \\
& \begin{array}{ll}
\text { Lard, } & 8 \text { ounces. } \\
\text { Olive oil, } & 1 \text { ounce. } \\
\text { Mix. } &
\end{array}
\end{aligned}
$$

Boil thoroughly and strain. This may be applied every second day, but only after the removal of the scabs by softening with warm water or oil. A strong decoction of tobacco water is also very frequently used, in many cases with success; but it is not always harnless in its effects on the patient. Tre append another very fine preparation, No. 70, which is of great benefit, most of all for dogs. A bath should be given occasionally.

No. 70 .

$$
\begin{array}{ll}
\text { Creosote, } & 1 / 2 \text { ource. } \\
\text { Olive oil. } & 7 \text { ounces. }
\end{array}
$$

Solution of potash, 1 ounce.

Mix, and apply every third day.

Treatment should be continued until all signs of the presence of mange has passed.

\section{Lice.}

These are very common on poorly fed horses that are kept in filthy stables. The lice from poultry kept in the same stable is sometimes the origin of the trouble.

Symptoms.- Itching is very prominent from the very first. The horse stamps, and rubs and bites the itchy spots in a mamner almost frenzied; in many instances the skin will be raw and torn, from his efforts to get rid of the irritation. In poultry lousiness small vesicles form on the skin, the hair and outer surface of which may fall off, and leave a small, circular, bare spot.

Treatment.-To kill the lice, No. 69, or a strong decoction of tobaceo water, should be rubbed into the skin. Guard anamst their recurrence by thoroughly clemsing the stable, brushes, ete, in the same way as directed for mange, and then whitewashing.

\section{Fleas.}

These pests particularly infest the dog, the hot, summer season heing the time that specially farors their growth. They can readily be discovered by brushing the hair back.

Treatment.-Fleas are readily removable with a decoction of tobacco water, which may, perhaps, have to he re-applied. The Per- 
sian and Dalmatian insect powders are both very effective, and, besides being cleaner in handling, have the advantage over tobacco of not being poisonous.

Cleanliness will generally prevent fleas from appearing on the horse at all.

\section{Ticks.}

These pests are very common in hot climates during the summer season, attaching themselves to the skin by means of a sucker or mouth. They attack horses, cows and sheep particularly, in many instances producing a condition of emaciation and debility. They are apt to be the most abundant among the thin hair, and inside the ears, where there is almost no hair at all.

The tick is of a dirty brown color, and without wings. So tenacious is his hold that frequently a small piece of skin will be pulled off with him.

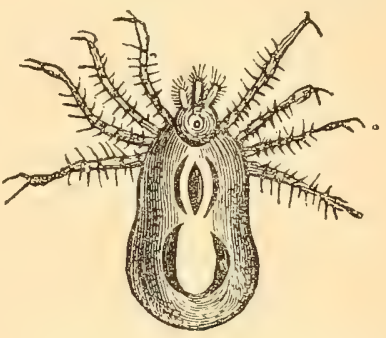

Treatment.-This will consist in pulling THE COMMON TICK (GREATthem off, or cutting off with a pair of scisLY MAGNIFIED). sors. Oil of turpentine is also good to remove them.

\section{$\mathrm{X}$. Warbles, or Wornils.}

The gad-fly, or developed bot, very frequently lays her egg in the skin of the back, hips and shoulders. In cattle, the presence of the fly excites great fear, and they frequently become uncontrollable. The penetration of the skin, preliminary to depositing the exg, doubtless causes intense pain. After a time, as the egg develops, a lump appears, which, perhaps, increases to the size of a hen's egg. When the egg is ripe the lump bursts, and out wriggles a tiny creature on to the ground, where it gradually develops into a gad-fly.

Treatment.-Generally the only thing needed is to press the lump, when it will burst; but if not sufficiently developed for that, use a knife and cut into the lump. If the slight wound thus made does not heal readily under the usual treatment, inject a little of the Solution No. 2. In hot weather it may be necessary to use a

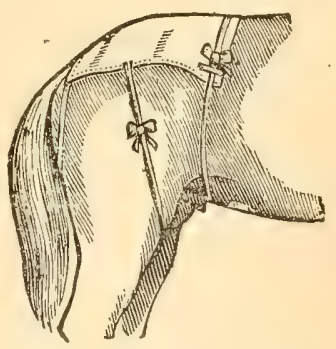

BANDAGE FOR THE CROUP. bandage, in manner as illustrated, to prevent the wound from becoming "fly blown." 


\section{Maggots.}

These are a very great nuisance during warm weather, when wounds are so readily infected, and become "fly blown."

The maggot is a small, white worm, from one-eighth to one-half inch long, and capable of only a wriggling kind of locomotion.

Treatment.-There is no difficulty in removing maggots from a wound by washing, and afterwards using a little oil of turpentine. They may be kept out of a wound-which is best of all-by using a bandage, to be changed whenever soiled. When the foot is the member discased, apply a boot made with a circular piece of leather or of zinc for a sole, and a canvas top to strap around the fetlock.

\section{Grease.}

This peculiar disease affects the back part of the heels, and the pastern and fetlock joints. It is considered by one high veterinary authority to be analogous to the pustular eczema of the human subject.

Causes.-Like so many other diseases, grease is found chiefly in stables where the surroundings are unhealthy. Heredity is also be-

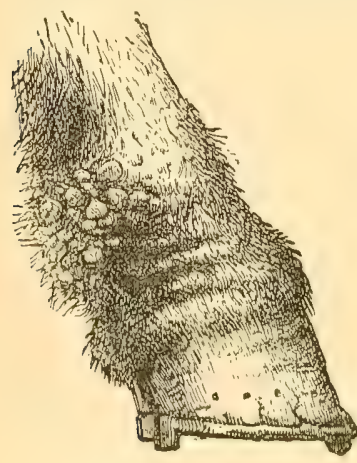

CHRONIC GIREASE.

Showing the "Grapes."

lieved to account for it sometimes, or at least to predispose to it. Some veterinarians assert that white-legged horses are subject to it beyond all others, but on this point opinions greatly differ. It is most frequently seen among the heavy breeds of horses that have long hair on the fetlocks.

The exciting causes, as given by Williams, are "improper food, especially moist, inferior, and cooked food; clipping the hair off the heels and legs; filth and neglect." Our own observation leads to the conclusion that the too plentiful use of water for cleaning the legs will also predispose to it.

Symptoms.-Although the fore legs are not exempt, the hind legs are those most frequently affected. Soreness of the skin in the regions above mentioned, with or without swelling of the legs, is the first thing notied. This is followed by the formation of pustules, and the dischare of a fetid matter, which mats the hair together, and, by its irritation, soon leaves the surface bare. In walking, the inflamed skin is liable to crack, and cause great pain. When the 
disease tends to become chronic, small bunches of proud flesh, called "grapes," spring up on the surface, usually covered with scabs, and, when the latter are removed, they readily bleed. From the masses of "grapes" issues a continual secretion of fetid matter. The swelling at first is sometimes absorbed, but if it continues and runs on into the chronic stage, the leg, as a rule, will remain permanently enlarged. In some cases a form of canker of the frog is developed, and occasionally, from the absorption of foul matter into the system, abscesses form along the course of the bloodvessels and in the groin, the disease running on at last into farcy.

Treatment.-The condition of the stable must be attended to first of all, and all unhealthy surroundings improved. Allow the patient a sufficiency of easily digested food, and regulate the bowels by using oil, or the Pill No. 20, if necessary. If the patient's system needs toning up, give the Tonic Powder No. 19, or No. 43. The use of the following recipe for one week, repeating the same the third week, after an interval covering the second week, is often of decided benefit:

No. 71.

Liquor arsenicalis, 3 ounces.

Acetate of potash, 6 drachms,

Water,

Mix.

A wineglassful constitutes a dose, to be given twice a day.

The local treatment, in the earlier stages, will consist in poulticing, afterwards applying No. 16, or No. 64. When the "grapes" have formed, the hope of a cure is often anything but bright. The prourl flesh should first be reduced by caustics or by the hot iron, and afterwards by the long-continued application of No. 64 and the following, in alternation:

No. 72 .

Sulphuric acid, 1 ounce.

Sulphate of copper, 2 ounces.

Water, to make 1 quart.

Mix.

Apply trice daily with a mop. Remember the alternation with No. 64.

The cure of the chronic form is never to be effected except by very persistent treatment, as this is a most obstinate disease.

\section{Hide-bound.}

Every horse owner is familiar with the condition known as hidebound. The popular conception figures it as a disease in itself-as 
truly so as big head or farcy, though of vastly milder type. But on carefully analyzing any case of it, and naking a thorough examination of the animal's system thus affected, some antecedent ailment of other parts may always be brought to light. In other words, hidebound is not itself a disease, but merely a symptom of certain derangements of the vital functions.

Causes.-The class of disorders most frequently producing it are those of the stomach and intestines, such as heart-burn, dyspepsia, constipation, worms, etc. Other causes are defective teeth, either from decay or from being too sharp. Chronic affections, of nearly all kinds of a constitutional nature, bring on a like condition-most notably big head or big jaw, described in Chapter XIV.

Manifestations,- Cnthriftiness in general; the hair loses its natural glossy look, because the glands in the skin no longer discharge their duties fully; the skin is bound down tightly on the ribs, and in many cases cannot be raised by the finger's with any amount of effort. All or any of the following conditions maly be noticed in different cases: loss of appetite, imperfect mastication of the food, licking whitewashed walls, heart-burn (shown by turning up the upper lip, as illustrated on page 348 ), flatulence, ete. In other cases, nothing abnormal may be perceived further than the gaunt condition, the animal greedily eating everything placed before him.

Treatment.-Carefully consider the various symptoms shown, and try to locate the disease; in other words, see, if possible, what particular part or function it is that is at fault. When this is accomplished, treat for that particular disease, according to the directions laid down for it elsewhere in this work.

In the general condition of hide-bound (due, probably, to digestive derangements), give Pill No. 18, and for several days feed a salted bran mash. Give the tonie preparations No. 19, or No. 30, or No. 71 . continuing same for several weeks. It is often of benefit to change the medicines after a week or two. The teeth should always be examined, and all irregularities corrected, as advised in Chapter XXIY. 


\section{CHAPTER XXXIX.}

\section{SPECIAL OPERATIONS.}

I. MANY OPERATIONS NOT BEYOND TIE FARMER'S SKILL.-II. ANASTHETICS. - III. HOW TO ADMINISTER CHLOROFORM.-IV. METHODS OF SECURING FOR OPERATION.-V. DOCKING.-VI. NICKING.-VII. NEUROTOMY, OR NERVING.-VIIT. TREPANATION, OR TREPHINING.-IX. SUBCUTANEOUS PERIOSTEOTOMY.—- $\mathrm{X}$. TENOTOMY.—XI. SETONS.—XII. FIRING.

\section{Many Operations Not Beyond the Farmer's Skill.}

In introducing a chapter devoted to some of the more difficult operations, we do so with the belief that it will be duly appreciated, especially by a large number of the more progressive farmers and horsemen. There is really little reason why a farmer should not himself perform the more common operations in veterinary surgery. If the proper kind of knives or other instruments are not at hand, take the next best-the most suitable in your possession; or, many of them can be made by an expert blacksmith from the engravings given in this book.

Before undertaking any operation, carefully read the instructions. Above all, bestow a careful, studious examination upon the different engravings which represent the part or organ to be operated on. Success in one case will give confidence for the next.

\section{Anæsthetics, and their Administration.}

The use of anæstheties for all painful operations in the lower animals, although not absolutely necessary, is called for, if only for humanity's sake. But there are additional reasons for it. Most animals will struggle violently under pain, and an otherwise simple operation may be greatly complicated, and thereby false cuts made, etc., and the operation be much prolonged, to say nothing of the risk of injury to the operator and his assistants.

Chloroform.-The anæsthetic most suitable for the horse, and the one generally used, is chloroform, being quick in its action, and followed by no after-effects. Chloroform may be mixed with ether and alcohol, but it is best to administer the pure article alone. Ether has 
been so little used on the horse as yet, that we can afford to pass it by with a bare mention. Later it may, perhaps, be more used.

The inhalation of chloroform is accomplished through an inhaler, which may be of any form that can be applied to the nostrils. The mouth may be left free, as the horse cannot breathe through it, owing to the great length of the palate. An excellent inhaler may easily be made of canvis, in the form of a cylinder, about twelve inches long and twenty inches in circumference, a draw string on each end serving to close it. Passing it over the nose and upper jaw, the strings

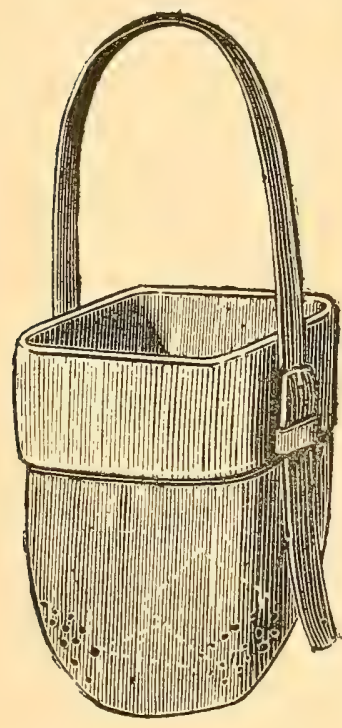

CHLOROFORM BAG. are drawn close to exclude the air, the hor'se's lower jaw and tongue being left entirely free. An ordinary canvas feed-bag will also answer the purpose, by running a string around the upper end. The improved form shown in the engraving will be stiil better.

\section{How to Administer Chloroform.}

Chloroform should never be given with the animal in the standing position. He should always be secured by the hobbles, etc., on a soft bed. The bag being placed in position, and the eyes protected by blinders, about half an ounce of the fluid may be poured on a small wad of cotton batting, or on any light cotton or linen goods, which is to be quickly placed in the end of the inhaler. As evaporation occurs, which will be in about two minutes, wet the batting again with the same amount. The time required to produce anesthesia being from five to ten minuter, the quantity of fluid needed will vary from one to four ounces, according to the susceptibility of the animal.

The Signs to be Watched.-The signs to be watched during inhalation are found in the respiration, the pulse, the eye and the tongue. Inumg the first few whiffs of the drug the horse will struggle, but will shortly quiet down, and as the stage of andusthesia approaches, he will neigh or squeal. "Then the muscles quiver, the breathing beomes quict and regular. and he lies perfectly still-the chloform has done its work. The pulse, after the first excitement, should remain firm and regular throughout the administration; any irregularity or fluttering is to be regarded with suspicion, and the in- 
halation should be suspended until the pulse regains its tone, when it may be again cautiously proceeded with.

The eye and tongue are good guides in deternining the degree of anæsthesia. For a time, when the cornea is touched, it will show a reflex, by causing the eyelids to wink; this will disappear as unconsciousness comes on, of which, therefore, it is the usual tent. Similarly the tongue will at first answer to a pinch by retracting; when it hangs out of the mouth and does not respond to a pinch, the state of anresthesia has been obtained.

During and After the Operation.-From now on the inhalation must be carefully regulated. It should be suspended at this point, and only renewed on the signs of returning consciousness. It is during this stage, when none of the parts show any reflex, and when the limbs are perfectly flaceid, that the operating should be done.

When the inhalation is stopped, the animal will gradually recover from its effects. He should be allowed to remain quiet. Remove the hobbles, and he will rise up himself at the proper time. In the horse, there is rarely any

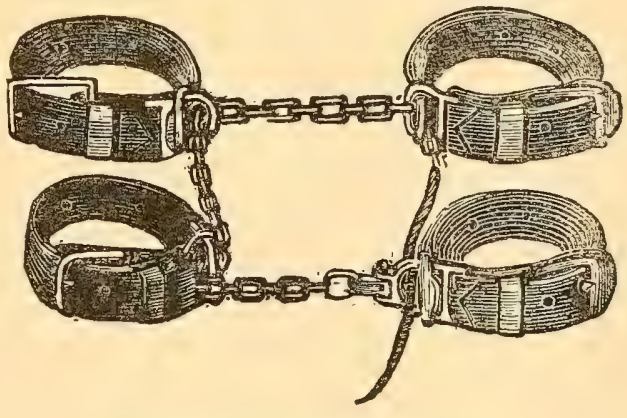

HOBBLES FOR THE HORSE.

sickness from the use of chloroform, such as is so common in the human subject. The animal will probably want to eat, but nothing more than a little hay and water should be allowed for several hours.

\section{Methods of Securing for Operation.}

There are many different ways of securing a horse for operation, but it will be sufficient here to consider only the most common ones. In fact, several methods of throwing and securing the horse, including the Rarey method, have already been described, and, by means of the index, may be referred to in a moment.

The Hobbles.-The use of hobbles, such as are here illustrated, is the favorite expedient for casting a horse. They are made with all sorts of modifications, some of which are very cheap. They are placed on the ankles like bracelets, the chief hohble being on the fore-leg. To throw a horse, one man should stendy the head, and another hold the tail tightly, while two or three pull on the rope. When this is carefully done, the horse will fall eatsily. A small open 
iron ring, called a "key," is now passed through one of the links next the chief hobble. Its use is to prevent the legs-coming loose during the animal's struggles, and it will also do away with the necessity of holding the rope.

The Operating Table.-This is not yet in general use, but a description of it will not be out of place. $\Lambda$ good general idea of the shape and mode of working the table may be obtained from the accompanying engraving. The table stands with the table-board at first in an upright position. The horse is walked alongside of it, the

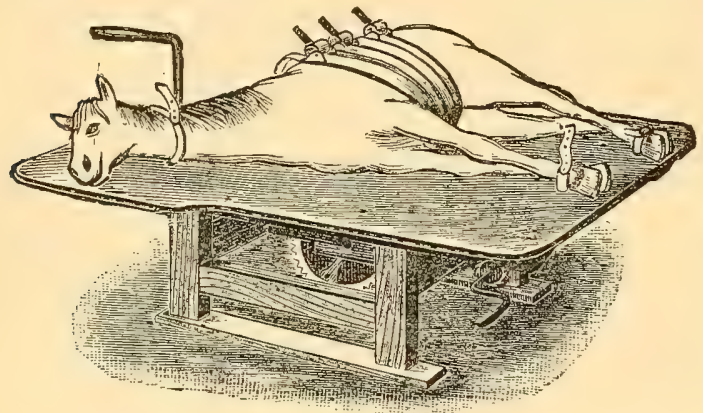

HORSE SECURED ON THE OPERATING TABLE. belly band is adjusted, the feet hobbled to the table, and the neck secured by a strap; then, by a few turns of the levers, the table and horse are brought to the positions shown in the cut. This table is certain to be very generally adopted by persons having occasion to handle many horses. Its superior advantages are obvious.

The Stocks, or Travis.-This, likewise, is a good way to secure a fractious horse in some of the less important operations, in which anæsthetics are not needed. The stocks are generally made by plac-

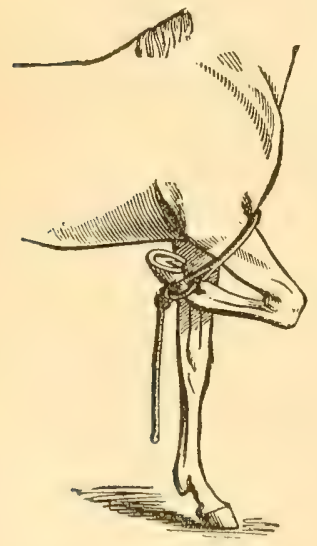

FORE LEG SECURED. ing six posts in two parallel rows, with side railings. The horse is secured between these posts by so passing bars, straps, ete., in front, behind, above and below him as to prevent movement in any direction.

Securing the Fore Leg. - Occasionally, in opening an abscess, shoe-boil or other ninor operation, some easy way of restraining the horse is necessary. In these cases the "twitch" on the nose, made by passing a loop of thick cord through an eyelet on the end of a stick, will be sufficient; but as an aid the fore leg may be secured with a strap or rope in the way shown in the amnexed ent.

\section{Docking.}

Tho horse's tail has from thirten to twenty small bones, extendtending in a continuous line, and likewise gradually lessening in size 
from the root to the tip. In some European countries, and particularly in England, fashion has succeeded in depriving the poor beast of the major portion of his caudal appendage. This craze has taken a firm hold also in this country, more particularly in the East, where nearly all carriage and saddle horses must lose their tails before they are fit for use! Some States have justly passed very stringent laws against the practice, on the ground of humanity (for the poor brute's feelings in "fly time" may be easily imagined); but their laws are easily circumvented by taking the animal to some adjoining State, and docking him there.

The operation consists in removing such portion of the tail as may suit the owner's idea of beauty, or rather his whims. In the mare, a sufticient length must always be left to at least cover the vulva.

The amount of tail to be removed having been decided on, the joint is located by movement of the bones, and at this spot the hair is parted and bound back out of the way. It is very important to make sure that the knife will cut through the cartilage or gristle between the two bones; otherwise, if a piece of bone is left without any blood to nourish it, its death will follow, the part will not heal, and another eutting will be

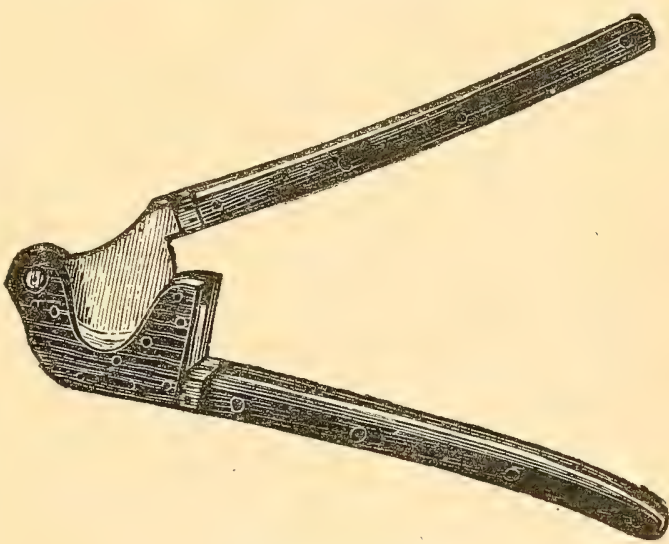

DOCKING KNIFE. necessary, or else a slow-healing sore may result, one that will take several months to skin over.

To cut through the tail, various sharp cutting instruments are used, such as a wide chisel, a carving knife, a regular docking knife, as here shown, etc.; or the amputation may be made with an ordinary scalpel, or a special V-shaped docking knife.

When a chisel or knife is used, the tail is placed over any firm wooden place, and the knife smartly hit by a hammer. The end of the tail-the stump-must be left perfectly smooth. The usual after-treatment is to sear the end with a hot iron, which 
promptly stops the bleeding. Some rosin may be seared on; this will form a scab that seals the end, and by thus excluding the air, 110 pus will be formed, the scab dropping off in course of a week or two.

The amputation of the tail is a more scientific piece of work, and requires some practical knowledge. The result is also. much better, the end exhibiting a pointed form, with the hair growing out to the tip, in this way hiding the small scar. In this method of docking, the skin is divided into two oval flaps back of the joint; these are turned back, and the bones separated at the joint. The bleeding of the larger arteries is stopped by tying them, and that of the smaller ones by pressing. The two flaps are brought together and held by a stitch. The tail may now be dressed by methods appropriate for wounds; but if it be bandaged with cotton batting, soaked in Antiseptic Lotion No. 1, or No. 12, it will heal much quicker. The amputation may be performed with an ordinary knife, but it is very slow work, and unless chloroform be used is very painful. We greatly prefer an instrument of a $\mathrm{V}$ shape, which is to be had of veterinary instrument dealer's, and operates very accurately and quickly.

\section{Nicking.}

This is very frequently performed, the results being invariably good. The cases mostly requiring it are crooked tails, or tails carried to one side, or in some cases even between the legs. Some horses which hold their tails perfectly straight when standing will, nevertheless, carry them to one side when in action.

The tail is moved by six muscles, two above, two below, and one on each side. These are connected with each bone by little branches, and extend to the very tip of the tail.

To remedy a defective tail, the horse should be put in motion, in order to get an accurate idea of the place to nick, which will generally be about eight inches from the root. The lower sets of muscles are the ones most commonly at fault in all these tail troubles, but sometimes the side muscles may be involved. In croolied tails only one side will need cutting, unless the tail has a douhle crook, but in a depressed tail both sides will need attention.

The operation of "nicking" consists in eutting through the offending muscles with the nicking lnife, a good form of which is here illustrated. There are many different methods of cutting. The simplest 
is to push the knife straight through the muscle to the bone, then cut to the right, and upwards towards the left. A little bleeding may result, but this is not serious. In the subcutaneous method (that is, under the skin), the knife is inserted by the side of the muscles as far as the bone, then the edge is turned and pressed outward, until it is felt under the skin. This is a more difficult way than

NICKING KNIFE.

the first, but has the advantage of leaving a very small opening only, which quickly heals.

After the muscle is cut, if the part has been crooked, it should be tied to the opposite side; if depressed, it should be elevated by a pully and weight. In either case, the corrective position may be maintained for twenty-four hours. Sometimes it is necessary to nick the tail in several different places, before it will straighten.

\section{Neurotomy, or Nerving.}

This is a very delicate operation, by which a certain part is deprived of sensation, by excising or removing a portion of the nerve. In the horse, the only parts thus operated on are the lower limbs.

The diseases that call for this operation are navicular disease, chronic corns, ring-bones, etc.,-that is, in chronic eases, that hold out no hope of recovery. "In determining whether it is judicious to operate or not, the following rules must be borne in mind: First, never operate on a very heavy, thick-legged cart-horse; second, never operate where the feet are thin, weak in the heels, full in the sole, or otherwise exhibiting a predisposition to laminitis (founder); and, third, operate only when the subject's foot is good and strong, his action not too high, and the lameness otherwise incurable."

There are two forms of nerving, known respectively as the high and low operations. The former, or complete one, deprives the foot of all sensation, and is never advisable when the low or partial form will suffice, for the reason that in case pus should afterward form in the hoof from corns, etc., or the foot be pricked by a nail, the injury may never be suspected until it has reached a very serious stage. The low operation is performed below the fetlock on only one branch of the nerve; this will leave some sensation in the foot, enough to serve as at safeguard against many accidents. The cutting of the 
nerve is exceedingly painful. Chloroform should, therefore, be used, or a solution of cocaine may be injected under the skin along the course of the nerve, producing local anesthesia.

High Nerving.- The high operation is performed thus: The horse being thrown by the hobbles, or other method, and the hair clipped

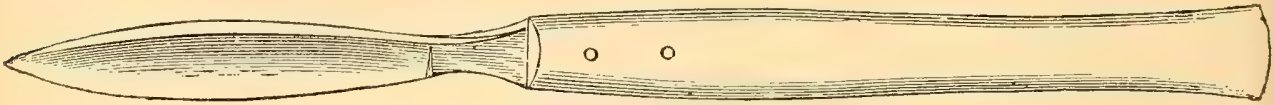

A USEFUL KNIFE FOR-NERVING, ETC.

off the spot to be operated on (ahout one and a half inches above the fetlock joint, at the anterior edge of the back tendon), the slin is cut through with a knife, such as is here shown, the opening not needing to be more than an inch long. This will sufficiently expose

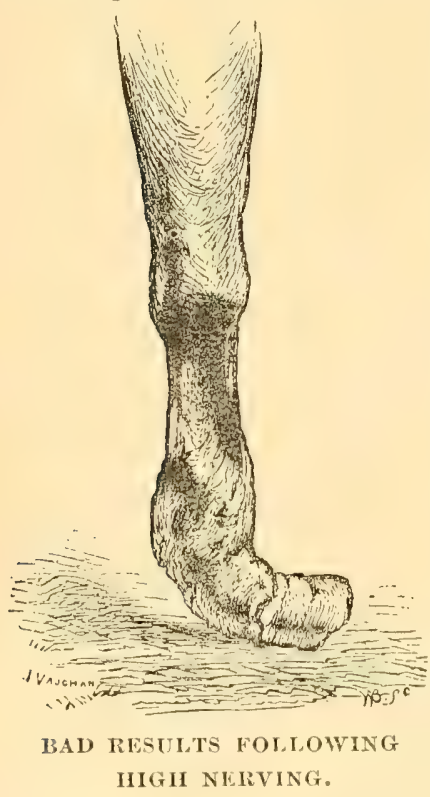
the loose tissues beneath, which are then to be cut through very carefully. The white nerve (that of sensation) will be found lying close to the tendon, with the artery in front of it, and the vein more forward still.

The utmost care mnst be taken to divide the nerve without injuring any of the blood vessels; if, nevertheless, this should unfortunately happen, they will have to be tied, and the blood sponged out of the cut. The nerve should be ent off as high as possible, during which the horse may struggle violently; then it is cut at the lower end of the opening, and in this way about three-fourths of an inch of the nerve removed. This mily then be repeated on the opposite side of the leg, the position of the nerve and ressels being the same on both sides.

Low Nerving. - In this, the operating is done below the fetlock, in the depression easily felt between the tendon and the bone, the point at which the nerve lies alongside the tendon, the same as mentioned in describing the high form. It is divided, and a section of nerve removed in the sime way as in high nerving. 
After-Treatment and Effects.-In either form of nerring the aftertreatment will consist in placing a stitch in the cut, and bandaging the leg regularly for a few days with the Cooling Lotion No. 4: Complete rest must be given.

The after-effects of neurotomy are very variable. The horse may, perhaps, travel sound and good for a great many years at slow work; or, on the other hand, unfarorable accidents may occur, such as breaking the pedal bone, rupturing a tendon, or a condition of complete breakdown, such as is reproduced in the illustration. It is always well to take the horse-shoer into your confidence after an operation of this kind, so that the feet may be better watched, and more care taken in driving the shoe nails.

\section{Trepanation, or Trephining.}

This consists in removing a piece of bone, most commonly from the head. The object, usually, is to allow matter to escape from some of the facial sinuses; to make an opening to insert a lever to elevate some broken part; or to open the cranial cavity, in order to remove tumors or worms. Occasionally, it is necessary also to trephine the scapula, in old cases of fistulous withers, to secure proper drainage for a deeply imbedded "pipe" beneath it. Opening" the cavities of the face is the only form necessitated at all frequently. The principal of these cavities, and the places to reach them by trephining, are shown so clearly in the illustration that they require no further description.

Trephining Described.-The hair is ${ }_{A-L \text { Left frontal sinus. }}^{\text {spots. }}$

first clipped at the point selected. The B-Superior maxilliry sinus (upper part) skin may either be cut out in a circle C-Superiormaxillary sinus(lower part) sufficiently large to allow the round trephine to work, or clse a T-shaped ineision may be made, and the edges turned back. All the skin and tissues must he carefully remored, to allow the teeth of the instrument to work. The central, sharp point of the trephine (see engraving) is now pushed into the centre of the bone, to prevent movement, and with a steady pressure the instrument is worked in a circle, or backward and forward. This must be done very care- 
fully towards the end of the operation, as otherwise the piece of bone might be forced into the sinus.

The carity now being open, any matter or tumor found therein may be removed, and the simus washed out. If an immediate closing

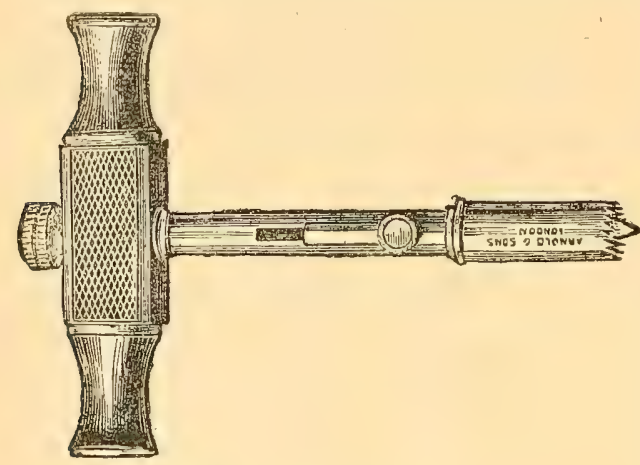

CIRCULAR TREPHINE. is desired, the ' $\mathrm{T}$-shaped cut of the skin will have been chosen; the edges may be stitched together and held by a bandage, or they may be retained by a pitch plaster. When the eavity is likely to need dressing every day, the circular skin opening is the best. It may be kept open by inserting a plug, or a cord. After the skin heals over, a soft spot will always remain, as the bone is never replaced.

\section{Subcutaneous Periosteotomy.}

This is the cutting of the periosteum-the thin, tough membrane covering the bone-to allow the escape of pus or fluid that has gathered below it, or to relieve pressure there. This membrane being very unyielding, any collection of fluid or swelling under it causes intense pain, and in the horse nearly always great lameness, by reason

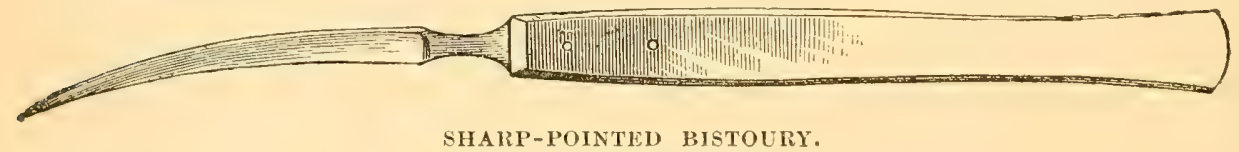

of its location. This is an operation seldom required among horses. Bony growths-splints, ete.,-during their formative period, are what call for them oftenest.

The knife is inserted side-ways under the skin, and the edge turned onto the enlargement, then by a little pressure the periostem is cut through orel the entire length of the growth. The after-treatment will be rest, and the application of healing lotions to the part.

\section{$\mathrm{x}$. Tenotomy.}

Tenotomy is the cutting, the division, of at tendon. It is practiced to remedy contracted tendons, in cases so bad as to cause the horse to walk on the toe. In the front feet the operation is generally suco 
cessful, but in the hind feet it is very difficult to prevent contraction from again occurring, notwithstanding a marked success temporarily.

The horse being first cast by the hobbles, the leg to be worked on is loosened from the hobble, and held extended by a rope. Then a sharp-pointed linife (like that illustrated on page 484) is inserted very close to the anterior edge of the tendon, at the middle of the leg, and pushed through until it can be felt under the skin of the opposite side, when it is withdrawn, and the probe-pointed bistoury is passed through the opening, until it in turn can be felt on the oppo-

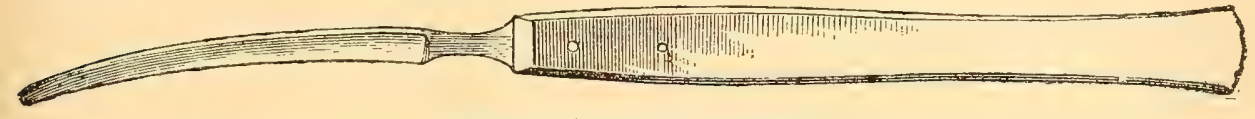

PROBE-POINTED BISTOURY.

site side. The leg is now extended, whereupon the tendon presses on the knife, which gradually cuts it through. Care must be taken not to cut through the skin, as that would probably be followed by a growth of proud flesh on the divided ends, and presently in the opening.

After the operation, the cut is to be stitched, or a pin passed through the skin, and a piece of thread wound around it. Apply bandages until the cut heals. The toe of the foot will probably turn up ever after, but this need not cause anxiety. If the hind foot has been the one affected, a flat shoe, with an extension piece forward on the toe, had better be used on it, as there is danger that the healing: may result in another case of contraction. The horse should not be worked for three to six months after undergoing tenotomy.

\section{Setons.}

Setons are not used nearly as extensively as they were twenty or thirty years ago. They are hardly ever brought into requisition now, except in chronic cases, where a continual irritation for several days or weeks together is desired, or to drain an abscess, or remove some growth under the skin. They are generally made of ordinary width tape.

To the directions already given in Chapter XXII, we add the following: A seton may be left in place for any length of time, up to one month. It should be moved up and down once a day, and any matter that has collected should be pressed out. If a strong enough action is not secured, rub a little turpentine or other blistering substance on the tape occasionally. 


\section{Firing.}

This is a time-honored way of restoring certain chronic cases to a healthy state-more especially chronic diseases of the bone and muscles, in our account of which it has been referred to time and again.

Firing is done either in lines by the convex-edged iron, or in points by the pointed iron. Both forms of the firing-iron are here depicted.
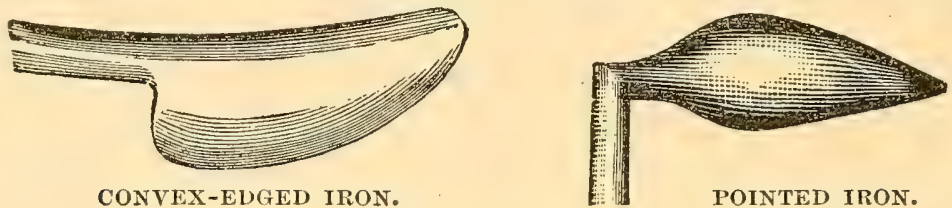

The lines, in the general run of diseases, are the most applicable, but the points leave a much smaller blemish, which is a great advantage.

The hair should be removed before firing a part. When it is rery long, this is really essential. The lines or points should not be closer together than half an inch, as otherwise they may cause a destruction of tissue by excessive burning, and hence an excessively large blemish. There are no set rules for conducting the operation of firing; but in the different parts of the body, the burning in of certain figures is by some considered of more advantage than others. The accompanying illustration shows the parts of the body on which firing is prineipally employed, with suitable designs for each.

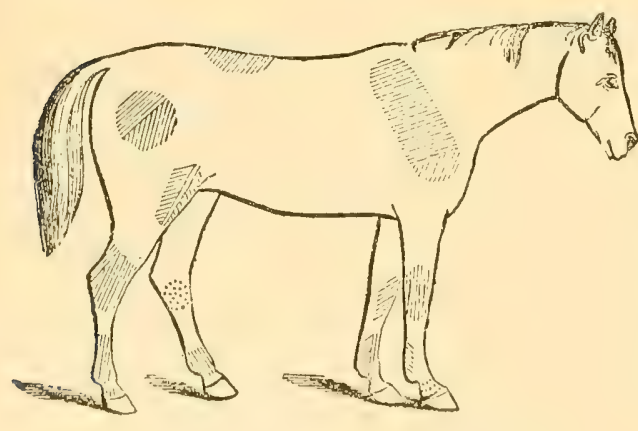

VARIOUS DESIGNS IN FIRING.

Firing, when not too extensive, may generally be done with the animal in the standing position, and a twitch on the nose. The iron is heated to a white heat, and the design first lightly traced on the part, to be afterwards gone orer again, so as to extend the marks deeper.

After the firing, the head should be tied up high to prerent the part from being bitten; or, still better will be the use of a cradle or siderrod. Both of these simple devices will be found exhibitod clswhere in this work. Blisters are frequently rubbed on, to increase the inflammatory action. 


\section{CHAPTER XL.}

POISONS, POISONOUS SNAKES AND INSECTS, ETC.

I. CONCERNING POISONS IN GENERAL. II. THE CHIEF SOURCES OF POISONING.-III. INTERNAL POISONS.-IV. POISONOUS PLANTS.—-V. POISONOUS PREPARATIONS FROM PLANTS. - VI. POISONS OF THE SKIN. - VII. SNAKE-MITES. - VIII. VENOMOUS SPIDERS. - IX. THE CENTIPEDE.— $\mathrm{X}$. STINGING SCORPIONS.-XI. IIORNETS, WASPS, ETC.

\section{Concerning Poisons in General.}

The action of poisonous substances is not uniformly the same upon the horse as it is upon the human. While some of them are nearly equally destructive to both, many that are deadly in their effects upon the biped are quite innocent when given the horse; and still others are in the highest degiree injurious to the latter, but not at all harmful to man.

In this chapter the design is not to describe the action of those poisons which are known to be universally destructive to animal life, for these there is no need to warn the reader against using. It is to call the attention of all classes to the dangers attending the employment of various drugs which many people are ignorantly accustomed to give their horses to purify the blood, and for the improvement of condition generally, and to point out the best known antidotes when they have been given either by accident or design. We shall also have oceasion to treat of the various animal poisons to whose operation the horse is sometimes exposed,-the bite of serpents, the sting of poisonous insects, and the like.

\section{The Chief Sources of Poisoning.}

Often nothing will avail in a case of poisoning. Poisons usually act very quickly, disorganizing the blood and the tissues of the body so rapidly that only the promptest possible measures will save the victim's life. Others, however, do not destroy the animal at once; he lingers along in ill-health and finally dies-it may be eren months afterwards. Innumerable cases of chronic disease and permanently impaired health are referable to nothing else in the world than 
the use of poisonous medicines. Such remedies every intelligent f:umer and horse-owner will entirely ignore in his veterinary practice, and upon no consideration be induced to have anything to do with them. There is no need to resort to the use of such poisons in any case, for there is an abundance of other medicines to select from which are equally or nearly as efficient, and attended with no dangerous consequences.

It is not often that the horse is poisoned internally, except as before adverted to,-by the careless or ignorant use of certain articles administered as medicines. Natural instinct teaches him to avoid most of the poisonous herbs that commonly grow in the pasturefields, where he seldom receives any injury of this kind, unless it be occasionally from the poisonous weeds and vines with which his nose may come in contact during grazing. Perhaps the chief danger of internal poisoning to which the horse is exposed proceeds from the mean, dastardly mode which some cowards adopt to take revenge upon an enemy - that of destroying or ruining his horse.

In many districts of the South and Southwest the stock-raiser has much more reason to dread the bites of venomous serpents, insects, etc., than any of the other sources of poisoning.

\section{Internal Poisons.}

This, of course, is the class of poisons which communicate their hurtful influenees through the medium of the stomach and the lacteal absorbents of the intestines. Nany of them prove deadiy at once; but these are all too well known to need enlarging upon. Our object is rather to warn against the employment of such as are slower in their action, and whose ill effects, in consequence, are more apt to be overlooked.

Cantharides, or Spanish Flies.-This is a poison of the strongest diuretic propertics. It is unsafe, given by the inexperienced in how small quantities soever; and for this reason, notwithstanding that nearly all veterinary writers prescribe it, with more or less strenuous cautions, we must condemn it altogether. Giren internally, it very often produces strangury and death ; and if these sad results do not follow, there will generally be found a permanenty diseased eondition of the minary organs, extending not unfeguently to the stomach and bowels.

The antidote for this form of poisoning is some kind of emollient drink. Linseed tea or oatmeal gruel will generally best meet the 
conditions of farm life. Tincture of opium, in half-ounce doses every hour, will be beneficial. No oils should be given, as they increase the action of the poison.

Corrosive Sublimate.-This is a poison of fearfully destructive effects when introduced into the stomach. Its principal use in reterinary practice is its local antiseptic properties when greatly diluted with water. In case it is accidentally given, it should be antidoted with eggs, starchy fluids, milk, etc, the animal being allowed to drink all the water he wants.

Acids.-None of these constitute a suitable medicine for the horse, unless very greatly diluted. They are principally the acetic, carbolic, citric, muriatic, sulphuric, nitric, tartaric, oxalic, and prussic. All of these are to be rejected as injurions, and some of them as most swift and deadly poisons.

To antidote the poison of all mineral acids, except sulphuric, give large quantities of water; also chalk, soap and any alkaline substance available. For carbolic acid, eggs, gruel and strong coffee and oils are useful.

Alkalies.-Alkalies and their salts may all be used at times with decided advantage as correctors of an acid condition of the stomach, or as mild and safe diureties. In this list of remedies, nitrate of potassa (the nitre, or saltpeter, of every-day life) stands high as a mild diuretic. It should be given only in small doses, and never except in clear cases of urinary disease. The tendency in the stomach of the horse is toward acidity and fermentation. Acids aggrarate this condition, and ruin the horse; alkalies correct the former, and relieve the animal.

To counteract the effect of poisonous doses of these salts, the acids must be usêd. Give them in the form of vinegar and water. Oils, eggs and gruels are also very helpful.

Turpentine.-Turpentine is an excellent constituent of external applications, such as liniments, the best of which can hardly be made without using it to some extent. It is a rubefacient (which means that it produces redness of the skin), and, opening the pores, it prepares the way for the other ingredients of the liniment to act; but, given internally to the horse in large doses, it is poisonous to both the digestive and urinary organs. In small doses, with oil, it is rery much used for the relief of flatulent colic. 
Tartar Emetic.-This is a powerful nauseant; in large quantities it has the effect of an active poison. In doses of from a drachm to a drachm and a half, when given with nitre and digitalis, it excites the secretions of the skin, acting as a powerful diaphoretic as well as diuretic. In overdoses it is apt to do injury. As the horse cannot vomit, it is safest to accompany tartar emetic with a small dose of salts.

Croton Oil.-Great danger attends the use of croton oil in veterinary practice. It is admissible only in very extreme cases of costiveness. Such is the rapidity and violence of its action, that it often does material injury before the bowels relax, having a strong tendency to produce rupture and death; or a fatal diarrhœa may be the result. The dose is from eight to ten drops, in some warm water or oil; but the instances are rare in which milder remedies will not serve a better purpose.

As an antidote for this species of poisoning, eggs, linseed tea, tincture of opium, and Astringent Mixtures Nos. 37, 38, and 39 will all be good. As an external application, in all cases where an active liniment is needed, croton oil is quite valuable.

\section{Poisonous Plants.}

Of the large number of vegetable poisons, there are very few which appear to be very injurious to the horse. We have often known him to eat with impunity the leares of the ground and fence iry of the meadows. Externally, these are poisons; but taken into his stomach they do no harm. We know of but three plants growing in America that the horse will ever eat which act as a poison to him. These are the poison-oak that grows upon dead trees and stmmips, the laurel growing upon the bluffs of creeks and rocky chasms, and the locoweed (or crazy-weed, as it is sometimes called), which is found in the Trestern and Southwestern States. This last he will eat because it appears so fresh and green before the spring grass appears. It produces emaciation and various nervous symptoms, in eonfirmed locoeaters.

Treatment.-For poisoning by the oak or laurel, the bowels must he evacuated as quickly as possible by use of Pill No. 18, and then plenty of chalk-water or lime-water be given.

The loco-eater may be eured by feeding him good food, if the weed can only be kept away. The trouble often is that he will hunt for the weed, and apparently must have it to satisfy his craving, when he 
has once acquired a taste for it. In these confirmed cases, no reliable cure has been found; they resemble the old toper with his dram.

\section{Poisonous Preparations from Plants.}

Belladonna, or Deadly Nightshade.-This is a deadly poison in its prepared form; but the horse will not eat it when growing wild, as in the United States it does in certain sections. It is a very powerful narcotic and sedative, and, in smiall doses, is a valuable auxiliary in all cases of undue action of the nervous and vascular systems, especially in affections of the heart and lungs.

The antidote is tincture of opium, which has a strongly stimulating effect upon the brain.

White Hellebore.-This is a virulent poison, very dangerous in the hands of those who are ignorant of its properties. In small doses, it may occasionally be used to advantage, but it is always to be administered with great caution. It is a very powerful cathartic. In diseases of the lungs, especially in inflammation, it acts with great force upon the pulse, lowering it very rapidly. The prominent symptoms of poisoning from this cause are a rapid sinking of the pulse, hanging of the head, frothing at the mouth, great weakness, and muscular spasms, followed by paralysis.

The antidotes are the familiar gruels and stimulants, with one drachm doses of tannin to remove the unabsorbed poison, with which tannin readily combines and forms an insoluble compound.

Black Hellebore.-Like the white hellebore, this seldom grows in our meadows and pastures. As they are very offensive to the horse, he is in little danger from either; nor are they often used by our farmers. The black hellebore, while not as poisonous as the white, possesses no special properties which can justify its use internally.

Poisoning by this plant results in a violent colice, with drastic purgation and heart depression. It may be antagonized by opiates and stimulants.

Opium.-This is obtained from any of the poppy plants so common. Horses will not eat them, but poisoning by opium is often seen where it is used as a medicine in the treatment of disease-especially colic. The excessive use of this drug produces a condition of delirium, a staggering walk, and sickness; the animal will walk aimlessly around, or stand in a colner pressing against the wall. 
The treatment is the use of oil for a purgative, giving gruels to drink, and exercise. Ammonia held to the nostrils will act as a stimulant.

\section{Poisons of the Skin.}

Concerning these there is little to be said, compared with those we hare been so far considering, in the great class of internal poisons.

Poison Oak, or Running Sumach.-The creeping plant known by this name is most frequently found climbing old stumps of trees, piles of stones, and the like. Although the horse will eat this only occasionally, it often poisons his nose and ears, and sometimes his feet, when they happen to come into contact with it in grazing. It causes blisters and scabby eruptions.

The treatment is to wash with a tea of golden seal three or four times during the day, and at night rub in some grease over the poisonous surface. In the morning wash off the grease with warm soapsuds, and apply the decoction of golden seal again. Continue this course as long as maly be necessary to heal.

Other Poisonous Plants, Vines, Etc. - There are several other poisonous plants and vines common in various parts of the country, such as the meadow ivy, the poison vine, the hemlock, the "sneezeweed" of the South, and some others. The weed last named is a great pest of the pastures and woods of many districts of the south, where many colts and horses are almost ruined by it during August and September.

The treatment for all external poisons of this class is that just preseribed for the poison oak, - frequent washing with the decoction of yellow-root, or golden seal, with nightly anointments with grease. If, as sometimes happens in cases of serere poisoning, the legs swoll and the joints become stiff, wash them repeatedly with hot salt and water; or, instearl, use the Soothing Lotion No. 3, or the Cooling Lotion No. 4. Give Purgative Pill No. 18, or No. 20, and maintain the strength by good food, with the addition of tonics, if necessany.

Burns from Acids. - The various acids are poisons to the skin, amsing the most painful burns. The treatment will be similar to that directed for burns in Chapter XXIII.

We come now to animal poisons, the third and last class to be considered.

VII. Snake Bites.

Nature has populated the Western Continent with many varieties of serpents and poisonous insects. Some of the Western and South- 
western States, especially those bordering upon the Mississippi river, are greatly infested with them. In West Temnessee-a land of thickets and underbrush - and elsewhere, the rat tlesnake abounds. Besides this venomous creature, there are others on all the tributaries of the Mississippi. The whole country on the lower portion of its course is tenanted not only with the rattlesnake, but also the spreading adder, the moccasin, the cotton-mouth, and the black and water vipers.

It is not often that the horse is bitten by a snake, yet it sometimes occurs. Nearly all serpents give warning to any animal approaching them; and the horse, unless his hearing is impaired, never fatils to take the alarm and flee from danger. Of those that are unquestionably poisonous, not all are equally so, the venom of some being much more active than that of others. Otherwise, the quality of the virus seems essentially the same in each, and hence a uniform course of treatment is to be practiced for counteracting their effects.

Antidote.-The common and most effectual treatment is large potations of proof whiskey-half a pint every hour in warm water, with a little hartshorn-and continued washing of the wound with hot salt and water. Half a pound of salt should be given the patient at the outset. This method will cure when the horse is first bitten; but after great swellings have taken place, no remedy can be depended on. Extensive suppuration and gangrene will probably supervene, followed by derangement, blindness, convulsions, and death.

If the bite is discovered immediately, the better plan would be to cut out the entire wound with a sharp knife, and touch the cut thoroughly with lunar caustic. A thimble pressed forcibly upon the wound, and bound fast, is said to often extract the poison.

\section{Venomous Spiders.}

Spiders abound in every part of the country, but only a very few are poisonous or ever bite. There is a species of black spider, with a small white spot upon the back, whose bite is nearly as deadly as that of the rattlesnake. All of the large black spiclers are more or less poisonous, and will sometimes resent pressure by biting; but none show such a viciousness as the one just referred to, except the terrible tarantula of the plains of Texas, etc. This latter monster, whose body sometimes attains to a length of two inches, while his legs are twice that in length, will attack both man and beast, and only the most prompt and energetic treatment can save the victim's life. 
Symptoms.-Horses are sufferers from these insects more frequently than is generally supposed. There is a swelling and soreness of the nose or legs, for instance, and the owner is apt to attribute it to some contusion or strain, when, in many cases, it is really caused by the sting of these detestable creatures. The proper course is to examine all such swellings, and see whether there is any appearance of a wound, or of a nucleus that is fuller and harder than the surrounding skin. If so, the case should be promptly treated as for poison.

Treatment.-Give half a pint of proof whiskey in some wam water, with a tea-spoonful of hartshorn in it. Wash the swelling with hot salt and water. If the horse has been bitten by one of these spiders, a running sore may be the result, in which case it may be washed with the Antiseptic Lotion No. 1, or No. 13.

\section{The Centipede.}

This is a poisonous worm found in the South, where the people have corrupted the name to "Santa Fe." It principally infests old, rotten logs, and dark, hidden places. Instead of possessing one hundred legs, as its name implies, it has twenty-four, each of them pointed with a hollow thorn, out of which exudes the poison from a little bag at its root. The construction of these legs, in fact, is very much the same as that of the fangs in the serpent. These venomous creatures, while not common, are very deadly. It is generally believed that their sting is necessarily fatal, death ensuing in a few minutes. Horses and cattle are often killed by them.

Treatment.-Life might probably be sared by the immediate use of proof spirits, both very freely as a drench and externally as a wash, mixed with equal parts of hartshorn.

\section{Stinging Scorpions.}

These are strange areatures, inhabiting the same regions as the centipede. They are everywhere, and infest every place,-houses, stables, piles of plank and of wood, and almost every hole and crevice. They dart from their retreat with almost the swiftness of lightning, and, dropping upon some person or animal, seek to hide under the elothing or the thickest hair, and, if molested in any manner, are sure to sting whaterer they may be upon. Their sting is not often fatal; it is somewhat more severe than that of a wasp or hornet, and its peculiarity is that, although hurting but little at first, the pain becomes very acute within half an hour afterward. 
Symptoms.-The symptoms are very peculiar. The first sensation of pain is felt under the tongue, which organ remains nearly paralized for a considerable time. Swelling and heat proceed from the region of the wound, with the accompaniments of nausea and giddiness. In the human being, these symptoms sometimes terminate fatally, but to what precise degree the sting affects the horse is not so well known. That it is poisonous, and exceedingly painful to horses and cattle is undoubted; but as stock runs at large in that country of universal grass, opportunities to trace the effects of the sting in their cases have not been very favorable.

Treatment.-In Texas, whiskey is the antidote for all ills. When stung by the scorpion, the people have recourse to the beverage at once, using it bountifully both internally and externally, and thus obtain relief in a short time. The treatment in the case of the horse will be of the same character.

\section{Hornets, Wasps, Etc.}

These do not often sting the horse, and are never very hurtful, so that a simple prescription to relieve the pain will be all that is necessary. The first thing to be done is to press the large end of a thimble around the sting, so as to make a deep indentation in the skin, and then to wash the place with hartshorn and oil, mixed in the proportions of three parts of hartshorn to one of oil. Hot salt and water is equal to anything ever used as a wash after the sting of bees or wasps.

Potato Bugs.-In a few instances, the potato-fly or bug has poisoned the horse. For this, grease the surface affected, and in two hours wash off with soap-suds, and when dry apply the decoction of yellow-root, or golden seal. Continue alternating with these applications until the horse is quite well.

\section{Gad-flies, Gnats, Etc.}

This will be the proper connection in which to consider the ravages of certain insects not really poisonous, but more dreaded by the stockraisers of the Southwest than the creatures that are.

Tobacco-smoke will keep away gnats, gadflies, and mosquitoes. Green pennyroyal placed on the head, under the top of the bridle, will also drive them away; or they may be kept at bay by rubbing the body and legs with a handful of the green herb. Any of the essential oils rubbed on the parts which they especially infest will keep them away. 
Buffalo Gnats.-There is a species of large gnat, known as the "buffalo gnat," about one-third as large as the common holise-fly, that is a terror to the horse, mule, and deer of the regions bordering the large river swamps of the lower Mississippi, but which does not often trouble other animals. It makes its appearance in the first warm days of spring, and comes in swarms of millions, which attack their victim with a murderous ferocity. They cover his side, flanks, belly, breast, head, and neck; the nostrils and ears are literally filled with them; and, unless prevented, they will even crawl up into the nasal cavities, so as to fairly strangle the horse to death. It is not at all uncommon for them to kill both horses and mules, but happily they never attack the human being. The swarms in which they al ways move come all at once, and go the same way. They remain usually about six weeks, and in one day's time will all be gone, so quick is their disappearance.

Ordinary coal-oil rubbed in the skin will keep these creatures away. So will a mixture composed of tar one part, and lard two parts; but it is a filthy preparation to use. 


\section{CHAPTER XLI. \\ RECAPITULATION OF REMEDIES.}

For the reader's convenience, - and especially as this work will frequently be consulted in emergencies, when every moment is precious, we herewith recapitulate the various prescriptions which have been given in the preceding pages.

No. 1. ANTISEPTIC LOTION.

$$
\begin{aligned}
& \text { Carbolic acid, } \quad 1 \text { part, } \\
& \text { Pure water, } \\
& \text { Mix. }
\end{aligned}
$$

Uses.-For cleansing and healing wounds. Wash or syringe two or three times a day.

\section{No. 2. Fistula LOTION.}

Corrosive sublimate, 1 part,
Alcohol,
8 parts.

Mix.

UsEs.-For treating fistulas. Being so powerful, this lotion should only be used once in two or three days. Use a glass syringe.

No. 3. SOOTHING LOTION.

Tincture of opium, 1 ounce, Sugar of lead, $\quad 1 / 2$ ounce, Pure water, 1 pint.

$$
\text { Mix. }
$$

UsEs.-For bruises, sprains of tendons, muscles, etc., to relieve the pain and reduce the fever. Rub on the affected part two or three times a day.

\section{No. 4. COOLING LOTION.}

Muriate of ammonia, 2 ounces, Common salt, 2 ounces, Nitrite of potash, 1 ounce, Water, Mix.
UsES. - Very useful to relieve the fever of bruises and sprains. Rub on the part two or three times a day.

No. 5. WEAK STIMULATING LOTJON.

Strong water of ammonia, 1 ounce, Soap liniment, 1 ounce, Pure water, 1 pint. Mix.

USES.-For sprains, bruises, etc., especially when they do not yield to other treatment. Rub on the parts two or three times a day.

No. 6. STRONG STIMULATING LINIMENT.

Strong water of ammonia, 1 part,

Water,

1 part,

Oil of turpciztine,

2 parts,

Olive or linseed oil, 4 parts. Mix.

UsEs.-For chronic sprains, etc. Rub on twice a day.

\section{No. 7. FLY BLISTER.}

Powdered Spanish flies, 1 part, Lard or vaseline, 8 parts. Mis.

UsES.-In ehronic enlargements or inflammations of bone or muscles, rub on carefully, and three days later rub on a little grease. This may be used every two or three weeks. 
No. 8. OIL HLISTER.

Powdered Spanish flies, 3 ounces, Olive oil,

1 pint,

Oil of thyme,

2 ounces

Mix the flies and olive oil together, and boil for six hours; then add the oil of thyme, and keep in a stoppered bottle.

UsEs.-For chronic swellings, etc. Apply the same as No. 7 .

No. 9. - SWEATING BLISTER.

Powdered Spanish flies, 2 ounces, Powdered euphorbium, $1 / 4$ ounce, spirits of wine, 40 ounces.

Mix, and set aside for a week to "digest."

UsES.-For reducing ehronic enlargements. Apply as directed for No. 7.

No. 10. MIXED BLISTER.

Red iodide of mercury, 2 parts, Powdered Spanish flies, 1 part, Lard, 6 parts. Mix.

UsEs.-For reducing chronic enlargements. Use as directed for No. 7.

No. 11. ABSORBENT BLISTER.

Red iodide of mercury, 1 part,

Lard, 4 parts.

Mix.

UsEs.-To reduce chronic swellings. Apply as directed for No. 7 .

NO. 12. ANTISEPTIC LOTION.

Corrosive sublimate, 5 grains,

P'ure water, 1 pint.

Mix, and bathe or syringe the wound.

UsEs.-For cleansing and healing wounds.
No. 13. ANTISEPTIC LOTION.

Corrosive sublimate, $\mathbf{1 5}$ grains,

Pure water, 1 quart.

Mix.

USES.-This is somewhat stronger than No. 12. Its uses are the same.

NO. 14. CIEANSING LOTION.

Solution of ehloride of lime, 1 part, Pure water, 10 parts. Mix, and syringe or bathe the wound.

UsEs.-For cleansing wounds.

No. 15. ASTRINGENT OINTMENT.

Blue-stone (blue vitriol), 1 part, Oil of tar, 4 parts. Mix.

UsEs.-For healing wounds of the foot.

No. 16. WHITE LOTION.

Sulphate of zinc, $3 / 4$ ounce, Acetate of lead, 1 ounce, Pure water, 1 quart. Mix.

Uses:-For washing cuts, etc. Shake well before using.

No. 17. INJECTION FOR FISTULA.

Chloride of zine, 2 ounces, Pure water, 1 quart.

Mix.

UsE. - This is sufliciently indicated by its name.

No. 18. PURGATIVE PILL.

Powdered aloes, 1/2 ounce,

Calomel, 1 drachm.

Vaseline, lard or water, suflicient to mix.

Mix, and make one pill.

Usf.-To elear the bowels. 
No. 19. TONIC POWDERS.

Powdered sulphate of iron, 3 ounces, Powdered gentian, 2 ounces, Powdered poplar bark, 4 ounces. Mix, and divide into twenty-four powders.

UsE.-To tone up the appetite and system generally.

No. 20. MILD PURGATIVE PILL.

Powciered aloes, 1/2 ounce, Powdered ginger, 2 drachms, Vaseline or lard, sufficient to mix. Mix, and make one pill.

UsE.-As a mild laxative.

No. 21. FEVER POWDERS.

Anti-febrin, 3 ounces,

Nitrate of potash, 2 ounces.

Mix, and divide into twentyfour powders.

UsE.-For the relief of fever.

No. 22. RHEUMATISM MIXTURE.

Salicylie acid, $11 / 2$ ounce,

Liquor ammonia acetate, 1 pint.

Mix.

UsE.-For the relief of rheumatism. Give a wineglassful four times a day.

No. 23. RHEUMATISM POWDERS.

Powdered colchicum, 21/2 ounces, Nitrate of potash, $\quad 2$ onnces.

Mix, and divide into twelve powders.

UsE.-Same as No. 22. Give one powder in the feed, or on the tongue, four times a day.

No. 24. STRONG AMMONIA LINIMENT.

Strong water of ammonia, 1 ounce,

Olive oil, 2 ounces.

Mix:

UsEs.-For stimulating the circulation, ete., in sluggish parts.
No. 25. IODINE SOLUTION.

Tincture of iodine, 1 drachm,

Water,

Mix.

UsES.-To cause absorption of any sac. It is to be injected into the same.

No. 26. DIURETIC POWDER.

Powd. nitrate of potash, $1 \frac{1}{2}$ ounces, Powdered rosin, $\quad 1 \frac{1}{2}$ ounces.

Mix, and divide into twelve powders.

UsEs.-To act on the kidneys, and increase the flow of urine.

No. 27. HEALING POWDER.

Powdered calamine, 1 part,

Powdered rosin, 1 part.

Mix.

UsE.-As a dusting powder for healing wounds.

No. 28. HEALING POWDER.

Powdered iodoform, 1 part, Powdered naphthaline, 2 parts. Mix.

Use.-Same as No. 27.

No. 29. MOUTH WASH.

Chlorate of potash, $1 / 2$ ounce, Pure water, 2 ounces. Mix.

UsEs.-To cool a feverish mouth.

No. 30. INDIGESTION POWDERS.

Bicarbonate of soda, 6 ounces, Powdered gentian, 4 ounces.

Mix, and divide into twentyfour powders.

USES.-To correct acidity of the stomach. 
No. 31. ANTI-FERMENTATION AND VERMIFUGE MIXTURE.

Oil of turpentine, $3 / 4$ ounce,

Oil,

1 pint.

Mix.

USES.-To neutralize and expel gas from the bowels. Give as one dose, and repeat, if necessary, in an hour. When used as a vermifuge, repeat the second day.

No. 32. ANTI-FERMENTATION MIXTURE.

Strong ammonia water, $1 / 4$ ounce, Oil, 1 pint.

Mix.

USES.-The same as No. 31. Give as one dose, and repeat, if necessary, in an hour.

\section{No. 33. CRAMP COLIC DRENCH.}

Tincture of opium, 1 ounce,

Linseed oil, 1 pint. . Mix.

UsE.-For the relief of cramps and other painful conditions. Give as one dose.

NO. 34. CRAMP COLIC DRENCH.

Tincture of opium, 1 ounce, Sulphuric ether, 1 ounce, Water or oil, 1 pint. Mix.

UsE.-For the relief of eramps and ether painful conditions. Give as one dose.

NO. 35. WIND COLIC DRENCH.

'I'incture of opium, 1 ounce,

Oil of turpentine, 1 ounce,

Linseed oil, 1 pint. Mix.

UsE.-To relieve cramps, and expel gas from the bowels. Give as one rlose.

No. 36. WINI COLIC DRENCH.

Extract of belladonna, 1 drachm.

Aromatic spirits of am-

monia,

Linseed oil,

Mix.

UsE.-Same as No. 35. Give as one dose.

No. 37. DIARRHEA MIXTURE.

Tincture of opium, 1 ounce,

Tannic acid, 1 drachm,

Water, $\quad 1 / 2$ pint.

Mix.

UsE.-To stop discharges from the bowels. Give as one dose. Repeat three times a day.

\section{No. 38. DIARRHEA PILLS.}

Powdered catechu, 1/2 ounce, Powdered op um, 1/2 ounce, Powdered camphor, $1 / 2$ ounce. Molasses or lard, sufticient to mix. Mix, and divide into four pills.

UsE.--The same as No. 37. Give one pill three times a day.

\section{No. 39. DYSENTERY MIXTURE.}

Perchloride of iron, 2 drachms, Tannic acid, 1 drachm. Water or milk, 1 pint. Mix.

UsE.-To ebeck dysentery. Give as one dose, and repeat in four hours, if necessary.

No. 40. ANTI-FETOR MIXTURE.

Hyposulphite of soda, 1/2 ounce, Water, 1 pint. Mix.

USE.-T' correct the foul odor of certain bowel discharges. Give as one dose. 
No. 41, CONSTIPATION MEdicine.

Tincture of nux vomica, 1 ounce,

Extract of belladonna, 1/2 ounce,

Powdered alum,

Water,

Mix.

UsE.-To relieve constipation. Give a wineglassful in a half pint of water four times a day.

No. 42. WORM POWDERS.

Powdered santonin, 1 ounce, Powdered areca nut, 15 grains.

Mix, and make one powder. UsE.-For the expulsion of worms.

No. 43. WORM AND TONIC POWDERS.

Sulphate of iron, 3 ounces, Sugar, 3 ounces.

Mix, and divide into twentyfour powders.

UsE.-For the removal_of worms, and as a digestive tonic. Give one powder three times a day.

\section{No. 44. PILE OINTMENT.}

Powdered galls, 1 drachm,

Powdered opium, 15 grains,

Lard or vaseline, $1 / 2$ ounce.

Mix.

UsE.-For the relief of piles or other painful local affections. Apply as needed.

NO. 45. FEVER MIEDICINE.

Tincture of aconite, $\quad 1 / 2$ ounce.

Liquor of ammonia acetate, 4 ounces. Mix.

USE.-For the relief of high fevers. Give a dessertspoonful on the tongue every two hours. Decrease the dose according to the strength of the patient.
No. 46. KIDNEY MEDICINE.

Iodide of potash, 1 ounce, Water, 1 pint.

Mix.

UsE.-To reduce the excessive discharge of urine. The dose is a small wineglassful every three hours on an empty stomach.

No. 47. ANTI-LITHIC MIXTURE.

Dilute nitro-hydrochloric

$\begin{aligned} \text { acid, } & 2 \text { ounces, } \\ \text { Water, } & 1 \text { pint. } \\ \text { Mix. } & \end{aligned}$

UsE.-For dissolving sandy matter in the bladder. The dose is a small wineglassful three times a day in a quart of water.

No. 48. KIDNEY STIMULANT.

Citrate of lithium, 1/2/2 ounces.

Divide into twelve powders.

USE.-To increase the flow of urine. Give one powder every four hours in the feed or on the tongue.

No. 49. SOLUTION FOR HYDROCELE, ETC.

Tincture of iodiue, 1 ounce, Pure water, 3 ounces. Mix.

USES.-To stop the secretion of fluid in any sac, especially the scrotum. Syringe a little into the sac.

No. 50. LEUCORRHAa SOLUTION.

Sulphate of zinc, 1 ounce, Tincture of opium, 1 ounce, Water, 1 quart. Mix.

USE.-As an injection, to stop the dis charges of leucorrhœea, etc. 
No. 51. INTERNAL ASTRINGENT MIXTURE.

Acetate of lead, 1 ounce, 'Tincture of opium, 5 ounces, Water, to make 1 pint.

Mix.

USE.-To relieve bleeding from any internal organ. Give a wineglassful every hour, as needed, in a half pint of water.

No. 52. SOOTHING MEDICINE.

Bromide of potash, 3 ounces,

Pure water, 1 pint.

Mix.

UsES.-To soothe irritable conditions of the sexual organs. Give a wineglassful every three or four hours, as required.

No. 53. BELLAdONNA LINIMENT.

Extract of belladonna, 1/2 ounce, Iinseed oil, $\quad 1$ pint. Mix.

UsES.-For the local relief of pain. Rub on the painful part.

No. 54. INTERNAL ASTRINGENT MXTURE.

Acetate of lead, 1 ounce,

Tineture of opium, 4 ounces,

Water, to make 1 pint.

Mix.

UsES. - To arrest bleeding from any internal part. Give a wineglassful in a half pint of water every hour, until relieved.

\section{No. 5\%. COUGH SYRUP.}

Syrup of squilis,

2 ounces,

Fluid extract belladonna, 2 ounces,

Powdered camphor, 1 ounce,

Honey,

3 ounces.

Mix.

USE.-For the relief of coughs and colds. Give a tablespoonful on the tongue every three hours.
No. 56. CoÚGH PILI.

Powdered opium, $\quad 3 / 4$ ounce,

Powdered eamphor, 3/4 ounce,

Powdered digitalis, $\quad 3 / 4$ ounce,

Powdered liquorice root, $1 \frac{1 / 2}{2}$ ounces, Vaseline, enough to mix.

Mix, and divide into six parts.

UsE.-For chronic coughs. Roll into pill shape (see page 368), and cover with thin paper.

No. 57. COUgh mixture.

Iodide of potash, $\quad 6$ drachms, Chloride of ammonia, 1 ounce,

Water, 1 pint.

Mix.

UsE.-For chronic disease of the lungs, bronchitis, etc. Give a wineglassful four times a day.

\section{No. 58. FEVER MEDICINE.}

Tincture of aconite, 1 drachm, Liquor ammonia acetate, 1 pint.

Mix.

UsE.-For the relief of high fevers. Give a wineglassful in a balf pint of water every four hours.

No. 59. STIMULATING FEVER MEDICINE.

Powdered camphor, 2 ounces, Alcohol, 6 ounces, Spirits of nitrous ether, 8 ounces, Water, sufticient to make 1 quart.

Dissolve the camphor in the alcohol, and then add the other ingredients.

UsEs.-For sustaining the strength in debilitating fevers. Give a wineglassful in a half pint of water every four hours.

NO. 60. MIXTURE FOL IIEAVES.

Spirits of ether, 1 ounce, Glycerine, $\quad 1$ ounce. Mix.

UsEs, - For the relief of broken wind. Give one lose in a half pint of water; repeat in one or two hours, if required. 
No. 61. HEART TONIC.

'Tincture of digitalis, 2 ounces, Tincture of nux vomica, 3 ounces, Water, to make 1 pint. Mix.

UsEs.-For disease or weakness of the heart. Give a wineglassful three times a day.

No. 62.- RHELMATISM POWDER.

Salicylate of soda, $4 \frac{1}{2}$ ounces.

Divide into twelve powders.

UsE.-For rheumatism. Give one powder every four hours.

No. 63. INTERNAL ASTRIGENT MIXTURE.

'I'inct. of chloride of iron, $1 / 2 \mathrm{drachm}$, Linseed oil, 2 ounces. Mix.

UsEs.-Give as one dose. Repeat three times a day.

NO. 64. SORE LOTION.

Sulphate of zinc, $1 / 2$ onnce, Carbolic acid, 1/2 drachm, Glycerine, $\quad 3$ ounces. Mix.

UsE.-For healing local sores. Apply twice a day.

No. 65. EYE DROPS.

Sulpuate of atropine, 4 grains, Pure water, 1 ounce. Mix.

UsE.-C'To relieve inflammation and soreness of the eyes. Put a dozen drops in the eye two or three times a day, with a feather or a medicine dropper.

No. 66. SIMPLE OINTMENT.

Oxide of zine, 1 part, Vaseline, 6 parts. Mix.

USE.-To heal any abrasion of the skin. Apply twice a day.
No. 67. LINIMENT FOR SCRATCHES, ETC.

Liquor plumbi acetate, 2 ounces, Olive oil, 6 ounces. Mix.

UsF.-For cracked heels, etc. Apply twice a day on cotton with a bandage.

NO. 68. RINGWORM LOTION.

Corrosive sublimate, 1 part,

Alcohol, 50 parts.

Mix.

UsE.-To heal ringworm. Apply with a mop every second day.

No. 69. MANGE MIXTURE.

Powdered stavesacre, 2 ounces,
Lard, 8 ounces,
Olive oil,
1 ounce.

Mix.

UsE-To kill the mange insect. Boil the mixture tholoughly and strain. Apply every second day.

No. 70. MANGE MIXTURE.

Creosote,
Olive oil, $\quad \frac{1}{2}$ ounce,
$\quad$ ounces,

Solution of potash, 1 ounce. Mix.

USE.-To kill the mange insect. Apply every third day.

No. 71. BLOOD MEDICINE.

Liquor arsenicalis, 3 ounces, Acetate of potash, 6 drachms, Water, 1 quart.

Mix.

USE.-As an alterntive for the blood. Give a wineglassful twice a day.

NO. 72. LOCAL ASTRINGENT LOTION.

Sulphuric acid, 1 ounce,

Sulphate of copper, 2 ounces,

Water, to make 1 quart. Mix.

UsE. - As a local astringent. Apply with a mop twice daily. 
No. 73. DisinfeCting FLUID.

Permanganate of potash, 3 ounces, Water, Mix.

1 gallon.

USES.-For general disinfecting purposes,-washing stalls, flushing drains, etc.
No. 74. DISINFECTING FLUid,

Crude carbolic acid, 1 pint, Hot water, Mix.

2 gallons.

USE. -Same as No. 73. 


\title{
THE AMERICAN TROTTER.
}

\author{
BY E. B. ABERCROMBIE.
}

THE ORIGIN, RISE AND PROGRESS OF THE AMELICAN TROTTING HORSE, WITH SHORT SKETCHES OF THE MOST CELEBRATED HEROES OF THE TRACK AND ROAD, AND ALSO A SET OF TROTTING STATISTICS AT ALL DISTANCES, CONPILED AND REVISED UP TO OCTOBER 1, 1892.

The discoveries which have benefited and delighted the world, have not all been invented by the mechanic, or registered in the patent office. Away from the smoky city, and the ceaseless roar of stean engines and factories, in the farm yard and the great ranch, experiment and discovery also go hand in hand. The agriculturist and stockman should be a diligent student of Nature's laws, for only by their intelligent application has he any right to succeed. As the inventor in the workshop has in his mind the ideal machine, towards the completion of which he toils steadily, so the breeder, with rare patience, experiments and develops until he has added to the world's wealth an absolutely new breed.

The creation of the American trotter is one of the grandest triumphs of the nineteenth century; it has given us a national amusement, and has added enormously to the national wealth. The growth and progress of this breed from the initial experiment to the perfect type, is a most fascinating study. Each step teaches valuable lessons, and as the loyal student adrances, the more clearly does he perceive the unerring accuracy of Nature's laws. The practical intellect of American horsemen quickly recognized both the utility and beauty of a high rate of speed at the trotting gait. They clearly saw that it was the only absolutely useful gait for all purposes and all clisses, and by the scientific application of the laws of selection and descent, in less than fifty years, the time test has been lowered from $2: 30$ to $2: 0.5 \frac{1}{4}$, and the bright and shining mark of $2: 00$ is conceded by many able judges to be within the legitimate possibilities of the future. 
The attempt to form a new breed necessitates a multitude of experiments, and many failures, before a solid foundation is reached. The early meeders availed themselves liberally of the blood of the thor-

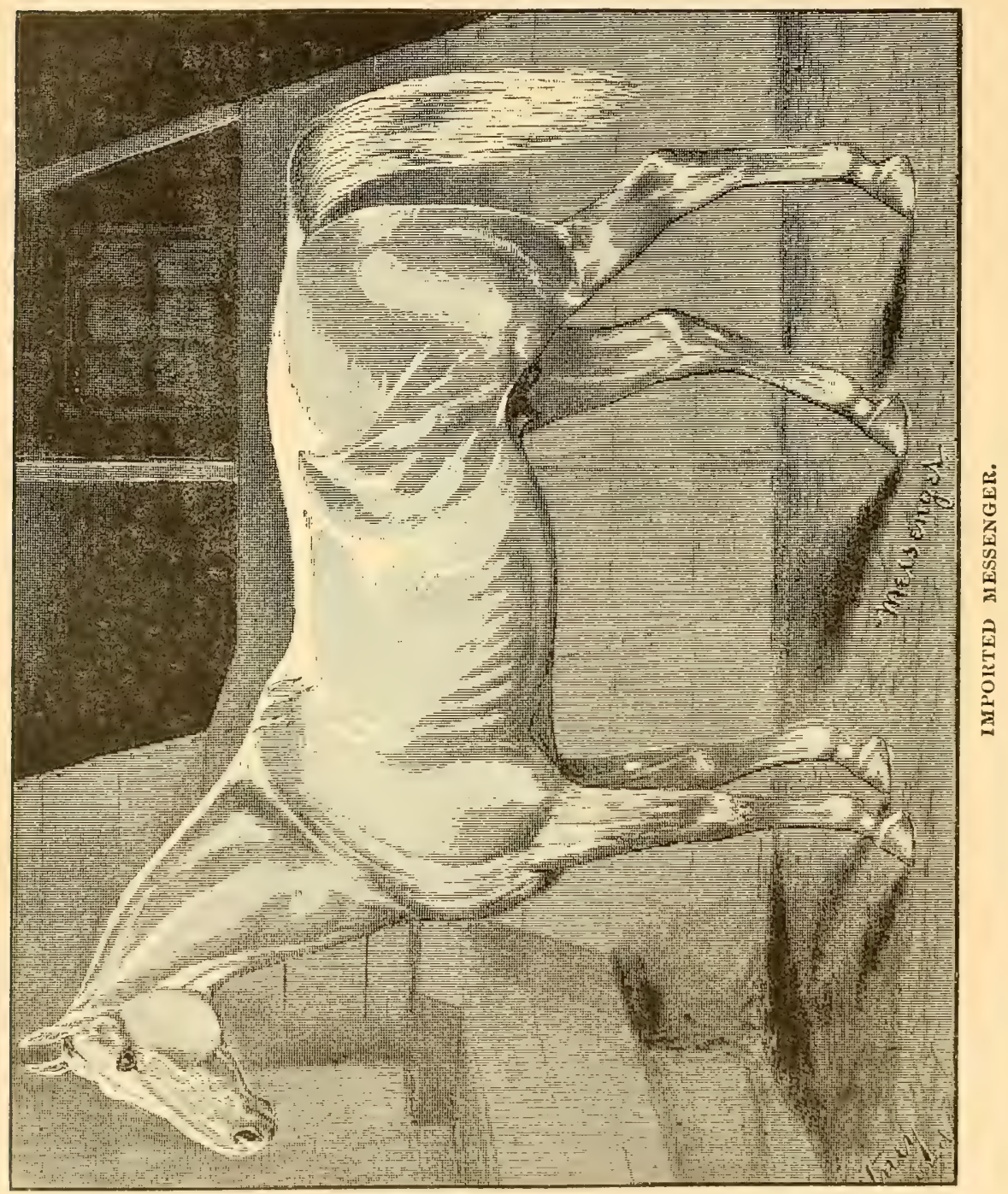

onghbred. From this soure they obtained speed and stamina, but thery had to look to other sourees for the instinct and desire to trot. The original and natural gait being the gallop), the great and ult imate

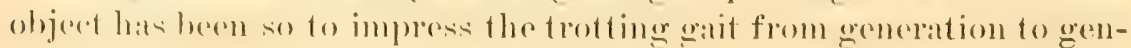


eration as to produce colts from whose natures the desire to gallop shall have been erased, and which absolutely know no other gait but the trot. As the English thoroughbred was originally created by breeding the imported Arab with native mares, so the American trotter of the early days was produced from the thoroughbred and the native American mare, the subsequent progress and perfection of the race arising through judicious selection and crossing. Thus the great Hambletonian family traces through the paternal line directly to the famous imported thoroughbred stallion "Messenger." The Mambrino Chief family in the same way goes back to "Messenger." The Clays find their paternal source in "Bashaw," an imported Barb, and though the origin of the Morgan family is in doubt, the balance of evidence is in favor of the thoroughbred.

The head of the Pilot family was of unknown breeding; he was a French-Canadian, but through his son, Pilot, Jr., and his grand-

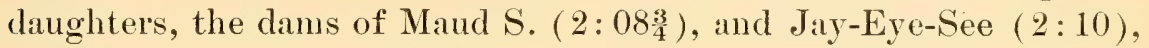
and other fast trotters, his blood has become one of the most formidable factors in the breeding problem. As the English discontinued the use of Arab blood as soon as the thoroughbred had assumed a distinct and superior type to the breeds from whence it had originated, so the breeders of the trotter now find that they obtain the highest results by cross-breeding the sons and daughters of these leading families.

\section{Rysdyk's Hambletonian.}

When the late William M. Rysdyk purchased the Charles Kent mare, with a foal at her side, for the small sum of $\$ 125$, he little dreamed that he had not only laid the foundation of his own fortunes, but that he had in the person of the foal the founder of the most celebrated trotting family in the world. Yet such was the case. He was placed in the stud at two years old, and covered four mares, three of whom had foals; one of these foals, under the name of Alexander's "Abdallah," became almost as famous as his illustrious sire. His daughter, Goldsmith Maid (2:14), was undoubtedly the greatest campaigner the trotting track has ever seen. Hambletonian's stud fee was advanced gradually but steadily from $\$ 25$ to $\$ 500$ the season, and his stud services netted his owner over $\$ 300,000$. He was foaled May 5th, 1849, and died in March, 1876. Hambletonian was sired by Abdallah, he by Mambrino, and the latter by imp. Messenger. His dam was the Charles Kent mare by imp. Bellfounder; the second 
dam, One Eye, by Bishop's Hambletonian; and the third dam was Silvertail, by imp. Messenger. He thus traces on both sides of the line back to the famous gray horse. Hambletonian sired forty animals with a record of $2: 30$ or better. His justly renowned son, Dexter $\left(2: 17 \frac{1}{4}\right)$, is the brightest gem in his crown. He was the fastest trotter of his time, and when he made his record of $2: 17 \frac{1}{4}$, at Buffalo, N. Y., on August 14th, 1867, it was the champion record of the

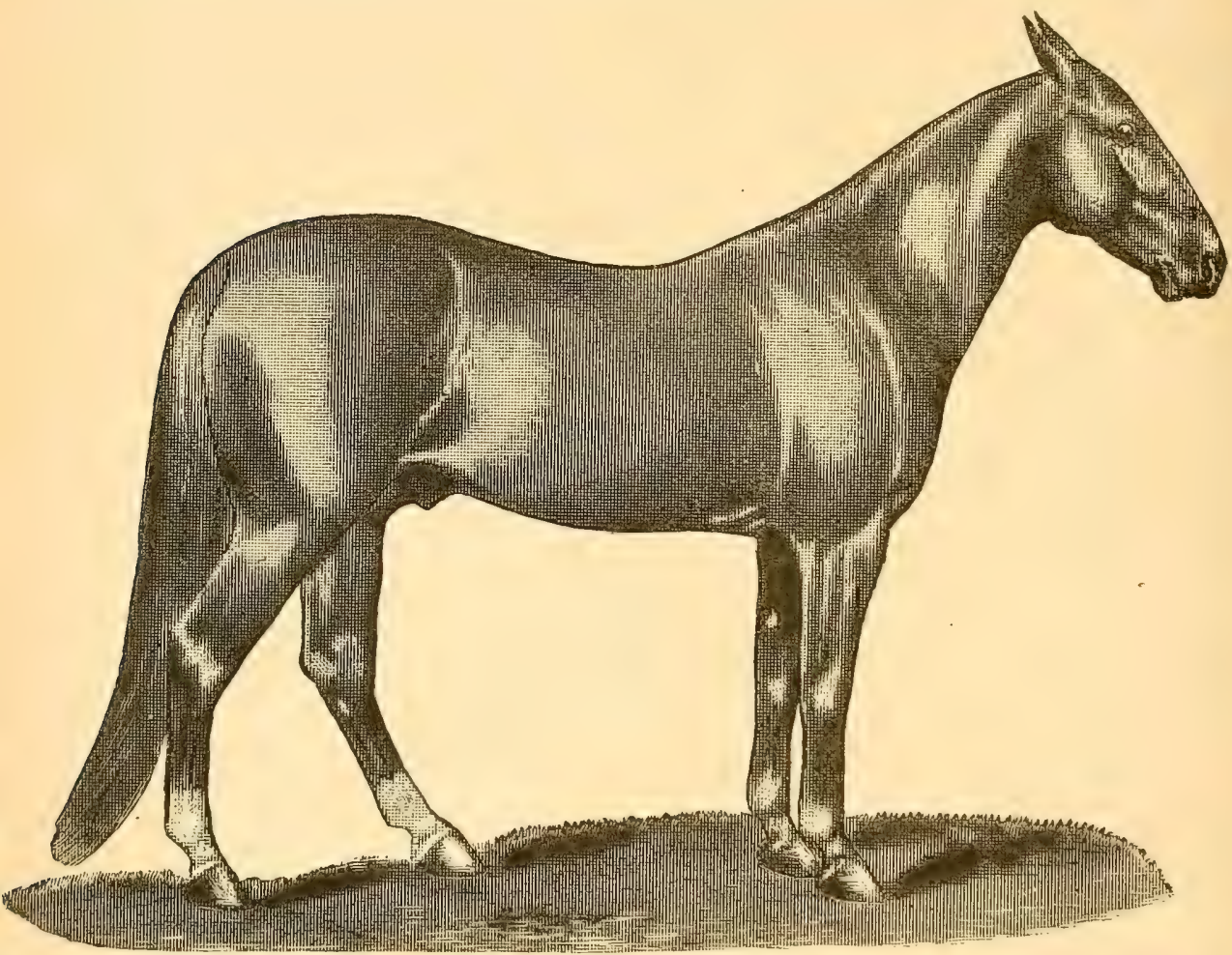

RYSUYK'S IIAMBLETONIAN.

track, and so remained till September 2d, 1876, when it was passed by Goldsmith Maid, $2: 14$.

But the erowning glory of Hambletonian is his own prepotency, and that of his sous and damghters. Ilis son Volunteer has twentynine 2:30 trotters to his credit, including the illustrions st. Iulien, 2:111. Alexander's Abdallah eontributed only six to the $2: 30$ list, but the six included that matehless star trotter, the invincible and immortal Goldsmith Maid. Dictator is the sire of thirty-two within 
the magic circle, and in that number will bo found Jay-Eye-See (2:10), the fastest trotting gelding in the world, and Phallas ( $\left.2: 13 \frac{3}{4}\right)$, at one time the trotting stallion King. Happy Medium ranges well up with his brothers in blood-he adds sixty-six to the

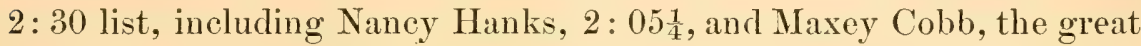
stallion which trotted a mile to harness in $2: 13 \frac{1}{4}$, and a mile to pole with his half-sister Neta Medium, in $2: 15 \frac{3}{4}$. Electioneer, the brilliant California representative of the premier trotting family, has sent one hundred champion trotters to the front, and as a sire of developed speed at an early age, he is the wonder of the age. In the list of this remarkable hundred will be found Bell Bird, yearling, 2:261 Arion, two-year-old, $2: 10 \frac{3}{4}$; Sunol, three years, $2: 10 \frac{1}{2}$ and $2: 08 \frac{1}{4}$ at

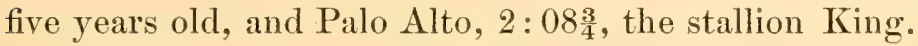

Harold has thirty-one sons and daughters which have proved his speed-transmitting power, and he has the further distinguished honor of being the sire of Maud S. (2:083), the acknowledged Queen of the trotting track from 1885 to 1891 . To George Wilkes, howerer, must be conceded the honor of being the greatest son of the mighty Hambletonian. He was a very small colt, and the death of his dam nocessitated his being brought up by hand. He developed early, and though a small horse he soon showed that he possessed high speed and the best campaigning qualities. The era in which he flourished was not favorable to a very fast public record. The large prizes of the turf were only to be gained in matches, and consequently the great object was to conceal speed as far as possible, not to expose it. In spite of this state of affairs George Wilkes left the track for the stud with a record of $2: 22$, and a reputation second to no trotter of his time. His career in the stud has been one long series of triumphs, and when we consider the speed-producing power of his sons and daughters, his right to the stud throne must be conceded.

George Wilkes has seventy-two trotter's in the $2: 30$ list, and seventy-two of his sons are represented in the same roll of honor with four hundred and six performers. The fastest son of George Wilkes is Harry Wilkes, $2: 13 \frac{1}{2}$.

Hambletonian was the sire of forty $2: 30$ performers; he has one hundred and twenty-nine sons, which hare sired nine hundred and fifty-five trotters which are in the same list, and his daughters to the number of fifty-nine are represented by seventy-three $2: 30$ performers. As the student of the seience of heredity traces this grand 
genealogical tree from the lordly trunk to its many grand and prolific branches, he will find speed on every limb, and records as plentiful as leaves. The intelligent reader must, however, carefully bear in mind this fact, that while the sire is entitled to receive his full percentage of credit, the work of the dam is equally important, and the phenomenal success of the Hambletonian sires is largely due to mares of the Star, Clay, Pilot and Mambrino Chief families, with which they have been mated.

\section{Mambrino Chief.}

Mambrino Chief, the head of the second great branch of the trotting family, was foaled in 1844. His sire was Mambrino Paymaster, and he by Mambrino. His dam was of unknown breeding, but of great individual excellence. Mambrino Chief died in 1861. During his short career in the stud, he contributed six to the $2: 30$ list, including the great campaigner, Lady Thorn, $2: 18 \frac{1}{4}$. Had this been his only claim to equine fame, he would have found no place in these annals, but his sons and daughter's manifested a marvelous speedpossessing and speed-transmitting capacity, which, with each succeeding generation, developed both in quality and quantity. He has twenty-three sons that have produced eighty-seven $2: 30$ trotters. In that roll of honor there will be found Woodford Mambrino $\left(2: 21 \frac{1}{2}\right)$, sire of twelve in the 2:30 list, including the famous Pancoast $(2: 213)$; which was sold at the great Glenview sale for $\$ 28,000$, the sire of Patron, with a record of $2: 14 \frac{1}{4}$.

Mambrino Patchen, another illustrious son, has eighteen 2: 30 performers to his credit. He has also thirty-seven sons which have sired seventy-six in the 2:30 list, and fifty-two daughters which have contributed an additional fifty-six to the roll. Ashland (hief, mother son of Mambrino Chief, is the sire of Black Cloud (2:17!). Clark Chief, another son, is the sire of six in the list, including Croxie ( $2: 1914$ ), while three of his daughters have the distinguished honor of being the dams of Majolica (2:15). Phallas (2:133) and Wilson ( $\left.2: 16 \frac{1}{1}\right)$.

The daughters of Mambrino Chief have contributed their full share in sustaining the honor of the name. Seventeen of his daughters have twenty-three of their produce in the list, including such turf magnates as Piedmont (2:174), Director (2:17), Indianapolis

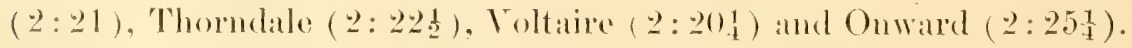
'The trotting turf has a right to be proud of the great Mambrino Chief f:mily. 


\section{The Clays.}

The Clay family of trotters, while not so numerous as either the Hambletonians or Mambrino Chiefs, has indelibly stamped its mark on the race, and its rich red tide flows in the veins of many of the leading heroes of the turf. Andrew Jackson, the founder of the race, was a son of Young Bashaw, out of a pacing mare; he was the sire of the great Kemble Jackson, Black Hawk and Henry Clay. The last named was the celebrated son from which the family has been named. The dam of Henry Clay was a pacer of unknown pedigree. Henry Clay sired Cassius M. Clay No. 18, and from this branch of the family high-producing speed has been the rule, and not the exception. In

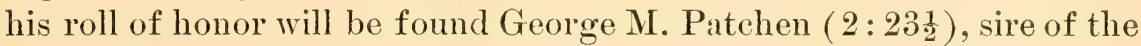
famous Lucy ( $\left.2: 18 \frac{1}{4}\right)$, and three other standard trotters. George M. Patchen has to his credit twelve sons which have forty-eight in the 2:30 list, and five of his daughters have six. Cassius M. Clay, Jr., No. 20, another son, has four representatives; Cassius M. Clay, Jr.,

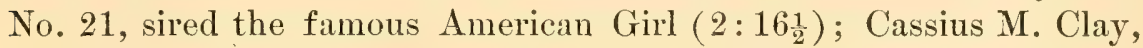

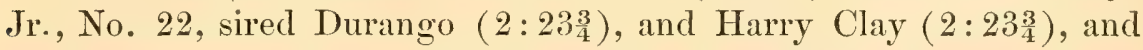
this excellent scion of a noble house has nine sons with twenty-one in the list, and twenty-two daughters which are also represented. The brightest jewel in the crown of Henry Clay, which shines on with increasing lustre, is Dolly Spanker, his famous daughter, the dam of George Wilkes $(2: 22)$, the phenomenal trotting sire of the age. The Clay family has become proverbial for producing excellent dams; the blood mixes kindly with the other trotting families, and produces the highest speed results.

\section{The Pilots.}

Pilot was a Canadian horse of no known pedigree, but he ranks high as a progenitor of extreme speed, through his celebrated son, Pilot, Jr. In the 2:30 list Pilot, Jr., has eight of his produce to his credit, but that by no means represents the enormous influence which he has exerted upon the highest developed speed of the trotting horse of America. In the 2:30 record he has six sons and two daughters to his credit, the fastest of them being John Morgan, with a record of $2: 24$, but on his sons and his daughters he depends for rendering his name illustrious. Bayard is the sire of eight in the $2: 30$ list, and he is also the sire of the dam of Jane R., with a record of $2: 20 \frac{1}{4}$. Tattler, another son with a record of $2: 26$, has to his credit four; and Clifton Pilot, Pilot Duroc, Roscoe and Woodburn Pilot 
have also added to the list. The speed-producing powers of the sons of Pilot, $\mathrm{Jr}$, are meritorious, but they are overshadowed by the magnificent capacity of his daughters.

Miss Russell, his most famous daughter, was the dan of Maud S. ( $\left.2: 08 \frac{3}{4}\right)$, and Nutwood $\left(2: 18 \frac{3}{4}\right)$. He is also the sire of the dams of Jay-Eye-See (2:10), Yambrino Gift (2:20), Noontide (2:2014), Viking $\left(2: 19 \frac{1}{4}\right)$, Naiad Queen $\left(2: 20 \frac{1}{4}\right)$, Scotland $\left(2: 22 \frac{1}{2}\right)$, and twenty-six others in the $2: 30$ list. Pilot, Jr., mares are highly prized, both in the first and second generation, and when crossed upon the sons of Hambletonian or Mambrino Chief, they have produced many of the leading heroes and heroines of the trotting track.

\section{Blue Bull.}

The greatest romance in the annals of the trotting horse is the history of the great Indiana sire, Blue Bull. An obscure horse, with an obseure pedigree (he was by a horse called Pruden's Blue Bull; dam Queen, by Young Selim), for years he was consigned to the meanest offices of the stock farm, and in his early career it was only at rare intervals that he had the opportunity to cover even the commonest and most cold-blooded of mares. It seemis almost impossible that from such unfavorable surroundings he should have emerged to take a front rank among trotting sires.

It is well within the bounds of wisdom and prudence to say that had Blue Bull enjoyed the advantages which George Wilkes and other great sires have possessed, he would have been the premier sire of the age, and that his sons and danghters would have perpetuated his name and fame for generations to come. Had his intrinsic excellence as a sire been adequately understood at an early period in his carecr, the perpetuity of the line might have been maintaned; as it is, in this respect he falls far behind his great rival, Georace Wilkes. Bho Bull is the sire of fifty-four $2: 30$ trotters, at the head of which are the great campaigners, Zoe B. ( $\left.2: 17 \frac{1}{4}\right)$, Bessie ( $\left.2: 17 \frac{1}{2}\right)$, Lena Swallow $(2: 19)$, and Will Cody $\left(2: 19 \frac{1}{2}\right)$. He has two sons which have followed in

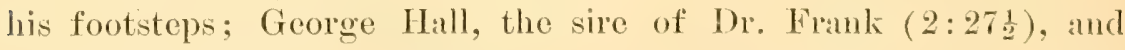
Prompter, the sire of Apex (2:26), and Tramsit (2:26:2). Blue Bull is also the sire of the dams of Laldy Elgin ( $\left.2: 25 \frac{1}{4}\right)$, Lowland Girl (2:26), Highland Mary (2:26), Stal W. (2:27:3), Polka Dot

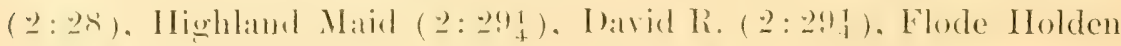
(2: :29!1) and twenty-one of her trotters in $2: 30$ or better, 


\section{Minor Families.}

In the minor families of the trotting horses of America may be mentioned American Star 14, who, although he contributed only four animals to the $2: 30$ list, yet assisted most materially through his daughters to increase and perpetuate trotting speed. Thirty-six of them are the dams of $2: 30$ performers, including Dexter ( $\left.2: 17 \frac{1}{4}\right)$, Driver

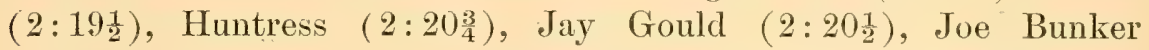
$\left(2: 19 \frac{1}{4}\right)$, Nettie (2:18), Orange Girl $(2: 20)$, Powers $(2: 21)$,

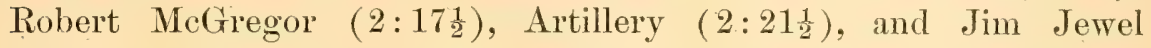
$\left(2: 19 \frac{1}{4}\right)$. He is also the sire of eight sons which have produced 2:30 performers. Black Hawk, by Sherman Morgan, is another sire that, if he has not founded a family, has contributed largely to the speed aggregate of trotting statistics. He has four in the 2:30 list, and he is the sire of sixteen sons and daughters which have produced twenty-five whose names will also be found inscribed there. One of these sons, Ethan Allen, sired six which trotted in $2: 30$, and nineteen of his sons sired sixty-two, and eleven of his daughter's foaled twelve 2:30 trotters; while in the third generation a son of Ethan Allen, Daniel Lambert, has thirty-six of his sons and daughters on his roll of fame. Green's Bas'aw, a son of Vernol's Black Hawk, sired seventeen trotters which complied with the 2:30 standard of the track. He is the sire of fifteen sons whose produce number thirtyfour in the 2:30 list, and his daughter's are well represented. Governor Sprague $\left(2: 20 \frac{1}{2}\right)$, by Rhode Island $\left(2: 23 \frac{1}{2}\right)$, be by Whitehall, was a great trotter, and at the age of five years obtained a record of $2: 20 \frac{1}{2}$, which at the time he made it, and for years after, was the fastest record at that age. During the short time he was in the stud he was the sire of twenty-eight animals which have records of from 2:18 to $2: 29 \frac{1}{4}$, and had he not died in the early morning of his stud career, it is reasonably presumptive that he would have made the name of Sprague illustrious in the ranks of the foremost trotting sires.

Columbus, Bellfounder, Knnox, Morrill, Royal George, Blanco, Norman and other sires of lesser magnitude have contributed their 'quota to the noble breed-a breed, which through tireless patience, careful selection, and a faithful application of the laws of heredity, has risen superior to the sources from whence it sprang, and has developed into a grand and distinct type, the most useful horse in the world-THe American Trotter. 


\section{BRIEF BIOGRAPHIES OF MONARCHS OF THE TRACK.}

In order to show in a brief and practical mamner the progress of the breed, the reader will now be introduced to the first animal, Lady Suffolk, which trotted below $2: 30$, and he will then be conducted through a short series of sketches of each of the great trotting horses which have in their time been the monarchs of the track; in this way it is hoped he will see in a brief yet intelligent manner the speed progress of nearly half a century.

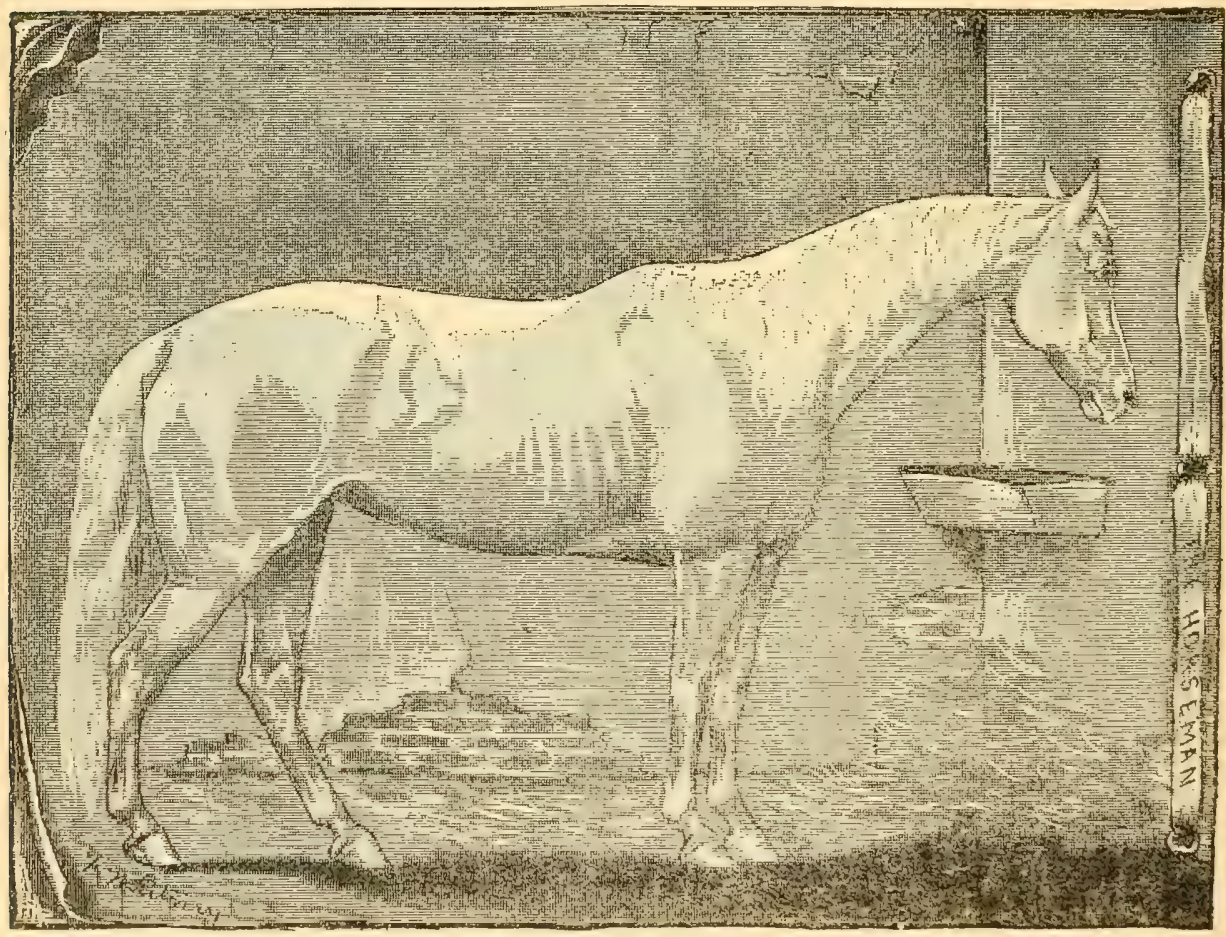

I. $\triangle$ DY SUFFOLK, $2: 26 \frac{1}{2}$.

Lady Suffolk, 2: 26 1-2.

Lady Suffolk mat be aptly styled the mother of the $2: 30$ list, as she was the first trotter to head that roll of honor, which is now the recognized standated of the trotting world. She was horn in suffolk County, Long Island, in 1833, and was bred by L. W. Lawrence, of Smithtown. IIer sire was Engineer 20l, son of Engineer, he hy imp. Messenger. Her dam was by Don Quixote, also a son of imp. Messenger. In color she was a dark iron-gray, which in old age became 
almost white. She stood but little if any over 15.1 high. She was well made, long in the body, with powerful quarters, short camnon bones and long fetlocks. She had good shoulders; a light, straight but muscular neck, and long ears. Such is a condensed description of Lady Suffolk, by the great pioneer trainer and driver, Hiram Woodruff. Her formal debut on the trotting track was at Beacon course, N. J., on June 20th, 1838, when she was defeated in poor time by Black Hawk and Apollo, but two days later, orer the same track, she defeated Lady Victoria, Black Hawk and Sarah Puff, in a race of two-mile heats in $5: 15$ and $5: 17$. Her last victory was on July 5th, 1852, when she defeated Boston Girl in the second, third and fourth heats in $2: 35 \frac{1}{2}, 2: 37$ and $2: 39$.

As a campaigner of marvelons endurance and great gameness she has had no superiors, and few equals. Her turf career lasted nearly fifteen years, and during that period she measured her speed against most of the celebrated horses of the time. She took part in one hundred and thirty-eight races, of which number she won eighty-eight in addition to receiving three forfeits. A large number of these contests were two and three-mile heats, and two of them races of four-mile heats. Her famous record is as follows: Four miles to saddle, 11:15, Centreville, L. I., June 30 th, 1840 ; three miles to saddle, $7: 40 \frac{1}{2}$, Philadelphia, May 15th, 1841; two miles to harness, 5:03, Centreville, L. I., July 14th, 1847; one mile to saddle, 2:26: Beacon Park, N. J.,

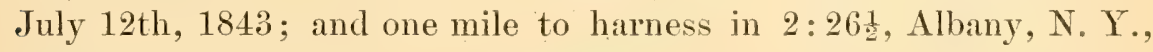
September 6th, 1844. Lady Suffolk died at Bridgeport, Tt., on March 7th, 1855.

Flora Temple, 2: 19 3-4.

The progressive spirit of the trotting turf received a grand stimulus when 2:30 was passed, and every effort was now made to invade the domains of Old Father Time; $2: 20$ was now the hoped for goal, and when that was reached, good judges of that day helieved that the speed limit would be attained. How fallacious this idea was, is now apparent. The animal destined to first accomplish the desired feat was Flora Temple, which she did at Kalamazoo, Mich., on Oetober 15th, 1859. Flora Temple was foaled in 1845, and was bred by S.Welch, of Oneida Co., N. I. There is a doubt about her sire, but her dam was the daughter of an Arabian horse. Her owner was a Mr. Tracy, who at four years old sold her for the paltry sum of $\$ 13$. She passed through several hands, and was at last purchased by 
George E. Perrin, of New York, for $\$ 350$. Under his skillful training she became track-wise, and developed into the fastest and gamest trotter of her day.

Her first regular appearance on the trotting track was at the Union course, L. I., on September 9th, 1850; she was a rank outsider, and to the surprise of both horsemen and the public she won the second, third and fourth heats, in $2: 55,2: 52$ and $2: 49$. Whitehall won the first heat in 2:52, and three others competed. In 1851 she was not

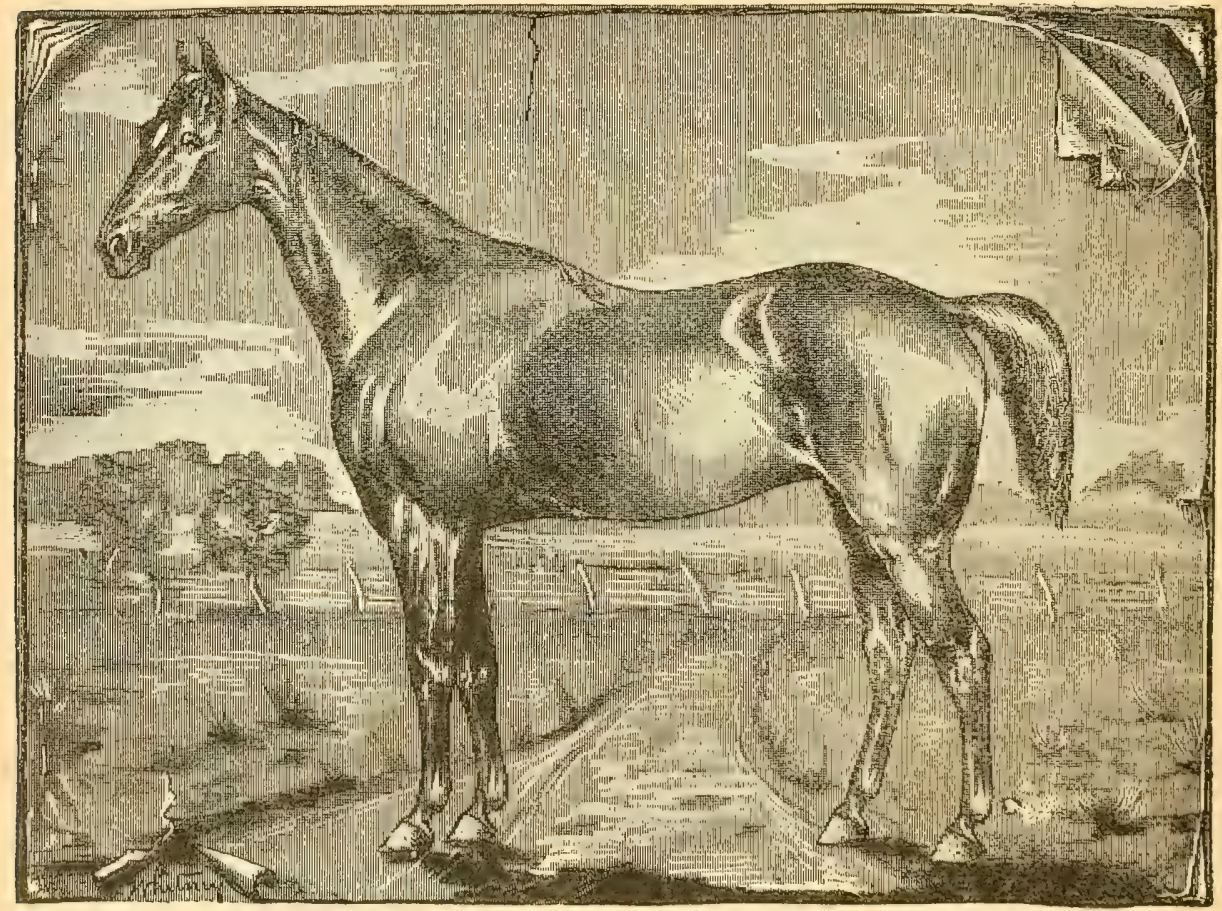

FLORA TEMPLE; $2: 193 / 4$.

in training, but in 1852 she trotted in three matehes, wimning them all. The best time made was $2: 36$. In 1853 she made a wonderful campaign-winning seventeen ralees; defeating such well knowa flyers of that time as Black Douglas, Takeny, Green Mountain Maid and Rhode Island. In that year she won nineteen races, and lost four times. In 185t she defeated Green Mountain Marid al two-mile heats in 5:07 and 5:07. In mile heats, three in five, for $\$ 2,000$, she won a rate from Mack in $2: 31_{4}^{3}, 2: 32$ and $2: 33$, and thirteen days 
later, for the same amount, she finished in front of Jack Waters in $2: 33,2: 39$ and $2: 37$.

In 1855 she lost her opening match with Sontag, and a match against time, and then won her next six engagements in rotation. In these grand exhibitions of speed she led to the wire such horses as Lancet, Sontag, Lady Franklin, Chicago Jack, Mack, Frank Forrester and Hero. In 1856, '57 and ' 58 she continued her career of victory, meeting successfully Lancet, Tacony, Ethan Allen, Rose of Washington, Princess, and others. In 1859 she achieved the crowning triumph of her life. On October 15th, at Kalamazoo, Mich., she met the California trotter, Princess, and Honest Anse. The purse was $\$ 2,000$, and she won in straight heats in $2: 32 \frac{1}{2}, 2: 22 \frac{1}{2}$ and $2: 19 \frac{3}{4}$; the first half of the last heat was trotted in $1: 09$.

The time marked a new departure in the progress of the trotter, and prepared the public mind for still grander achievements. Flor:a Temple long survived her fame, the time of her decease being December 21 st, 1877.

\section{Dexter, $2: 17$ 1-4.}

The fight between Time and science and breeding now became a stubborn one, and it was not till 1867 that the record was again lowered, when the mighty Dexter fought the "man with the scythe" to a finish, and achieved a great victory. Dexter was foaled in 1858 ; his sire was Rysdyk's Hambletonian; his first dam was Clara, by Seely's American Star, and his second dam was the McKinstry mare, the dam of Shark, $2: 27 \frac{3}{4}$. He was the first horse to demonstrate the marvelous speed-possessing qualities of the Hambletonian-Star families. Dexter won his first regular turf engagement at the Fashion course, L. I., May 4th, 1864; he then met and defeated Stonewall Jackson, Lady Collins and General Grant, in $2: 33,2: 36$ and $2: 34 \frac{3}{4}$. In 1865 he met the famous trotting horse, General Butler, in a match for $\$ 2,000$; he again won in straight heats, time $2: 26 \frac{3}{4}, 2: 26 \frac{1}{4}$ and $2: 24 \frac{1}{2}$. On June 2d, to saddle, he met Stonewall Jackson in a race of three-mile heats; the first heat was won by Stonewall Jackson in $8: 02 \frac{1}{2}$, Dexter winning the next two and the rare in $8: 05$ and $8: 09 \frac{1}{2}$.

On September 7th, of the same year, he again met General Butler, the race being trotted to saddle, and again the speedy son of Hambletonian won in $2: 26 \frac{1}{2}, 2: 24 \frac{1}{2}$ and $2: 22 \frac{1}{2}$. Septenber 21 st was a memorable day in trotting annals, for on that date he met and defeated General Butler, and that great trotter and still greater sire, George 
Wilkes; time $2: 25 \frac{1}{2}, 2: 26 \frac{1}{2}$ and $2: 25$. On October 10 th, for a purse of $\$ 6,000$, he trotted against $2: 19$, and won in $2: 18 \frac{1}{4}$. Two more victories over General Butler completed the list of his triumphs for that year.

His career in 1866 was one blaze of triumph. On June 15 th he defeated George W. Patchen; best time, 2:273. On July 2d he won a $\$ 2,000$ purse from General Butler and Commodore Vanderbilt; July 9th, at Suffolk Park, Philadelphia, for a purse of $\$ 2,000$, he again defeated George W. Patchen. Ten days later, at the Fashion course, to saddle, he trotted against General Butler and Toronto Chief, winning the race in $2: 24 \frac{1}{4}, 2: 19$ and $2: 22$. During the year he won twenty-five matches and races, defeating Rollo Golddust, Silas Rich, George W. Patchen and General Butler, the fastest and gamest horses of the season. In 1867 he scored a victory on May 16th, at Middletown, N. Y., against the queen of the trotting track, Goldsmith Maid. The purse was $\$ 3,000$, and he won in the comparatively slow time of $2: 28 \frac{1}{2}, 2: 32$ and $2: 28$. He next met the redoubtable Lady Thorne, and defeated her in five matches, two of them being two-mile heats; the best time of the two-mile was $4: 51$, and the best time to harness was $2: 20 \frac{1}{2}$. At Troy, N. Y., Providence, R. I., and Boston, Mass., he trotted for $\$ 2,000, \$ 2,500$ and $\$ 5,000$ respectively, against Brown George and running mate, winning all three races.

On August 14th, 1867, he won the throne of the turf, and trotted so fast that not only did he leave all previous records, including his own, far behind, but he also placed upon the record a bright and shining mark, $2 ; 17 \frac{1}{4}$, which it took six years to overtake and pass. Ile was then purchased by the millionaire horseman, Robert Bonner, and as soon as his existing engagements were completed he was retired from the turf. It is the firm belief of his admirers that had he lived in these days of fast tracks, patent sulkies, and improved methods of training, he would have emulated the speed trimphs of the fastest trotters of the present day.

\section{Goldsmith Maid, 2:14.}

With the exception of Occident, which trotted in California in $2: 163$, on September 17th, 1873, and Gloster, which trotted on August 14th, 187t, the time record received no serere shock till (roldsmith Maid achieved her wouderful record of $2: 14$, on September $2 \mathrm{~d}, 1874$. 
Goldsmith Maid was foaled in 1857; she was by Alexander's Abdallah, he by Hambletonian; her dam was by Abdallah 1, the sire of Hambletonian, so that on both sides of the line she traced back direct to the famous old thoroughbred, imported Messenger. Measured by all the standards, Goldsmith Maid was the greatest campaigner of the trotting track. She was capable of the highest flights of speed; she had indomitable courage; she could trot from the beginning to the end of a long season, and for seven years she was the undisputed empress of the trotting track. Her full record would fill a volume. In her youth she was unreliable, but as she became acquainted with the trotting track she rapidly rose in racing quality, but it was not till July 30 th, 1868 , that she really proved herself capable of holding her own in any company. On that date, at Buffalo, she met and defeated Silas Rich, American Girl, Clara and Panic, in a five-heat race; best time, $2: 24 \frac{1}{2}$.

In the same year she met George Wilkes, George Palmer, General Butler and American Girl, and was again victorious, reducing her record to $2: 22 \frac{1}{2}$. During the season of 1869 she won the famous $\$ 10,000$ purse, at Buffalo, and was successful in seven other engagements. In these contests she met such heroes of the track as Lucy, George Palmer and American Girl, and had to reduce her record to 2:19 The following year, 1870, again found her in the arena, and her season was a succession of the most brilliant triumphs. She won eleven engagements, and a grand cash aggregate of $\$ 48,500$.

The year of 1871 found her with the mantle of invincibility; only once did she suffer defeat. She scored against that defeat fourteen victories, and on September 6th, at Milwaukee, she reduced her record to 2:17. In 1872, sighing for fresh worlds to conquer, she took a trip to California, where she defeated the famous champion of the Pacific slope, Occident. She won every engagement of the year, with one exception, finishing the season with a record of $2: 16 \frac{3}{4}$.

The season of 1873 was an active one, and victory seemed to be still securely perched upon her sulky. She met American Girl, Lulu, Camors, Gloster, Judge Fullerton, Sensation and Jim Irving, and defeated them without being forced to reduce her record. The crowning achievement of her great career was during the season of 1874, when, at Mystic Park, Boston, Mass., on September 2d, she passed her own and all previous records, and trotted in $2: 14$, a record which remained at the head of the list until passed by Rarus, 


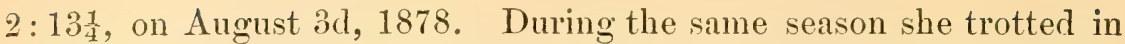
and won twenty races, meeting and defeating the fastest trotters of the day. Her season of 1875 was an uneventful one, but that of 1876 was made memorable by her remarkable duels with the stallion king, Smuggler. At Cleveland, on July 27 th, she won the first and second heats in $2: 15 \frac{1}{2}$ and $2: 17 \frac{1}{4}$, the stallion winning the next three in $2: 16 \frac{1}{4}, 2: 19 \frac{3}{4}$ and $2: 17 \frac{1}{4}$. But at IIartford, on September 7 th, after Smuggler winning the first and second heats in $2: 15 \frac{1}{4}$ and $2: 17$, and trotting a dead heat in $2: 16 \frac{3}{4}$, she won the race in $2: 17 \frac{1}{4}, 2: 18$ and $2: 19 \frac{3}{4}$. During the season she won fifteen races, and her only defeat was the one just mentioned.

With the season of 1876 her career on the turf ended, althongh she trotted again as late as 1879 . During her unparalleled career she trotted in one hundred and forty-eight races and exhibitions. In these contests she trotted four hundred and fifty-six heats, three hundred and fifty of which were in 2:30 or better. Her triumphs extended from Maine to California, and every prominent trotting course was the scene of her marvelous speed. She was the idol of the populace, and her name will go down in the annals of trotting speed as not only the greatest trotter of the period, but as one of the grandest of the age. Goldsmith Maid died on September 24th, 1885, and the following lines were aptly written on her decease:

\section{IN MEMORIAM.}

She has gone to her grave, but we ne'er can forget her,

The marvelons Maid with a mark of "fourteen;"

In the ranks of the tlyers we"ll ne er find a better,

For a gamer and faster there never was seen.

As we think of the track, and read its full story,

Her name and ber fame shall have the first place.

Her trots and her triumphs are her's, and its glory;

She was Queen of the I'urf, and Queen of her race.

Some may smile and say that others have beaten

The records she made in the fights that are past,

But her's were no holiday battles, I reckon,

'They were geunine contests from first to the last.

Tes, we'll drink in remembrance, there ne'er was a better

A faster and gamer there never was seen;

She has left us forever, but we ne'er can forget her,

The marvelous Maid with a mark of "fourteen." 


\section{Rarus, 2:13 1-4.}

Rarus, the next time-surpasser, and the successor to Goldsmith Maid on the trotting throne, was foaled in 1867, the year in which the mighty Dexter made his triumphal mark of $2: 17 \frac{1}{4}$. He was got by Conklin's Abdallah, and his dam was Nancy Awful by Telegraph, and his second dam was by Vermont Black Hark. Under the skillful guidance of John Splan, Rarus became a great campaigner, and on August 3d, 1878, he passed all previous records, trotting the full mile in 2:131. Rarus won his first saddle race at Hornellsville, N. Y., on August 21st, 1874; he had six competitors; Barbara Knox won the first heat, $2: 47$, Rarus winning the next three heats in $2: 46,2: 45 \frac{1}{2}$ and $2: 46 \frac{1}{2}$. On October 6 th and 7 th, of the same year, at Prospect Park, he won a seven-heat contest in a field of ten, winning the first, sixth and seventh heats in $2: 32 \frac{1}{2}, 2: 30$ and $2: 30 \frac{3}{4}$. He pliced two more purses to his credit during this season, in one of which he trotted in $2: 28 \frac{1}{2}$.

In 1875 he clearly demonstrated that he was a phenomenally fast horse. His first victory was at Sandusky, O., on July 22d, which he won in slow time. On July 30th, at Cleveland, for a purse of $\$ 3,500$, he defeated a strong field of seven in the fourth, fifth and sixth heats, in $2: 24 \frac{1}{2}, 2: 23 \frac{1}{2}$ and $2: 26 \frac{1}{4}$. At Rochester, N. Y., on August 12 th and 14 th, for a purse of $\$ 4,500$, he won the first, third

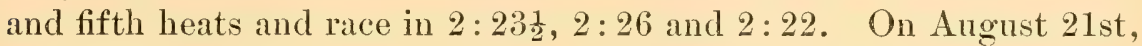
at Utica, N. Y., he placed a $\$ 4,000$ purse to his credit in $2: 25,2: 23$ and $2: 23$. At Hartford, Conn., on September 1st, he won the first money in $2: 20 \frac{3}{4}, 2: 25_{4}^{1}$ and $2: 22 \frac{3}{4}$, and two days later he won the $\$ 4,000$ purse in straight heats in $2: 21 \frac{1}{4}, 2: 22 \frac{1}{2}$ and $2: 24 \frac{3}{4}$. His last victory for that year was at Prospect Park, when he defeated Kansas Chief and Joker in $2: 25 \frac{1}{4}, 2: 24 \frac{1}{4}$ and $2: 25$.

In 1876 he won nine engagements of the first class at Buffalo, Rochester, Utica, Poughkeepsie, Hartford, Springfield, Fleetwood Park and Cincinnati; the total amount of the purses being $\$ 23,500$. In these races he defeated such celebrated horses as General Garfield, May Queen, Clementine, Adelaide, Sam Purdy, Bodine, Cozette, Great Eastern, Judge Fullerton, Lucille Golddust and Smuggler. He opened the season of 1877 on January 14th, at San Francisco, Cal., by defeating Sam Purdy in a match to wagons for $\$ 10,000$; the time was $2: 31 \frac{1}{2}, 2: 27 \frac{1}{4}$ and $2: 26 \frac{1}{4}$; and during the season he won nineteen purses, the best time being at Rochester, N. Y., August 8th, 
1877, when he defeated Lucille Golddust and Cozette in $2: 17 \frac{1}{2}, 2: 17 \frac{1}{2}$ and $2: 16$. The aggregate amount of purse money in these races was over $\$ 40,000$.

The year 1878 was the crowning one of his life. He opened the season on May 31st, at Pittsburg, Pa., and closed it at San Francisco, Cal., on December 21st. Most of his performances were exhibitions or matches against time. At Buffalo, N. Y., on August 3d, he trotted against the record of Goldsmith Maid for a purse of $\$ 500$, and at the third attempt he broke the record, trotting in $2: 13 \frac{1}{4}$. He made a short season in 1879, and was then sold to Robert Bonner for $\$ 35,000$, who at once retired him from the turf.

\section{St. Julien, $2: 11$ 1-4.}

The attacks upon the time limit from the days of Rarus to the present date (1892) have been rapid and successful, but they have come in seconds and fractions of seconds, showing that the highest possible speed goal cannot be far off. Rarus did not reign as king of the trotting track for a long period; he was dethroned by St. Julien on October 25th, 1879, the latter trotting the Oakland track, California, in 2:123, a record which he subsequently reduced on August 27 th, 1880 , to $2: 11 \frac{1}{4}$.

St. Julien was foaled in 1869 ; he is by Volunteer, son of Rysdyk's Hambletonian; his first dam was Flora, by Sayre's Harry Clay, his second dam was the Adams' mare, by Napoleon. St. Julien won his first race on August 4th, 1875, at Poughkeepsie, N. Y.; he had eleven competitors, including Great Eastern, which won the first heat, St. Julien taking the next three and the race in $2: 30,2: 26 \frac{1}{4}$ and $2: 30 \frac{3}{4}$.

On August 7th he again met and defeated a strong field, winning the first, second and fourth heats in $2: 26 \frac{3}{4}, 2: 28$ and $2: 263$. At Springfield, Mass., on August 24 th, he won first money in a $\$ 1,000$ purse, defeating Sister, Queen, Great Eastern, Ed. Chapin, Calmar, Goldfinder, Pet and Baty Fearnought in straight heats in 2:293, 2:28 and $2: 29$. Three days later he won a $\$ 3,000$ purse; the contest was a keen one, and lasted through five heats, St. Julien wimning the last three and the race in $2: 22 \frac{1}{2}, 2: 26 \frac{1}{2}$ and $2: 27$.

At IIartford, Conn., on August 31st, for the same amount, he defeated in straight heats, time $2: 28 \frac{1}{2}, 2: 26.1$ and $2: 26 \frac{1}{2}$, Great Eastern, Goldfinder, Dan. Bryant, Queen, Voltaire, Sister, Calmar and Lady IBomer. Ilis last victory of the year was on September 2d, at the same meeting, when he again defeated Sister, Great Lastern and 
Goldfinder in $2: 25 \frac{3}{4}, 2: 23 \frac{3}{4}$ and $2: 24 \frac{1}{2}$. He only appeared once in 1876 , winning a $\$ 10,000$ match at San Francisco, Cal., on September 2d, from Dan. Voorhees, in slow time. He was then given a rest of two years, but in 1879 he only won two races, one in which he defeated Graves and Nutwood, and one against time, in which he trotted in $2: 12 \frac{3}{4}$.

The following year, 1880, he achieved his greatest triumph. He won ten matches, exhibitions and races, including the match against time at Hartford, Conn., on August 27th, when, for a purse of $\$ 2,500$, he trotted against 2:113 (the record he had made at Rochester, N. Y., on August 12th), and won in 2:114. In 1881 and 1883 he won six engagements, since which time he has been retired from the turf. Although possessed of a world of speed, and with a faster record than his predecessors on the trotting throne, he cannot compare with them in the number of performances or in campaigning merit.

Jay-Eye-See, $2: 10$.

Jay-Eye-See was not the next in the line of succession-to Maud S. $\left(2: 08 \frac{3}{4}\right)$ belongs the honor-but as he holds the fastest record for a gelding, and did for one day, pass even Maud S.'s record (at that time $2: 10 \frac{1}{4}$ ), he is placed next to the brilliant St. Julien.

Jay-Eye-See was foaled in 1878; he is by Dictator, he by Hambletonian; first dam, Midnight by Pilot, Jr.; second dam, Twilight by Lexington. He was bought when a yearling for $\$ 500$, by the Hon. J. I. Case, of Racine, Wis., and is still owned by his estate. He made his debut on the trotting track at the summer meeting of 1882, in a fouryear-old stake, meeting Waiting, Breeze, Jim Bowman, Ed. Geers and Adelaide. The race ought to have been won by Jay-Eye-See, but it was foolishly prolonged into a seven-heat contest, Jay-Eye-See winning the fifth and sixth heats in $2: 22 \frac{3}{4}$ and $2: 23 \frac{1}{2}$, though there is little doubt that the previous heats were at his command. In the seventh heat, as the word was given, he made a very bad break, which lost him the heat and race.

At the autumn meeting, in the same class, he won easily, taking the first, third and fourth heats in $2: 22 \frac{3}{4}, 2: 19$ and $2: 19$, a performance which stamped him as the greatest four-year-old of the day, and also gave bright promise of the brilliant achievements which were yet to come. He opened the season of 1883 at Louisville, Ky., by defeating Charlie Ford in straight heats. His next performance was at Morrisania, N. Y., in a race for five-year-olds, when he distanced 
the field in the third heat in $2: 19 \frac{3}{4}$. In the same class, at Washington, he won in straight heats in $2: 19,2: 193$ and $2: 23$. At Chicago he captured the same purse in $2: 29,2: 31$ and $2: 19$. At Pittsburg he met the famous Majolica, but in order to win he had to trot in $2: 22 \frac{1}{2}$, $2: 17$ and $2: 17 \frac{1}{2}$.

At Cleveland the illustrious pair fought the battle over again, JayEye-See wimning in $2: 20 \frac{1}{2}, 2: 16$ and $2: 15 \frac{1}{4}$. At Buffalo he boldly entered the class for six-year-olds and under, and carried away the prize, defeating Director and Clemmie G., to whom he conceded one year. At Rochester he trotted against time, 2:15, and defeated the "man with the scythe" in $2: 14$. At Hartford he essayed to beat this record, but failed by half a second. The week following, at Narragansett Park, he broke his record, trotting in $2: 10 \frac{3}{4}$. His last great engagement of the year was his match with St. Julien, at Fleetwood Park, N. Y., on September 29th. The weather was bad and the track muddy, but the wonderful pony defeated his great antagonist in straight heats in $2: 20 \frac{1}{4}, 2: 18 \frac{1}{2}$ and $2: 19$.

On June 11th, 1884, he essayed to beat $2: 10 \frac{1}{4}$, but was defeated, his best time being 2:111 ; but at Providence, R. I., on August 1st, for a purse of $\$ 2,500$, to beat $2: 10 \frac{3}{4}$, he passed all previous records, and became the absolute monarch of the turf. His time for the mile was $2: 10$. He only retained the honor for one day, as at Cleveland, August 2d, Maud S. trotted in 2:093. At Buffalo, on August 8th, he trotted a mile in 2:103. At Belmont Park, Philadelphia, on August 15th, he trotted two heats in $2: 11$ and $2: 10 \frac{1}{4}$. He also trotted at Prospect Park, L., I. Minneapolis, Minn., and Kalamazoo, Mich., but in neither case did he approach his great record.

\section{Maud S., 2:08 3-4.}

Maud S., for six years the empress and queen of the track and the road, and the most popular animal of the century, was foaled in 1874. She is by Harold; first dam, Miss Russell by Pilot, Jr.; seeond dam, Sally Rusiell by Boston; third dam, Maria Russcll by Thornton's Rattler; fourth dam by Stockholder; fifth dam hy Topwallant; sixth dam by imp. Diomed. There is a striking likencess between this breeding and that of her famous contemporary, Jay-EyeSee. On the sire's side they are both by sons of II:mbletonian; on the dam's side they are both out of daughter's of Pilot, Jr., and both on the maternal side have close ul) a magnificent foundation of the best thoroughbred blood. 
Maud S. signalized her first victory on the turf by trotting below $2: 30$. At Cincinnati, O., on July 6th, 1880, she won in straight heats in 2:25,2:30 and 2:28. On July 24th, at Chicago, she met and defeated Trinket in $2: 19,2: 21 \frac{1}{4}$ and $2: 13 \frac{1}{2}$. On August 4th, at Buffalo, N. Y., Charlie Ford won the first heat in $2: 17$; she then won the next three heats and the race in $2: 15 \frac{1}{4}, 2: 16 \frac{3}{4}$ and $2: 16 \frac{1}{2}$, defeat-

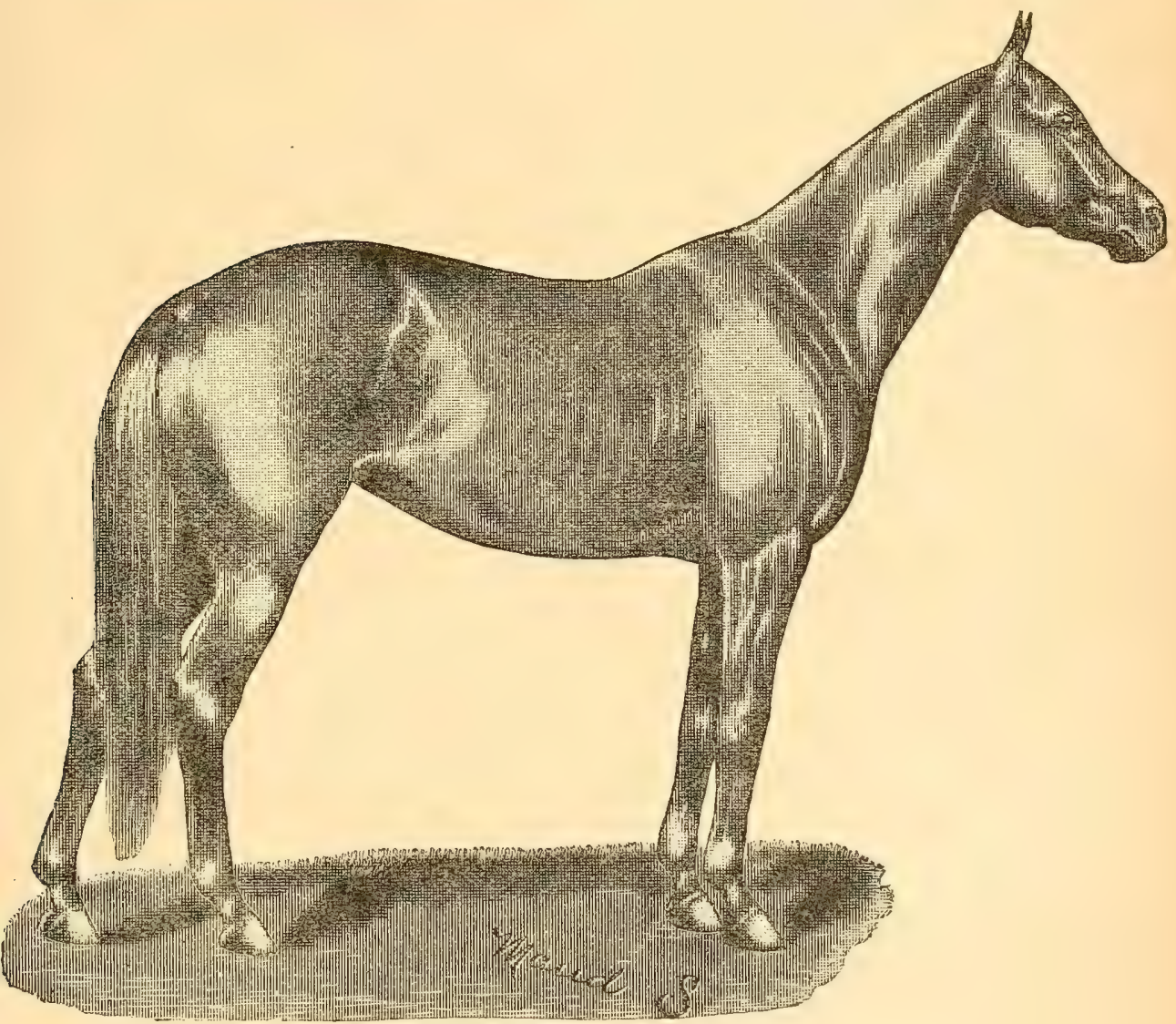

MAUD S., $2: 083 / 4$.

ing Charlie Ford, Inamis and Driver. At Rochester. N. T., on August 12 th, for a purse of $\$ 2,000$, she trotted against $2: 12 \frac{3}{4}$, and won in $2: 11 \frac{3}{4}$. At Chicago, Ill., on September 18th, she trotted against $2: 11 \frac{1}{4}$, and won in $2: 10 \frac{3}{4}$. She was now the Queen of the trotting track, and with the exception of one brief day she held the sceptre until October 20th, 1891, when Sunol trotted in 2:081. 
At Pittsburgh, Pa., on July 13th, 1881, for a purse of $\$ 2,500$, she trotted against her own record of $2: 10 \frac{3}{4}$, and won in $2: 10 \frac{1}{2}$. At Chicago, Ill., on July 23d, she trotted three heats in $2: 21 \frac{1}{2}, 2: 11 \frac{1}{4}$ and $2: 11$. At Belmont Park, Philadelphia, on July 29th, she trotted three heats in 2:12,2:131 and 2:121. On August 4th, at Buffalo, N. Y., she trotted in 2:10 $\frac{3}{4}$, and one week later, at Rochester, she trotted in $2: 101$. She retired for the year the heroine of the road, the Queen of the track, and undoubtedly the fastest horse at the trotting gait in the world.

The season of 1884 developed the fact that Maud S. had not reached her speed limit; her season was made still more sensational by her sale from W. H. Vanderbilt, the railroad king, to Mr. Robert Bonner, for the sum of $\$ 40,000$. Speculating horsemen had offered $\mathrm{Mr}$. Vanderbilt $\$ 100,000$ for the mare, but he was determined that she should not be submitted to the ignominy of an hippodroming career; he, therefore, determined to offer her to Mr. Bommer, who makes it a rule not to trot his horses for money. The offer was gladly accepted, and Maud $\mathbf{S}$. became the stable companion of Dexter (2:17 $)$, Rarus ( $\left.2: 13 \frac{1}{4}\right)$, and the other equine notabilities which have made the owner famous throughout the Union.

On August 2d she trotted at Cleveland, O., against time. The previous day Jay-Eye-See had defeated her record of $2: 101$, but it was a short-lived triumph, as the marvelous mare trotted in 2:093, and quickly regained her throne. Her owner was strongly of the opinion that her speed limit had not been reached, and she was specially prepared for another assault on Old Father Time. The contest occurred at Lexington, $\mathrm{Ky}$, , on November $11 \mathrm{th}$, in the presence of one of the most distinguished and characteristic audicnces ever brought together on one track, and again the mare cut down her own record, trotting the mile in $2: 091$. In 1885 she electrified the trotting world by again defeating her ow record, which she did at Cleveland, O., on July $30 t h$, trotting the mile in $2: 08^{3}$, which remained the fastest time on record up to October 20th, 1891, when it was passed by Sunol.

\section{Sunol, $2: 08$ 1-4.}

It has been aptly said that some men are born great, some achieve greatness, and some have greatuess thrust upon them. Of Sunol it can be truthfully said that she was both born great and achieved greatness. She was hred and owned hy senator Leland Stanford, at his famous Palo Alto Finm, Menlo Park, Cal., and was foaled on 
April 14th, 1886. As a yearling her education was commenced, though she did not compete in public, but her flights of speed on the private track gave her trainer, Charles Marvin, high hopes that she would become one of the bright stars of the trotting turf. She was born great, for she was by that champion sire, Electioneer, out of Waxana, by General Benton, while her second dam was by the immortal thoroughbred sire Lexington. She thus united the choice trotting blood of Hambletonian and Clay and the superb blood of the thoroughbred. As a two-year-old she made her debut at Los Angeles, Cal., on August 10th, 1888, defeating Vesolia in 2:321 and 2:25. On August 23r, at Petaluma, she again led the way to the wire, har-

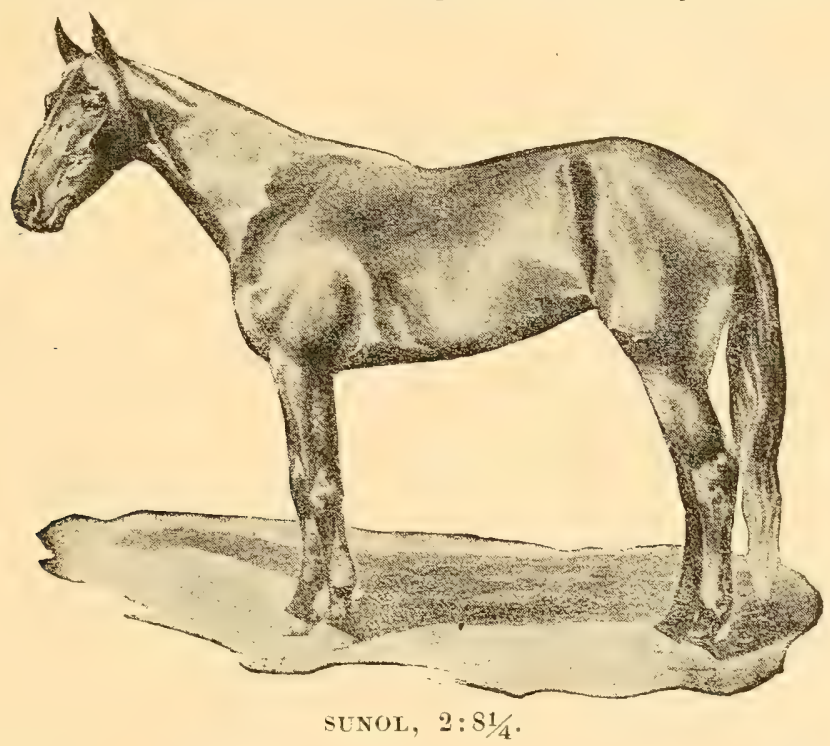

ing behind her such good fillies as Margaret $\$$. and Fortuna. The

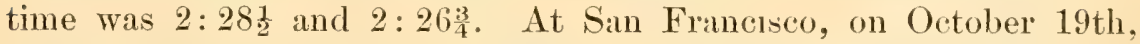
she trotted against time in $2: 20 \frac{1}{2}$, and on October 27 th she defented her own record by trotting in 2:18, which remained the champion two-year-old record until 1891, when the phenomenal Arion reduced it to $2: 10 \frac{33}{4}$. The eyes of the trotting world were now turned upon Sunol, and she was eren then hailed as the next queen of the turf. She made her first victorious appearance as a three-year-old, at Oakland, Cal., on September 5th, 1889, and defeated Margaret S. and Lillian Wilkes in $2: 21,2: 24 \frac{1}{4}$ and $2: 20$. It Silcrumento, on September 12 th, she trotted in $2: 16 \frac{1}{2}$. At the same place, on Scptember 
17th, she met her old competitor, Margaret S., and won in 2:201, $2: 213$ and $2: 18$. It was now time that she should show the phenomenal time her friends credited her with, and at Fresno, on October 2d, she achieved a record of $2: 13 \frac{3}{4}$, and at San Francisco, on November 9 th, 1889, she trotted in $2: 10 \frac{1}{2}$, the fastest time ever achieved by a three-year-old. It was now only a question of time and health for Sunol to become the queen of the trotting turf, though as a fouryear-old she did not lower her record. She began the season of 1890 at Detroit with an exlibition half-mile in 1:021. At Cleveland, O., on July 31st, she trotted in 2: 15, and at Buffalo, N. Y., on August 8th,

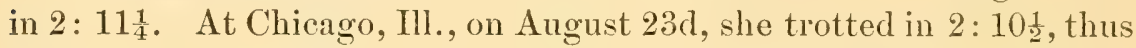
adding the four-year-old championship to her laurels. Her other great miles as a four-year-old were as follows: At Philadelphia, Pa., September 4th, 2: 1134; Cleveland, O., September 18th, 2:1311; San Fran-

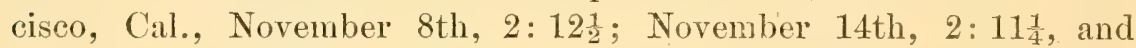
November 15 th, 2: 123. This was indeed a magnificent series of sensational miles, but her friends were not satisfied, yet full of confidence that as a five-year-old she would justify their highest expectations. Nor were they disappointed, as on October 13th, 1891, at Stockton, Cal., she trotted in 2:10, and on October 20th she crowned herself with glory, and became the queen of the trotting turf by trotting in 2:081. She thus defeated the time of Mand S., who for six years had been the all-aged champion of the trotting gait. Sunol now holds the triple honor of the three, four and five year's' championships. She is without doubt the grandest realization of modern breeding science. She is owned by Robert Bonner, who, when she was three years old, bought her from Senator Stanford for $\$ 41,000$.

This, in brief, is the marvelous history of the famous animals which, from Lady Suffolk to Sunol, have in the space of forty-cight vears redueed the record from 2:30 to $2: 08 \frac{1}{t}$, and have demonstrated from year to year the power of the American trotter to successfully assault and carry the strongholds of Time.

\section{THE STALLION KINGS.}

The history of the sires of the trotting rale is of supleme interest to every one interested in this great breed of the equine race. Hence, though the leading stallions have never held the trotting championship, their speed efforts have always been watehed with the 
keenest interest, and the one with the fastest record has always been called the Stallion King. This honor has always been most eagerly contended for, and the holder of the sire's crown has always held an equal if not a higher rank than the holder of the champion record. The first of the great stallion kings was Smuggler.

Smuggler, 2:15 1-4.

Smuggler was foaled in 1866 ; he was by Blanco, son of Iron's Cadmus, out of a pacing mare of unknown breeding. His career on the turf was not a long one, and he appeared rather as a magnificent meteor than as a star of the first magnitude. On August 18th, 1874, he won first money in a $\$ 4,000$ purse at Springfield, Mass., winning the second, fourth and fifth heats in 2:27,2:31 and 2:31. At Beacon Park, Boston, Mass., he again won from a good field in

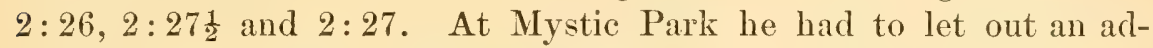
ditional link, winning a $\$ 10,000$ purse in $2: 23,2: 23$ and $2: 20$.

At Belmont Park, Philadelphia, Pa., on July 15th, 1876, he defeated Judge Fullerton, winning the first, third and fourth heats in $2: 17 \frac{1}{4}, 2: 17$ and $2: 20$. At Cleveland, O., on July 27th, 1876, he met Goldsmith Maid, Bodine, Lucille Golddust and Judge Fullerton, in a purse of $\$ 4,000$; Goldsmith Maid won the first and second heats in $2: 15 \frac{1}{4}$ and $2: 17 \frac{1}{4}$, Smuggler winning the next three in $2: 16 \frac{1}{4}$, 2: $19 \frac{3}{4}$ and $2: 17 \frac{1}{4}$. On August 10th, at Rochester, for a $\$ 4,000$ purse, he defeated Judge Fullerton, Lucille Golddust and Bodine, in $2: 15 \frac{3}{4}, 2: 18$ and $2: 19 \frac{1}{2}$. His record of $2: 15 \frac{1}{4}$ was made at Hartford, Conn., on August 31st, when he won the first heat in that time, the race being won by his great antagonist, Goldsmith Maid. The year 1877 witnessed his last victorious efforts on the turf, and he was sold for $\$ 30,000$, and retired to the stud. For eight years his record was a bright and shining mark, and it was not till 1884 that his reign was terminated by the advent of Phallas.

\section{Phallas, $2: 13$ 3-4.}

Phallas came of most excellent trotting stock, and his great career was foreshadowed in his splendid speed heritage. He ras foaled in 1877, and was bred by Major H. C. MeDowell, Woodlake, Ky. He is by Dictator; first dam, Betsy Trotwood, by Clark Chief; second dam by Eriesson; third dam by Sir William, and fourth dam by Hannibal. When the magnificent speed-producing power of this lineage is examined, the reader realizes that by all the laws of heredity Phal- 
las had a right to trot. Dictator, his sire, is a full brother to Dexter ( $\left.2: 17 \frac{1}{4}\right)$, and is also the sire of Jay-Eye-See $(2: 10)$, and Director (2:17), and thirty others which have trotted in $2: 30$ or better. Through his first and second dams he obtained the blood of Mambrino Chief, and back of that he rests on a thoroughbred foundation which goes back to imp. Diomed.

His first public appearance, with the exception of a half-mile heat race when four years old, and a public exhibition at the Chicago

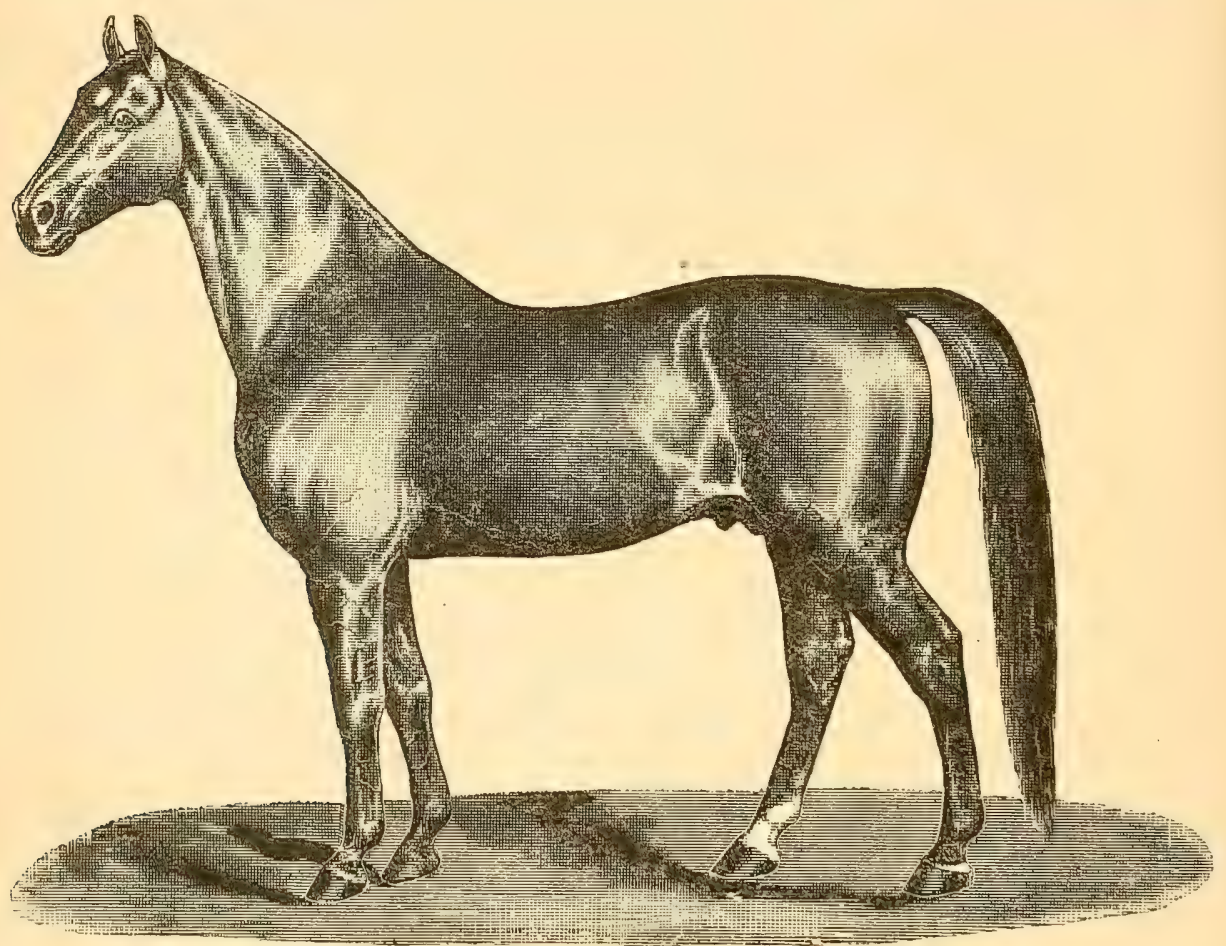

PIIALAAS, 2: $1: 3^{3}$.

Fair of 1882, when he trotted a mile in $2: 22 \frac{1}{1}$, was at Cleveland, O., on June 5th, 1883, in the 2:3t elass. Index won the first and second heats on sufferance, Phallas wimning the next three in $2: 29 \frac{1}{4}, 2: 22 \frac{1}{4}$ and $2: 181$; the last heat heing won in a jog by twenty lengths. At Fleetwood and Island Park he was defeated by Majolica, but at (hiago he redecmed his character. On July 1 th he met Index and Arlatide in the $2: 40$ elasis, and defeated them in 2:2212 2:23 and $2: 21$, and on July 19th, at the sime neeting, he was vietorious orer 
Majolica, the latter winning the first and second heats, and Phallas taking the next three in $2: 16 \frac{1}{2}, 2: 20$ and $2: 21 \frac{1}{4}$.

On August 1st, at Cleveland, he again lowered his record. Duquesne won the first heat in $2: 19 \frac{1}{4}$, and Phallas the next three in $2: 15 \frac{1}{2}$, $2: 21 \frac{1}{2}$ and $2: 17 \frac{1}{2}$. At Buffalo and Utica he won in slow time, there being nothing in either race to make him trot. This was a most marvelous showing. Phallas began the year in the great three minute class, and finished it with a record of $2: 15 \frac{1}{2}$. When he went into winter quarter's his friends confidently prophesied that with another year on the turf he would easily defeat the stallion record, and assume the imperial purple which had so long been worn by the illustrious Smuggler.

In 1884 he realized the fond anticipations of his friends and the public. On July 14th he met the three fast and famous mares, Catchfly, Clemmie G. and Fanny Witherspoon. Clemmie G. won the first heat in $2: 19 \frac{3}{4}$. By this time the future king had warmed up to his work, and he won the second heat in $2: 15 \frac{3}{4}$; the third heat he won with the most consummate ease in $2: 16 \frac{3}{4}$, and it was now determined that he should be sent for the great effort of his life. The word was given and the grand animal, as if he knew what was expected of him, shot from the wire with the speed and regularity of a steam engine. The quarter pole was reached in $33 \frac{3}{4}$ seconds; this speed was evenly maintained to the half, which was passed in $1: 07 \frac{1}{2}$. From the half to the three-quarters the excitement was intense, for the faithful watches indicated that the speed had increased, and the three-quarter pole was reached in $1: 401$, the third quarter having been trotted in 33 seconds. The last quarter was successfully accomplished in $33 \frac{1}{4}$ seconds, and the entire mile in $2: 13 \frac{3}{4}$. The wonderful feat had been accomplished, and Phallas $\left(2: 13 \frac{3}{4}\right)$ was the stallion king, vice Smuggler $\left(2: 15 \frac{1}{4}\right)$.

The next great performance of the year was at Belmont Park, Philadelphia, where he trotted three heats to beat $2: 13 \frac{3}{4}$; this he failed to do, but he trotted it in $2: 15,2: 14 \frac{1}{4}$ and $2: 15 \frac{1}{2}$, a performance which has not yet been beaten. In 1885, for a match and added money of $\$ 15,000$, he met and defeated Maxey Cobb (Maxey Cobb, in the autumn of 1884, had trotted against time and obtained a record of $2: 13 \frac{1}{4}$, thus technically passing the record of Phallas, 2:133), at Cleveland, O., on July 4th. With the first heat the contest was over, Phallas making the pace hot from the start. Naxey Cobb trotted gamely to the finish, but was defeated by three-quarters of a 
length. But the heat had told on Maxey Cobb, and in the second heat he was defeated easily in $2: 15 \frac{3}{4}$ by a full length and a half. In the third heat Phallas won in a jog in the slow time of $2: 20 \frac{1}{4}$.

On July 24th, at Morrisania, N. Y., for a purse of $\$ 5,000$, he met his old antagonist, Majolica, and again the son of Dictator won in straight heats; time $2: 16,2: 18 \frac{3}{4}$ and $2: 26 \frac{3}{4}$. Phallas is a deep rich bay, 153 hands high, his massive quarters, great muscle; good head and general make up shows the perfection of proportion and power. He was purchased as a colt by the Hon. J. I. Case, of Racine, Wis., and is still owned by his estate.

\section{Maxey Cobb, 2 : 13 1-4.}

Maxey Cobb (2:131) had a short but most brilliant career, and when he died at the opening of a great stud career he left behind two great performances-his record to harness, against time $\left(2: 13 \frac{1}{4}\right)$, and his team record of $2: 15 \frac{3}{4}$. Maxey Cobb was foaled in 1875 ; he was by Happy Medium, dam Lady Jenkins, by Nebo. At eight years of age he had attained a record of $2: 20 \frac{1}{4}$, but the following year, 1884, he achieved his crowning triumphs. He had shown in his training that he possessed phenomenal speed, and at Hartford, on August 28th, he trotted against time $(2: 15)$ and gained a record of $2: 15 \frac{1}{4}$.

At Providence, R. I., on Sept. 9th, he trotted in a race with Zoe B., St. Albans, Belle F., Adelaide, Judge Davis and Butterfly, winning in straight heats; the time was $2: 20 \frac{1}{4}, 2: 17 \frac{1}{2}$ and $2: 16 \frac{1}{4}$. On Sept. $30 \mathrm{th}$, at the same track, he trotted his famous mile against the time made by Phallas $\left(2: 13 \frac{3}{4}\right)$ and accomplished the feat in $2: 13 \frac{1}{4}$. It is but fair to say that in trotting against time a horse has a far better opportunity of obtaining a fast record than he has in an actual race, many good judges placing the difference as being equal to two seconds. On Nov, 13th, at Morrisania, N. Y., with his companion. Neta Medium, he won the double team championship in $2: 15 \frac{3}{4}$.

In 1885 they won the team race at Washington Park, Chicago, Ill., in 2:211 and 2:181. At St. Louis, on Oct. Sth, he won the freefor-all stallion race, defeating Bonnie MeGregor and Epaulette in $2: 25 \frac{3}{4}, 2: 20 \frac{1}{4}$ and $2: 20 \frac{1}{2}$. This was his last race, as he died in the spring of 1ss6. Maxey Cobb was a remarkibly handsome horse, and the fastest son of IIaplyy Medium. With his death the stallion crown reverted to Phallas $\left(2: 13 \frac{3}{4}\right)$. 
Axtell, $2: 12$.

Maxey Cobb held the stallion championship from Sept. 30th, 1884, to Oet. 11th, 1889, when the phenomenal three-year-old stallion Axtell trotted in 2: 12, and won the double honor of being the champion at his age and at all ages. The history of Axtell is a romance, and also a valuahle lesson to young men, and especially to the small breeder and young farmer of limited means. His owner, (. W. Williams, of Independence, Ia., had been a telegraph operator. but with a little

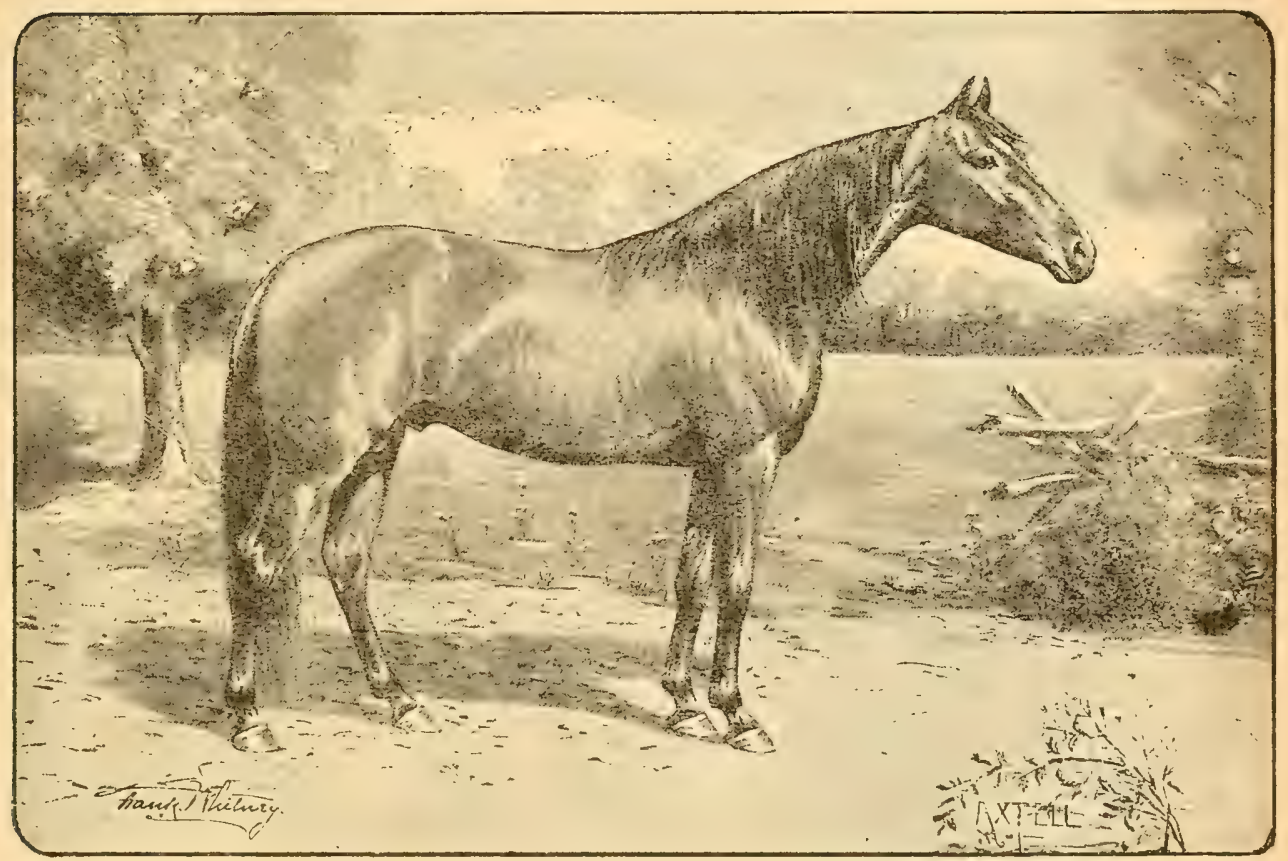

AXTELL (3 YEARS), 2: 12 .

money left him hatd stanted a modest dairy farm, and incidentally decided on a small breeding renture. He rould not afford to buy expensive hood mares, nor could he afford to breed to expensive statlions. But he hatd studied the hreeding problom, and he dreided to get the hlood of Mambrino Chief on the dam side and that of (reoroe Trilkes on the sire side, and see what the union would produre. II bought two males from a wealthy hreader. Who looked upon them ats (ulls unworthy of stalls in his harem, and for the sum of s:300 Mr. Williams bonght the future dams of Axtoll and Allerton, fwo of the 
greatest horses which have adorned the American turf. One of the mares, Lou, by Mambrino Boy, was sent to the embraces of William L., one of the youngest sons of George Wilkes, who was standing at avery moderate fee; the result was Axtell. Mr. Williams was his own trainer and driver, and before he had given Axtell many lessons he discovered that he had a colt right rovally endowed with speed. He won his first victory as a two-year-old in a race against three-yearolds, and trotted three straight heats in $2: 50 \frac{1}{2}, 2: 41 \frac{1}{4}$ and $2: 31 \frac{1}{4}$. At Chicago, Ill., on August 23d, 1888, he trotted against time, and secured a record of $2: 24 \frac{3}{4}$. At Minneapolis, Minn., on Aug. 30th, he reduced this to $2: 24$; and at Lexington, Ky., on Nov. 1st, he trotted in $2: 23$, and retired with this record as a two-year-old.

His career as a three-year-oid was one grand series of superb speed triumphs. At Cedar Rapids, Ia., on June 27th, 1889, he trotted in $2: 21 \frac{3}{4}$, and five days later, at Minneapolis, Minn., he trotted in $2: 15 \frac{1}{2}$. Two days later, on July 4th, at Independence, Ia., he trotted in $2: 20 \frac{1}{2}$, and on July 11th, at St. Paul, Minn., he again trotted in $2: 15 \frac{1}{2}$. On August 1st, at Cleveland, O., he trotted in $2: 14 \frac{3}{4}$. He then journeyed back west to Chicago, where, on August 22d, he trotted in 2:15t and the following day defeated Earl McGregor in a stallion race in $2: 19,2: 14$ and $2: 20 \frac{3}{4}$. At Terre Haute, Ind., on Oct. 9th, he trotted in 2:144, and on Oct. 11th, at the same track. he won his record of $2: 12$, which made him the champion trotting stallion of the world.

IIe also obtained distinction in another way, for after this performance he was sold for $\$ 105,000$, the largest price ever paid for a horse in the world up to that time. He was bought by a company, of which Mr. W. P. Ijams, of Terre IIaute, is the head, and the romg hero of the trotting turf wis at once placed at the head of the stud at that gentleman's fine stock farm, Waren Park. His stud fee was placed at $\$ 1,000$, and during the three seasons he has been in service he has more than earned his purchase prieg. Axtell did not long retain the championship, but as he is again to enter the arena it is quite possible he may again resume the crown; but if he does not, he will ever remain a stal of the first mannitude, and one of the grandest and most superl, representatives of the trotting race which the continent has ret produced. 
As a three-year-old Nelson materially increased his reputation and obtained a record of $2: 26 \frac{3}{4}$. He placed four victories to his credit, and made his record on Sept. 25th, 1885, at Lewiston, Me. As a four-year-old he was in the stud, and as a five-year-old he did not make his victorious appearance till Sept. 28th, 1887, at Mystic Park, Boston, when he had a walk-over in $2: 31 \frac{1}{4}$. On Sept. 30th, at the same track, he trotted in $2: 21 \frac{1}{4}$, which was his record for that year.

The following year was spent in the retirement of the stud, but in 1889 he burst upon the trotting world as a star of the first magnitude, and was placed in the list of the most promising candidates for the honor of the stallion championship. On July 5th, at Lancaster, N. H., he defeated Home Rule, Rex and Lulu H. ; $2: 26,2: 30$ and $2: 24 \frac{1}{2}$. At Boston, on July 18th, he met T. T. S. Argentine, W. K. Olaf, William Kearney, and Captain, winning in straight heats in $2: 21 \frac{1}{4}, 2: 17 \frac{1}{2}$ and $2: 16 \frac{1}{2}$. At Buffalo, N. Y., on August 7th, he won a sensational race in straight heats in $2: 15,2: 17 \frac{1}{1}$ and $2: 15$, defeating a strong field of seven. At Boston he won the celebrated stallion race, on Sept. 23d, defeating Alcryon, Pilot Kinox, Junemont and Granby, in $2: 18 \frac{1}{2}, 2: 17 \frac{1}{4}$ and $2: 18 \frac{3}{4}$. At the same track, on Sept. 27th, he trotted in $2: 18 \frac{1}{2}, 2: 18$ and $2: 17 \frac{1}{2}$. His fastest performance in 1889 was in the $\$ 10,000$ stake at Hartford, Comn., on

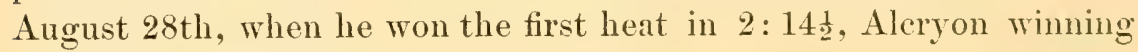
the race in slower time.

The season of 1890 was for Nelson a brilliant one, and at its close he was the stallion champion. At Bangor, Me., on Sept. 3d, 1890,

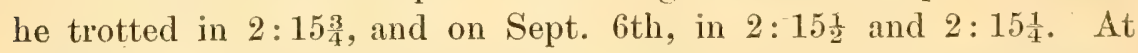
Kankakee, Ill., on Sept. 24th, he trotted in 2:12, and tied the stallion record, at that time held by Axtell, and on Sept. 26th, two days later, at the same track, he trotted in $2: 11 \frac{1}{2}$, and became the champion. At Rushville, Ind., on Oet. $3 d$, he trotted in $2: 11 \frac{3}{4}$; and on Oet. 9th, at Terre Hante, Ind., he reduced his time to $2: 11$. He closed this grand series of phenomenal miles at Cambridge City, Ind.. on Oct. 21 st, by trotting in $2: 10 \frac{3}{4}$, and retired for the season in a blaze of glory.

The scason of 1891 found him again to the fore, and at Saginaw, Nich., on July 17th, he trotted in 2:11:3; and at Detroit, on July 22d, he trotted in 2:111. On August 5th, he made the same time at Freeport, Ill.; and on August 27th, at Independence, Ia., he trotted in 2:103. IIis next effort was at Rockford, Ill., in 2:121. On Sept. 
17th, at Grand Rapids, Mich., he trotted in $2: 14$ and $2: 10$. This time was beaten by Allerton, and as a result the two great sires met at Grand Rapids, on Oct. 8th, when Nelson won the first heat in $2: 13$, the fastest heat of the race, which was won by Allerton.

\section{Alierton, 2:09 1-4.}

Allerton was one of the two colts (the other one being Axtell) which resulted from G. W. Williams' famous venture as a breeder of trotters on a small scale. Never in the history of trotting horse breeding did a breeder obtain such magnificent results from so small a beginning. Allerton was foaled in 1886. He is by Jay Bird, dam Gussie Wilkes, by Mambrino Boy; 2d dam, Nora Wilkes, by George Wilkes. As a two-year-old he did not create any sensation, as his owner was intent upon placing Axtell prominently before the trotting world, but he did good work, as the following record will show. At Keokuk, Ia., he won a five-heat race in the last three heats, in 2:52, 2:50 and 3:10. At Des Moines, Ia., on September 3d, he defeated a good field in $2: 49 \frac{1}{4}$ and $2: 48 \frac{1}{2}$. He won again, at In-

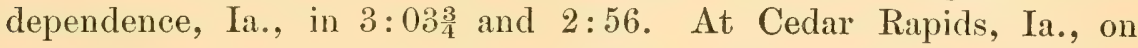
September 19th, he trotted in $2: 42 \frac{3}{4}$, and at Lexington, Ky., on November 1st, he trotted in $2: 40 \frac{1}{4}$.

As a three-year-old he came to the front rank, and though he did not show the marvelous speed of his stable companion, Axtell, he developed into a campaigner of the first rank, and in fields of his own age and in class races against aged horses, came out victorious. His first triumph of the season was at Minneapolis, Minn., on July 3d, when he won in $2: 27,2: 26 \frac{1}{4}$ and $2: 24 \frac{1}{2}$, after Ichi Ban had won the first heat in 2:29. His next victory was at St. Paul, Minn., on July 13th, when he defeated a good field in straight heats in $2: 29,2: 23$ and $2: 24 \frac{3}{4}$. At Cleveland, $\mathrm{O}$, on August 2d, he went against time and trotted in 2:201, and on the following day he reduced that record to 2:19. He then returned west to Chicago, and on August 20th he defeated a great field, consisting of John W., Victoria Wilkes, Poem, Alaric, Sir Goy, Mineola, Nelly Allison and North Anna, in the first, second and fifth heats, in $2: 21 \frac{1}{4}, 2: 24 \frac{1}{2}$ and $2: 24$. At the same meeting, three days later, he defeated another first-class field in straight heats in $2: 24,2: 21$ and $2: 18 \frac{1}{1}$. He retired for the season with the last named record.

He began his four-year-old campaign at Independence, Ia., on July 4 th, by trotting against time in $2: 18$, and the same day reduced it to 
2: 163. At Terre Hante, Ind., on October 9th, he defeated Ketch and Dick Smith in $2: 20,2: 17 \frac{1}{2}$ and $2: 15 \frac{1}{2}$. At Independence, Ia., on October $2:$ l, he trotted in $2: 18 \frac{1}{4}$ and $2: 14$. On October 28th, at the same place, he put in two heats in $2: 15$ each, and three days later he trotted in $2: 14$. On November 1st he trotted in $2: 13 \frac{3}{4}$, and on the same day he reduced his record to $2: 13 \frac{1}{2}$. He was then retired for the season, while his friends confidently predicted that before another season was over he would have achieved the stallion championship.

The campaign of 1891 was a long and brilliant one. He opened it at Independence, Ia., on . July th hy reducing his record to $2: 13$, and on August 5th, at the same place, he again reduced it to $2: 12$. On August 31 st he cut it down to 2:11. On September 12 th he trotted in $2: 10 \frac{1}{2}$, and on September 14th in $2: 11 \frac{1}{4}$ and $2: 11 \frac{1}{4}$. On September 4th he trotted in 2:10, and on September 17th, Nelson, at Grand Rapids, Nich., trotted in the same time, but Allerton only allowed him to have the divided honors for two days, as on September 19th he trotted at Independence, and again beame the undisputed King of the trotting sires. On September 25 th he trotted in 2:09x, and on the same date he trotted to wagon in $2: 15$, which is the champion

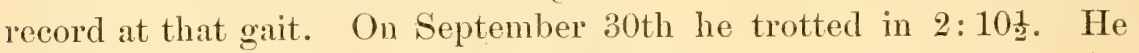
won two great victories against other horses during the season. On October 8th, at Grand Rapids, Mich., for a purse of $\$ 10,000$, he de-

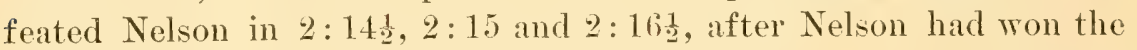
first heat in 2:13. A week later, on October 15th, at Lexington, Ky., he defeated the stallion Delmorsh $\left(2: 11 \frac{1}{2}\right)$ in straight heats in $2: 13 \frac{1}{4}$, $2: 15$ and $2: 15 \frac{3}{4}$. Such in brief is the history of Allerton, who has made good the boast of his owner, who said, when he sold Axtell for $\$ 105,000$, "that he had just as good a one, if not better, still left in the barn."

\section{Palo Alto, 2 : 08 3-4.}

While Nelson and Allerton wore fighting for supremacy in the East, Senator Leland Stanford's ereat trainer, Charles Marvin, was quietly training the stallion Palo Alto with the view of wimning the stallion champiomshe. Then they had closed their eampaigus, and Allerton with a mark of 2:091 had won the crown, Palo Alto was sent to the Kite track, at Stockton, Cal., and at once began his assaults on the ramparts of Time. Palo Alto is by Electioneer, dam Dame Wimie, hy Planet. Ite is, therefore, half thoroughbred. 


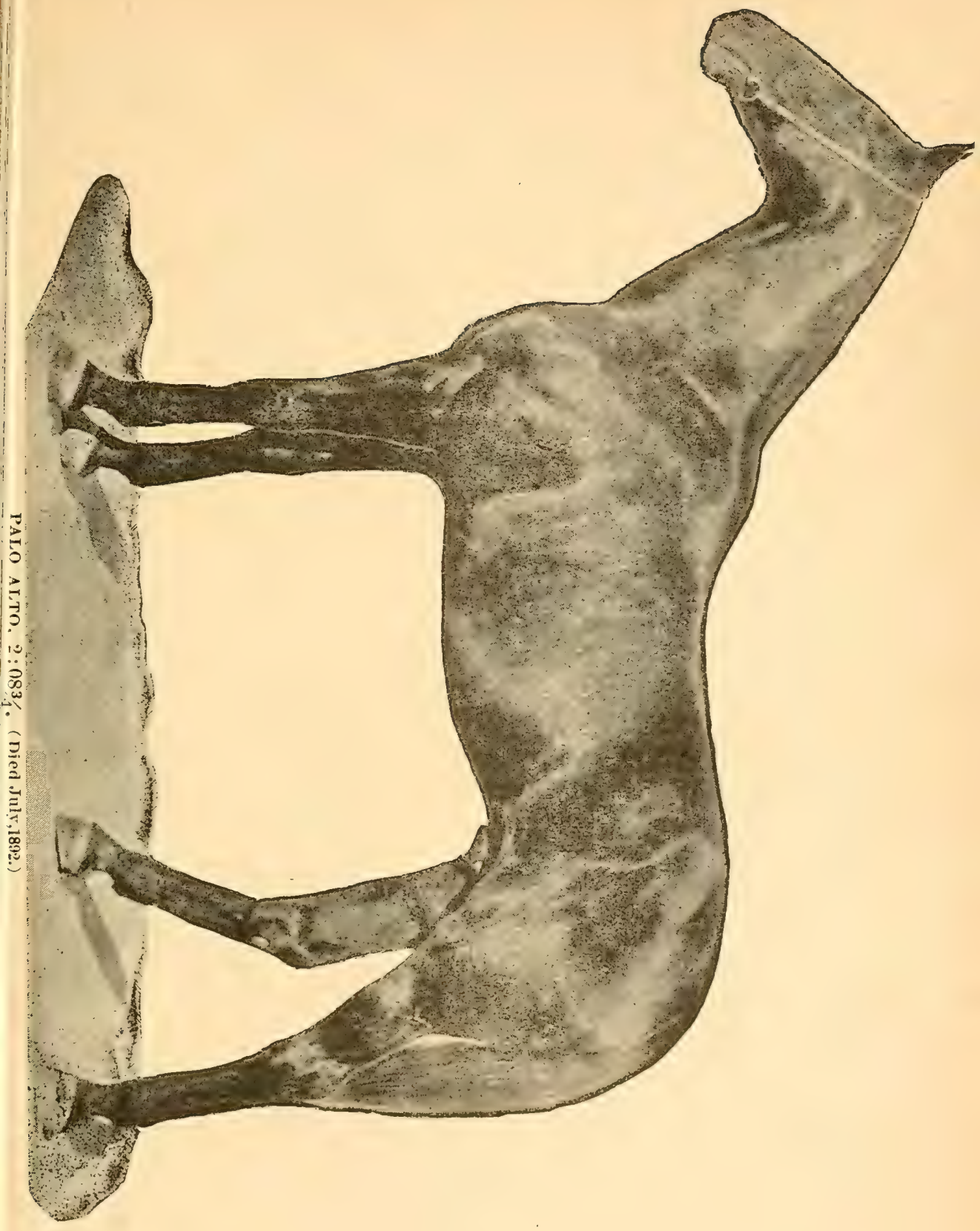


Contrary to the rule at this famous California stock farm, he was not sent for a record in his early colt days, and his first appearance on the turf was as a four-year-old, when he was sent East, and won some notable victories against aged horses. At Kalamazoo, Mich., on June 29 th, 1886, he defeated a large field in $2: 32 \frac{1}{2}, 2: 32 \frac{3}{4}$ and $2: 33$. At the same meeting, on July 1st, he was again victorious in $2: 30 \frac{1}{2}$, $2: 30 \frac{3}{4}$ and $2: 29 \frac{3}{4}$. At East Saginaw, Mich., on July 14th, he was again victorious in 2:22,2:22 and $2: 20 \frac{1}{4}$. At Cleveland, O., on July 30 th, he won in $2: 23,2: 22 \frac{1}{4}$ and $2: 21$. At the same track, on September 18 th and 20 th, he won again. At St. Louis, Mo., on October 8th, he defeated such horses as Charley Hogan, C. F. Clay,

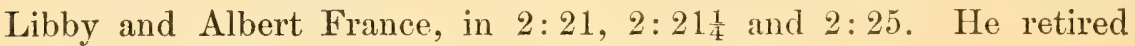
for the year with a four-year-old record of $2: 20 \frac{1}{4}$.

He did not appear in public in 1887 and 1888, but in 1889 he made a memorable campaign. He began the season at Napra, Cal., on August 13th, and defeated Bay Rose, Jim L. and Victor in 2:211, $2: 20$ and 2:18. At Petaluma, Cal., on August 29th, he won again in $2: 20 \frac{1}{2}, 2: 21 \frac{1}{4}$ and $2: 23 \frac{1}{2}$. At Oakland, Cal., on September $2 d$, he added another scalp to his belt in $2: 22 \frac{1}{4}, 2: 20$ and $2: 19 \frac{1}{4}$, and at the same place, five days later, he won again in $2: 18 \frac{1}{4}, 2: 19 \frac{1}{4}$ and 2: 201. At Stockton, Cal., on September 26th, he defeated those two great stallions, Direct and Bay Rose, in 2:16 $\frac{1}{2}, 2: 17 \frac{3}{4}$ and $2: 13 \frac{3}{4}$, and at once loomed up as a formidable candidate for stallion honors. At San Francisco, Cal., on November 9th, he trotted in 2:121, and on November 16th, at Napa, he trotted in 2:121. This record he retired with for the year, just one quarter of a second behind the championship, at that time held by Axtell, 2:12.

In 1890 he came East, and his first appearance was at Detroit, where he defeated those great mares, Houri and Susie S., in 2:15.12, $2: 17$ and $2: 164$. At Buffalo, on August 9th and 11th, he met Rosalind Wilkes, Jack and Susie S., the pick of the free-for-all brigade, and in a race of five beats defeated them in $2: 16 \frac{1}{2}, 2: 16$ and $2: 15$. At Chicago, on August 20th, he met Jack alone, and won in 2: 18.4. $2: 15$ and $2: 13$. At Philadelphia, on September the he trotted against time in $2: 12 \frac{1}{2}$. He failed to beat his record in 1890 , and the enemies of the thorough-bred-blood-in-the-trotter idea declared he had reached his speed limit, but the season of 1891 amply rindicated his regal speed powers. 
On October 13th, at the Kite triak, Stockton, Cal., he trotted in $2: 12 \frac{3}{4}$. At the same track, on October 21 st, he reduced his record to $2: 11 \frac{1}{4}$, and on October 27 th, he trotted in $2: 10$. Four days after

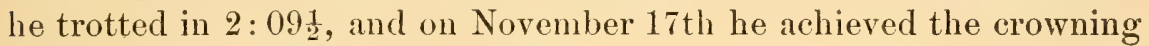
glory of the trotting sire, by beating all previous stallion records by

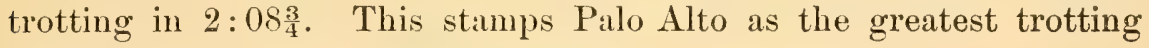
stallion which the world has yet seen.

\section{OTHER GREAT PERFORMERS.}

In order that the reader may have a more comprehensive idea of the immense progress made recently in the science of trotting horse training and early development, a brief resume of the best performances on the trotting track at the various ages will be here given, presenting a complete view of the situation. In 1881, the brown filly Pride, on November 5th, trotted in $2: 44 \frac{1}{2}$, and she was the champion yearling of that time. In the same year, on November 14th, the brown filly, Hinda Rose by Electioneer, dam Beautiful Bells, trotted

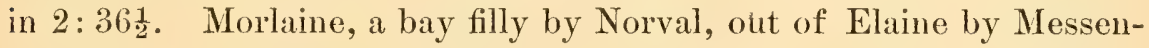
ger Duroc, captured the yearling championship in $2: 31 \frac{1}{2}$, on November 12th, 1887, at San Francisco, Cal. But the first yearling to enter the 2:30 list was the bay colt Freedom by Sable Wilkes, dam Laura Drew by Arthurton, who at Napa, Cal., on October 18th, 1890, trotted in 2:293. In 1891, Bell Bird by Electioneer, dam Beautiful Bells, at Stockton, Cal., on October 21st, trotted in $2: 26 \frac{1}{4}$, and at the same track, on November 28th, 1891, the chestnut filly

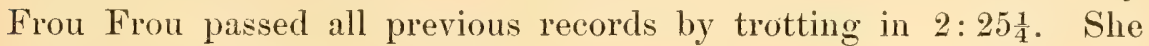
is by Sidney, dam by Buccaneer.

The progress of the two-year-olds during the past twelve years has been phenomenally rapid. In 1880 the brown filly Sweetheart by Sultan, dam Minnehaha by Bald Chief, on September 25th, at Sacramento, Cal., trotted in $2: 26 \frac{1}{2}$, and then led bher age into the $2: 30$ list. The bay gelding, Fred Crocker by Electioneer, on November 20th, 1880, trotted in 2:251, reducing the record. On October 22d, 1881, at San Francisco, Cal., the bay filly Wildflower by Electioneer, dam Mayflower by St. Clair, put the record down to 2:21, where it stayed till the illustrious Sunol by Electioneer, dam Waxana by General Benton, on October 27th, at San Francisco, Cal., reduced it to 2:18. November 10th, 1891, the two-year-old colt Arion 


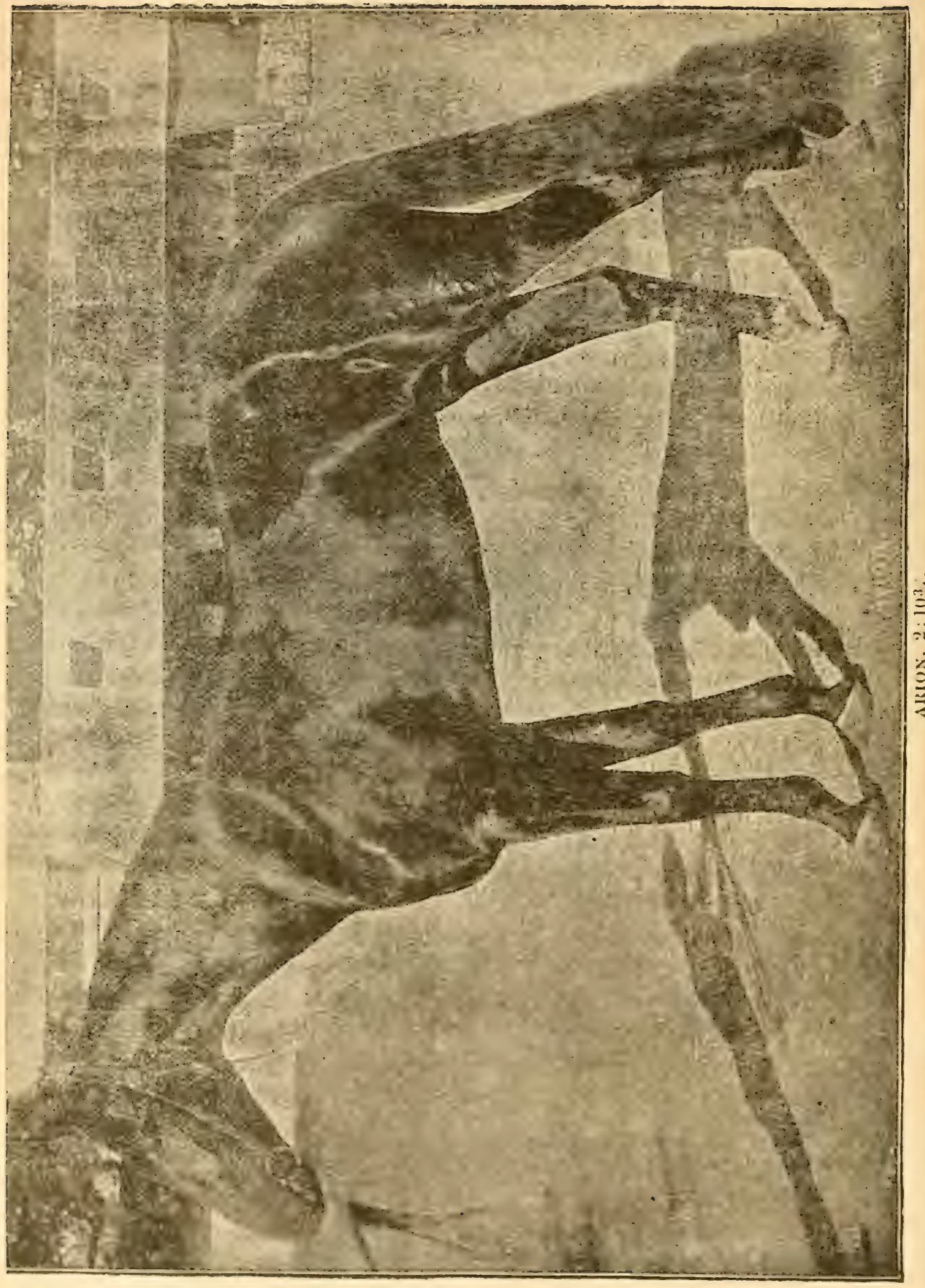




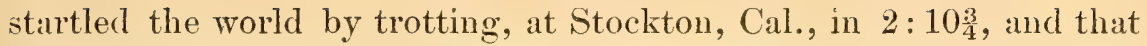
record is not liable to be beaten for some time. Arion is also by Electioneer, dam Manette by Nutwood, and after his great victory against time, he was sold for $\$ 125,000$, the largest price ever paid for a horse in the world.

Of the champion three and four-year-olds it is needless to write,

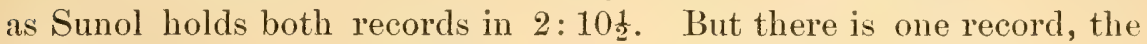
race record, which is worthy of special mention, because it is held by that famous mare Nancy Hanks, who so recently wrested the championship from Sunol.

\section{Nancy Hanks, $2: 05$ 1-4.}

Nancy Hanks is a handsome bay mare by Happy Medium, dan Nancy Lee by Dictator. She made her debut on the trotting track as a three-year-old, and quickly established a high reputation as a fast and game performer. Her first race was at Harrodsburg, $\mathrm{K}_{y}$., July 31st, 1889, when she defeated Bonny Wilmore, Abbie V., Twist, Catherine Leybourne, Minnie Moore and Mattie H., in $2: 27 \frac{1}{4}, 2: 25 \frac{1}{4}$ and $2: 25 \frac{1}{2}$. At Danville, $\mathrm{Ky}$., on August 7th, she again defeated Bonnie Wilmore and Abbie $V$, in $2: 26 \frac{3}{4}, 2: 24 \frac{1}{2}$ and $2: 29 \frac{1}{4}$. At Sharpsburg, Ky., in August, she won in slow time, and at Lexington, Ky., on September 13th, she was again in front, in $2: 36 \frac{1}{2}, 2: 26 \frac{1}{4}$ and $2: 30 \frac{1}{2}$. At Eminence, Ky., on September 21st, she was again victorious in the slow time of $2: 50 \frac{1}{2}, 2: 46 \frac{3}{4}$ and $2: 30$. Her last appearance for that season was on October 14th, at Lexington. Ky., when she defeated those two great stallions Bonny Wilmore and Campbell's Electioneer, in $2: 26 \frac{1}{4}, 2: 25 \frac{3}{4}$ and $2: 26 \frac{1}{2}$.

As a four-year-old her career was even more brilliant. July 30th, 1890, she defeated a great field at Harrodsburg, Ky., in 2:241 $2: 20$ and 2:191 . At Nicholasville, Ky., on August 13th, she won again in 2:223, 2:20 and 2:18; at Maysville, Ky., on August 23d, in $2: 21 \frac{3}{4}, 2: 21 \frac{3}{4}$ and $2: 19 \frac{1}{4}$; and at Lexington, Ky., on Angust 28th, in $2: 19 \frac{1}{2}, 2: 19 \frac{1}{2}$ and $2: 14 \frac{1}{2}$. She placed two more victories to her credit in that year, and retired for the season without a defeat, and with a record of $2: 14 \frac{1}{2}$. In 1891, when five years old, at Chicago, August 20th, she defeated Margaret S. in $2: 20 \frac{1}{4}, 2: 19$ and $2: 12 \frac{1}{4}$. At Rochester, N. Y., on August'13th, she trotted again in 2:121. On Angust 26th, at Independence, Ia., she defeated the famous Allerton and Margaret $\mathrm{S}$. in $2: 12,2: 12 \frac{3}{4}$ and $2: 12$, the fastest three 
heats ever made in a trotting race, and at Richmond, Ind., on September 30th, she trotted in 2:09. She was then sold to Malcolm Forbes, of Boston, Mass., for $\$ 40,000$.

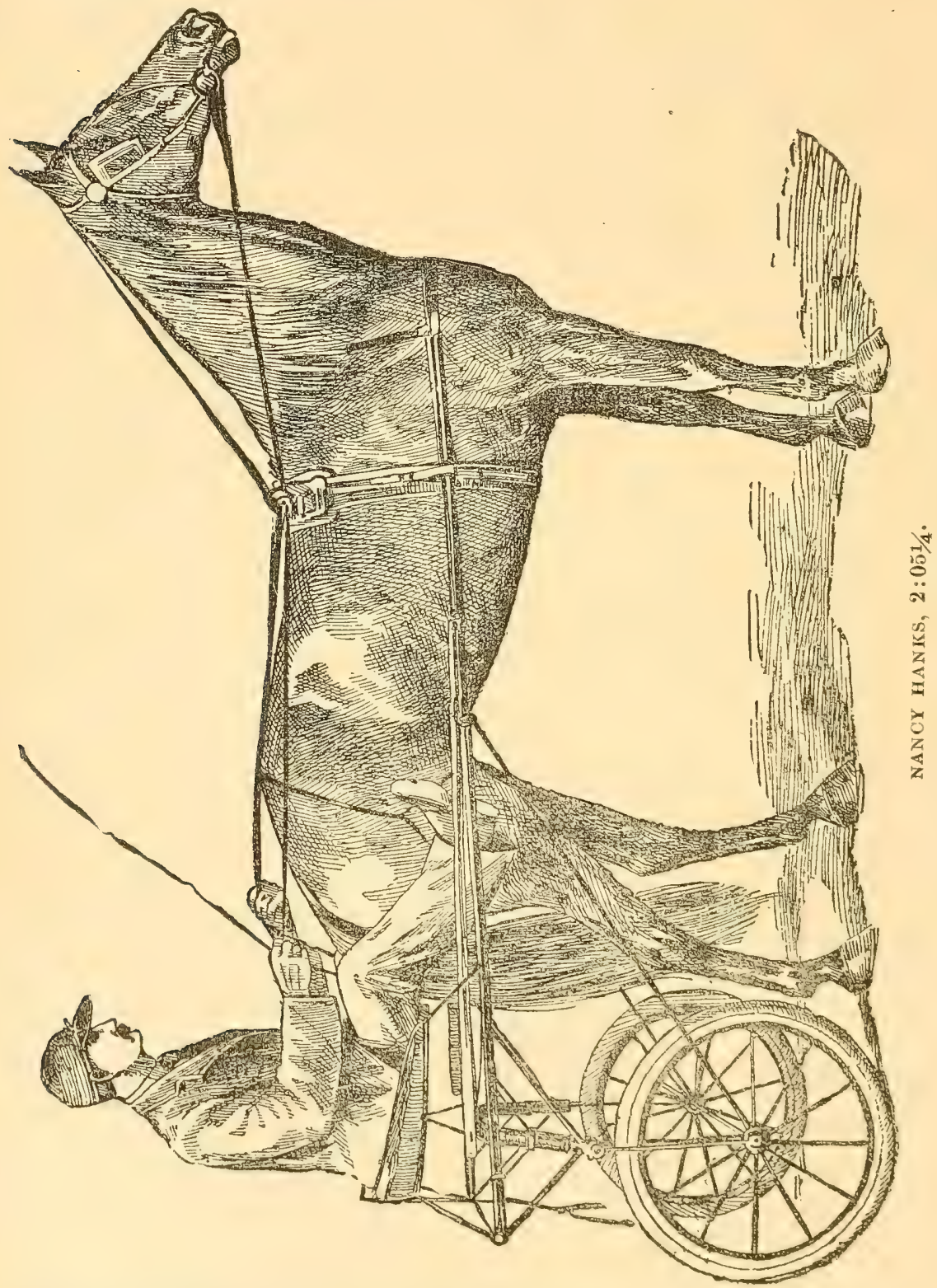

Nancy Hanks made her first public appearance in 1892. at Belmont Park, Philadelphia, when she trotted against the track reeord made. 


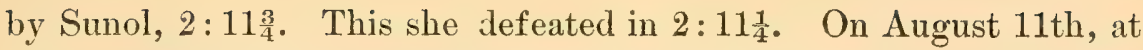
Grand Rapids, Mich., she tied her record, trotting in 2:09. Six days later, on August 17th, at Washington Park, Chicago, she trotted in

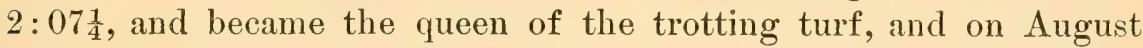
31st, at Independence, Ia., she reduced this record to $2: 05 \frac{1}{4}$. In one supremely magnificent effort she has cut down her own record two seconds, and she has reduced in one season the trotting record three seconds, and has re-crowned herself the Empress of the trotting turf.

\section{EDUCATING YOUNG TROTTERS.}

The education of the trotter should begin with foaling, and the teaching be so thorough and yet simple that the "breaking" process has really no beginning or end. Why not have the confidence of the colt as well as of the house dog or the pet cat? The little thing is just as susceptible to kind treatment. In a week or two the foal should wear a halter, and it is surprising how soon it will learn to lead. A bit can be introduced into its mouth at any time after weaning, and the youngster can be driven at a tender age. If, however, the harness education begins when the youngster is a yearling, it will be quite early enough, and if the preparatory handling has been of the right kind, the "breaking" will soon be over. I am assuming that no reader intends to train and trot his yearlings, but merely designs to prepare for speed in the two or three-year-old form. The best time for breaking to harness is in the spring of the yearling form, if it is designed to hurry the preparation of the youngster; or in the autumn, if it is designed to wait for speed until the age of three years. Remember that liberal feeding and care are all essential in growing hig, lusty yearlings. An average sized horse should be fourteen hands when a yearling, and fifteen hands when two years old. The ultimate size will not be affected, but by foreing the youngster along, you get the benefit of added size for early handling and work, and leave less for growing between the ages of two and five years. Three years is as young as any colt should be taxed by trotting races, or even a full mile at speed. If this is the idea of the reader, the colt will graze all summer as a yearling, and get in addition a liberal allowance of grain night and morning. This will insure a big, growthy, yet mature colt by September, and then the harness education may properly begin. There are many plans for breaking and handling 
youngsters, and each is, no doubt, productive of good results. In former times, when a colt was not broken until three or four years of age, it was customary to use force, and generally to harness the pupil beside a steady going, mature horse, to insure against the young pupil running away and demolishing things generally. If kind and frequent handling begins as soon as the foal is ushered into the world, and continues and is supplemented by beginning the harness education at the age of about eighteen months, the so-called breaking will be very easy, and in a few days the breaker may ride behind his pupil with all comfort and safety.

Let us suppose the colt has been kindly and rationally handled up to the autumn of the yearling form. We will now begin the harness education, by putting on an easy bridle and letting it remain a few hours, to show the colt that the bit is not umpleasant. On the morrow we can attach a bridle rein, and passing it orer the colt's neck and taking a rein in either hand, we walk beside him and guide him about for a short lesson. In a day or two more the harness may be fitted, and the colt again shown that it is harmless, by being allowed to wear it a few hours and thoroughly inspect it. Then, having left the halter on when adjusting the harness, snap a leadstrap in the halter, and give that to the groom while you step behind, and with the reins attempt to drive and guide the colt. Of course, he will attempt to turn around and do many other umecessary and unpleasant things, but in that erent the groom can lead him, until little by little he begins to obey the guidance of the rein. About two lessons will complete this, and enable you to drive and guide the colt by the reins with but little trouble.

We are now ready for the next step. Many hitch with another horse or to a stout break cart in an open field, but my plan has been to use two long shafts or poles cut in an adjoining woods, and what the farmers term saplings. These cut about fifteen or sixteen feet long, and trimmed elosely of branches are about the diameter of an ordinary wagon shaft. At the proper distance I drive an ordinary sterl staple, and further back insert a common serew hook, the former fo hold the breeching or side straps and the latter to serve as at hitch or whiftletree for the trace.

We are now ready to harness the colt in the shafts, and it is done, leaving the rnds of the poles behind the colt to drag upon the 
ground, and having them sharpened so they will penetrate the ground if the colt begins to move backward.

The colt is now in a position where you are complete master of the situation. If he kicks he camnot do harm, and if he lands a foot outsicle the poles in kicking, he can continue kicking until it is again on the inside, and no harm can result. I once broke a mature thoroughbred stallion that had never worn a harness, and he soon tired of kicking against the air. A horse knows almost as quickly as a human being when damage results, and when resistance is without results. The poles being long, the colt cannot turn about short and face you, consequently the only unrestricted movement he can make is to move ahead. He may do this hurredly and tax your strength, but in that case it will be necessary to pull his head sharply to one side. Do not, by any means, allow him to get away from you. Always be kind, but be firm and make no mistakes. A colt is easily ruined by a mistake at such a time. After about one lesson the colt will begin to drive and obey the rein fairly well. I usualiy continue the use of the poles for several days, often for from two to three weeks. As the pupil becomes more tractable, I extend the drives, and frequent traveled roads and the viciaity of steam and street cars. It is vastly easier to control and overcome the fear when you have the colt harnessed in this manner, rather than when he is hitched to a vehicle, and able to carry you with him.

With careful and persistent handling the colt is well waywised in from ten to fifteen days, and is ready to be harnessed to a vehicle. Of course, the wheels in motion and your presence in the seat will have a tendency to alarm the pupil. Have a stout kicking strap adjusted, and keep it on for several months. When the colt is securely harnessed to the cart, snap a lead strap in the halter which is worn under the harness bridle, and let the groom lead him for an hour, or until the fear of the motion and noise of the wheels is overcome. Then attach a longer lead strap, and allow the groom or assistant to sit beside you. If all goes well it will do no harm, and if your colt becomes frightened, and bolts or backs, the groom can step from the rear of the cart in an instant, and have the same control he would have if leading the colt by halter.

You now have the colt ready for driving, and a few weeks' education should fit the pupil for the training stable. 
Young horses can take considerable work without injury, if care is used, and the work be not too prolonged. Short, sharp brushing makes speed, not long, easy jogging. If you have early engagements or expect to trot the youngster as a two-year-old, the work coild begin as soon as the colt is thoroughly broken, and should be continued judiciously but steadily under about the following conditions:

First.-Be sure that every point liable to injury is well protected by boots. Do not take any chances of injury from this source. A colt is inexperienced and awkward, and liable to make a mistake. An injury to the quarter, or knee, or ankle, may necessitate a long let up. Shoe the colt as light as possible, and study carefully his action and what weight of shoe will be necessary to balance. A skeleton wagon is preferable for jogging, as then you can study the action and the effect of any changes you make.

Do not make the colt track-sick. If you train on or near a track, keep away from it all you can. If you have good roads, give the colt his work there. About four miles a day is sufficient work, and he should not go to the track oftener than twice a week. When you are jogging on the road and come to a nice spot brush him out, and do this two or three times during every jog. Do not keep up an eternal jog, jog, jog; colts do not require it. You must study to make speed. Always hitch as light as possible; drawing weight is a great drawback to a colt, and it is very liable to indure hitching, which, when once acquired, requires time and patience without limit to remove. If these few directions are followed, the colt should show a gradual but sure increase in speed, if Nature has put any speed there.

\section{DIFFERENT GAITS IN COMBINATION.}

A narrative of the leading track horses of America would not be complete without a brief notice of the achievements of the trotter with rumning mate, and of the pacer under the same conditions. The running gait being the fastest, the pionecrs of the trotting track conceived the idea that hy ingenionsly hanessing a good thoroughned to the pole with either a trotter or pacer, so that the rumning horse would have to pull the full weight of the vehiele and the driver, his companion would be ahle to show the highest possible speed at his own gait. The idea was correct, and though the effort is not graceful, some marvelous speed results have been attained. It must be 


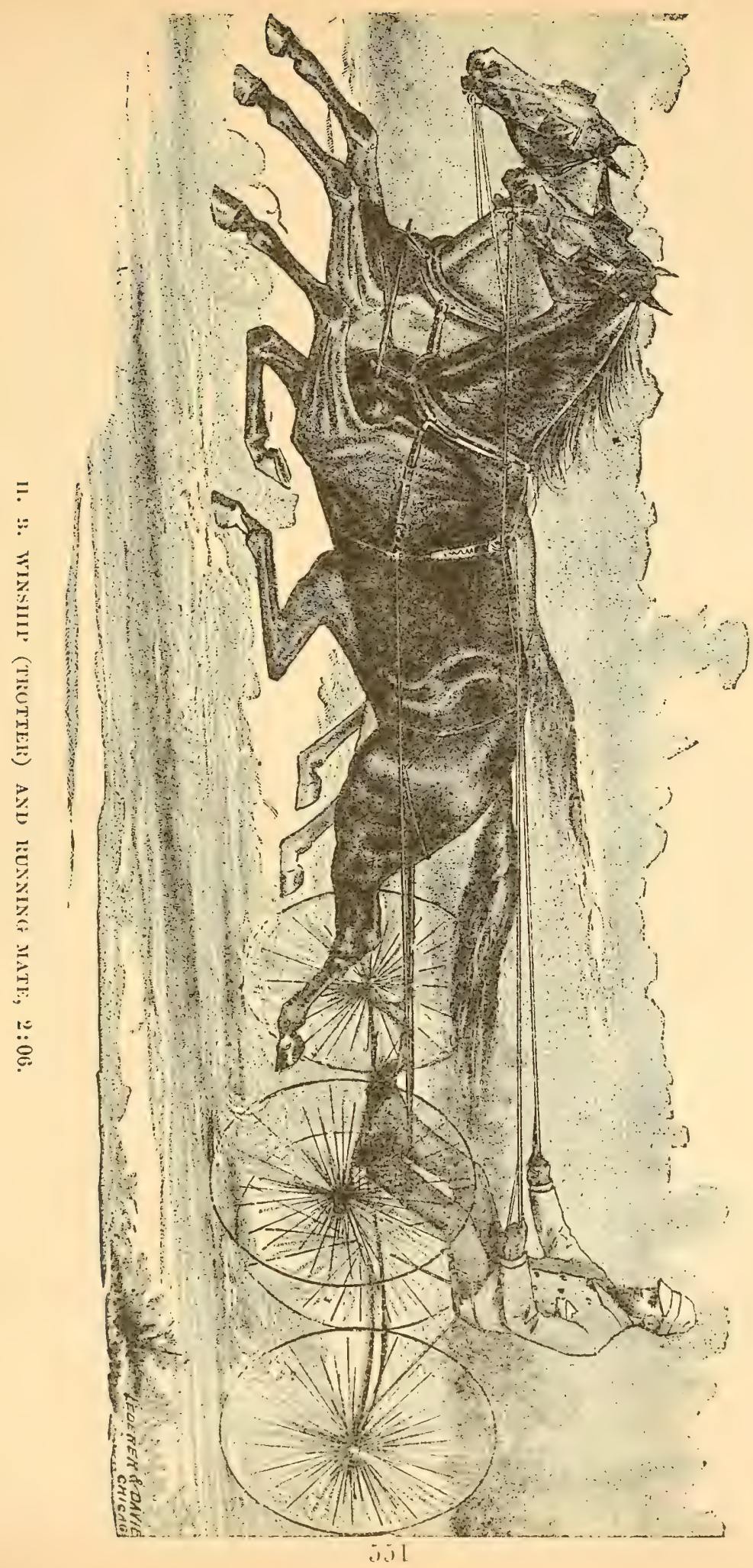


borne in mind that the records thus made are only good at such ways of going, and do not. count against regular harness records-thus Wrestmont's regular pacing record is $2: 13 \frac{3}{4}$, while with running mate he has a record of $2: 01 \frac{3}{4}$ and $2: 02$. Both records are given. It has been erroneously stated that in the first instance he did not carry his proper weight. These performances not having been fashionable, have only happened at intervals, and have never at any time become a regular part of the programme of the track. The last instances have been the most conspicuous, and as the records attained are the fastest, the holders thereof being the champions, a description of them will give the reader an adequate idea of these modes of attaining the highest rate of trotting or pacing speed.

\section{H. B. Winship and Mate, 2:06.}

H. B. Winship is a black gelding by Aristos, son of Daniel Lambert; he has a regular trotting record of $2: 20 \frac{1}{4}$, hut when tried with a running mate he showed a much higher velocity. On July 4th and 5 th, 1884, at Chicago, Ill., for a purse of $\$ 4,000$, he, with rumning mate, met and defeated Frank and mate. The latter team won the first heat in $2: 16, \mathrm{H}$. B. Winship and mate wimning the next three

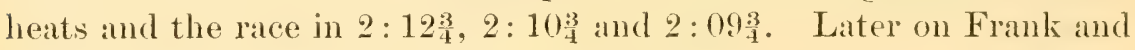
mate made a record of $2: 08 \frac{1}{2}$, and at Providence, R. I., a purse of $\$ 1,000$ was offered to $I I .{ }^{*} B$. Winship and mate to beat this record. The great speed contest against time took place on August 1st, 1884. The first quarter was accomplished in the astonishing time of $30 \frac{1}{2}$ seconds, and the half mile was passed in 1:012. The three-quarter pole showed $1: 34 \frac{33}{4}$, and without a break they shot under the wire in the then unprecedented time of $2: 06$. The American trotter had again carried the stars and stripes into the hostile domains of Old Father Time.

\section{Westmont and Mate, 2;01 3-4.}

Westmont, the famous pacer, has a regular record of $2: 13 \frac{3}{4}$, but his f:me will rest upon his greatest performance, 2:01:3 with rumning mate, which took place on July 10th, 188t, at the West side Driving Park, Chicago, Ill. The public did not expect a great exploit, but when the watches marked 304 seromds as the pair shot past the quarter pole, they realized that they were wathing a performance the like of which they might never see again. The excitement rose to ferer heat als wh even areelerated speed the Hying pair reached the 


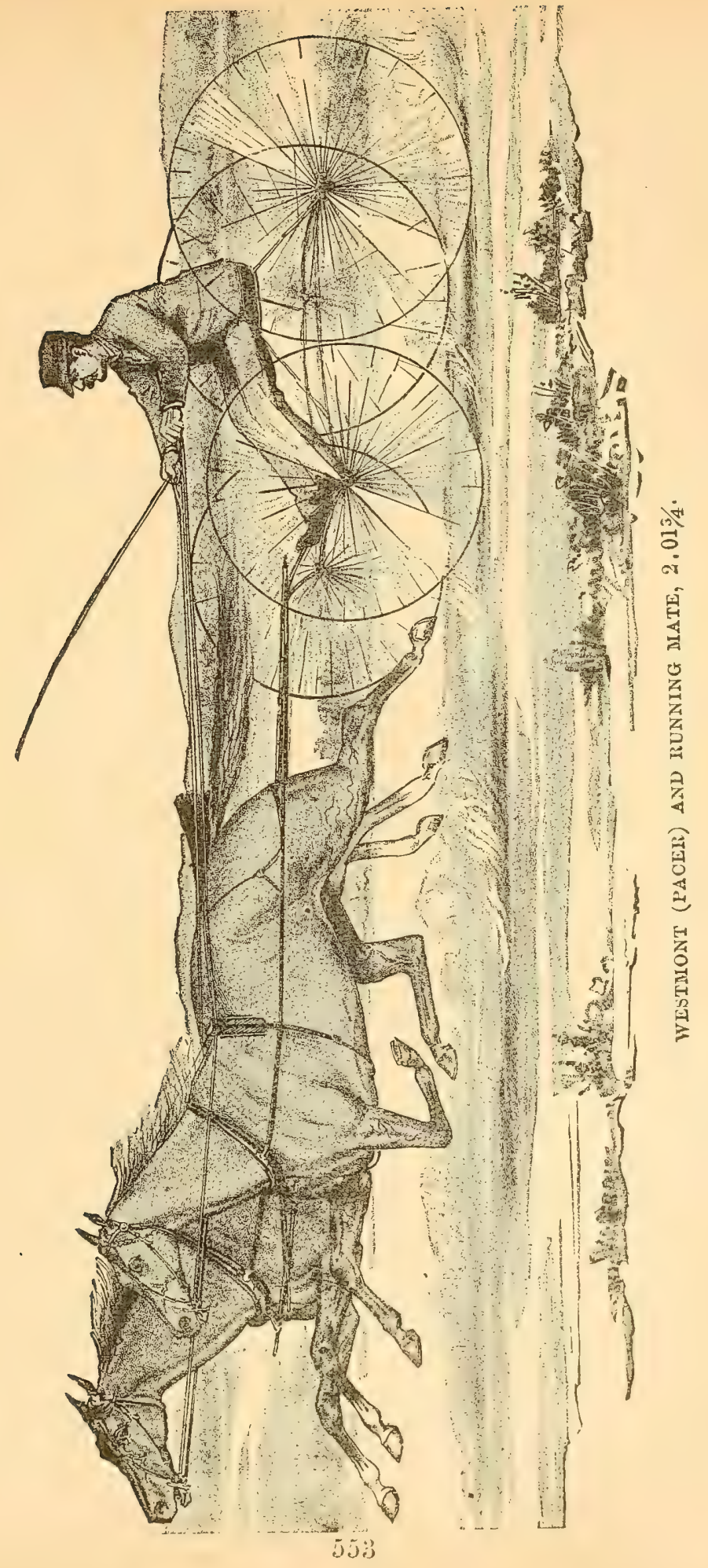


half-mile pole in exactly one MINUTE. Like an animated flash they shot round the top turn and at the three-quarter pole the timers called 1:30. As they came down the stretch it looked for a moment as if the bright and shining mark of 2:00 would be passed, but the thoroughbred falters and Westmont breaks, yet all previous records are swept away as the pair pass under the wire in 2:013. A week later, at the Homewood Park, Pittsburg, Pa., Westmont and mate attempted to beat this record, but only succeeded in obtaining a record of 2:02. Westmont, after a most brilliant career on the track, was sold for a large sum to the millionaire Frank Siddals, of Philadelphia, $\mathrm{Pa}$, in whose possession he still is.

\section{THE PACING HORSE.}

The pacers of America hare labored under many disadrantages. As a distinct breed, they have never been recognized. For years on the turf and road they were systematically ignored, and the gait was generally declared to be unfashionable. It was true that distinct lines of blood which came from pacing ancestors were found in some of the most fashionable of our trotting sires and dams, but it was not till Maud S. had astonished the world by trotting in $2: 08 \frac{3}{4}$, and Jay-Eye-See in 2: 10, both with pacing crosses on the matemal side, and that Little Brown Jug had paced in 2:113, and Johnston had passed all previous records in harness by pacing in 2 : (ofix, that the breeding world woke up to the full value of the pacer as a most formidable factor in breeding for extreme speed.

That the gaits are closely allied does not admit of a doubt. Blue Bull, a pacer, stands at the head of the $2: 30$ list with Georee Wilkes. Pilot, a pacer, was the sire of Pilot, Jr., the sire of Tattler and Indianapolis, and of the dams of Maud S. Jay-Eye-See, and other $2: 30$ trotters. On the other hand, we have Almont, a trotting sire of the bluest blood, the sire of Westmont, the marvelous pacer which, with a rumning mate, paced the track of the Chicago Driving Park in $2: 013$, and woukd have undoubtedly aceomplished it in $2: 00$, hat not his thoroughbred companion tired in the home streteh.

Manager, 2:111 , is another instance of a great pacer which was trotting bred, and the king of the track, Direet, before he erer got his pacing recordof $2: 06$, had a trotting record of $2: 181$. Of the pacers, it is also to be said in their favor that they come to the 
limit; of extreme speed much emrlier than the trotters, and that in proportion to their numbers they have produced a far larger number of first-class performers. Time, which does justice to all, has vindicated the pacer. Though heavily handicapped, he has boldly hurled the gauntlet into the arena for the crown of speed, and while the battle has been a long and obstinate one, distinguished by many memorable conflicts and brilliant victories, the final verdict is on the side of the pacers. The record and history of all pacers pale before the following great champions at this gait, as a short sketch of the career of each will show.

\section{Little Brown Jug, 2 : 11 3-4.}

Little Brown Jug was not the fashionable foal of a patrician matron by an illustrious sire, nor was his birth heralded by the leading turf papers of the day. He was foaled on April 6th, 1875, at Moorfield, Tenn. ; he was sired by Tom Hal ; his first dam was by Bryants, he by Clipper; his second dam was by John Eaton, a thoroughbred. In January, 1876 , he was sold for $\$ 27.50$, and in August, 1877 , he changed hands agair for the paltry sum of $\$ 45$; his new owner broke him to the saddle, but sold him again for $\$ 65$. He now manifested that speed which was soon to make him famous. In the antumn of 1879 he won a race at Huntsville, Alabama, and one at Nashville, Temnessee. In the spring of 1880 he was bought by H. V. Bemis, of Chicago, and his education for the track was at once commenced. He made a short and brilliant season in 1880, and the following year he was also successful. At East Saginaw, Mich., he won the $2: 25$ class in $2: 20,2: 20$ and $2: 19 \frac{1}{2}$. At Toledo he closed out his class in straight heats.

The season of 1881 was one long series of triumphs. At Washington, D. C., he won the $2: 20$ class in straight heats, time $2: 24$, $2: 19 \frac{3}{4}$ and $2: 23 \frac{3}{4}$. He then went to Philadelphia, and won in his class in $2: 24 \frac{1}{4}, 2: 21 \frac{3}{4}$ and $2: 22$. At Fort Wayne, Ind., he won the free-for-ail, defeating Bay Billy and Mattie Harter. At Jackson, Wich., he won the 2: 20 purse, defeating Buffalo Girl and Silas P., and at Ealst Saginaw he again defeated Buffalo Girl in the same class. He continued his wonderful career till he came to Chicago, when he paced three heats in $2: 121,2: 14 \frac{1}{2}$ and $2: 14$, the three fastest heats ever paced or trotted up to that time. At Buffalo he paced one heat in $2: 13 \frac{3}{7}$. At Rochester he defeated his field in stritight heats in $2: 15,2: 15$ and $2: 16$. His culminating performance was 


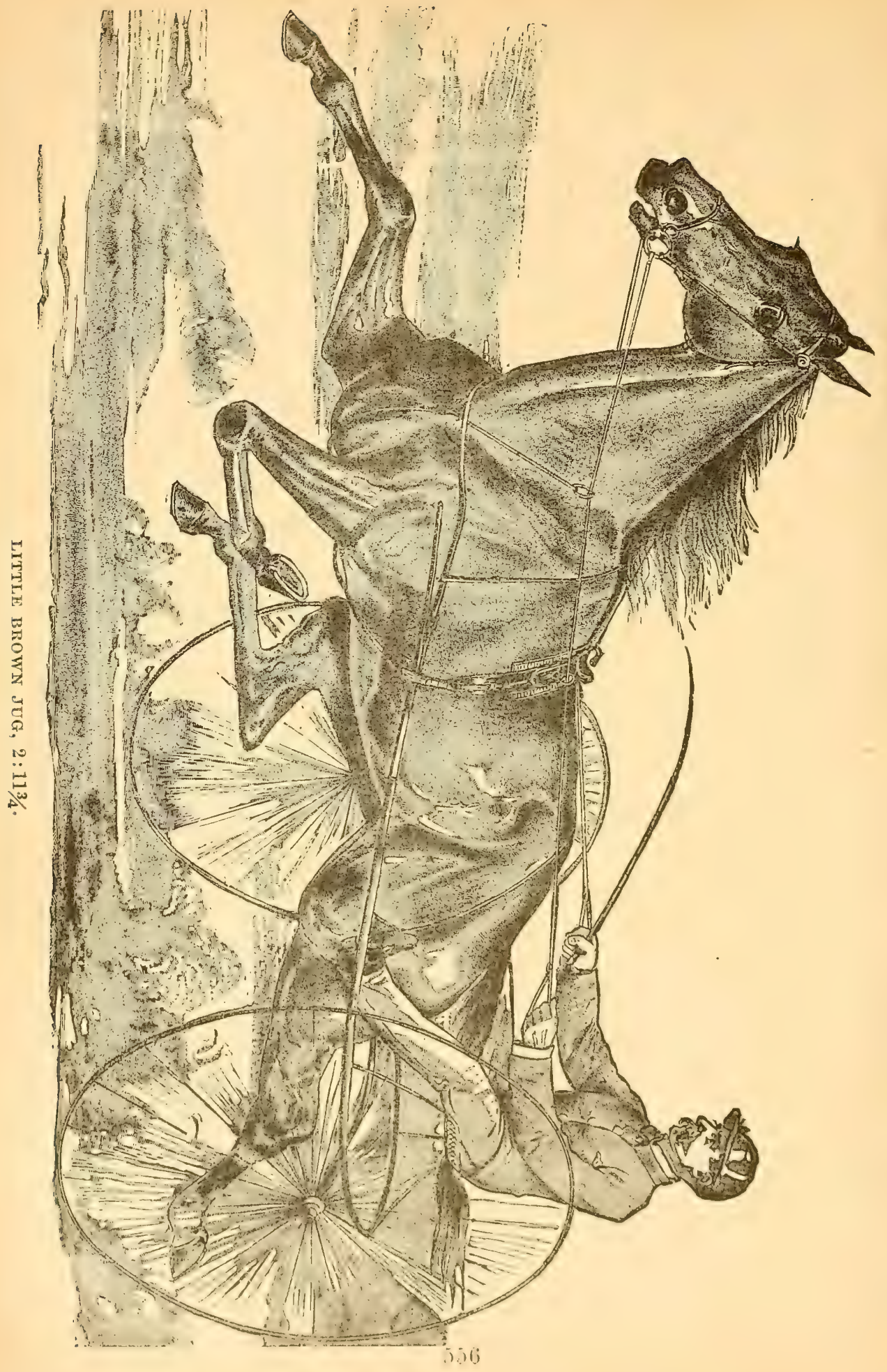


at Hartford, Conn., on August 24th, when he achieved the three fastest straight heats to harness, viz: $2: 11 \frac{3}{4}, 2: 11 \frac{3}{4}$ and $2: 12 \frac{1}{2}$. The following year he was sold to Commodore Kittson, of St. Paul, Mimn., for $\$ 17,500$. The gallant gelding has not done much since on the turf, but his memorable three heats remained a bright and shining mark to all equine aspirants, until surpassed in 1891 by Direct.

\section{Johnston, 2:06 1-4.}

Johnston is certainly a most illustrious member of the pacing family; he may aptly be called the Napoleon of the track. His ancestry is obscure, and he relies upon the grandeur of his own performances in preference to the reflected light of a noble lineage. He is by Joe Bassett, dam Cary More by Sweeting's Ned Forrest. He was foaled on June 20th, 1877. When five years old he was placed in the hands of that veteran of the ribbons, P. V. Johnston, to receive his turf education. He had hardly received his preliminary lessons when his trainer confidently declared that he was the fastest horse in the world, and that he would make him trot in $2: 30$, or pace in $2: 15$, within thirty days.

For a horse without a record this was a bold prediction, but it was warranted by the facts. At the summer meeting of 1883, at Detroit, he made his debut and won in straight heats. On July 4th, at East Saginaw, he won again. At Kalamazoo he won with even greater ease, wiuning the last heat in 2:173. At Chicago, on July 15 th, he achieved a most phenomenal victory; he won the first heat in 2: 13, distancing the entire field except Gurgle; in the second heat

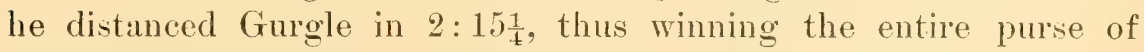
$\$ 2,500$, and the $\$ 500$ extra for beating 2:20 in two heats. At the same meeting he tied the time of Little Brown Jug, 2:113. At the October meeting, at Chicago, he paced a mile against time and beat the best record at that date (Mand S., 2:104), accomplishing his task in 2:10. He was then purchased by Com. Kittson for $\$ 20$,000, and passed into the hands of that skillful reinsman, John Splan, and as the pacing king was barred in the free-for-all purses, his performances were principally confined to atsiatuls upon the dominion of Father Time.

At Indianapolis, on June 21st, he opened the ball, and over a poor half-mile track, pacing thirty fect from the pole, he made $2: 27$ and repeated in 2:29. At Chicago, the scene of his greatest 
triumphs, on July the 12 th, he attempted to beat his own record, but the weather and track were not farorable. The preliminary heat was accomplished in $2: 23 \frac{3}{4}$, the second in $2: 11 \frac{1}{4}$, and the third in $2: 12 \frac{1}{4}$. In the free-for-all pacing race at Buffalo, under the new departure clause, he won the first heat and first money in $2: 121$, Billy S. taking second money in 2:141, and Fuller the third in $2: 17 \frac{1}{2}$. At Rochester he made a grand effort to beat the "man with the scythe," and again the state of the track was unfavorable. The opening heat was paced in $2: 20$, and the two for blood in $2: 11 \frac{1}{4}$ and $2: 12 \frac{1}{4}$. The partisans of Richball, $2: 12 \frac{1}{2}$, the little bald-faced wonder, would not be convinced of the speed superiority of Johnston, contending that in an actual race the latter would show the white feather. A match was made for $\$ 2,500$ a side, which came off at Chicago, on August 23d, 1884. Johnston won in straight heats by from six to a dozen lengths, in $2: 13,2: 11 \frac{3}{4}$ and $2: 13 \frac{1}{4}$. At Minneapolis the contest was fought over again, best two in three, Johnston winning the first and third heats in $2: 13$ and $2: 17 \frac{1}{4}$.

At Milwaukee, on September 18th, in a trial against time, he made $2: 11_{4}^{1}$, and on September 27th, over the same track, he paced a warming-up heat in $2: 17 \frac{1}{4}$, and in the next heat tied his own record of $2: 10$. This performance orer an ordinary track prepared many shrewd horsemen for the grand exhibition that awaited them at Chicago, on October 3d, the opening day of the Chicago fall meeting. Johnston was again sent to beat the record. For once fickle fortune smiled, and all the circumstances conspired to secure success. The weather and track were perfect. No zreeze disturbed the serene sky, the track was smooth and elastic, horse and driver were eager and determined. The first heat marked 2: 19:3. At the work for the second heat the pacing cyclone shot from the wire, and apparently without an effort reached the quarter in 32 seconds. With a frictionless velocity as rapid as it was deceiving, the half was

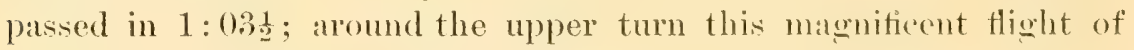
speed was mantaned, and at the three-quarter pole the timer's marked 1:35, and now for the first time the famous driver called upon the king to add to the jewels in his crown. No voice is heard, naught but the lightning-like beating of the flying hoofs and splan is final call. The crowd, as he shoots under the wire, at last breaks the almost painful silence in a volley of ehecrn, all previous records are 


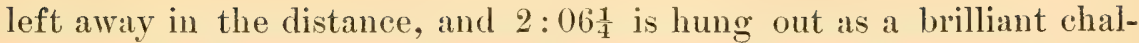
lenge to the aspirants of both the trottiug and pacing arenas.

Johnston has since done excellent work, but he has never yet, and probably never will, beat the time he made on that memorable day.

\section{Direct, 2:06.}

Direct, in his lineage, is the exact antipodes of lis illustrious predecessor Johnston. Direct was born in the purple. He is bred in the highest trotting lines, being by Director, $2: 17$, he by Dictator, the brother of the famous Dexter, $2: 17 \frac{1}{4}$. His dam is Echora, with a trotting record of $2: 23 \frac{1}{2}$, by Echo, who was by Hambletonian 10 . On both sides of the line he inherits the blood of Hambletonian and American Star, while on the sire's side he also obtains the invaluable blood of Mambrino Chief. With such a superb trotting lineage he should have been a fast trotter, and he became one, for as a fouryear-old he achieved a trotting record of $2: 181$. In order to trot fast he had always required to be very heavily shod, and his owner, Mr. Monroe Salisbury, of Pleasanton, Cal., conceived the idea that by shoeing him very lightly he could be trained to pace, and would in all probability be a champion at that gait. He carried out his idea in 1890, and in 1891 Direct came East, and in one season captured the pacing championship of the turf. He began a season which, without exaggeration, is the most memorable in turf annals, at Grand Rapids, Mich., on July 2d, by winning the $2: 33$ class, his fastest time being $2: 26 \frac{1}{4}$. At Cleveland, O., on July 31st, he paced a wonderful race, and demonstrated that he possessed great speed and high courage. He started in a field of eight in the $2: 24$ class, his strongest competitor being the brown gelding, Mascot, who won the first and second heats in $2: 16 \frac{3}{4}$ and $2: 15 \frac{1}{4}$. Direct won the next three and the race in $2: 15 \frac{1}{4}, 2: 18$ and $2: 19 \frac{3}{4}$. One week later, on August 7 th, at Buffalo, N. Y., he won the $2: 24$ class in straight heats in $2: 17 \frac{1}{2}, 2: 22$ and $2: 16 \frac{1}{4}$, and again, on August 14th, at Rochester, he won in the same class in $2: 16 \frac{1}{2}, 2: 21$ and $2: 22 \frac{1}{2}$. From Rochester he went to Chicago, and on August 17th he paced a marvelous race in the $2: 19$ class. He won the first heat in $2: 11 \frac{1}{2}$, distancing three of his competitors. The second heat was paced in $2: 13$, and one more was distanced, while $2: 18$ was the time of the last heat. At the

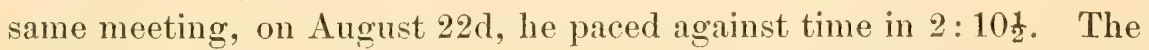
next field of his exploits was the celebrated Kite track, at Inde- 
pendence, Iowa, and here he again covered himself with glory. On August 25th, in a field of twelve, he won in straight heats in $2: 15 \frac{1}{2}$, $2: 17$ and $2: 13 \frac{3}{4}$. It was the $2: 30$ class, and the purse was $\$ 5,000$.

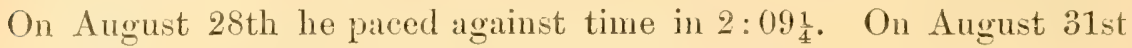
he tied that record, but on September 4 th he paced in 2:06, thus

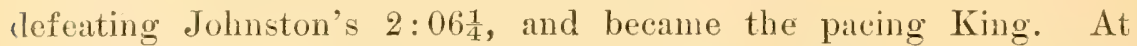
Terre Haute he met the great Hal Pointer, 2:093, the champion of the race record, and the three fastest heats. Direct was not quite well, and the track did not suit him. He won the first lieat in $2: 13$, but lost the next three in $2: 11,2: 10 \frac{1}{4}$ and $2: 12 \frac{3}{4}$. Many judges thought that the little wonder had at last met his match, and

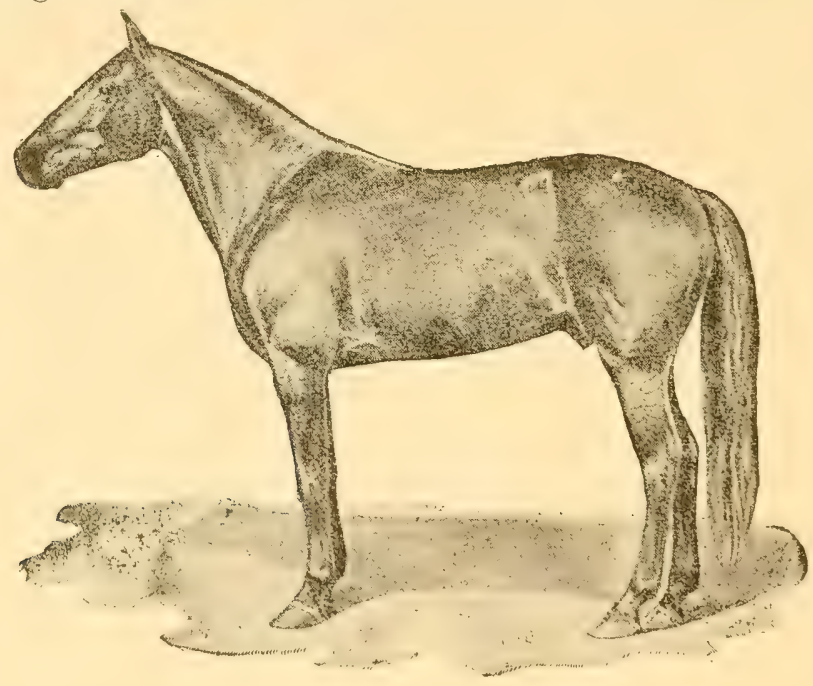

DIRECT, $2: 06$.

that the pacing-bred pacer from Temnessce was the master of the trotting-bred pacer from California. But their triumph was shortlived. On Oetoher 14th, at Lexington, Kir., he palced three preat exhibition heats in $2: 11 \frac{3}{4}, 2: 10 \frac{1}{4}$ and $2: 10 \frac{1}{2}$. But at Nashville, Temm., on Oetober 21st, he again met the hrown gelding, Inal Pointer by Tom Hal. The meeting was the more memorable, because the latter was on his native heath, and all Temessee was there to see their favorite win. To their astonishment they saw the little black stallion dofeat him in straight heats in the fastest time on record, $2: 10,2: 09.1$ and 2:11. By this performance he added the race champiomship. and the fastest heat in a race to his other honors; but he had not 
yet achieved his highest honors. At Columbia, Temn., on October 26th, he again met Hal Pointer. The match attracted the attention of the turf world, for it was the third of the series of matches between these equine giants, and it was admitted that the winner would undoubtedly be the fastest and gamest horse at the pacing gait that the world had ever seen. The race was worthy of the competitors and the audience. Direct won in straight heats in $2: 09,2: 08$ and $2: 08 \frac{3}{4}$. Direct had the unique honor of holding the stallion's pacing championship, the fastest heat in a race, and the fastest three heats in a race championship. Direct is a remarkable instance of the tendency of fast trotters to change their gait, and as he is yet a young horse, it is within the regions of possibility and probability that he may yet reduce his record and approach still nearer the supposed limit of speed for the light harness horse, $2: 00$.

\section{Hal Pointer, 2 : 05 1-4.}

At Washington Park, Chicago, on August 18th, 1892, the already famous bay gelding, Hal Pointer, broke the world's record for pacing to harness, placing the mark at 2:05 $\frac{1}{4}$. This great performer came honestly by both his gait and his speed. His sire, Tom Hal, ranks as the greatest of all sources of pacing speed, having to his credit

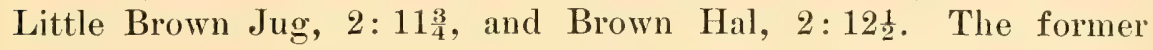
held for years the championship for the three fastest heats in a race, while the latter is one of the greatest stallions that ever appeared on the track, and is also a sire of speed. Tom Hal has also several others to his credit. Hal Pointer's dam was by Knight's Snow Heels, also a pacer. The Champion was foaled in 1884, so that he is yet a young horse, and may, even yet, in the near future, reduce his own champion record.

His first victory was a very modest one, and, like the first achievements of many of the great champions, gave but little promise of his future brilliant career.

October 4th, 1888, when four years old, he paced at Columbia, Tennessee, for a purse of $\$ 20$, and won it in $2: 29 \frac{1}{2}, 2: 29 \frac{1}{4}$, and 2:34; his first appearance on the turf having been made at the same place two days previously in a race in which he won two heats in $2: 32 \frac{1}{2}$, and $2: 33 \frac{1}{2}$. But the following year, 1889, he came out as a star of the first magnitude. He won his races at Cleveland, Buffalo, Hartford, Springfield, New York, St. Louis, and Terre Ilaute, wimning eight races. He was only defeated once, and retired for the 
season with a record of $2: 13$. In 1890 he won all his engagements, eight in number, and at Terre Haute, Indiana, he won his race in $2: 093,2: 12 \frac{3}{4}$, and $2: 13$. This performance gave him the fastest heat in a race, and the fastest three heats championships. His career in 1891 was one grand march of victory, till at Nashville and Columbia, Tennessee, the champion Direct, who had previously paced in 2:06, at Independence, Iowa, defeated him and at the latter place, paced in 2:09, 2:08, and 2:083. This gave Direct both the heat and race championships. The season of 1892 found him again to the fore, and in a series of sharp and fast battles he has defeated Direct; and at Chicago, on August 18th, he paced against the champion pacing record of 2:06, held by Direct, and defeated it in 2:051.

\section{THE AMERICAN THOROUGHBRED.}

Unlike the trotter, the American thoroughbred is a strictly imported article, either directly or from imported parents. The race, in fact, is identical with the English thoroughbred, which for orer a century has provided the world with representatives of this supert, breed. The English passion for horse racing had made it a national amusement over two centuries ago, and before that time the Arabian and the Barb had been imported to its shores to cross up the native mares. The native stock had been previously improved by importations from France and Spain, and with this additional infux of warm blood, the English began the foundation of that great breed of horses which at length attained to such perfection as to absolutely limit the meaning of a word, and be called par excellence thoroughbred. As early as 1791 the English stud book was commenced, and it has been published with unceasing regularity to the present time. The American branch of the family has its stud book, ably edited hy Col. s. D. Bruce, of which there are four volumes, and no animal is considered a simon-pure thoroughbred, unless it is registered in the stud book, and has a duly authenticated pedingee, traceable through the stud book for six generations on both sides of the line.

The first winner of the English Derhy, Diomed, was imported to Ameriea, and many other turf heroes quickly followed. Prior to that time the wealthy colonists had imported laredy of the hreed. which hats grown and prospered in the land of its adoption, until now the fashionahle race courses of America fairly vie with those across the Atlantic. Nor has the quality degenerated by transplanting, as was proved when 
Prioress, Parole, and other good performers, went over and won the principal handicaps of the English turf, and later on when Iroquois won the English Derby, the St. Leger and other great turf events, and in the same year the equally famous Foxhall won the grand prize of Paris, in France, and the two great autumn handicaps, the Cambridgeshire and the Cesarewitch, in England. The thoroughbred is a model of courage, stamina, intelligence, proportion and beauty, and crossed on cold-blooded animals invariably produces the most beneficent results. Appended will be found a table of the highest speed attained at all distances. 
FASTEST RUNNIYG RECORDS ON THE AMERICAN TURF, UP TO JUNE 1, 1892.

MILES.

1\%. Jim Miller, 2, at Deer Lodge (Mont.), Aug. 16, 1888

3/8. Fashion, 4, at Lampasas (Tex.), Aug. 15, 1891..

(Geraldine, 4, 122 lbs.; at New York Jockey Club, $\Lambda$ ug. 30, 1889 (straight course)...

TIME.

$0: 21 \frac{1}{2}$

$0: 34$

1/2. April Fool, 122 lbs., Butte (Mont.), July 31, 1891 (circular course).......................... $0: 47$

(Britannic, 5, 122 lbs., at New York Jockey Club, $\Lambda$ ug. 31, 1889

Fordham, 6, 115 lbs, at New York Jockey Club, Oct. 4, 1889

5\%. Sallie McClelland, 2, 115 lbs., at New York Jockey Club, May 31, 1890

Annie Quen, ? 110 lus a New York Jockey Club, June 12, 1891

(Johnny Heckscher, 2, 115 lbs., at New York Jockey Club, Oct. 10, 1891.....................)

513 fur. La Tosca, 3, 111 lbs., at New York Jockey Club, June 4, 1891............................... 1:041/1

3\%. Fides, 4, 116 lbs., at New York Jockey Club, May 31, 1890.................................. . 1:101/2

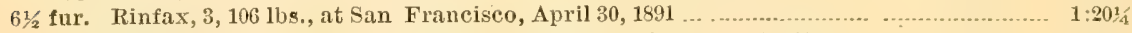

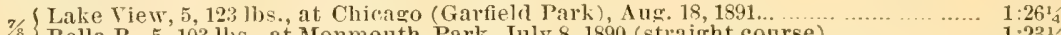

Bella B., 5, 103 lbs., at Monmouth Park, July 8, 1890 (straight course)..................... 1:231/2

(Salvator, 4, 110 Ibs., at Monmouth Park, Aus. 28, 1890 (amainst time, straight course). 1:351/3

1. Raveloe, :, 107 16s., :t Monmouth Park, July 31, 1890 (straight course) ............... 1:391.

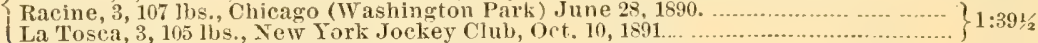

$1 \mathrm{~m} .79 \mathrm{yds}$. Whitney, 3, at Chicago (Garfield Park), $\Lambda$ ug. 18, 1891. ................................. 1:441/2

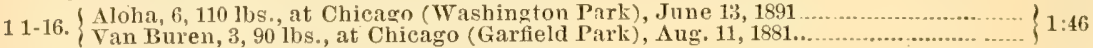

11/8. Tristran, 6, $114 \mathrm{lbs}$., at New York Jockey Club, June 2, $1891 \quad$................................... 1:511.2

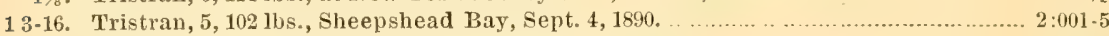

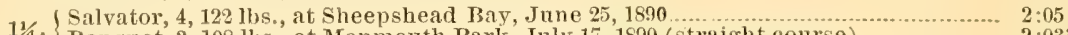

11/4. Banquet, 3, 108 lbs, at Monmouth Park, July 17, 1890 (straight course).................. 2:033/4

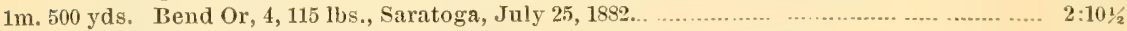

13/8. Ormie, 4, 105 lbs., at Chicago (Washington Park), July 7, 1890.......................... 2:201/4

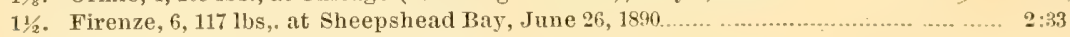

15\%. Hindoocraft, 3,75 lbs., New York Jockey Club, $\Lambda$ ng. 27, 1889............................. 2:48

13\%. Hotspur, 5, $117 \mathrm{lbs}$., at San Francisco, April 30, 1891 ......................................... $3: 003 / 1$

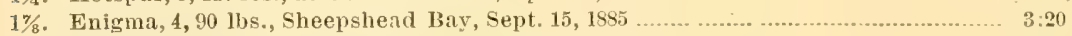

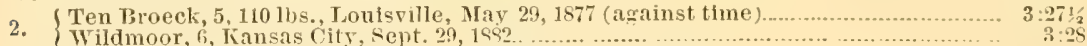

21/. Monitor, 4, 110 lbs., T3altimore, Oet. 20, 1880, ................................................. $3: 441 / 2$

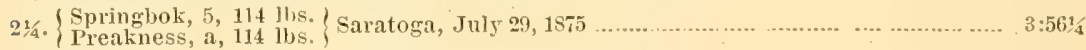

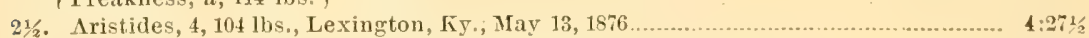

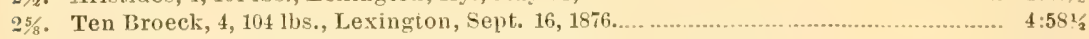

23/4. Hubbard, 4, 107 lbs., Saratoga, Ang. 9, 1873.................................................... 4:583/4

3. Drake Carter, 4, 115 lbs., Sheepshead Bay, Sept. 6, 1584..................................... $5: 24$

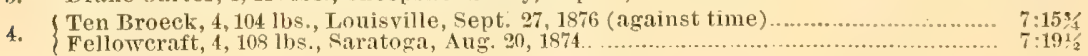

HEAT RACES.

1/4. Sleepy Dick, aged, Kỉowa (Kían.), Nov. 24, 1888

1. \{Bogus, aged, 113 lbs., Helena (Mont.), Aug. a.2, 1888

$1 / 2 .\{$ Eclipse, Jr., 4, Dallas (Tex.), 1890.

5, \{ Kibie Pease, 4, Dallas (Tex.), Nor. 2, 1kst.

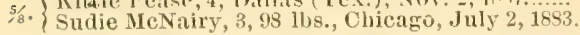

31. Tizzie $5,5,11411$ s., Louisville, Rept. $24,14 \div, 3$

1. Guido, 4, 117 llos., Chicago, (Washington P’ark), July 11, 1891.

1. 3 in 5. L'Argentine, 6, 115 lbs., St. Louis, June 14, 1879.

11-16. Slipalong, 5, 115 lbs., Chicago (Washington 1'ark), Sept. 2, 1885

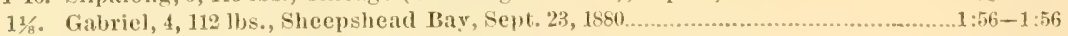
$0: 21 \frac{1}{2}-0: 22 ! \frac{1}{4}$ $0: 48-0: 48-0: 48$ $1:(1)-1:(1) 0$ $1: 02 \frac{1}{4}-1: 03$

$1: 1: 3^{3}-1: 13^{2} \cdot 1$

$1: 41^{1}:-1: 11$

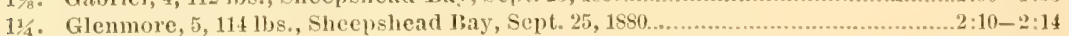

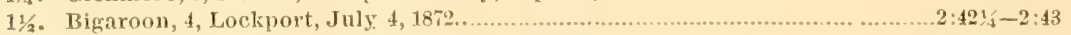

2. Miss Woodford, 4, 1071/2 1bs., Sheepshead Bay, Sept. 20, 1884 ............................3:33-3:31/4

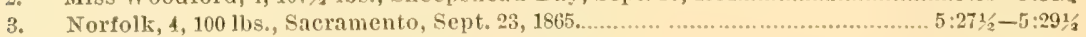

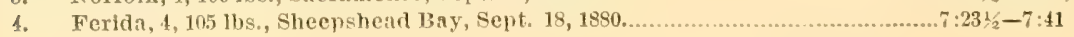




\section{A CHAMPION TABLE.}

Below will be found a table containing the names, breeding, date and place of performance of the champion trotters and pacers in races and against the watch; also whether made on a kite or regulation track, up to the present date (Sept. 1st, 1892):

\section{FASTEST YEARLINGS-COLT AND FILLY.}

Frou Frou, bay filly, by Sidney, 2: 193 , dam Flirt, by Buccaneer; Stockton, Cal., Nov.28, 1891; time, kite, $2: 25 \frac{1}{4}$.

Athadon, bay colt, by Matadon, dam Athalie, by IIarkaway; Stockton, Cal., Nov. 28, 1891; time, kite, $2: 27$.

\section{TWO-YEAR-OLDS-COLT AND FILLY.}

Arion, bay colt, by Electioneer, dam Manette, by Nutwood; Stockton, Cal., Nov. 10, 1891; time, kite, $2: 10 \frac{3}{4}$.

Sunol, bay filly, by Electioneer, dam Waxana, by General Benton; San Francisco, Cal., Oct. 27, 1888; time, regulation, 2:18.

\section{THREE-YEAR-OLDS-COLT AND FILLY.}

Sunol, bay mare, by Electioneer, dam Waxana, by General Ben-

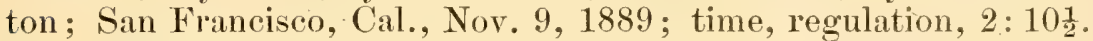

Axtell, brown stallion, by William L., dam Lou, by Mambrino Boy ; Terre Haute, Ind., Oct. 11, 1889; time, regulation, 2: 12.

\section{FOUR-YEAR-OLDS-COLT AND FILLY.}

Sunol, bay mare, by Electioneer, dam Waxana, by General Benton; Chicago, Ill., Aug. 23, 1890; time, regulation, 2:10 $\frac{1}{2}$.

MeKinney, brown stallion, by Alcyone, dam Rosa Sprague, by Governor Sprague; Stockton, Cal., Nov. 17, 1891; time, kite, 2: 12⿺辶.

\section{FIVE-YEAR-OLDS-COLT AND FIILY.}

Sunol, bay mare, by Electioneer, dam Waxana, by General Benton; Stockton, Cal., Oct. 20, 1891; time, kite, 2:081.

Allerton, bay stallion, by Jay Bird, dam Gussie Wilkes, by Mambrino Boy; Independence, Ia., Sept. 19, 1891; time, kite, 2:091.

$$
\text { WORLD'S RECORD. }
$$

Nancy Hanks, brown mare, by Happy Medium, dam Nancy Lee, by Dictator; Independence, Ia., August 31, 1892; time, kite, 2:0.5.

\section{STALLION RECORD.}

Palo Alto, bay stallion, by Electioncer, dam Dame Winnie, by Planet; Stockton, Cal., Nov. 17, 1891; time, kite, 2:083.

\section{GELDING RECORD.}

Jay-Eye-See, black gelding, by Dictator, dam Midnight, by Pilot, Jr.; Providence, R. I., Aug. 1, 1884; time, regulation, 2: 10 .

\section{RACE RECORD TO SULKY.}

Martha Wilkes, bay mare, by Aleyone, dam by Clark ('hief: Independence, Ia., Aug. 26, 18.92; $2: 09 \frac{3}{1}$. 
TO WAGON-RACE.

Alfred S., hay gelding by Elmo, dam Nora Marshall, by Union • Philadelphia, Pa., sept. 4, 1890; regulation, $2: 16 \frac{3}{4}$.

TO WAGON-TIHE.

Allerton, bay stallion, by Jay Bird, dam Gussie Wilkes, by Mamhrino Boy; Independence, Ia., Sept. 25, 1891; 2 : 15.

\section{UNDER SADDLE-RACE.}

Great Eastern, bay gelding, by Walkill Chief, 330, dam by Consternation; Fleetwood Park, New York, Sept. 22, 1877 ; regulation, $2: 15 \frac{3}{4}$.

TEAM RECORD-RACE.

Maxey Cobb, bay stallion, by Happy Medium, dam Lady Jenkins, by Black Jack, and Nata Medium, bay mare, by Happy Medium, dim Sally, by Yankee Tricks; Chicago, Ill., Sept. 25, 1885; regulation, $2: 18 \frac{1}{4}$.

TEAM RECORD-TO TOP ROAD WAGON.

Lynn, W., brown gelding, by Sponseller Tuckahoe, dam Topsy, by Rollman IIorse, and Clayton, bay gelding, by Harry Clay, dam Star Maid, by Jupiter Abdallah; Fleetwood Park, New York City, N. Y., May 28, 1891; time, regulation, $2: 19$.

\section{TEAM RECORD-TIME.}

Belle Hamlin, bay mare, by Almont, Jr., dam Toy, by Hamlin's Patchen, and Justina, by Almont, Jr., dam Black Golddust, by Hamlin's Patchen; Independence, Ia., Oct. 28, 1890; kite, 2:13.

\section{TROTTER WITII RUNNING MATE-RACE.}

Frank, bay gelding, by Abraham, dam by Green Mountain Boy; Prospect Park, L. I., N." T., Nov. 15, 1883 ; regulation, 2 : 08.

\section{TROTTER WITII RUNNING MATE-TIME.}

H. B. Winship, black gelding, by Aristos, dam Willful, by Colonel Moulton; Providence, R. I., Aug. 1, 1884; regulation, 2:06.

\section{'TANDEM-TIME.}

Mambrino Sparkle, bay mare, and William H., bay gelding: Cleveland, O., Sept. 16,1886 ; regulation, $2: 32$.

\section{A TEAM OF TIIREE TROTTING IN IIARNESS ABREAST-TIME.}

Belle Hamlin, bay mare, by Almont, Jr.; Justina, bay mare, by Amont, Jr., and Crlobe, bay gedding, by Almont, Jr. : Cleveland, O., July 31, 1891; regulation, 2:14.

FOUR-IN-IIAND-RACW.

Frank Ross, roan gelding: Peculiar, bay golding (leaders): Rumps, bay matre: Tom Bradler, brown gedeline (wheelers): ('leveland, O., Scipt. 7, 1882; regulation, 2:40;: 


\section{FOUR-IN-HAND-TIME.}

William H., Nobby, Mambrino Sparkle and Clemmie G.; Cleveland, O., Sept. 17, 1886; regulation, 2: 37.

\section{TWO MLES IN HARNESS-RACE.}

Steve Maxwell, gray gelding, by Ole Bull, Jr., dam Weaver Mare;

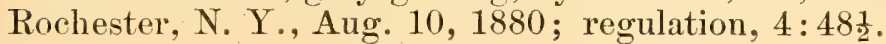

IN HARNESS-TIME.

Fanny Witherspoon, chestnut mare, by Almont, dam Lizzie Witherspoon, bv Wagner; Chicago, Ill., Sept. 25, 1885; regulation, $4: 43$.

\section{UNDER SADDLE.}

Lady Suffolk, gray mare, by Engineer; 2d dam by Don Quixote; $1840 ; 4: 59$.

\section{THREE MILES IN HARNESS-RACE.}

Huntress, bay mare, by Volunteer, dam Lady Sears, by American Star; Prospect Park, L. I., N. Y., Sept. 21, 1872; regulation, $7: 21 \frac{1}{4}$.

IN HARNESS-TIME.

Flora Temple, bay mare, by Bogus Hunter, dam Madame Temple, by Spotted Horse; Centreville, L. I., N. Y., Sept. 27, 1860; resulation, $7: 33 \frac{3}{4}$.

TO WAGON-RACE.

Prince, chestnut gelding, by Woodpecker; Union Course, L. I., N. Y., Sept. 15, 1857; regulation, $7: 53 \frac{1}{2}$.

UNDER SADDLE-TIME.

Dutchman, bay gelding, by Tippoo Saib, Jr.; Beacon Course, N. J., Aug. 1, 1839; regulation, $7: 32 \frac{1}{2}$.

\section{FOUR MILES IN HARNESS-RACE.}

Trustee, chestnut gelding, by imp. Trustee, dam Fanny Pullen, by Winthrop Messenger; Union Course, L. I., N. Y., June 18, 1849 ; regulation, 11:06.

\section{IN HARNESS-TIME.}

Satellite, chestnut gelding, by Tempter, dam Lucy; Keokuk, Ia., Aug. 12, 1887 ; regulation, $10: 52 \frac{1}{2}$.

\section{UNDER SADDLE.}

Dutchman, bay gelding, by Tippoo Saib, Jr., dam Nettie; May, 1836 ; regulation, $10: 51$.

FIVE MILES IN HARNESS-RACE.

Lady Mac, bay mare, Oakland, Cal., April 2, 1874; regulation, $13: 00$.

$$
\text { TO WAGON-RACE. }
$$

Fillmore, chestnut gelding: San Francisco, Cal., April 16, 1863; regulation, $13: 16$. 
TEN MILES IN HARNESS-RACE.

Controller, bay gelding, by General Taylor; San Francisco, Cal., Nov. 23, 1878; regulation, $27: 23 \frac{1}{4}$.

IN IIARNESS-TIME.

John Stewart, bay gelding, by Tom Wonder, dam by Harris' Hambletonian; Boston, Mass., June 30, 1868; regulation, 28:021.

TO WAGON-RACE.

Julia Aldrich, chestunt mare ; San Francisco, Cal., June 15, 1858; regulation, $29: 04 \frac{1}{2}$.

TWENTY MILES IN HARNESS-THME.

Captain McGowan, roan stallion; Boston, Mass., Oct. 31, 1865; regulation, $58: 25$.

THIRTY MLES IN HARNESS-THE.

General Taylor, gray stallion, by Morse Horse, dam Flora; San Francisco, Cal., Feb. 21,$1857 ; 1: 47.59$.

FIFTY MILES IN IIARNESS-TINE.

Ariel, bay gelding; Albany, N. Y., 1846; $3: 55.40 \frac{1}{2}$.

ONE IIUNDRED MLLES IN HARNESS-TIME.

Conqueror, bay gelding, by Bellfounder (Latourette's), dam Lady MeClaire, by imp. Bellfounder; Centreville, L. I., Nor. 12, 185:3; $8: 55.53$.

FASTEST THREE HEATS IN A RACE.

Naney IIanks, brown mare, hy Happy Medium, defeating Allerton;

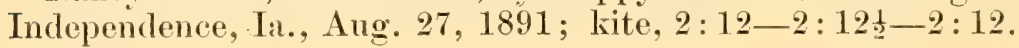

\section{PACERS.}

FASTEST YEARLING-COLT AND FILLY.

Fausta, bay filly, by Sidney, dam Faustina, by Crown Point; Stockton, Cal., Nov. 28, 1891; time, kite, $2: 233$.

Rollo, gray gelding, by Jerome Eddy, dim Grey Betsy, by Mambrino Patchen; Independence, Ia., Oct. 27, 18.91; time, kite, 2:281.

TWO-YEAR-OLDS-COLT AND FILLY.

Manager, gray stallioin, by Nutwood, dam Carrie, by George Wilkes; Independence, In., Än. 29, 1890; time, kite, $2: 16 \frac{1}{2}$.

Alice Wilken, bay filly, by Gambetta Wilken, dam Alice, by Onwatrd; Cambridge (ity, Ind., Sept. 26, 1s:1; regulation, 2:221.

THIEE-YEAR-OLDS-COLT AND FILLY.

Mamager, gray stallion, by Nutwood, dam Carrie, by George

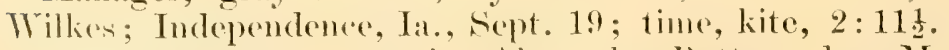

Folo Maid, bay mane, hy Alexander Button, dam Molly, by St.

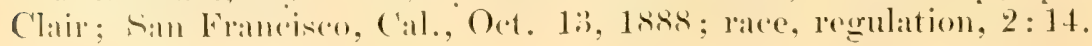


FOUR-YEAR-OLDS.

Strong Boy, gray stallion, by Allendorf, dam by Arnold; Lexington, Ky., Oct. 17, 1891; time, regulation, $2: 12$.

Gold Leaf, chestnut mare, by Sidney, dam Fern Leaf, by Flaxtail;

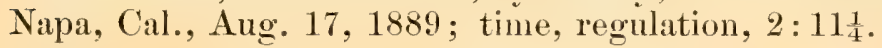

WORLD'S RECORD.

Hal Pointer, nay gelding, by Tom IIal, dam by snow Heels; ('hieago, Ill., Aug. 18, 18.92; time, regulation, $2: 05 \frac{1}{4}$.

STALLION IIECORD.

Direct, black stallion, by Director, 2:17, dam Echora, by Echo; Independence, Ia., Sept. 4, 1891; time, kite, 2:06.

\section{GELDING RECORD.}

Johnston, bay gelding, by Joe Bassett, dam by Swetting's Edwin Forrest; Chicago, Ill., Oct. 3, 1884; time, regulation, 2:064.

Jay-Eye-See, black gelding, by Dictator, dam Midnight, by Pilot, Jr.; Independence, Ia., Aug. 26, 1892; 2:061.

MARE'S RECORD.

Cricket, bay mare, by Steinway, dam by Dolphin; Independence, Ia., Aug. 30, 1890 ; time, kite, $2: 10$.

\section{RACE RECORD TO SULKY.}

Flying Jib, bay gelding, by Alcona, dam by Middletown; Independence, Ia., August 31: 2:07.

TO WAGON-RACE.

Johnston, bay gelding, by Joe Bassett; Detroit, Mich., July 21; regulation, $2: 14 \frac{1}{2}$.

$$
\text { TO WAGON-TME. }
$$

Roy Wilkes, by Adrian Wilkes, dam Flora, by Blue Bull; Independence, Ia., Oct. 30, 1891; kite, 2:13.

\section{UNDER SADDLE.}

Johnston, bay gelding, by Joe Bassett; Cleveland, O., Aug. 3, 1888 ; regulation, $2: 13$.

TEAM RECORD-TIME.

Daisy D., brown mare, by Black Star, and Silvertail, gray gelding, by Tempest, Jr.; East Saginaw, Mich., July 15, 1887 ; requlation, $2: 18$.

\section{PACER, WITH RUNNING MATE-TIME.}

Westmont, chestnut gelding, by Almont, dam Annie, hy Cottrill Morgan; Chicago, Ill., July 10, 1884; regulation, 2:013.

$$
\text { TWO MILES IN HAINESS-RACE. }
$$

Defiance, bay gelding, by ('hioftain, and Longfellow, chestmut gelding, by Red Bill, dead heat; Silcamento, ('al., Sept. 26t, 1872; regulation, $4: 47 \frac{3}{4}$. 


\section{UNDER SADDLE.}

James K. Polk, chestnut gelding, and Roanoke, dead heat; Philadelphia, $\mathrm{Pa}$., June 30,1850 ; regulation, $4: 57 \frac{1}{2}$.

\section{THREE MILES IN HARNESS-RACE.}

James K. Polk, chestnut gelding; Centreville, L. I., N. Y., Sept. 13,1847 ; regulation, $7: 44$.

\section{IN HARNESS-TIME.}

Joe Jefferson, brown stallion, by Thomas Jefferson; Knoxville, Ia., Nov. 6, 1891; regulation, $7: 33 \frac{1}{4}$.

\section{UNDER SADDLE-RACE.}

Oneida Chief, chestnut gelding, by Kentucky Hunter; Benson Course, N. J., Aug. 14, 1843; regulation, $7: 44$.

$$
\text { TO WAGON-RACE. }
$$

Longfellow, chestnut gelding, by Red Bill; Sacramento, Cal., Sept. 21,1868 ; regulation, $7: 53$.

\section{FOUR MILES IN HARNESS-RACE.}

Longfellow, chestnut gelding, by Red Bill; San Francisco, Cal., 1869 ; regulation, $10: 34 \frac{1}{2}$.

\section{IN HARNESS-TIME.}

Joe Jefferson, brown stallion, by Thomas Jefferson ; Knnoxville, Ia., Nov. 13, 1891; regulation, 10:10.

$$
\text { FIVE MLES IN HARNESS-RACE. }
$$

Fisherman, bay gelding, by Lightning; San Francisco, Cal., Dec. 19, 1874; regulation, $13: 03 \frac{1}{2}$.

\section{TO WAGON-RACE.}

Lady St. Clair, by St. Clair; San Francisco, Cal., Dec. 11, 1874; regulation, $12: 54 \frac{3}{4}$.

Direct, by Director, dam Echora, hy Echo: Columbia. Tenn., Oct. 26, 1891, defeating Hal Pointer; kite, 2:09-2:08-2:08:. 
GLOSSARY OF SCIENTIFIC AND IMPORTANT TERMS, USED IN VETERINARY WRITINGS, WITH THEIR DEFINITIONS.

Abdomen-The portion of the body containing the stomach and in testines; the belly.

Abnormal-That which is not natural or regular.

Abortion-The casting of the young in an unnatural manner, and before the proper time.

Abrade-To rub off, to wear away by contact, as rubbing off the surface of the skin, producing galls.

Abrasion-A rubbing off; an abraded and sore spot on the skin. Abrupt-Quick, sudden; an abrupt turn or twist in the intestine may produce strangulation of the parts.

Abscess-A swelling and its cavity containing pus or matter. A cavity containing pus.

Absorb-Swallowing up, drinking in.

Absorbent-In anatomy, those vessels which imbibe or suck up, as the lacteais or lymphaties. In medicine, any substance, as chalk, magnesia, etc., used to absorb acidity in the stomach. Absorption-The taking up by the vessels of the body of any substance either natural or unnatural, as the serum of dropsical swellings. Accelerate-Growing quicker or faster, as an accelerated pulse.

Acid-Sour. The last fermentation before the putrid.

Acidulate-To make slightly sour, as with lemon, vinegar, or the mineral acids.

Accretion-Increase, or growing as an exostosis or unnatural growth of bone.

Acrid-Sharp, pungent, biting, irritating, as the strong acids.

Acute-Severe, sharp. In diseases, those which soon come to an end in contradistinction to chronic.

Action-The paces of a horse, either natural or acquired.

Actual-The production of an immediate effect, as by the use of a

hot iron (actual cautery), in contradistinction to the effect of escharotics, as a caustic application.

Adenitis-Inflammation of a gland or glands. 
Adhesion-A joining together, as the union of parts in healing. Adhesive-That which adheres, as certain plasters.

Adipose-Fatty matter; belonging to fat.

Adolescence-The period between puberty (the age of procreation)

and the full development of the physical system.

Adult-The age succeeding adolescence, and preceding old age.

Acrate-Mixing with air, as the blood in the lungs, by which it ab-

sorbes oxygen.

AEtiology-Relating to the doctrine or probable cause of a disease.

Affection-Disease, or disease of some particular part.

Affinity-The attraction which causes particles of bodies to adhere and form compounds. That which causes substances to cohere. Affuence-Determination of the blood or of humors to a part. Albuminura-That condition in which the urine contains albumen

and an excess of urea, coagulable by means of nitric acid and heat. Albumen-Substances, animal and vegetable, resembling the white of an egg.

Aliment-Solid or liquid substance taken as food. Alimentary Canal-The bowels.

Alkali-Any substance which will neutralize an acid, as magnesia, soda, potash, etc.

Alkcloid-A salifiable base existing in some vegetables, differing

from alkali in composition and general properties, and having nothing in common except their basic properties. Brucia, emetia, morphia, strychnia, strontia, etc., are alkaloids. Alter-A term in common use for castration.

Alterative-A medicine changing the functions and condition of the organs of the body. Alum-Sulphate of alumina and potassa.

Alveoli-The sockets in the jaw bone in which the teeth are situated. Amaurosis-Partial or total loss of vision from paralysis of the retina. Ampulation-The operation in surgery of cutting off a limb. Anamia-Poverty of the blood as opposed to plethora. Too few red corpuscles and too many white corpuscles in the blood. Anasarca-Dropsical swellings, as of the limbis, abdomen, chest, etc. Aneurism-Dilatation of an artery producing a tumor; lesion of an

artery; dilatation of the heart.

Analysis-Separation into parts; resolving a thing or substance into its original elements. 
Anatomy-The art of dissecting, or separating the different parts of the body. The science of the structure of the body, as learned by dissection.

Anchylosis-The stiffening, or rendering rigid, a joint.

Ancesthetics-Agents which deprive of sensation and suffering, as chloroform, ether, etc.

Anodyne-A medicine to allay or diminish pain.

Antacid-Opposed to, or an antidote to, acids.

Antagonism-Opposed in action; one contradicting another.

Anthelmintic-Medicine to kill or expel worms.

Antidote-That which counteracts hurtful or noxious substances.

A remedy to counteract the effects of poison.

Antiperiodic-Medicine to arrest or retard the return of a paroxysm in periodic disease.

Antiseptic-Agents for preventing, arresting or retarding putrefaction.

Anus-The fundament, or lower portion of the bowel at the tail.

Aperient-Laxative medicine; that which gently operates on the bowels.

Aphtha-Ulceration of the mouth, beginning with minute vesicles and ending in white sloughs.

Apoplexy-Sudden effusion of blood into the substance of the brain. Sometimes used for effusion into the substance of other organs or tissues.

Approximate-Coming near to. An approximate cure is by inoculating for another disease.

Aqueous-Watery; having the property of water, as watery matter, aqueous pus.

Aromatic-Strong smelling stimulants, given to dispel wind and relieve pain.

Artery-Blood-ressels which carry the red blood from the heart. Articulate-Joining, working together or upon one another, as the bones.

Asthma-A disease attended with difficulty of breathing, and a sensation producing wheezing, coughing and other distressing symptoms.

Asphyxia-Death from strangulation of the lungs, from want of air. Assimilate-To make like another; assimilation of food in the nutrition of the body. 
Astragalus-The largest bone of the hock-joint, lying below the os calcis.

Astringent-That which causes contraction of the bowels or vital structures. Astringents are medicines which suppress discharges, as from the bowels, blood, mucus. Attenuate-To draw out, to make thin, reduce in size. Atrophy-Wasting of a part, as the muscles. Atlas-The first bone of the neck or first cervical vertebra, Augment-To increase.

Auricle-The exterual part of the ear; also parts of the heart, one on each side resembling ears.

Auscultation-The act of listening to sounds given by different parts of the body when struck, especially to the sounds produced by the functional motions of the lungs and heart by pereussion. Bars-(Of the hoof.) The two ridges of horn passing from the heels of the hoof toward the toe of the frog. (Of the mouth.) The transverse ridges on the roof of the mouth of the horse.

Bicipital-Two-headed, as biceps muscles, bicipital groove, etc.

Bitiary-Belonging to or pertaining to bile. Biliary duct, a canal containing bile.

Bolt-To swallow the food hurriedly without proper chewing.

Bolus-Medicines formed into a round or cylindrical mass, for ease in administering, often termed a ball. The cylindrical shape is the proper one.

Bots-The grub of the fly equus equi, when in the stomach of the horse.

Bounded-Parts lying about another, surrounded by .

Bronchia-The first two branches of the wind-pipe. Bronchitis is an inflammation of the bronchia.

Bursal-A bursal enlargement is an enlargement of the oil-sac found at or near many of the joints.

Casarian Operation-To cut into the womb by way of the abdomen, when natural delivery cannot be accomplished.

Calcareous-Containing lime; lime-like.

Calculus-Any hard, solid concretion found in any part of the body, as stone in the bladder, gall-stones, etc.

Calks, or Callins-The heel of the horse-shoe when turned down to prevent slipping.

Callous-Induration; a hard deposit; excess of bony matter. 
Canal-A tube or passage-as the alimentary canal (digestive tract), tympanic canal of the ear, etc.

Cancer-A hard, unequal, ulcerating tumor, which usually proves malignant and fatal.

Canine Teeth-The teeth between the lateral incisors and the small molars of the jaw.

Canker-Eroding ulcers of the mouth; virulent, corroding ulcers. Any sore which eats or corrodes.

Cannon-bone-The shank, or bone below the knee or hock. The metacarpal or metatarsal bone of the horse.

Cantharis-A coleopterous insect. The cantharis vesicatoria; powdered, it is the active principle in ordinary blistering plasters.

Canula-A hollow tube of metal or other substance, variously used in surgery.

Capillary-Hair-like; applied to the minute ramifications of the blood-vessels.

Capped Hock-A swelling on the points of the hock of the horse.

Capsicum-Cayenne pepper. The small, long red pepper.

Capsular Ligaments-Ligaments surrounding the joints.

Capsule-A membranous bag or sac.

Cardiac-Pertaining to the heart.

Caries-Ulceration of the substance of the bones.

Carotid Canal-A canal in the temporal bone, through which the carotid artery, and also some nervous filaments, pass.

Cartilage-Gristle; the substance covering the ends of bones, moving and working upon each other.

Castrate-To geld, emasculate, deprive of the testicles.

Catarrh-A cold attended with running of the nose.

Cataract-An opacity of the crystaline lens of the eye, causing partial or total blindness.

Cathartic-Purgative medicine, used for freely opening the bowels.

Catheter-An instrument used for drawing the water from the bladder, and for other purposes.

Caustic-Any burning agent, as potash, nitrate of silver. To cauterize is to burn, generally applied to the use of the hot iron in diseases.

Cavity-A depression, as the cavity of a wound.

Cellular Tissue-The membrane or tissue which invests every fiber of the body, composed of minute cells communicating with each other, and which serve as reservoirs of fat. 
Cevebral--Pertaining to the brain.

Cervical_-The neck; belonging to the neck.

Characteristic-A symptom of character. Characterize, to distinguish.

Chemistry - The science which investigates the composition of substances, and the changes of constitution produced by their mutual action.

Chronic-A lingering, long-standing disease, generally succeeding the acute stage. A seated, permanent disease.

Chyle-The milky liquid, as taken from the food during digestion, and prepared from the chyme, and ready to be absorbed by the lacteal vessels before being poured forth into the blood.

Chyme-The food modified and prepared by the action of the stomach.

Cicatrice-The scar left after the healing of a wound or ulcer.

Circumscribed-Limited. In pathology applied to tumors distinct at their base from the surrounding part.

Circulation-The vital action which sends the blood through the arteries, and back again through the veins to the heart.

Cleft-A mark; division; furrow.

Coagulate-To elot, as the blood when drawn.

Colic-Acute pain in the abdomen, intensified at intervals.

Collapse-A falling together. A closing of the vessels. Extreme depression of the vital powers.

Colon-The largest of the intestines, or, more properly, the largest division of the intestinal canal.

Coition-The act of copulation; union of the sexes.

Coma-Lethargy. Drowsiness produced by depression of the brain and other causes.

Condition-A healthy, serviceable state of the system. A firm state of the muscular tissue.

Congenital-Born with another; of the same birth. Belonging to the individual from birth.

Congestion-An accumulation of clogged blood in the vessels, or in the parts, as the lungs, brain, etc.

Constrict-Drawing or binding together, as a constriction of the muscles of a part.

Comagions-A disease that may be eommunicated by contact, or the matter communicated, or proceding from the breath, or emanations of the body. 
Contorted-Twisted, twisting, writhing, as the body in pain, or from the result of disease.

Contusion-A bruise; a wound made by a blow or bruise.

Concretion-Adherence of parts naturally separate. In chemistry, condensation of fluids or other substances into more solid matter.

Constipation-A state of the bowels in which the evacuations are umnaturally hard. A stoppage of the evacuation of the bowels.

Continuity-Parts united so completely that they cannot be separated without laceration or fracture.

Convalescent-Returning to health after sickness.

Convoluted-Rolled together or upon itself. The cerebrum is convoluted. The irregular foldings of the intestines are convolutions. Copious-Plentiful, abundant, as a copious discharge.

Core-The hard portion of purulent matter, as in boils.

Corn-A diseased portion of the foot,-in the horse, between the bar and the quarter, usually on the inside.

Coronet-The upper part of the hoof, just where it joins the skin.

Corrosive_Eating away and destroying the texture of the living body. Corrugation-Contracting the skin into wrinkles.

Costa-A rib. Costal: belonging to the ribs.

Counter-irritation-An application to irritate one part, to relieve pain in another. A blister or mustard poultice does this.

Cranium-The skull. Cranial: pertaining to the skull.

Crest-The back or upper part of the neck of the horse:

Crepitation-Applied to the noise made by the ends of fractured bones, when they grate together. The sound produced by pressing together cellular tissue in which air is contained.

Cribbing (of horses) - The act of seizing any hard substance, or pressing thereon with the teeth, and gulping; sometimes called wind-sucking, though the latter is not necessarily cribbing.

Crisis-In disease, that point or period which determines a favorable or unfavorable termination.

Crust-The hoof is so called. The outside laminæ of the hoof.

Crusta-A scab.

Cul-de-sac-A passage closed at one end.

Curb-A soft swelling, becoming hard, situated on the back part of the hind leg, just below the point of the hock. 
Cuticle-The epidermis or scurf skin. The skin is composed of the cutis vera, reta mucosum and cuticula.

Cutaneous-Of the skin, as a cutaneous affection.

Cyst-A small bladder or sac; one containing morbid matter or parasites, which become encysted, or inclosed in an envelope.

Cystitis-Inflammation of the bladder.

Debility_The condition of weakness or feebleness.

Decoction-Extraction of the soluble parts of substances by boiling.

Decompose-To decay. To separate into component parts.

Defecation-Purifying from impurities of foreign matter. Voiding the excrement from the body.

Degenerate-To become worse or inferior.

Deleterious-Injurious, poisonous or destructive.

Delirium-Insanity; a wandering of mind in disease.

Demulcent_-That which sheaths and protects irritated surfaces.

Dermal-Belonging to the skin.

Develop-To increase. A disease develops its intensity. To show increasing muscular form. Bringing to perfection.

Diabetes-An excessive flow of urine containing saccharine matter.

Diagnosis-The distinguishing of one disease from another.

Diaphoretic-A medicine which causes perspiration or sweating.

Diaphragm - The midriff. The membrane, or broad muscle, which divides the thorax or chest from the abdomen or belly.

Diarhoea-A continued and profuse discharge from the bowels.

Diet-Any kind of food or drink. Dietary: a regulated allowance of food.

Diffuse-To extend or drive out. That which may flow or spread, as a diffusible stimulant.

Digestion - The separation and dissolving of the food in the stomach. Digestive ointment has the power of resolving tumors.

Dilate-To open wide, as dilation of the eye.

Dilatation-The expanding of a body, as of the heart, arteries, the bladder, etc., from over-fullness.

Dilute-To make thin, as a medicine with water or oil.

Diminution-A lessening, or decreasing, as of pain, ete.

Diploma-A document granted by a legally chartered college, showing that the person named is entitled to practice his profession.

Disinfectant-An agent capable of neutralizing morbutic eflturia, or the cause of infection. 
Dislocation_Putting or being out of joint.

Disorganization-A complete morbid change in, or even total destruction of, the structure or texture of an organ.

Dissection-Exposing the different parts of a dead body, that their arrangement and structure may be studied.

Distorted-Deformed, crooked, out of the natural shape.

Distend-To stretch out, or swell.

Diuresis-An extraordinary or abundant excretion of urine.

Diuretic-A medicine to increase the flow of urine.

Dorsal-Pertaining to the back. The dorsal column is the back-bone. Drachm-The eighth part of an ounce.

Drastic-Powerfully acting medicines or poisons.

Drench-Liquid medicine given by the mouth.

Drug-Originally, a medicines in its simple form, but now applied to medicines generally.

Duct-A tube for conveying a fluid or the secretions of the glands.

Duodenum_The first portion of the small intestine, through which the bile is poured.

Dura Mater-A fibrous, semi-transparent membrane, lining the cavity of the cranium, and containing the brain (of which it may be considered the outer membrane), and protecting the same by its thickness and great resisting power.

Dysentery-Inflammation of the mucous membrane of the large intestines, producing mucous or bloody evacuations.

Dyspepsic-Serious derangement of the digestive functions.

Dyspnoea-Difficulty of breathing.

Dysuria-Painful and incomplete passage of urine.

Eczema-Irritation of the skin, usually followed by small pustules crowded together-not contagious, but producing a smarting pain. Effusion-A flowing out, as of blood, water or lymph, into the tissues. Elephantiasis-Chronic lymphangitis, by which the limb is cularged, resembling the leg of an elephant.

Embryo-The impregnated ovum in the womb, after growth begins. Emetic-A medicine given to produce vomiting.

Emollients-Agents which have the power of softening or relaxing.

Enamel-The hard outer covering of the teeth.

Encysted-Enclosed in a sac.

Enema-Medicines given by injection into the bowels. 
Engorgement-In animals, vascular congestion, generally the result of over-feeding.

Epidemic-Disease that affects a large number, as though in the air. Epiglottis-The covering of the glottis. A tongue-shaped projection, to prevent food or liquids from entering the wind-pipe.

Epizoötic-Contagious disease, attacking large numbers of horses at one time. Applied to catarrhal fever in influenza, which spreads rapidly.

Equine-Belonging to the horse.

Eruption-Pimples, blisters, rash, ete., breaking out on the skin.

Essence-The properties or virtues extracted from any substance.

Evacuate-To empty or pass out, as to evacuate the bowels.

Ewe-necked-In the horse, having a neck like a shorn sheep.

Excision-Cutting out, or cutting off, any part.

Excoriate-To tear or strip off the skin; to wear away or abrade; to break the skin in any manner, as in galling, or with acrid substances. Excrement-Refuse matter. The dung.

Excrescence-Unnatural or superfluous growth.

Excretion-The act of throwing off effete matter from the animal system; that which is thus thrown off.

Exfoliation-Separation or scaling off of dead from living bone. Separation of scales (laminæ) from any substance.

Exhale-Breathing out, evaporating.

Exostosis-Unnatural growth or projection of bone.

Extensor-tendon-The tendons which stretch out the limbs.

Extirpation-The complete removal of a part by means of the knife. Extravasate-To let out of the proper vessels, as blood, after the rupture of a blood-vessel.

Exudation-A sweating, or passing out of a liquid through the walls or membranes containing it.

Facial-Pertaining to the face.

Foces-The excrement.

Fat-The animal substance, whose natural function it is to protect the organs, mantain the temperature, and nourish in cascof need. Febrifuge-A medicine to lower the temperature of the body, and counteract fever.

Femur-The thigh bone proper.

F'ementation-Incipient decomposition of vegetable substances, from souring. 
Fester-To suppurate, and discharge corrupt matter.

Fetid-Having an offensive odor.

Fibrin-An organic substance found in the blood, and composing a

large part of the tissues of the body. Fibrous membrane is a membrane composed of fibers.

Fibula-The small or splinter bone of the leg. The outer bone of

the hind leg of the horse, etc.,-much smaller than the tibia. Filtration-Straining a liquid to clarify it.

Fissure-An opening, a crack.

Fistula - A deep, narrow ulcer, having a passage leading to it.

Fistulous-Resembling a fistula, either in form or nature.

Flanks-That part of the horse between the false ribs, hips and stifle. Flatulent-Affected with, or caused by, the generation of gas, or

wind, in the stomach or intestines, as flatulent colic.

Flex-To bend, as the neck or limb; as, a muscle flexing the arm. Flexor-A muscle which bends a part; in opposition to extensor. Frotus-The young, yet unborn.

Fomentation-The application of warmth and moisture, as with a liquid or poultice.

Foramen-A cavity pierced through and through.

Fumigate-The application of smoke or vapor.

Fundament-The anus, or extremity of the bowel; end of the gut. Fungus-An unnatural growth resembling mushrooms.

Gall-The fluid contained in the gall-bladder, consisting, principally, of the bile secreted by the liver.

Gangrene-Mortification or death of any part or tissue of the body. Gastric-Pertaining to the stomach.

Genital-Relating to reproduction, or to the generative parts.

Gestation-The condition of pregnancy, or being with young.

Gleet-Thin matter issuing from an ulcer. In horses, applied to nasal gleet exclusively.

Glottis-The narrow opening at the top of the windpipe.

Haunch-That part of the body which lies between the last ribs and the thigh. In the horse, the bony region of the hips.

Haw-The process of the eye-socket, which is thrown over the eye to clear it of foreign substances.

Homatin-The coloring matter of the blood.

Hectic-A constitutional and remitting fever exhibited in consumption; produced also by ulcers, sores, ete. 
Hemorrhage-A discharge of blood from the vessels containing it. Hepatic-Belonging to the liver.

Hepatitis-Inflammation of the liver.

Herbivorous-Feeding on herbs.

Hermaplororlite-Possessing the attributes of both sexes, in a greater or lesser degree; being of, or including, both sexes. Said of animals, plants or flowers.

Homogeneous-Being of the same kind or quality throughout.

Humor-Any fluid of the body, excepting the blood.

Humerus-The upper arm-bone; upper bone of the fore-leg.

Hybrid-The offspring of two different species of animals, as that of the horse and ass (the mule).

Hydragogue-A medicine to remove effused fluids from the system. Hydrocephalus-Water in (dropsy of) the head.

Hypertrophy-Excessive growth.

Hypodermic-Beneath the skin. Used principally of medicines-as morphia, ete.,-applied by injection under the skin.

Ileum-The lower part of the small intestine.

Impotence-Inability to perform the sexual function.

Impregnation-The act of rendering, or state of being, pregnant.

Incision-Cutting into; a clean cut; a cutting, as in any operation.

Incontinence-Inability to retain the natural evacuations.

Induration-The hardening of a part from the effects of disease.

Infection-Communicating disease by miasma, or by emanations from a diseased body.

Influenza-An epidemic disease, causing general depression, fever, etc. Infusion-Liquid produced by steeping an insoluble substance in water, without boiling.

Ingesta-Food taken into the stomach.

Inhalation-A drawing into the lungs; the inbreathing of medicated or poisonous fumes.

Inoculation-The production of disease by virus or matter from a sore, communicated from one animal to another.

Integument-The covering which ilivests the body (the skin), or a membrane covering any particular part of it.

Intercostal-Between the ribs.

Interfering-The cutting of one foot or leg with the other.

Intermittent-In fevers, a characteristic by which the paroxysms intermit or cease, returning at regular, or nearly regular, intervals. 
Invert-To turn about or upside down.

Invigorators-Strengthening medicines, or agents.

Iris-The circular membrane of the eye floating in the aqueous humor, and perforated to form the pupil.

Issue-A running sore, artifically produced, and kept open to relieve irritation or morbid action in a neighboring part.

Jejunum-That part of the small intestines comprised between the duodenum and ileum.

Jugular-The large vein of the neck.

Labial-Belonging or relating to the lips.

Lachrymal-Pertaining to the tears. The lachrymal duct is the duct leading from the eye to the membrane of the nose.

Lactation-The act of giving suck, or time of suckling.

Lamella-A thin plate or scale of anything; pertaining to the anatomy of the hoof.

Larynx-The swell at the upper part of the wind-pipe, and extending into the throat.

Laleral-At or to one side.

Laxative-A medicine which gently opens the bowels.

Lens-In oculary anatomy, a portion of the eye situated immediately back of the cornea.

Lesion-Disease of a structure; any hurt or injury.

Levator-A general name for a muscle whose office it is to raise some part, as the lip or eyelid.

Ligaments-The bands of the joints binding them strongly together. Ligature-Silk or flax thread, or any material suitable for tying arteries. A bandage used in the operation of bleeding.

Liquefaction - The act or process of reducing a solid to a liquid form. Lithotomy-An operation for extracting stone from the bladder.

Liver-The largest gland of the body; its office is to secrete the bile. Lobe-A round projecting part of an organ.

Local-Confined to a certain part or district.

Lubricate-To moisten, as the lubrication of the joints and moving parts by their appropriate fluids.

Lumbago-Rheumatism of the lumbar region.

Lymph-The fluid contained in, and pour out by, the lymphatics.

Lymphatics-The vessels of animal bodies which contain the lymph. Malanders-An ulcerous condition on the inside of a horse's legs.

Malaria-Infectious and noxious effluvia, from decomposing animal or vegetable matter. 
Mammary Glands-The glands which secrete the milk Mastication-The act of chewing the food.

Maxilla-The upper or lower jaw.

Mediastinum-The partition formed by the meeting of the pleura, dividing the chest into two lateral parts, and separating the lungs. Medullary-Consisting of, resembling, or pertaining to, marrow.

Mesentery-The membrane which attaches the intestines to the spine. Metastasis-The transference or removal of disease from one part to another, or such change as is succeeded by a solution.

Micasma-Impalpable germs, the product of putrefaction (animal or vegetable), producing disease.

Midriff-The diaphragm.

Milk Fever-A fever preceding or attending the secretion of milk. Morbid-A state of disease; the product or result of an unnatural state, as morbid humors; a failing, sinking state.

Mortification-The death of a part from gangrene.

Molor-That which causes, or is the instrument of, movement; as, the motor muscles.

Mucus-The substance secreted by the mucous membranes, and effused upon the surfaces of the membranes.

Muscular Fiber-Fibers composing the body of a muscle, disposed in distinct bundles.

Myology-The branch of anatomy treating of the muscles.

Narcoma-Stupor from the influence of opium or other narcotic.

Nareotics-Drugs which allay pain and produce sleep.

Nasal-Pertaining to the nose.

Nauseants-Medicines that sicken the stomach.

Navel-The umbilicus.

Nerves-The fibrous system which conveys sensations to the brain and through the body.

Neuralgia-A painful disease of one or some of the nerves.

Neurotomy-The cutting or division of a nerve.

Nitrate of Silver-Lunar caustic.

Nutritive-Tending to nourish or build up); strong, healthy food.

Nutrition-The process by which the food talien is assinilated; to repair waste and promote growth.

Obesity_Exceeding fatness.

Obliteration-Alteration in the appearance or function of al part, prerenting its action. 
Occult-Hidden. Applied to diseases which are not understood.

Ocular, oculary-Relating to the eyes.

Edema-Effusion of serous fluid into the cellular tissues, producing swelling.

Esophagus-The gullet.

Omentum-The caul. A fold of the peritoneal membrane, covering the intestines in front, and attached to the stomach.

Opacity-Want of transparency; that quality of bodies by virtue of which they cannot transmit rays of light.

Optic-Relating to the sight, or to the laws of vision.

Oiltit-In ocular anatomy, the bony cavity in which the eye is situated.

Organ-The natural iustrument by which a process or function is carried on.

Organic-Composed of, or pertaining to, an organ or its functions; dependent on, or resulting from, organism.

Os-The technical name for bone.

Osseous-Bony, or resembling bone.

Ossification-Changing to bone. Bony formation.

Ostalgia-Pain in one or some of the bones.

Osteophyte-An abnormal bony enlargement, or excrescence.

Osteo-sarcoma-A fleshy, cartilaginous mass, growing within a bone, enlarging and sometimes fracturing it.

Ovariotomy-The art or operation of removing the ovaries from the female animal; spaying-analogous to the gelding of the male.

Ovaries-The organs connected with the uterus that mature and give off the ova (eggs) which, when impregnated, produce the fotus. Ovule-The impregnated germ or egg.

Oxydize-The change formed by the action of oxygen, or air containing oxygen, on any substance. The changing of the black or venous blood into red or arterial blood, in the lungs.

Pabulum-That which is proper for food.

Palpitation-A rapid, thumping movement of the heart.

Panacea-A supposed universal cure. A medicine applicable to many cases.

Pancreas-The narrow, flat gland extending across the abdomen, sometimes called the sweet-bread.

Parotid-Near the ear. Parotid gland: the largest salivary gland. Paroxysm-In disease, a recurrence coming on after an intermission. Parturition-The act of bringing forth young. 
Patella-The knee-pan.

Pathology - The science which treats of the causes, nature, symptoms and eure of diseases.

Paunch - The first stomach of ruminating animals.

Pectoral-Pertaining to the breast, as the pectoral muscles. A medicine adapted to relieve affections of the chest and lungs.

Pedunculated-Growing with a stem supporting a larger head.

Pelvis-That part of the trunk bounding the abdomen, containing a part of the intestines, and the internal urinary and genital organs. Pepsin-A substance assisting digestion.

Peptic-Promoting digestion; relating to digestion.

Pericardium-The serous membrane enclosing the heart.

Perichondrium-The membrane covering the cartilages.

Pericranium_-The membrane lining the bones of the skull.

Perinoum-The space between the anus and the genital organs.

Periosteum-The fibrous membrane investing a bone.

Peritoneum-The serous membrane lining the eavity of the abdomen. Peritonitis-Inflammation of the peritoneum.

Pharynx-The opening or tube at the back part of the mouth which leads to the stomach.

Phlebitis-Inflammation of a vein.

Phlebotomy_The operation or act of bleeding.

Phthisis-Consumption.

Physiology-The science which treats of the functions of the varions organs of a living body.

Piles-A disease consisting of chronic dilatation or small tumors of the blood-vessels immediately about the anus, and attended with more or less pain.

Placenta-The membrane covering the young in the womb; the after-birth.

Plethora-A full habit of body; full of blood.

Pleura-The serous membrane lining the interior of the chest, and covering the lungs, which it lubricates with its secretions.

Plexus-Any union of vessels, nerves or fibers in the form of net work.

Poison-Any substance, animal, vegetable or mineral, which applied externally or taken internally, camses either death or serioms hurtful changes. Poisons are elassified as irritant, nareotic, sedative, acro-narcotic and acro-sedative. 
Polypus-A tumor with narrow base, in nostrils, uterus, vagina, etc. Post-mortem-Literally, after death. The examination of a dead body.

Predisposed-Prepared or fitted for beforehand; inclined to-as, being predisposed to disease.

Prepuce-The cutaneous fold covering the glans penis.

Process-Prominence; a projecting part; any protuberance, eminence or projecting bone.

Prognosis-The act or art of judging by the symptoms the probable course of a disease.

Prolapsus Uteri-Falling of the womb.

Prolapsus Recti-Falling of the rectum.

Proud Flesh-A fungous growth on an ulcer, or an excrescence of flesh in a wound from excessive granulation.

Pulmonary-Pertaining to, or affecting, the lungs.

Pupit_The ball or apple of the eye, through which the rays of light pass to the erystaline humors.

Purgative-Any medicine having the power of operating strongly on the bowels.

Pus-The matter discharged from a tumor when lanced, or from sores. Healthy pus is yellowish white in color, and is always secreted in the process of healing.

Putrefaction-The process of decomposition; state of corruption; rottenness.

Pylorus-The lower orifice of the stomach on its right side, through which the food passes to the intestines.

Quiescent-At rest. Showing no pain. Making no sound.

Ramify-Branched; running in various directions.

Rash-An eruption of the skin.

Rectum-The last intestine. The anal gut.

Reflux-In medicine, the return of the blood from the head, or from towards the extremities to the heart.

Refrigerants-Medicines or lotions to diminish heat.

Regurgitate-To throw or pour back; to swallow again.

Relax-To abate; to become more mild, or less rigorous.

Remittent-Ceasing for a time, as a fever or a pain.

Resolvent-A substance or medicine that will scatter inflammatory or other tumors, and prevent their suppuration.

Respiration-The act of breathing. 
Respiratory Murmur-The murmer which, when the ear or stethoscope is applied to the chest, is heard in the lungs, and attending the act of breathing.

Retention-A stopping or withholding, as retention of the urine. Retina-The expansion of the optic nerve in the back part of the eye, on which the image is produced, in the act of seeing, or vision. Retract-To withdraw; to pull in.

Rumination-The act or habit of chewing the cud.

Rupture-The act of breaking or bursting, or the state resulting therefrom. The common name for hernia.

Saccharine-Containing, or having the qualities of, sugar.

Sacral-Belonging to the os sacrum.

Saline-Containing salt in solution; tasting saltish.

Saliva-The secretion of the salivary glands, which moistens the food in chewing, and also keeps the mouth and tongue moist.

Salivation-An excessive secretion of saliva. White clover will sometimes produce it in horses, or it may be produced by certain medicines, especially calomel.

Sanguine-Full of blood. Abounding with blood.

Sanitary-Relating to the preservation of health; tending to health. Sarcoma-A fleshy tumor.

Scab_-The incrustation on a sore. A verminous disease of sheep.

Scapula-The shoulder-blade.

Sclerotic-The thick, hard, white outer coat of the eye.

Sciatica-A rheumatic or neuralgic affection of the hip.

Sedatives-Soothing medicines; remedies to depress nervous power, or lower circulation.

Semen-The male generative product secreted in the testicles.

Sensitive-Having feeling, or sensibility.

Septic-Causing or hastening putrefaction.

Serum-The yellowish, watery portion of the blood remaining after coagulation.

Shank-The bone of the leg from the knee to the ankle.

Simus-An orifice or canal containing pus or matter.

Shin-The corering of the body, and the organ of touch. It is com-

posed of the scarf skin (cuticle), the middle (reta mucosum), and the inner or true skin (derma).

Slink-To abort; to produce young before the natural time. 
Slough (pronounced sluff)-To fall away, separate from, as in disease, or in mortified parts.

Socket-The depression in which one bone works on another.

Soporific-A medicine to induce sleep.

Spasm-A sudden involuntary contraction of the muscles; a convulsion.

Spasmodic-Characterized by spasms, as cramping, fits, etc.; recurring at intervals, as colic pains, ete.

Spinal-Relating to the spine, or back-bone.

Spleen-A livid colored gland in the abdomen, the office of which is not yet well known.

Spontaneous-Occurring without any apparent cause from without. Sporadic-Separated, scattered; occurring here and there, as sporadic cases of disease.

Sternum-The breast-bone, situated in the fore part of the thorax. Slimulants-Medicines to temporarily excite the nervous or circulatory systems.

Stomachics-Agents to promote digestion.

Strangulated-Choked; having the circulation stopped in any part.

Strangury-Stopping of a passage.

Stricture-Stoppage or obstruction of a passage of the body, by morbid or spasmodic action.

Styptic-A powerful astringent for restraining or stopping bleeding. Sudorific-That which will cause perspiration or sweating.

Suppuration-The process of forming pus or matter; the result of inflammation in an abscess or wound.

Suture-A stitch or fastening on joining together. The seam or joint which unites the bones of the skull.

Symmetry-As applied to animals, signifies that they are well proportioned, handsomely and stoutly formed.

Sympathy-The connection existing between two or more organs, by which the diseased condition or abnormal action of one is transmitted, secondarily, to the others.

Symptom-Any circumstance observed to occur constantly in the same form of disease, and serving to point out its true nature and seat; any change occurring in the progress of a disease, indicative of its course and probable determination. 
Synovia-A fluid resembling the white of an egg, secreted at the joints and articulations, which it lubricates and keeps in healthful condition. Joint-oil, so called.

Tonia-The scientific name of the tape-worm.

Tarsus-The cartilage towards the edge of each eyelid, giving it shape and firmness. That part of the human foot with which the leg joins, and whose front is called the instep. The hock-joint of the horse.

Tendon-The dense, fibrous structure in which a muscle ends, and by which it is joined to a bone.

Testicle-The male gland containing the seminal fluid.

Therapeutics-That part of medicine which relates to the discovery and application of remedies for diseases.

Thorax-The chest; the part between the neck and abdomen.

Tibia-The large bone of the hind leg of the horse, etc.

Tonics-Agents which gradually and permanently improve the system.

Tonsil-An oblong gland situated on each side of the fauces, terminated by the larnyx and pharynx, at the rear of the mouth, and having excretory ducts opening into the mouth.

Torsion-The act of turning or twisting, as often in drawing a tooth.

Trachea-The windpipe.

Tractile-That which may be drawn out.

Tread-Tramping upon, as the tread of one hoof upon the other. The part of the hoof resting upon the ground.

Trichina Spiralis-A minute entozoon (parasitic mite), which burrows in the muscles, and which, before becoming encysted, sometimes causes the death of the animal. They are principally generated in swine, fowls, rats and other omnivorous feeders.

Tuber-A rounded projection, especially of a bone.

Tubercle-A small tumor, as tubercles in the lungs.

Tumor-A swelling or enlargement, generally permanent.

Tympanum-The drum of the ear.

Ulcer-A running sore.

Ulna-The larger of the two bones of the arm.

Ulterior-Remoter; yet to come; last or final.

Umbilicus-The naval.

Ureter-One of the two canals or ducts which convey the urine from the kidneys to the bladder. 
Urea-The principal characteristic constituent of urine. It is white, transparent and crystalizable.

Urinary-Pertaining to the urine.

Urine-The saline secretion of the kidneys.

Uterus-The womb.

Vagina-The canal, in female animals, from the vulva to the uterus.

Varicose Veins-Veins, most commonly in the legs, which are permanently dilated, knotted and irregular.

Vascular-Pertaining to the vessels of animal and vegetable bodies, as the vascular functions. The arteries, veins, lacteals, and the like, compose the vascular system. Animal flesh is vascular.

Venous-Pertaining to the veins, or contained in the vein.

Ventral-Pertaining to the abdomen, or belly.

Ventricose-A swelled appearance, making the object look bellied.

Vermicular-Worm-like in shape or appearance.

Vermifuge-A medicine or agent to kill or expel worms.

Vertebra-A division or separate bone of the spinal column.

Vertigo-Dizziness. An indication of plethora, or, frequently a symptom of some disease.

Vesicle-A small blister. Any membranous cavity.

Veterinarian-One skilled in (and, usually, legally qualified for) the treatment of the diseases of the horse, cattle and other domestic animals.

Veterinary-Pertaining to the diseases of domestic animals, and treatment of the same; connected with the art of the veterinarian.

Virulent-Dangerous, or malignant; as, a virulent type of disease.

Virus-Contagious or infectious matter.

Viscera-The organs contained in any cavity of the body, particularly of the head, thorax and abdomen.

Viscid-Sticky or tenacious, with a glutinous consistency.

Vision-The act or faculty of seeing; that which is seen.

Vital-Having or containing life. Necessary to life.

Volatile-Giving off vapor, of flying off in vapor.

Vulnerary-Plants, lotions, ointments, drugs or other substances useful in the healing of wounds.

Vulva-The outer opening, in female animals, of the generative parts. Warbles-Small, hard tumors on the back of a horse, from irritation of the saddle. Tumors occasioned by the depositing of the eggs of the gad-fly in the backs of horses and cattle. 
Warts-Spongy excrescences on various parts of the body.

Wen-A distinctly defined tumor under the skin, seldom hurtful. An encysted tumor.

Wind-galls-A distension of the synovial membranes of a horse's fetlock joints.

Withers-The bony crest of the shoulders, in a horse.

Womb-The uterus, or bag in which the young are carried hefore birth.

Wound-A breach of the shin or flesh. Surgery classities wounds as contused, incised, punctured or poisoned.

Wry Neck-An involuntary fixed position of the head towards one of the shoulders.

Xiphoid-Sword-like. A small cartilage at the bottom of the breastbone.

Zygoma-The cheek-bone.

Zygomatic-Pertaining to the cheek-bone, or to the bony arch under which the temporal muscle passes. 


\section{N D EX.}

Abdallah.................. 509

Abortion..................... 392

"6 from leucolrhœea........ 390

" " metritis........... 392

"6 sporadic.............. 392

"6 accidental............. 392

66 enzootic............... 392

"6 contagious............. 392

"6 age of fotus in.......... 394

66. from equine syphilis..... 401

Abscesses.................. 197

"6 treatment............. 198

"6 in blood poisoning....... 449

Absorbents of intestines.......... 184

Accidents producing wounds...... 323

Acids, poisoning by ............ 491

"6 burns from............. 494

Action, scrutinize, in buying...... 117

" method of horse's........ 67

" in the walk............ 68

6 $\quad$ bad, in walk................ 72

$"$ in the trot............. 74

6 "6 " canter............ 75

6 6 6 " 6allop........... 76

" low, as unsoundness........ 116

"6 paddling............... 117

" short-coupled............ 121

" defective, of fore limbs..... 124

" 6 from broken hock 243

" " in elicking...... 248

See I Iameness.

Actual cautery, castrating by...... 385

See Firing.

Acute inflammation............ 193

"6 abscesses.............. 197

" founder................ 255

" bronchitis................4 418

"6 rheumatism................440 440

Adhesion of wounds............ 327

After-birth...............404, 409

" in cow.............4 405

، retention of........... 410

38
Age, to tell by the teeth.......... 333

"6 of foetus, to tell............. 394

Air in stables............ See Ventilation.

Alimentary canal............... 184

Alkalies, poisoning by.......... 491

Allerton...................... 539

Amaurosis.................. 460

America, horse in............ 33

6. handling of colts in...... 98

American Star $14 \ldots . . . \ldots \ldots \ldots . . .515$

"6 thoroughbred......... 562

" turf, records.....564, 565, 56s

Ammonia in stables............ 441

Amputating the penis........... 350

66 "6 tail (docking)..... 48?

Anæsthesia................. 477

" Iocal, by cocoaine...... 484

Anæsthetics................. 477

See Chloroform.

Aneurisms.................. 434

Animal language.............. 99

Ankles, swelled............... 321

Ankylosis in ring-bones......... 226

" of shoulder-joint...... 241

" " " knee..............2 241

"6 " joints...........300, 301

Antidotes.. See Poisons, Cantharides, etc.

Antilithies................... 373

Anus ...................... 186

Aorta...................162, 165

Arab maxim in breeding......... 62

"6 versus Indian horse......... 97

Arion...................... 545

$\Delta$ rsenic, dreadful use in big head... 212

$\Delta$ rteries.................... 161

" to stop bleeding from...324, 435

Articuiation of bones............ 151

"6 new, in dislocations.... 303

Artificial foods............... 86

Ascarides.................... 360

Ass, wild...................... 137

"6 she, in America............ 139 
PAGE.

Asthma..................... 422

6. as unsoundness........... 115

Atrophy of muscles ... . . . . . . . 309

6 heart............... 432

Attitude, horse's, in standing...... 67

Auricles of the heart............ 165

Auscultation, defined.........419, 421

Axtell..................... 53 ..

Azoturea......................... 374

Back, teaching to .............. 100

Back-bone................... 148

Backs, good and bad............ 121

Backing, vice of.............. 116

Back-raking.................. 353

Bag, steaming.............. 412

" chloroform.............. 478

See Scrotum and Udder.

Balking, vice of ............... 116

Balling-irons...............367, 436

Bandages................... 325

Bandage for neck.............. 346

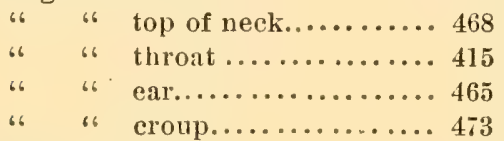

Barbs, or pikes............... 344

Barn, a model farm............. 132

" goorl, described............ 133

Bars of hoof...........166, 270, 279

66 66 mouth................. 342

66 66 6 burning........... 344

Bashaw................ 509, 515

Bean in penis................. 372,379

"6 how to know.............. 372

Bearing of foot. .............. 279

"6 surface of foot.......... 281

" " 6 in special cases... 283

66 of shoe.......... 295

Bedding, straw for............ 85

6 importance of good...... 88

"6 eating, as vice......... 116

"6 changing............ 130

Beef, spaying for............... 399

Beer, etc., caution.. ........... 357

Bees, sting of............... 497

Belladonna poisoning........... 493

13.1lfounder................. 54, 515

Big head.................... 209

6 66 Dr. Stewart's account of... 211
Big head, Dr. Stewart's treatment. 215 Big jaw............... See Big Head. 6 $\operatorname{leg} \ldots \ldots \ldots \ldots \ldots \ldots \ldots \ldots \ldots . . .449$

Bile, in horse................. 187

See Liver.

Birth................ See Parturition.

" size of different animals at......395

Bistoury, sharp-pointed.........486

"6 probe-pointed.......... 487

Bite of mad $\operatorname{dog}$, etc........... 448

66 "6 snake.................. 494

See.Sting.

Biting, vice of................ 117

Black Hawk................... 515

" hellebore............... 493

66 tumors.................. 449

Blacksmith versus farrier......... 280

Bladder...................... 188

" inflammation of .......... 375

6 rupture of ............. 376

"6 spasm of ................. 376

66 stone in............... 376

"6 gravel in.............. 376

" calculus in.............. 376

" catheter for relieving....... 372

Bleeding ................202, 435

"6 to stop............248, 324

66 after castration.......... 388

66 from nose............. 413

Blemishes, what are........... 117

"6 in warrantee......... 113

Blindness in warrantee........... 114

6 moon............. 461

$6 \quad$ test for,............ 463

See Eye.

Blind staggers.................. 349

Blisters... .................. 201

Blood, the.................. 159

66 purification in lungs ....... 163

$6 \quad$ its oftices.............. 163

6. making in spleen........... 188

"6 diseases................ 439

66 poisoning............... 449

$66 \quad 6$ in gangrene...... 199

6 spavin................ 386

"6 medicines, caution........4 489

Bloodstick .................. 202

Blood-vessels.... See Arteries and Veins. diseases of,......... 428 aneurisms,......... 434 
PAGE.

Blood-vessels, wounds of, ........ 435

Bloody dung...............357, 361 6 urine.....................

". vaginal discharge.......391, 395

" discharges of purpura hemorrhagica.............. 4442

Blue ball................... 514

Bog spavin.................. 305

Boils ..................... 437

Boil, shoe................... 316

Bolting, vice of. ............... 116

66. the food.............. 348

Bone diseases as unsoundnesses.... 11 5

6 dead.................... 205

6 scraper................. 205

66 cancer.................. 208

"6 tumors.................. 209

"6 chisel .................... 209

6 spavin ................. 220

6" how a broken, knits......... 229

Bones of the horse............. 146

is structure of ............. 150

66 classes of .............. 150

"6 of birds................ 151

66 covering................. 151

6 articulation.............. 151

46 brittleness in big head...... 210

66 injuries and diseases.......2 218

6 fractures of ............. 228

"6 of shank and fetlock......... 264

66 6 foot.................. 265

Boot, shoe-boil ............... 317

Boots, their use in breaking...... 550

Bots ...................... 346

66 popular errors respecting..... 347

Bowels, rupture (hernia)......... 362

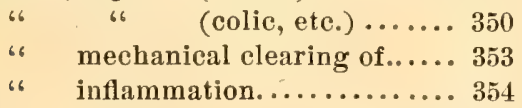

66 to discriminate 355

See Intestines.

Brain and skull ................. 168

66 its wonderful structure ...... 170

"6 human and equine.......... 170

"6 anatomy................ 170

6 fever.................. 452

"6 tumors in .............. 453

Breaking.

See Gentling, Training and Taming.

Breath, poisonous element in ..... 177
Breath offensive, causes, ........ PAGE.

Breathing............ See Respiration.

66 in bronchitis...........4 418

66 6 6 peumonia.......420,421.

66 "6 broken wind......... 424

66 "6 asthma........... 424

"6 6 heaves............. 424

64 " " pleurisy............ 425

.6 6 strangles........... 446

$66 \quad$ "6 anæsthesia..$\ldots \ldots \ldots \ldots 478$

Breeding the hunter............ 35

"6 6 trotter.....53, 56, 508, 512

for excellence......... 57

to maintain excellence... 61

exercise important....... 57

points in ...........59,61

definite aim in........ 61

Arab maxim in........ 62

Murray's six rules........ 62

Stonehenge's laws....... 63

in-and-in ............ 65

hits in .............. 66

of mules...........139, 142

of jacks.............. 142

peculiarity in first....... 142

and spavins, caution..222, 223

and ringbones, caution... 225

"6 navicular disease, do. 259

aborting mare, caution... 394

and equine syphilis, do... 402

roarers, caution........ 416

and weak eyes, caution... 461

British horses.............33, 39, 42

Broken wind..............177, 422

6 $\quad \operatorname{legs...\ldots \ldots \ldots \ldots ...230,240,242}$

ribs................. 238

hip................. 239

shonlder............... 240

knee................. 241

. 6 cap.............. 243

thigh................ 242

hock ................ 243

muscles................ 310

bones. See Fractures, Slings, ete.

Bronchial tubes................ 17s

inflammation.........4 418

Brouchitis...................4 41 s

Broucho-pneumonia........... 420

Brruises of sole................ 247

Brush and curry-comb......... 92 
Chyme..................... 183

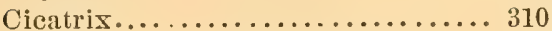

Circulation, process described..... 158 general............. 160 pulmonary........161, 163

See Heart, Lungs, ete.

Circulatory system, described..... 159 66 6 diseases of.... 428

66 process described...... 161

Clamps, castration with.......... 385

Claws on horse-shoe............ 290

Clays, the.................. 513

Cleaning the horse............. 88

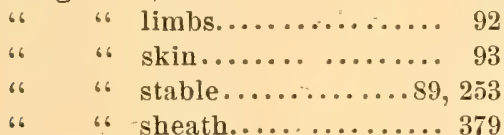

Cleansing a wound............ 323

Cleft of frog.................. 273

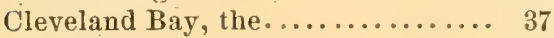

Clicking .................... 248

Clips on shoes................. 292

Clitoris ...................... 192

" excision for nymphomania.. 398

Clydesdales.................. 41

Coach horses, Yorkshire........ 36

" " French...........38, 45

" " " German........... 45

"6 "6 Hanoverian........ 45

6 6 in America........ 46

Cocoaine, for local anæesthesia..... 484

Coecum, or blind gut............ 185

Cold, common................ 411

6 6 as unsoundness...... 113

، abscesses............... 198

Colic, cramp................ $3 \overline{5} 1$

6 6 to know from enteritis. 355

"6 spasmodic............... 351

66 flatulent................ 353

"6 wind .................. 353

6. 66 tapping for............ 354

"6 in stallions, caution......... 362

"6 from calculus............. 373

"6 spasm of bladder in........ 376

66 simulated by pleurisy....... 425

"6 opium for, caution......... 493

Collar-galls................. 467

Colon....................... 185

Color, how determined.......... 155 and navicular disease...... 258
Colts, food for................ 82

" gentling................. 97

" handling in America........ 98

" teething................330, 331

"6 to tell age............... 334

"6 casting.................. 384

" educating trotter........... 547

See Castration.

Compound fractures............229

$66 \quad$ "6 treatment....2 231

Concretions in intestines......... 359

" in bladder.... See Calculus.

Condimental foods.............. 86

Conestoga horse.............. 43

Conformation, object lessons on.... 119

Congestion of lungs.

See Pleurisy and Pneumonia.

Conjunctiva.................. 175

" inflammation........ 460

Conjunctivitis................ 460

Constipation................. 358

Contagion of farcy........... 443

"6 of glanders..........443

66 of horse pox........ 447

Contagious abortion........... 392

eczema.............4 400

influenza............438

Contraction of hoof...........116, 250

" of tendons........... 319

" of sheath............ 380

Contused wounds.............. 323

Copperas for deodorizing......... 89

Cord, indurated............... 389

"6 seirrhus................ 389

Corn, as food................. 85

، and fodder at South........ 213

"6 founder................. 254

" diet is tooth-wearing........ 337

Cornea, bulging of............ 459

Corns........................ 246

.66 as unsoundness............. 114

Coronary ring of hoof.......... 166

"6 cushion..............268

"6 frog band............ 272

Corrosive sublimate poisoning..... 491

Cough, as unsoundness.......... 115

of common cough........ 412

of laryngitis..........414, $41 \tilde{5}$

of bronchitis............. 419

of broken wind........... 423 
PAGE.

Cough, of pleurisy.............. 425

Counter-irritants............... 201

Cow and mare compared .... 396, 402, 408

66 spaying, its advantages....... 399

Cracked hoof................25 1

66 heel................4 466

Cradle, Walker's.............. 237

66 neck ................. 316

Cramp of muscles.............. 311

Crepitation, defined............ 236

Crib-biting, as unsoundness....... 115

$6 \quad$ effects on teeth....... 337

Crazy weed.................. 492

Croton oil, caution............. 492

Croup, bandage for.............. 473

Cruelty versus kindness........... 87

66 in the stable............ 99

Cruiser, tamed by Rarey........101, 110

Crust of hoof.................. 269

Cryptorchid, or ridgling........... 3S6

66 castrating.......... 386

Curb....................... 318

Currycomb and brush........... 92

Cushions of the foot............ 267

Cuticle, the.................. 155

Cutis, or true skin............. 155

Cuts.....................See Wounds.

Cutting, as unsoundness......... 116

"6 from bad shoeing........ 288

66 horses, care in shoeing.... 293

"6 teeth........... See Teething.

Cystitis........................ 375

Dead bone.................. 205

Deadly nightshade............. 493

Decay of the teeth.............. 332

Delirium of blind staggers. . . . . . . 349

Delivery.....See Parturition, Mare, etc.

Dental star.................... 338

Dentition .................... 330

Dentistry, veterinary .........332, 341

Deodorizers, cheap............ 89

Deposits, interstitial............ 199

Dermis, or true skin ............ 155

Dexter..................... 519

Diabetes....................... 371

Diaphragm, spasm of ......... 436

Diaphoretics................ 202

Diarrhoa.................. 350

from worms.......... 360
PAgE.

Diarrhœa from blood poisoning.... 449

Difficult parturition..........408, 409

\begin{tabular}{|c|c|c|}
\hline & 66 & of mare....... 408 \\
\hline & 66 & of cow....... 408 \\
\hline & 6 & due to mare.... 40 \\
\hline & 66 & due to foal. \\
\hline
\end{tabular}

Diffuse inflammation........... 193

Digestion, horse's.............. 84

"6 organs of ............ 180

"6 how accomplished....... 182

"6 bile in............. 187

6 pancreatric fluid in..... 187

Dimple.................... 310

Direct...................... 559

Director, grooved............. 197

Direct union of wounds......... 326

Disease promoted by artificial life.. 82

" any, as unsoundness....... 115

"6 navicular.............. 257

Diseases, bone, as unsoundness.... 115

Dishing, in action........... 72

Dislocations.................. 303

6 of stifle-joint....... 303

Diuretics.................... 202

66 caution........369,459,490

"6 to deplete system....... $3 \pi 4$

Distemper................... 435

See Strangles.

Docility through training........ 97

Docking..................... 14s, 480

66 how performed.......... 481

knife................. 481

Draft horses, English.......... 38

6) "6 French............ 44

" 6 outline and points.... 49

Drafts, protection from........94, 411

“6 in stables.............. 129

Draining stables................ 131

Drenching-horns.............. 366

Dressing wounds............. 327

Drinking water, kinds of ........ 90

6 6 clean is best...... 91

6 6 horse's........ 90

6 $\quad 6$ in paralysis of lips. 455

Driving, training for........... 549

Dropsy, after inflammation....... 197

6 of testicle............... 351

6 from heart disease.....432, 433

66 from influenza.......... 439

Drugs, caution.............. 4s? 
PAGE.

Dysentery

Dyspepsia................... 348

Dysurea................... 372

Ear, the................... 51

6 diseases of ............... 465

“ bandage ................ 465

Ecraseur. .................... 386

6 castrating with......... 385

Ectropium................... 459

Eczema, contagious............ 400

66 of ear.............. 465

Efiusion in inflammation........ 197

Elbow, sprained............... 313

6 capped ............... 316

Emetics, caution.............. 492

Emphysema of lungs..... . . . . . . 422

England, Rarey in............. 111

6 American horses in. .... 562

English draft horses............. 38

"6 - cart horses............. 42

6 neglect of gentling........ 98

6s stud book............. 562

Enlargements, as unsoundness..... 116

Enteritis.................... 354

Entropium.................. 459

Epidemies, or scarf skin........ 154

Epistaxis, or nose-bleed......... 413

Epizootic, chancre............ 400

6 infiuenza............. 438

Equine syphilis.............. 400

Erysipelas....................468

Eithan Allen................. 515

Eıher as anzesthetic............. 477

Examination of the eye........51, 464

.6 of stock........... 59

6 of action in trotting... 74

6. before buying........ 117

6 of the hock......... 223

66 : for curb .......... 318

6 before gelding........ 383

66 of mouth......... 413

66 or test of wind ...... 416

Excretion, defined............. 179

$\left.\begin{array}{c}\text { through skin, bowels } \\ \text { and kidneys........... }\end{array}\right\} 93$

66 blood as an aid to... 162, 163

“ kidneys' function of..... 188
Exercise, for breeding stock..... PAGR.

6 6 essential to health........ 57

"6 amount of........... 88

Exostosis, defined..........203, 220

See Splints, Ringbone, etc.

Extracting teeth.............. 333

wolf teeth........... 344

Eye, what indicating........... 51

6 its examination.........51, 464

66 unsound ................ 114

6 anatomy of ............. 173

66 parts and functions.......... 174

6. yellow, in jaundice......... 367

"6 in lockjaw.............. 457

6. diseases of ..............458

، glass....................460

6 spots on ..............462, 463

6 cataracton.............. 462

Eye opener.................. 465

66 in giving chloroform........ 479

Eyelashes, turning in........... 458

$66 \quad$ out......... 459

Eyelids torn................... 458

warts on............. 458

Fæces, nature's disposal of........ 186

Falling of the womb........... 396

False quarter................ 252

66 .6 as unsoundness...... 114

joints................. 230

"6 treatment of......... 231

open joint............. 300

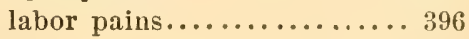

Farcy...................... 443

" identity with glanders... .... 443

Farrier versus blacksmith......... 280

Farmel, his study of horse.. ...... 144

6. as veterinary operator.... 477

Fat versus muscle.............. 152

66 horses................... 118

66 a azoturea in .......... 374

Fatty liver.................. 366

degeneration of heart...... 432

Fecundity of mange insect....... 471

Feed of mule versus horse.......140, 141

"6 in fractured jaw ........... 236

Feet, importance of sound..165, 167, 261

66 diseases, etc............ 244

66 fever in..............254, 277

66 hind and fore, compared..... 279 
PAGE.

Feet, over-reduced............. 285

66 over-grown ...........287, 298

6) straight................ 287

(.) care of feet in stable........ 298

66 $\quad 66$ 66 66 at grass.......... 299

6 stopping, folly of ......... 298

See Foot, Shoeing, etc.

Fetlock, bones of............... 264

66 deformed............. $30 \mathrm{~s}$

"6 sprained............. 314

Fever in the feet.............. 254

$66 \quad 66 \quad 66$ 6r hoof after....... 277

6. lung.................. 420

“ pulse as sign of........... 429

"6 temperature as sign of.......431

"6 brain................ 452

6. mud................... 468

Firing ..................... 488

. irons................... 488

66 with a wire............. 250

6 in lines................. 488

66 in points............... 488

Filaria oculi............... 459

Fistula of withers............. 219

6 66 66 to prevent.......4 467

66 foot................ 249

Fitting of shoe, the true test......2 263

66 preliminaries to........... 282

"6 outline, not important...... 283

66 what is good............ 294

66 cold and hot............. 296

Fleam .................... 202

Fleas ..................... 472

Flemish horse, the............. 43

Flooding................... 395

Floor, height of stable.......... 130

Flora Temple................ 517

Fly-blown, to prevent.......473,474

Fly muscle, the............. 156

Foal, care at birth............ 407

6 difticulties at birth......... 409

"6 born dead............... 410

Foaling, emptying bladder before. . 376

" false labor pains........ 396

6 signs of approaching..... 403

66 mare at.............. 406

See Parturition.

Foals, rheumatic.............. 303

knuckling in............ 308

6 choking.............. 3(5)
Page.

Foals, dyspepsia.............348, 349

6. hernia..............362, 363

Fodder, use at South............ 213

Fotus.................... See Abortion:

" to determine age of......... 394

66 expulsion at birth.......... 404

6 dead.................. 410

See Parturition.

Food for young animals.......... 82

"6 bolting the.............. 348

Foods, perfect................ 82

"6 how to know sound........ 84

6 artificial.............. 86

66 condimental............ 86

Foot, fistula of ................ 249

66 horny tumor of............ 257

6 structure................ 261

"6 bones of................. 265

66 tendons, etc., of .......... 266

"6 cartilages of............. 267

"6 cushions of ............. 267

6 the sensitive.............. 269

6 sole of................. 271

"6 relation of its parts......... 274

" part that first touches ground. 278

" not elastic.............. 27s

6 and leg, relative position...275, 286

6. form and bearing........... 279

"6 preparing it for shoeing..2s0, 283

6 bearing surface............ 281

6. advantages of strong......... 286

" securing a proportionate.... 287

66 sides should be even......... 28s

See Feet, Hoof, Nerving, Shoeing, etc. Forage, green, as food........... 85

Force in training.............. 96

Forceps for tooth-pulling........ 333

6 6 lithotomy.......... 377

6 $\quad$ " erushing, in lithotomy. 375

i6 torsion..............4400

6 veterinarian's........... 434

Fore-quarters................ 52

Fore-leg, bones of............. 146

fractures of........... 240

securing.............. 480

Forging, or clicking............. $24 \mathrm{~s}$

Form and proportion.......... 62

Founder of feet.............. 254

chest................. 257

Fractures, causes............. 22s 
PAGE.

Fractures, kinds ............... 229

compound, treatment... 231

See Broken.

Frame, in lieu of slings.......... 233

Frame-work, horse's.......... 146, 149

French draft horses............44, 45

"6 coach 6 6 ...........35, 45

Frog of the foot............... 166

6 disease from its disuse.... 227, 250

" proper; the............... 268

6 structure of.............. 272

6 nature and uses............ 273

"6 bearing of............... 279

“ should not be pared........ 285

See Canker, Grease, etc.

Funnel and hose, use of, in clear- $\} 353$

ing the bowels...............

Gad-fly.................... 447,473

6 sting of................ 497

Gaits in combination, records ..... 550

Gallop, hand................ 76

6 true, analysed.......... 76

6 pictorial misrepresentation 78

"6 change of leg in......... 79

6 length of stride......... 79

Galls....................... 467

Ganglia...................... 172

Gangrene..................... 199

Gastric fluid................... 183

Gelding.............. See Castration.

General inflammation........... 193

$6 \quad 66 \quad$ treatment of... 201

Generation, Stonehenge's laws of... 63

66 male organs of ....... 190

"6 mare's "6 " ....... 190

See Breeding, Mare and Stallion.

Gentling colts.............97,99

" neglect of, in England.... 98

6 trotting colts.......... 547

George Wilkes................ 511

German coach horses........... 45

Gestation, seven periods of ....... 394

Gland, defined.............. 179

Glanders..................... 443

"6 how to know.........206, 444

Glands of the skin........94, 152, 156

$\begin{array}{llll}6 & \text { " mouth and throat........ } & 179 \\ 6 & \text { mesenteric............... } & 186 \\ 6 & \text { mammary ..... } \ldots \ldots \ldots \ldots & 192\end{array}$
PAGE.

Glands, swollen................ 344

as unsoundness.... 116

See Farcy, Glanders, Strangles, etc.

Glass eye.................. 460

Gleet, nasal................. 206

Gnats, sting of .............. 497

66 buffalo................ 498

Going wide, as unsoundness...... 116

Gold Dust horses............... 53

Goldsmith Maid... . . . . . . . . . . . 520

Goodenough shoes............. 296

Goveruor Sprague.............. 515

Grabbing........... See Over-reaching.

Granulation of wounds.......... 327

Grapes of grease.............. 475

Grass, horse's feet when at....... 299

" founder............... 254

" staggers................ 349

Gravel in bladder............ 376

Grease.................... 474

"6 as unsoundness........... 115

Greedy feeders, to regulate....... 424

Green forage food............. Sa

$16 \quad 66 \quad 66$ staggers from.... 349

Grinders...............330, 334, 336

Gristle, structure of ............ . .

Groggy lameness............... 257

Grooming...............ss, 92, 93

"6 misuse of water is....... $\$ 9,92$

6. nervous animals......... 93

when to defer........... 94

Grooved director............... 197

Grunters.................. 416

Gullet...................17s, 180

Gunshot wounds.............. 323

Gunther's operation............ 417

Gypsum as deodorizer........... 89

Hackney, the................ 35

Hair, structure and uses of........ 158

6 shedding................ $15 \mathrm{~s}$

"6 as index of health.......... $15 \mathrm{~S}$

Hair-balls.................... 359

IIal Pointer................... 561

Halter, putting on colts.......... 99

66 Rarey's favorite.......... 111

Hambletonian.............. 54, 509

Ham-string muscles............ 243

I I n gallop................ 76

Handling colts.......... See Gentling. 
PAGE.

Hanoverian coach horses........ 45

H. B. Winship and mate......... 552

Harness, washing, for mange..... 471

breaking to........... 5 48

Haunch, bones of ............ 147

Hay, to know good............. 85

Head, the.................. 51

66 object lessons on.......... 119

66 bones of............147, 167

66 big (disease)............ 209

$6 \quad$ staggers................ 452

Healing wounds, Nature's modes... 326

Health, the hair as index to...... 158

6 blood and.............. 159

66 pulse in................ 431

6 temperature in...........441

Heart. .................162, $16 t$

6. and pulse..............165, 429

6 affected in diabetes, etc....37 1,470

"6 diseases................. 428

" foreign bodies in........... 431

6 hypertrophy.............. 432

"6 atrophy................. 432

" fatty degeneration.......... 432

" valvular disease............ 432

6 tumors in................. 433

66 rupture of .............. 433

Heartburn................. 448,476

Heat, sign of inflammation......... 194

"6 animal, how produced....... 195

See 'Temperature.

Heat races, records............. 564

Heaves.................... 422

Heel, contracted............. 250

6 lowering............284, 287

" opening.................. 2s4

6 not weakest part.......... 294

"6 cracked................. 466

See Hoof.

Hellebore, white.............. 493

6 black.............. 493

6 antidotes ............ 493

Hemlock poisoning.............. 494

Hemoglobinuria .............. 374

Hemorrhage after castration....... 388 of womb.......... 395 nasal .............4 413

See Bleeding.

Temorrhoids.................. 361

IIepatitis................ 365, 366
PAGE.

Heredity...............61, 63, 65

66 maternal...........139, 512

66 of spavins............ 223

6. " " ringbone............. 225

6. "6 navicular disease... 257, 259

"6 " roaring ............ 416

6 " " whistling............ 416

66 " "broken wind.......... 423

66 "6 heaves.............. 423

66 "6 weak eyes............ 461

66 "grease.............. 474

Hernia.................... 362

6 test for................ 363

"6 to know from hydrocele...... 3\$1

" 66 "6 "6 orchitis....... 381

"6 after castration........... 388

Hide-bound.............. 157, 475

$66 \quad$ what it is.......... 476

Hind quarters............... 52

$66 \quad$ "6 object lessons....... 122

66 leg, bones of ............. 147

6. 66 fractures.............. 244

66 6 sprains................... 314

Hip, bones of................ 147

"6 fracture................ 239

"6 sprained.................. 314

Hipped, as unsoundness.......... 115

Hobbles.................... 479

Hock, structure of ............. 220

“ lameness................ 222

"6 examination............. 223

is rough.................. 223

. broken................ 243

" capped...................... 317

"6 curbed................. 318

Hoof, contraction of .........116, 250 bars of ..............166, 270 bones................146, 166 structure............ 166; 275 cracked................. 251 false quarter............ 252 wall, or crust............ 269 mutual relation of parts..... 273 growth.................275 decay................. 277 changes from bad shoeing.... 281 preparing for shoeing....2s1, 283 knives................. 2s4

See Feet, Foot, Shoeing, etc.

Hooks, obstetric........... 110 
PAGE.

Horn, of hoof................ 275

" imperfect.............. 252

6 growth................ 275

"decay................. 277

6 drenching............... 266

Hornets, sting of ............. 497

Horny tumors of the foot......... 257

Horse, his attitude in standing.... 67

66 mode of progression ........ 67

66 should be kept comfortable. 94

66 care of exhausted .......... 94

“. Arab versus Indian ......... 97

"6 his language............. 99

"6 the fat................. 118

"6 trading, honesty in......... 118

"6 versus mule..........138, 139, 141

"6 as a subject for study........ 144

66 his skeleton.............. 146

66 care of feet in stable........ 298

66. 66 66 at grass ........ 299

"6 free from liver complaints... 364

$66 \quad$ pox.................. 447

Horses for labor, kinds.......... 33

66 British and American...... 33

6 hunting................. 34

66 carriage................ 35

66 French Coach...........38,45

66 Cleveland Bay........... 39

66. Shire................. 39

"6 Suffolk Punch........... 41

"6 Clydesdale............... 41

"6 English Cart-horse........ 42

66. Flemish ............... 43

66 Conestoga.............. 43

66 French Draft............. 44

66 Norman..............44, 45

66 Norman-Percherou........ 45

"6 Hanoverian Coach......... 4 5ั

“6 German Coach............ 45

66 thoroughbred............ 46

6 trotting............... 52

"6 Mustang............... 53

66 pacing............53, 95, 554

"6 Morgan................ 53

66 washy................ 356

66 white-legged............ 474

6. poisoned, in revenge....... 490

Hunter, the................. 34

. shoes for ................ 292

Hybrids, infertility of ........137, 139
Hydrocele........................ 381

Hydrophobia.................. 448

Hydrothorax.................. 425

Hygiene, important to understand, 81, 94

Hypertrophy of the heart......... 432

nlium.................... 185

In-and-in-breeding ........... 65

Incised wounds ... . . . . . . . . . 322

Incisors . .............. 330, 333, 334

Indian horse versus the Arab....... 97

Indigestion .................. 348

unsoundness from...... 116

from worms ......... 360

Indurated cord. ... . . . . . . . . . . 388

Inflaned periosteum..........151, 203

" joint................ 300

Inflammation, why correct knowl-
edge of it so important $\quad 193$

66 kinds defined......... 193

"6 causes .............. 194

6s symptoms............ 194

66 results...........196, 309

66 healthful termination ... 196

66 treatment of local...... 200

66 66 6 general.... 201

66 of a bone, etc......... 203

66. sweeny from.......... 309

66 of cellular tissues....... 320

66 " $\quad$ "stomach versus bots... 347

66 66 bowels............ 354

66 6 liver............ 365

66 66. kidneys.......... 369

66 "6ladder ........... 375

" do. to discriminate...370, 375

66 of testicle........... 381

66 66 womb........... 391

"6 "6 udder............ 402

66 66 bronchial tubes......4 418

66 66 lungs ........... 420

"6 6 6 pleura ........... 425

66 $\quad$ 6 pericardium........ 433

66 66 jugular vein........4 435

$66 \quad 66$ conjunctiva........ 460

Influenza.................... 438

Inhaler, chloroform ........... 478

Insects, poisonous............489, 496

Instruments, obstetric .... . . . . . . 409

66 veterinary, for farmers, 477

Internal poisons.... . . . . . . . . . 490) 
PAGE.

Interstitial deposits ............. 199

Intestines, anatomy of .......... 183

small ................. 184

large................ 184

diseases of ............ 351

concretions ............ $3 \cdot 9$

Inversion of uterus............ 396

Involuntary museles........... 151

" motion, nerves of ...... 172

Iodine, tincture of, uses.......... 201

Iris of the eye................ 175

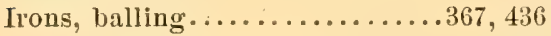

" firing................ 4ss

Itehing, as symptoms..... 467, 470, 472

Ivy, meadow, poisonous......... 494

Jacks, Washington's............ 138

" Sonth their home......... 138

"6 breeding of ............ 142

Jaundice ................. 187, 367

Jaw, lumpy................. 207

" fracture of upper.......... 235

66 66 lower.......... 236

Jay-Eye-See................ 525

Jejunum................... 185

Jennets................... 138

Johnston................... 557

Jog trot, the................. 73

" bad for trotters............ 550

Joint, navicular.............. 266

" $\quad$ oil........................301

Joints, false................. 230

66 "6 treatment............231

" inflamed................ 300

"6 open................. 300

"6 " how to know.......... 301

"6 false open............... 301

"6 rhemmatic.............. 302

Judging animals, accuracy in...... 59 See Standard and Examination.

Jugular pulse................ 431 vein, to bleed from....... 202

" inflammation....... 435

Keratoma...................257

Kernel of teeth............... 334

Kicking, as vice............... 116

Kidneys, structure............ 188

function............ $18 s$

diseases of ........... 369
PAGE.

Kidneys, inflammation of........ 369

" " 6 to distinguish... 370

Kindness to stock pays.......... 87

$6 \quad$ in training $\ldots \ldots \ldots \ldots .96,97$

"versus cruelty in stable.... 99

Kite tracks, records on........ 565, 568

Klippart, J. H., on the Pereheron.. 44

Knee, broken............... 241

"6 cap, broken.............. 242

Knee-sprung..............113, 308

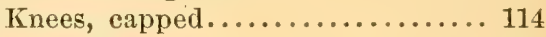

Knife, sage................ 245

"6 toeing................. 283

" hoof.................. 284

" castrating.............. 384

"6 docking .............. 481

" nicking................. 483

" for nerving............. 484

Knives.... See Bistoury and Instruments.

Knitting of broken bones......... 229

Knuckling ................113, 308

Labor, horses for, kinds.......... 33

" mule versus horse, for...... 140

" premature......... See Abortion.

" pains, falsé............. 396

See Parturition.

Lacerated wounds.............. 322

Lady Suffolk............... 516

Lameness, from bone inflammation. . 203

of big head.......... 210

from spavins......... 222

hock............... 222

from splints......... 225

" ringbones......... 226

" sidebones........ 227

"6 nail wounds...... 245

of corns............ 246

6" bruised sole........ 247

" quittor ............ 249

" contracted hoof...... 250

"false quarter....... 252

" founder........... 255

"6 foot tumors........ 257

$\operatorname{groggy} \ldots \ldots \ldots \ldots \ldots .257$

from navicular disease...25ร

" bad shoeing....... 261

" open joints........ 301

"6 rheumatism ....... 302

of stifle............. 304 
Lameness of bog spavin........... 305

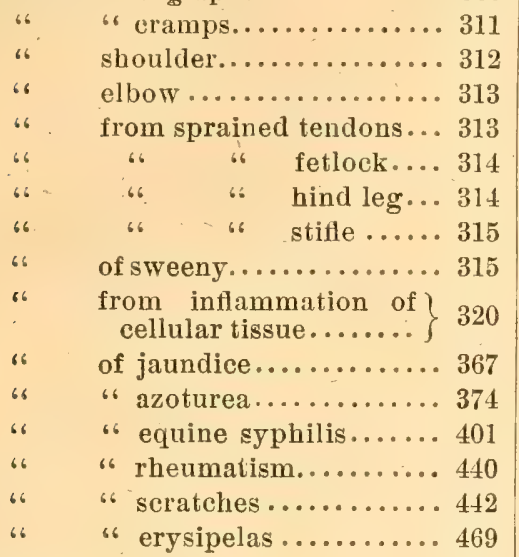

Laminitis, or founder.......... 254

Lampas.................... 342

Language of animals........... 99

Laryngeal paralysis...........416

Laryngitis ................. 414

Larynx..................... 178

"6 inflammation of.......... 414

Laurel poisoning............. 492

Lead, teaching colts to......... 100

Leap, not a gallop.............. 76

Leg, tendons of ............... 313

"4 hind, sprains of............ 314

" swelled................319, 449

" fore, securing............ 480

Legs, hind, object lessons on... 123, 124

"6 " 6 fracture of........... 244

"6 fore, 66 "6.....124, ]26, 240

"6 flexor tendons of........... 167

" "broken ................... 230

" " " nothopeless......... 231

" of horse "are the horse"..... 261

"6 and feet, relationship of...2 78,286

Lencorrhœe.................. 390

Lice....................... 472

Licking off gad-fly eggs......... 347

" walls, ete..........248,476

"6 habit of .............. 359

Life, its harmonious functions..... 194

Ligature, castrating with......... 385

Light for stables.............. 132

" in model barn........... 136

Limbs, fore, good and bad..123, 124, 126

6 "6 fractures of......... 240
PAGE.

Limbs, hind, good and bad........ 124

" faulty, a bad investment..... 126

"6 broken............... 230

"6 6 not hopeless......... 231

"6 and feet, relationship of..278, 286

"6 tendons of ............. 313

"6 hind, sprains of .......... 314

Ligaments of the foot............ 266

Liniments, stimulating......... 200

turpentine for......... 491

Linings of stomach............. 182

"6 intestines............ 183

Lips, paralysis of............. 454

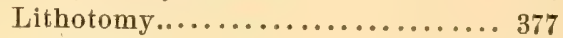

Little Brown Jug............... 555

Liver, structure, etc.......... 186

" diseases of.............. 364

" functions............... 364

" changes of structure........ 365

Local inflammation............. 193

" treatment...............200

Lockjaw................... 456

$\begin{array}{cccc}\text { " } & \text { from nail wounds........... } & 244 \\ \text { " " } & \text { " } & \text { poisoned wounds...... } & 323 \\ \text { " } & \text { castration........... } & 38 s\end{array}$

Loco-weed.................. 492

Longevity of the mule........... 139

Louvre boards for stables......... 130

Low action as unsoundness....... 116

" "6 from splints.......... 225

Lump of warbles............. 473

Lumpy jaw................... 207

Lung fever................... 420

Lungs....................163, 176

"6 structure of.............. 177

6 diseases of.............. 418

6 inflammation of........... 420

"6 emphysema.............. 422

See Breathing, Respiration, etc.

Lymph and its uses............ 199

Lymphangitis................ 449

Mad staggers............... 452

"6 dog, bite of.............. 448

Maggots.................... 474

Malpresentations............. 406

"6 correcting...........4 409

6 66 instruments for 410

Mambrino Chief.............. 512

Patchen............. 512 


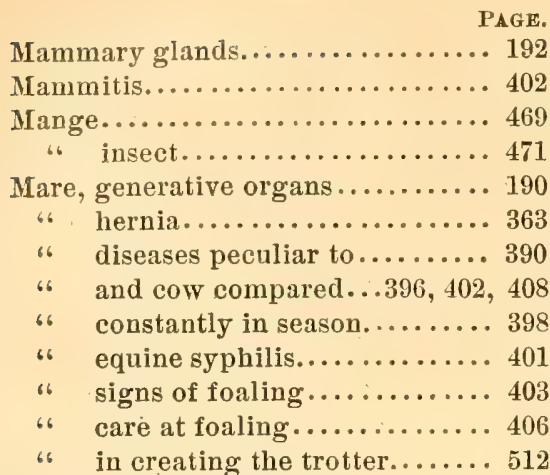

Marks of age, teeth as........... 333

Marrow, the................... 150

Maud $5 . . . . . . . . . . . . . . . .526$

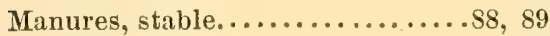

Maxey Cobb................... 534

Meadow ivy, poisonous........... 494

Medicines, caution............ 489

Melanosis................... 449

Membranes, the...............153

6. t'deir nomenclature.... 154

" and nerves.......... 171

Mesentery and glands........... 186

Messenger................54, 509

Metritis.................... 391

Midriff................ See Diaphragm.

Milk teeth..................331, 335

" flow, in spayed cow......... 399

Milt, or spleen................. 188

"6 enlargement of............ 368

Mississippi Valley, big head in..... 211 6 6 6 its elimate.....4 411 66 66 6 snakes...... 495

" lower, buffalo gnats of.. 498

Molars,.......................... Gee Grinders.

Monday morning disease.......... 449

Moon blindness............... 461

Mortification of a part........... 199

of a bone...........205

Mosquitoes, sting of........... 497

Mouth, glands of.............. 179

" feverish ............. 329, 331

" parrot................. 341

" diseases of.............. 342

" bars of................ 342

speculum.............. 413

Mucous membranes............ 153

Mud fever....................468
PAGE.

Mule, defined................ 139

"6 loves warmth............. 138

" longevity................ 139

" value for labor............ 139

"6 amount of feed...........140, 141

"6 is not vicious.............. 141

". colts training............ 143

"6 healthier than horse....... 141

" not exempt from disease.... 142

"6 breeding...............139, 142

Muscle versus fat.............. 152

" $\quad f 1 y \ldots \ldots \ldots \ldots \ldots \ldots \ldots \ldots \ldots$

Muscles, functions and structure... 151

" voluntary.............. 151

6، involuntary............ 151

" limited sensibility....... 152

"6 ham-string............. 243

" diseases of............. 309

"6 wasting away of......... 309

"6 broken................ 310

" cut.................. 310

"6 $\quad$ cramp of .............. 311

$" 6$ of tail .............. 482

Mustang.................... 53

Muzzle, a simple.............. 424

Nailing on of shoes............ 292

Nails for horse-shoes........... 292

Nail wounds.................. 244

-Nancy Hanks............... 545

"6 her stride......... 80

Nasal gleet............ 206, 412, 444

"6 polypus................ 412

" hemorrhage.............. 413

Navicular disease............. 257

" joint................. 266

Neck, the................... 51

object lessons on.......... 119

" bones.............. 147, 148

" anatomy ............... 169

" cradle................. 316

“ bandaging........... 346, 468

“ swollen....... S See Distemper.

" of bladder, spasm of........ 372

Necrosis of a bone............. 205

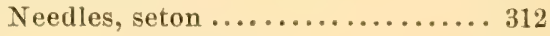

" veterinary ............ 325

holder for ............ 326

Nelson..................... 537 
PAGE.

Nephritis ..................... 369

Nerves...................... 171

6 of sensation............ 171

66 66 involuntary motion....... 172

6 spinal cord and ganglia. .... 172

Nerving.................... 483

66 high............... 484

6 low.................. 484

66 knife for............... 484

66 unsoundness after........ 115

Nervous system............. 170, 171

66 66 depressed........ 194

66 66 diseases of.......452

Neurotomy ................. 483

66 unsoundness after..... 115

Nicking....................... 482

6 knife................. 483

Nightshade, deadly............. 493

Nippers, or incisors.......330, 333, 335

Norman horses................ 44,83

Norman Percherons............ 45

Nose, diseases of ............... 411

"6 bleed ................... 413

Nostrils..................... 178

Nutrition.................82, 162

" defective from worms..... 361 See Stomach and Intestines.

Nymphomania................. 398

Oak, poison.................. 494

Oats, how to know good ......... 84

Object lessons on conformation..... 119

Obstetric instruments........... 409

Esophagotomy ................ 345

Esophagus ............... See Gullet.

Oil, joint.................... 301

" administering............ 366

" croton, its danger.......... 492

Open joints.................. 300

"6 "6 false.............. 301

66 66 how to know........ 301

Operator, farmer as........... 477

Operating table.............. 480

Operation, standing, in castrating.. 383

\begin{tabular}{|c|c|}
\hline 66 & lying down, in eastrating 384 \\
\hline 66 & of spaying........... 398 \\
\hline 66 & Gunther's .......... 417 \\
\hline 66 & securing for......... \\
\hline 66 & ${ }^{66} \mathrm{minor}$. . \\
\hline
\end{tabular}

See Chloroform, Castration, etc.

Page.

Operations, special............4 477

farmer performing..... 477

two kinds in nerving... 4s3

Opium poisoning.............. 493

Opthalmia, periodic...........4461

Optic nerve................. 174

Orchitis...................... 381

to know from hydrocele... 381

Organization defined.........209, 435

Osteophytes defined............ 585

Ovaries of mare.............. 191

. extirpating ............ 395

Over-reaching ...............248

"6 as unsoundness...... 116

Oxygenization of the blood.....163, 177

Pacing horse............ 53, 95, 552

"6 his speed victory ......... 552

"6 champion records........ 568

Pack mules................... 140

"6 "6 breeding............ 142

Paddling action............... 117

Pain as sign of inflammation...... 195

Palo Alto.................... 540

Palsy..................... \$53

Pancreas.................... 187

Paps, or barbs............... 344

Paralysis, or palsy............ 453

is as unsounduess........ 116

"6 from fractured spine.....235

6 or azoturea........... $37 \pm$

"6 from equine syphilis.... 401

66 laryngeal............4 416

6 complete............4 403

6. partial.............. 453

" of lips and tongue...... 454

Paring foot, its abuses........262, 285

Parrot mouth................ 841

Parturition, signs of approaching... 403

6. natural stages in...... 403

" presentation in........ 405

66 difficult.........408, 409

6. do. in mare and cow 408 compared........ 408

66 do. due to mare....... 409

"6 do. "6 "foal....... 409

See Foal and Mare etc.

Pasterns, straight............ 265

$6 \quad$ sloping.............. 265

Pusteur's inoculation............ 448

Patella, dislocation of .......... 303 


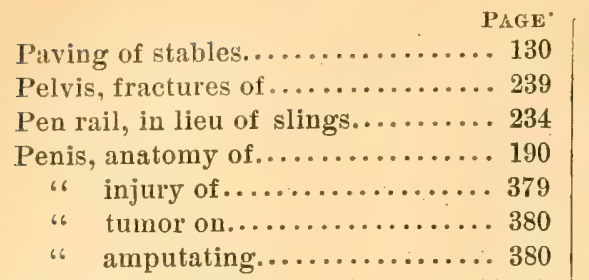

Percheron, the..............44, 57

Percussion defined .............. 419

Perfect foods................. 82

Peri, prefix, its meaning......... 153

Pericardium................. 433

Pericarditis.................443

Perineum.................. 192

" rupture of ............. 390

Periodic opthalmia.............461

Periosteotomy...............486

Periosteum .................. 151 6 inflammation of....... 203

Peritonitis................... 38s

Peritoneum.................. 186

Perspiration................94, 157

Phallas.................... 531

Pharynx................... 180

Phlebitis.................... 435

Pikes....................... 344

Piles...................... 361

Pills, administering...........367, 368

Pilot....................509, 513

Pink-eye................... 43s

Pipes of poll evil.............. 218

66 "6 fistula................2 219

"6 "quittor ............... 249

Placenta............... See After-birth.

Plantar cushion of foot.......... 26S

Plantation ill-usage of horse....... 214

Pleura..................... 177

" inflammation of........... 425

Pleurisy................... 425

"6 from broken ribs......... 239

Pneumonia.................. 420

See Lungs, etc.

Pointing of abscess............ 197 " boils ............. 437

Points of the thoroughbred........ 48

66 66 6 draft horse.......... 49 judging of............58, 61 form and proportion....... 62 are many............. 62

Poisoned wounds.............. :323
PAGE.

Poisoning................. 489

" blood............... 449

Poison oak................... 494

vines..................494

Poisons................... 489

" slow action of some........ 489

"6 internal ............... 490

Poisonous herbs............... 490

insects...........4490, 496

serpents ..........490,494

plants............492, 494

preparations from plants. 493

Poll evil..................... 21s

Polypus in the nostril........... 412

Pores of the skin............. 157

Potato bug, sting of............ 497

Poultices.................... 200

Poultice for throat............ 415

Pox, horse................. 447

Practical, the, in veterinay science. 81

Poultry lousiness.............. 472

Presentations in foaling .......405, 409

Prevention of disease........... \$2

Probang..................... 345

Progression, horse's mode........ 67

"6 in the walk . ...... 69

Pulse.................... 165, 429

" in health............... 131

"6 where to find in horse........ 429

"6 quick................... 429

"s slow.................. 430

"6 long..................... 430

" infrequent................ 430

" volume of ............... 430

"6 feeble .................. 430

"6 small................... 430

"6 hard.................. 430

" soft.................. 430

" full................... 430

" large................... 430

"6 gaseous.................. 430

"6 corded ................ 430

" wiry.................. 430

6 thready.................. 430

" venous................ 431

"6 jugular................. 431

6 in giving chloroform.....478, 479

Pulmonary circulation........... 161 oxygenization of blood.. 163

Pummiced sole............... 113 
PAGE.

Punctured wounds............. 322

Pupil of the eye............... 175

Purgatives, use of............. 202

to deplete system..... 371

Purpura hemorrhagica........... 441

Pus, burrowing of.............. 198

66 of nasal gleet.............. 206

See Suppuration.

"Putting back" big head.......... 212

Pyæmia..................... 449

Quick, the, or sensitive foot....... 269

Quittor..................... 249

Rabies...................... 448

Races, running................ 564

66 heat, records............. 564

66 trotting, champion table... 565

6. pacing, .. " 6 ... 56S

Rail pen, in lieu of slings.......... 234

Rasping, bad...............275, 282

"6 foot........281, 283, 2s8, 296

6 tooth............... 340

Rarey, John S................ 111

66 " 6 his favorite halter.... 111

66 66 his method described.. 101

Rarus...................... 523

Rattlesnake bites............... 495

Rearing, vice of ............... 116

Recapitulation of remedies........ 499

Records, running............. 564

66. champion........... 565

6 on regulation track....565, 568

6 on kite track.........565, 568

Rectum..................... 186

6 exploring in vari- $\{370,375,377$

Redness as sign of inflammation.... 196

Regulation track, records on.......55

Remedies, recapitulation of......... 499

Resolution of inflammation........ 196

Respiration................. 176

See Breathing.

Respiratory organs.........176, 178

"6 diseases of .....4 411

Retention of urine..........372, 376

" placenta......... 410

Retina of the eye.............. 174

Rheumatic joints.............. 302

Rheumatism............... 440
Rheumatisu, simulated by navio- PAGE. ular disease........ $\} 259$

Ribs, horse's.................. 148

66 broken .................. 238

Ridgling, castrating the.......... 356

Ringbones.................. 225

Ringworm................ 467

Roaring................... 416

66 as unsoundness............ 115

"6 from nasal polypus....... 413

Rosin, dangers of. .............. 37 5

Rough hocks.................. 223

Roughing, ill effects of.......... 29s

Rubefacients.................4 491

Running away, vice of........... 116

66 sumach (poison)......... 494

66 records................ 56

Rupture of stomach............. 350

66 66 bowels (colic)........ 350

66 6 6 (hernia)........ 362

$\because \quad 6$ bladder............. 376

66 6 perineum........... 390

66 .6 heart............. 433

$66 \quad 66$ anewrism........... 434

Russian substitute for castration.... 356

Saddle galls.................. 467

66 horses................... 95

"6 for ladies.........76, 79

Sage knife.................. 245

Saliva, its quantity............. 179

Salivary glands................ 179

Saltpetre, danger of..........375, 491

Sand-crack.................. 251

"6 as unsoundness......... 114

"Santa Fe," or centipede........ 496

Sarcocele.................. 389

Scabbing of wounds............ 327

Scalds .................... 328

Scarf-skin.................. 154

Scarification for lampas.......... 343

of swollen penis...... 379

Scirrhus cord................. 3s!

Science not unpractical.......... S1

Scorpions, stinging............ 496

Scraping, castration by .......... 355

Seratches .................. 466

Serotal hernia............... 362, 363

"6 to know, from orchitis....... 381

"6 hydrocele.... $3 \$ 1$ 
Page.

Secretion defined............... 179

Sedatives, use of............... 202

Seeds...... See Testicles and Castration. Selling, directions for........... 118

See Buying.

Sensation, nerves of............ 171 of sight, how produced... 174

Sensitive foot ................ 269

Serous membrane................ 153

\section{6 its insensibility... 154}

Setting a broken leg............ 230

Setons...................312, 487

Sewing wounds................ 324

Shank, bones of .............. 264

Sheath, keeping clean.........379, 380

"6 swelling after castration... 388

Shedding the hair............. 158

6 teeth............. 331

Sheltering stock, importance...... \$2

6 6 economy of...... 87

Shins, sore.................. 204

Shire horses.................. 39

Shoe, good, its features............ 288

"6 its foot surface..........289, 295

66 6 ground surface........... 290

6 seated .................. 289

6 flat. .................... 289

66 Charlier .................. 296

66 calkins ................. 290

66 claws................... 290

${ }_{66}$ clips..................... 292

66 for carriage horses.......... 291

66 6 hunters............... 292

66 "6 horse at grass............ 299

$66 \quad 6$ colts in training .........550

"6 nails for................. 292

"6 nailing on............... 292

"6 preliminary fitting .......... 293

66 outline fitting............. 293

6 surface "6 ............ 294

6 putting it on.............. 295

6 cold fitting.............. 296

6 hot 66 .............. 296

، Goodenough............... 296

See Shoeing.

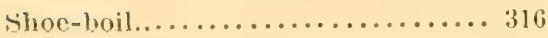

Shoeing a necessary evil.......... 260

its principles........... 260

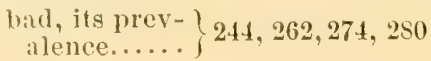

PAGE.

Shoeing, bad, lameness from.261, 262, 274

6. 66 changes in foot from.. 281

"6 " 6 cutting from........ 288

66 66 to prevent evil......294

"6 good, fit the test of....... 263

66 "6 art of .......... 280

"6 W. Hunting on.......... 261

6 two-fold object......... 262

66 preparing foot for........ 280

"6 Charlier sjstem.......... 296

" leather soles, etc., injurious. 297

"6 proper intervals for....... 298

6. of colts in training........ 550

Shoulder-blade, its fracture....... 240

Shoulder-slip ................ 315

Shoulders, oblique............ 52

"6 upright............. 52

6 defective........... 113

6 object lesson on........ 122

66 bones of........... 147

" sprained............ 312

66 swollen, in azoturea.... 374

6 sole............... 467

Shying as unsoundness.......... 115

66 $\quad .6$ vice.............. 116

Side-bones.............. 227, 267

Side lines for casting............ 384

$6 \operatorname{rod} . . \ldots \ldots \ldots \ldots \ldots \ldots . . . \ldots 44$

Sight, how produced............ 174

Signals, use in trainiog.......... 100

Sinuses in skull............... 148

Size of new-born animals......... 395

66 66 colt at one and two years.... 547

Skeleton, horse's............ 146, 149

Skin, horse's................. 93

6 eleanliness of ............ 93

6 glands of..............94, 152

6 structure of.............. 154

.6 appendages and functions.... 156

6 how oiled and suppled........ 157

6 pores of ................ 157

"6 diseases of.............. 466

$66^{\circ}$ in erysipelas............. 469

See llide-bound.

Skittishness, when a vice......... 116

skill, bones of .............. 147

and brain.............. 167

.6 fracture of............. 235

Sleepy staggers.............. 453

Slings, ete................. 231 
PAGE.

Slings, simpier form............ 375

Small-pox, relation to horse-pox... 447

Smuggler.................... 531

Snake-bites .................... 494

Sneeze-weed poisoning............ 494

Sole, pummiced................. 113

" bruises of ................. 247

"6 structure and uses...........271

" bearing of............... 279

"s should not be pared.......... 284

"6 diseases of.See Thrush, Canker, etc.

"6 of leather not advisable....... 297

Sore shins.................... 204

Soundness, its technical meaning... 113 "6 popular 6 ... 113

See Unsoundness, Examination, ete. Soups as food for horse........... 86 South whe jack's own home ....... 138 "6 mùles at.............. 138 breeding of mules at........ 143 "6 big head at..........211, 214

"6 ill-usage of stock at........ 213 Spanish flies, as poison.......... 490 6. "6 blister, caution...... 369 Spasm of bladder................. 376

"6 " neck of bladder......... 372

"6 "diaphragm............ 436

Spavin, bone................. 220

" bog..................... 305

blood................... 306

Spavins are hereditary........... 222

"6 as unsoundness........... 115

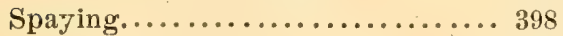

" cow for beef, etc.......... 399

"6 through flank........... 399

" " vagina.......... 400

"6 for nyphomania........... 398

Speculum, mouth ............. 413

6 vaginal.............391, 396

Speed, essentials to............ 62

"6 rate of, in walk.......... 72

"6 training for............. 550

Spinal cord.................. 172

Spine, bones of............... 148

"6 fracture of...............23s

Spiders, venomous ............. 495

Spleen...................... 188

"6 enlargement of ........... 368

Splint-bones .................264

Splints (disease) .............. 224
Page.

Splints, as unsoundness.......... 22t

" in bone-setting............ 230

" iron, "6 ........... 242

Sprained shoulder.............. 312

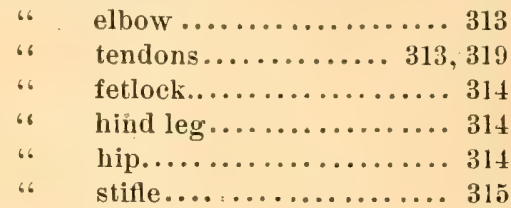

Spring-halt................. 456

"6 as unsoundness........ 115

Stables, hygiene in..... 82, 253, 444, 474

Stable, cleanliness in........... 89

construction of............ 127

in a model barn.......... 135

temperature of........... 94

ventilation in...........129, 130

paving for............ 130

floor of, height........... 130

construction of stalls....... 131

site of..............131, 370

light in............... 132

draining............... 131

care of feet in............ 298

for foaling............. 407

Staggers, stomach...........349, 452

blind................. 349

grass................. 349

head................452

$\operatorname{mad} . . . . . . . . . . . . . .452$

"6. sleepy............. 453

Stallion, generative organs of..... 190

" colic in, caution......... 362

" hernia in............362, 363

" debility of, and abortion.... 392

"6 equine syphilis of ........ 400

" kings................. 530

Stalls, slope of ............... 131

" cattle................. 135

" washing, for mange....... 471

Standard of excellence is variant. $49,61,62$

" for judging horse........ 80

"6 of perfection is too high... 125

Standing over...........See Knuckling.

Staphyloma................ 459

Steaming-bag.............. 412

Stewart, Dr. R., on big head....... 211

on building the frame. . . 233

on building the rail-pen... 234 
PAGE.

Stiff joint.... See Ankylosis, Spavin, etc. Stifle, sprained................ 315

66 joint, dislocation......... 303

Stimulants, their uses.......... 202

stimulating liniments........... 200

Sting by snakes................. 494

$66 \quad 66$ spiders, etc........... 495

66 66 centipede............4496

6. "6 scorpion............. 496

66 6 hornets, etc........... 497

66 6 wasps.............. 497

66. 66 gnats.............. 497

66 6 gad-flies ............. 497

66 . 6 potato bug............ 497

"6 66 buffalo guats........... 498

St. Julien ..... . . . . . . . . . . . 5 524

Stocks.................... 480

Stomach, horse's..............84, 181

\begin{tabular}{|c|c|c|}
\hline 66 & 6 & size, etc......... 303 \\
\hline 66 & ، & anatomy......... 182 \\
\hline 66 & $66^{\circ}$ & functions........ 346 \\
\hline 66. & 66 & peculiarity ...... 346 \\
\hline 66 & 66. & bots in........ \\
\hline 66 & 6 & staggers...... \\
\hline 66 & 66 & rupture of...... \\
\hline
\end{tabular}

Stone in bladder..........373, 375, 376

66 66 6 test for.......... 377

Stoppage of bowels... See Constipation.

6 6 urine............ 372

Stopping, vice of............... 117

66 the feet, its folly....... 298

Straddling action............. 117

Strangles.................... 445

6 as unsoundness......... 113

Straps, the Rarey............102, 111

Straw as food................ 85

"6 66 bedding............... 85

Stricture of intestines........... 183

"6 "6 urinary passage....... 372

Stride, its length in gallop........ 79

6 Nancy Hanks'............ so

String-halt........... See Spring-halt.

Stud.................... See Stallion.

6 book, English............. 562

i6 66 American........... 562

Stumbling................... 124

$6 \quad$ as unsoundness.......... 116

Sudden death from liver disease. 365,366

6 . 66 66 heart 66 ... 429

Suffocation from polypus......... 413
PAGE.

Suffolk Punch horses............ 11

Sumach, running, poisoning by..... 494

Sunol..................... 52s

Supporter, testicle.............. 381

Suppuration, process of......... 197

See Pus.

Sutures, kinds, etc............... 324

Sway back in horses............. 121

Sweeny defined................ 309

of shoulder............ 315

Sweet-bread.................... 187

Swelled glands...............344, 412

"6 as unsoundness..... 116

See Farcy, Glanders, Strangles, etc.

"6 $\quad \operatorname{legs...\ldots ..........319,~} 449$

6 head ..........209, 441, 445

6 ankles................ 321

Swelling, sign of inflammation.... 196

66 of hernia...........362, 363

"6 $\left.\begin{array}{c}\text { shoulders and loins in } \\ \text { azoturea................. }\end{array}\right\} 374$

"6 " $\quad$ penis............... 379

66. 66 sheath after gelding.... $38 s$

66 of erysipelas........... 469

See Swelled.

Switching of tail, sign of piles......361

$66 \quad 66$ 6 6 6 abortion.. 393

Sympathetic nerves............ 172

Synovia, or joint oil............ 301

Syphilis, equine............. 400

Syringe, substitute for........... 324

Table, operating.............480

"6 champiou (racing) ........ 565

Tail, graceful................. 123

"6 bones in,..............148, 480

"6 switching, sign of piles....... 361

$66 \quad 66$ abortion...... 393

" muscles of .............. 482

". to correct crooked...........483

See Docking and Nicking.

Taming horses, special methods.... 100

Rarey wethod.......... 101

'Tape-worm................... 360

'lapping, or percussion. .......... 419

for blind staggers........ 350

6 wind colic.......... 354

‘ hydrocele.......... 352

"6 hydrothorax......... 427

"6 the chest............. 427 
PAGE.

'Taruntula bites................ 495

'Tartar emetic poisoning .......... 492

Teats..................... See Udder.

Teeth, the................147, 330

diseases of ............ 329

blind, or wolf......... 330, 344

shedding............... 331

decayed................ 332

extracting............. 333

as index of age........... 334

permanent............. 335

effects of corn diet....... 337

of crib biters............ 337

irregular.............. 340

constant change in........ 342

See 'Iooth.

Teething..................... 330

often painful........329, 331

Temperature in health............ 431

6 as sign of fever......4 431

66 of stable.......... 94

Tendons..................... 153

"6 none in involuntary muscles. 151

66. flexor of leg........... 167

6 of the foot............ 266

"6 diseases of............. . 309

66 contracted.............. 319

66 6 6 operation for.... 486

Tenotomy..................4 486

'Testicles, anatomy of............ 190

.6 inflammation........... 381

6 supporter for........... 381

.. dropsy of...............381

"retention in abdomen.... 386

See Castration.

Tetanus.................. See Lockjaw.

Thermometer, clinical.......... 431

$6 \quad 66$ its use...... 195

Thick $\operatorname{leg} \ldots . . . \ldots . . . . . . . . . .449$

Thigh, broken.................. 242

Thirst, mixtures to relieve....... 371

'Thoroughbred, the...........47, 57

outline and points.. 48 in breeding trotter.. $50 \mathrm{~s}$ American........ 562

Thorough-pin................. 306 I'hreads for veterinary use........ 325

'Throat, glands of .............. 179

6 bandage............... 415

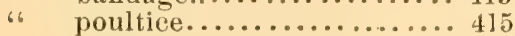

See Larynx, Wind-pipe, Gullet, ete.
Throving............... See Casting.

Thrush...................... 252

6 as unsoundness........... 115

Thumps.................... 436

Ticks....................... 473

'Tobaceo water for mange, ete...472, 473

smoke for mosquitoes..... 497

Toe turned up (neurotomy)........487

Toeing-knife................... 283

'longue, paralysis of............. 454

test for anasthesia........ 479

Tooth-ache.................. 332

cutters.................. 341

"6 pullers, old time............ 212

"6 rasp................... 340

Torn eyelids.................. $45 \mathrm{~s}$

Torsion, castration by ........... 386

66. forceps............... 400

'I'rachea............... See Wind-pipe.

Tracheotomy................ 417

Track, regulation, records......565, 568

kite, records.......... 565, 568

Trading, horse, honesty in........ 118

See Buying, Examination, etc.

'Training, use of force in .......... 96 must teach subserviency .. 97 should begin young. ...97, 547 whip in............. 98 of colts.............. 99 of mule colts........... 143 use of voice in ........ 100 "6 " siguals in ........ 100 Rarey's three axioms..... 101 young trotter........... 547 See 'Taming and Gentling.

Travis..................... 480

Treads......................... 247

Trepanation................... 485

Trephine.................... 486

Trephining................ ... 485

T'rochar and canula ..........350, 354

Trot, the................... 73

6 jog................... 73

66 good and bad action in...... 74

6. value of this gait.......... 507

Trotter, as hunting horse......... 34

the only American breed... 52

blood widely diffused..... 53

how bred up..........53, 507 
Trotter, creation of............. 507 early breeding of......... 508 mare in breeding of...... 512 minor families.......... 51 educating young.........5 547 See Records.

Trotting events to $1856 \ldots \ldots \ldots \ldots$. 54

"6 " late............ 543

" champion records....... 565

Tumors, bone................ 209

" cartilage............... 209

66 horny, of foot........... 257

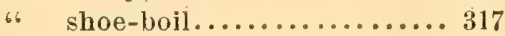

"6 of piles................ 362

$"$ in urinary passages........ 374

$"$ on penis................. 380

"6 nasal.................. 412

"6 in the heart.............. 433

" soft, of aneurism.......... 434

"6 black.................. 449

" in brain................. 45

" trephining to remove........ 485

Turf, American, its records..564, 565, 568

'I'urpentine as diuretic.........375,491

"6 in liniments.......... 491

Tushes, the...................330, 336

'Twisted suture................ 325

Twiteh.................... 480

'Tying a blood-vessel........... 435

Udder of mare................ 192

6. intlammation............. 402

Ulceration of a part............. 199

، " bone.............. 204

Umbilical hernia.............362, 363

Unnerved as unsoundness......... 115

Unsoundness, principal forms..... 113

Urethra ................... 189, 372

" structure of..........372,373

Urinary organs............... 188 " diseases.. See Bladder, Kidneys.

Urine.................... 188

، bloody .................370,375

" dribbling.................. 370

" excessive flow.............. 371

. stoppage................ 372

" chocolate............... 37t

" straining in passing.370,371,372,377

"6 squirting.............. 377

Uterils. 191
PAGE.

Uterus, inversion of ............. 396

See Womb.

Vagina ....................... 191

Vaginal speculum ............391, 396

Valvular disease of heart........ 432

Varicose veins................ 3s2

Variola equina............... 447

Vasenlar defined .............. 269

Veins....................... 161

" to stop bleeding from....... 32t

" varicose................. 382

Venomous serpents............. 495

" spiders............. 495

Venous pulse.................. 431

Ventilation in stables........... 29

6 6 " 6- itsimportance.. 94

"6 Jouvre-boards for..... 130

"6 in model barn........ 136

Ventral hernia................362, 363

Ventricles of the heart........... 165

Vermifuges................... 361

Vertebræ.................. See spine.

Vice in horse defined............ 116

" principal kinds............. 116

"6 inules free from............ 141

Vines, poison................ 494

Voice, its use in training......... 100

Voluntary museles............. 151

Vomiting, impossible to horse...1s2, 492

Vulva...................... 192

Walk, analyzed............... 68

" rate of speed............. 72

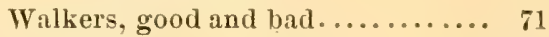

Wall of hoof................ 269

Warbles.................... 473

Warrantee in buying.......... 112

" selling............ 118

form of ........... 112

why desirable......... 118

Warts on eyelids............... 458

Washington's jacks............... $13 \mathrm{~s}$

Washing stalls, etc., for mange.... 471

Washy horses............... 356

Wasp stings............... 497

Wasting away of muscle......... 309

Water, misuse in grooming....... 89

$6 \quad$ its use and abuse......... 90

" as to chill from drinking.... 90 


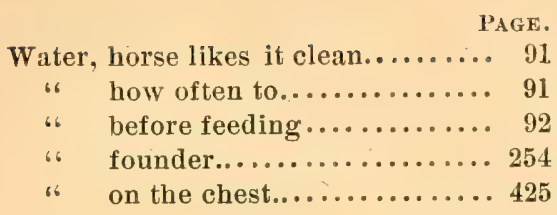

See Urine.

Weed $\operatorname{leg} . . . \ldots \ldots \ldots \ldots . . . \ldots . . .449$

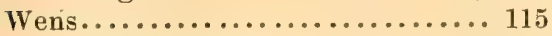

Westmont and mate........... 552

Whip, its use in training.......... 98

Whiskey for snake bites.......... 495

Whistling.................. 416

، as unsoundness.......... 115

White hellebore.............. 493

Whites....................... 390

Whitleather.................. 148

wild ass.................. 137

" horses in America.......... 53

Wind, to test.................416

Wind-broken...............177, 422

6 $\quad 66$ as unsoundness....... 115

Wind-galls.................. 306

Windows in stable.............. 129

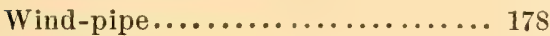

Wind-puffs................. 306

Wind-sucking as unsoundness..... 115

Winter, sheltering in........... 87

"6 watering in ............ 92
Withers, fistula of.............. 219

66 66 to prevent...... 467

Wolf teeth..................330, 344

Womb, anatomy of............. 191

"6 inflammation of ......... 391

"6. hemorrhage............. 395

"6 flooding............... 395

"6 falling of............... 396

"6 in foaling.............. 404

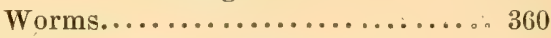

.6 caution in diagnosing....... $35 \mathrm{~s}$

"6 tape................... 360

6 in the eye............ 459

Wornils................... 473

Wounds, kinds................ 322

.6 as unsoundness.......... 116

" nail................. 244

"6 causes of.............. 323

"6 cleansing............. 323

"6 sewing .............. 324

66 modes of healing......... 326

"6 dressing.............. 327

" of blood vessels......... 435

" treatment to prevent hy- $\}_{448}$ drophobia............. $\} 448$

"6 preceding lockjaw....... 45 6

" " $\quad$ erysipelas..... 469

"6 flyblown, to prevent...473, 474

Yellows..................187, 367 








\section{LIBRARY OF CONGRESS}

|||||||||||||||||||||||

00028603241 